
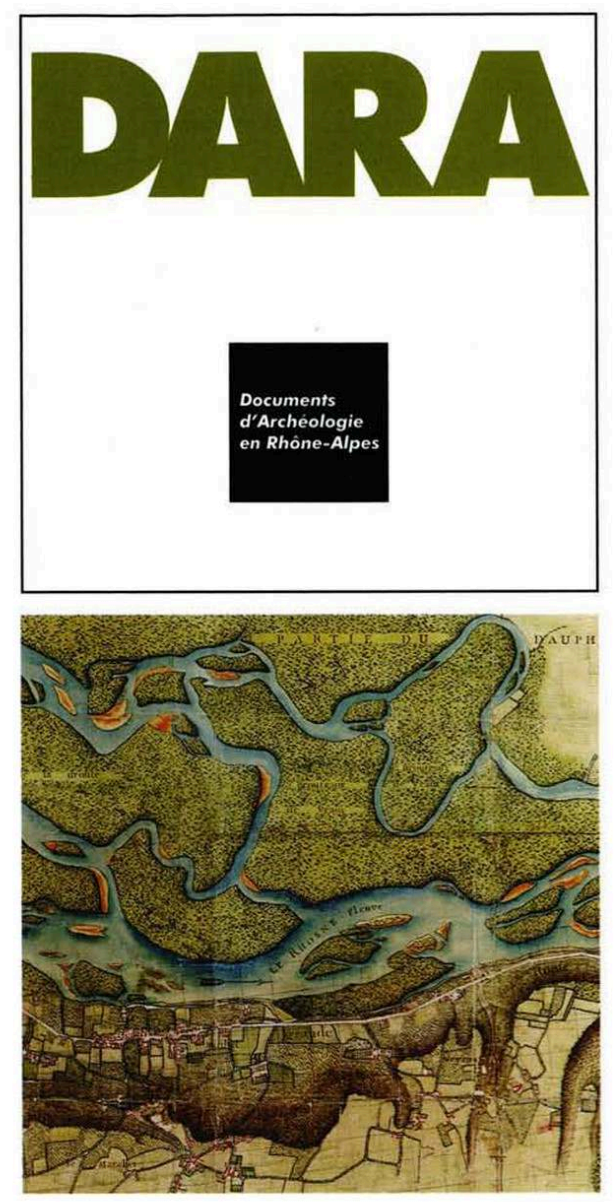

\title{
DYNAMIQUE DU PAYSAGE
}

ENTRETIENS DE GÉOARCHÉOLOGIE

Table ronde tenue à Lyon les 17 et 18 Novembre 1995

Sous la coordination de J.-P. BRAVARD ET M. PRESTREAU 


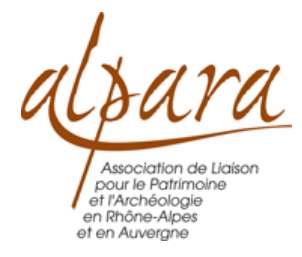

Alpara

\section{Dynamique du paysage}

Entretiens de géoarchéologie (Table ronde tenue à Lyon les 17 et 18 novembre 1995)

Jean-Paul Bravard et Michel Prestreau (dir.)

DOI : 10.4000/books.alpara.1458

Éditeur : Alpara

Lieu d'édition : Lyon

Année d'édition : 1997

Date de mise en ligne : 2 juin 2016

Collection : DARA

EAN électronique : 9782916125343

\section{OpenEdition}

\section{Books}

https://books.openedition.org

\section{Édition imprimée}

EAN (Édition imprimée) : 9782906190191

Nombre de pages : 282

\section{Référence électronique}

BRAVARD, Jean-Paul (dir.) ; PRESTREAU, Michel (dir.). Dynamique du paysage : Entretiens de géoarchéologie (Table ronde tenue à Lyon les 17 et 18 novembre 1995). Nouvelle édition [en ligne]. Lyon: Alpara, 1997 (généré le 28 juin 2022). Disponible sur Internet : <http://books.openedition.org/alpara/ 1458>. ISBN : 9782916125343 . DOI : https://doi.org/10.4000/books.alpara.1458.

Ce document a été généré automatiquement le 27 janvier 2021. Il est issu d'une numérisation par reconnaissance optique de caractères.

(C) Alpara, 1997

Conditions d'utilisation :

http://www.openedition.org/6540 
Il est une forme d'archéologie qui s'intéresse non pas aux témoignages matériels laissés par les civilisations passées, mais à un objet bien modeste en apparence, la terre et l'eau. Cette archéologie nouvelle puisqu'elle est née il y a à peine plus de 20 ans, est la géoarchéologie.

En concertation étroite avec les archéologues plus classiques, des chercheurs spécialisés dans les sciences de la terre et l'environnement - géomorphologues, palynologues, anthracologues (spécialistes des charbons de bois), limnologues (spécialistes des lacs) etc. - fouillent les archives du sol pour restituer les milieux de vie des sociétés du passé. En effet, il est aujourd'hui difficile de concevoir une archéologie qui fasse abstraction des lieux et de leur évolution au fil des siècles, des ressources disponibles et des contraintes subies par les populations. Discipline vivante, l'archéologie s'enrichit sans cesse de nouveaux éclairages.

Ce volume rassemble les contributions de spécialistes de la France du Sud-Est réunis pour la première fois à l'initiative du Service Régional de l'Archéologie de Lyon. Il fait le point sur les recherches réalisées depuis 15 ans dans la région Rhône-Alpes, montre la richesse des acquis dans le domaine de la géoarchéologie et ouvre des perspectives pour le futur. 
SOMMAIRE

Les auteurs

Préface

Jean-Pierre Daugas

Avant-propos

Jean-Paul Bravard et Michel Prestreau

\section{Géoarchéologie des grottes}

Géoarchéologie des grottes : contexte et sédiments

Évelyne Debard

Le milieu « grotte»

Les sédiments

Intérêt et limites de l'étude des grottes

Les grottes du Vercors et des massifs Subalpins

Relations Homme et milieu végétal

Stéphanie Thiébault et Pierre Bintz

Rappel des découvertes

Les principaux acquis des dernières décennies

Apports de la collaboration

Perspectives

Formation des dépôts archéologiques en Grotte

La Grotte du Gardon (Ain) durant le néolithique

Dominique Sordoillet

Processus de formation des sites archéologiques troglodytiques

Méthode d'étude des remplissages de grotte

L'exemple de la grotte du Gardon (Ain)

Conclusion

\section{Géoarchéologie des versant et terrasses}

Géoarchéologie des versants

Les dépôts de pente

Pascal Bertran et Jean-Pierre Texier

Principaux processus, faciès associés et exemples en contexte archéologique

Reconstitutions paléoenvironnementales

Rôle des processus de versant dans la formation des sites archéologiques

Remontages lithiques

Tri granulométrique

Fabriques

Conclusions 
Contexte morphodynamique et habitat humain de la moyenne vallée du Rhône au cours de la Préhistoire récente

Jacques-Léopold Brochier

Évolution des idées : la variabilité du relief de la plaine rhodanienne

La planation de la vallée du Rhône

Structure géomorphologique et taphonomie archéologique

Les ethnofaciès sédimentaires, les sédimentations anthropogènes

Les relations géoarchéologie archéologie

Géoarchéologie du Bassin Valdainais (Drôme)

Jean-François Berger

Géoarchéologie, archéologie et paléoenvironnements

Démarche et méthodes

Quelques applications géoarchéologiques et paléoécologiques au sud du bassin valdainais

Une certaine utilisation des données géomorphologiques et pédologiques : la paléopédologie

L'apport de la géomorphologie et de la pédologie à la cartographie archéologique (analyse

taphonomique)

Les modèles d'évolution du paysage au premier millénaire ap. J.-C.

\section{Géoarchéologie des vallées et cours d'eau}

\section{Géoarcheologie des vallées alluviales de Rhône-Alpes depuis le Tardiglaciaire} Jean-Paul Bravard

Potentiel archeologique des vallées fluviales : principes de la taphonomie

Les acquis de la recherche

Les recherches à développer

Archeologie du lit mineur de la Saône : les recherches en chalonnais Louis Bonnamour

Historique des recherches en Saône

Les recherches en cours

À propos de la fondation de Grenoble : un réexamen de l'hypothèse d'une installation primitive sur un môle alluvial

Jean-Luc Peiry et Cyril Féougier

L'hypothèse d'un môle alluvial en rive gauche de l'Isère

La reconstitution de la topographie de l'alluvium de graviers et galets

Interprétation et discussion des résultats

Conclusion

Paléodynamique du site fluvial de Lyon depuis le Tardiglaciaire Jean-Paul Bravard, Agnès Vérot-Bourrely et Odile Franc

La dynamique des plaines du Rhône et de la Saône au Tardiglaciaire et au début de l'Holocène La dynamique fluviale de l'Atlantique à l'époque moderne

Potentiel archeologique des plaines alluviales

Milieu et sociétés dans la vallée des Baux

Philippe Leveau

La vallée des Baux, le cadre naturel et l'histoire récente

Sites archéologiques et évolution du milieu

Taphonomie des sites et des parcellaires : les forages et l'histoire des dépôts

Conclusion 


\section{Géoarchéologie lacustre}

L'archéologie subaquatique dans les lacs Alpins Français

Yves Billaud et André Marguet

Historique de la question palafittique

Historique de la recherche dans les lacs alpins français

Potentiel archéologique des sites lacustres

État des connaissances sur les occupations littorales des lacs alpins français

Perspectives et recherches à développer

L'approche paléoclimatique des habitats lacustres Jura et Alpes du Nord Michel Magny

Les problématiques et les méthodes

Sortir du ghetto

En guise de conclusion

\section{Annexe}

Résumé des interventions orales

\section{Abreviations}

Credits Illustrations 


\title{
Les auteurs
}

\author{
C. ARLAUD - AFAN. Montpellier
}

A. BEECHING - Centre Archéologie Préhistorique de Valence. U.P.R. 7558

J.-F. BERGER - U.S.R. 708 du CRA du CNRS et AFAN-Méditerranée

P. BERTRAN - Inst. du Quaternaire U.M.R. 9933 CNRS, Talence

5 Y. BILLAUD - Association pour la Recherche et l'Etude des Occupations Littorales Lacustres (AREOLL)

P. BINTZ - Inst. Dolomieu, Grenoble, U.R.A. 0164

7 L. BONNAMOUR-Musée de Chalon-sur-Saône

8 J.-P. BRAVARD - Univ. Paris-Sorbonne, U.F.R. de Géographie

9 J.-L. BROCHIER - Centre Archéologie Préhistorique de Valence, U.P.R. 7558 du CNRS et AFAN-Méditerranée

G. CHOUQUER - U.M.R. 9966 Tours (DRASSM), Annecy

E. DEBARD - Univ. Lyon I, Centre d'archéométrie. U.F.R. Sciences de la terre

C. FÉOUGIER - Inst. de Géographie Alpine, Univ. Joseph Fourier, Grenoble, 38031 Cedex

O. FRANC - AFAN. U.M.R. Environnement Villes et Sociétés, Lyon

Ph. LEVEAU - Centre Camille Jullian, U.M.R. 9968

F. MAGNIN - U.R.A. 1152 du CNRS, Marseille

M. MAGNY - Univ. de Franche-Comté, U.M.R. 6565

A. MARGUET - Départ, des Recherches Archéologiques Subaquatiques et Sous-Marines

T. ODIOT - S.R.A. Languedoc

J.-L. PEIRY - Inst. de Géographie Alpine, Univ. Joseph Fourier, Grenoble, 38031 Cedex

D. SORDOILLET - Centre des Sciences de la Terre, Université de Bourgogne, Dijon

J.-P. TEXIER - Inst. du Quaternaire, U.M.R. 9933 CNRS, Talence, 33405 Cedex

S. THIEBAULT - UPRESA 5059 du CNRS, Montpellier

A. VEROT-BOURRELY - AFAN. U.M.R. Environnement Villes et Sociétés, Lyon 
24 Qu'ici soient remerciés les membres du comité scientifique ayant assuré la relecture des contributions :

Pierre Bintz, Jean-Claude Blanchet, Franck Braemer, Jean-Paul Bravard, Michel Campy, Jean-Pierre Daugas, Evelyne Debard, Armand Desbat, Alain Ferdière, Maurice Jorda, Anne Le Bot, Michel Magny, André Marguet, Chantai Mazard, Michel Prestreau, Mireille Provansal, Pierre-Gil Salvador, Jacques Tarrette, JeanPierre Texier, Paul Van Ossel, Gérard Vernet, Jean-Louis Voruz, Julia Wattez. 


\title{
Préface
}

\author{
Jean-Pierre Daugas
}

1 Durant deux jours, en novembre 95, près de quatre vingt spécialistes de l'archéologie, des sciences de la Terre et des sciences de la Nature se sont réunis à Lyon sous le signe de l'hospitalité chaleureuse de Jacques Lasfargues, Conservateur du Musée de la civilisation à l'initiative de Jean-Paul gallo-romaine, Bravard et Michel Prestreau. Cette manifestation interinstitutionnelle a, certes, permis de montrer la vivacité de la communauté des archéologues rhonalpins, mais elle avait pour objet principal de souligner l'apport fondamental de la restitution des paléoenvironnements et de leurs mutations, comme cadre des activités humaines et comme moteur de leur adaptation ou de leur évolution.

Dans les années soixante dix et quatre vingt, de nombreux chercheurs ont réuni de nouvelles données concernant les remplissages en grottes, les dépôts lacustres et les formations alluviales. Jean-Paul Bravard et ses élèves ont ainsi multiplié les observations, particulièrement à l'occasion de fouilles archéologiques, dans le Dauphiné et le Lyonnais. L'équipe du Centre d'Archéologie Préhistorique de Valence a constitué une véritable base de données en Valdaine, Tricastin et dans l'ensemble de la moyenne Vallée du Rhône en suivant systématiquement les tranchées de travaux publics ou le drainage. D'autres, en Auvergne par exemple, se sont intéressés à la relation entre l'Homme et les volcans durant le Pléistocène et l'Holocène. Les démarches ont toutes en commun de s'être placées dans la lignée des travaux conduits, après la dernière guerre, par une génération de préhistoriens-géologues eux-mêmes soucieux de développer une tendance de la recherche française : F. Bourdier, F. Bordes, Guillen, P. Bout et, plus récemment encore, H. Laville, ont illustré le fait que l'archéologie est indissociable de la méthode stratigraphique, de la reconnaissance des dynamiques sédimentaires et de la définition des cadres naturels qu'elles impliquent.

3 Une brève revue des données historiques montre que cette tendance n'est pas nouvelle et trouve ses origines aux débuts mêmes de la recherche préhistorique.

4 Le courant naturaliste issu des travaux paléontologiques de G. Cuvier (1769-1832), puis des thèses évolutionnistes, laisse une large place aux recherches de terrain fondées sur l'observation stratigraphique et l'association des restes. John Frère dès 1797 dans le Sufolk, A. Boue en 1823 dans les loess rhénans, Paul Tournal en 1827 à Bize, Schmerling 
en 1833 dans la région de Liège, Casimir Picard puis Boucher de Perthes en 1835 et 1837 dans la vallée de la Somme, l'Abbé Croizet, Pomel, Bravard et Lyell en 1843 en BasseAuvergne, puis bien d'autres, multiplient les fouilles qui mettent en avant le rôle des vestiges fossiles dans la datation des terrains et leur intérêt pour restituer les cadres naturels au sein desquels l'Homme est apparu et a évolué.

De cette école, est née la Préhistoire européenne, indissolublement liée à la géologie et aux sciences environnementales dont le premier professionnel fut Edouard Lartet (1801-1871) accompagné en Périgord par l'Anglais Christy. A cet égard, il convient de remarquer que le titre de l'un des premiers périodiques spécialisés fut celui des "Matériaux pour l'histoire naturelle et primitive de l'Homme ».

On l'a constaté, sciences naturelles, sciences de la terre et archéologie sont constitutivement liées et je ne suis, pour ma part, pas certain que le néologisme de géoarchéologie soit bien utile pour rebaptiser la géologie du Quaternaire, avec un effet de mode... Plus sérieusement, au-delà des définitions, il est plaisant d'observer le dynamisme de la recherche actuelle et de constater comment ces méthodes ont pu renouveler l'approche des historiens. Au point qu'un récent congrès de l'Association française des archéologues médiévistes ait pu être totalement consacré aux approches paléoenvironnementalistes et à leur contribution au discours historique.

7 Dans ce volume, vingt trois auteurs issus du CNRS, de l'Université, de la Culture, des collectivités territoriales et de l'AFAN ont réuni treize communications présentant des synthèses régionales et thématiques concernant les grottes, les versants, les vallées et les lacs durant les vingt dernières années, où l'apport des approches actualistes est bien souligné. Le produit en est original à plus d'un titre et constitue, pour l'étudiant, mais aussi pour l'honnête homme soucieux d'élargir sa culture, et également pour le chercheur, désireux de trouver une somme des principaux acquis récents, une façon de manuel d'actualité dont il existe peu d'exemples en bibliothèque. Comme directeur de la publication des DARA, je suis heureux de cette ouverture de la collection et je remercie le Comité de rédaction de la confiance qu'il a ainsi témoignée aux spécialistes des sciences de la Terre. Il leur revient désormais de démontrer que audace éditoriale puisse se traduire en terme de succès de diffusion. 


\title{
Avant-propos
}

\author{
Jean-Paul Bravard et Michel Prestreau
}

1 Depuis 15000 ans, les paysages évoluent de manière complexe sous l'effet conjugué des variations climatiques et des actions humaines. L'étude des sociétés intègre de plus en plus le cadre de vie et ses changements à différentes échelles d'espace et de temps. Née de ces interrogations, la géoarchéologie rassemble la communauté des archéologues et des spécialistes de l'environnement sur un projet commun. Afin de faire le point, le Service régional de l'archéologie a pris l'initiative de ces entretiens qui se sont déroulés au mois de novembre 1995. Ils ont été accueillis par J. Lasfargues au musée gallo-romain de Lyon.

2 La région Rhône-Alpes offre une gamme de milieux très variés qui se sont prêtés à un ensemble de travaux interdisciplinaires associant archéologues, naturalistes et archéomètres. Dès le milieu des années 70 , des résultats d'une grande importance étaient acquis dans les milieux lacustres de la périphérie alpine et dans les grottes des massifs calcaires du Vivarais, des Préalpes et du Jura; il fallut attendre le milieu des années 80 pour que des études soient réalisées sur des versants et dans les plaines alluviales. Ces entretiens ont eu pour ambition de faire pour la première fois le bilan des principaux acquis dans le domaine de la géoarchéologie en Rhône-Alpes en rassemblant des spécialistes des différents domaines concernés par ces collaborations. Il nous a paru opportun de confronter ces résultats avec ceux obtenus dans les régions voisines que sont la Provence et la Bourgogne.

3 Une grande partie des résultats précédemment acquis a fait l'objet de publications scientifiques dans des revues spécialisées et est donc connue de la communauté des chercheurs. Toutefois, il est apparu important de réunir les équipes pour témoigner de l'intérêt des démarches interdisciplinaires en archéologie. Ces entretiens furent l'occasion de riches échanges entre des archéologues spécialistes de différentes époques et les chercheurs impliqués dans de multiples collaborations.

4 Ce volume rassemble l'essentiel des contributions présentées lors de ces journées. Il s'articule autour de quatre thèmes majeurs correspondant aux quatre milieux mentionnés ci-dessus : les grottes, les versants, les fonds de vallée et les lacs. Chaque ensemble comprend une synthèse des principaux résultats acquis depuis une vingtaine d'années et une série d'articles qui font le point sur des études interdisciplinaires 
particulièrement démonstratives. La bibliographie des synthèses permettra au lecteur de se reporter aux travaux publiés antérieurement.

5 Les discussions qui sont jointes aux contributions présentées dans ce volume témoignent du vif intérêt des débats suscités par ces entretiens. Ils furent l'occasion d'exprimer à nouveau les attentes et les réserves de communautés aux sensibilités différentes en matière de collaboration interdisciplinaire. La notion de complémentarité entre les recherches a rassemblé les spécialistes présents qui se sont accordés sur l'intérêt de renouveler cette démarche. 
Géoarchéologie des grottes 


\section{Géoarchéologie des grottes : contexte et sédiments}

\section{Évelyne Debard}

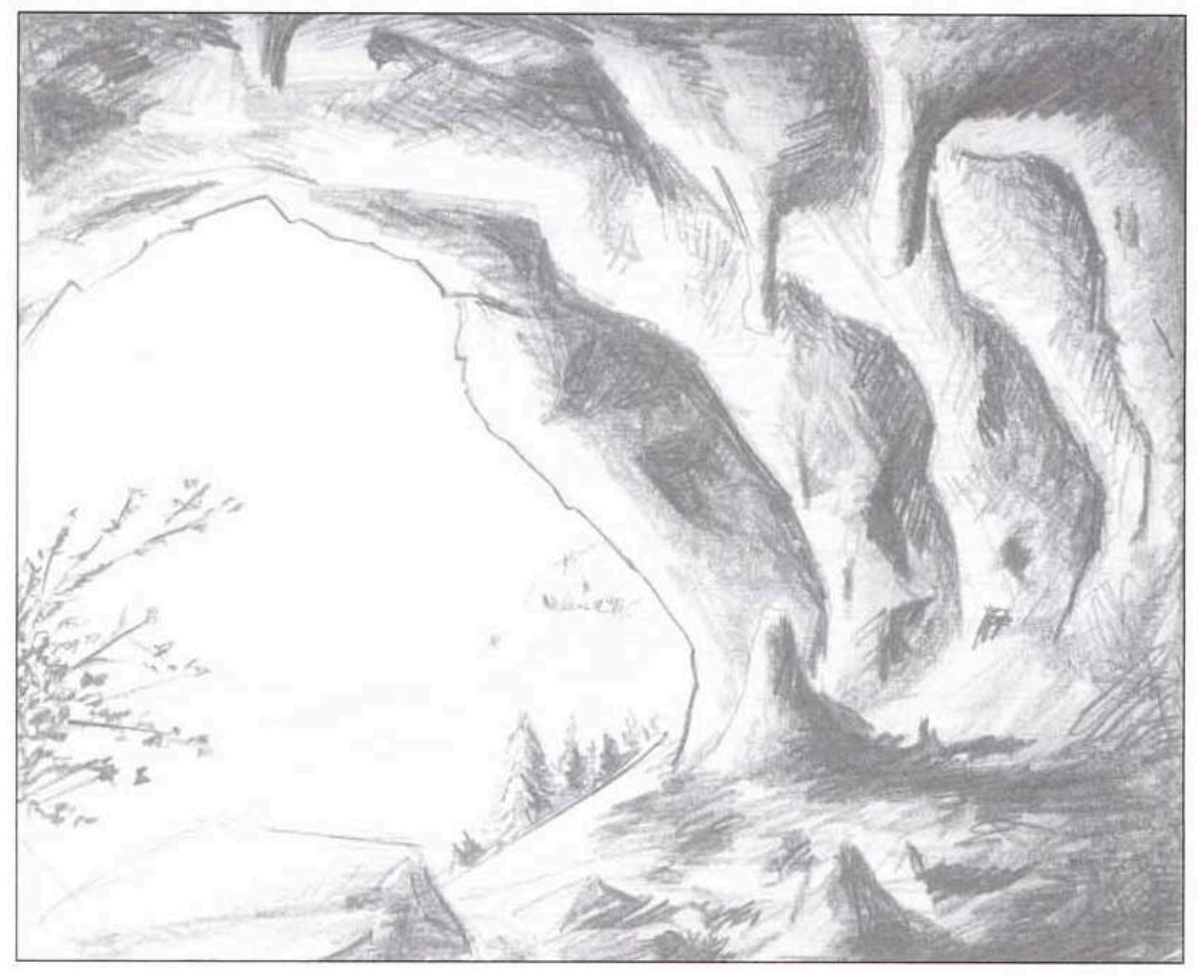

1 Pendant longtemps, les grottes ont été l'habitat préhistorique par excellence. En effet, on peut y observer des stratigraphies discontinues mais parfois très longues qui ont joué un rôle important dans l'établissement de la chronologie de base de la Préhistoire. Depuis plusieurs années, ces sites ont été délaissés pour d'autres contextes «plus porteurs » qui ont mis en évidence les défauts et les limites des stratigraphies en grottes. Toutefois, le développement de l'archéologie spatiale a montré que ces sites 
appartenaient bien au patrimoine archéologique et que leur étude s'intégrait dans une analyse globale du milieu de vie des populations préhistoriques.

2 Les habitats en grottes sont des milieux particuliers, à extension limitée par l'encaissant rocheux. Le contexte, souvent calcaire, détermine plusieurs types de sites et influe fortement sur la nature et l'évolution des remplissages.

\section{Le milieu « grotte »}

3 L'appellation générique "grottes » recouvre en réalité plusieurs catégories de cavités rencontrées dans des contextes géomorphologiques de versants ou de plateaux, et soumises en conséquence à des conditions de milieux diverses.

\section{Les types de sites}

$4 \quad$ Les grottes sensu stricto sont des cavités souterraines se développant en réseaux plus ou moins complexes. La plupart sont creusées dans des calcaires et dépendent donc des processus de karstification. Il existe des exceptions comme par exemple les galeries connues dans les grès du Trias en Ardèche ou la grotte de Rouffignac (Vézère) située dans l'argile à silex. L'essentiel du creusement des réseaux s'est fait pendant les périodes chaudes et humides de la fin du Tertiaire et s'est poursuivi en partie au cours du Quaternaire.

5 Les grottes débouchent à l'extérieur au niveau d'un porche d'entrée qui correspond au recoupement des réseaux souterrains par l'évolution des versants. Elle peuvent également communiquer avec la surface du massif calcaire par un puits ou aven.

Les porches d'entrée constituent un milieu particulier, intermédiaire entre un domaine typiquement karstique et un domaine externe, et les remplissages qu'on y observe reflètent fréquemment cette dualité. A la base, on trouve généralement des dépôts issus des réseaux karstiques (fig. 1 A) : argiles, limons, sables, brun rouge mais aussi versicolores, associés parfois à des éléments plus grossiers roulés (fragments calcaires des parois, concrétions et planchers stalagmitiques). Ces sédiments, résultant d'une phase d'activité du karst profond, sont recouverts par des dépôts provenant de la gélivation des parois du porche et/ou de processus géodynamiques externes variés : déplacements de formations superficielles sur les pentes par le ruissellement ou la gravité, alluvionnement fluviatile, sédimentation éolienne,... (fig. 1 B) 
1- Evolution d'un remplissage (ensembles sédimentaires 1,2,..6) sous un porche d'entrée de grotte en fonction du recul de celui-ci et des différents types d'apports (karst, paroi, versant, vent)

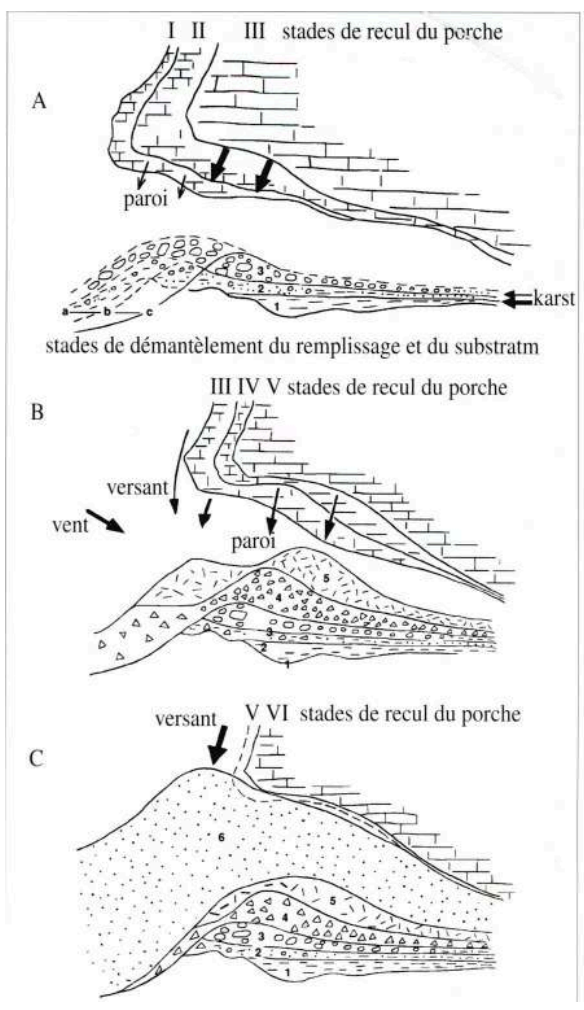

A : DÉbUt DE LA SÉDIMENTATION :

B : PHASES DE SÉdIMENTATION PRINCIPALES ;

C : PHASE finAle. L'ÉPAISSEUR des flèches SOULIgNe LA PRÉdoMinANCE de TEL OU TEL TYPE D'APPORTS

7 Lorsque ces porches sont totalement colmatés (fig. 1 c), ils peuvent être confondus avec des abris sous roche; leur relation avec un réseau profond n'apparaîtra que lorsque leur remplissage sera en partie fouillé. C'est le cas de l'abri des Pêcheurs et de l'abri Moula en Ardèche, petites cavités peu marquées au départ et dont la fouille a montré leur appartenance à des réseaux karstiques développés.

Les avens sont des cavités naturelles souterraines, pénétrables, s'ouvrant en surface par un conduit proche de la verticale. Ils correspondent au recoupement par l'érosion dorsale de réseaux verticaux simples, ou bien à l'effondrement de la voûte au droit d'un réseau horizontal. Les sites de Baume-Ronze et d'Orgnac III représentent deux stades d'évolution des avens: le premier se présente comme une vaste cavité large d'une soixantaine de mètres, aux parois verticales sur une hauteur de 10 à $25 \mathrm{~m}$, donnant accès à une galerie descendante tapissée d'un éboulis de blocs anguleux. L'aven d'Orgnac III correspond à une ancienne galerie dont l'effondrement de la voûte a permis le piégeage de sédiments qui l'ont entièrement comblé : à travers l'évolution de leurs caractéristiques au sein du remplissage, on peut suivre l'ouverture progressive de la cavité et l'influence de plus en plus grande des apports extérieurs (Debard 1988).

Les abris sous roche correspondent à des cavités naturelles de faible profondeur, souvent largement ouvertes dans une paroi rocheuse. Ce sont des formes superficielles, rarement en relation avec d'anciens réseaux souterrains. Leur amorce s'effectue au niveau d'une discontinuité de la roche : joint de stratification, changement de faciès ou de lithologie. Ces discontinuités servent de drains naturels et donne de multiples 
suintements humidifiant la paroi. Par le jeu de la dissolution et de la gélivation, ces drains s'élargissent progressivement. Une fois l'abri amorcé, son évolution se fait par une succession d'approfondissements par gélivation et d'effondrements des surplombs, d'autant mieux marqués que la roche est fissurée. L'alignement des baumes ou des abris souligne les niveaux de drainage préférentiels dans les parois rocheuses.

\section{Le contexte : le karst}

La répartition des grottes habitées dans la région Rhône-Alpes est calquée sur les zones calcaires soumises à la karstification (fig. 2). Dans l'Ardèche, les habitats se situent dans les secteurs où affleurent les calcaires du Jurassique supérieur (Kimméridgien supérieur, Tithonique) et ceux du Crétacé inférieur (Barrémo-Bédoulien à faciès urgonien). Dans la Drôme, les cavités se trouvent soit dans des calcaires néocomiens (Haute vallée de la Drôme), soit barrémo-bédouliens à faciès urgonien (massifs en bordure de la vallée du Rhône et Vercors). En Isère, ce sont les massifs calcaires urgoniens du Vercors et de la Chartreuse qui abritent l'essentiel des habitats en grottes et on trouve le même contexte géologique pour ceux de Savoie et de Haute-Savoie. Dans l'Ain, les grottes se situent dans des formations d'âge plus varié: Bajocien, Kimméridjien - Portlandien, Néocomien inférieur, Barrémo-Bédoulien.

\section{2- Répartition des habitats en grottes dans la région Rhône-Alpes}

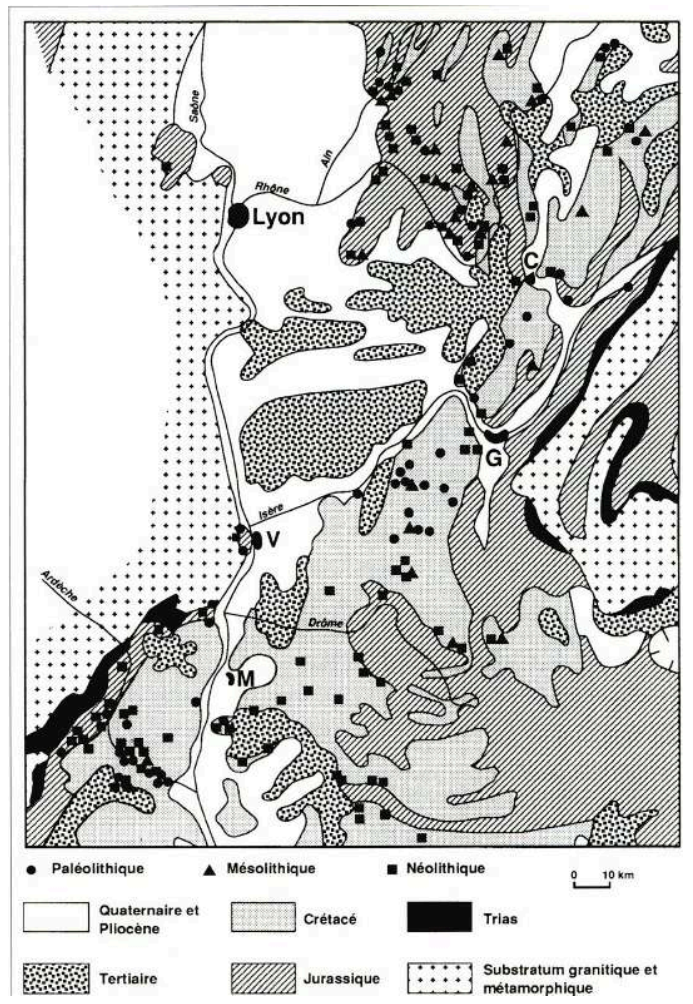

Localisation des sites d'après la base de données de la carte archéologique, mise à jour 1996 
Cette répartition reflète l'aptitude à la karstification des diverses assises calcaires jurassiques ou crétacées. Celle-ci se produit lorsque certaines conditions géologiques, climatiques et biologiques sont réunies :

- série calcaire au chimisme pur, épaisse, intensément fracturée, ce qui favorise l'infiltration des eaux et l'organisation d'un important drainage souterrain;

- eaux chargées en $\mathrm{CO}^{2}$ contenu dans l'atmosphère mais surtout dans la couverture biopédologique ;

- précipitations abondantes ;

- eaux froides plus chargées en $\mathrm{CO}^{2}$.

\section{Un milieu en constante évolution}

12 Si la répartition des cavités est tributaire de la géologie (aptitude des roches à la dissolution et à la karstification), d'autres facteurs sont à prendre en compte, comme les contextes géomorphologique et climatique qui ont varié au cours des temps et ont pu être très différents de l'actuel. L'évolution des cavités karstiques et de leurs remplissages est en effet liée (fig. 3) :

-à celle des versants, responsable du recul des surplombs, des remaniements des sédiments accumulés en position externe,

-à celle des plateaux, qui entraine une ablation en surface,

-à celle des drainages karstiques, qui peuvent induire un effet de soutirage vers des galeries inférieures.

Le climat joue un rôle essentiel en activant ou en ralentissant les phénomènes d'érosion. Ainsi en est-il de la dissolution des reliefs calcaires.

3- Evolution géomorphologique des remplissages de porches de grotte (A) et d'avens (B)

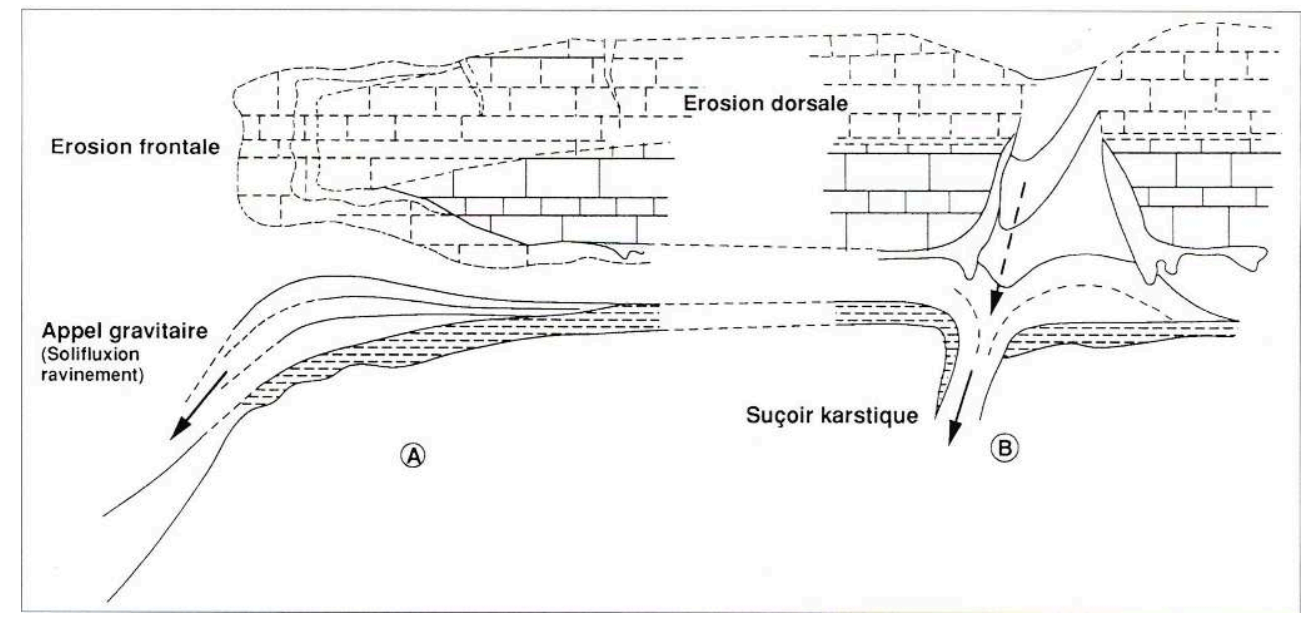

D'après Campy 1982

Tout plateau calcaire est soumis à une dissolution qui est sous la dépendance de plusieurs facteurs liés les uns aux autres par des relations complexes : climat, eau, fissuration, formations résiduelles, sol, végétation,... Cette ablation du relief s'effectue à deux niveaux : en surface, c'est l'érosion dorsale, sur la tranche, c'est l'érosion frontale (Aubert 1967). 
15 L'érosion dorsale se fait d'une façon relativement uniforme à l'échelle de l'unité géographique. Elle intéresse également les sols et les formations superficielles qui couvrent les plateaux et ce d'autant plus qu'ils sont chargés en squelette calcaire (Aubert 1969). L'ablation superficielle moyenne a été estimée pour de nombreux massifs calcaires français (Jura, Vercors, Languedoc, Quercy) et étrangers. Elle dépend beaucoup des facteurs climatiques comme les précipitations qui conditionnent la présence d'eau et son renouvellement. La température qui contrôle le $\mathrm{CO}^{2}$ dissous dans l'eau. Ainsi, pour les plateaux ardéchois situés en zone méditerranéenne, en se basant sur la composition chimique des eaux, on peut proposer un taux d'ablation karstique compris entre 12 et $25 \mathrm{~mm} /$ millénaire (Fabre 1980). Si on utilise la valeur moyenne de $20 \mathrm{~mm} /$ millénaire, on peut estimer à $6 \mathrm{~m}$ l'épaisseur de calcaire ayant disparu sur le plateau urgonien d'Orgnac-Saint-Remèze depuis le dépôt de la couche $\mathrm{dl} d \mathrm{du}$ gisement d'Orgnac III, datée de 300000 ans (Debard 1988). Si on retient qu'au cours de cette période de 300000 ans, le Bas-Vivarais a connu des conditions climatiques plus humides et plus froides que celles régnant aujourd'hui, il est certain que ces valeurs sont sous-estimées. En admettant que, pendant les périodes froides du Pléistocène, le climat de cette région était comparable à celui régnant actuellement sur le karst Slovène, région montagneuse humide de la zone méditerranéenne où la dissolution est de l'ordre de $60 \mathrm{~mm} /$ millénaire (Corbel 1956, 1959), ce ne sont plus $6 \mathrm{~m}$, mais plus de 15 $\mathrm{m}$ de calcaire qui auraient disparu depuis le dépôt de la dernière couche archéologique d'Orgnac III. C'est une approximation grossière, la valeur d'ablation réelle se situant sans doute autour de $10 \mathrm{~m}$. Dans le massif du Vercors, l'ablation moyenne atteint 100 à $120 \mathrm{~mm} /$ millénaire, voire $170 \mathrm{~mm}$ dans certains secteurs (Delannoy 1981, 1995). Ces fortes valeurs s'expliquent par le climat humide et frais de cette région (fortes précipitations, températures moyennes basses), par l'étendue de l'étage forestier et des sols bien développés. Pour le Jura, les valeurs seraient sensiblement les mêmes (Aubert 1967, 1969). Dans le secteur de l'aven de Vergranne, M. Campy (1990) propose une érosion superficielle de l'ordre de 5 à $8 \mathrm{~m}$ en 400000 ans environ. Ces quelques exemples montrent que, quelle que soit sa valeur estimée, les conséquences de l'érosion dorsale sur les sites de plateau et leurs dépôts sont importantes : elle a pu modifier la composition de certains remplissages, les faire disparaître partiellement et même totalement.

16 Pour les porches de grottes ou les abris, c'est l'érosion frontale qui fait disparaître les dépôts. Elle est plus active que l'érosion dorsale: dans le Jura, elle atteindrait des valeurs 5 à 6 fois plus forte (Aubert 1969). En Ardèche, on peut estimer que l'évolution des versants au cours du Quaternaire a fait reculer l'émergence de la grotte de SaintMarcel d'environ $150 \mathrm{~m}$. L'érosion frontale dépend de la somme de plusieurs facteurs : climatiques (possibilité de gélivation principalement), géologiques (nature de la roche, présence de diaclases, épaisseur des bancs, pendage des couches,...), biologiques (développement de racines, de lichens,...). Elle varie beaucoup d'une falaise à l'autre et sur la même paroi. La présence de blocs d'effondrement volumineux dans les remplissages, comme ceux du Maras (Debard 1988) ou de Payre (Moncel 1993), dénote bien une ablation des surplombs au cours du temps et il est vraisemblable qu'un certain nombre de sites, plus particulièrement d'abris, et de remplissages ont ainsi partiellement ou totalement disparu. Et ce d'autant plus que le recul des surplombs entraine une érosion gravitaire plus forte. 
17 L'érosion gravitaire, phénomène d'appel au vide exercé par le versant, entraine le tronquage des remplissages vers l'extérieur, voire leur destruction totale. Elle est d'autant plus active que le recul des surplombs expose les sédiments en situation externe aux phénomènes d'érosion. Les sédiments entraînés sur les versants vont alors alimenter des colluvions ou des cônes d'éboulis.

Des remaniements et des destructions de remplissages peuvent également se produire par soutirage karstique des sédiments vers les galeries à pente descendante ou vers des galeries inférieures. De tels phénomènes ont été observés dans les niveaux inférieurs des sites d'Orgnac III (Debard 1988), de l'abri des Pêcheurs (Gmira 1989), de l'abri Moula (Chennaoui 1992).

Inversement, de nombreux sites restent à découvrir. En effet, de puissants éboulis, nourris par l'érosion gravitaire se développant sur les versants, masquent des entrées de grottes ou comblent de nombreuses cavités. De nombreux exemples illustrent ce phénomène : ainsi la grotte de SaintMarcel découverte en 1838 par un chasseur dont le chien, à la poursuite d'un lapin, s'était faufilé entre la voûte du plafond et l'éboulis qui cachait entièrement le porche d'entrée (fig. $1 \mathrm{C}$ ), ou bien la grotte des Ours de la Balme à Collomb révélée en 1988 par un courant d'air s'échappant d'une diaclase bouchée par une trémie (Papet et al. 1991), ou encore la grotte Chauvet dont l'entrée naturelle est totalement colmatée par un éboulis (Clottes et al. 1995). Dans les réseaux souterrains, ce sont des cônes d'argile entraînée à travers les fissures du karst ou des cônes d'éboulis liés à des phénomènes de décompression des parois qui peuvent colmater certaines galeries. La découverte de ces sites « cachés » est souvent liée à des travaux de repérage et de désobstruction de la part de spéléologues, d'où l'importance des suivis spéléologiques par les services archéologiques.

\section{Les sédiments}

20 Les remplissages de porche, d'abri sous roche ou d'aven résultent de divers processus de sédimentation et de transformations post-dépositionnelles qui selon les sites vont être différents. La mise en place des sédiments et leurs caractéristiques dépendent en effet de nombreux facteurs comme le climat, les caractéristiques de l'encaissant, le contexte géomorphologique, l'action de l'homme.

21 D'une façon schématique, on peut décomposer l'histoire de tout sédiment archéologique en trois phases :

- une phase précédant l'occupation humaine contrôlée par des processus naturels, sédimentaires ( $=$ mise en place des dépôts) et pédologiques ( = transformations secondaires de ces dépôts) ;

- une phase contemporaine de l'occupation humaine intégrant l'ensemble des modifications anthropiques ;

- enfin une dernière phase postérieure à l'occupation humaine, relevant à nouveau de phénomènes naturels.

Selon les sites, la part de ces trois phases dans l'édification du sédiment diffère. Dans le cas d'un sédiment faiblement anthropisé (par exemple dans un site paléolithique), aucune modification sensible des caractères du sédiment n'est enregistrée au cours de la 2ème phase et l'étude de tels sédiments peut alors se résumer à une reconstitution paléoenvironnementale. Par contre, à partir de l'Holocène, les phénomènes 
anthropiques deviennent tellement importants qu'ils oblitèrent et remplacent dans leur quasi-totalité la signature des processus naturels.

Dans toute étude des remplissages karstiques, il convient donc de faire la part des processus de sédimentation, c'est-à-dire constructeurs, qu'ils soient d'origine naturelle ou d'origine anthropique, et la part des processus de remaniement, de transformation, c'est-à-dire destructeurs, dus à l'action des agents géodynamiques ou à celle de l'homme.

\section{Les processus de sédimentation}

\section{Sédimentation naturelle}

Deux types de sédimentation se rencontrent: la sédimentation détritique et la sédimentation carbonatée.

\section{La sédimentation détritique}

Grossière, elle a généralement une origine locale : elle est le plus souvent le résultat de la gélifraction ou de l'effondrement des parois du site. Dans de nombreux gisements karstiques, on peut suivre à la fois le recul des surplombs par éboulement de blocs et l'effritement des autres parois en petits fragments gélifs (fig. 1). Selon les gisements, parfois dans le même, on observe que le délitage des parois ne s'effectue pas de la même manière. Ce phénomène, bien que contrôlé par l'intensité et la durée de la gélivation traduit des différences faciologiques et structurales de la roche. Ainsi au niveau du porche de la grotte de Saint-Marcel existent deux faciès de l'Urgonien superposés qui produisent des fragments gélifs totalement différents (Debard 1988). On voit ici une des limites de l'interprétation climato-sédimentaire qui associe le type de sédiments, en particulier la taille des cailloux calcaires, à l'intensité du froid.

Parfois le matériel grossier provient d'éboulis situés au-dessus du gisement, non stabilisés par la végétation et se déplaçant sur les pentes soit par simple gravité, soit en coulées de boue, soit sous l'action des eaux de ruissellement. Ce type de mise en place est fréquent pour les grottes à pente rentrante : par exemple, l'abri Moula se présente comme une cavité en cheminée, largement ouverte sur l'extérieur, qui a recueilli plusieurs coulées (Chennaoui 1992). Ces mises en place entraînent des taux de sédimentation élevés ( $20 \mathrm{~cm}$ de dépôts par siècle au Dryas II dans l'abri de la Cure Bintz et Girard 1995) et peuvent se faire en un laps de temps très court comme le montrent des observations actuelles (dépôt d'un cône de cailloutis « cryoclastiques » de $1 \mathrm{~m}$ de hauteur à l'entrée de la grotte de Saint-Marcel lors d'un orage à la fin de l'été 1976). Ces phénomènes sont amplifiés par l'anthropisation du milieu. Cela indique que la mise en place des fractions grossières n'est pas toujours sous le contrôle général du climat.

Dans d'autres sites, les éléments grossiers proviennent du remaniement de formations situées soit à l'intérieur du karst (cailloux karstiques roulés et émoussés, morceaux de concrétions stalagmitiques, vieux remplissages de galets fluviatiles ou fluvio-glaciaires piégés dans la partie amont des réseaux), soit à l'extérieur sur le plateau et ayant transité par les fissures et les conduits du karst avant d'être piégés. Ce type de sédimentation se produit principalement avant l'installation des hommes. 

plus lointaines transportées par des rivières en crue et déposées dans les cavités proches des cours d'eau. C'est le cas dans certaines cavités du Jura méridional au Tardiglaciaire (Loebell 1979) ou en Ardèche comme à la grotte Chabot où des sables de débordement sont interstratifiés avec des niveaux solutréens (Combier 1967). Les cavités sont également des milieux favorables au piégeage de particules transportées par voie aérienne. Ce type de sédimentation, soit d'origine éolienne, soit d'origine volcanique, a été mise en évidence dans plusieurs sites d'Ardèche. Les apports éoliens observés dans les gisements d'Orgnac III, de Saint-Marcel, du Maras (Debard 1987) se manifestent par des associations minéralogiques argileuses allochtones, le façonnement éolien des quartz, la granulométrie des fractions fines proche de celle des loess. Cette sédimentation éolienne est le marqueur des phases pléniglaciaires, les phases interglaciaires et de transition se traduisant par une sédimentation autochtone à partir des formations meubles de l'environnement proche. Des retombées volcaniques ont été mises en évidence dans l'aven d'Orgnac III où un téphra originaire du Sancy date le sommet du remplissage de 300000 ans (Debard et Pastre 1988; Khatib 1994) et dans le remplissage supérieur de l'abri Moula où une retombée phréatomagmatique issue d'un maar du Haut-Vivarais s'est trouvée piégée, il y a environ 40000 ans (Pastre et al. 1994). Dans la Drôme. un téphra en provenance du Mont Dore a également été découvert dans le gisement plio-pléistocène de Saint-Vallier (Pastre et al. 1996).

\section{La sédimentation carbonatée}

31 Elle résulte de la réaction inverse à celle qui préside à la dissolution. L'étude des spéléothèmes et des tufs dans le Vercors (Delannoy 1995) montre que leur formation est sous la dépendance des conditions extérieures et qu'elle indique des conditions biostasiques et écologiquement stables: les périodes de croissance des concrétions correspondent aux optima climatiques alors que les phases de rémission ou d'arrêt sont liées à des crises rhéxistasiques d'ordre morphoclimatique (refroidissement) ou anthropique (déforestation). Ainsi, la présence de planchers stalagmitiques dans les grottes d'Ardèche (Les Pêcheurs, Saint-Marcel, Ranc Pointu nº 2) (Debard 1988) comme dans celles du cirque de Choranche (Delannoy 1995) soulignent l'optimum climatique éémien. Des concrétionnements plus discrets, mis en évidence dans les gisements des Pêcheurs et du Ranc Pointu n ${ }^{\circ}$ 2, correspondent à l'interstade wûrmien. 


\section{Sédimentation anthropique} ou organiques ou résulter d'activités :

- apport de matériaux pour la construction, l'aménagement de l'habitat (construction de murs, structuration des foyers);

- apports de sédiments fins pour les torchis ou la confection des céramiques ;

- apports de végétaux pour les litières ou comme constituant de certains matériaux de construction;

- apport de bois pour les feux produisant des charbons et des cendres ;

- accumulation de fumiers par les animaux domestiques (Brochier J.-E. 1983; Brochier, J.-L. 1986). Ces apports permettent d'appréhender des activités saisonnières comme cela a été démontré dans les grottes-bergeries d'Antonnaire (Brochier 1986; Argant 1988) ou de la Baume Ronze (Beeching \& Crubezy 1991);

- apports par les pieds d'agrégats sablo-limonoargileux ou cônes de dévalement de troupeaux comme dans la Baume Courtinasse (Brochier 1994).

\section{Processus de transformation}

Après leur mise en place, les sédiments sont soumis à des processus de transformations dues à des causes naturelles ou à des causes anthropiques.

\section{Transformations d'origine naturelle}

Ce sont essentiellement :

- des phénomènes physiques responsables de la gélifraction des blocs tombés à terre (Laville 1975), de la ségrégation des particules argileuses en lits minces ou en revêtement pelliculaire autour de particules plus grossières, de transferts de particules fines par les eaux de percolation ;

- des phénomènes d'érosion liés aux eaux courantes entraînant le plus souvent la disparition ou la perturbation des sédiments situés au débouché des galeries, à l'aplomb des fissures karstiques ou au-dessus de conduits (fig. 3) ;

- des phénomènes d'altération biochimique (d'autant plus marqués que les sites sont éloignés des zones englacées) comme la dissolution des débris calcaires, des cendres, des os, des éléments siliceux. Ces transformations entraînent des migrations dans les sols et des réactions avec les autres composants: par exemple dans le dernier niveau archéologique d'Orgnac III, la silice issue de l'altération des silex (Masson 1981) a induit des néogenèses sur les grains de quartz (Debard 1988);

- des phénomènes d'appel au vide sur les versants lorsque les surplombs ne protègent plus les sédiments (fig. 3);

- de la bioturbation due à des terriers de rongeurs, d'annelides ou de larves d'insectes pouvant remanier les sédiments sur plusieurs centimètres voire plusieurs mètres de profondeur (Courty et al. 1989) et produisant des microagrégats caractéristiques. Les racines entraînent la formation de vides permettant des circulations d'eau qui, jusqu'à des profondeurs importantes, vont transformer les sédiments par lessivage ou apports d'éléments détritiques ou solutés qui précipitent sous des formes variées (nodules, pseudo-mycelium, manchons radicellaires). 


\section{Transformations d'origine anthropique}

Elles sont liées à l'aménagement du site, aux circulations humaines ou animales, aux activités pratiquées.

- C'est le cas des remaniements de dépôts réalisés pour aménager des sépultures ou des foyers : par exemple, dans l'abri des Pêcheurs, les aurignaciens ont creusé dans les niveaux moustériens une petite fosse, étayée par une murette de blocs et de plaquettes alignés parallèlement à la paroi, parfois placés de chant (Lhomme 1979). Ces remaniements peuvent correspondre aux nivellements des surfaces d'occupations, tels ceux mis en évidence dans les niveaux du Bronze final IIIa de la grotte du Gardon (Sordoillet, ce volume).

- Les circulations humaines ou animales entrainent le déplacement des sédiments ou des particules par tassement et étalement (Courtin \& Villa 1982 ;Brochier 1994).

- Les foyers entraînent la transformation des sédiments sur lesquels ils reposent par rubéfaction et calcination.

Toutes ces transformations pèsent sur la notion de sol d'habitat. En effet, quelle valeur accorder à tel ou tel témoin d'activité lorsqu'on prend conscience des évolutions multiples que peuvent subir les sédiments archéologiques? Un autre élément vient compliquer l'interprétation : c'est l'évalution du temps écoulé entre le moment où s'est élaborée une structure et la fixation de son image telle que nous la voyons aujourd'hui.

\section{Intérêt et limites de l'étude des grottes}

Pendant très longtemps, les grottes ont constitué l'unique terrain de la recherche préhistorique. En effet, presque toutes les cavités d'accès aisé ont été occupées épisodiquement à de nombreuses reprises au cours de la Préhistoire et de l'Histoire jusqu'à l'époque actuelle. Parallèlement, les études sur les sédiments de ces sites se sont développées et les travaux de J.C. Miskovsky (1974) et H. Laville (1975) ont servi de référence pour de nombreuses interprétations paléoclimatologiques. Mais depuis quelques années, on s'est rendu compte de l'intérêt limité de tels gisements aussi bien dans la connaissance de la culture des groupes humains qui les ont fréquentés que dans les reconstitutions paléoenvironnementales. En effet, ces sites ne représentent bien souvent que des abris temporaires ou de complément à des villages de plaine. La recherche archéologique s'est alors reportée sur la fouille des sites de plein air correspondant aux structures d'habitat principales. Par ailleurs, leurs séquences stratigraphiques présentent de nombreuses lacunes (Campy 1985) et reflètent souvent des conditions locales d'évolution du milieu encaissant: par exemple, au sein de la même formation géologique, on constate que le délitage des parois par le gel/dégel est spécifique à chaque site (Debard 1988). Les grottes correspondent à un milieu tamponné n'enregistrant que certains paramètres du climat. A ce titre, les remplissages karstiques ne sont pas de bons enregistreurs du climat général ou même régional (Campy 1990 ; Campy et al 1994). De même, la faune, les charbons de bois ou les pollens recueillis dans ce type d'environnement n'ont bien souvent qu'une valeur locale en raison de l'empreinte anthropique qui les caractérise.

Cependant, le développement de nouvelles méthodes d'analyse, en particulier celles de l'archéologie spatiale et celles de la géoarchéologie, est venu renouveler l'intérêt des remplissages de grotte, et cela pour plusieurs raisons. Les grottes ont toujours rempli 
de multiples fonctions et les recherches dans la région ont contribué à bien le démontrer depuis une quinzaine d'années.

- On connaît la fonction habitat qui a fait la réputation des grottes pendant des décennies. Le développement des fouilles sur de larges surfaces et des observations stratigraphiques à une échelle fine a mis en évidence les difficultés rencontrées pour cerner cet aspect. Toutefois dans de nombreux cas, la géoarchéologie, en particulier au travers de la micromorphologie, apporte des réponses.

- L'utilisation des grottes comme lieux de sépultures est bien connue.

- La fonction halte de chasse est démontrée par l'étude de la faune chassée à certaines saisons (Chaix \& Bridault 1994).

- Depuis une quinzaine d'années, l'étude des limons de grottes (Brochier J.-E. 1983; Brochier J.-L. 1986; Brochier et Beeching 1994) et des pollens associés (Argand 1988) a démontré l'utilisation des grottes comme bergeries, pendant tout le Néolithique et pendant la Protohistoire aussi bien en Ardèche (Baume Ronze, Grotte de SaintMarcel), dans la Drôme (grottes d'Antonnaire, de la Tune de la Varaime, baume Courtinasse), que dans l'Ain (grotte du Gardon).

- La fonction sanctuaire utilisant les zones profondes des cavités est connue depuis lontemps. On peut y rattacher la fonction paléospéléologique, évoquée pour plusieurs grottes du Vercors (Bintz \& Picavet 1992), qui montre que des hommes ont exploré en totalité des réseaux, franchi des obstacles techniques, dans un but purement gratuit ou bien symbolique. - La fonction ressources peut être également évoquée dans le cas de la collecte d'eau avec l'aménagement de certaines cavités comme la grotte de Gaude et de Chazelles en Ardèche (Combier 1971; Combier \& Nikitine 1973), de l'extraction et l'exploitation des silex observées dans les grottes de Pellebit en Haute Drôme (Brochier 1994), de la collecte d'argile pour les poteries ou de concrétions incorporées aux céramiques.

Toutes ces fonctions montrent la complémentarité des grottes avec d'autres sites. Ainsi en est-il avec les grottes-bergeries, comme à Antonnaire et à Baume Ronze, qui impliquent la transhumance entre les lieux d'habitat en plaine ou en fond de vallée et les zones de pâturage situées en hauteur (Brochier \& Beeching 1994). C'est également le cas des grottes sépulcrales qui peuvent être en relation avec des habitats de plein air : on peut citer l'exemple de l'éperon barré du Ranc Pointu en Ardèche où un habitat de plein air du Bronze final IIIb a pu coexister avec une occupation en grotte à fonctions multiples: artisanat, funéraire, habitat temporaire (Durand 1994). Les études de paléoenvironnement ont un rôle essentiel pour percevoir et cerner les diverses utilisations des sites en grotte (Sordoillet ce volume ; Thiebaut \& Bintz ce volume)

D'autre raisons viennent justifier les études sur les remplissages karstiques. Les grottes présentent souvent des stratigraphies développées. Elles servent alors de référence pour des stratigraphies réduites. C'est particulièrement net pour les Alpes du Nord (Thiebaut \& Bintz ce volume). En Ardèche, la Baume-Ronze sert d'élément de comparaison à l'échelle de la Moyenne Vallée du Rhône (Brochier \& Beeching 1994).

41 Les grottes, espaces clos et protégés, permettent la conservation de certains dépôts, non préservés dans d'autres contextes. L'étude de leurs remplissages apporte alors des données irremplaçables sur les processus géodynamiques du milieu quaternaire et post-glaciaire. Nous avons vu en particulier que les grottes ardèchoises ont été des pièges pour les sédiments éoliens et les téphras (Debard 1988). Ces cas illustrent également les apports réciproques entre l'archéologie et la géologie du Quaternaire. Prenons l'exemple des retombées volcaniques: elles permettent de dater de façon 
précise les gisements comme cela a été fait à Orgnac III (Debard \& Pastre 1988), mais inversement, elles apportent des éléments nouveaux sur le volcanisme (précision sur l'âge de l'éruption phréatomagmatique de la Vestide de Pal grâce à l'industrie de l'abri Moula, aire de dispersion du panache), (Pastre et al. 1994). Un exemple tout à fait comparable pourrait être développé avec l'étude du matériel lithique qui fournit à la fois des données purement archéologiques (origine des matériaux, choix des roches selon les outils, échanges) mais aussi des connaissances approfondies sur les formations géologiques utilisées (composition pétrographique, genèse). Les opérations pluridisciplinaires peuvent être à bénéfice mutuel!

\section{BIBLIOGRAPHIE}

\section{Bibliographie}

Argant 1988 : ARGANT (J.) - Analyses palynologiques de gisements quaternaires du Bassin du Rhône. Thèse Doct., Univ. Cl. Bernard Lyon I, 219 p.

Aubert 1967 : AUBERT (D.) - Estimation de la dissolution superficielle dans le Jura. Bull. Soc. Vaud. Sc. Nat., Lausanne, vol. 69, $\mathrm{n}^{\circ}$ 8, pp. 365-376.

Aubert 1969 : AUBERT (D.) - Phénomènes et formes du karst jurassien. Eclogae Geol. Helv., Bâle, vol. 62, n 2, pp. 325-399.

Beeching et Crubezy 1991: BEECHING (A.) \& CRUBEZY (E.) - Sépultures, territoire et société dans le Chasséen méridional : l'exemple du bassin rhodanien. In : L'environnement et son anthropisation à l'optimum néolithique dans la moyenne vallée du Rhône. La dynamique homme/milieu naturel, rapport Piren mars 1991, Centre d'Archéologie Préhistorique de Valence, 24 p.

Bintz et Picavet 1992 : BINTZ (P.) \& PICAVET (R.) - Deux exemples de paléospéléologie sur les hauts plateaux du Vercors : la grotte du Campagnol et la grotte charbonnière. In: Actes des Rencontres Néolithiques de Rhône-Alpes, 7-1992, Univ. Lumière Lyon II, Centre d'Archéologie préhistorique de Valence, pp. 55-60.

Bintz et Girard 1995 : BINTZ (P.) \& GIRARD (M.) - Le Tardiglaciaire et l'Holocène à l'abri de La Cure (Baulmes, Vaud, Suisse) et dans quelques sites préhistoriques des Alpes du Nord et du Jura méridional. Rev. Paléobiol., Genève, vol. 14, n 1, pp. 107-123.

Brochier 1983 : BROCHIER (J.-E.) - Combustion et pacage des herbivores domestiques. Le point de vue du sédimentologue. Bull. S.P.F., Paris, t. 80, n 5, pp. 143-145.

Brochier 1986 : BROCHIER (J.-L.) - Sédiments - documents archéologiques : la grotte d'Antonnaire - grotte bergerie. In : Culture et milieu des premiers paysans de la Moyenne Vallée du Rhône. ARENERA, Lyon, Centre d'Archéologie préhistorique de Valence, pp. 32-33.

Brochier 1994 : BROCHIER (J.-L.) - Utilisation de grottes d'altitude dans les préalpes du Haut Diois : exploitation de silex à Pellebit inférieure et supérieure, bergerie à Courtinasse. In : Archéologie spatiale en Vallée du Rhône, Centre d'Archéologie Préhistorique de Valence, pp. 17-19. 
Brochier et Beeching 1994 : BROCHIER (J.-L.) \& BEECHING (A.) - Milieu naturel et impact anthropique. Un exemple : l'homme et le mouton. L'apport des grottes de bergeries des Préalpes Dioises. In: Archéologie spatiale en Vallée du Rhône, Centre d'Archéologie Préhistorique de Valence, 1994, pp. 25-32.

Campy 1982 : CAMPY (M.) - Le Quaternaire franc-comtois : Essai chronologique et paléoclimatique. Thèse Doct. Etat, Univ. Franche-Comté,, Besançon, 557 p.

Campy 1985 : CAMPY (M.) - Continuités et discontinuités sédimentaires dans les sites archéologiques de porches de grotte. Implications sur les séquences palynologiques correspondantes. Edit, du CNRS. Notes et Monographies techniques, $\mathrm{n}^{\circ} 17, \mathrm{pp} .227-244$.

Campy 1990 : CAMPY (M.) - L'enregistrement du temps et du climat dans les remplissages karstiques : l'apport de la sédimentologie. In : Colloque Remplissages karstiques \& paléoclimats, Karstologia, Mém. n 2, pp. 11-22.

Campy et al. 1994 : CAMPY (M.), BINTZ (P.), EVIN (J.), LAVILLE (H.) \& CHALINE (J.) - Sedimentary record in French karstic infillings during the last climatic cycle. Quaternaire, Paris, 5 (3-4), pp. 157-163.

Chaix et Bridault 1994 : CHAIX (L.) \& BRIDAULT (A.) - Nouvelles données sur l'exploitation des animaux sauvages de l'Epipaléolithique au Mésolithique final dans les Alpes du Nord et le Jura. Preistoria Alpina, Museo Tridentino di Scienze Naturali, vol. 28, pp. 115-127.

Chennaoui 1992 : CHENNAOUI (K.) - Etude sédimentologique des sites préhistoriques de Soyons (Ardèche, France) : dynamique sédimentaire et paléoclimatologie. Thèse Doct., Univ. Cl. Bernard Lyon I, $126 \mathrm{p}$.

Clottes et al. 1995 : CLOTTES (J.), CHAUVET (J.-M.), BRUNEL-DESCHAMPS (E.), HILLAIRE (C.), DAUGAS (J.-P.), ARNOLD (M.), CACHIER (H.), EVIN (J.), FORTIN (Ph.), OBERLIN (C.). TISNERA (N.) \& VALLADAS (H.) - Les peintures paléolithiques de la Grotte Chauvet-Pont-d'Arc (Ardèche, France) : datations directes et indirectes par la méthode du radiocarbone. C. R. Acad. Sc., Paris, t. 320, série IIa, pp. 1133-1140.

Combier 1967 : COMBIER (J.) - Le Paléolithique de l'Ardèche dans son cadre paléoclimatique. Publ. Inst. Préhist. Bordeaux, Mém. n 4, 462 p.

Combier 1971 : COMBIER (J.) - Anciennes civilisations retrouvées entre Rhône et Cévennes. Et. préhist., Lyon, $\mathrm{n}^{\circ} 1$, pp. 24-26.

Combier et Nikitine 1973 : COMBIER (J.) \& NIKITINE (S.)- L'Azilien de la caverne de Chazelles à Saint-André-deCruzières (Ardèche). Et. préhist., Lyon, n 7, pp. 1-4.

Corbel 1956 : CORBEL (J.) - Le karst du Vercors. Rev. Géogr. Lyon, vol. XXXI, n 3, pp. 221-241.

Corbel 1959 : CORBEL (J.) - Vitesse de l'érosion. Zeitsch. Geomorph., Berlin, Bb. 3, Heft 1, pp. 1-28.

Courtin et Villa 1982 : COURTIN (J.) \& VILLA (P.) - Une expérience de piétinement. Bull. S.P.F., Paris, t. 79, n 4, pp. 116-123.

Courty, Goldberg et Macphail 1989: COURTY (M.-A), GOLDBERG (P.) \& MACPHAIL (R.-I.) - Soils and Micromorphology in Archaeology. Cambridge manuals in Archaeology, Cambridge University Press, $344 \mathrm{p}$.

Debard 1987 : DEBARD (E.) - L'apport allochtone éolien dans les remplissages karstiques quaternaires du Bas-Vivarais (S.E. France). Bull. AFEQ, Paris, vol. 4, pp. 183-193. 
Debard 1988 : DEBARD (E.) - Le Quaternaire du BasVivarais d'après l'étude sédimentologique des remplissages d'avens, de porches de grottes et d'abris sous roche. Dynamique sédimentaire, paléoclimatologie, chronologie. Doc. Lab. Géol. Lyon, 315 p.

Debard et Pastre 1988 : DEBARD (E.) \& PASTRE (F.) - Un marqueur chronostratigraphique du Pléistocène moyen à la périphérie du Massif Central : la retombée à clinopyroxènes vert du Sancy dans l'aven d'Orgnac III (Bas-Vivarais, S.E. France). C. R. Acad. Sc., Paris, pp. 1515-1520.

Delannoy 1981 : DELANNOY (J.-J.) - Le Vercors septentrional. Le karst de surface et le karst souterrain. Recherches géomorphologiques sur un karst de moyenne montagne alpine. Thèse 3ème cycle, Univ. Grenoble, 517 p.

Delannoy 1995 : DELANNOY (J.-J.) - La spécificité karstique du Massif du Vercors : la contribution du karst dans la reconstitution paléogéographique et paléoenvironnementale d'un massif calcaire. In : Epipaléolithique et Mésolithique en Europe, Livret-Guide de l'excursion Préhistoire et Quaternaire en Vercors, 1995, pp. 20-27.

Fabre 1980 : FABRE (G.) - Les karsts du Languedoc oriental : Recherches hydrogéomorphologiques. Mém. Assoc. fr. Karstologie, Nîmes, nº 2, 446 p.

Gmira 1989 : GMIRA (A.) - L'abri des pêcheurs (Ardèche) : Etude sédimentologique de la séquence moustérienne. D. E. A. Univ. Cl. Bernard Lyon 1, 29 p.

Khatib 1994 : KHATIB (S.) - Datation des cendres volcaniques et analyses géochimiques du remplissage d'Orgnac III (Ardèche, France). Quaternaire, Paris, 5 (1), pp. 13-22.

Laville 1975 : LAVILLE (H.) - Climatologie et chronologie du Paléolithique en Périgord : étude sédimentologique de dépôts en grottes et sous abris. Et. Quatern., Marseille, mém. n 4, 422 p.

Lhomme 1979 : LHOMME (G.) - Campagnes de fouilles 1978 et 1979 dans l'abri des Pêcheurs à Casteljau (Ardèche). Nouv. Arch. Mus. Hist. nat. Lyon, fasc. 17, suppl., pp. 65-70.

Loebell 1979 : LOEBELL (A.) - Les quinze derniers millénaires en Jura méridional : études sédimentologiques de trois sites. Bull. AFEQ, Paris, $\mathrm{n}^{\circ}$ 3, pp. 143-153

Masson 1981 : MASSON (A.) - Altération des silex préhistoriques : dissolution, néogenèses siliceuses, implications sédimentologiques et chronologiques. C. R. Acad. Sc., Paris, t. 292 (II), pp. 1533-1537.

Miskovsky 1974 : MISKOVSKY (J.C.) - Le Quaternaire du Midi méditerranéen. Stratigraphie et paléoclimatologie. Et. Quatern., Marseille, mém. n³, 331 p.

Moncel 1993 : MONCEL (M.-H.) - Le site de Payre (Commune de Rompon, Ardèche) : une occupation humaine du Paléolithique moyen ancien. Quaternaire, Paris, 4 (4) pp. 149-157.

Papet et al. 1991 : PAPET (M), GUICHEBARON (P.), PHILIPPE (M.) \& COCK (H.) - La Balme à Collomb (commune d'Entremont-Le-Vieux, Savoie). Spelunca, Paris, ${ }^{\circ}{ }^{4}$ 2, pp. 13-22.

Pastre, Debard et Chennaoui 1994 : PASTRE (J.-F.), DEBARD (E.) \& CHENNAOUI (K.) - Un tephrarepère du volcanisme phréatomagmatique du Vivarais dans la séquence Pléistocène supérieure de l'abri Moula (Soyons, Ardèche, France). C. R. Acad. Sc., Paris, t. 319, série II, pp. 937-943.

Pastre et al. 1996 : PASTRE (J.-F.), BILLARD (A.), DEBARD (E.), FAURE (M.) et GUERIN (C.) - Un horizon téphrique du Mont-Dore dans les loess plio-pléistocènes de Saint-Vallier (Drôme, France). C.R. Acad. Sc., Paris, t. 323, (II), n 7. pp. 607-614.

Sordoillet 1993 : SORDOILLET (D.) - Le remplissage de la grotte : origine et vecteurs sédimentaires des matériaux constitutifs. In : Voruz J.-L., dir. La grotte du Gardon à Ambérieu-en- 
Bugey (Ain) : Rapport de fouilles - 1993. Univ. de Genève, Société Préhistorique Rhodanienne, pp. 89-101.

\section{Document}

Durand 1994 : DURAND (E.) - Saint-Martin d'Ardèche : l'éperon barré du Ranc Pointu. Bilan Scientifique, S.R.A., Rhône-Alpes, p. 64. 


\title{
Les grottes du Vercors et des massifs Subalpins
}

Relations Homme et milieu végétal

\author{
Stéphanie Thiébault et Pierre Bintz
}

\section{Rappel des découvertes}

1 L'archéologie en Vercors doit beaucoup à Hippolyte Millier qui fut le premier à découvrir, explorer, fouiller et publier de nombreuses grottes. A. Bocquet rappelait récemment (Bocquet 1995) la liste des gisements paléolithiques: Bobache à La Chapelle-en-Vercors, les grottes Colomb et de la Passagère à Méaudre, l'abri de l'Olette à Engins, la Balme de Glos à Fontaine, les grottes de Fontabert et de l'Ermitage à la Buisse-Voreppe, l'abri du Calvaire à Saint-Laurent du Pont, comme celle des gisements néolithiques ou protohistoriques : Fontaine, La Buisse, Vif, Varces, Seyssinet etc. dont il fut l'inventeur. La plupart des gisements découverts à la fin du XIXe et au début du XXe s. ont fait, d'ailleurs, l'objet de nouvelles fouilles approfondies ces dernières décennies.

2 Les plus anciennes occupations humaines sont attribuées, en Vercors, au Paléolithique moyen, c'est-à-dire dès le dernier interglaciaire Riss-Wiirm. Lorsque les glaciers le permirent les moustériens s'installèrent afin d'exploiter, selon Th. Tillet et S. BernardGuelle (Tillet et Bernard-Guelle 1995), deux ressources abondantes : le silex et le gibier. Ainsi, bien que très pauvres en vestiges, de nombreuses grottes ont été fréquentées. Plusieurs cavités, dans le massif des Coulmes: grottes de Prélétang, de Bury, de Marignat, du Grand Serre ou de l'autre côté de la Bourne : grotte de Tende, offrent les restes de séries lithiques à débitage levallois prépondérant.

Malgré un hiatus culturel qui sépare la déglaciation du Würm fixée dans la région aux alentours de 20000 B.P. et les premières implantations du Paléolithique supérieur datées vers 14000 B.P, ce dernier est bien représenté, comme l'ont prouvé les fouilles entreprises de 1967 à 1972 par J.-E. et J.-L. Brochier aux abris du Taï et du Campalou (Saint-Nazaireen-Royans) dans lesquels de nombreux vestiges artistiques ont été mis au jour, dont un bâton poli en ivoire de mammouth et des os gravés (Brochier et Brochier 
1973 et 1995). L'industrie lithique montre une fréquentation attribuée au Magdalénien supérieur et offre, dans les niveaux supérieurs, un caractère aziloïde. L'industrie récoltée par $\mathrm{H}$. Müller à l'abri Bobache (La Chapelle-en-Vercors) où 4 galets peints ont été découverts dans les niveaux aziliens y est comparable. L'industrie de la grotte des Freydières (Saint-Agnan-enVercors), fouillée par A. Bocquet et P. Lequatre en 1965 dont l'occupation est contemporaine du réchauffement de l'Allerød, est attribuée au Magdalénien final. Le Magdalénien supérieur a été remarqué dès 1911 par H. Müller et M. Filhol à l'abri du Calvaire à Saint-Romans. Plus récemment la fouille du gisement de Saint-Thibaud, réalisée entre 1969 et 1972 par P. Bintz, A. Bocquet, P. Lequatre et R. Desbrosse, a été l'occasion d'une étude poussée intégrant les différentes composantes du milieu naturel et de l'archéologie pour les périodes du Tardiglaciaire et de l'Holocène (Bintz et al. 1994, 1995). Dans le même esprit G. Pion a entrepris ensuite l'étude des gisements de la Fru (Saint-Christophe, Savoie) (Pion 1995) et de la grotte de Bange (Allèves, Haute-Savoie) qui offrent des habitats variés du Magdalénien, de l'Azilien et du Mésolithique.

4 Fouillée ces 25 dernières années, une douzaine de sites et grottes ou abris (fig.1), à stratigraphies développées et répartie du nord au sud des Alpes, a fourni des données paléoenvironnementales et notamment anthracologiques en relation directe avec les occupations humaines bien calées chronologiquement. D'autres données, essentiellement palynologiques, issues de nombreux sites lacustres ou palustres, non anthropisés, de plaine ou de haute montagne, permettent, notamment, de préciser l'étagement de la végétation en rapport avec les occupations de plein air et d'altitude.

1- Localisation des principaux gisements mentionnés dans le texte

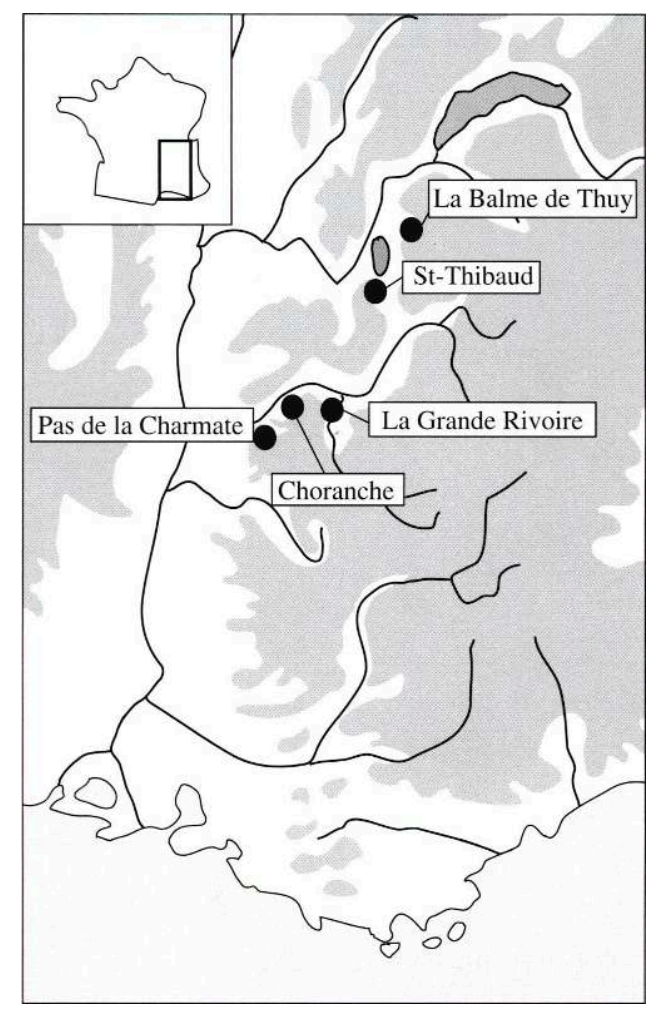

5 La plupart des gisements offrent des stratigraphies qui se développent du Tardiglaciaire au début de l'Holocène, comme à Saint-Thibaud-de-Couz (Savoie); 
d'autres couvrent tout ou une partie importante de l'Holocène. Ainsi, dans le cirque de Choranche, plusieurs grottes ont abrité des habitats datés de la fin du Paléolithique au Moyen Âge. C'est le cas des abris de Coufin 1 et 2 et de Balme-Rousse fouillés par P. Bintz (Bintz et al. 1987). Face au cirque de Choranche, le Pas de la Charmate (Châtelus, Isère) est un vaste abri fouillé par P. Bintz dont les occupations se sont succédé de la fin de l'Épipaléolithique au Néolithique ancien. De même, plus au nord, à la Balme-de-Thuy (Haute-Savoie) où J.-P. Ginestet a fouillé une stratigraphie proposant des vestiges de l'Azilien au Bronze final (Ginestet et al. 1984), ou à Sassenage la Grande-Rivoire, fouillée par R. Picavet et qui fut fréquentée pendant tout l'Holocène, du Sauveterrien au GalloRomain (Picavet 1991). Enfin, la grotte des Sarrasins à SeyssinetPariset, fréquentée à partir du Néolithique récent jusqu'à l'âge du Fer, fit l'objet d'une fouille dans les années 70 sous la direction de A. Bocquet (Bocquet 1976).

Dans les zones d'altitude, vers $1840 \mathrm{~m}$, s'ouvre la grotte du Campagnol (Gresse, Isère), découverte en 1982. Elle a donné des indices de fréquentation à l'Epipaléolithique dans un milieu végétal principalement constitué par le pin à crochet. A $1600 \mathrm{~m}$ à SaintAndéol (Isère) la grotte Charbonnière, découverte au début des années soixante, a fait l'objet de sondages à la suite de la découverte d'un racloir en silex. Le bouquetin est bien représenté, l'industrie est mésolithique (Bintz et Picavet 1995).

7 Plus récemment encore et dans le cadre d'un programme de prospection thématique ayant pour objectif l'étude de l'extension spatiale des occupations et les rapports entre plaine et montagne, plusieurs gisements en grotte ou sous abri ont été découverts à côté de nombreux sites de plein air. Il s'agit du Pas de l'Échelle (Rovon, Isère) situé au nord du plateau des Coulmes. Cet abri se trouve sur un passage naturel reliant la plaine de l'Isère à la haute vallée de la Drevenne, il se situe sur un axe de circulation privilégié permettant de relier le Vercors nord au Vercors sud. Le premier sondage réalisé en 1994 par P. Bintz et R. Picavet a permis la reconnaissance d'occupations attribuées au Moyen-Age, à la Protohistoire et au Méso-Néolithique. De même le site de l'Aulp du Seuil (Saint-Bernard du Touvet, Isère) a été découvert en 1992. C'est un site de fond de vallon, à 1700 mètres d'altitude, constitué de 3 abris sous-blocs et d'une station de plein-air. Des vestiges du Mésolithique et du Néolithique ont été découverts (Bintz et al. à paraître).

\section{Les principaux acquis des dernières décennies}

8 Après ce rapide panorama des séquences archéologiques fouillées depuis près d'un siècle dans les grottes du Vercors, nous allons tenter de brosser les résultats géoarchéologiques obtenus depuis une vingtaine d'années dans cette région.

9 La plupart des grottes fouillées ces dernières années ont, en effet, été perçues par les naturalistes comme offrant des archives tout à fait fondamentales. Ce constat tient à plusieurs raisons.

\section{Géographie}

Globalement, par sa position géographique cette région joue un rôle de frontière et reçoit, tant culturellement que climatiquement d'ailleurs, des influences très diverses. Située aux confins des remontées méditerranéennes et au carrefour des influences montagnardes, elle offre un terrain idéal pour comprendre l'importance des différentes 
emprises. A cette position dans les marges et en dérivant naturellement, il faut ajouter une grande variété dans la position des grottes et abris, tant dans leurs altitudes, variant du domaine collinéen au montagnard que dans leur situation topographique : en pied de falaise, dans des cols ou passages etc., ce qui augure d'une variété de paysages d'une part, d'un fort potentiel pour l'occupation des sites d'autre part. De plus, avec ses 17000 hectares, cet espace représente un territoire immense et diversifié. Par sa situation charnière entre Alpes du Nord et Alpes du Sud. le Vercors est soumis à des influences climatiques contrastées et recèle des espèces animales et végétales à caractères atlantique, médio-européen et méridional et, de plus, abrite des espèces boréales, témoins des périodes glaciaires. Les Hauts-Plateaux du Vercors qui se déploient sur une trentaine de kilomètres, culminant au Grand Veymont à $2341 \mathrm{~m}$ d'altitude, dominent à l'est le reste du massif comme une banquette surélevée et isolée. Ils ont connu une importante fréquentation des groupes mésolithiques qui ont utilisé les quelques points d'accès existants : Pas de Bachassons, Pas de l'Aiguille et Combeau.

11 Le Vercors constitue donc un excellent terrain de recherche permettant de mettre en relation les sites entre eux (grottes et plein air qu'on ne peut dissocier) pour une plus large compréhension des modes d'organisation territoriale et économique entre plaine et montagne.

\section{Histoire}

Outre les travaux de Müller, cette région avait, jusqu'à une époque encore récente, peu retenu l'attention. Plus que tout autre, le milieu montagnard enregistre particulièrement bien les fluctuations climatiques et naturelles qui sont amplifiées par l'altitude; l'impact humain y est également perceptible et durable. Les fouilles, entreprises ces trente dernières années, ont pu être effectuées selon des techniques modernes. Ainsi, aux côtés des objets manufacturés, un abondant matériel susceptible d'intéresser les naturalistes, ossements, charbons de bois, graines etc. a été récolté. Cependant, l'une des raisons majeures de la prise en compte des études naturalistes aux côtés et avec l'archéologie, est, il faut le souligner, l'équipe formée à l'occasion de l'A.T.P. « Archéologie Métropolitaine » animée par R. Vivian, programme sur contrat, agréé en 1982 : Paléoenvironnement holocène et Archéologie dans les Alpes du Nord et leurs Piémonts. Plus d'une quarantaine de chercheurs, archéologues, géographes et naturalistes, avaient alors été réunis pour travailler finement et avec des moyens sur une période de temps qui englobait tout l'Holocène. Cette équipe était constituée de 11 chercheurs en paléobotanique dont 9 palynologues (dont 3 travaillant sur les sites archéologiques), 2 anthracologues (dont 1 travaillant aussi en carpologie), 1 archéozoologue, 1 paléontologue, 4 sédimentologues, au moins 9 géographes et une quinzaine d'archéologues. Les quelques réunions qui eurent lieu alors furent le point de départ de nombreux travaux dont les résultats, sous la direction de P. Bintz et de A. Bocquet, sont résumés dans: "Paléoenvironnement holocène et Archéologie dans les Alpes du nord et leur Piémont » (Vivian, 1991).

Depuis les recherches continuent dans des directions diverses. Les études ayant pour thème l'environnement végétal et l'exploitation des animaux sauvages par les chasseurs-cueilleurs dans les grottes de la Chartreuse et du Vercors constituent une illustration des recherches en cours. Cet exemple se fonde notamment sur les travaux de L. Chaix et A. Bridault en ce qui concerne les changements diachroniques des 
spectres de chasse, la caractérisation de la prédation et la saisonnalité en parallèle avec le milieu végétal obtenu par les données anthracologiques de S. Thiébault et palynologiques de M. Girard et Bui Thi Mai principalement (Chaix et Bridault 1992, BuiThi-Mai et al. 1987, Girard et al. 1981, Thiébault 1988, 1994a, b et à paraître). Dans cet exemple 5 gisements o nt retenu notre attention: il s'agit de la Balme de Thuy (HteSavoie), Saint-Thibaud-deCouz (Savoie), La Grande-Rivoire, Balme-Rousse et du Pas de la Charmate (Isère).

\section{La Balme-de-Thuy} Bornes, en Haute-Savoie, sur la commune de la Balme-de-Thuy, à $17 \mathrm{~km}$ au nord-est d'Annecy et à $3 \mathrm{~km}$ à l'ouest de la ville de Thônes, sur la rive droite du Fier qui coule à proximité. C'est un vaste abri sous roche qui s'ouvre au sud, à une altitude de $620 \mathrm{~m}$. Cette cavité a été creusée au pied d'une falaise urgonienne, appartenant aux unités géologiques « Bornes-Aravis ».

Le gisement est actuellement situé à la charnière supérieure de l'étage collinéen, série septentrionale du Chêne pubescent et de l'étage montagnard. La carte de végétation (Richard et Hainard 1979) montre un environnement très contrasté. L'abri se trouve dans un îlot de la série du Chêne pubescent encadré, de chaque côté du Fier, par l'étage montagnard avec la série mésophile du Pin sylvestre et la série du Hêtre et du Sapin. L'étage subalpin avec les séries subalpines de l'Épicéa et préalpine du Pin à crochet se situe à moins de $5 \mathrm{~km}$. Il tombe, en moyenne, de 1200 à $1500 \mathrm{~mm}$ de pluie par an sur la région.

16 de 1970 à 1990. Le gisement offre une séquence présentant treize niveaux stratigraphiques (Ginestet et al. 1984).

- Les niveaux 9A et $8 \mathrm{~A}$ sont situés au-dessus du substratum. Ils ont livré une abondante microfaune en cours d'étude et une hémimandibule de marmotte.

-Au-dessus, la couche 7 a été subdivisée en deux : 7B assez pauvre en vestiges et 7A d'une épaisseur moyenne de $20 \mathrm{~cm}$. qui a livré des vestiges attribués à l'Azilien terminal et une faune composée surtout de bouquetins, cerfs et chevreuils.

- Le Mésolithique est représenté par la couche 6, subdivisée elle aussi. Les couches 6 et 6B indiquent le passage progressif de l'Epipaléolithique au Mésolithique ; la couche $6 \mathrm{~A}$ est plus particulièrement attribuée à un Sauveterrien de faciès local. La faune y est abondante, notamment les cerfs, bouquetins et chamois mais aussi, dans une bonne proportion, le sanglier.

- Le Néolithique est représenté dans la couche 5. La couche 5B, Néolithique ancien, est séparée de la précédente par une lacune stratigraphique. Si elle ne contient pas de céramique elle a livré de nombreux restes d'animaux domestiques, caprinés et bovidés essentiellement ; la chasse y reste très importante malgré tout.

La couche $5 \mathrm{~A}$ a permis la mise au jour de nombreux foyers, minutieusement fouillés et dont les charbons de bois ont été très méticuleusement prélevés. L'industrie lithique, comme la céramique, confèrent à cette occupation des affinités du Chasséen et du Cortaillod. Une armature tranchante s'apparente au Mésolithique tardif méditerranéen. Si le cerf est 
toujours l'espèce dominante, les animaux domestiques sont présents dans de bonnes proportions, de même que l'aurochs et l'ours brun.

- La couche 4B a, elle aussi, livré un foyer important. Elle est attribuée au Campaniforme. Si la faune chassée est toujours importante, la faune domestique s'accroît avec la présence du porc.

- La couche 4A a livré des foyers. Au sud-est d'un de ces foyers, la sépulture d'un jeune enfant a été dégagée. Des vestiges d'objets en bronze et en cuivre ont été récoltés. Cette couche est attribuée au Bronze final.

- Les trois couches sus-jacentes ont, respectivement, livré des vestiges de La Tène III, de la période romaine et du Moyen Âge.

L'analyse anthracologique du gisement de la Balme de Thuy repose sur l'identification de 3700 charbons de bois, parmi lesquels 31 taxons ont été reconnus.

Le diagramme anthracologique des principales essences (fig. 2) montre que tous les niveaux n'ont malheureusement pas fourni le même nombre de fragments (Thiébault 1994b). C'est pourquoi nous attirons l'attention sur la couche 6B qui n'a fourni que 4 fragments (les points servent de référence) et $5 \mathrm{~B}, 55$ seulement (d'où l'utilisation d'une trame différente). Les autres niveaux ont permis l'identification d'un nombre statistiquement fiable de charbons en $4 \mathrm{~A}$, le Pin possède une trame différente en raison d'une potentielle sélection de cette essence comme combustible, ses plus forts pourcentages provenant d'un foyer, l'information paléoécologique perd alors de sa valeur. D'une façon générale, tous les charbons prélevés ont été analysés, aucun choix, lié au nombre minimal des fragments à identifier, ne s'étant avéré nécessaire au cours de l'étude.

2- Diagramme anthracologique des principales essences identifiées dans le gisement de la Balmede Thuy (Haute-Savoie)

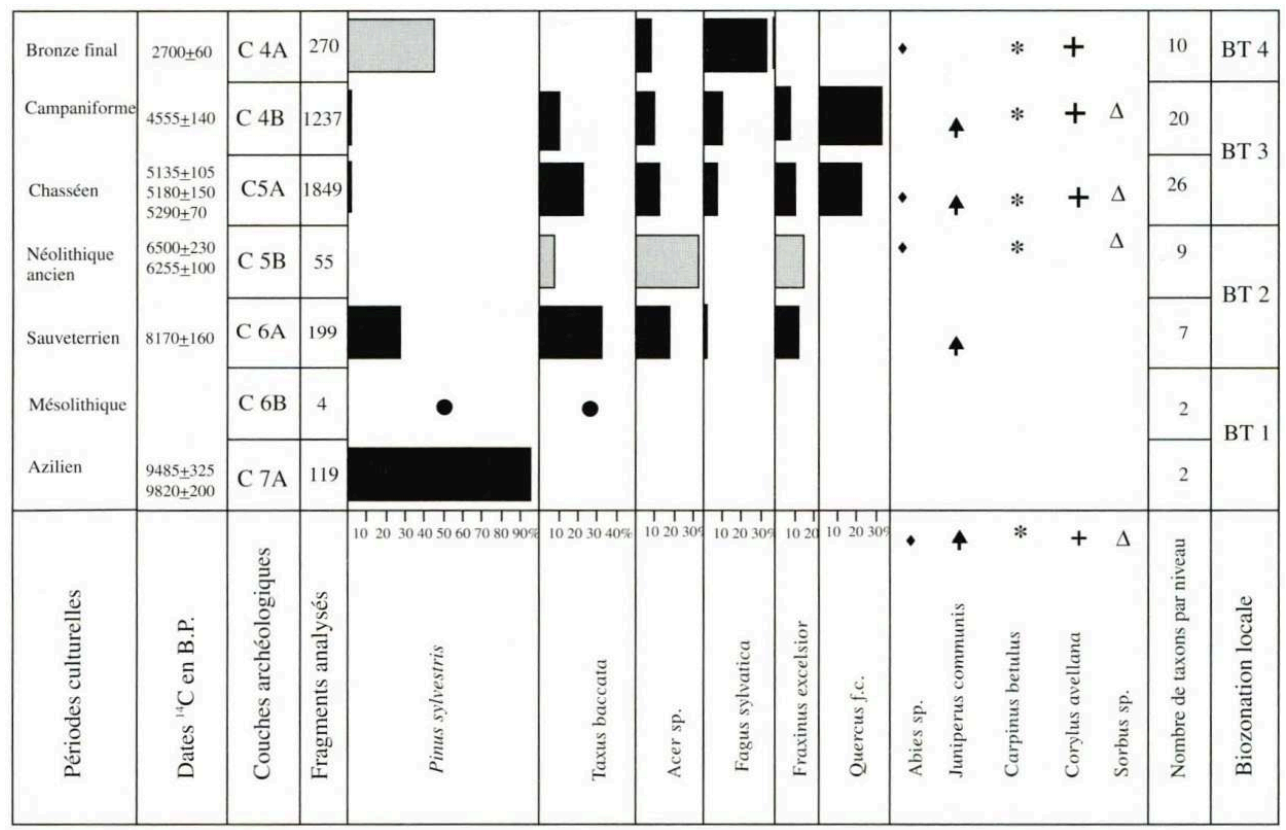

Les résultats de l'analyse anthracologique nous autorisent à proposer une biozonation locale qui comporte 4 parties. La première (BT 1) correspond à une végétation héritée du Tardiglaciaire et presque exclusivement dominée par les Pins sylvestres. La seconde (BT 2) est caractérisée, durant le Sauveterrien et le Néolithique ancien, par le déclin du 
Pin et le développement de l'If et du Frêne; la phase 3 (BT 3) voit se développer le Hêtre, le Sapin, mais aussi le Chêne à feuillage caduc, absent auparavant, et la courbe de l'If décliner. Dans la dernière phase (BT 4) la hêtraie-sapinière est installée, le Chêne et l'If ont disparu, le Pin sylvestre recolonise les terrains appauvris par l'exploitation humaine.

L'ouverture du milieu, corollaire de l'installation des hommes et de l'exploitation des terres (qui s'effectue traditionnellement au Néolithique moyen), ne semble pas très marquée sur le site ou bien elle n'est pas traduite dans la végétation à moins que Hêtre et Pin sylvestre jouent un rôle de marqueur anthropique, ce qui est toujours possible. D'après les analyses de L. Chaix sur la faune (Ginestet et al. 1984), la chasse au cerf a constitué un apport important dans l'alimentation des derniers chasseurs, cependant, la couche $5 \mathrm{~A}$ (Chasséen) a livré quelques restes d'animaux.

\section{Saint-Thibaud-de-Couz}

Situés sur le versant occidental du massif de la Chartreuse, les abris de Saint-Thibaudde-Couz offrent des séquences où sont enregistrées les évolutions naturelles et culturelles de la fin du Tardiglaciaire au début de l'Holocène. Récemment publié (Bintz et al. 1994, 1995), le site se présente comme une référence pour la connaissance du peuplement et l'évolution des milieux naturels au Tardiglaciaire et à l'Holocène. P. Bintz (Bintz et al. 1994) (fig. 3) propose un tableau synthétique des principaux résultats. Le cadre chronologique est assuré par un ensemble de datations radiométriques bien corrélées avec la biozonation pollinique. La fin du Dryas 1 est marquée par des paysages découverts sous climat froid et sec. La faune des grands vertébrés et des oiseaux se caractérise par des éléments nordiques. Dès le début du Boiling le site connaît sa première occupation. Si on retrouve les mêmes faunes qu'à la période précédente, les faunes montagnardes sont mieux représentées. L'anthracologie donne l'image d'un paysage assez découvert sous climat froid avec une tendance à l'humidité. Ce caractère humide et contrasté du climat est bien enregistré par la sédimentation et la présence de faunes palustres ou aquatiques. La coexistence de faunes à biotopes variés suggère un paysages en mosaïque où se juxtaposent marécages en fond de vallée, zones rocheuses, escarpements de versant etc. L'Allerød se distingue par un changement bioclimatique majeur, particulièrement bien marqué dans la composition des cortèges faunistiques: diminution des espèces d'espaces découverts au profit des espèces forestières, disparition des espèces nordiques et périglaciaires, augmentation des faunes montagnardes. Des conditions encore fraîches et humides sont enregistrées par la sédimentation. La palynologie ne montre pas de changement significatif dans les taux de pollens d'arbres, bien que la composition du spectre change. L'optimum se situe plutôt au milieu de cet épisode, et plutôt en fin pour les autres indicateurs biologiques comme l'attestent les rongeurs, l'apparition du chevreuil et de l'ours, le développement des pins. P. Bintz constate dans cette synthèse que "L'amélioration climatique de l'Allerød coïncide avec la mise en place du processus d'azilianisation qui peut être interprété comme une réponse adaptative aux changements des conditions bioclimatiques» (Bintz et al. 1994, p. 237). Le Dryas III est diversement marqué. L'occupation humaine semble brève, les oiseaux sont des espèces d'espaces secs, les rongeurs des espèces héliophiles alors que les sédiments, les pollens et les charbons indiquent une phase froide et sèche avec une régression du couvert forestier. Le Préboréal voit le retour de conditions plus tempérées et humides, surtout à la fin de 
l'épisode. Deux horizons culturels ont été identifiés: un Épipaléolithique terminal au tout début et un Mésolithique ancien, encore peu évolué, en fin de période. A partir du Boréal le site n'est plus fréquenté. Les résultats les plus marquants de l'analyse de cette séquence sont : la mise en évidence, d'un point de vue paléoclimatique, à la transition Tardiglaciaire-Holocène, d'une forte instabilité climatique, avec des alternances de phases sèches et humides, froides puis progressivement tempérées, d'un point de vue paléoécologique du rôle majeur de l'Allerød et enfin la rapidité du réchauffement climatique (3 millénaires).

\section{3- Synthèse des données paléoécologiques et paléoclimatiques d'après l'étude du remplissage} sédimentaire de SaintThibaud-de-Couz

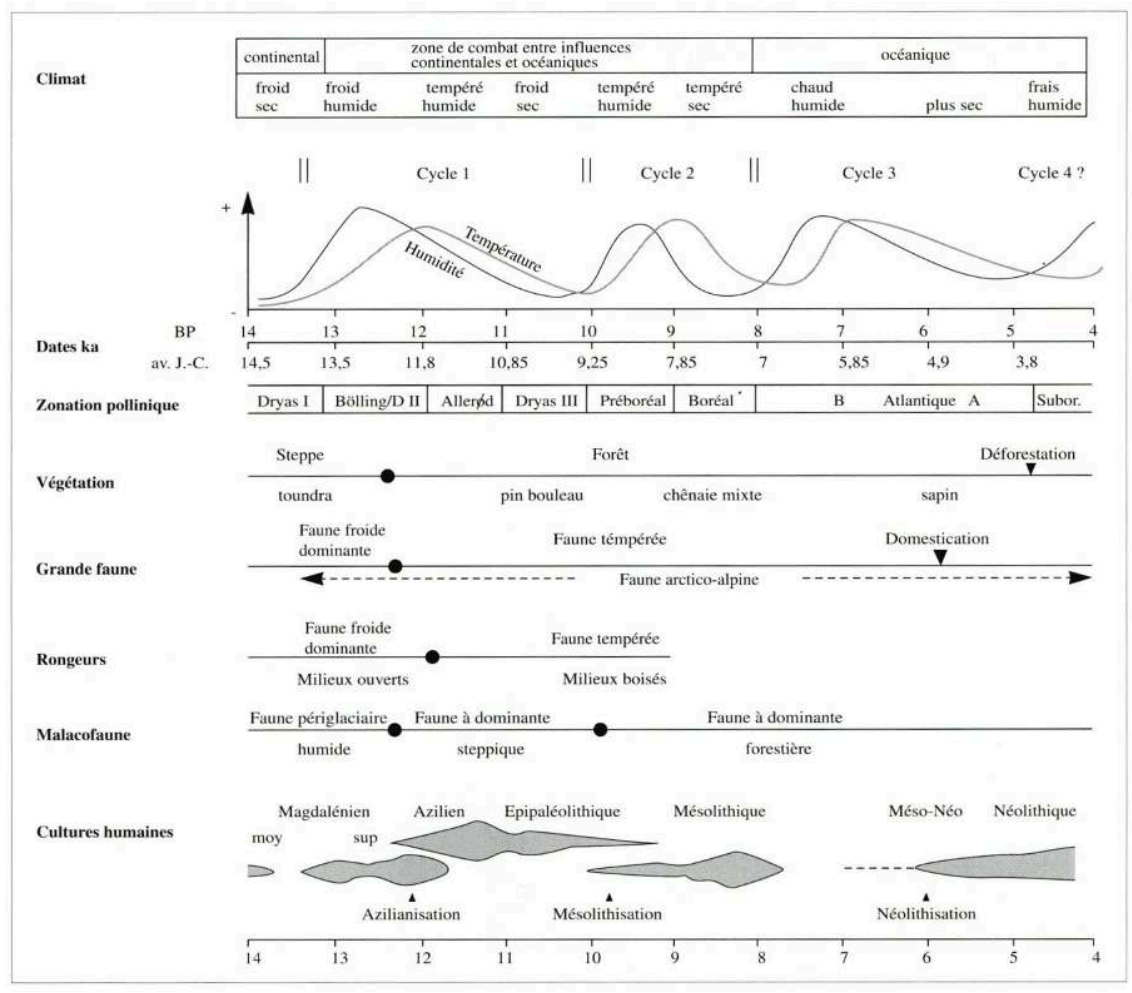

D'après Bintz et al. 1994

À partir des études faites sur les restes de pêche (truite majoritairement et lote d'eau douce, analyse N. Desse) et de chasse (dominée par le bouquetin mais avec : l'élan au Magdalénien, lièvre variable, marmotte, oiseaux), le site apparait comme un lieu de passages et de séjours temporaires. Cette utilisation du site par des groupes à forte mobilité est confirmée par la circulation du silex.

\section{La Grande-Rivoire}

L'abri sous roche de la Grande-Rivoire est un site de bordure de massif, localisé à $580 \mathrm{~m}$ d'altitude, dans un rétrécissement des gorges du Furon. L'abri, orienté au sud, est surplombé par une falaise d'une quarantaine de mètres de haut constituée de calcaire sénonien à silex. Il est actuellement localisé dans l'étage collinéen, dans la série du Chêne pubescent. 

sous la direction de R. Picavet, qui ont permis la découverte d'une puissante séquence stratigraphique avec 13 niveaux d'occupation allant du Mésolithique au Gallo-romain (Picavet 1991).

L'analyse anthracologique a identifié plus de 2730 fragments de charbons; ils montrent une bonne diversité taxonomique puisque 30 genres ou espèces différents ont été déterminés (Thiébault, 1994a). Ils appartiennent principalement à deux étages bioclimatiques: le montagnard avec Pinus sylvestris, Abies alba, Taxus baccata, Acer platanoides/pseudoplatanus, cf. Laburnum anagyroides, Fagus sylvatica, Sorbus aucuparia... et le collinéen: Quercus f.c., Acer campestre, Buxus, Carpinus, Ligustrum, Ilex aquifolium, Clematis, Corylus avellana, divers Prunus, Tilia, Ulmus minor... ainsi qu'à la ripisylve avec Fraxinus excelsior, Sambucus sp., Salix et Populus.

Les occupations les plus anciennes de l'abri ont été attribuées aux mésolithiques sauveterriens et datées de 8740 B.P. +/-110 (Ly. 5434) pour la couche D et de 8280 B.P. +/-80 (Ly. 5433) pour la couche C. La végétation (fig. 4) est constituée par la Chênaie caducifoliée avec quelques reliques des végétations antérieures puisque le Pin sylvestre n'a pas entièrement disparu. Le Chêne à feuillage caduc accompagné du Noisetier se développe pendant toute la première partie de cette séquence. C'est lors de la transition Mésolithique/Néolithique vers, 5995 B.P. +/-150 (Ly. 5099) couche B2, que le Sapin apparaît en même temps que démarrent les courbes de l'If et du Frêne, ce qui a pour corollaire une diminution des valeurs relatives du Chêne; le Pin est toujours présent. La courbe de l'If se développe entre la transition Mésolithique/Néolithique et le Bronze final, couche AC datée de 3340 B.P. +/-140 (Ly. 5184). La courbe de l'If est simultanée de celle du Frêne, elle même contemporaine des premiers indices de domestication animale donnés par l'archéozoologie.

4-La Grande Rivoire (Isère), (Thiébault, 1995)

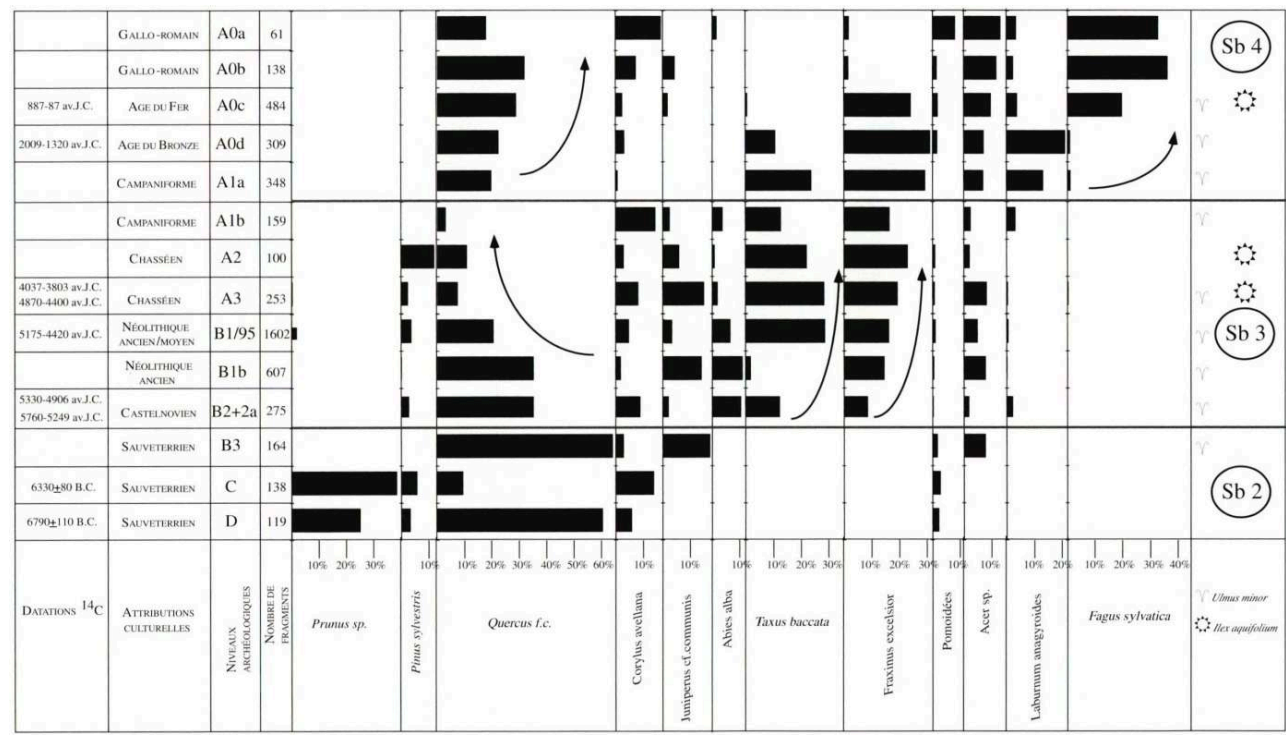

DIAgRAMME ANTHRACOLOgIQUE DES PRINCIPALES ESSENCES IDENTIfiéES DANS LE giSEMENT DE LA GRANDE-RIVOIRE (ISÈRE)

La troisième partie de la séquence est caractérisée par le développement du Hêtre au moment de la transition Chalcolithique/Bronze ancien (c.AIa). Cette phase voit une 
légère reprise de la courbe des Chênes à feuillage caduc, la régression de celles de l'If et du Frêne et le développement de celle de Fagus et surtout de celle des Faïbacées comme Laburnum anagyroides.

Tout comme à la Balme de Thuy, le cerf semble être l'espèce la plus chassée (80 à 90\% des restes déterminés). Les études entreprises par Anne Bridault et Louis Chaix sur la saisonnalité des occupations (Chaix et Bridault 1992), sont effectuées à partir des méthodes classiques d'estimation de l'âge, fondées notamment sur les éruptions dentaires. Elles montrent, si l'on choisit une fourchette maximale ou minimale correspondant à la zone de recouvrement des estimations pour l'ensemble des espèces, une occupation de la miaoût à la mi-octobre pour la couche B2 (transition Mésolithique/Néolithique) de ce site et une occupation allant du début mars à fin décembre dans le cas d'une fourchette maximale; deux occupations l'une de début mars à mi-juin et une autre de mijuillet à fin décembre pour la couche B3 (Sauveterrien), dans le choix d'une fourchette minimale. Il en résulte que les occupations de ce site auraient été plus longues au Sauveterrien et plus courte (miaoût/mi-octobre) à la fin du Mésolithique. Les études menées en archéozoologie permettent aussi de caractériser la nature des activités. Ainsi la couche B2b a, elle aussi, livré des restes d'espèces domestiques dans un contexte de chasse dominante. A la Grande-Rivoire, site assez aisé d'accès, les espèces sauvages sont représentées par l'ensemble de leur squelette. De rares os de boeuf domestique semblent indiquer la présence d'un animal entier.

\section{Balme-rousse}

Situé face au Pas de la Charmate dont il est séparé par la vallée de la Bourne, le cirque de Choranche a permis à $\mathrm{P}$. Bintz et son équipe de découvrir et de fouiller trois gisements: BalmeRousse, Coufin 1 et 2. Le cirque de Choranche est situé dans l'étage collinéen, dans la série xérophile et mésoxérophile du Chêne pubescent.

La grotte de Balme Rousse est une vaste cavité qui s'ouvre plein sud, au pied de la falaise de Presles à $650 \mathrm{~m}$. d'altitude. Fouillée de 1981 à 1985, elle a livré une stratigraphie témoignant d'occupations attribuées au Magdalénien supérieur, au Mésolithique, au Néolithique ancien puisque comprenant des vestiges d'animaux domestiqués, au Néolithique moyen puis aux Chalcolithique et Bronze ancien et final ainsi qu'au Moyen-Âge.

31 Comme dans la plupart des gisements, les résultats de l'analyse anthracologique, qui portent sur l'identification de plus de 940 fragments, indiquent que les influences s'interpénétrent puisque l'étage montagnard est caractérisé par : Pinus sylvestris, Taxus baccata, Fagus sylvatica, Laburnum cf. anagyroides, Sorbus cf. aucuparia. ; le collinéen par Quercus cf., Acer campestre, Buxus sempervirens, Corylus avellana, Ilex aquifolium, Prunus sp., Sorbus sp., Ulmus minor et la ripisylve par Salix sp. et Fraxinus excelsior.

L'analyse anthracologique (Thiébault, 1988) montre (fig. 5), après un début désormais classique où la végétation au Mésolithique est dominée par le Pin sylvestre, une montée rapide de l'If dans des proportions très importantes au Néolithique ancien : $\mathrm{C} 1$ datée de 6020 B.P. +/-150. Si la chênaie caducifoliée n'est jamais très développée, elle est néanmoins présente dans la séquence jusqu'au Bronze final. Bien qu'une occupation attribuée au Néolithique ancien ait été reconnue, il est intéressant de constater que l'ouverture des milieux, corollaire de l'utilisation de son environnement par l'Homme, 
est déjà fortement entamée au Chalcolithique. La courbe de l'If, en effet, est en nette régression et le développement des courbes des Buis et Noisetier avec, pour les niveaux du Moyen Âge, le Genévrier et le Cytise témoignent de l'anthropisation. Il faut noter l'apparition de Fagus autour de 6000 B.P.

5-Diagramme anthracologique des principales essences identifiées dans le gisement de BalmeRousse (Isère)

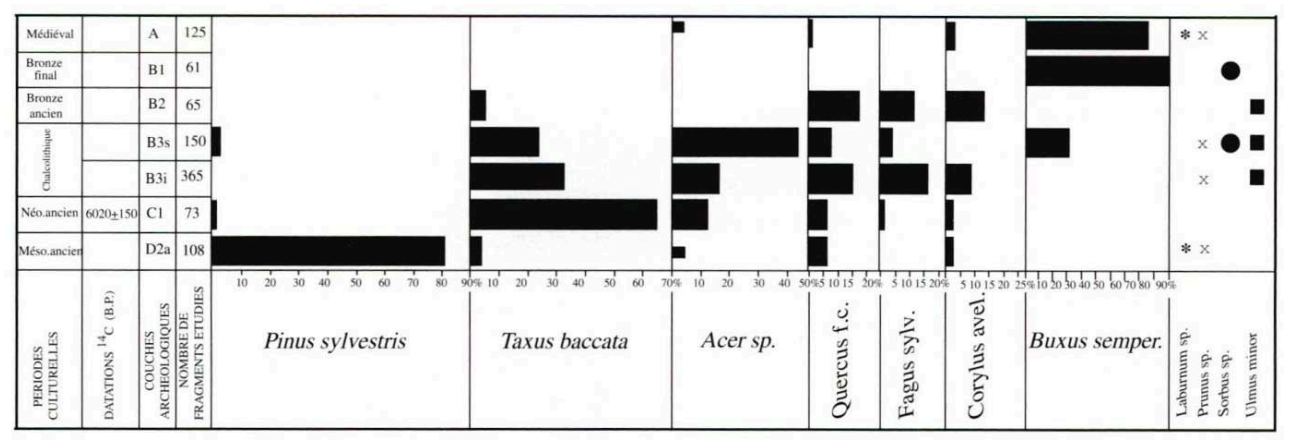

33 À Balme-Rousse, abri d'accès difficile, les animaux domestiqués (caprinés, boeuf et porc) sont représentés, dans les niveaux attribués primitivement au Mésolithique récent et qui, par voie de conséquence, seraient Néolithique ancien acéramique, par la totalité des os de leur squelette alors que les animaux sauvages (cerf, chevreuil, bouquetin et chamois) ne sont attestés que par des éléments crâniens et des bas de pattes (Chaix et Bridault 1992).

\section{Le pas de la Charmate}

Ce gisement, orienté plein nord, s'étend sous un vaste abri sous roche à $1100 \mathrm{~m}$ d'altitude. Il est localisé dans l'étage montagnard inférieur, dans la série mésophile du Hêtre.

Le site, fouillé de 1985 à 1992 par P. Bintz et son équipe, a livré une stratigraphie présentant des niveaux d'occupation allant de l'Epipaléolithique au Néolithique moyen. Le diagramme anthracologique (fig. 6) a porté sur l'identification de plus de 2300 fragments de charbons de bois (Thiébault, 1994a). 
6- Diagramme anthracologique des principales essences identifiées dans le site du Pas de la Charmate (Thiébault, 1994a)

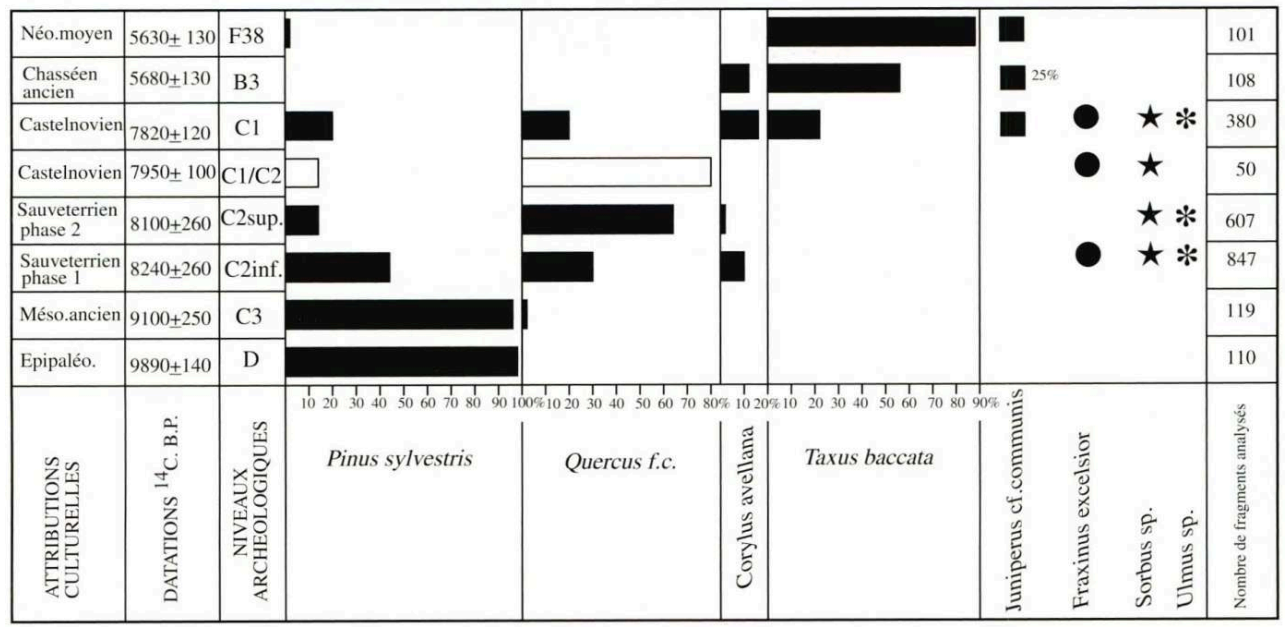

Les paléovégétations observées présentent de fortes interactions entre l'étage collinéen et l'étage montagnard avec pour le montagnard: Pinus sylvestris, Taxus baccata, Acer platanoïdes, Sorbus cf. aucuparia, Ulmus cf. montana et le collinéen: Quercus à feuillage caduc, Acer campestre, Corylus avellana, Ilex aquifolium, Prunus sp., Sorbus sp., Tilia sp., Ulmus minor, Juniperus sp. La ripisylve est représentée par Populus sp. et Fraxinus excelsior.

Le diagramme anthracologique propose trois phases dans l'évolution de la végétation: la première dans laquelle prédomine le Pin sylvestre, correspond aux occupations Épipaléolithique couche D datée de 9890 B.P. +/-140 (Ly. 4203) et C3 Mésolithique ancien datée de 9100 B.P. +/-250 (Ly. 5245) ; la seconde est caractérisée par l'installation de la chênaie caducifoliée; elle correspond au Sauveterrien, couches C2inf. datée de 8240 B.P. +/-260 (Ly. 4204) et C2sup. datée de 8100 B.P. +/-100 (Ly. 5662) et au Castelnovien C1/C2 datée de 7950 B.P. +/-100 (Ly. 4380) et C1 datée de 7820 B.P. +/-120 (Ly. 3786). Enfin, la troisième phase se différencie par la disparition des Chênes à feuillage caduc et la prédominance de l'If et du Genévrier, elle se situe dans la couche attribuée au Néolithique moyen : B3 datée de 5680 B.P. +/-130 (Ly. 3785) et le foyer F38 daté de 5630 B.P.+/-110 (Ly. 4381).

Les résultats obtenus à la Charmate posent quelques points d'interrogation. En effet, si dans les niveaux les plus anciens, Épipaléolithique et Mésolithique ancien, la végétation est conforme à celle connue dans les autres gisements de la région, avec la prédominance des gymnospermes et notamment du Pin sylvestre caractérisant le début du Postglaciaire, les datations venant confirmer cette attribution, la phase suivante, qui se place, du point de vue chronologique, dans le Boréal (8700-7400 B.P.), voit la régression de la courbe des Pins sylvestres au profit de l'installation de la chênaie caducifoliée accompagnée de l'Orme, Tilleul, Noisetier et Rosacées. Cette phase liée à la chênaie caducifoliée s'amenuise lors de l'occupation castelnovienne vers 7820 pour laisser la place à une végétation appauvrie taxonomiquement et composée principalement de gymnospermes avec Taxus, accompagnées, dans une moindre mesure, de Juniperus et de Pinus sylvestris. Tout se passe comme si l'influence montagnarde devenait beaucoup plus importante. Il nous parait, dans ce cas, difficile d'imputer à l'action humaine ce changement dans la composition de la végétation alors qu'il n'existe encore nulle part de réelles preuves de néolithisation pour cette culture. 
Si nous refusons, a priori, une origine anthropique à ce changement, il faut alors invoquer une origine climatique due à une péjoration du climat.

Les études de saisonnalité (Chaix et Bridault 1992) ont montré une fréquentation maximale de début mars à la mi-septembre et minimale de début mai à mi-septembre dans le niveau C2inf $(8240+/-260$ B.P) sauveterrien et début avril à fin novembre (maximum) ou début avril à mi-août puis du début octobre à fin novembre dans la couche $\mathrm{C} 1$, castelnovienne.

7- Diagramme synthétique montrant l'évolution de la végétation dans les principaux gisements du Vercors selon une zonation anthracologique proposant trois anthracozones pour le début de l'Holocène : 10 000-6 000 B.P.

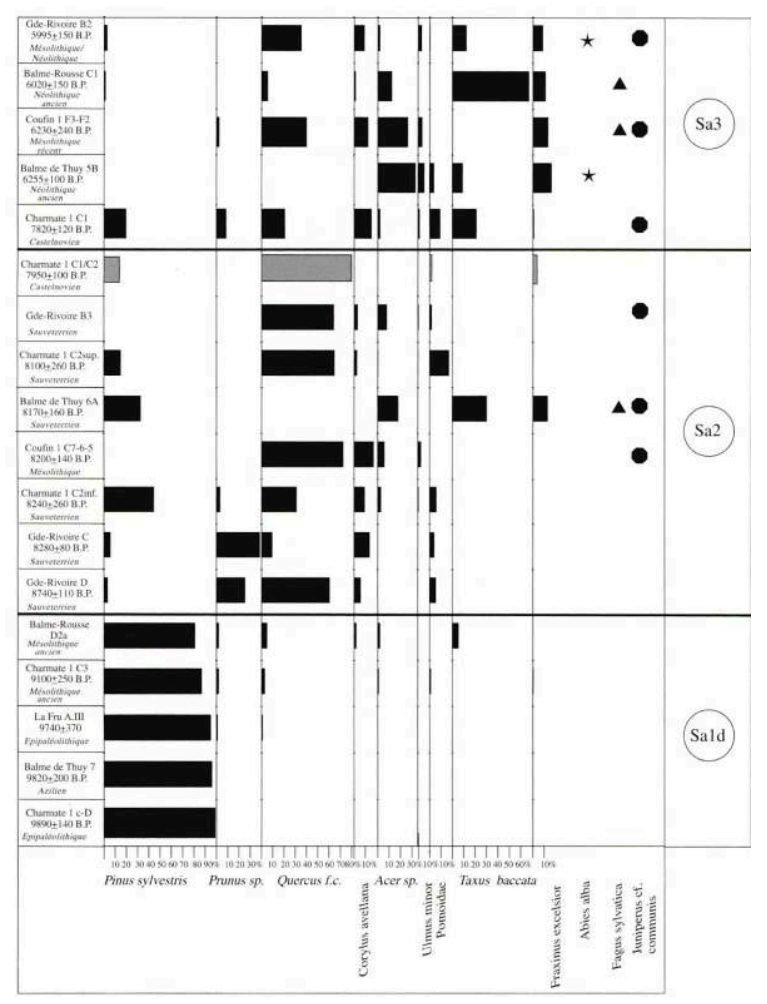

Afin de synthétiser le milieu végétal dans lesquels évoluèrent les derniers chasseurs et les premiers agriculteurs (fig. 7) nous pouvons dire que les derniers paléolithiques et les mésolithiques anciens vécurent dans un milieu relativement ouvert, composé, d'une façon générale, de 3 principaux ligneux : à savoir le Genévrier, le Pin sylvestre et le Bouleau, dans lequel se retrouvent, souvent en filigrane, quelques Prunus notamment. $\mathrm{Au}$ début du Postglaciaire ces populations assistent, à l'issue du changement climatique, à une fermeture de leur milieu avec le développement des chênaies caducifoliées, avec un début de diversification dans le catalogue des espèces végétales et l'émergence des différents domaines de végétation et une individualisation plus marquée des écosystèmes. La question de savoir si les divers groupes humains ont eu des réponses différentes aux modifications de l'environnement se trouve alors posée (Thiébault, à paraître). Nous avons vu à la Balme de Thuy, La Grande-Rivoire et BalmeRousse la présence de faunes domestiquées dans un contexte de chasse. Les auteurs de ces études proposent deux hypothèses (Chaix et Bridault 1992) : - la première suppose une population d'éleveurs-agriculteurs, habitant des villages de plaine et pratiquant la chasse de manière épisodique, utilisant des abris-sous-roche en milieu montagnard 
comme halte de chasse, la seconde se fonde sur l'existence de contacts entre populations de chasseurs-collecteurs-nomades et éleveursagriculteurs sédentaires. Les types de contacts peuvent être variés, allant de l'échange de produits, au vol et à l'agression en passant par la récupération d'animaux échappés. Le fait qu'à BalmeRousse ce sont les animaux domestiqués qui sont représentés par la totalité des os du squelette alors qu'à la Grande Rivoire c'est la faune chassée, va, pour les auteurs, à l'encontre d'un transport de quartiers de viande de la plaine vers les sites de montagne et tend à infirmer l'hypothèse d'une population d'éleveurs pratiquant des chasses saisonnières. Les conclusions d'Anne Bridault et de Louis Chaix indiquent que, s'il existe une spécifité de la chasse en zone alpine, elle se marque surtout dans les phases anciennes de la séquence (Azilien) par la présence non négligeable de certaines espèces comme le bouquetin, le chamois, la marmotte, le lièvre variable. Durant le Mésolithique, seuls le bouquetin et le chamois continuent à être exploités.

D'autres exemples pourraient être développés notamment sur les processus d'anthropisation du milieu à partir de l'installation des populations néolithiques, et l'impact de la Protohistoire. Il s'agit là de démêler les processus induits de l'évolution climatique de ceux issus des changements culturels. Peu à peu, en effet, la confrontation des résultats des disciplines géoarchéologiques tend à mettre en évidence des cycles d'exploitation des territoires (apparition des plantes cultivées, mise en évidence de l'exploitation de la forêt, importance de l'élevage, du pastoralisme etc.) auxquels succèdent des périodes de déprise (crise de l'âge du Bronze ?). De même un axe de recherche visant à la compréhension des surfaces d'exploitation de ces territoires est entrepris, toujours à partir de l'étude du matériel des gisements de grotte en relation avec les sites de plein-air.

\section{Apports de la collaboration}

\section{À l'échelle d'un gisement (approche diachronique)}

42 Il est intéressant d'observer si les périodes de changement du milieu végétal correspondent ou non, dans les évolutions culturelles, à des ruptures. Au Pas de la Charmate, par exemple, la principale "rupture» culturelle marquant le passage Epipaléolithique/Mésolithique correspond à un changement du paysage végétal (passage d'une végétation ouverte à pin sylvestre à l'arrivée de la chênaie caducifoliée).

43 L'anthracologie, par exemple, peut aussi fournir des données précises sur la durée, le mode de fonctionnement et les lieux d'approvisionnement en combustible pour les foyers, comme à la Balme de Thuy (Thiébault, 1995).

\section{À l'échelle de la zone géographique (approche synchronique)}

Par la mise en évidence d'un gradient nordsud, de nombreuses questions peuvent être posées.

- Comment, du point de vue végétal, le passage Méso-Néolithique ancien est-il perçu? Rupture ou continuité ?

- Les spécificités culturelles observées du nord au sud du territoire correspondent-elles à des différences dans le milieu végétal ? Quel est le rôle du climat?

- Comment se marquent, sur le milieu, les premiers indices de l'impact humain? 


\section{Perspectives}

\section{BIBLIOGRAPHIE}

\section{Bibliographie}

Bintz à paraître : BINTZ (P)., ARGANT (J.), PELLETIER (D.), THIEBAULT (S.). - L'Aulp du Seuil (Saint-Bernard du Touvet, Isère), un site d'altitude du Mésolithique ancien. Actes du congrès UISPP (commission XII), Grenoble, sept. 1995.

Bintz et al. 1987 : BINTZ (P.), BUI-THI-MAI, CAILLAT (B.), GIRARD (M.) et THIEBAULT (S.). $L^{\prime}$ 'occupation mésolithique de la grotte Coufin à Choranche (VercorsIsère). Premiers acquis. Actes du $108^{\circ}$ congrès Nat. des Soc. Sav. Grenoble 1983, Ed. du CTHS, 1987, pp. 41-66.

Bintz et al. 1994 : BINTZ (P.), BOCQUET (A.), CHALINE (J.), DESSE-BERSET (N.), EVIN (J.), GIRARD (M.), LEQUATRE (P.), MONJUVENT (G.), MOURER-CHAUVIRE (C.), VERNET (J.-L.). - Les grottes Jean-Pierre 1 et 2 à Saint-Thibaud-de-Couz-1ère partie : Paléoenvironnement et cultures du Tardiglaciaire à l'Holocène dans les Alpes du Nord. Gallia Préhistoire, t. 36, 1994, pp. 145-266.

Bintz et Picavet 1994 : BINTZ (P.) et PICAVET (R.). - La fin du Paléolithique supérieur et le Mésolithique dans les Alpes du Nord françaises : paléoenvironnement, peuplements et modes d'exploitation du milieu, Preistoria Alpina, Museo Tridentino di Scienze Naturali. vol. 28, 1994, pp. 255-273.

Bintz et Picavet 1995 : BINTZ (P.) et PICAVET (R.). - Deux sites d'altitude des hauts plateaux du Vercors : les grottes du Campagnol et de Charbonnière. In : Epipaléolithique et Mésolithique en Europe, Livret-Guide de l'excursion Préhistoire et Quaternaire en Vercors, 1995, pp. 154-157.

Bintz et al. 1995 : BINTZ (P.), CALLEY (S.), PHILIBERT (S.), TABORIN (Y.). - Les grottes Jean-Pierre 1 et 2 à Saint-Thibaud-de-Couz (Savoie); Paléoenvironnement et cultures du Tardiglaciaire à l'Holocène, 2ème partie : la culture matérielle. Gallia Préhistoire, t. 37, 1995. 
Bocquet 1976 : BOCQUET (A.). - La grotte des Sarrasins à Seyssinet-Pariset. Livret-Guide A9, IXe congrès UISPP, Nice, 1976, pp. 133-138.

Bocquet 1995 : BOCQUET(A.). - Hippolyte Millier. In : Epipaléolithique et Mésolithique en Europe, Livret-Guide de l'excursion Préhistoire et Quaternaire en Vercors, 1995, pp.12-13.

Borel 1973 : BOREL (J.-L.). - La grotte des Sarrasins à Seyssinet-Pariset (Isère, France) : les habitats des âges des métaux, analyse pollinique. In : Musées royaux d'art et d'histoire, Bruxelles, 1973, pp. 238-243.

Borel 1976 : BOREL (J.-L.). - Climat et écologie aux âges des métaux dans les Alpes du Nord. In : Bocquet (A.) dir. - Les âges des métaux dans les Alpes. IXème congrès de UISPP, colloque XXVI, Nice, 1976, pp. 93-118.

Brochier et Brochier 1973 : BROCHIER (J.E.), BROCHIER (J.-L.). - L'art mobilier de deux nouveaux gisements magdaléniens à Saint-Nazaire en Royans (Drôme). La grotte du Taï et l'abri du Campalou. Etudes Préhistoriques, 4, 1973, pp. 1-12.

Brochier et Brochier 1995 : BROCHIER (J.E.), BROCHIER (J.-L.). - Les sites magdaléniens et aziliens de la grotte du Taï et de l'abri du Campalou à St-Nazaire en Royans (Drôme). In : Epipaléolithique et Mésolithique en Europe, Livret-Guide de l'excursion Préhistoire et Quaternaire en Vercors, 1995, pp. 144-146.

Bui-Thi-Mai et al. 1987 : BUI-THI-MAI, GIRARD (M.), BINTZ (P.), VITAL (J.). - Végétations, variations climatiques et évolution culturelle du Tardiglaciaire à l'Holocène à Choranche (Vercors, Isère). Revue de Paléobiologie, Genève, Déc. 1987, vol. 6, n² 2, pp. 411-431.

Chaix et Bridault 1992 : CHAIX (L.), BRIDAULT (A.). - Nouvelles données sur l'exploitation des animaux sauvages de l'Epipaléolithique au Mésolithique final dans les Alpes du Nord et le Jura. Preistoria Alpina, Museo Tridentino di Scienze Naturali. vol. 28, 1992, pp. 115-127.

Clerc 1988 : CLERC (J.). - Recherches pollenanalytiques sur la paléoécologie tardiglaciaire et holocène du BasDauphiné. Thèse de Doctorat d'Etat de l'Univ. d'AixMarseille, 1988, 179p.

Delannoy 1995 : DELANNOY (J.-J.)._- La spécificité karstique du massif du Vercors, la contribution du karst dans la reconstitution paléogéographique et paléoenvironnementale d'un massif calcaire. In : Epipaléolithique et Mésolithique en Europe, Livret-Guide de l'excursion Préhistoire et Quaternaire en Vercors, 1995, pp. 20-27.

Ginestet et al. 1984 : GINESTET (J.-P.), BINTZ (P.), CHAIX (L.), EVIN (J.), OLIVE (C.). - L'abri sous roche de la Vieille Eglise, La Balme-de-Thuy (Haute-Savoie), premiers résultats. Bull. S.P.F. t. 81, $\mathrm{n}^{\circ}$ 10-12, 1984, pp. 320-342.

Girard, Bintz, Bocquet 1981 : GIRARD (M.), BINTZ (P.), BOCQUET (A.). - La végétation et les climats au Tardiglaciaire et à l'Holocène en Savoie d'après l'étude pollinique des grottes de StThibaud de Couz. Bull. AFEQ, 2, 1981. pp. 89-106.

Picavet 1991 : PICAVET (R.). - L'abri sous roche de La Grande Rivoire, Sassenage, Isère. Mém. de diplôme de l'EHESS, Toulouse, 1991,216 p.

Picavet 1995 : PICAVET (R.). - L'occupation préhistorique de la Grande-Rivoire à Sassenage (Isère). In : Epipaléolithique et Mésolithique en Europe, Livret-Guide de l'excursion Préhistoire et Quaternaire en Vercors, 1995, pp. 63-69.

Pion 1995 : PION (G.).-Les habitats préhistoriques de la Fru (Saint-Christophe la Grotte, Chartreuse, Savoie)-Les premiers alpins - Des derniers chasseurs de la Préhistoire au premiers paysans, éd. Musée Dauphinois. Grenoble, 1995, pp. 51-64 
Richard et Hainard 1979 : RICHARD (L.), HAINARD (P.). Carte de la végétation de la France, feuille : Annecy $n^{\circ}$ 48. 1979, C.N.R.S. ed.

Ruffaldi 1993 : RUFFALDI (P.). - Histoire de la végétation du Jura méridional depuis le retrait du glacier würmien à partir des analyses palynologiques du lac de Cerin (Ain, France). Thèse de Sciences, Université de Franche-Comté, 1993.

Thiébault 1983 : THIEBAULT (S.). - L'homme et le milieu végétal à la fin du Tardiglaciaire et au Postglaciaire : analyses anthracologiques de six gisements des Préalpes sudoccidentales. Thèse III ème cycle, Paris 1, 1983, 215p., 74 fig., 5 pl.

Thiébault 1988 : THIEBAULT (S.). - L'homme et le milieu végétal - analyse anthracologique de six gisements des Préalpes sud-occidentales aux Tardi et Postglaciaire-. Maison des Sciences de l'Homme, D.A.F., $n^{\circ} 15,1988,112 p$.

Thiébault 1994a : THIEBAULT (S.). - L'exploitation des hautes terres : l'exemple des Préalpes sud-occidentales françaises - l'apport de l'anthracologie. Actes du colloque de Brescia 1993 « Highland zone exploitation in southern Europe » P. Biagi and J. Nandris (eds) Monografie di «Natura Bresciana » 20 : 1994, pp. 73-93.

Thiébault 1994b : THIEBAULT (S.). -Evolution de la végétation holocène à la Balme de Thuy (Haute-Savoie, France), l'apport de l'anthracologie. Revue de Paléobiologie, vol. 13, 1994, p. 341-350.

Thiébault 1995 : THIEBAULT (S.). - Functioning of hearths and ancient vegetation at the Balme de Thuy (HauteSavoie, France), the charcoal contribution. Quaternaria Nova, V, pp. 129-170.

Thiébault à paraître : THIEBAULT (S.). - Derniers chasseurs, premiers éleveurs : fréquentation et exploitation du milieu végétal dans les Préalpes, nouvelle synthèse anthracologique. Actes du Vème congrès international UISPP, Grenoble, sept. 1995.

Thiébault, Girard, Bui-Thi-Mai 1995 : THIÉBAULT (S.), GIRARD (M.), BUI-THI-MAI. — Le milieu végétal du Tardiglaciaire à l'Holocène d'après les analyses de charbons de bois et de pollens. In : Epipaléolithique et Mésolithique en Europe, Livret-Guide de l'excursion Préhistoire et Quaternaire en Vercors, 1995, pp. 32-37.

Tillet et Bernard-Guelle 1995 : TILLET (TH.), BERNARDGUELLE (S.). - Le Paléolithique moyen en Vercors. In : Epipaléolithique et Mésolithique en Europe, Livret-Guide de l'excursion Préhistoire et Quaternaire en Vercors, 1995, pp. 44-47.

Vivian 1991 : VIVIAN (R.). éd - Paléoenvironnement holocène et Archéologie dans les Alpes du Nord et leur Piémont, éd. du CTHS, Paris, 1991, 184 p.

\section{RÉSUMÉS}

Après une présentation des recherches archéologiques entreprises dans le Vercors et les massifs subalpins depuis les débuts de la Préhistoire, les principaux acquis des dernières décennies, fondés en partie sur la confrontation des études archéologiques et paléoenvironnementales, sont exposés. Cinq gisements ont été choisis en exemple afin de décrire les principaux résultats obtenus. Les apports de la démarche en collaboration, que ce soit à l'échelle du site ou de la zone géographique sont, enfin, analysés.

Les massifs subalpins, situés à l'ouest du séparant les Alpes calcaires des massifs cristallins externes, sont par sillon alpin marqués la prépondérance des terrains calcaires (essentiellement d'âge barrémo-bédoulien) qui en constituent l'ossature. Leur solubilité et leur perméabilité sont à l'origine de très nombreuses formations karstiques qui offrent de bons abris à l'homme et 
constituent des réceptacles privilégiés pour l'enregistrement des données paléoclimatiques et culturelles (Delannoy 1995).

Ces massifs sont largement ouverts à la circulation par des couloirs profonds façonnés par les glaciers. Par ses spécificités physiques (pentes, neige, glaciers, torrents, expositions, altitudes) la montagne alpine offre une grande diversité de paysages et de milieux biogéographiques dont les hommes ont fait un large usage à toutes les époques, réinventant sans cesse de nouveaux modes d'exploitation. Au gradient climatique lié à l'altitude se superpose un gradient nord-sud pouvant expliquer certains faciès locaux. La basse vallée de l'Isère et le couloir rhodanien constituent l'axe de circulation privilégié nord-sud, mais l'axe Durance-Buëch-Drac a également joué un rôle à partir du Mésolithique. 


\section{Formation des dépôts archéologiques en Grotte}

La Grotte du Gardon (Ain) durant le néolithique

Dominique Sordoillet

\section{Processus de formation des sites archéologiques troglodytiques}

1 Les remplissages de grottes résultent de divers processus de sédimentation, d'altération, de remaniement et d'érosion qui se traduisent par des accumulations complexes de différents types de dépôts (Bar Yossef 1993, Strauss 1993). L'analyse sédimentologique de ces dépôts nécessite au préalable une ordination stratigraphique minutieuse (Butzer 1982, p. 35-156. Harris 1989, Barton et Clark 1993). Il devient ensuite possible de rechercher, en identifiant les constituants et les processus sédimentaires, la signification des dépôts observés. L'inventaire qui suit, alimenté par les publications de différents auteurs, expose les principaux constituants et processus impliqués dans la formation des sites de grotte. Il montre leur diversité et la complexité de l'histoire des remplissages. Il souligne aussi le nombre d'interrogations qui subsistent encore à leur sujet. Dans cet exposé, les processus naturels et anthropiques de sédimentation sont abordés dans un premier temps, puis viennent ceux liés aux transformations postdépositionnelles.

\section{Sédimentation}

\section{Sédimentation naturelle}

2 Les processus naturels de sédimentation (fig. 1) impliqués dans la formation des remplissages karstiques sont bien connus par plusieurs études sédimentologiques (Miskovsky 1970 et 1974, Laville 1975, Campy 1982). Ces processus sont conditionnés essentiellement par le contexte climatique (précipitations, températures) et par la 
nature du substrat (lithologie, structure et fracturation) (Renault 1987, Campy et Macaire 1989, p. 125).

\section{1 - Les processus naturels de sédimentations}

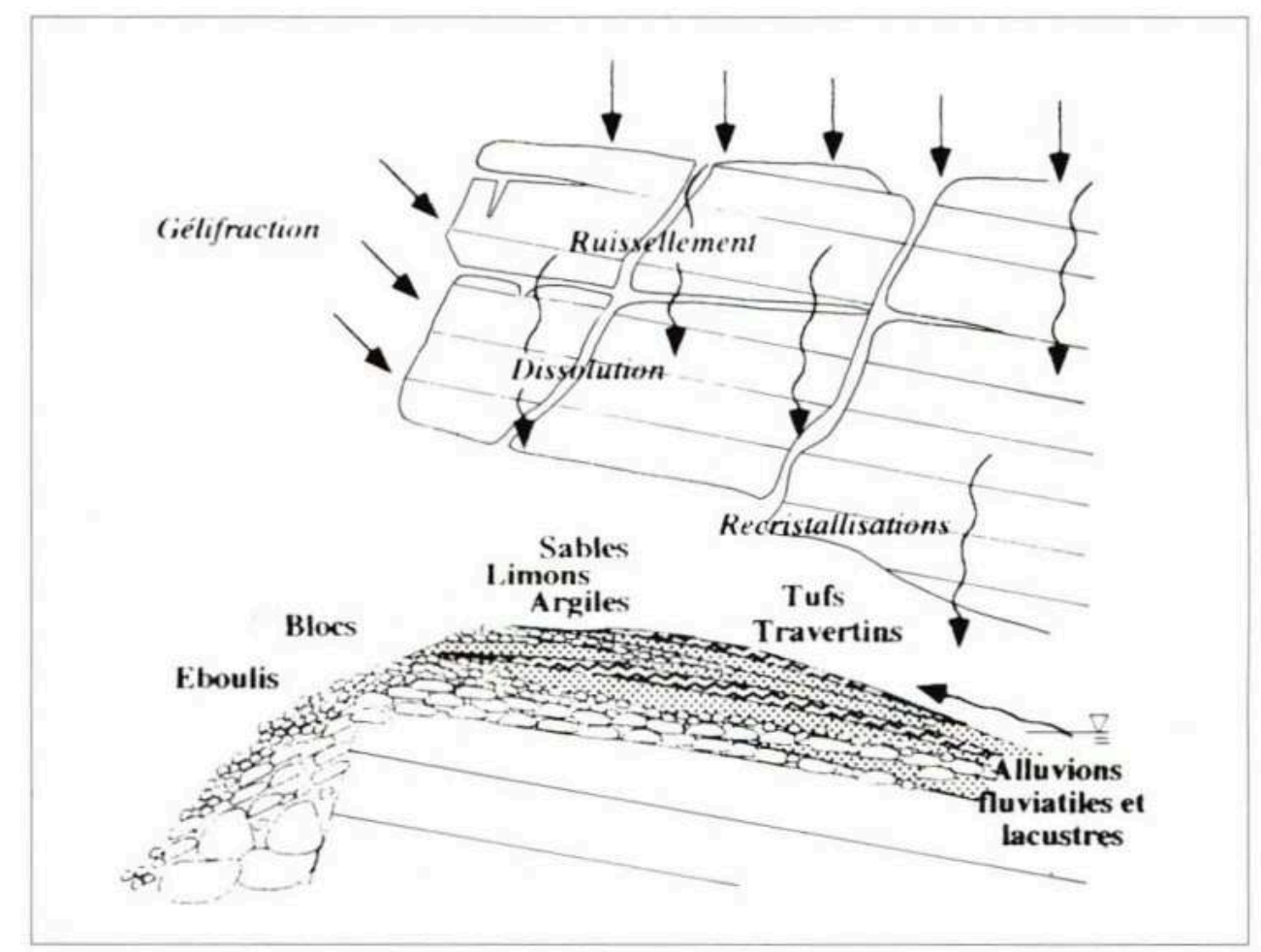

La géli-fraction, le ruissellement, la dissolution et les recristallisations sont les principaux processus sédimentaires naturels intervenant dans la formation des remplissages de grotte. Ils sont à l'origine des blocs, des cailloux, des sables, des limons, des argiles et des constructions algaires qui forment en proportions variables les différentes couches sédimentaires

\section{Gélifraction}

Les alternances de gel et de dégel créent des tensions mécaniques au sein de la roche et favorisent sa désagrégation. Selon l'intensité de ces processus de gélifraction et la nature de l'encaissant, on peut assister au détachement de gros blocs ou à la formation d'éboulis plus petits, qui viennent s'accumuler sur le plancher de la grotte.

Dans le Jura les couches profondes des remplissages karstiques sont essentiellement constituées de blocs, de taille fréquemment supérieure au mètre, et d'éboulis, souvent pauvres en matrice. Leur genèse est généralement attribuée aux phases froides du Pléistocène (Pléniglaciaire et Tardiglaciaire) (Campy 1982, Pétrequin et al. 1985, Vivian et al. 1991). La possibilité d'une origine cataclysmique pour les plus récents d'entre eux, vers le début du cinquième millénaire, est envisagée, mais reste à démontrer (Brochier et al. 1995). Plus tard dans l'Holocène, l'abondance et la taille des cryoclastes tendent à diminuer, en conséquence de l'adoucissement général des conditions climatiques... et tectoniques?. 


\section{Ruissellement et dissolution chimique}

$5 \quad$ Le ruissellement des eaux de pluie sur les plateaux et leur infiltration dans les fissures et les diaclases du réseau karstique, favorisent le lessivage des horizons de sols et la dissolution du calcaire (Aubert 1967). Les éléments solubles (carbonate de calcium) et insolubles (graviers, sables, limons et argiles) sont entraînés avec l'eau dans la partie profonde du karst et se retrouvent dans les remplissages de grotte. Plusieurs types de dépôts peuvent être différenciés en fonction de leur mode de mise en place :

- Les éléments insolubles sont transportés puis déposés par les rivières souterraines sous forme d'alluvions. Celles-ci apparaissent grossières (galets, graviers) et mal triées en cas de crue. Elles sont plus fines (sables, limons) et litées si elles sont mises en place par un régime hydrodynamique plus calme.

- Dans le cas où un barrage sédimentaire ferme partiellement le débouché de la galerie karstique ou dans celui d'une émergence vauclusienne, des lacs peuvent se former en arrière du porche. C'est le cas par exemple à la grotte des Planches (Arbois, Jura : Pétrequin et al. 1985) et à la grotte du Gardon (Ambérieu, Ain: Treffort 1991). Des dépôts fins sablolimoneux à limono-argileux, varvés par les fluctuations de la nappe, se mettent alors en place (fig. 2).

- Le carbonate de calcium dissous dans l'eau reprécipite au sein des dépôts préexistants, qu'il transforme en brèches, ou au sommet de ces dépôts, sous la forme d'encroûtements tels que les tufs ou les travertins (fig. 3). Ces édifices carbonatés, très communs dans les remplissages karstiques (Brochier 1979, Campy et Macaire 1989, p. 142, Goldberg et Macphail 1991), sont formés par des colonies algaires (Casanova 1984) sous une faible tranche d'eau. Ils traduisent le réchauffement relatif d'un climat tempéré froid (Ambert 1981). Dans la grotte de l'Abbaye (Chazey-Bons, Ain) (Buard et al. 1994), de tels dépôts tuffacés, d'âge atlantique probable, recouvrent et englobent des éboulis cryoclatiques, mis en place au Tardiglaciaire ou au tout début de l'Holocène. 
2- Alluvions microlitées (Grotte du Gardon, couche 17, lumière naturelle, hauteur du cadre : $3 \mathrm{~mm}$ )

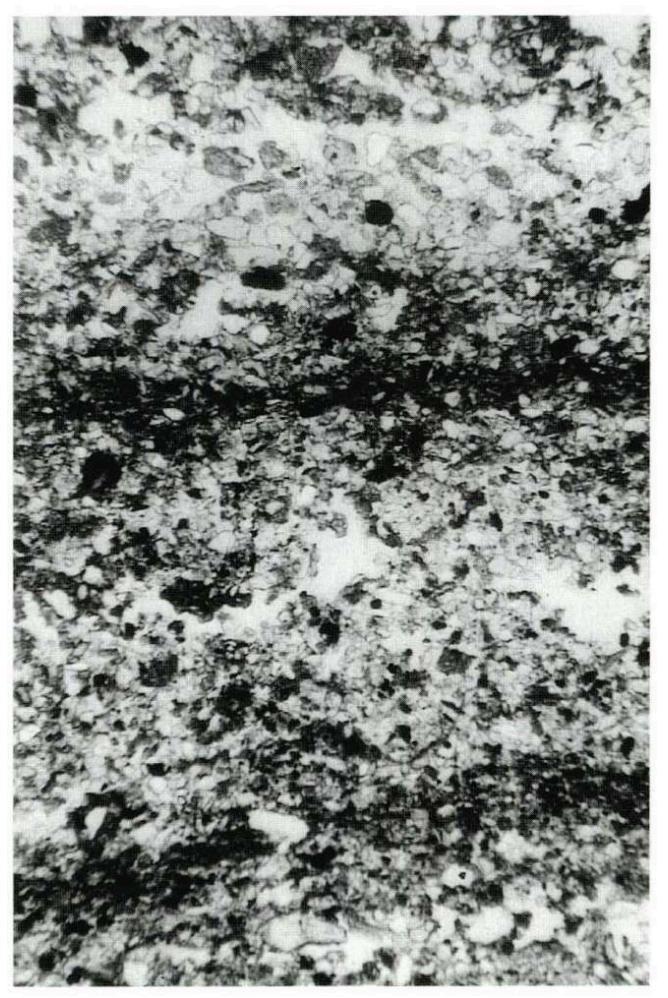

À CHAQUE CYCLE DE CRUE ET DE DÉCRUE CORRESPOND LA MISE EN PLACE D'UN LIT SABLEUX À LA BASE, ARgILEUX AU SOMMET. EN L'ABSENCE D'APPORT ANTHROPIQUE INTERMÉDIAIRE, LA SUPERPOSITION DE CES LITS D'ALLUVIONS PEUT ENTRAÎNER LA FORMATION D'ÉPAISSES COUCHES D'INONDATION. SI DES OCCUPATIONS INTERVIENNENT ENTRE LES CYCLES DE CRUE, LES ALLUVIONS SABLEUSES SERONT DILUÉES DANS LES SÉDIMENTS ANTHROPIQUES 
3- Encroûtement algaire (Grotte du Gardon, structure $\mathrm{C} 134$, lumière naturelle, hauteur du cadre : $3 \mathrm{~mm})$

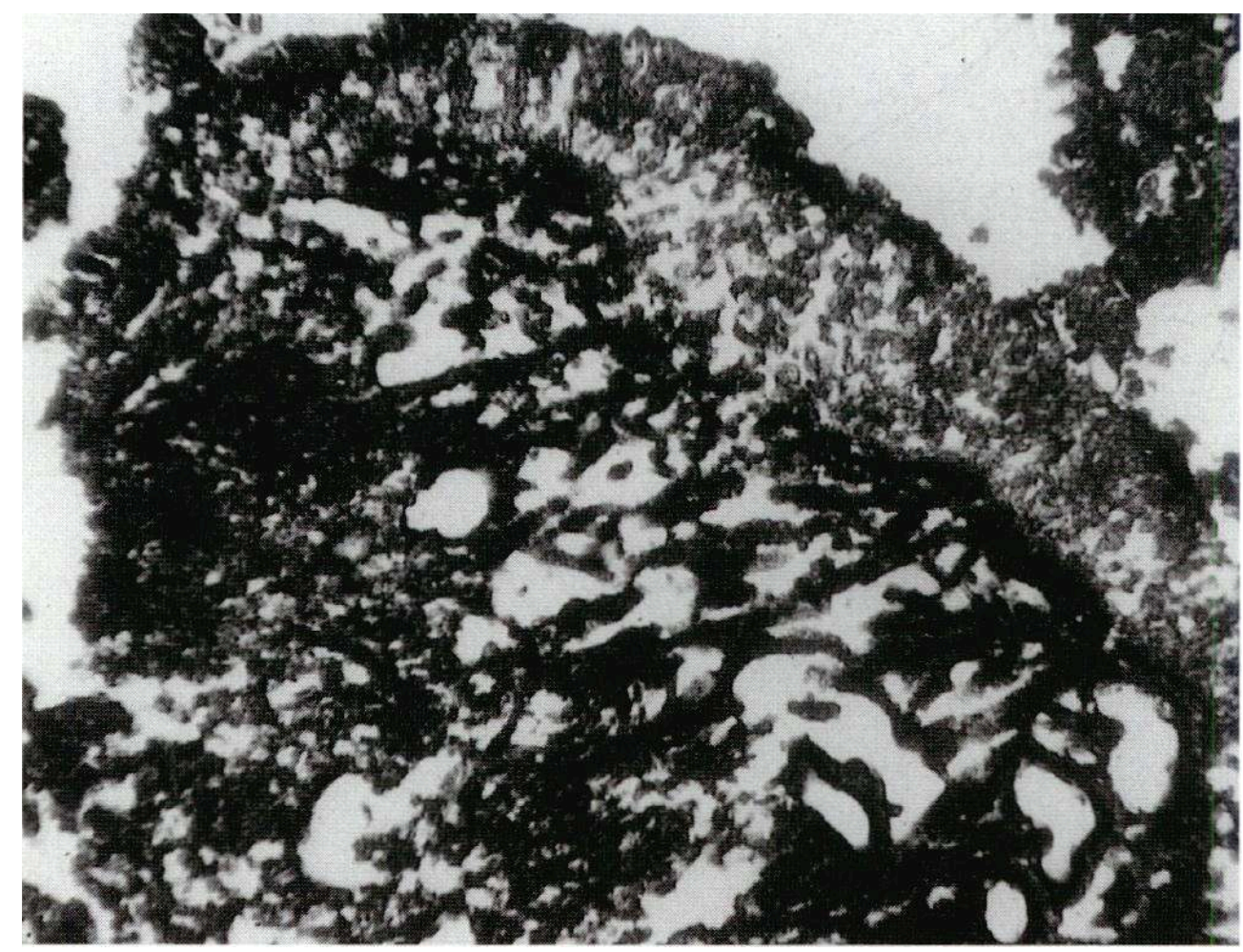

DANS LES SEcteurs où La tRANCHE d'EAU EST PEU ÉPAISSE (AU GARDon : AU NIVEAU dU SEUIL SÉPARANT LA gALERIE DU PORCHE), DES ENCROÛTEMENTS ALgAIRES PEUVENT SE FORMER. Difficilement IDENTIfiables À L'OEIL NU, CES Édifices CARBONATÉS PEUVENT ÊTRE CONFONDUS AVEC DES SOLS AMÉNAgÉS

\section{Processus sédimentaires naturels favorisés par l'anthropisation}

6 Les processus sédimentaires évoqués précédemment peuvent être accentués par les activités humaines.

\section{Défrichements et agriculture}

7 Les défrichements des forêts et les labours ameublissent les sols (Kwaad et Mücher 1977, Fedoroff 1987), qui peuvent être plus facilement érodés et entraînés dans les porches de grotte ou les abris sous roche. Dans le Jura, les premiers défrichements enregistrés par les pollens remontent à la fin de l'Atlantique ancien (Cupillard et al. 1988). Dans l'abri de Roche-Chèvre (Bretonvillers, Doubs : op. cit.), ces défrichements de versant sont évoqués pour expliquer l'accélération de la sédimentation entre 4500 et 4000 av. J.-C. En revanche, dans les abris du Midi de la France, les dépôts engendrés par les défrichements, les cultures et le pâturage, ne sont réellement perceptibles qu'à partir du Moyen Âge (Brochier 1987). Ces apparentes contradictions chronologiques sur la manifestation sédimentaire des défrichements résultent probablement de contextes géomorphologiques, climatiques et anthropiques différents. Elles soulignent l'importance des recherches géo-et pédo-archéologiques de plein air visant à comprendre l'évolution des sols et les causes anthropiques ou naturelles de cette évolution (Berger 1995, Fedoroff et Courty 1995). 
Les feux allumés pendant l'occupation des grottes sont susceptibles d'accélérer la desquamation des plafonds rocheux par thermoclastie (Pétrequin et al. 1985). Aucune corrélation positive n'a cependant été établie avec certitude entre le nombre des foyers et l'abondance des fragments rocheux dans les couches (Butzer 1982).

\section{Sédimentation anthropique}

9 A partir du Néolithique, les produits de la sédimentation naturelle sont dilués dans les sédiments générés par l'occupation humaine (Brochier 1987). Ces apports anthropiques, de nature minérale ou organique, témoignent de l'exploitation du milieu naturel pour l'aménagement et le fonctionnement du site (fig. 4).

4- Les processus anthropiques de sédimentation

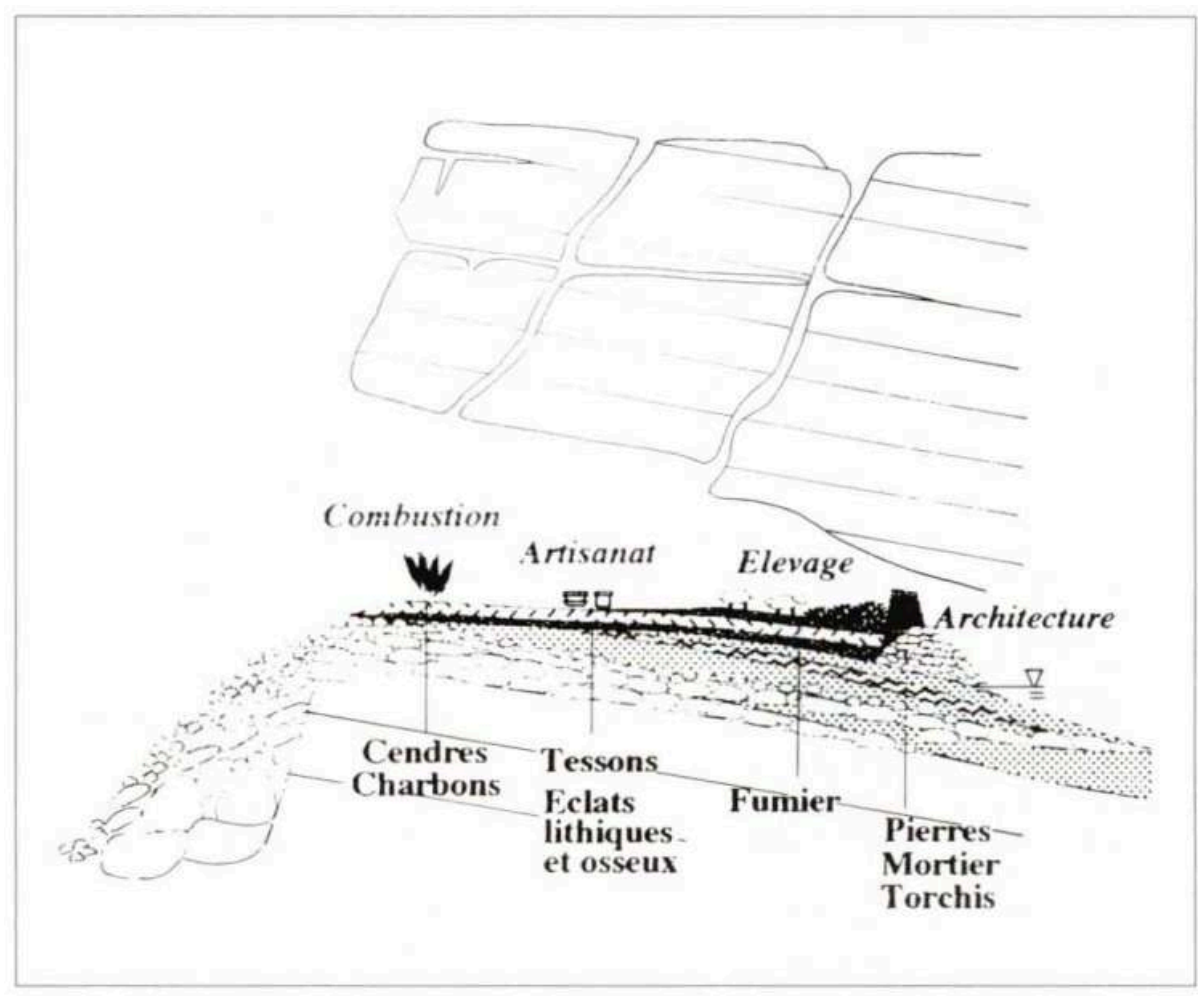

LES PROCESSUS ANTHROPIQUES DE SÉDIMENTATION SONT CONDITIONNÉS PAR LES ACTIVITÉS HUMAINES LIÉES À L'OCCUPATION. L'ARTISANAT, LE BÂTIMENT, LES COMBUSTIONS ET L'ÉLEVAgE SONT DES ACTIVITÉS PRODUCTRICES DE DÉCHETS, QUI PARTICIPENT À LA FORMATION DES COUCHES ARCHÉOLOgIQUES

\section{Aménagement}

Lors de l'occupation, des blocs sont déplacés ou introduits dans la grotte pour la construction de murs en pierres sèches ou de foyers. Des cailloux, des sables, des limons et des argiles, provenant d'éboulis, d'alluvions, de dépôts lacustres ou palustres, peuvent également être utilisés pour la fabrication de murs en terre. 
11 Les végétaux (bois, herbes) et les excréments des animaux domestiques (moutons, chèvres) entrent eux aussi dans la composition de certains matériaux de construction (torchis).

Dans la grotte du Gardon (Ambérieu-enBugey, Ain) quelques fragments de mortier microscopiques retrouvés dans les dépôts du Bronze final I témoignent de l'existence de ces constructions anthropiques (fig. 5).

5- Mortier de boue (sur les côtés) et phytolithes d'herbacées (au milieu)

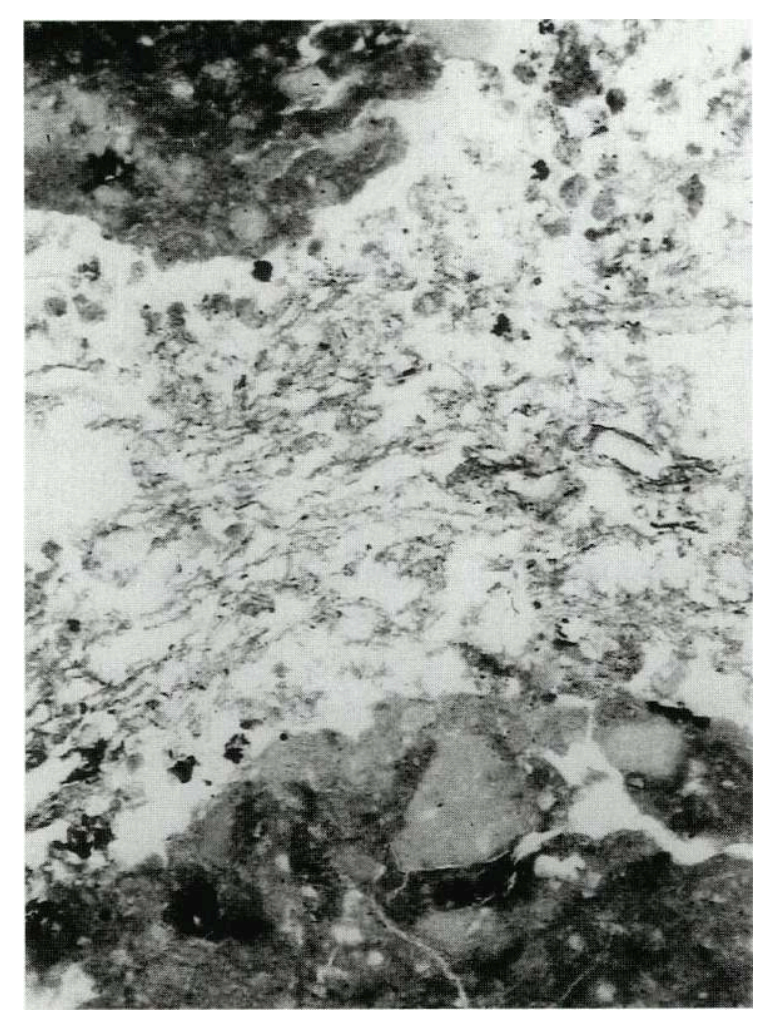

Grotte du Gardon, couche 22, lumière naturelle, hauteur du cadre : $3 \mathrm{~mm}$

L'identification d'assemblages de mortier et de phytolithes (torchis) dans les dépôts associés à

l'occupation du Bronze final 1. plaide pour une installation confortable et durable des populations. Le statut de la grotte est ainsi clairement lié à l'habitat

\section{Fonctionnement}

Différents matériaux liés aux activités de subsistance peuvent être intégrés aux dépôts formés lors de l'occupation. La fabrication d'outils lithiques dans les sites peut enrichir considérablement les dépôts en éclats de taille. La confection de poteries implique l'introduction d'argile et de dégraissants minéraux ou organiques (sables, limons, esquilles osseuses, coquilles). Ces différents apports anthropiques ne sont pas toujours aisément différenciables des sédiments naturels, surtout lorsque les sources de matières premières se situent dans les environs immédiats du site.

14 Ces activités artisanales, tout comme les activités culinaires, nécessitent l'utilisation du feu. Des végétaux et des excréments animaux sont utilisés pour l'alimentation des foyers de la grotte du Gardon. Ces combustibles se retrouvent dans les remplissages sous forme de charbons et de cendres qui peuvent parfois former des dépôts d'épaisseur pluri-décimétrique. Quelques unes de ces cendres présentent la 
morphologie caractéristique de l'espèce brûlée et livrent, de ce fait, des informations d'ordre paléoécologique (Brochier 1990). L'étude en lame mince (micromorphologie) des accumulations cendreuses apporte des informations sur le mode d'utilisation de ces foyers.

Des productions agricoles peuvent être stockées dans les grottes (Pétrequin et al. 1985). La décomposition des herbacées enrichit les remplissages en phytolithes, particules siliceuses résistantes formant le squelette de ces plantes. La grande variabilité morphologique de ces phytolithes et l'existence de formes communes à plusieurs espèces, fait de leur étude une spécialité à part entière (Brown 1984, Piperno 1988...).

L'utilisation des grottes pour le parcage des animaux domestiques est à l'origine d'importantes accumulations de fumiers où se mélangent les apports de litière, de fourrage et les déjections animales (Brochier J.-E. 1983 et 1987, Brochier J.-L. 1986).

Enfin la simple déambulation des occupants humains ou animaux entraîne l'intégration dans les couches d'agrégats sablo-limono-argileux apportés sous les pieds.

\section{Effets des conditions climatiques sur la sédimentation anthropique}

Si l'introduction des matières premières minérales est peu sujette aux fluctuations climatiques, celle des matières organiques est en relation directe avec les saisons. A Arènes Candides, une relation a ainsi été établie entre la nature des sédiments, les pratiques pastorales et la saison d'occupation (Courty et al. 1992).

\section{Transformations post-dépositionnelles}

19 Après leur mise en place, les dépôts sont sujets à des processus de transformation postdépositionnelle, d'origine naturelle ou anthropique (Butzer 1982). Ces processus sont ici subdivisés en trois grandes catégories d'après leurs modalités d'action et leurs effets sur les dépôts originels :

- processus d'altération : transformations chimiques ou mécaniques in situ ;

- processus de remaniement : transformations avec déplacement des matériaux;

- processus d'érosion : transformations avec évacuation des matériaux.

Ces différents processus agissent essentiellement à partir du sommet des dépôts. Leur identification permet de préciser si les couches archéologiques sont en place ou remaniées, et d'expliquer l'origine des limites qui les séparent (hiatus d'érosion ou de sédimentation). La reconnaissance de ces processus est essentielle à la compréhension de l'organisation spatiale du site, du rythme et de la durée des occupations.

\section{Transformations naturelles}

21 Les transformations post-sédimentaires naturelles (fig. 6) se marquent essentiellement pendant les phases d'abandon du site. Leur étude permet d'apprécier le contexte climatique et la durée de ces phases d'abandon. 


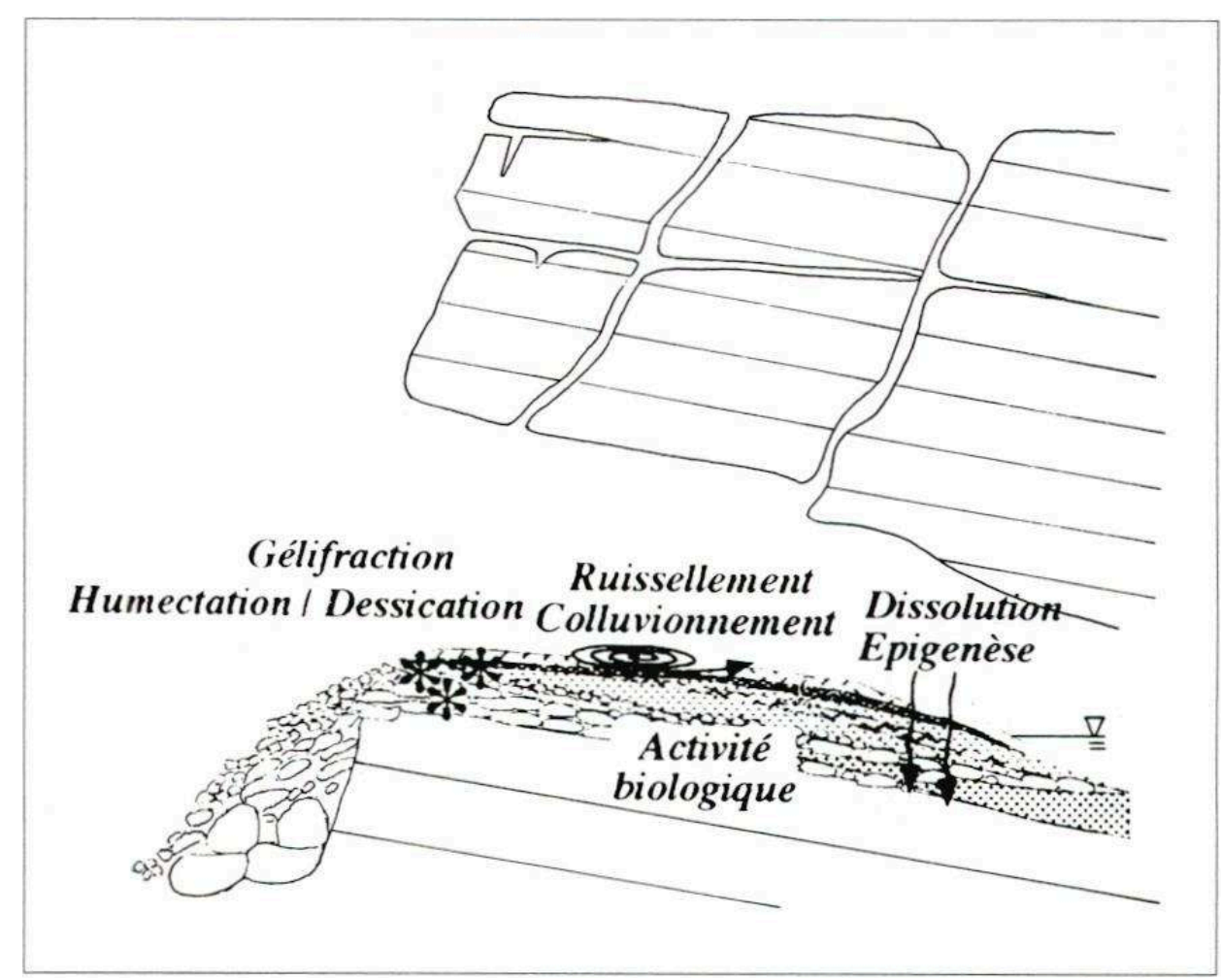

LES AgENTS NATURELS DE SÉdiMENTATION PEUVENT ÉgALEMENT AgIR SUR LES dÉPôTS, APRÈs LEUR MISE EN PLACE DANS LE REMPLISSAgE. ILS CONDUISENT À LA REMOBILISATION PLUS OU MOINS IMPORTANTE DE CES DÉPÔTS, ENTRAÎNANT DES MÉLANgES DE COUCHES OU LEUR ÉVACUATION HORS DE LA CAVITÉ

\section{Altération}

Les processus d'altération, physiques ou biologiques, modifient les caractéristiques initiales du dépôt sans le déplacer. Leurs effets sont d'autant mieux marqués que les hiatus de sédimentation et d'occupation sont prolongés.

\section{Altération physique}

Les processus d'altération physique sont essentiellement causés par des facteurs climatiques (humidité, température) et sont à l'origine de transformations mécaniques à l'intérieur des dépôts.

Les alternances de gel/dégel, déjà évoquées comme agent de sédimentation naturelle, peuvent également affecter le remplissage sédimentaire. La gélifraction des blocs tombés au sol conduit à leur désagrégation en éléments plus petits (Laville 1975) (fig. 7). Sur les matériaux fins, les alternances de gel/dégel conduisent à la ségrégation du sédiment en lentilles. Ce phénomène de ségrégation lenticulaire, démontré sur des dépôts de plein-air (Van Vliet-Lanoë et Valladas 1983, Van Vliet-Lanoë 1987), affecte également les sites préhistoriques qui ont connu des périodes glaciaires (Courty 1988b). 
7- Eclatement physico-chimique d'un gravier calcaire (Grotte du Gardon, couche 18 , lumière polarisée, hauteur du cadre : $3 \mathrm{~mm}$ )

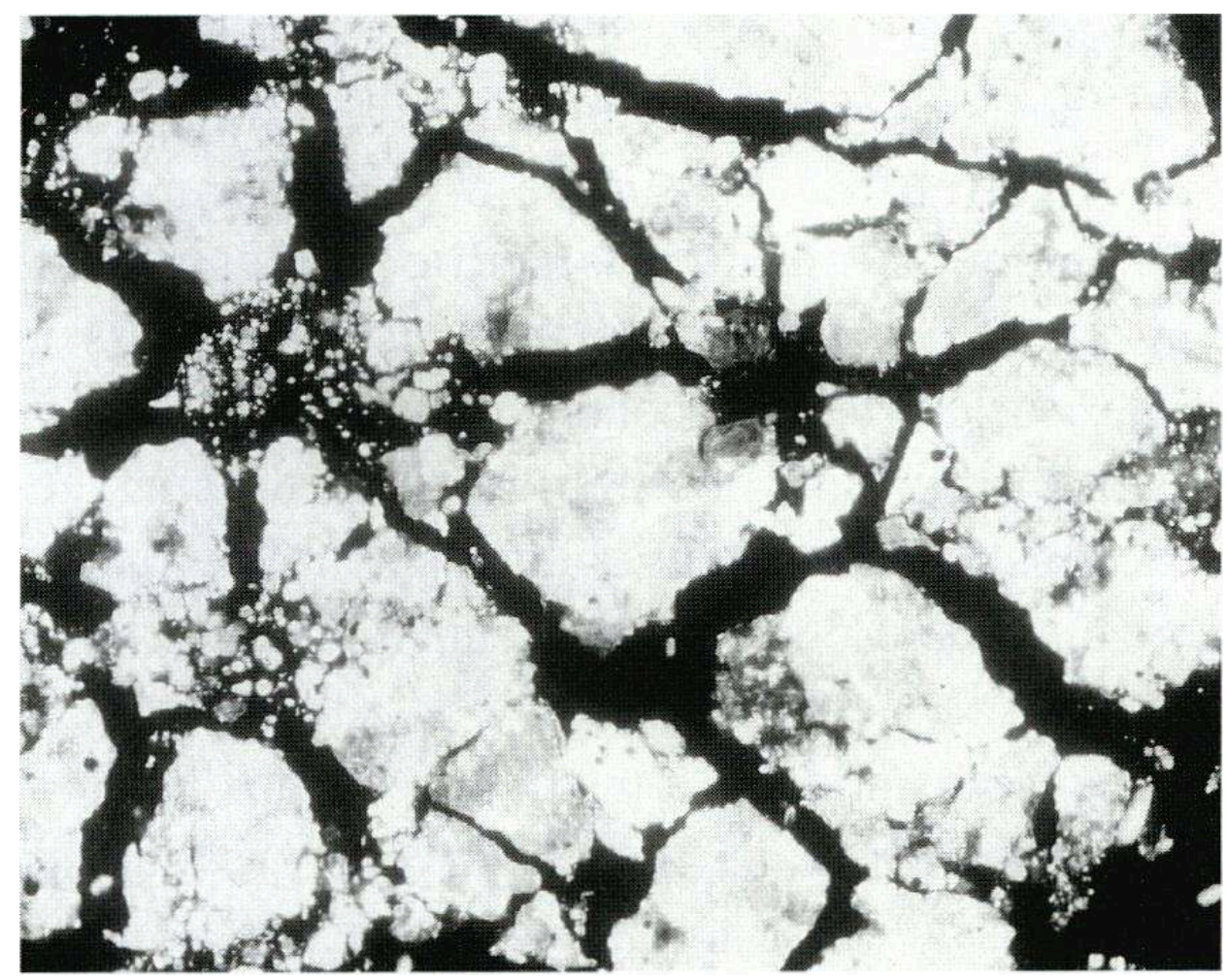

LALTÉRATION BIOCHIMIQUE ET LA gÉLIFRACTION PEUVENT CONDUIRE À L'ÉCLATEMENT DES CAILLOUX CALCAIRES PRÉSENTS DANS LES COUCHES. CE TYPE DE PROCESSUS SECONDAIRE PEUT OBLITÉRER COMPLÈTEMENT LES CONDITIONS INITIALES DE LA SÉDIMENTATION

Les variations d'humidité au sein des dépôts entraînent le déplacement des particules les unes par rapport aux autres. Les argiles sont regroupées en lentilles intercalées dans la matrice ou forment des pellicules autour des fragments de roches et des agrégats de sédiments (Courty et al. 1989, p. 156). Parallèlement des concentrations sablolimoneuses peuvent s'individualiser.

Le ruissellement provoque la migration et l'accumulation de particules fines, minérales ou organiques dans les vides. Dans les dépôts lessivés apparaissent des plages appauvries en éléments fins. Ces transferts de particules, comparables à ceux décrits pour la formation des horizons de sols éluviaux et illuviaux (Fedoroff et Courty 1987), peuvent également être observés dans les dépôts de grotte (fig. 8). 
8- Illuviation limono-argileuse au sommet d'agrégats sablo-limoneux (Grotte du Gardon, couche 56, lumière naturelle, hauteur du cadre : $3 \mathrm{~mm}$ )

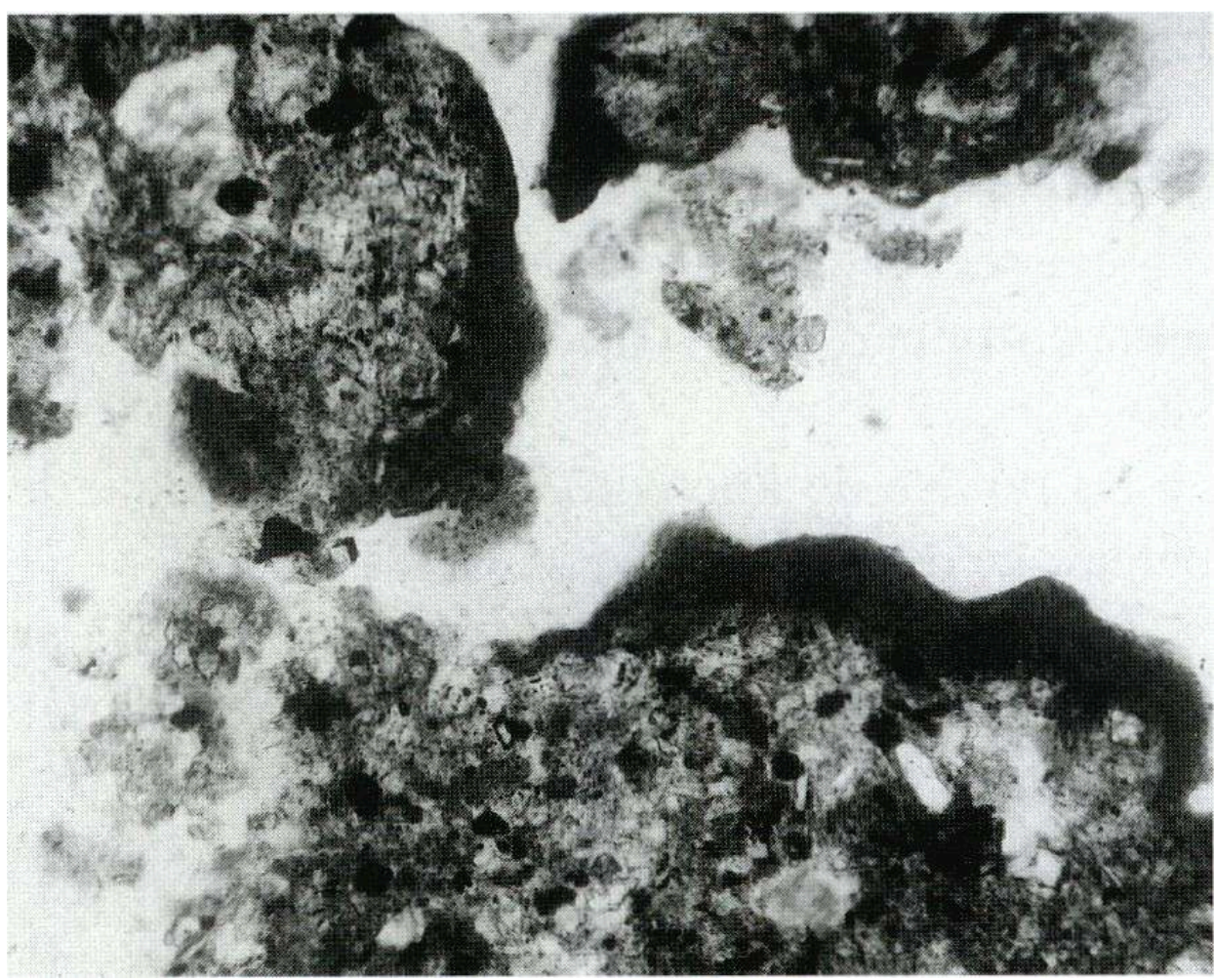

LE RUISSELLEMENT QUI SURVIENT DANS LES CONTEXTES HUMIDES CONTRIBUE, COMME DANS LE CAS DE LA fig. 7. À EFFACER LES CARACTÉRISTIQUES ORIgINELLES DES DÉPÔTS

\section{Altération biologique} biologique conduisent à des transformations mécaniques et biochimiques des dépôts. Ces processus biologiques sont particulièrement actifs dans la transformation des couches anthropiques riches en matières organiques. des racines, conduisent à la formation de pores et d'agrégats aux formes caractéristiques (microagrégats de larves d'enchytrides, agrégats arrondis et striotubules de lombrics, chenaux racinaires à parois épaissies). Cette activité biologique peut aboutir à la déstructuration totale des briques en terre et à leur transformation en dépôts microagrégés meubles (Courty 1990).

tes eaux enrichies en acides organiques sécrétés par les plantes favorise la dissolution des cendres, des os et des fragments calcaires, ainsi que l'épigenèse des carbonates par des solutions phosphatées (Courty 1986). 


\section{Remaniement} sont favorisés par l'altération préalable des dépôts.

- Un ruissellement superficiel, plus important que celui évoqué dans les processus d'altération, peut entraîner des particules sédimentaires, les trier et les redéposer en une accumulation microlitée hors de leur site de formation (Courty 1990).

- Sous l'effet de la gravité, des matériaux humides sont soumis à des processus de colluvionnement. L'intensité du déplacement est fonction de la pente et de la teneur en eau.

\section{Érosion}

Les processus d'érosion sont provoqués, comme les précédents, par l'eau et par la gravité, qui agissent cette fois avec une intensité suffisante pour entraîner l'évacuation des dépôts hors du site.

- La reprise de l'activité karstique provoque le déblayage des dépôts (Bar Yossef, 1993).

- Des processus de colluvionnement importants peuvent entraîner l'évacuation complète des dépôts hors de leur site de formation.

\section{Transformations anthropiques}

Pendant l'occupation, les activités humaines entraînent des modifications de la surface occupée (fig. 9). Comme dans le cas des transformations naturelles, les transformations anthropiques s'effectuent selon les cas : sans déplacement du dépôt préalablement mis en place (altération); avec déplacement à l'intérieur du site (remaniement); ou avec évacuation vers l'extérieur (érosion). Quelle que soit leur ampleur, ces transformations apportent des informations sur les modalités d'occupation. Les limites sédimentaires liées à ces processus n'impliquent pas forcément une interruption d'occupation, mais peuvent simplement correspondre à des changements dans les activités ou dans l'organisation spatiale du site. 


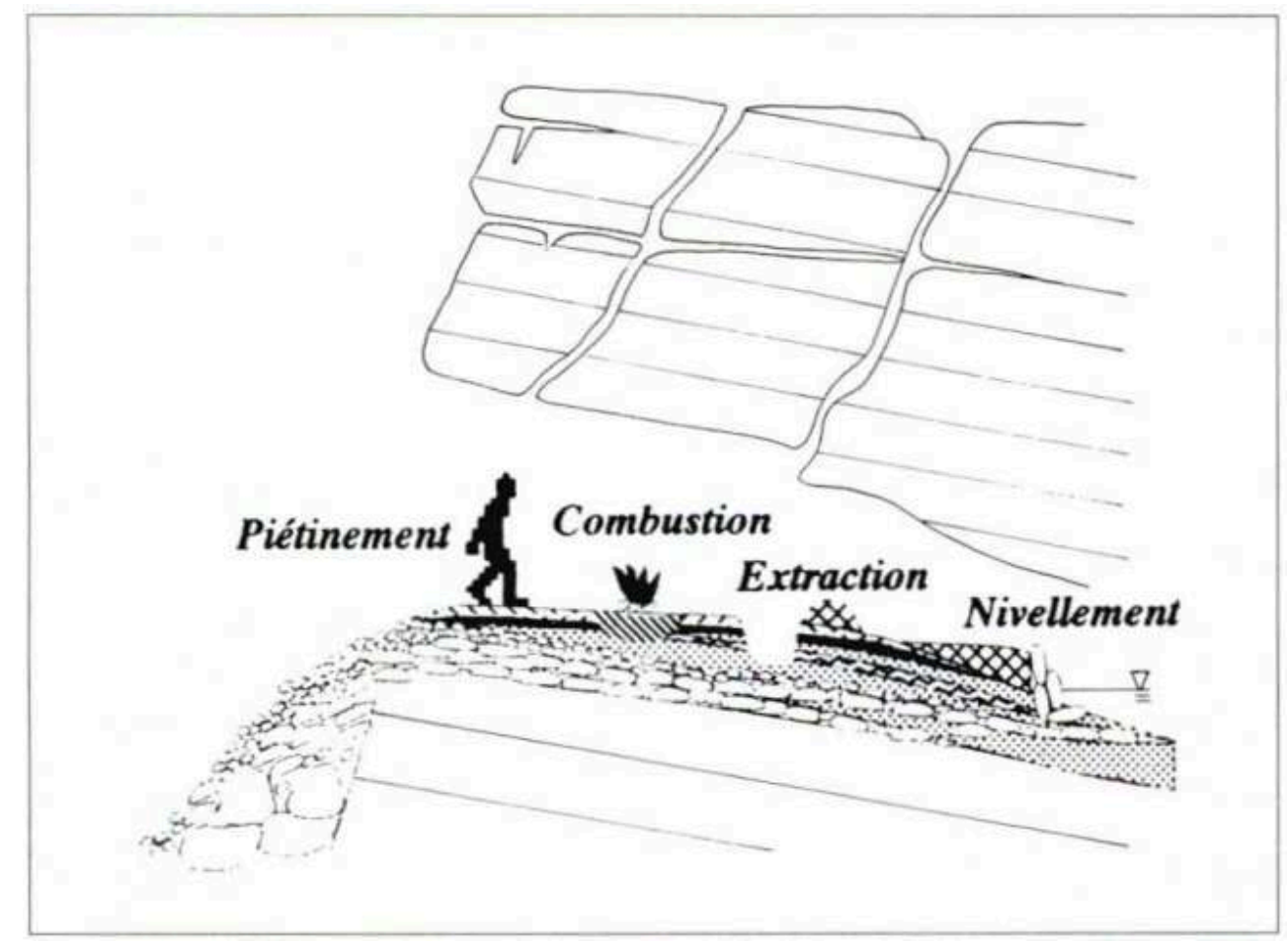

COMME LES AgENTS NATURELS DE SÉdIMENTATION, L'HOMME ET SES ACTIVITÉS CONTRIBUENT AU REMANIEMENT PERMANENT des SÉdimENTS, PRÉALABLEMENT DÉPOSÉS PAR VOIE NATURELLE OU ANTHROPIQUE

\section{Altération}

Parmi les activités humaines entraînant des modifications de la surface d'occupation sans déplacements massifs de sédiment, les mieux connues sont la circulation des occupants à l'intérieur du site et la combustion.

- La circulation des habitants sur la surface d'occupation est essentiellement marquée par le tassement des dépôts sous-jacents (Gé et al. 1993) (fig. 10).

- Les foyers allumés à même le sol, sans aménagement intermédiaire de sole foyère, provoquent la cuisson du substrat, qui selon sa nature et l'intensité de la combustion, se brunifie, se rubéfie ou est complètement calciné (Wattez 1992). 


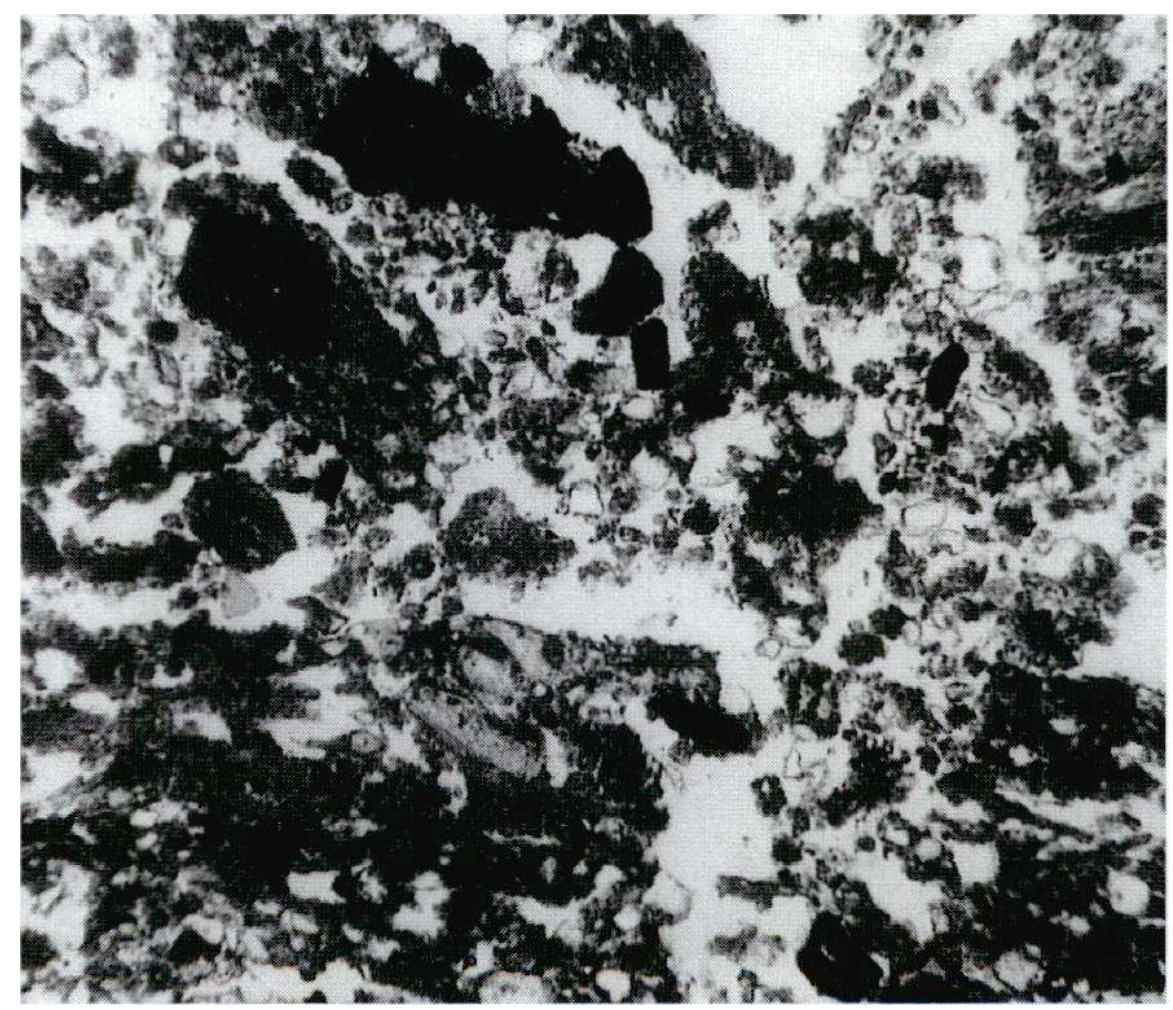

Grotte du Gardon, couche 18, lumière naturelle, hauteur du cadre : $3 \mathrm{~mm}$

Parmi les effets secondaires de l'occupation, le piétinement conduit à la compaction des dépôts, anthropiques ou naturels, sur lesquel évoluent les habitants

\section{Remaniements}

Les remaniements engendrés par l'homme sont liés au fonctionnement et à l'entretien de l'espace occupé. Ils se traduisent par le déplacement à l'intérieur du site de dépôts anthropiques ou naturels.

- Les vidanges de foyers entraînent l'accumulation, souvent à proximité de l'aire de combustion, de dépôts cendro-charbonneux. Sur le terrain, ces rejets se caractérisent par une certaine hétérogénéité texturale et structurale. Plus meubles et moins purs que les résidus de combustion trouvés in situ, ils reposent sur un substrat non transformé par la combustion.

- Le nettoyage des aires de parcages du bétail peut être à l'origine d'accumulations secondaires de fumiers, destinés à être brûlés ou utilisés comme engrais dans les champs. Si les indices de ces nettoyages sont difficiles à mettre en évidence, les accumulations secondaires peuvent se caractériser par leur localisation limitée dans l'espace et par leur hétérogénéité texturale et structurale.

- Les matériaux extraits des fosses-silos ou des trous de poteaux, s'ils ne sont pas réutilisés, peuvent former des dépôts secondaires qui se caractérisent, comme les précédents, par leur hétérogénéité texturale et structurale.

- Le nivellement des surfaces d'occupation par des actes de déblayage et de remblayage de sédiments naturels ou anthropiques peut être démontré par l'existence de dépôts dont la structuration interne est caractéristique d'un rejet massif. De telles structures sédimentaires 
de rejet existent par exemple dans les niveaux du Bronze final IIIa de la grotte du Gardon (Ambérieu-en-Bugey, Ain).

\section{Érosion} au niveau des interfaces de ces couches doivent, dans un premier temps, être classés en chronologie relative par l'étude stratigraphique du site (Harris 1989). La description des coupes de terrain, d'autant plus nombreuses que la sédimentation est complexe, et la définition des couches sont généralement effectuées de concert par l'archéologue et le sédimentologue. Les reconstitutions palethnographiques nécessitant la fouille en plan de grandes surfaces isochrones et des coupes stratigraphiques théoriques pallient l'absence de tranchée verticale dans ces secteurs (Sabatier 1995). Cette analyse macroscopique du terrain aboutit à l'établissement d'une séquence stratigraphique synthétique de l'ensemble du remplissage.

\section{Micromorphologie}

Le but de la micromorphologie (étude au microscope pétrographique de lames minces confectionnées à partir d'échantillons non perturbés de couches) (Courty et al. 1989) est d'extraire du sédiment des informations sur les processus sédimentaires, naturels ou anthropiques, impliqués dans la formation du site. L'étude de la composition et de la structure des dépôts d'une même phase d'occupation est à même de livrer des informations sur la nature, l'organisation spatiale et la durée relative de cette occupation. L'analyse des processus naturels de sédimentation et de transformation post-dépositionnelle apporte de la même manière des indications sur les événements climatiques survenus tout au long de la formation du site. 


\section{Radiochronologie}

39 La datation au carbone 14 des différentes couches du remplissage fournit un jalon chronologique sur lequel viennent se placer les différents événements enregistrés par le remplissage. L'étude micromorphologique permet d'assurer l'homogénéité sédimentaire des dépôts datés et de relativiser en termes de dynamique sédimentaire et d'occupation, la représentativité de ces dates. Ainsi les dates obtenues sur des dépôts manifestement remaniés et pouvant englober plusieurs niveaux d'occupation, n'ont pas la même signification que celles issues d'aménagements bien individualisés, comme des foyers par exemple.

\section{Autres méthodes d'étude}

$40 \mathrm{Au}$ terme de cet exposé analytique succinct, on n'aura garde d'oublier que diverses approches, non discutées ici, contribuent largement à l'interprétation des remplissages archéologiques. Sans les citer toutes et sans rentrer dans le détail ni dans les finalités de chacune d'elles, on rappellera simplement au titre de quelques exemples: l'archéozoologie, l'anthracologie, la carpologie, la palynologie...

\section{L'exemple de la grotte du Gardon (Ain)}

41 Un grand nombre des processus sédimentaires et post-dépositionnels évoqués en première partie de cet article ont été observés dans le remplissage de la grotte du Gardon. La reconnaissance de ces processus permet d'interpréter les dépôts en termes de dynamique et de rythme sédimentaires, et d'en tirer des informations sur les modalités d'occupation et sur l'ambiance climatique des cinq derniers millénaires. L'interprétation fonctionnelle des dépôts anthropiques de l'âge du Bronze ayant déjà été abordée en d'autres circonstances (Sordoillet 1994), c'est plutôt vers l'aspect environnemental et temporel des occupations du Néolithique que nous nous tournerons ici. Pour ce faire, nous tenterons une étude comparative entre les données climatiques régionales livrées par M. Magny (1995) et celles évoquées par le fonctionnement intermittent de la résurgence du Gardon. Par cet essai, nous chercherons à discuter d'une part des rythmes d'occupation du site, d'autre part d'un éventuel déterminisme climatique de ces occupations

\section{Présentation générale du site}

42 La grotte du Gardon se situe à $2 \mathrm{~km}$ à l'est d'Ambérieu-en-Bugey, dans la partie méridionale de la chaîne jurassienne (fig. 11). Son porche s'ouvre à $373 \mathrm{~m}$ d'altitude, au fond d'une reculée façonnée dans les calcaires du Bas-Bugey. Il se poursuit par une galerie descendante conduisant à un lac souterrain dont le drainage s'effectue par les conduits inférieurs du réseau. Le porche et l'entrée de la galerie ont été occupés à plusieurs reprises entre le Néolithique ancien et le Moyen Âge. Ces passages répétés sont à l'origine de nombreuses couches archéologiques superposées, localement isolées les unes des autres par des dépôts sablo-limoneux d'inondation. 
11- Situation géographique et topographie de la grotte du Gardon

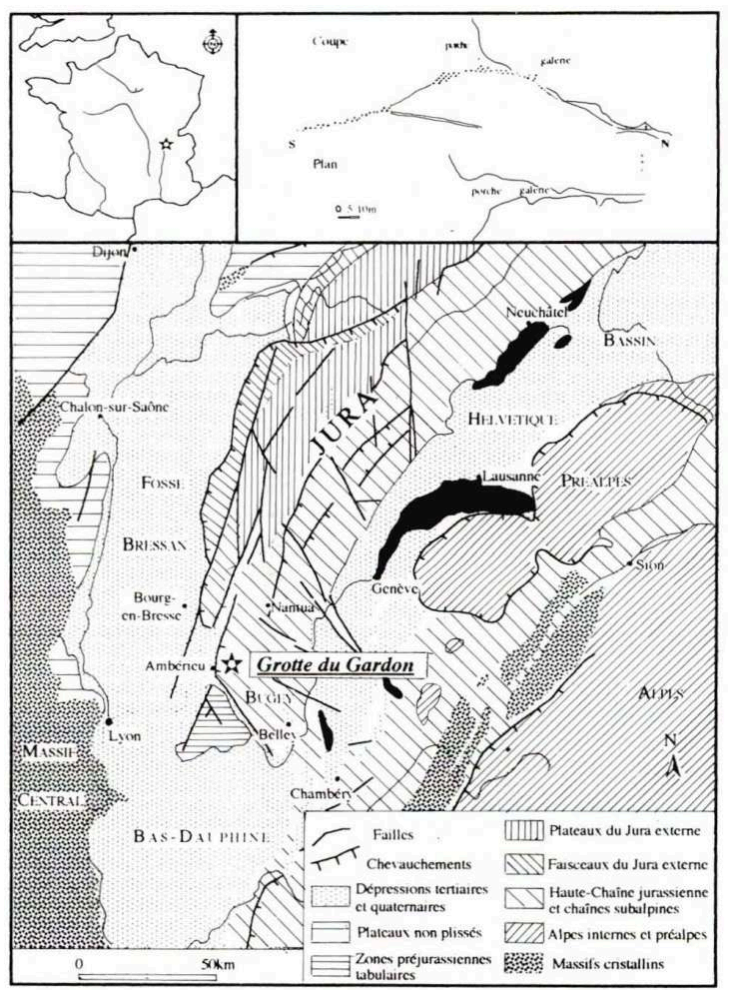

LA gROTTE DU GARDON EST RATTACHÉE À UN RÉSEAU KARSTIQUE CREUSÉ DANS LES CALCAIRES dU JURA MÉRIDIONAL, A PROXIMITÉ DU gRAND AXE DE CIRCULATION QUE CONSTITUE LA VALLÉE DU RHÔNE. LA CONFIgURATION DU PORCHE ET DE LA gALERIE A PERMIS L'ACCUMULATION ET LA CONSERVATION DES DÉPÔTS gÉNÉRÉS PAR LES CINQ MILLE ANS D'OCCUPATION DE LA gROTTE ET PAR LES FRÉQUENTES CRUES DE LA RIVIÈre

\section{Processus de formation du remplissage et comparaison avec les données climatiques régionales}

Une soixantaine de couches constituent le remplissage archéologique, de 1 à $3 \mathrm{~m}$ d'épaisseur, sur près de $300 \mathrm{~m}^{2}$ (Joly et al. 1991, Sabatier et al. 1993). La stratigraphie, les vestiges archéologiques et les datations radiocarbones permettent actuellement la sériation de ce remplissage en 14 ensembles pour les périodes allant du Néolithique ancien à la Tène (Voruz 1996) (fig. 12,13) :

- couches 60 à 54 : Néolithique ancien, vers 5100 à 4800 av. J.-C.

- couches 53 à 51 : Saint-Uze ancien, vers 4750 à 4450 av. J.-C.

- couches 50 et 49 : Saint-Uze récent, vers 4400 à 4200 av. J.-C.

- couche 48 : abandon, vers 4200 à 4100 av. J.-C.

- couches 47 à 43 : Chasséen récent, vers 4100 à 3800 av. J.-C.

- couches 42 à 39 : Néolithique Moyen Bourguignon, vers 3800 à 3500 av. J.-C.

- couche 38 : abandon, vers 3500 à 2800 av. J.-C.

- couche 37 : Néolithique final entre 2800 et 2450 av. J.-C.

- couches 36 et 34 : Bronze ancien, vers 2300 à 1800 av. J.-C.

- couches 33 à 24 : Bronze moyen, vers 1700 à 1400 av. J.-C.

- couches 23 à 21 : Bronze final I, vers 1400 à 1250 av. J.-C.

- couches 20 à 18 et 14 : Bronze final III, vers 1100 à 1000 av. J.-C. 
- couches 17 à 15 : abandon, vers 850 à 450 av. J.-C.

- couches 13 : La Tène, vers 450 à 150 av. J.-C.

C'est sur la base de ce découpage chronoculturel que nous discuterons des processus sédimentaires naturels et anthropiques mis en oeuvre lors de l'édification du remplissage. Les caractéristiques lithostratigraphiques et micromorphologiques des dépôts conduisent à un découpage quelque peu différent qui peut se traduire en termes d'activités humaines ou de sédimentation naturelle. La signification climatique de cette sédimentation naturelle est discutée en confrontation avec les données régionales déduites des fluctuations lacustres (Magny 1995) (fig. 13). Rappelons à ce sujet, que les phases de transgression lacustre sont en relation avec des périodes de refroidissement.

12- Profil du remplissage et principaux ensembles chrono-stratigraphiques de la grotte du Gardon

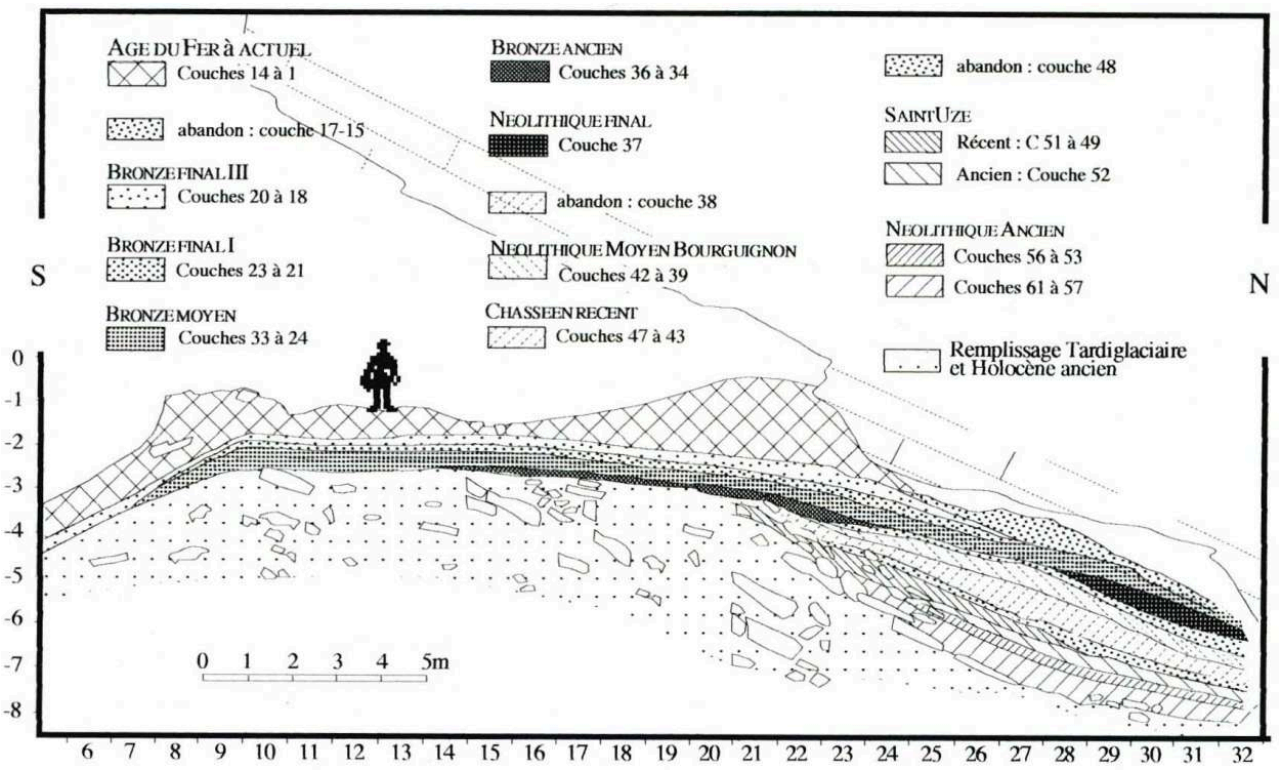


13- Confrotation des données lithostratigraphiques, des dotations, des ensembles culturels et des interprétations micromorphologiques du remplissage de la grotte du Gardon (Ambérieu-en-Bugey) I Ain) avec les données climatiques des lacs jurassiens

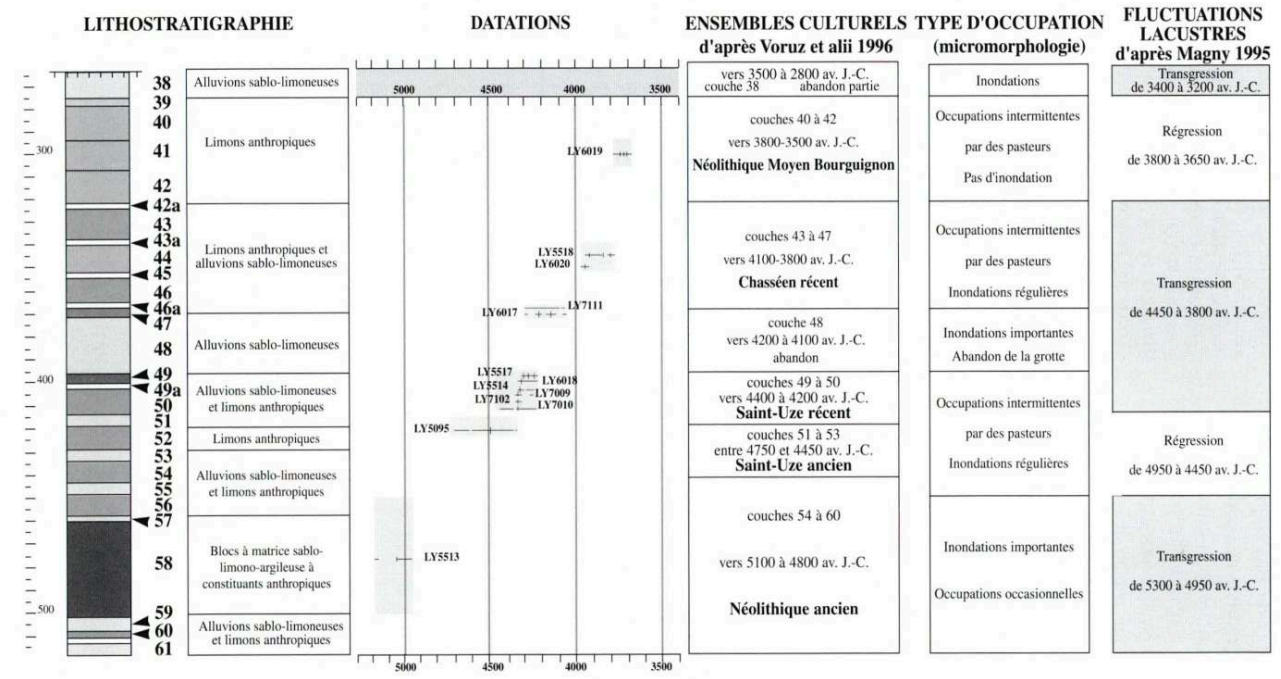

Les dégradations climatiques enregistrées par les hauts niveaux lacustres, se traduisent par la mise en place d'épaisses couches sablo-limoneuses formées par la superposition de plusieurs lits d'alluvions. La grotte apparaît peu ou pas fréquentée durant ces périodes, comme par exemple entre 4200 et 4100 av. J.-C. A l'inverse, les régressions lacustres se traduisent par une plus grande dilatation de la sédimentation anthropique qui peut même devenir exclusive, comme dans le cas des couches 39 à 42

\section{Les couches 60 à 54 du néolithique ancien}

Cet ensemble culturel est subdivisé en deux sous-ensembles en raison de leurs caractéristiques sédimentologiques différentes.

- De la couche 60 à la couche 57, la sédimentation est largement dominée par l'alluvionnement (couches 59 et 57) et par le démantèlement du plafond rocheux (C58). La sédimentation anthropique est limitée à deux minces lentilles (C60) et à des infiltrations de matériel entre les blocs de la couche 58. L'abondance des alluvions traduit le haut niveau général de la nappe phréatique. Le microlitage de ces dépôts (succession de plusieurs lits à granulométrie décroissante depuis les sables jusqu'aux argiles) révèle les fluctuations de cette nappe, où crues et décrues alternent régulièrement. C'est à la faveur de quelques unes de ces décrues que surviennent les premières fréquentations humaines, au Néolithique ancien (couches $60 \mathrm{a}$ et $\mathrm{b}$ ). La première d'entre elle (couche 60a) est très fugace : au sommet d'un lit fluviatile, quelques micro-fragments de charbons, d'os et de céramique sont mêlés aux argiles de fin de crue. La faible épaisseur de cette couche et la pauvreté des apports anthropiques plaident pour une installation de fort courte durée. La seconde occupation (couche 60b) apparaît un peu plus importante. Elle est marquée par une sédimentation anthropique plus abondante et plus diversifiée qu'en 60a (charbons, cendres, sphérolites de calcite, os) et par la présence d'un foyer. Non encore daté, cet ensemble des couches 61 à 59 est probablement antérieur à 5100 av. J.-C., date approximative de la couche 58 sus-jacente. La forte humidité qui le caractérise semble concorder avec les hauts niveaux que connaissent les lacs jurassiens à la même époque (transgression vers 5300 à 4900 av. J.-C.), et pourrait expliquer la rareté des occupations dans une grotte encore trop sujette aux inondations. On ne peut toutefois exclure que les occupations aient été plus importantes et les vestiges déblayés par l'activité karstique. Au dessus des alluvions précédentes, un 
amoncellement de blocs (couche 58) témoigne de l'effondrement d'une partie du toit de la cavité. Ce phénomène peut être associé à un adoucissement succédant à une période de grand froid (Campy 1982). L'humidité reste importante ainsi qu'en témoignent les nombreuses coiffes argilo-limoneuses de la couche 57, recouvrant l'amoncellement de blocs. Cette amélioration climatique, qui pourrait annoncer l'Atlantique récent vers 4880 av. J.-C., semble s'accompagner d'une fréquentation un peu plus importante de la grotte. Les sédiments fins des couches 58 et 57 s'enrichissent en constituants d'origine anthropique (cendres, charbons, sphérolithes de calcite, os - brûlés ou non - et tessons de céramiques).

- Les couches 56 à 54, que l'on pourrait situer en déduction de ce qui précède vers 4 900-4 800 av. J.-C., traduisent une diminution de la sédimentation fluviatile (couche 55) au profit de la sédimentation anthropique (couches 56 et 54 ). Les sables et les limons d'inondation de même que les blocs de gélifraction se raréfient, tandis que les couches limono-argileuses anthropiques s'épaississent et s'enrichissent en sphérolithes de calcite, en quelques phytolithes, en de rares coprolithes et surtout en matière organique indifférenciée. L'amélioration climatique annoncée par les couches 58 et 57 semblent ainsi se confirmer, à une date où débute une importante régression dans les lacs jurassiens (régression vers 4900 à 4 400). L'atténuation des inondations favoriserait ainsi les occupations humaines, mais là encore on ne peut totalement exclure que le rythme des fréquentations ait été constant et que seule diminue l'action érosive de la résurgence. Concernant les modalités d'occupation, les caractéristiques micromorphologiques des dépôts plaident pour la stabulation répétée de caprinés. A la fin du Néolithique ancien, la grotte aurait ainsi fait principalement office de refuge pour des pasteurs. Cette interprétation n'est pas contradictoire avec les premières données archéozoologiques (Chaix et Nicod 1991).

\section{Les couches 53 à 51 du Saint-Uze ancien} équivalentes à celles de la fin du Néolithique ancien et cet ensemble pourrait être rattaché aux couches 56 à 54 du Néolithique ancien. Nous sommes entre 4750 et 4450 av. J.-C., toujours pendant une phase de régression lacustre. Ce contexte climatique favorable semble être en relation avec la poursuite, voire l'intensification, de la fréquentation du site. De nombreux résidus végétaux et des esquilles osseuses, brûlés ou non, des coprolithes, des fragments de sol piétinés, le microlitage et la compaction importante des dépôts, plaident pour une installation prolongée des populations du Saint-Uze ancien. D'un point de vue sédimentologique, la grotte apparaît de moins en moins comme un simple refuge temporaire pour les bergers et leurs troupeaux, mais plutôt comme un habitat bien aménagé et occupé sur une longue durée. Cette hypothèse n'est cependant pas étayée par les données archéologiques qui décrivent un assemblage de mobilier plutôt maigre (Nicod 1996).

\section{Les couches 50 à 49, Saint-Uze récent}

Vers 4400 à 4200 av. J.-C., alors qu'une transgression importante s'amorce dans les lacs jurassiens (transgression vers 4400 à 3800 ), la grotte du Gardon n'enregistre d'abord que quelques crues exceptionnelles et de modeste envergure (couches 51 et 49a). Après l'inondation de la couche 51, qui marque le sommet de l'occupation du Saint-Uze ancien, la fréquentation de la grotte reprend, mais avec, semble-t'il, une intensité moindre. Les dépôts de la couche 50 sont peu compactés par le piétinement, et amplement digérés par les vers pendant des périodes d'abandon. L'habitat est 
néanmoins réel, révélé aussi bien par l'aménagement de fosses et de foyers, que par l'abondance des résidus cendreux dans les sédiments. L'élevage, qui d'après les coprolithes, concerne à la fois la chèvre et les bovins, compte également parmi les activités principales. Les dépôts de la couche 49 apparaissent un peu mieux conservés que ceux de la couche 50. Il en va de même pour le mobilier et les structures archéologiques qui apparaissent particulièrement abondants dans cette couche (Nicod 1996). L'intermittence des occupations y est toutefois enregistrée par des phases d'inondation ou d'activité biologique. Ainsi, entre 4400 et 4200 av. J.-C., la grotte du Gardon apparaît occupée de manière intermittente (probablement pendant la saison sèche) par des groupes dont l'activité économique principale semble être l'élevage. Les séjours sont suffisamment longs pour justifier l'aménagement de structures d'habitat, qui peuvent être réutilisées à chaque nouvelle occupation du site. La bonne conservation des dépôts et du matériel de la couche 49 est probablement liée à son enfouissement catastrophique sous les dépôts d'inondation de la couche 48 .

\section{La couche 48 , abandon de la grotte}

Une série d'inondations, enregistrées par le microlitage de la couche 48, interrompt momentanément ces occupations vers 4200 à 4100 av. J.-C., soit vers le maximum des transgressions lacustres jurassiennes de cette période.

\section{Les couches 47 à 43 , Chasséen récent}

La fréquentation de la grotte reprend vers 4100 av. J.-C., dans des conditions comparables à celles précédant l'inondation de la couche 48. Des groupes occupent régulièrement la grotte de plus en plus rarement soumise aux inondations. Le fonctionnement plus occasionnel de l'exurgence semble annoncer l'amélioration climatique, enregistrée par une régression lacustre vers 3800 av. J.-C. L'activité principale semble toujours être l'élevage d'après la nature des sédiments, mais les données archéozoologiques montrent que la chasse est également importante (Chiquet 1996). L'occupation la plus intense de cette période semble se produire vers la fin du Chasséen. Elle correspond à la moitié inférieure de la couche 44, caractérisée par une compaction importante, par de nombreux agrégats piétinés et par la présence de résidus de litières d'herbacées.

\section{Les couches 42 à 39 , néolithique Moyen Bourguignon}

Les dépôts générés par les populations du Néolithique Moyen Bourguignon, vers 3800 à 3500 av. J.-C., apparaissent très différents des précédents bien que d'une épaisseur équivalente. Les indices d'élevage et d'habitat sont mal conservés mais le sédiment fin comporte néanmoins les principaux indicateurs de l'occupation humaine (restes végétaux brunifiés ou carbonisés, esquilles osseuses, sphérolithes de calcite, matière organique amorphe). Seul le sommet de cet ensemble (couche 39) présente des indices témoignant d'une occupation relativement importante (compaction de la couche, nombreuses esquilles osseuses plus ou moins brûlées, fragments de mortier). Cette mauvaise conservation des dépôts semble pouvoir être corrélée avec la complète diparition des niveaux d'inondation dans la grotte, elle-même corrélable à la régression lacustre qui marque cette période. Les dépôts anthropiques n'étant plus régulièrement protégés des perturbations biologiques par des phases d'inondation, ils sont plus 
intensément dégradés et ne permettent pas l'identification des caractéristiques primaires des dépôts. Seule la couche 39, recouverte par les sables de la couche 38, est relativement préservée des évolutions post-dépositionnelles.

\section{La couche 38}

51 Entre 3500 et 2800 av. J.-C., plusieurs hauts niveaux lacustres, séparés par des phases de régression, sont enregistrés dans le Jura. Au cours de cette période, la couche 38 de la grotte du Gardon, très influencée par le fonctionnement de l'exurgence, se met en place. Formée par l'alternance de lits sableux et limoneux d'inondation, elle contient deux couches anthropiques interstratifiées. Découvertes seulement en 1997, ces couches n'ont pas encore été étudiées.

\section{Conclusion}

52 L'objet de cet article était de montrer l'importance de l'identification des processus sédimentaires et post-sédimentaires dans l'étude des sites archéologiques pour la reconstitution de l'histoire culturelle et environnementale de ces sites. Cette importance est soulignée au début de cet article par l'exposé des multiples et divers agents et processus, naturels et anthropiques, qui peuvent concourir à l'élaboration d'un remplissage. L'identification de ces processus dans le remplissage de la grotte du Gardon permet de proposer, à l'appui du cadre chrono-culturel (Voruz 1996) et des fluctuations climatiques des lacs jurassiens (Magny 1995), une histoire des occupations préhistoriques dans leur contexte environnemental. Le principal résultat de cette étude est la mise en évidence d'une corrélation entre la nature des dépôts accumulés sur le site et les fluctuations climatiques enregistrées dans les lacs. En effet, les principales accumulations sédimentaires liées aux inondations de la grotte du Gardon se mettent en place pendant des périodes de hauts niveaux lacustres, tandis que le maximum de sédimentation anthropique est plutôt enregistré pendant les phases régressives. Les fluctuations climatiques révélées par les variations des niveaux lacustres seraient donc également enregistrées par le système karstique. À ce stade, plusieurs hypothèses sont envisageables :

- les fluctuations climatiques ont conditionné la fréquentation de la grotte et les dégradations climatiques s'accompagnent de l'interruption des fréquentations (déterminisme climatique);

- les arrêts d'occupation interviennent indépendamment des variations du climat, mais la sédimentation naturelle est mieux enregistrée car non perturbée par la présence de l'homme.

- le rythme de fréquentation reste identique, mais les dégradations climatiques engendrent le fonctionnement plus violent de l'exurgence qui évacue les dépôts anthropiques de ces périodes.

53 La poursuite des recherches sur ces dépôts et sur ceux de l'âge du Bronze permettra vraisemblablement d'affiner notre compréhension du fonctionnement de l'exurgence et de son influence sur le rythme des occupations.

Concernant le statut de ces occupations, les sédiments témoignent de la pratique de l'élevage du Néolithique ancien au Néolithique Moyen Bourguignon. Cette activité s'accompagne d'indices d'habitat témoignant de l'aménagement des lieux pour 
l'installation humaine. Au vu de la digestion importante des dépôts par les vers, ces occupations sont vraisemblablement intermittentes, régulièrement ponctuées, on l'a $\mathrm{vu}$, par des phases d'inondation. Le rythme de ces occupations n'est pas encore définitivement établi, mais l'utilisation saisonnière de la grotte paraît envisageable. Là encore la poursuite des recherches permettra vraisemblablement d'en savoir plus sur le statut socio-économique de ces populations.

$\mathrm{Au}$ terme de cet article je tiens à saluer tous les membres de l'équipe gardonologique, sans le travail desquels cette étude n'aurait pas été possible. Je remercie plus particulièrement L. Chaix et $\mathrm{P}$. Chiquet pour les données archéozoologiques, PierreYves Nicod pour l'archéologie du Néolithique ancien et moyen, et enfin Philippe Sabatier et Jean-Louis Voruz pour le cadre chrono-culturel.

\section{BIBLIOGRAPHIE}

\section{Bibliographie}

Ambert 1981 : AMBERT (P.). - Chronologie locale et synchronisme paléoclimatique. Actes du Coll. de l'A.G.F., Formations carbonatées externes, 1981, p. 201 - 206.

Aubert 1967 : AUBERT (D.) - Estimation de la dissolution superficielle dans le Jura. Bull. Soc. vaud. Sci. Nat., 69/8. p. 365-376.

Barton et Clark 1993 : BARTON (C. M.) et CLARK (G. A.) - Cultural and Natural Formation Processes in Late Quaternary Cave and Rockshelter Sites in Europe and the Near East. In : Goldberg P., Nash D. T. and Petraglia M. D., Formation Processes in Archaeological Context., monographs in World Archaeology n 17, Prehistory Press, Madison, Wisconsin, p. 33-52.

Bar Yossef 1993 : BAR YOSSEF (O.) - Site formation processes from a Levantine viewpoint. In : Goldberg P., Nash D.T. and Petraglia M.D. (eds), Formation processes in Archaeological context. Madison, Wisconsin, Monographs in World Archaeology, $n^{\circ} 17$, Prehistory Press, $\rho$ 13-32.

Beeching 1992 : BEECHING (A.) - L'archéologie des cavernes. Introduction au débat. In : Beeching A. (éd.), Archéologie des grottes, ARENERA, vol. 7,1992, p. 9-12.

Berger 1995 : BERGER (J.-F.) - Facteurs anthropiques et naturels de l'évolution des paysages romains et protomédiévaux du bassin valdainais (Drôme). L'Homme et la dégradation de l'environnement. XVe Rencontres internationales d'Archéologie et d'Flistoire d'Antibes. Ed. APDCA, Juan-les-Pins, p. 79 - 114.

Brochier 1983 : BROCHIER (J.-E.). - Combustion et parcage des herbivores domestiques. Le point de vue du sédimentologue. Bull. S.P.F., t. 80, n5, p. 143-145.

Brochier 1987 : BROCHIER (J.-E.) - Phénomènes anthropiques dans les sédiments : l'homme, agent majeur de la sédimentation holocène. Le courrier du CNRS., suppl. au n ${ }^{\circ} 67$ : images des Sciences de l'Homme, 1987. 
Brochier 1990 : BROCHIER (J.-E.). - Des techniques géoarchéologiques au service de l'étude des paysages et de leur exploitation. Archéologie et Espaces, Xes Rencontres internationales d'Archéologie et d'Histoire, Antibes, Octobre 1989. Ed. APDCA, Juan-lesPins, 1990, p. 453-472, 8 fig.

Brochier 1979 : BROCHIER (J.-L.). - Etude sédimentologique de l'abri Jean Cros. In : Guilaine J. et al. , L'Abri Jean-Cros. Centre d'Anthropologie des Sociétés Rurales, Toulouse, 1979, p. 219-232.

Brochier 1986 : BROCHIER (J.-L.). - Sédiments - documents archéologiques : La grotte d'Antonnaire - grotte bergerie. In : Culture et milieu des premiers paysans de la Moyenne Vallée du Rhône. ARENERA, Lyon, Centre d'archéologie préhistorique de Valence, 1986, p. 32-33.

Brochier 1988 - BROCHIER (J.-L.). - Les sédiments : documents archéologiques. Les Nouvelles de l'Archéologie, $\mathrm{n}^{\circ}$ 31, éd. Errance, p. 15-17.

Brochier et al. 1995 : BROCHIER (J.-L.), BEECHING (A.), EVIN (J.) et VALLADAS (H.) - Espace et temps : recherche de repères chronologiques pour la préhistoire récente rhodanienne. In : Voruz (J.-L.), Chronologies néolithiques, de 6000 à 2000 avant notre ère dans le Bassin rhodanien. Ed. de la Société Préhistorique Rhodanienne, Ambérieu-en-Bugey, 1995, p. 151-161.

Brown 1984 : BROWN (D) - Prospects and limits of a phytolith key for grasses in the central United States. Journal of Archaeological Science, n¹1, p. 221-243.

Butzer 1982 : BUTZER (K. W.). - Archaeology as Human Ecology : Method and Theory for a Contextual Approach. Cambridge University Press, 1982, 364 p.

Cammas 1994 : CAMMAS (C.) - Approche micromorphologique de la stratigraphie urbaine à Lattes : premiers résultats. In : Garcia D. (dir.), Exploration de la ville portuaire de Lattes, Lattara 7, Montagnac, 19p., 2 fig., 12 tabl.

Campy 1982 : CAMPY (M.). - Le Quaternaire FrancComtois. Essai chronologique et paléoclimatique. Thèse Univ. Franche-Comté, Faculté des Sciences, Besançon, 575p., 219 fig., 8 pl.

Campy et Macaire 1989 : CAMPY (M), et MACAIRE (J-J). - Géologie des formations superficielles : géodynamique, faciès et utilisation. Ed. Masson, Paris, $433 \mathrm{p}$.

Casanova 1984 : CASANOVA (J.-P.). - Genèse des carbonates d'un travertin pléistocène ; interprétation paléoécologique du sondage Peyre I (Compregnac, Aveyron). Geobios, Mem. sp. n8, 1984, p. 219-225.

Chaix et Nicod 1991 : CHAIX (L.) et NICOD (P.-Y.) - La faune du Néolithique ancien. Rapport sommaire. In : Voruz et al., Archéologie de la grotte du Gardon (Ain). Rapport de fouilles 1985-1990. Doc. du Départ. d'Anthropologie et d'Ecologie de l'Univ. de Genève, p. 151 à 154.

Chiquet 1996 : CHIQUET (P.) - La faune des vertébrés du Néolithique moyen II : Premiers résultats. In : Voruz (J.-L.) dir., La grotte du Gardon à Ambérieu-en-Bugey (Ain), Rapport de fouilles 1994-1996, ed. de la Société Préhistorique Rhodanienne, Ambérieu-en-Bugey, p. 201-203.

Courty 1986 : COURTY (M.-A.). - Quelques faciès d'altération de fragments carbonatés en grottes et abris sous roches préhistoriques. Bull. AFEQ, t. 3/4, 1986, p. 281-289.

Courty 1988a : COURTY (M.-A.) - Archéologie et sédiment. Les Nouvelles de l'Archéologie, $\mathrm{n}^{\circ}$ 31, éd. Errance, p. 9-14.

Courty 1988b : COURTY (M.-A.). - Analyse microscopique des sédiments du remplissage de la grotte Vaufrey (Dordogne). In : RIGAUD (J.-P.) et al. La grotte Vaufrey, paléoenvironnement, chronologie, activités humaines. Mém. S.P.F., t. XIX, 1988, p. 183-209. 
Courty et al. 1989 : COURTY (M. A.), GOLDBERG (P), et MACPHAIL (R-I.). - Soils and Micromorphology in Archaeology. Cambridge manuals in Archaeology, Cambridge University Press, 344 p., 8 pl., 101 fig.

Courty 1990 : COURTY (M.-A.). - Environnements géologiques dans le nord-ouest de l'Inde. Contraintes géodynamiques au peuplement protohistorique (Bassins de ta Ghaggar-Saraswati-Chautang). Thèse d'Etat es Sciences, Univ. Bordeaux I. 1990, 328 p.

Courty et al. 1992 : COURTY (M.-A.), MACPHAIL (R.I). et WATTEZ (J). - Soil micromorphological indicators of pastoralism ; with special reference to Arene Candide, Finale Ligure, Italy.

Archeologia della pastorizia nell'Europa méridionale. Actes de la Table Ronde internationale, Chiavari, 22-24 sept. 1989, 1992, p. 127-150.

Cupillard et al. 1988 : CUPILLARD (C)., PÉTREQUIN (P)., PININGRE (J.-F.), RICHARD (H.). - La Néolithisation du Jura. Actes du 113e Congrès Nat. Soc. sav., Strasbourg, 1988. Mésolithique et Néolithisation en France et dans les régions limitrophes, éd. CTHS, 1991, p. 347-387.

Fedoroff 1987 : FEDOROFF (N.) - Sensibilité à l'agriculture intensive des principaux types de sols de l'Europe du Nord-Ouest. Fondements scientifiques pour la protection des sols dans la communauté européenne, Actes du Symposium de Berlin, 6-8 oct. 1986., éd. Barth et L'Hermite, 1987, p. 65-87.

Fedoroff et Courty 1987 : FEDOROFF (N.) et COURTY (M.-A.). - Paléosols. In : Miskovsky J-C., éd., Géologie de la préhistoire : méthodes, techniques, applications. Ass. pour l'ét. de l'env. géol. de la préhist., Paris, 1987, p. 251-280.

Fedoroff et Courty 1995 : FEDOROFF (N.) et COURTY (M.-A.) - Le rôle respectif des facteurs anthropiques et naturels dans la dynamique actuelle et passée des paysages méditerranéens. Cas du bassin de Vera, sud-est de l'Espagne. L'homme et la dégradation de l'environnement. XVème Rencontres internationales d'Archéologie et d'Histoire d'Antibes. Ed. APDCA, Juanles-Pins, p. 115-141.

Gé et al. 1995 : GÉ (T.), COURTY (M.-A.), MATTHEWS (W.) et WATTEZ (J.) - Sedimentary formation processes of occupation surfaces. In : Goldberg P., Nash D.T. and Petraglia M.D. (eds), Formation Processes in Archaeological Context. Madison, Wisconsin, Monographs in World Archaeology, $\mathrm{n}^{\circ} 17$, Prehistory Press, $\rho$ 149-163, 6 fig.

Goldberg et Macphail 1990 : GOLDBERG (P.) et MACPHA1L (R. I.). - Micromorphological evidence of middle pleistocene landscape and climatic changes from southern England : Westbury-sub-Mendip, Somerset and Boxgrove, W. Sussex. In : Douglas L. A., Soil Micromorphology : a Basic and Applied Science. Proceedings of the VIIIth International Working Meeting of Soil Micromorphology, San Antonio, Texas, 1988, 1990, p. 441-447.

Harris 1989 : HARRIS (E. C.) - Principles of Archaeological Stratigraphy (2nd edition). Academic Press, Inc., $170 \mathrm{p}$.

Joly et al. 1991 : JOLY (B.), SORDOILLET (D)., VORUZ (J.-L.). - Stratigraphie et chronologie. In : Voruz (J.-L.) éd., Archéologie de la grotte du Gardon. Rapport de fouilles 1985-1990, Ambérieu-en-Bugey, Société Préhistorique Rhodanienne, Genève, Document du département d'Anthropologie et d'Ecologie de l'Université de Genève, $n^{\circ}$ 17, 1991, p. 79-111.

Kwaad et Mücher 1977 : KWAAD (F.J.P.M.) et MÜCHER (H.J.). - Formation and evolution of colluvium on arable land in northern Luxembourg. Geoderma, 22, 1979, p. 173-192.

Laville 1975 : LAVILLE (H.). - Climatologie et chronologie du Paléolithique en Périgord : étude sédimentologique de dépôts de grotte et sous abris. Etudes quaternaires, n4, publ. de l'Univ. de Provence, Marseille. 
Magny 1995 : MAGNY (M.). - Une histoire du climat, des derniers mammouths au siècle de l'automobile. Ed. Errance, Coll. des Hesperides, 1995, 176 p.

Miskovsky 1970 : MISKOVSKY (J.-C.). - Stratigraphie et paléoclimatologie du Quaternaire du Midi méditerranéen. Thèse, Paris, 1970, 747 p., 303 fig.

Miskovsky 1974 : MISKOVSKY (J.-C.). - Le Quaternaire du Midi méditerranéen. Stratigraphie et paléoclimatologie d'après l'étude sédimentologique du remplissage des grottes et abris sous roche (Ligurie, Provence, Bas-Languedoc, Roussillon, Catalogne). Etudes Quaternaires n 3, Publ. de l'Univ. de Provence, Marseille.

Nicod 1996 : NICOD (P.-Y.) - Remontages céramiques et datation C14 des couches 48 à 60. Précisions chrono-stratigraphiques. In : Voruz (J.-L.) dir, La grotte du Gardon à Ambérieu-en-Bugey (Ain), Rapport de fouilles 1994-1996, éd. de la Société Préhistorique Rhodanienne, AmbérieuenBugey, p. 165-190.

Pétrequin et al. 1985 : PÉTREQUIN (P.), CHAIX (L.), PÉTREQUIN (A.-M.) et PIN1NGRE (J.-F.). - La grotte des Planches-près-Arbois (Jura). Proto-cortaillod et âge du Bronze final, Paris, éd. de la Maison des Sciences de l'Homme, coll. Archéologie et Culture matérielle, 1985, 273 p., 216 fig.

Piperno 1988 : PIPERNO (D. R.) - Phytolith Analysis. An Archaeological and Geological Perspective. Academic Press. 280 p.

Renault 1987 : RENAULT (P.) - Phénomènes karstiques. In : Miskovsky et alii, 1987, Géologie de la Préhistoire: Méthodes, techniques, applications, Ass. pour l'Etude de l'Environnement Géologique de la Préhistoire (éd.). Maison de la Géologie, Paris, 1987, p. 169-196.

Sabatier 1995 : SABATIER (P.). - La grotte du Gardon (Ain) : Méthodologie de l'approche verticale. In : Voruz (J.-L.), Chronologies néolithiques, de 6000 à 2000 avant notre ère dans le Bassin rhodanien. Ed. de la Société Préhistorique Rhodanienne, Ambérieu-en-Bugey, 1995, p. 113-122.

Sabatier et al. 1993 : SABATIER (P.), SORDOILLET (D.) et VORUZ (J.-L.). - Stratigraphie et Chronologie. In : Voruz (J.-L.,) dir. La grotte du Gardon à Ambérieuen-Bugey (Ain), rapport de fouilles 1993. Ambérieu-enBugey, Société Préhistorique Rhodanienne ; Départ. d'Anthropologie et d'Ecologie de l'Univ. de Genève, 1993. p. 33-73.

Sordoillet 1994 : SORDOILLET (D.) - Fonction et aménagement de la grotte du Gardon à l'âge du Bronze : approche micromorphologique. In : Beeching A. et Vital J. (éd.), Préhistoire de l'Espace habité en France du Sud, Résumé de communication, Premières Rencontres méridionales de Préhistoire récente, Valence 3 et 4 juin 1994.

Strauss 1993 : STRAUSS (L. G.) - Hidden assets and liabilities : Exploring archaeology from the earth. In : Goldberg P., Nash D.T. and Petraglia M.D. (eds), Formation Processes in Archaeological Context. Madison, Wisconsin, Monographs in World Archaeology, $n^{\circ} 17$, Prehistory Press, 1993, $\rho$ $1-10$.

Treffort 1991 : TREFFORT (J.-M.). - Contexte géographique. In : Voruz et al. Archéologie de la grotte du Gardon (Ain). Rapport de fouilles 1985-1990. Doc. du Départ. d'Anthropologie et d'Ecologie de l'Univ. de Genève, 1991, p. 33-42.

Van Vliet-Lanoë 1987 : VAN VLIET-LANOË (B.). - Dynamique périglaciaire actuelle et passée. Apport de l'étude micromorphologique et de l'expérimentation. Bull.AFEQ, 3, 1987, p. 113-132.

Van Vliet-Lanoë et Valladas 1983 : VAN VLIETLANÖ̈ (B.) et VALADAS (B.). - A propos des formations déplacées des versants cristallins des massifs anciens : Le rôle de la glace de ségrégation dans la dynamique. Bull. AFEQ, 4, 1983, p. 153-160. 
Vivian et al. 1991 : VIVIAN (R.), BINTZ (P.), BOCQUET (A.), BOREL (J.-L.), COLARDELLE (M.), DANGREAUX (B.), EDOUARD (J.-L.), MAGNY (M.), MAZARD (C.), OLIVE (P.) et VIVIAN (H.). Paléoenvironnement Holocène et Archéologie dans les Alpes françaises du Nord et leur Piémont, éd. du CTHS, Paris, 1991, 184 p.

Voruz 1996 : VORUZ (J.-L.) dir. - La Grotte du Gardon à Ambérieu-en-Bugey (Ain). Rapport de fouilles 1994-1996. éd. de la Société Préhistorique Rhodanienne, Ambérieu-en-Bugey, 308 p., 106 fig.

Wattez 1992 : WATTEZ (J.). - Dynamique de formation des structures de combustion de la fin du Paléolithique moyen au Néolithique moyen. Approche méthodologique et implications culturelles. Thèse de Doctorat, Univ. de Paris I., 1992, 375 p.

\section{Document}

Buard et al. 1994 : BUARD (J.-F.), FÉBLOT-AUGUSTIN (J.), PERRIN (T.), SORDOILLET (D.) et VELARDE (I.). - La grotte de l'Abbaye à Chazey-Bons, Rapport de fouilles, Dép. d'Anthropologie de l'Université de Genève, Genève, 1994, 55 p.

\section{RÉSUMÉS}

Après un inventaire des principaux processus de formation des sites archéologiques en grotte et un bref aperçu méthodologique sur la manière de les appréhender, les résultats de l'étude micromorphologique du remplissage de la grotte du Gardon (Ain) permettent, grâce au cadre chronoculturel établi par l'archéologue et aux données climatiques régionales tirées du milieu lacustre, de discuter du statut et du rythme des occupations sur ce site pendant le Néolithique. Le potentiel cognitif des sédiments anthropiques, c'est-à-dire des sédiments directement issus des activités n'est humaines, plus à démontrer (Brochier J.-E. 1987, Brochier J.-L. 1988, Courty 1988a...) L'étude de ces sédiments apporte des informations sur les modalités d'occupation et sur l'organisation de l'espace intra-site (Courty et al. 1992, Cammas 1994). L'interprétation archéologique des dépôts anthropiques repose sur l'identification des constituants et des faciès sédimentaires, significatifs de leur mode de mise en place et de leur évolution postdépositionnelle (Courty et al. 1989). La lecture et l'interprétation du message de la sédimentation anthropique impliquent toutefois que cette dernière évolution post-dépositionnelle n'ait pas eu une importance telle qu'elle brouille totalement les caractéristiques primaires du dépôt. Pour cette raison, tous les sites ne se prêtent pas d'égale manière à l'étude des sédiments anthropiques. Les grottes, parce qu'elles sont un abri tout naturel pour les gens et pour les aménagements qu'ils y ont apporté, constituent souvent un milieu propice à la formation des sites archéologiques et à la préservation des sédiments anthropiques (Renault 1987, Beeching 1992, Strauss 1993). Les parois et le plafond rocheux, en limitant l'extension latérale de ces dépôts et en les protégeant de l'altération météorique, favorisent leur superposition chronostratigraphique et leur conservation. Même si ces dépôts de grotte n'échappent pas à de possibles érosions, liées par exemple à l'activité karstique, aux bioturbations par les vers ou par d'autres animaux fouisseurs, ni encore à la confusion de plusieurs phases d'occupation en un même niveau archéologique, ils restent néanmoins parmi les plus appropriés du domaine terrestre pour l'individualisation et pour la caractérisation des niveaux d'occupation. 
Géoarchéologie des versant et terrasses 


\section{Géoarchéologie des versants}

Les dépôts de pente

Pascal Bertran et Jean-Pierre Texier

Nous remercions M. Prestreau (Service régional de l'archéologie, Lyon) pour avoir suscité la rédaction de cet article, D. Caclin (AFAN, Lyon), J.-J. Cleyet-Merle (Musée National de Préhistoire, les Eyzies), D. Legoupil (Institut d'Art et d'Archéologie, Paris), A. Rebiscoul (AFAN) et J.P. Rigaud (Institut de Préhistoire et Géologie du Quaternaire, Bordeaux) pour nous avoir fait part de données inédites ainsi que M. Provansal (Université d'Aix-Marseille) qui a bien voulu corriger le manuscrit.

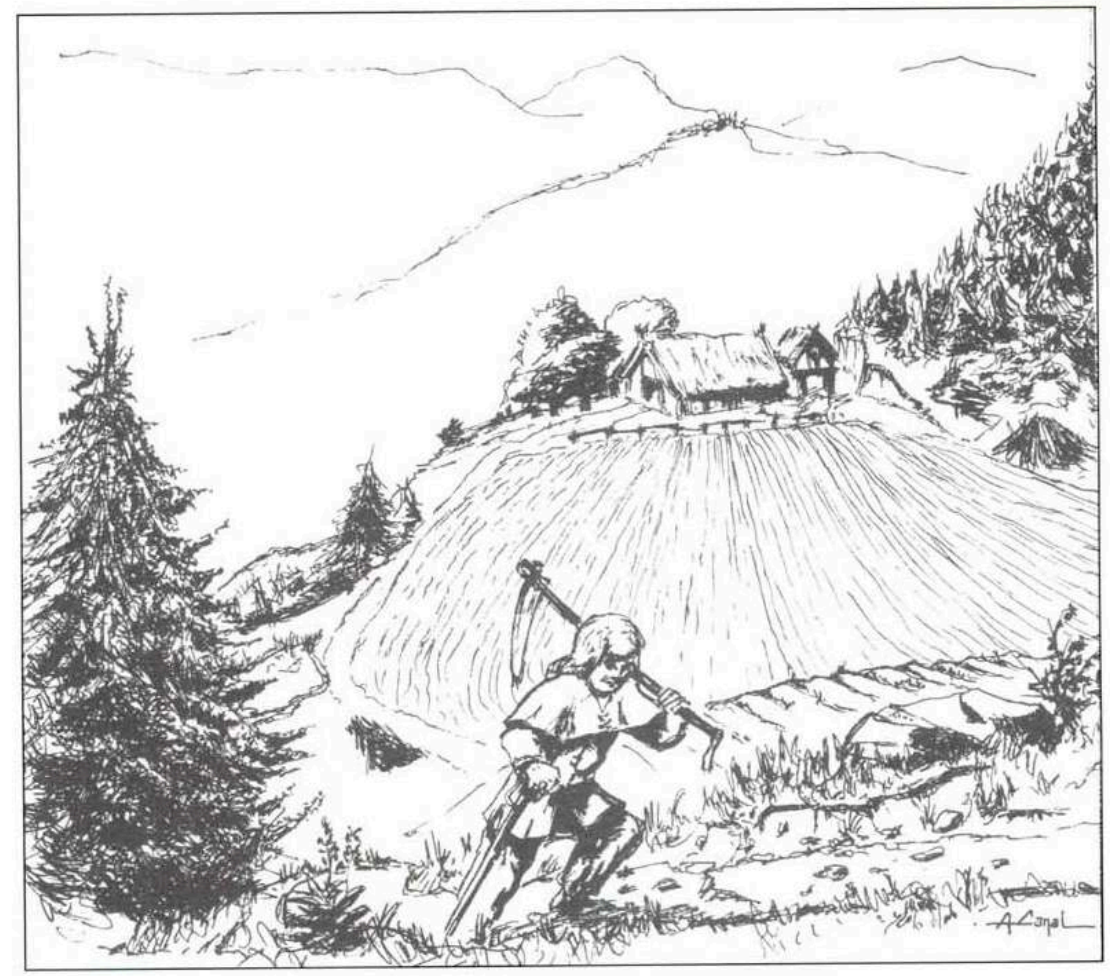

1 De nombreux mécanismes de transport des débris rocheux se produisent sur les versants, sous l'influence de la seule gravité ou aidés par l'eau, l'activité biologique ou 
anthropique. Les accumulations détritiques qui en résultent sont très répandues; elles peuvent atteindre des épaisseurs considérables en particulier dans les régions montagneuses et posséder un intérêt économique non négligeable. Les versants ont souvent constitué un milieu attractif pour l'homme, en raison des structures d'accueil offertes par les parois rocheuses, la présence d'écoulements ou encore celle de matières premières facilement exploitables. De ce fait, de très nombreux sites archéologiques ont été découverts dans ce type d'environnement.

2 Avec les dépôts fluviatiles, les formations de pente constituent donc un contexte sédimentaire privilégié pour la recherche archéologique. Alors que les milieux de sédimentation et les principales caractéristiques des dépôts en domaine alluvial sont abondamment décrits dans la majorité des manuels de sédimentologie (Reineck et Singh 1980, Reading 1986), les mécanismes de versant ne sont généralement que très partiellement abordés dans les ouvrages généraux et les développements récents de la géologie de ces formations restent difficilement accessibles aux archéologues.

Cet article se propose de faire une revue de quelques aspects des dépôts de pente concernant directement l'archéologie, illustrés à partir d'exemples essentiellement pris dans le Paléolithique. Trois points sont développés sucsuccessivement: une brève revue des différents processus et des faciès associés, l'intérêt des dépôts de pente pour les reconstitutions paléoenvironnementales et enfin, le rôle de ces mécanismes dans la formation des sites archéologiques.

\section{Principaux processus, faciès associés et exemples en contexte archéologique}

4 Sous l'action de différents facteurs, les parois se dégradent et forment à leur pied des talus détritiques, englobés dans leur ensemble sous le terme général d'éboulis. La fragmentation des parois peut s'effectuer de manière plus ou moins régulière et continue pour donner naissance à des tabliers ou des cônes d'éboulis. Elle peut parfois prendre un caractère catastrophique suite à des éboulements et des avalanches rocheuses.

5 Les avalanches rocheuses sont des mouvements en masse d'un grand volume de roche $\left(>10^{3} \mathrm{~m}^{3}\right)$ consécutifs à un écroulement ou à un glissement, qui forment des accumulations épaisses en forme d'éventail ou de langue (Hsü 1975, Eisbacker 1979) (fig. 1). Ces mouvements peuvent être extrèmement rapides (plus de $300 \mathrm{~km} / \mathrm{h}$ ) et s'écouler à plusieurs kilomètres de leur zone de départ, voire le cas échéant remonter sur le versant opposé de la vallée. Les dépôts sont principalement caractérisés par une très forte fragmentation de la roche initiale, donnant naissance à une matrice fine plus ou moins abondante, et par la présence de mégablocs souvent concentrés au sommet de la masse du matériel accumulé (Yarnold 1993, Bertran 1996) (fig. 2). Certains auteurs pensent que les avalanches rocheuses sont à l'origine de la plus grande partie du volume des accumulations détritiques en pied de paroi dans les régions montagneuses (Gray 1972, Gardner 1977). De nombreux exemples ont été ainsi inventoriés en France ces dernières années grâce aux études suscitées par la prévention des risques naturels et l'aménagement du territoire, dans des zones où ces phénomènes étaient jusqu'alors totalement passés inaperçus (Vidal et al. 1996). Les avalanches rocheuses peuvent avoir un impact morphologique considérable et avoir de grandes conséquences sur les 
populations. Les exemples suivants sont très démonstratifs à cet égard. Au Mont Granier en Savoie, un glissement dans des marnes entraînant l'écroulement de la barre calcaire qui les surmontait a mobilisé environ $5 \times 108 \mathrm{~m}^{3}$ de roche (Goguel et Pachoud 1972). Cet événement précisément daté de 1248 grâce aux archives, a provoqué la disparition de plusieurs villages et les débris se sont étalés sur plus de $7 \mathrm{~km}$ de longueur. Plusieurs exemples d'avalanches rocheuses sont également connus pour avoir barré une vallée et entraîné la formation d'un lac en amont. Ryder et al. (1990) citent le cas d'un tel événement au cours de l'Holocène à Texas Creek (Canada) qui eu pour conséquence la quasi-disparition d'un groupe amérindien en raison de la raréfaction du saumon dans la rivière Frazer, suite à la formation d'un barrage à l'aval du territoire du groupe. L'impact sur les structures anthropiques est essentiellement destructif. Heim (1932) qui a étudié l'écroulement survenu en 1881 à Elm (Suisse) mobilisant environ $10^{6} \mathrm{~m}^{3}$ de roche, donne les détails suivants : «les maisons ont été cisaillées au niveau de la jonction fondations-superstructures et déplacées vers l'aval par la coulée de blocs ; une canalisation enterrée à $1 \mathrm{~m}$ de profondeur a été arrachée et déplacée sur $1 \mathrm{~km} »$.

\section{1- Avalanche rocheuse, Alpes du sud}

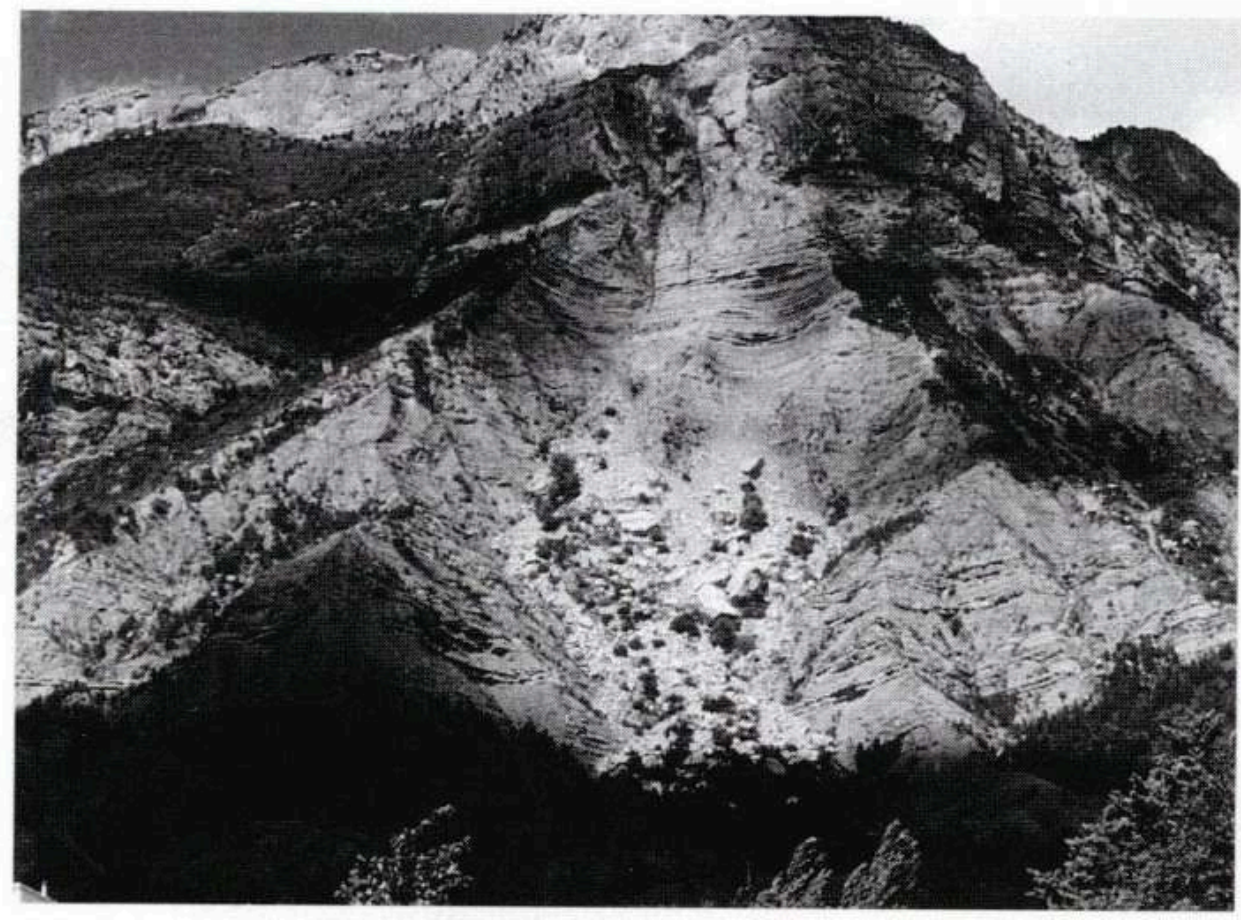

Noter la présence de mégablocs à la surface du dépôt et les bordures nettes de l'accumulation, qui résultent d'un mouvement en masse des débris rocheux 


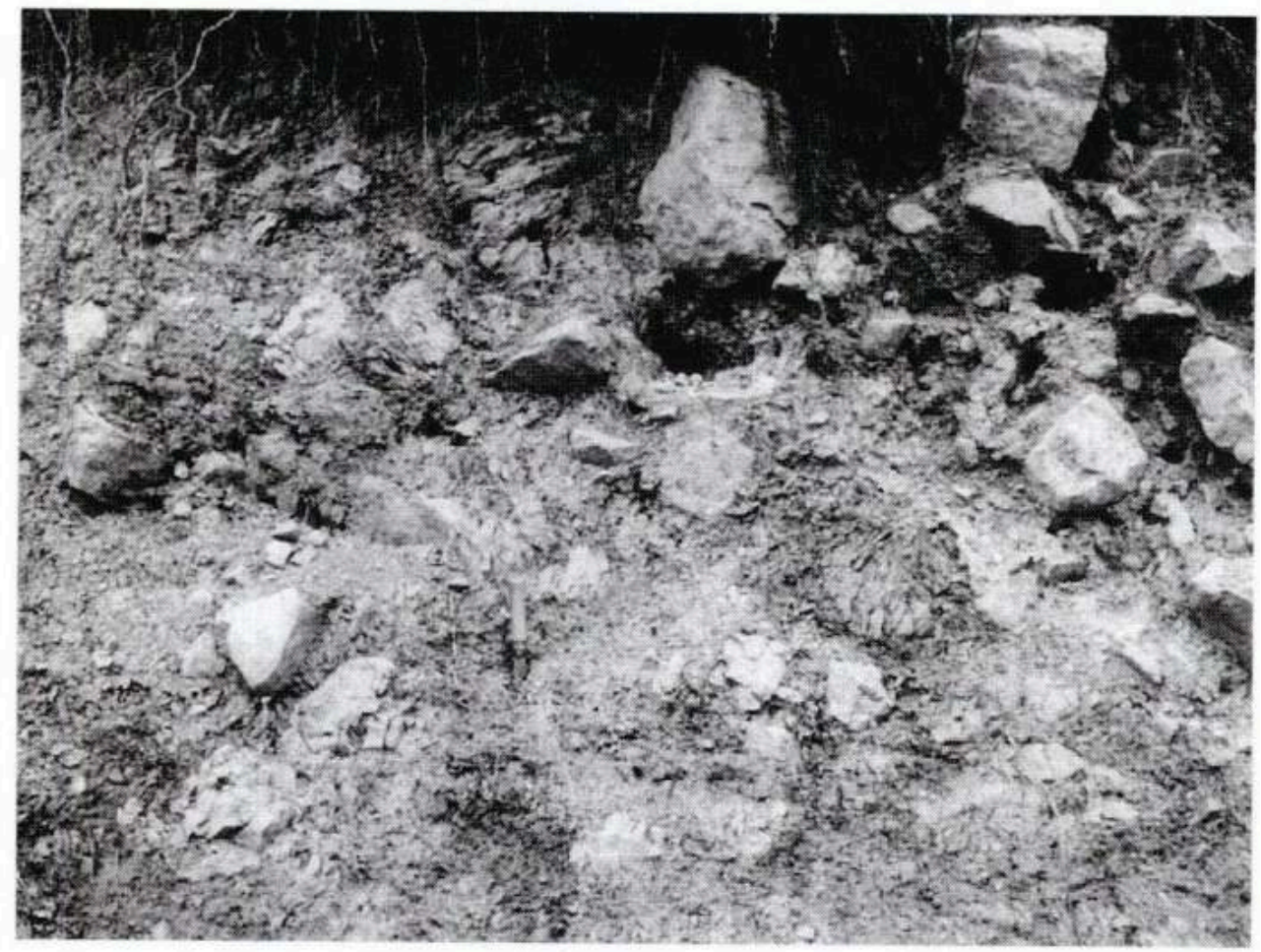

Les blocs sont emballés dans une abondante matrice limono-argileuse, qui provient de la fragmentation intense des débris

6 Les éboulis gravitaires résultent de l'accumulation en pied de paroi de pierres tombées isolément ou sous forme de paquets de volume relativement faible, au sein desquels les éléments suivent chacun une trajectoire autonome (fig. 3). Le talus construit en pied de paroi possède une pente forte, la pente modale mesurée par de nombreux auteurs avoisinant $35^{\circ}$ (Chandler 1973, Francou 1991). Dans le segment amont du talus, les débris rocheux sont affectés après leur dépôt par une reptation rapide (creep), de quelques centimètres à une dizaine de mètres par an, liée aux réajustements provoqués par l'impact des pierres tombant sur le talus, le lavage, les variations de température et le piétinement par la faune (Gardner 1979, Francou 1991). En coupe, les dépôts se présentent comme un matériel caillouteux assez mal trié, massif ou avec une stratification rudimentaire (fig. 4). Les cailloux sont jointifs et les vides entre les éléments sont généralement incomplètement colmatés par une matrice fine. Ce type de faciès constitue rarement l'ensemble des éboulis naturels, mais se rencontre fréquemment interstratifié avec des dépôts résultant de mouvements en masse des débris. Les éboulis gravitaires sont très peu favorables à une implantation humaine en raison de la pente très forte et de l'instabilité des débris. Quelques sites enfouis dans la partie distale d'éboulis sont cependant connus, comme le Roc Allan en Dordogne (Paléolithique supérieur) et le sanctuaire gallo-romain de Viuz-Faverges en HauteSavoie (Rebiscoul 1994). Le mur d'enceinte de ce dernier, encore préservé par endroits sur près de deux mètres de hauteur, a fait l'objet de plusieurs phases de réfection vraisemblablement à la suite des destructions causées par la chute de blocs (fig. 5). Les divers édifices cultuels ont finalement été totalement abandonnés et recouverts par les débris rocheux au IVe s. ap. J.-C. 


\section{3- Eboulis gravitaire alpin}

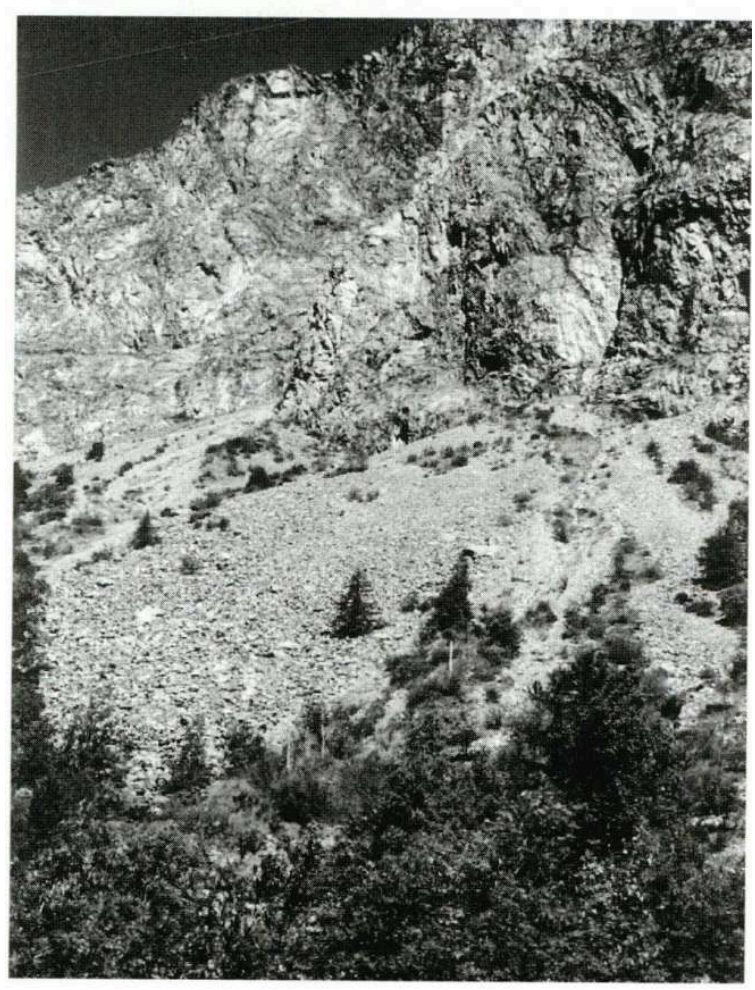

On distingue le granoclassement longitudinal des débris, marqué par une concentration des éléments les plus volumineux vers la base du talus. A l'aplomb des couloirs rocheux, de part et d'autre de l'éboulis, d'autres dynamiques sédimentaires interviennent (ruissellement, flots de débris) 
4 - Faciès d'un éboulis gravitaire

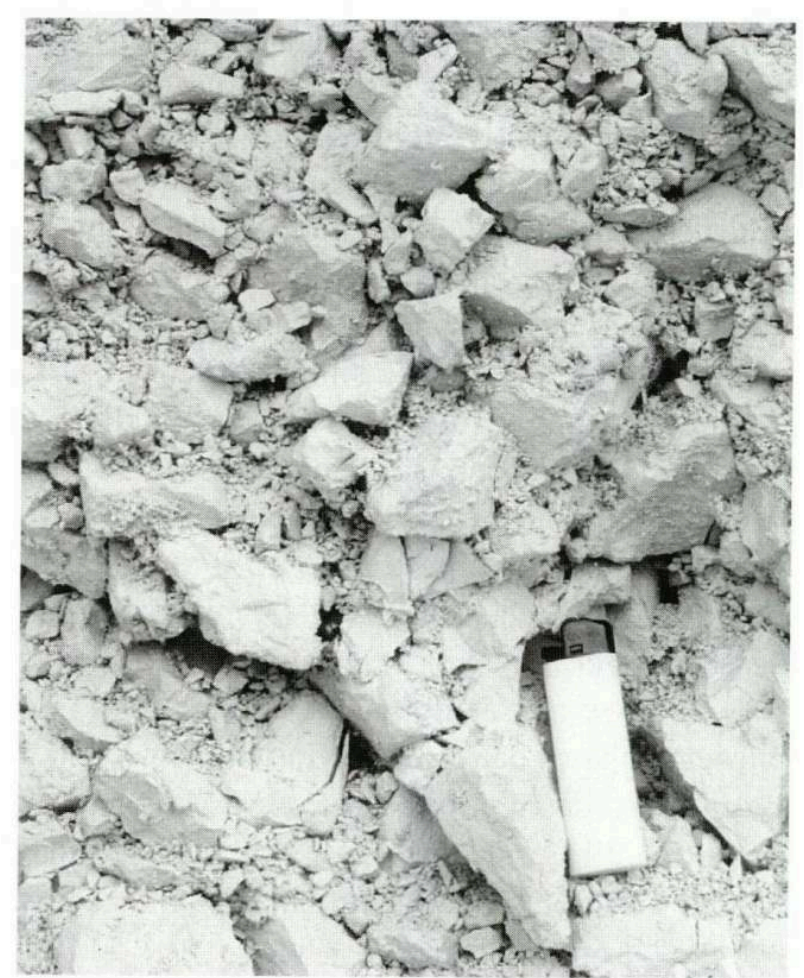

Matériel caillouteux, non stratifié et faiblement colmaté 


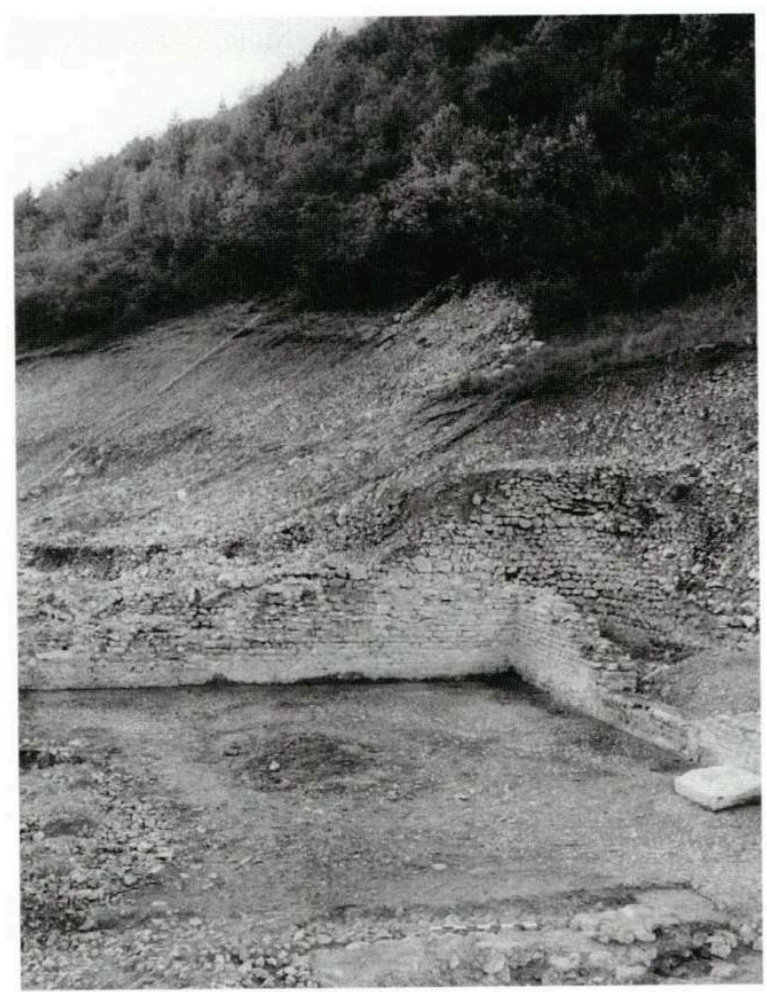

Les bâtiments sont enfouis sous plusieurs mètres de débris rocheux dans la partie distale d'un talus d'éboulis gravitaire

Photo aimablement communiquée par A. Rebiscoul (AFAN)

Divers processus de redistribution des débris sur la pente interviennent fréquemment en association avec l'éboulisation sur les talus naturels (éboulis polygéniques ou éboulis assistés) et donnent naissance à des talus moins pentus, dont le potentiel archéologique est important. Sur les talus situés au pied de parois qui libèrent des débris en abondance, ces processus comprennent essentiellement les coulées de pierres sèches, les avalanches de neige et les flots de débris (également appelés laves torrentielles, coulées de boue ou coulées de débris). En l'absence de paroi ou sous une paroi peu productive, d'autres processus de versant deviennent prépondérants. Ils comprennent la solifluxion, caractéristique des milieux périglaciaires, les glissements de terrain, notamment aux dépens de matériaux riches en argile, le ruissellement et la reptation du sol sensu lato liée à une combinaison de phénomènes variés. Coulées de pierres sèches (Hétu et al. 1995) et avalanches (Luckman 1977) ne sont citées ici qu'à titre indicatif, dans la mesure où ces phénomènes n'ont jusqu'à présent pas été identifiés en contexte archéologique. Ces processus de redistribution des débris sur les talus génèrent fréquemment des dépôts stratifiés, caractérisés par une succession plus ou moins régulière de couches à texture différente. Van Steijn et al. (Van Steijn et al. 1995) font une revue des différents modèles de stratification connus à partir d'exemples pris dans des milieux de sédimentation actuels. Ces travaux peuvent être directement appliqués à l'interprétation de la mise en place de la plupart des sites paléolithiques français situés en pied de paroi, en abri-sous-roche ou sous porche de grotte. Ils montrent en particulier, en contradiction avec le point de vue traditionnellement adopté en géoarchéologie (Laville 1975), que les différents lits ne sont pas le reflet de variations de la production de débris par la paroi sous l'influence du climat, mais sont 
d'origine dynamique, c'est-àdire qu'ils résultent d'une ségrégation des différentes fractions granulométriques au cours de la sédimentation. Différents exemples sont illustrés sur la figure 6 (fig. 6).

\section{6- Exemples de dépôts de pente stratifiés}

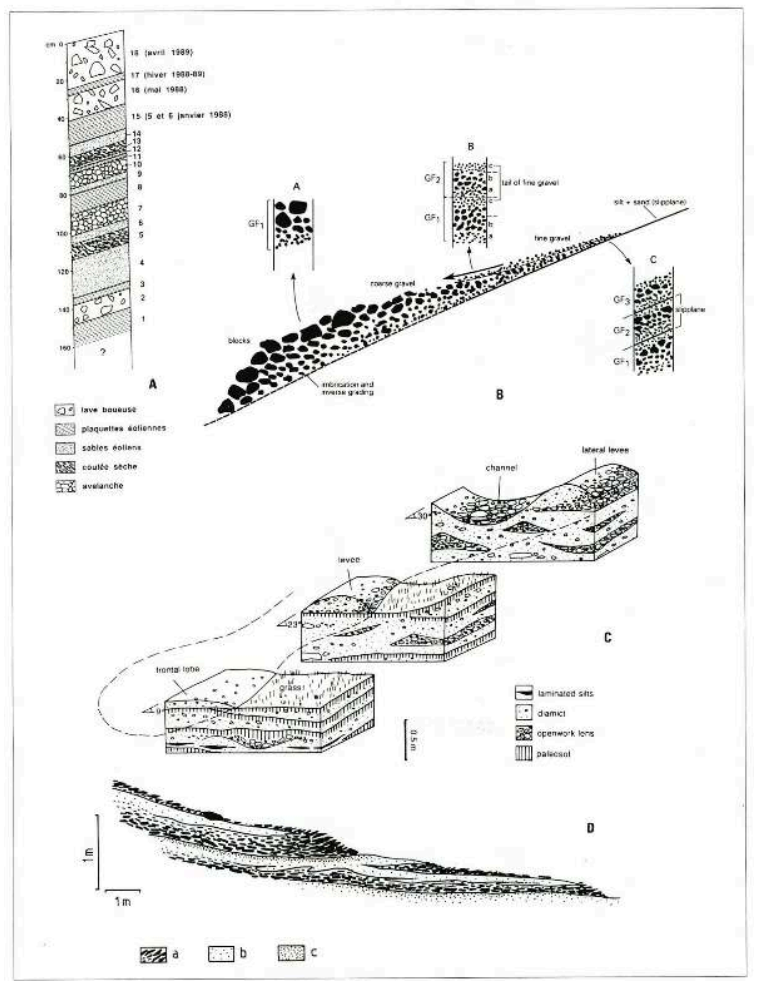

A - Empilement de dépôts mis en place par différents mécanismes sur un talus du Québec, d'après Hétu (1991).

B - Stratification produite par des coulées de pierres sèches, d'après un exemple provenant d'un talus des Pyrénées (Van Steijn et al. 1995). Les variations de granulométrie résultent d'une ségrégation des débris au cours du mouvement sur la pente.

c - Dépôts stratifiés mis en place par des flots de débris, d'après un exemple alpin (Bertran et Texier 1994). La formation des niveaux caillouteux sans matrice résulte d'une ségrégation des débris au cours de la sédimentation et du lavage secondaire des dépôts.

D - Empilement de coulées de solifluxion à front pierreux, donnant naissance à des dépôts stratifiés, d'après un exemple provenant des Andes de Bolivie (Bertran, Francou et Texier 1995). La

cryoexpulsion et le lavage provoquent la différenciation d'un pavage en surface de la coulée et d'un front caillouteux. Ce dernier est progressivement enfoui au cours de l'avancée de la nappe riche en matrice, a : niveau caillouteux, $b$ : niveau riche en matrice, $c$ : niveau d'accumulation des limons consécutif au lavage des dépôts

Les flots de débris sont des écoulements rapides d'eau, de cailloux et de particules plus fines, le plus souvent déclenchés par des averses violentes sur des versants peu végétalisés (Johnson et Rodine 1984, Sauret 1987, Bertran et Texier 1994), qui impliquent des volumes allant de quelques $\mathrm{m}^{3}$ à plusieurs milliers de $\mathrm{m}^{3}$ (fig. 7). Suivant les caractéristiques du bassin-versant, le temps de retour de ce type d'événement est très variable, des valeurs entre 10 et 400 ans étant souvent citées dans la littérature. Les flots de débris s'interstratifient fréquemment avec d'autres types de dépôts ou construisent des cônes au débouché de couloirs rocheux ou de ravins. Les dépôts sont caractérisés par un matériel mal trié, dont les cailloux sont dispersés dans une masse de sédiments fins (fig. 8), avec souvent des lentilles caillouteuses ouvertes (sans matrice interstitielle) dans les faciès proximaux (fig. 9). Les flots de débris 
constituent un agent morphogénétique très actif dans les régions montagneuses et causent régulièrement à l'heure actuelle des dommages importants aux installations humaines. Des exemples d'événements exceptionnels en Rhône-Alpes sont détaillés par Peiry (Peiry 1990) et Ballandras (Ballandras 1993). L'impact sur des sites archéologiques peut être assez variable : destruction du bâti (voir les photographies des destructions causées par des flots importants dans Colas 1987 et Johnson et Rodine 1984), remaniement et dispersion sur la pente du matériel mais aussi enfouissement brutal et relativement bonne préservation locale des vestiges. Des observations très précises sur l'action érosives des flots de débris sont fournies par Suwa et Okuda (1980). Dans la partie amont du tracé suivi par les écoulements, le fond du vallon est périodiquement recreusé et les matériaux accumulés précédemment sont évacués, des blocs de taille métrique étant traînés sur plusieurs mètres. Dans la partie distale des accumulations, en revanche, de nombreux auteurs ont souligné le caractère peu érosif des flots de débris (Johnson et Rodine 1984, Bertran et Texier 1994). La végétation basse et des structures délicates sont ainsi enfouies sans perturbation.

\section{7- Cône polygénique alpin}

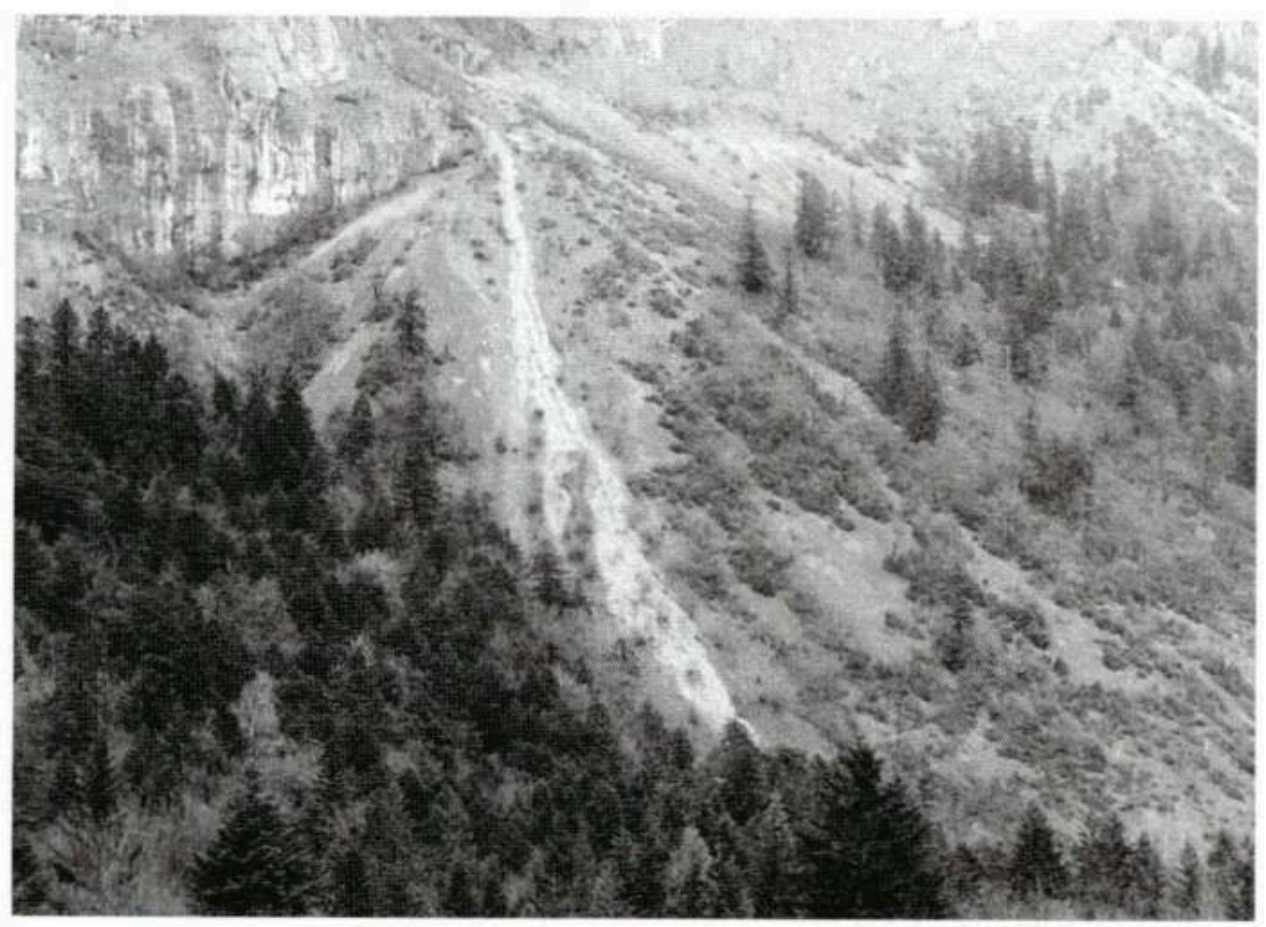

La dynamique sédimentaire est dominée par l'éboulisation, les avalanches de neige et les flots de débris, dont on voit un exemple récent composé par un matériel boueux de couleur claire 
8- Coupe dans la partie distale d'un cône de flots de débris en Dordogne

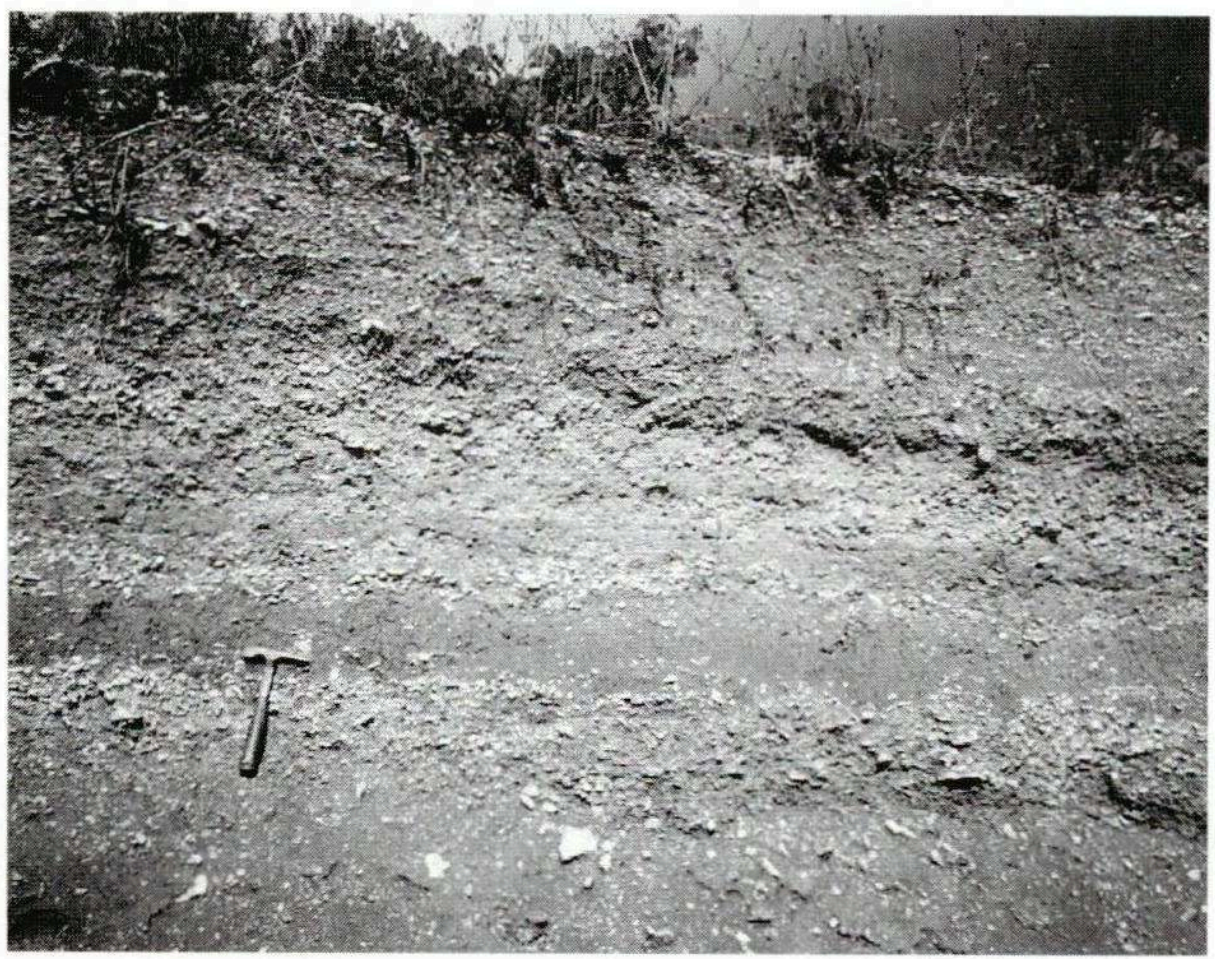

On observe une succession de niveaux de texture différente, qui correspondent à l'empilement de coulées boueuses plus ou moins chargées en graviers 


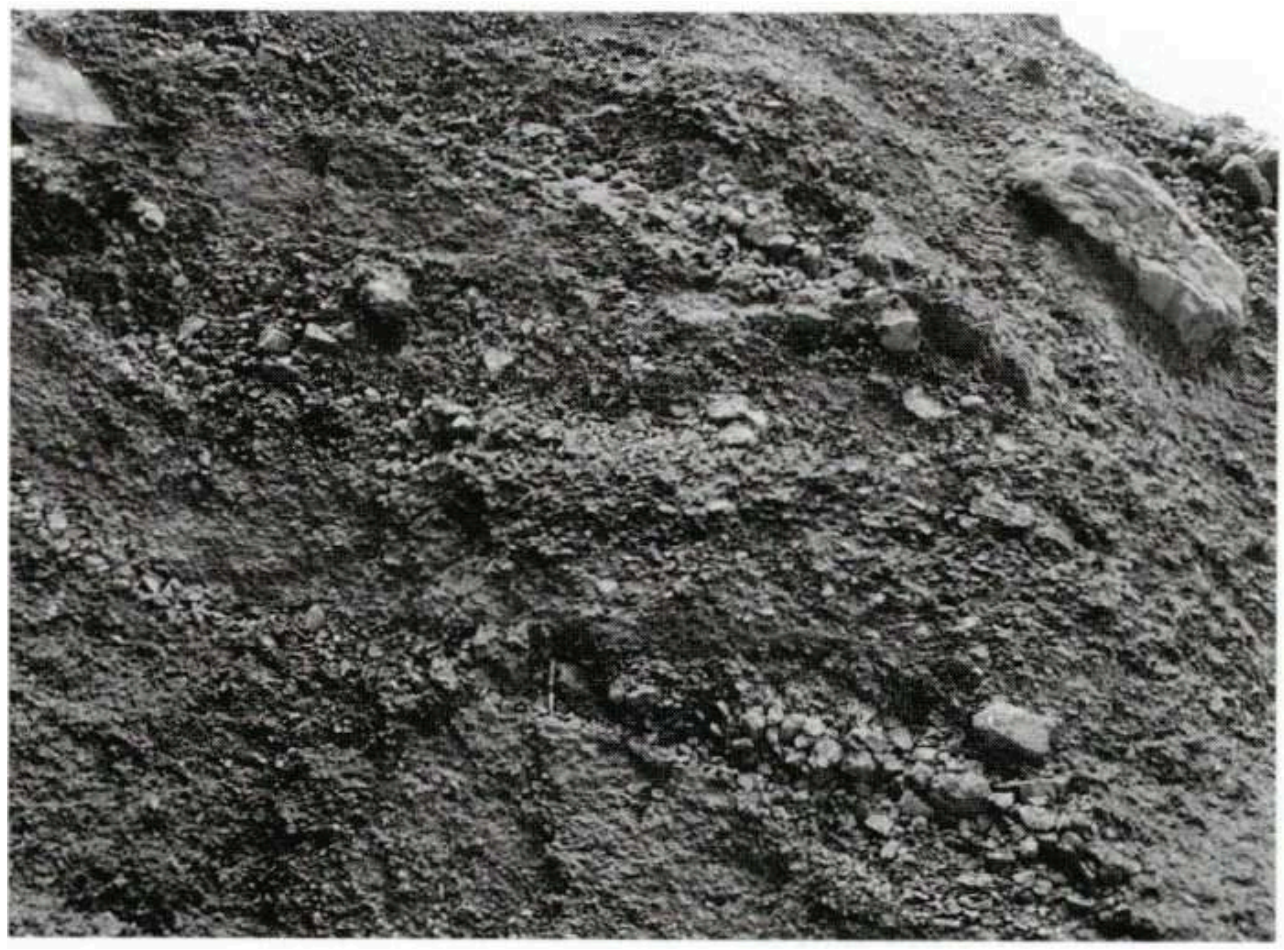

Les dépôts présentent une stratification rudimentaire, marquée par des lentilles caillouteuses sans matrice dans un matériel colmaté. On distingue localement des sables et des graviers lités correspondant à des niveaux repris par le ruissellement

9 Plusieurs sites paléolithiques français semblent s'être constitués par l'empilement de flots de débris. Combe-Capelle-bas en Dordogne, situé au pied d'un long versant rocheux, a ainsi été interprété comme un petit cône torrentiel interstratifié avec d'anciens dépôts fluviatiles de la Couze (Bertran et Texier 1995b). Ce site, connu de longue date, a livré une abondante industrie moustérienne (Dibble et Lenoir 1995). La dispersion verticale à peu près uniforme du matériel archéologique et l'orientation préférentielle des objets allongés selon la pente suggèrent fortement que la physionomie actuelle du site est le résultat d'une redistribution complète des niveaux d'occupation. L'analyse archéologique a cependant montré que des ensembles lithiques relativement différents pouvaient être distingués, autorisant une approche chronologique des caractères typologiques et technologiques de l'industrie (Dibble et Lenoir 1995). Les vestiges gallo-romains de Montgilbert en Isère (Caclin 1995) sont installés sur un cône de déjection construit par un torrent affluent de l'Arc (fig. 10). Ce site a été brutalement enfouis au IIe ou au IIIe s. ap. J.-C. par des flots de débris et se retrouve actuellement enterré sous environ $5 \mathrm{~m}$ de dépôts. Les murs ont été préservés sur 1 à $2,5 \mathrm{~m}$ de hauteur, mais plusieurs présentent des déformations en liaison avec l'impact des coulées, en particulier un basculement vers l'aval d'une dizaine de degrés par rapport à la verticale ou un cisaillement à la base accompagné d'un déplacement en bloc. 
10- Vue du site gallo-romain de Montgilbert en Savoie

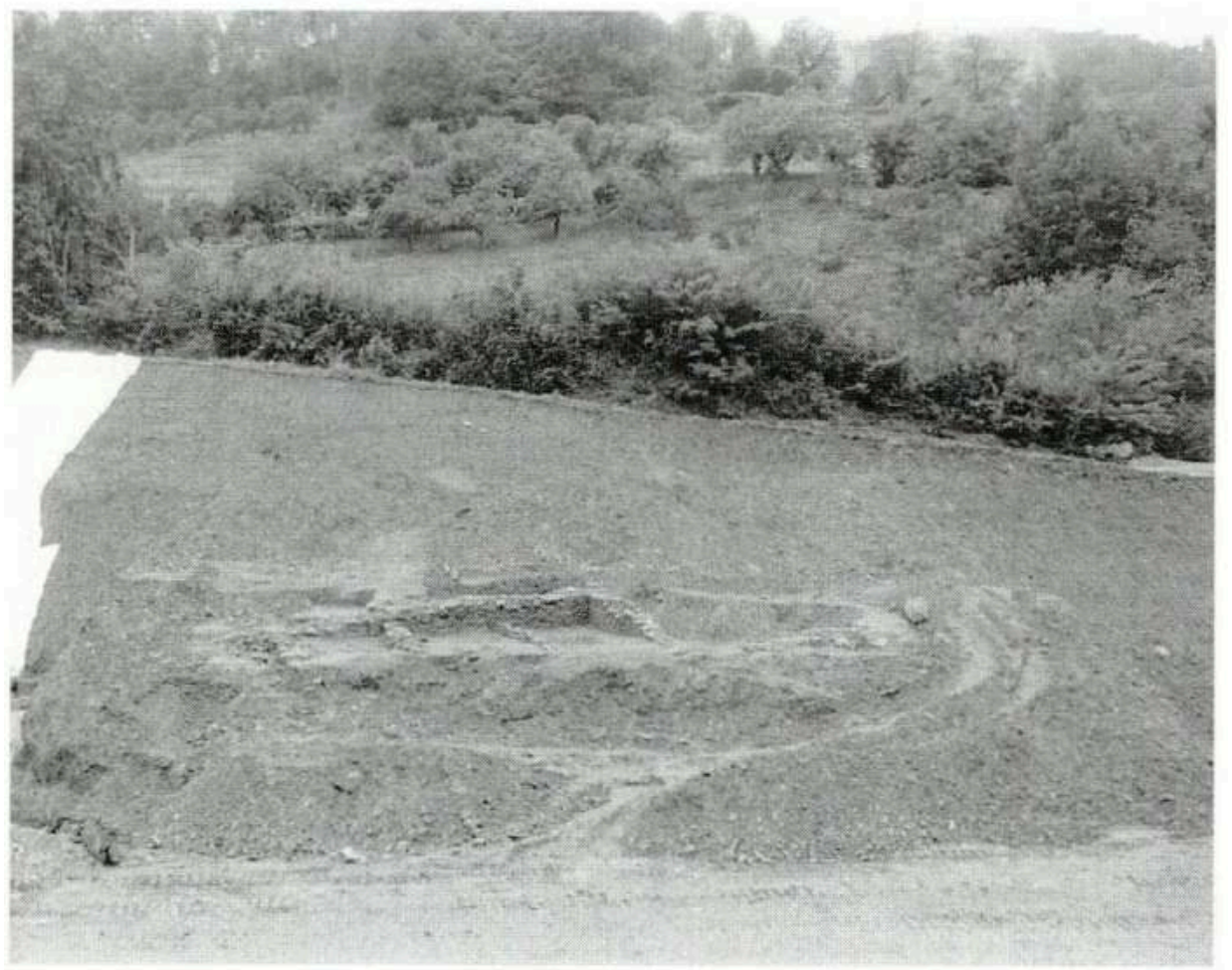

Les restes de plusieurs bâtiments sont enfouis sous plusieurs mètres de matériaux déposés par des flots de débris

Photo aimablement communiquée par C. Caclin (AFAN) 


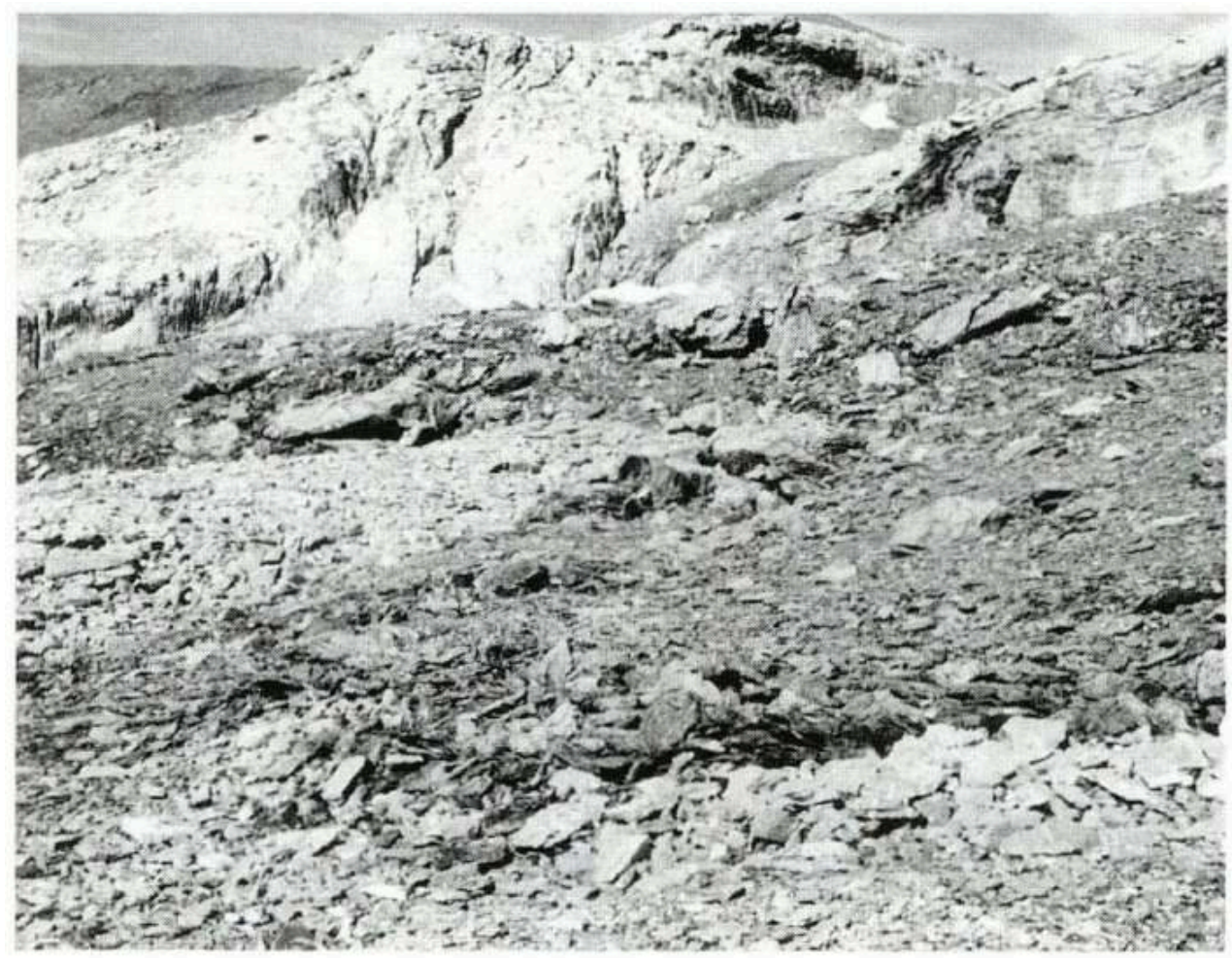

Des lobes essentiellement composés de débris de schistes noirs affleurant en sommet de versant progressent sur un pavage de débris calcaires de couleur plus claire. La longueur des blocs transportés par les coulées peut dépasser un mètre

10 La solifluxion périglaciaire correspond à une lente déformation du sol (quelques centimètres par an) résultant du soulèvement et de l'affaissement répétés du sol sous l'action des cycles de geldégel ainsi que de l'écoulement lent du sédiment sursaturé pendant les périodes de dégel (Williams et Smith 1989, Harris et al. 1993). Ce phénomène est étroitement lié aux environnements froids (fig. 11, 12). La solifluxion se produit sur des pentes supérieures à $3-4^{\circ}$ et construit des dépôts généralement mal triés (cailloux jointifs ou dispersés dans une matrice fine). Les accumulations liées à une solifluxion pelliculaire ou à des lobes et des banquettes de solifluxion non triés, typiques des zones possédant une couverture herbacée, sont massives ou possèdent une stratification rudimentaire, parfois marquée par des sols organiques enfouis (Benedict 1970, Matthews et al. 1986) (fig. 13). En revanche, les lobes et nappes de solifluxion à front pierreux que l'on rencontre dans les déserts périglaciaires mettent en place des dépôts stratifiés, présentant une alternance de couches caillouteuses ouvertes et de couches colmatées (Bertran, Francou et Texier 1995) (fig. 14). 


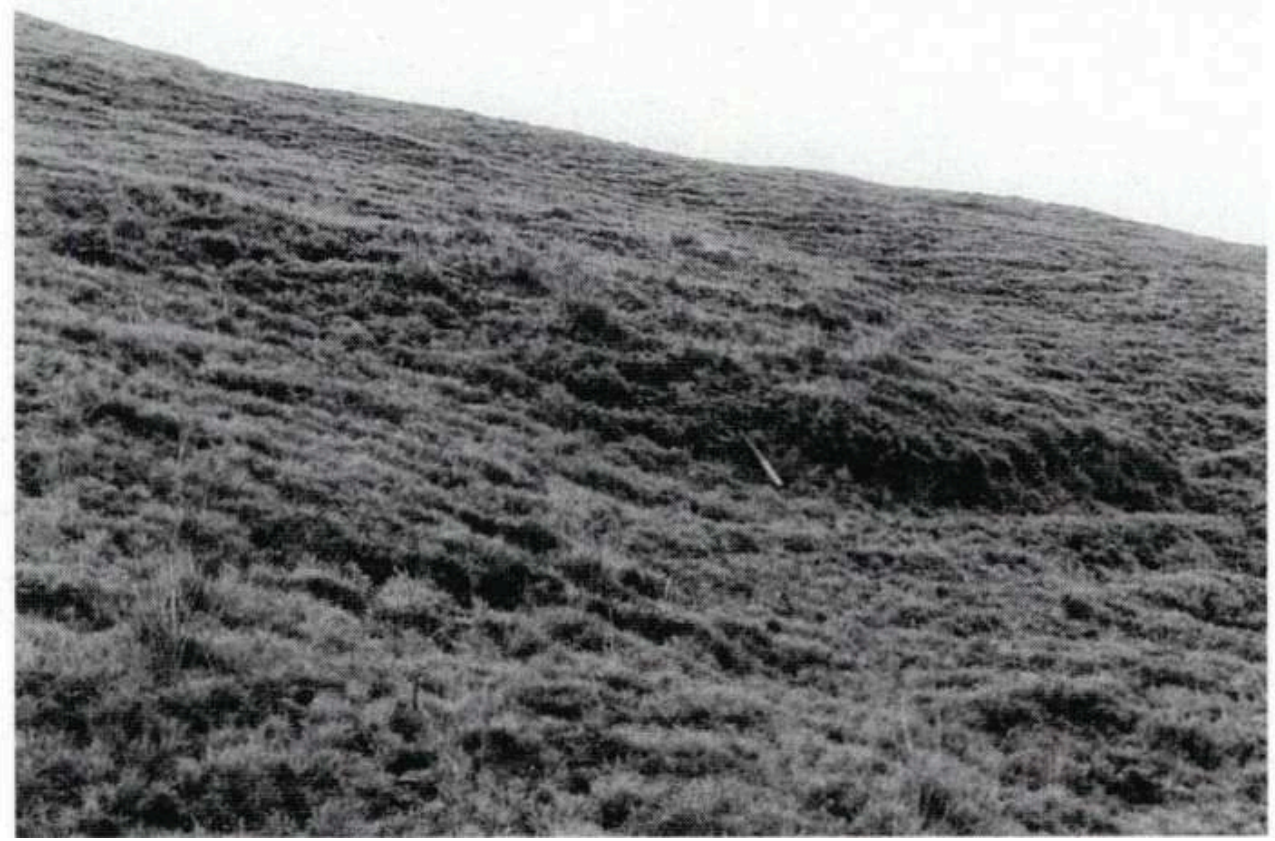

13- Coupe de dépôts de solifluxion à stratification rudimentaire, site des Jamblancs en Dordogne

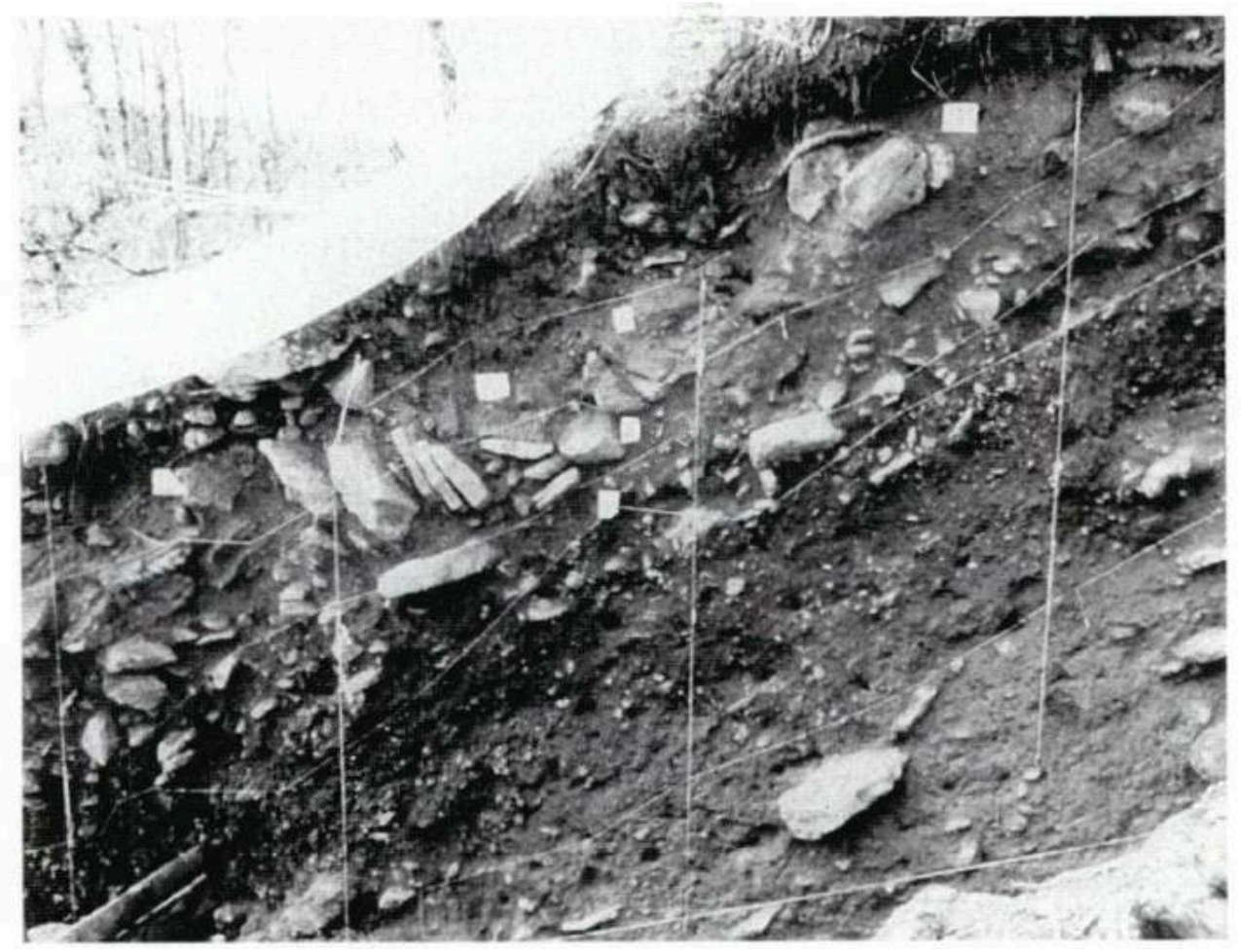

II s'agit d'un dépôt caillouteux riche en matrice, avec des cailloux majoritairement orientés dans le sens de la pente. On distingue également des blocs imbriqués, qui correspondent à des zones de compression au sein de la masse de sédiment en mouvement sur la pente, ainsi qu'un niveau plus sombre dans la partie médiane de la coupe, très riche en matériel archéologique et en charbons de bois. Ce niveau provient de l'étalement sur le talus de niveaux d'occupation du Paléolithique supérieur, dont des lambeaux plus faiblement perturbés sont conservés en pied de paroi

Photo aimablement communiquée par J.-J Clayet-Merle (Musée National de Préhistoire) 
11 L'étude réalisée par Texier (Texier et al. sous presse) sur un site archéologique expérimental installé sur un versant de solifluxion alpin permet de se faire une bonne idée des transformations qui s'opèrent dans ce type de milieu. Les principales conclusions qui ont été obtenues sont les suivantes. Des modifications très rapides et importantes se sont produites. Les déplacements moyens des artefacts varient entre 1,66 et $4,75 \mathrm{~cm} / \mathrm{an}$, avec des maxima dépassant $2 \mathrm{~m}$. De forts déplacements individuels affectant essentiellement les objets peu denses (os), liés au ruissellement et au vent, s'ajoutent à des déplacements collectifs provoqués par la solifluxion. La vitesse de translation des objets vers l'aval varie très rapidement latéralement et induit une déformation de l'organisation initiale. L'enfouissement des objets suit un schéma complexe. Certains éléments s'infiltrent entre les cailloux au niveau du front des coulées et sont recouverts par l'avancée de la nappe. D'autres restent à proximité de la surface et continuent à progresser sur la pente. La cryoexpulsion est un phénomène très actif. $23 \%$ des objets enfouis à $5 \mathrm{~cm}$ de profondeur et $4 \%$ de ceux enfouis à $10 \mathrm{~cm}$ sont réapparus à la surface en 5 ans. Tandis que les traces d'utilisation sur les silex n'ont pas été affectées de manière sensible et restent parfaitement identifiables, les os ont subi une fragmentation très importante due aux alternances gel-dégel.

14- Coupe de dépôts de solifluxion stratifiés, site paléolithique moyen de Baume-Vallée en HauteLoire

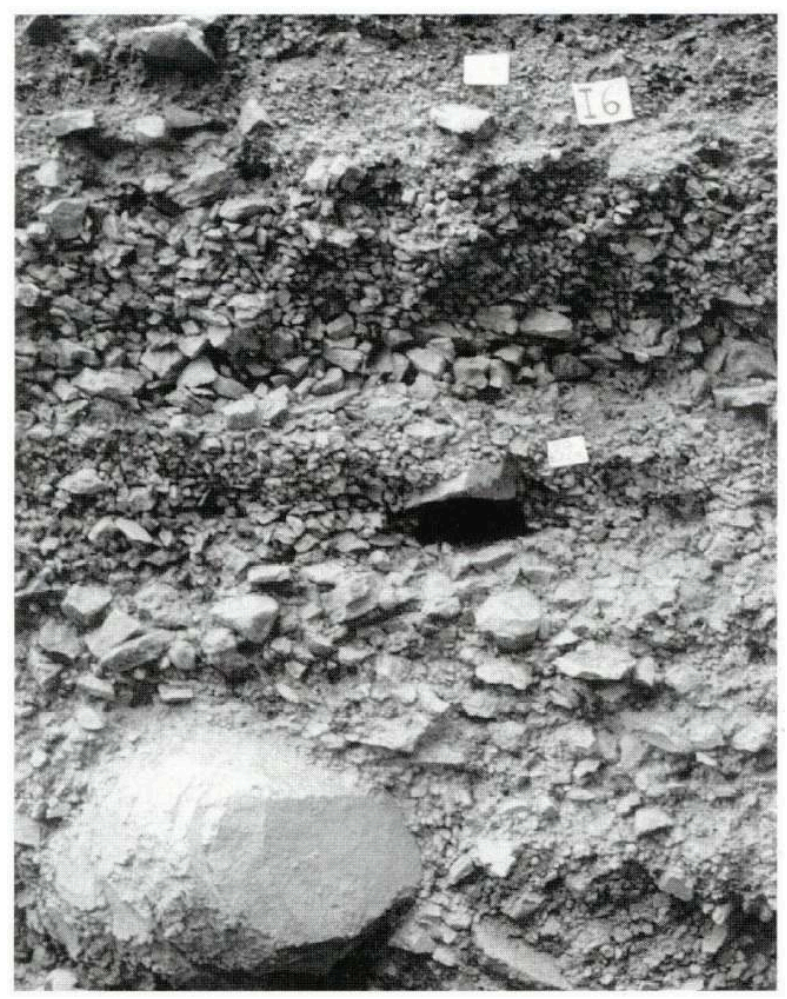

Les lits grossiers sans matrice correspondent à des pavages et des fronts caillouteux progressivement enfouis par la progression des coulées

12 Ces mécanismes ont été identifiés dans de nombreux sites paléolithiques français, qui sont pour un grand nombre d'entre eux contemporains de climats périglaciaires, comme Laugerie-Haute et Le Callan en Dordogne (Paléolithique supérieur), BaumeVallée (Paléolithique moyen) et La Roche à Tavernat (Paléolithique supérieur) en Haute-Loire (Bertran 1994). Le site de BaumeVallée en Haute-Loire peut servir 
d'exemple pour illustrer ces mécanismes. Il a livré une industrie moustérienne (Raynal et Decroix 1987) inclue pour une grande part dans des dépôts stratifiés, sur une pente d'environ $10^{\circ}$ (fig, 14). Ces dépôts présentent de nombreuses figures typiques des lobes de solifluxion, notamment la présence de plis étirés dans la pente indiquant une lente déformation du sol, des accumulations de limon au sommet des niveaux colmatés sous l'action du lavage associé à la fonte des neiges, et des grano-classements verticaux dans les niveaux caillouteux provoqués par l'effet de crible, c'est-à-dire l'infiltration des sables et des graviers entre les éléments plus grossiers des pavages en surface des coulées. Quelques lentilles de sédiment fin sont interprétées comme des taches de boue (ostioles) formées par la cryoturbation. La distribution des vestiges, en particulier l'orientation préférentielle des objets allongés selon la pente, indique que le matériel archéologique a été significativement remanié. Ceci explique probablement l'absence de structure anthropique évidente et la présence de témoins de combustion dispersés dans l'ensemble du sédiment.

\section{5- Petit glissement rotationel dans un talus artificiel}

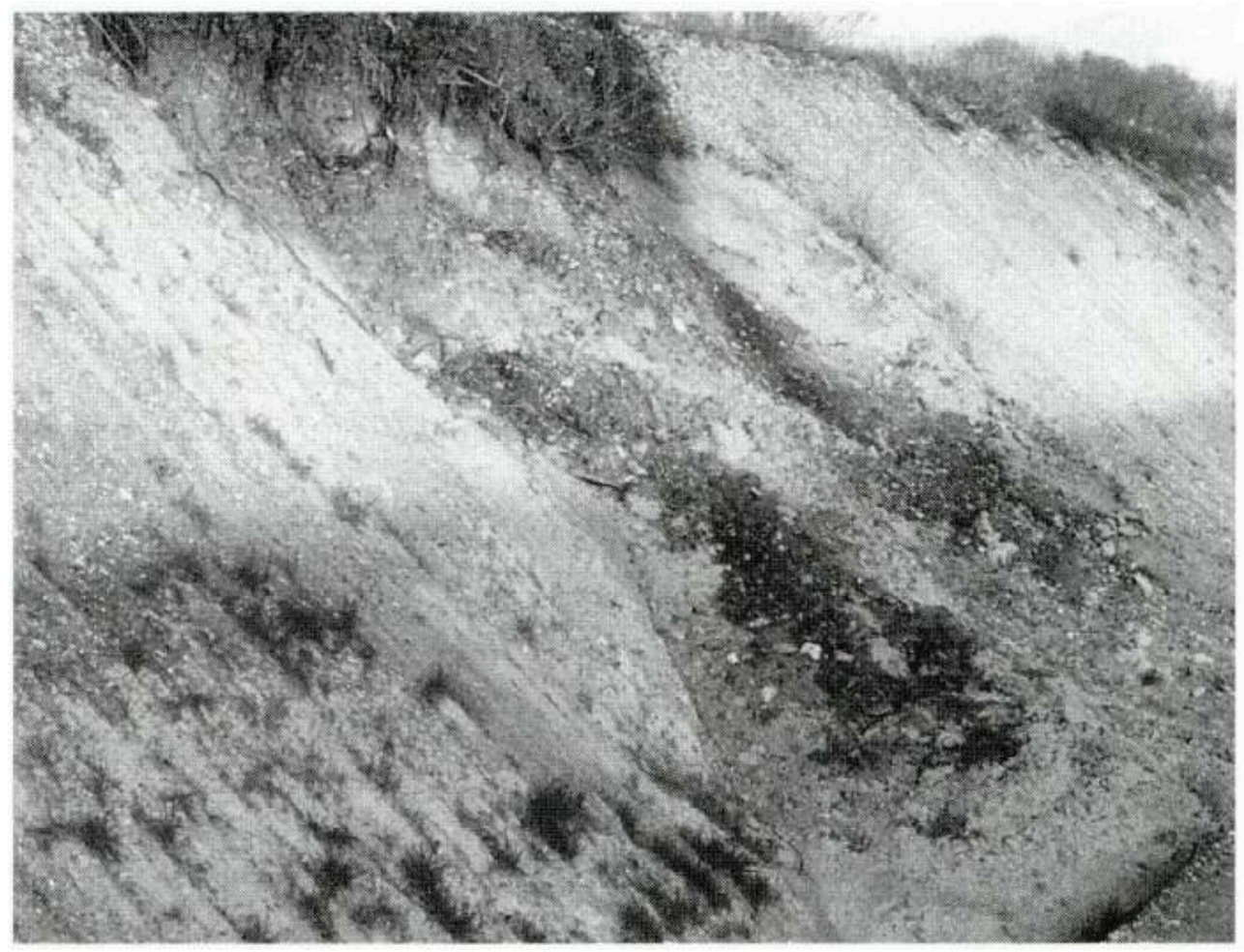

Les glissements de terrain correspondent à des déplacements en masse du sol, où le mouvement se concentre principalement au niveau de surfaces distinctes, à la base et à l'intérieur de la masse en mouvement (fig. 15). La masse peut glisser en blocs ou se désintégrer à des degrés variables et s'écouler lentement, ou encore donner naissance à un flot de débris par incorporation d'eau et liquéfaction. Ils se déclenchent en réponse à un accroissement de la contrainte de cisaillement exercée sur le sol (suppression de la butée de pied, surcharge...) ou à une diminution de la résistance du sol (forte pression d'eau interstitielle, altération, chute de la résistance suite à une reptation lente...) (Varnes 1978). En coupe, les principaux critères d'identification concernent la présence de plans de glissements striés et brillants, une structure «bréchique » caractérisée par des fragments du sédiment originel dispersés dans une matrice homogénéisée ou bien 
une déformation (plissement des lits, étirements) ou un basculement à contre-pente du litage préexistant (fig. 16). Les glissements sont la cause principale des désordres enregistrés actuellement sur la voirie et le bâti dans certaines régions à substratum argileux. Peu de sites archéologiques connus sont directement associés à des glissements de terrain. Les dépressions formées en tête des glissements peuvent donner naissance à des marais, autour desquels s'implantent des habitats. Un site de l'âge du Bronze a par exemple été décrit près de Sinard (Isère) dans ce type de contexte (Thierriot 1994). Pour les périodes historiques, les terrains affectés par des glissements constituent souvent une zone repoussoir. La dépression du Trièves (Isère), en grande partie occupée par des terrains glaciolacustres, est démonstrative. La géographie humaine de cette région et le mode d'exploitation des sols apparaissent en effet fortement contraints par la nature du sous-sol. La localisation actuelle des villages est étroitement liée à celle des plateaux graveleux, plus rarement, aux collines marnocalcaires. La confrontation des données de la carte archéologique et de la géologie indique que l'implantation des sites, qu'ils soient préhistoriques ou gallo-romains, suit un canevas à peu près identique à celle du bâti actuel. Il en est de même pour les voies de communication et notamment les vestiges de voies "gallo-romaines ", qui évitent largement les terrains argileux instables.

16- Coupe dans un glissement de terrain aux dépens de till et de laminites glacio-lacustres, sud Chili

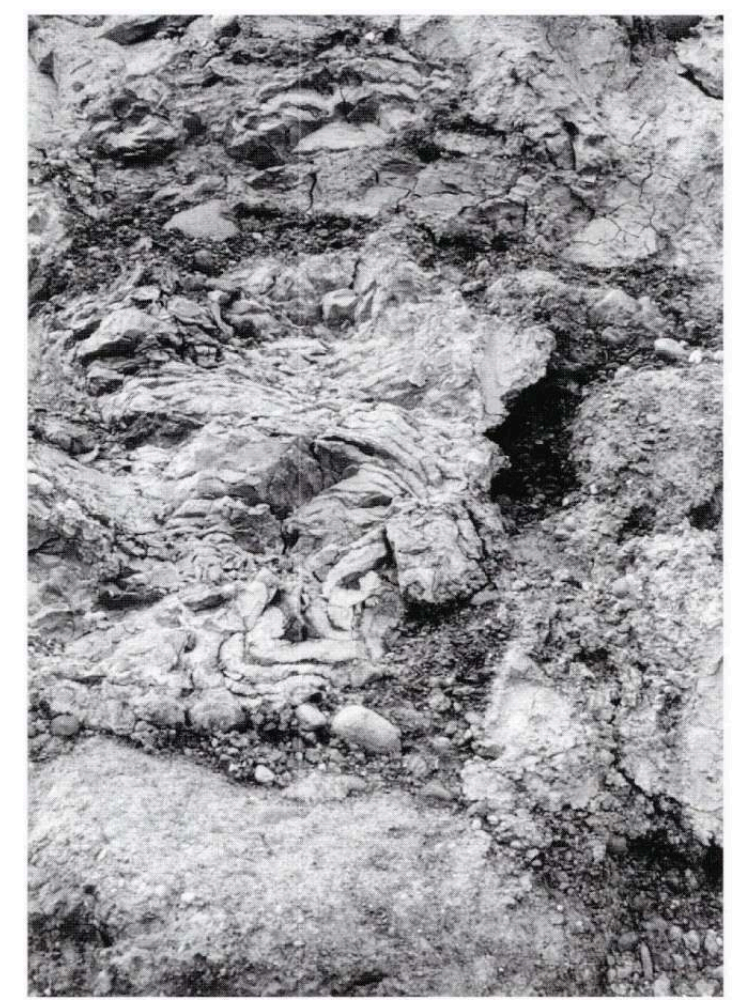

Les dépôts sont caractérisés par la juxtaposition de blocs de sédiments plus ou moins intensément déformés

Le ruissellement peut être localement un agent de sédimentation important et construire des cônes colluviaux d'épaisseur plurimétrique (fig. 17). Sur les versants, les lames d'eau écoulées sont rarement très épaisses (quelques centimètres) et les conditions de transport des particules sont généralement assez différentes de celles qui 
régnent en milieu fluviatile : mélange des éléments en saltation ou tractés sur le fond et des particules en suspension en raison de la faible épaisseur de l'écoulement (Moss et Walker 1978), perturbation de l'écoulement liée à l'impact des gouttes de pluies (Moeyersons et De Ploey 1976), rapides variations de la concentration en particules suite à l'éboulement des parois des rigoles (Govers 1987), sédimentation forcée induite par la végétation (Faury 1990). Suivant la morphologie de la zone d'érosion, la composition granulométrique et les propriétés mécaniques des matériaux parentaux, l'accumulation de sédiments est dominée soit par des écoulements dilués avec des figures de traction (litage, granoclassement) bien développées, soit par des écoulements hyperconcentrés d'aspect massif ou avec des laminations peu marquées. Les dépôts sont généralement caractérisés par un tri médiocre. En coupe, on observe typiquement des lentilles litées (remplissages de rigoles, nappes) interstratifiées avec des dépôts massifs (fig. 18). Les premières correspondent à des zones où l'accrétion par des écoulements dilués est rapide, les secondes à des zones où l'accrétion est lente et les perturbations post-dépositionnelles corrélativement fortes (activité biologique et anthropique, gel-dégel, humectation-dessication...) ou bien des zones où l'accumulation est essentiellement due à des écoulements hyperconcentrés, voire à des flots de débris.

\section{7- Cônes ruisselés dans des badlands des Alpes du sud}

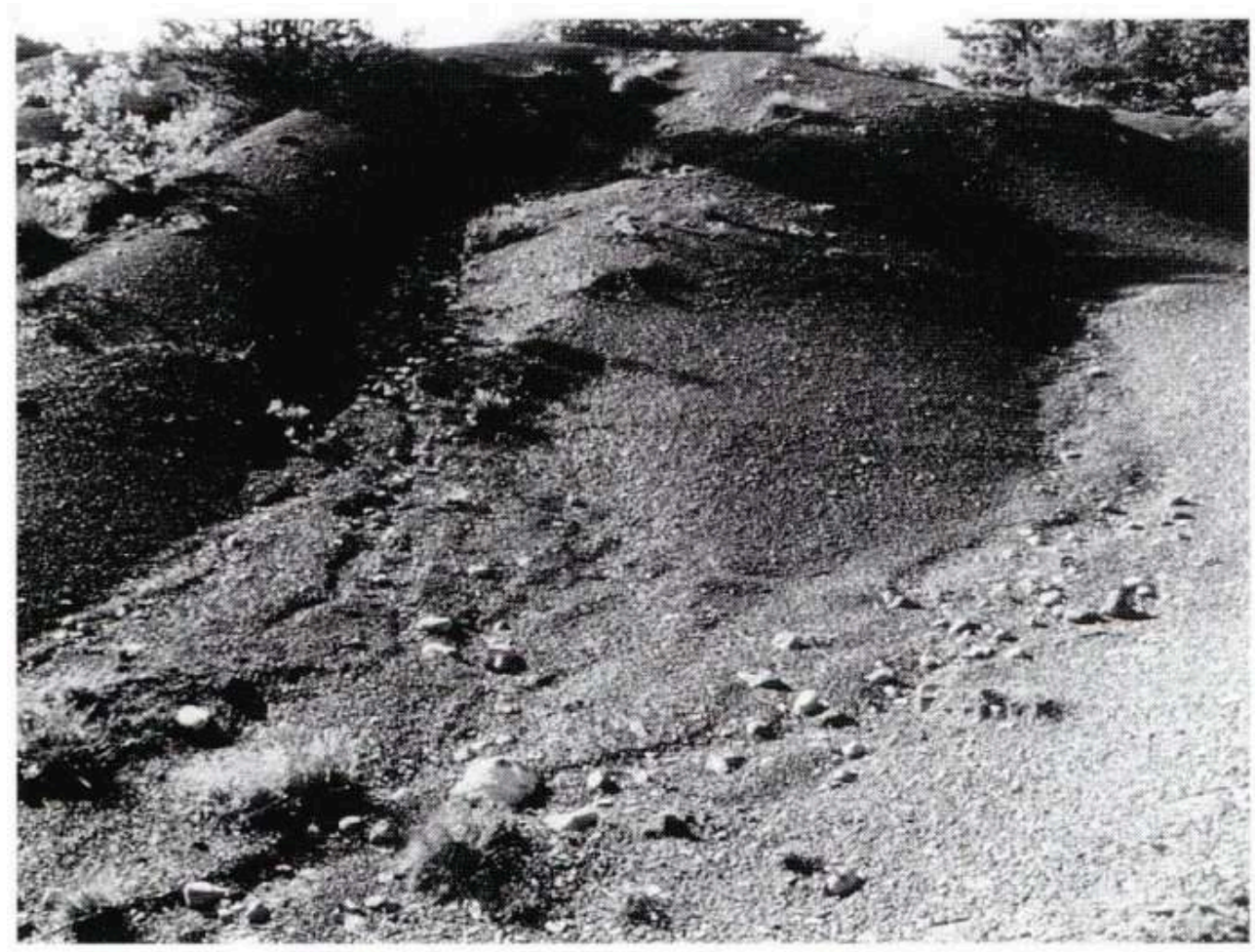

À l'aval, les cônes deviennent coalescents et donnent naissance à un large épandage de graviers, sur une pente de 4 à $8^{\circ}$. Les débris grossiers sont concentrés dans les rigoles 


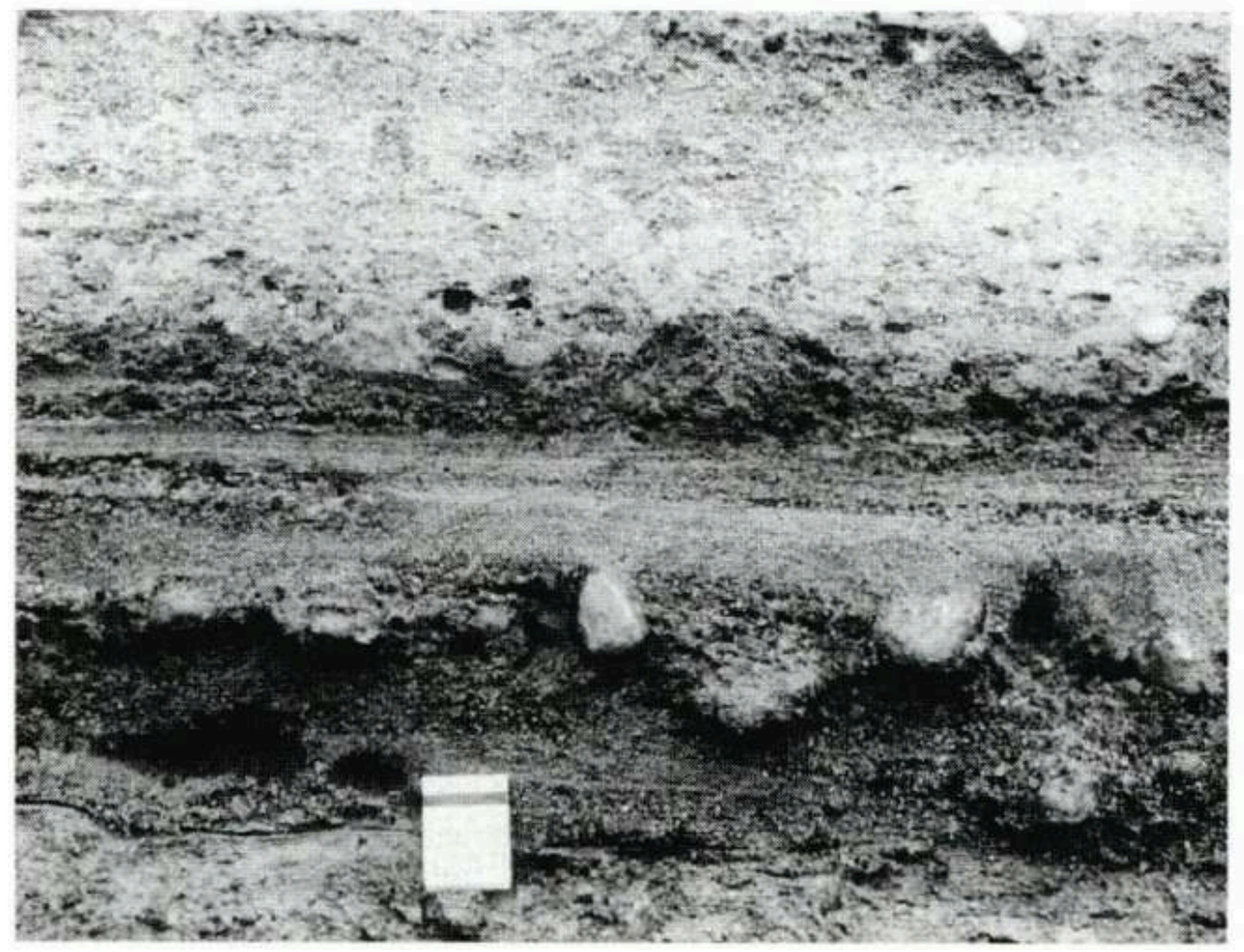

On observe une alternance de niveaux lités correspondant à des écoulements de haute énergie à faible charge en suspension et de niveaux sableux massifs, avec quelques graviers dispersés, qui proviennent d'écoulements hyperconcentrés

Plusieurs travaux concernant la vitesse de transport des graviers ont été réalisés par des géomorphologues et peuvent donner d'utiles indications pour l'interprétation des sites archéologiques situés dans ce type de contexte. Sur des versants faiblement végétalisés d'Arizona, Kirkby et Kirkby (1974) ont enregistré un transport de débris environ 100 fois plus important dans les rigoles qu'en dehors. Dans les zones interrigoles, seules les particules de taille inférieure à $5 \mathrm{~cm}$ étaient mobiles, le déplacement maximum atteignant $50 \mathrm{~cm}$ au cours d'une pluie (pente $17^{\circ}$ ). Sur des sols limoneux de Belgique, Poesen (Poesen 1987) note également un transport relativement lent des graviers dans les zones inter-rigoles, d'au maximum $5 \mathrm{~cm} /$ an sur des pentes de 3 à $16^{\circ}$, soit environ 10 fois moins que dans les rigoles. Cet auteur cite des déplacements par le ruissellement concentré atteignant $12 \mathrm{~m} / \mathrm{an}$. En particulier, un galet de 9,8 cm de longueur a parcouru $2,7 \mathrm{~m}$ pendant une seule pluie modérée sur une pente de $7^{\circ}$. La plupart des auteurs trouvent également une corrélation positive entre l'ampleur du déplacement et la valeur de la pente, le débit maximal ou l'intensité de la pluie, négative entre le déplacement et la taille des éléments (Kirkby et Kirkby 1974, Abrahams et al. 1984, Poesen 1987). Des expérimentations en laboratoire ont également été réalisées avec du matériel archéologique (Wainwright 1992). Elles montrent que l'apparition du ruissellement sur la pente expérimentale induit un déplacement apparemment aléatoire et très variable des artéfacts. $89 \%$ des objets de moins de $2 \mathrm{~cm}$ ont été déplacés lors d'une seule pluie. Les simulations réalisées suggèrent que l'essentiel du mouvement se produit immédiatement après l'abandon du site (stabilisation rapide par la repousse de la végétation, enfouissement des objets) et 
conduit à une resédimentation du matériel archéologique dans un cône à l'aval du site initial.

De nombreux sites archéologiques sont associés à des dépôts de ruissellement. Ainsi, le site de Gorge-de-Loup dans le Rhône (Vérot-Bourrely et al. 1995) a livré une série d'occupations allant de l'âge du Bronze à la période médiévale, interstratifiées dans un petit cône de déjection. Le site paléolithique supérieur du Flageolet en Dordogne (Rigaud 1982) et le site paléoindien de Ponsonby (Chili) (Legoupil et Bertran 1996) peuvent également être pris comme exemples. Ils correspondent à des cônes colluviaux où le ruissellement concentré joue un rôle important. Dans les deux sites, l'étude de la distribution du matériel archéologique montre la juxtaposition sur de courtes distances de niveaux d'occupation bien préservés, caractérisés par la présence de structures anthropiques scellées par des écoulements en nappe, et des zones fortement perturbées dans lesquelles les objets ont été transportés dans des rigoles.

17 Les pratiques agricoles favorisent le ruissellement et constituent le principal facteur à l'origine des colluvions classiquement rencontrées sous forme de nappes au pied des versants cultivés (fig. 19). Ce sont des dépôts non ou mal stratifiés, mal triés mais souvent à dominante texturale fine, avec des lentilles de graviers qui représentent des colmatages de petits ravins, des cailloutis résiduels ou des petits cônes déposés au débouché de rigoles (Allen 1992). Ces dépôts sont fréquemment totalement homogénéisés par l'activité biologique et le labour et il est généralement impossible de déterminer si l'accumulation résulte d'une accrétion relativement continue ou si elle ne reflète qu'un nombre limité d'événements exceptionnels (fig. 20). Le transit des particules de sol est essentiellement assuré par le ruissellement dans des rigoles ou des ravins éphémères (Vandaele et Poesen 1995) mais aussi par le labour lui-même. Les mesures effectuées par Guiresse et Revel (1995) montrent que la quantité de terre transportée vers l'aval sur une parcelle pentue résultant du déplacement cumulé des mottes par la charrue peut dépasser l'érosion produite par le ruissellement. 
19- Epandage colluvial à l'aval d'une parcelle cultivée dans la région de Grenoble

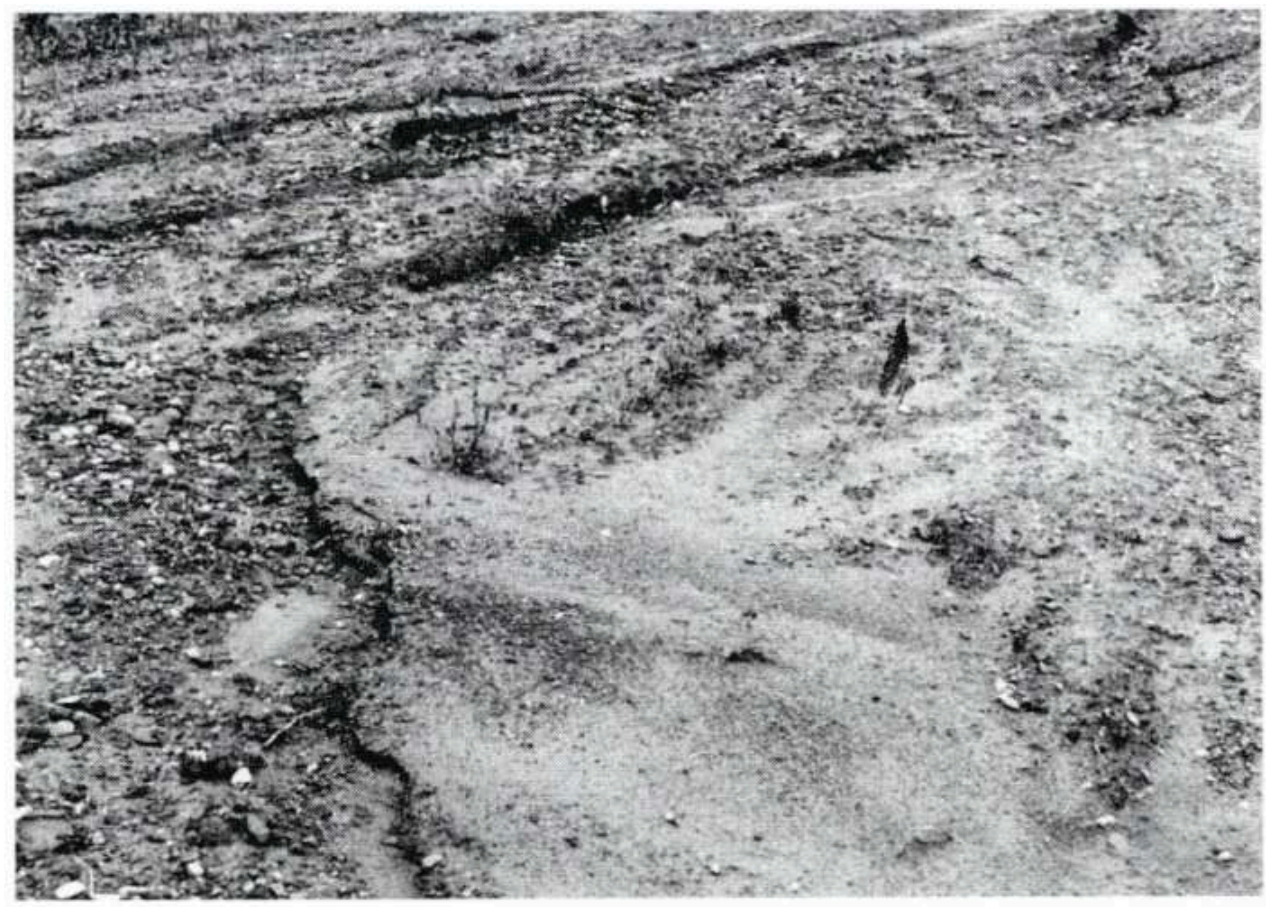

20- Colluvions probablement liées aux pratiques agricoles sur le site gallo-romain de Sinard (Isère)

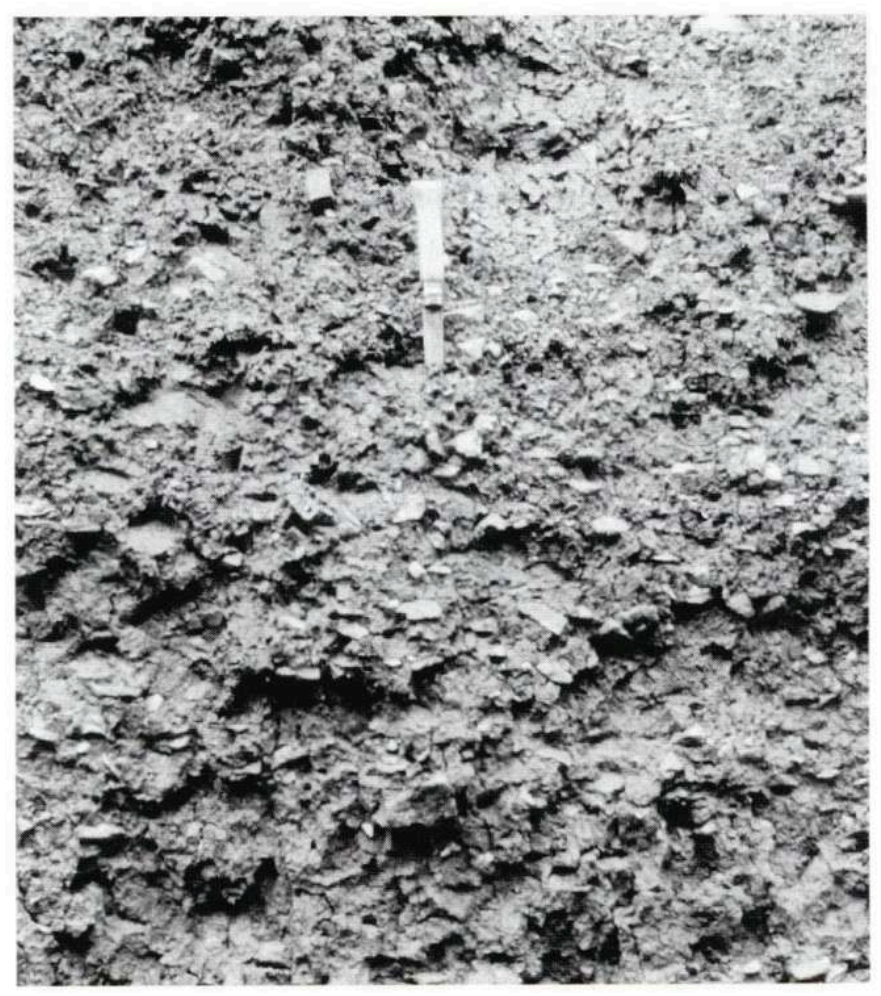

Dépôts massifs composés de limon avec des graviers dispersés dans la masse

18 Les phénomènes englobés sous le terme de reptation du sol (déplacement lié aux alternances humectation-dessication, l'activité biologique, le ruissellement diffus et l'impact des gouttes de pluies, le fluage visqueux lent du sol...) ont globalement une 
efficacité morphogénétique de plusieurs ordres de grandeur moindre que celle des processus décrits plus haut. Leur action peut cependant avoir une influence non négligeable sur un site archéologique. Kirkby (1967) cite des taux annuels de transport de terre sous prairie en Ecosse de $2,4 \mathrm{~cm}^{3} / \mathrm{cm}$ pour la reptation liée aux cycles humectation-dessication $\mathrm{du}$ sol, $0,25 \mathrm{~cm}^{3} / \mathrm{cm}$ pour l'activité des vers de terre et des rongeurs, à comparer aux $0,089 \mathrm{~cm}^{3} / \mathrm{cm}$ liés au ruissellement sur le même site. Au Canada, Smith et Gardner (Smith et Gardner 1985) chiffrent le volume annuel de terre ramenée en surface et redistribuée sur le versant (par le ruissellement notamment) sous l'action des spermophiles à $0,61,5 \mathrm{t}$./ha. Le piétinement du bétail peut également avoir un impact significatif. Schumm (1967) a ainsi enregistré des déplacements de cailloux dans la pente 3 fois plus forts sur des parcelles exposées au piétinement que sur des parcelles protégées et seulement soumises à l'action de la reptation thermique et du ruissellement. Ces processus sont également actifs sous forêt, en particulier la reptation due à l'impact des gouttes de pluie sur les taches de terre remontée en surface par l'activité biologique (Kwaad 1977, Sala 1988, Hazelhoff et al. 1981). Ils sont à l'origine de nombreux sols colluviaux à texture fine rencontrés en pied de versant dans nos régions, qui se sont progressivement constitués au cours de l'Holocène (Kwaad et Mücher 1977). Le sol colluvial décrit sur certains secteurs du site mésolithique de Vaise, contenant une industrie mésolithique dispersée sur toute sa hauteur, est probablement représentatif de ces phénomènes (Bertran et al. sous presse).

\section{Reconstitutions paléoenvironnementales}

Les données paléoenvironnementales susceptibles d'être déduites de l'étude des dépôts de pente sont de plusieurs types. Elles sont d'abord de nature locale et concernent le milieu de sédimentation, sa caractérisation, son fonctionnement et son évolution au cours du temps. Ces données permettent de décrire les caractéristiques physiques du milieu occupé par l'homme et d'en déduire certaines des contraintes et des opportunités d'exploitation qu'il pouvait offrir.

Les dépôts de versant sont également susceptibles de contenir un signal climatique. Par exemple, les bases de données concernant les glissements de terrain en Angleterre (Brunsden et Ibsen 1993) mettent en évidence des pics d'activité liés à des épisodes climatiques spécifiques (fig. 21A). Cette relation s'observe aussi bien à l'échelle du dernier cycle climatique pléistocène qu'à l'échelle de l'Holocène, des cinq derniers siècles ou des dernières décennies. Les périodes de recrudescence des glissements coïncident soit avec des phases climatiques humides, comme le dernier interglaciaire, l'Atlantique, le début du Subboréal et du Subatlantique et le Petit Age de Glace, soit, pour des échelles de temps plus restreintes, à des années ou des séquences d'années particulièrement pluvieuses.

21 Des constatations analogues ont été faites pour d'autres mécanismes, notamment dans les milieux fragiles au voisinage des limites entre les étages de la végétation en altitude. Matthews et al. (1993) identifient ainsi plusieurs périodes favorables à la solifluxion périglaciaire dans les montagnes d'Europe au cours de l'Holocène, sur la base des nombreuses dates ${ }^{14} \mathrm{C}$ obtenues à partir de paléosols enfouis sous des coulées. Alors que très peu d'évidences de solifluxion sont connues dans la première partie de l'Holocène, des phases d'activité ont été enregistrées au début du Subboréal et du Subatlantique ainsi que pendant le Petit Age de Glace. En Scandinavie, Jonasson (1993) pour les flots 
de débris (fig. 21B) et Blikra et Nemec (1993) pour les avalanches retrouvent des enregistrements comparables. Grove (1972) montre également d'après l'analyse méticuleuse des archives, une recrudescence des glissements, des avalanches, des inondations et des chutes de pierres pendant le Petit Age de Glace en Norvège.

À partir de ces travaux, des variations plus ou moins synchrones de l'activité des phénomènes de versant semblent se dessiner en Europe au cours de l'Holocène. Sur cette base, la mise en évidence de variations similaires peut être légitimement espérée de l'étude détaillée des formations plus anciennes, en particulier des dépôts de pente du Pléistocène supérieur. Cet optimisme doit cependant être tempéré par un certain nombre de constatations qui montrent toute la difficulté d'une interprétation climatique simple des dépôts de pente.

Les études menées en domaine actif soulignent en effet que les causes du déclenchement des différents mécanismes sont très diverses, souvent multiples et parfois difficiles à cerner clairement. Environ un tiers des glissements inventoriés en Angleterre (Brunsden et Ibsen 1993) n'ont pas de cause identifiée; ils pourraient être liés à une évolution " normale » du sol, causée par une détérioration progressive de ses caractéristiques mécaniques jusqu'à un seuil critique. Lorsqu'ils sont identifiés, les facteurs climatiques impliqués sont variables. Pour la solifluxion périglaciaire, Matthews et Berrisford (1993) font une revue des données acquises récemment et montrent que les paramètres influents diffèrent selon les régions considérées. La solifluxion semble ainsi favorisée dans les Alpes par des hivers froids et des chutes de neige faibles, tandis qu'en Scandinavie le facteur épaisseur de la couverture neigeuse semble au contraire positivement corrélé avec la vitesse de solifluxion. Dans l'Arctique, la solifluxion est surtout liée à des étés chauds et humides, qui permettent la fonte du pergélisol. 

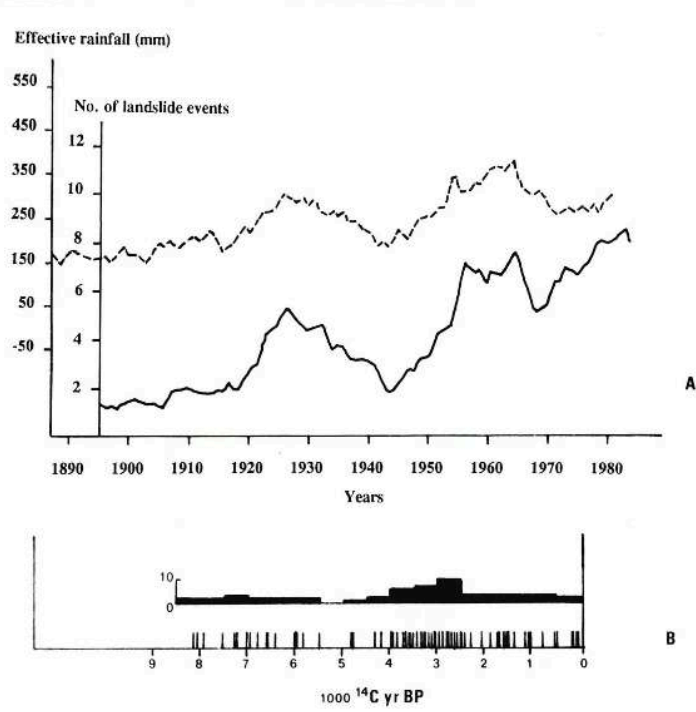

B

$1000^{14} \mathrm{Cyr} B$

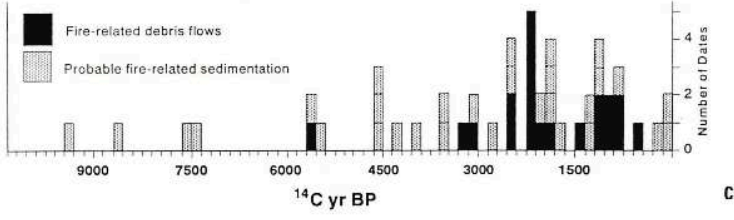

A - Glissements de terrain en Angleterre, d'après Brunsden et Ibsen (1993). Le trait continu représente la moyenne mobile sur 11 ans du nombre de glissements et le trait en pointillé correspond à la moyenne de la pluie efficace (pluie - évapotranspiration). Les deux courbes montrent une étroite corrélation pendant le XXe s.

B - Flots de débris en Scandinavie, d'après Jonasson (1993). En haut, nombre d'événements enregistrés par période de 500 ans. En bas, détail des événements. L'activité des flots de débris apparaît très importante dans la seconde moitié de l'Holocène, en particulier pendant le début du Subboréal et du Subatlantique ainsi que pendant le Petit Age de Glace.

c - Activité des flots de débris dans le Parc de Yellowstone (USA), d'après Meyer et al. (1995). Au cours des deux derniers millénaires, les dates obtenues sur les écoulements vraisemblablement déclenchés par des incendies de forêt se regroupent pendant les périodes les plus chaudes, notamment pendant l'optimum climatique médiéval

Un autre exemple est celui des flots de débris. En Norvège, les étés frais et pluvieux du Petit Age de Glace sont invoqués pour expliquer la recrudescence des flots de débris (Jonasson 1993). En revanche, Zimmerman et Haeberli (Zimmerman et Haeberli 1992) indiquent que les deux tiers des écoulements qui se sont produits récemment en haute montagne suisse trouvent leur origine dans le remaniement de matériaux libérés par la fusion du pergélisol ou le retrait des glaciers, en relation avec un réchauffement du climat. De son côté, Meyer (Meyer et al. 1995) dans le Parc de Yellowstone (USA) suggère que les pics d'activité des flots de débris identifiés au cours de l'Holocène, essentiellement sous le contrôle des feux de forêts, sont corrélés avec des périodes chaudes, notamment l'optimum climatique du Moyen-Age (fig. 21C). Par ailleurs, si de fortes pluies constituent le principal facteur immédiat du déclenchement, le seuil d'intensité varie largement suivant l'échelle du phénomène considéré et les caractéristiques mécaniques des sédiments (Wieczorek 1987).

De nombreux facteurs autres que climatiques ont souvent une influence déterminante et peuvent être difficiles, voire impossibles, à mettre en évidence lorsqu'on s'adresse à l'enregistrement fossile. Ces facteurs sont d'ordre géologique ou morphologique: 
sapement de la base des versants dû à l'action des cours d'eau ou de la mer, caractéristiques et histoire de la roche déterminant la vitesse de fourniture de débris pouvant être remobilisés, sismicité régionale, déformations tectoniques... L'activité anthropique intervient elle-même comme facteur principal ou accessoire: modifications du drainage lié à la déforestation, aux carrières, à la création de voirie, surpâturage, incendies, surcharges locales liées à la construction d'édifices...(Cleveland 1973, Castex 1985, Wells II 1987, Martin 1993).

Le fonctionnement d'un système paroi-talus est par ailleurs complexe et son évolution en dehors de tout stimulus climatique entraine l'apparition successive de différents mécanismes sédimentaires. On constate une diminution de l'importance prise par l'éboulisation au fur et à mesure de la dégradation de la paroi et le développement concomitant de dépôts liés à des mouvements en masse de type avalanches de neige, flots de débris ou solifluxion. Des séquences de ce type dans des talus pléistocènes sont décrites par Bertran (Bertran et al. 1995) (fig. 22). Démêler les différents facteurs contrôlant l'évolution d'un talus reste cependant difficile. Par exemple, Kotarba et Stromquist (1984) mettent surtout en avant des causes climatiques à la transformation d'éboulis gravitaires en cônes torrentiels en Pologne, tandis qu'Hétu (1986) ne trouve pas de corrélation nette entre la dynamique sédimentaire et le climat sur des talus du Québec. Il montre en particulier que la phytostabilisation s'effectue tout au long de l'Holocène et que l'accumulation détritique est surtout déterminée par l'héritage glaciaire de la région et l'exportation ou non de matériaux à la base des talus par les rivières. 


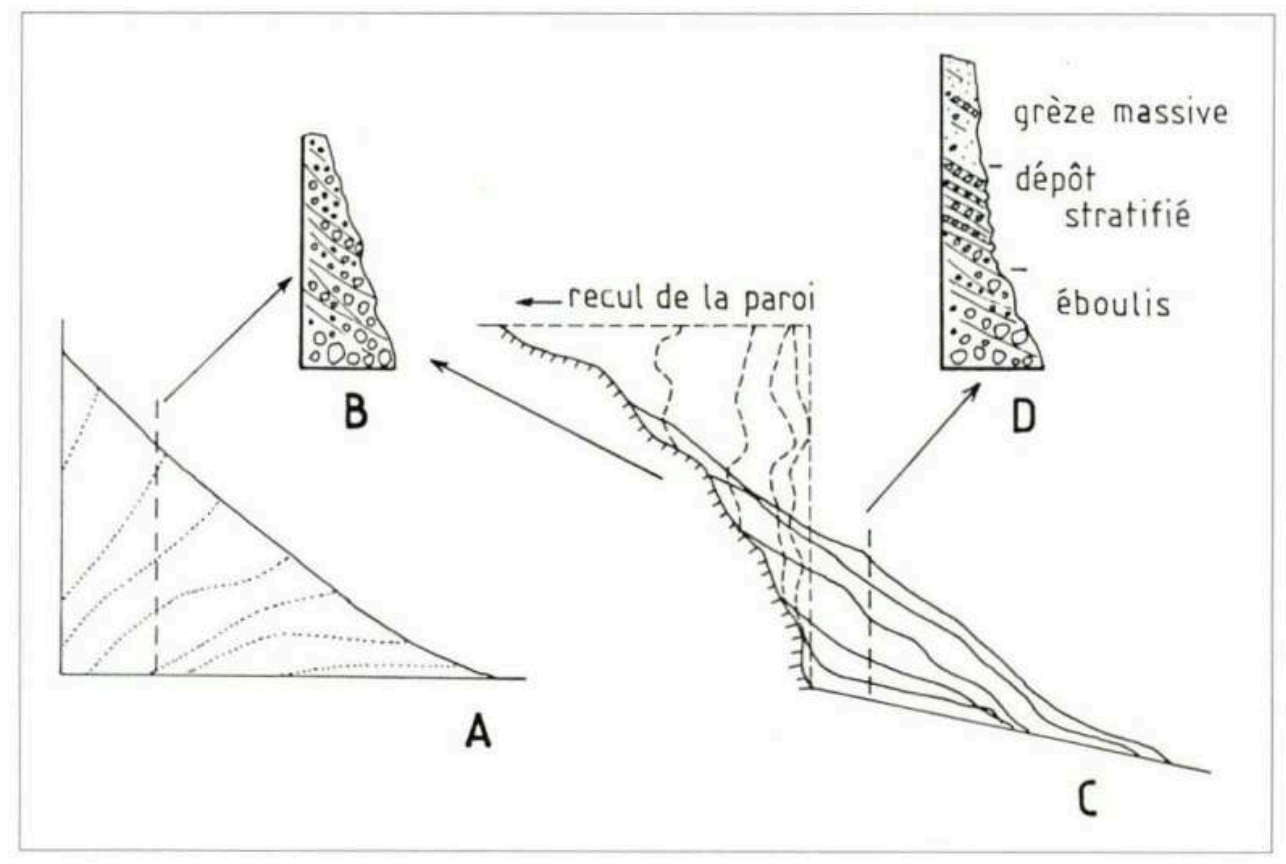

A - Courbes d'isogranulométrie dans un talus expérimental, d'après Kirkby et Statham (1975).

B - Séquence typique observée sur une coupe verticale dans un éboulis, avec une diminution de la taille des débris vers le haut, lié au recoupement de différentes courbes isogranulométriques.

c - Courbes d'accrétion d'un talus gravitaire et du recul consécutif de la paroi, d'après une simulation de Kirkby et Statham (1975).

D - Dérive granulométrique dans une séquence complexe d'Aquitaine, comportant un éboulis gravitaire à la base, des dépôts de pente stratifiés caillouteux, puis des dépôts massifs de graviers. Cette dérive résulte d'un accroissement de la fragmentation des débris lié à l'allongement de la surface de transit et à une diminution des apports par enfouissement progressif de la partie inférieure de la paroi

De nombreuses difficultés ont aussi trait à la datation des dépôts de pente (discussion in Corominas et al. 1993). Outre les problèmes inhérents à l'échantillonnage et à la représentativité des données, ces auteurs soulignent les biais introduits dans les tentatives de datation, liés à la surreprésentation des événements de faible importance et de court temps de retour pour les périodes récentes. Ce point est souvent crucial, dans la mesure où les facteurs de déclenchement sont différents selon que l'événement implique un petit volume de matériaux ou correspond au contraire à un phénomène profond et de grande ampleur.

En conclusion, les dépôts de pente sont porteurs d'une certaine information sur l'évolution climatique régionale. Cependant, l'extraction du signal climatique est généralement complexe et ne peut être envisagée qu'à partir d'un grand nombre de dépôts bien datés et représentatifs d'une période et d'une région données. Cela nécessite également d'identifier précisément les mécanismes sédimentaires et de les replacer au sein de l'évolution du versant, pour dégager ce qui est lié à une évolution sous le contrôle de facteurs intrinsèques au système de ce qui reflète des commandes extrinsèques, notamment climatiques.

À titre d'exemple, deux tentatives de bilan sur la morphogénèse holocène à l'échelle des Alpes méridionales (Jorda et Provansal 1996) et de la Valdaine (Berger 1995) montrent, au-delà d'importantes variations entre les divers enregistrements 
sédimentaires ponctuels analysés, des crises successives qui semblent trouver leur origine dans le jeu de contraintes à la fois climatiques et anthropiques.

\section{Rôle des processus de versant dans la formation des sites archéologiques}

Une abondante littérature a été consacrée depuis plus de trente ans à la géologie des sites archéologiques situés en pied de paroi, dans des abris-sous-roche ou en porche de grotte, principalement dans une optique chronostratigraphique (par exemple Laville 1975). Selon le point de vue généralement adopté dans ces études, les dépôts résulteraient d'une accrétion progressive du talus suite à l'accumulation de pierres détachées de la paroi, sans mouvement significatif des matériaux sur la pente (fig. 23). Les niveaux d'occupation seraient ainsi enfouis et préservés sans perturbation majeure. De manière corollaire, les mélanges d'industries se produiraient essentiellement à l'interface entre deux niveaux d'occupation successifs et seraient dépendants de la rapidité de la sédimentation (degré de résolution stratigraphique, cf. Petraglia 1993).

23- Formation d'un site préhistorique dans un abri-sousroche, selon Bordes (1984)

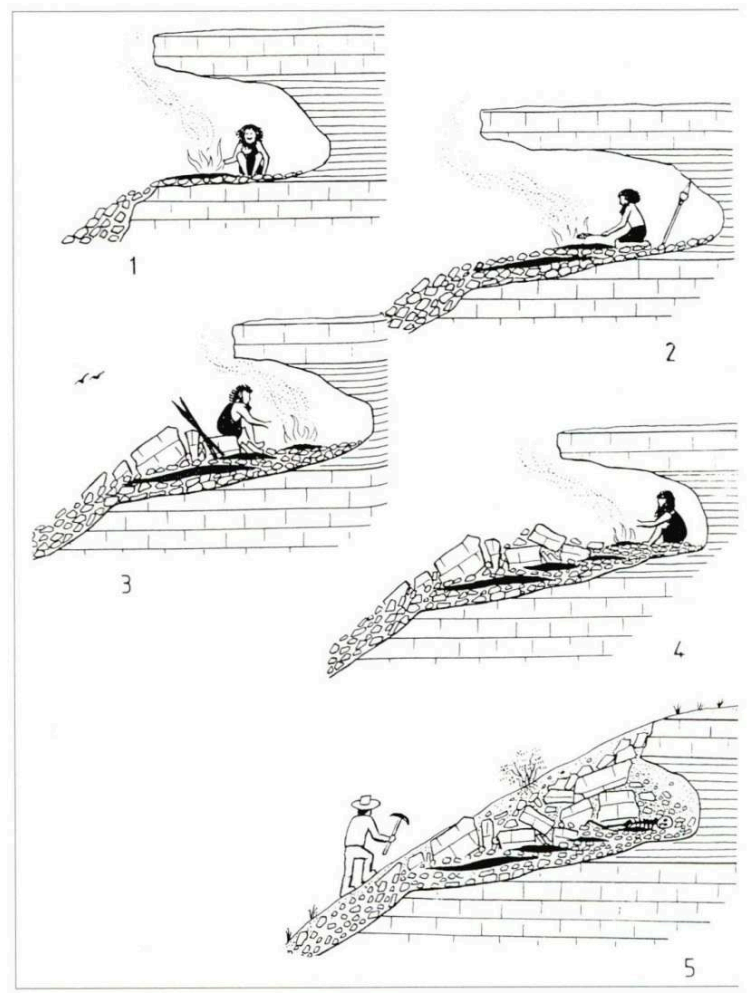

LES DÉPÔTS SE FORMENT PAR EXHAUSSEMENT PROgRESSIF DU SOL, EN RAISON DE L'ACCUMULATION DE MATÉRIAUX ANTHROPIQUES ET DE FRAgMENTS DÉTACHÉS DE LA PAROI. LES DIFFÉRENTES figURES SUggèRENT CLAIREMENT QUE LA FOSSILISATION DES NIVEAUX D'OCCUPATION S'EFFECTUE PAR UN SIMPLE ENFOUISSEMENT, SANS REDISTRIBUTION DES MATÉRIAUX SUR LA PENTE. ON PEUT EN PARTICULIER NOTER QUE LA POSITION DES BLOCS ET LA PHYSIONOMIE DES NIVEAUX ANTHROPIQUES NE VARIE PAS AU COURS DE LEUR ENFOUISSEMENT. LINE TELLE CONCEPTION EST PROBABLEMENT ASSEZ ÉLOIgNÉE dE LA RÉALITÉ

31 Le développement des études concernant la dynamique de versant dans les milieux naturels indique de manière évidente l'inadéquation de ce point de vue. Les 
expériences réalisées sur des cailloux marqués déposés à la surface de talus montrent en effet un déplacement parfois considérable des éléments avant qu'ils ne soient enfouis, quel que soit le processus sédimentaire mis en oeuvre. Cette constatation soulève donc le problème de savoir dans quelle mesure les phénomènes qui se sont exercés après l'abandon d'un site par l'homme ont modifié la physionomie initiale des niveaux d'occupation. Les données acquises dans les milieux naturels suggèrent que la dynamique de versant doit être envisagée comme un facteur essentiel de la formation du site. L'impact sur la préservation des niveaux archéologiques peut cependant varier considérablement. Il est donc nécessaire de s'attacher à déterminer avec la plus grande précision possible l'ampleur des remaniements, de manière à comprendre la signification des assemblages industriels récoltés et à fixer des limites à l'interprétation paléthnologique des niveaux.

Différents outils sont à la disposition des archéologues dans cette démarche. La mise en évidence de déplacements du matériel s'appuie essentiellement sur 1) l'analyse de la répartition spatiale des produits issus d'un même nucleus (remontages lithiques), 2) la constatation de tris granulométriques au sein des objets 3) l'étude de l'orientation et du pendage des pièces (fabrique).

\section{Remontages lithiques}

L'étude des remontages lithiques est l'une des méthodes privilégiées dans l'analyse des configurations spatiales au sein des sites paléolithiques, pour différencier des aires d'activité et comprendre la chronologie de ces activités. La distribution des remontages a également été utilisée dans le but d'évaluer les perturbations subies par le matériel archéologique (Villa 1982, Kroll et Isaac 1984, Collcutt et al. 1990). Peu de données sont cependant publiées à ce jour en ce qui concerne les sites localisés sur une pente. Deux exemples sont présentés ici, l'un provenant de la grotte de Lunel-Viel d'après l'étude de Le Grand (1994), l'autre de l'abri du Flageolet.

La grotte de Lunel-Viel I dans l'Hérault a livré de nombreux restes fauniques ainsi qu'une industrie du Paléolithique ancien (Bonifay 1981). Les dépôts graveleux forment un cône dont l'apex est situé à l'aplomb de l'ouverture de la grotte et qui passent vers le fond de la cavité à des dépôts plus fins. L'analyse des remontages a permis de démontrer de façon très probante le caractère naturel de l'accumulation d'objets archéologiques (Le Grand 1994) (fig. 24). Les principaux critères retenus par cet auteur peuvent se résumer aux points suivants :

1. la faiblesse numérique des raccords reflète une importante dispersion du matériel, que l'on ne peut mettre en relation avec une cause anthropique sur la base de l'étude technologique,

2. la majorité des raccords mettent en jeu des pièces provenant de couches différentes,

3. les raccords sont systématiquement orientés parallèlement à l'axe de la grotte (c'est-à-dire selon la ligne de plus grande pente),

4. les distances entre les pièces peuvent être considérables, puisqu'elles dépassent $10 \mathrm{~m}$ pour 17 des 43 remontages. 


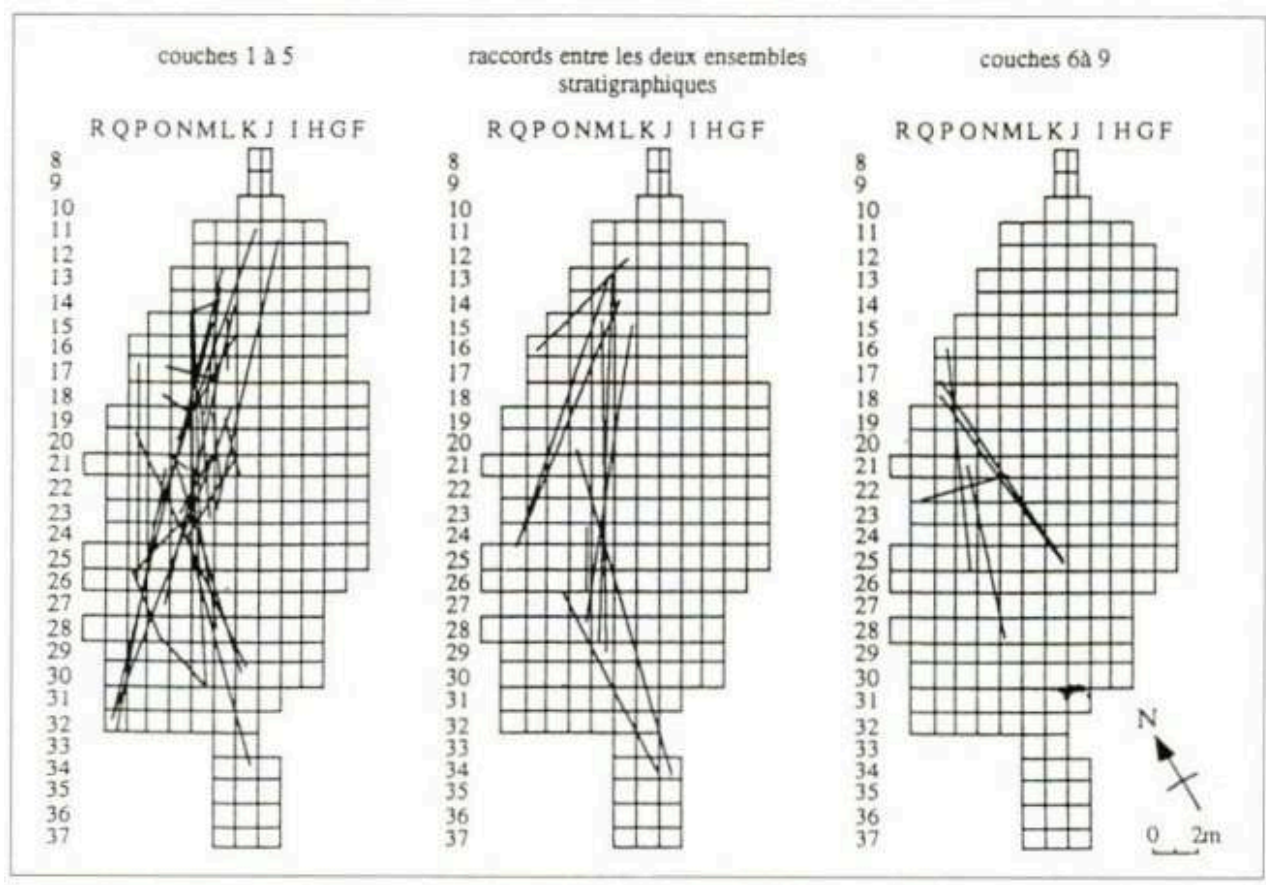

Noter les grandes distances séparant les objets et l'orientation systématique des raccords dans le sens de la pente. Plusieurs remontages s'effectuent à travers des couches différentes. Cette organisation est interprétée comme le résultat de la resédimentation à l'intérieur de la grotte d'un stock d'objets initialement localisé sous le porche

Ces observations témoignent de façon claire du remaniement d'un ou de deux stocks d'objets initialement localisés à proximité de l'entrée de la grotte.

Le site paléolithique supérieur du Flageolet en Dordogne (Rigaud 1982) correspond à un cône détritique situé en pied de paroi à l'aplomb d'un vallon fossile. Une concentration lithique a fait l'objet d'une série de remontages (Ploux 1986) (fig. 25). L'auteur a conclu à un amas résultant de l'évacuation (balayage du sol ou rejet à partir d'une peau) de produits de débitage. Il semble en fait que l'on puisse réinterpréter ces données de manière plus pertinente en terme de processus sédimentaire, à la lumière des nouvelles données sur la géologie du site (Texier à paraitre). La concentration d'objet a une forme allongée, en creux, qui correspond probablement à une ancienne rigole, avec une morphologie typique de seuils et de cuvettes successifs. L'analyse détaillée effectuée par Ploux montre :

1. la présence d'un tri granulométrique marqué par l'absence relative des éléments les plus fins (débris de taille),

2. une dispersion verticale du matériel sur environ $15 \mathrm{~cm}$, avec les objets les plus volumineux (nucleus) systématiquement à la base de la concentration,

3. une densité du matériel régulièrement décroissante d'amont en aval ainsi que de la base vers le sommet de la concentration,

4. une microstratification de l'amas ne révélant aucune succession chronologique cohérente des différentes phases d'exploitation des nucleus, mais au contraire une structure très homogène. 
25- Distribution en plan des raccords dans un amas lithique de l'abri du Flageolet, d'après Ploux (1986)

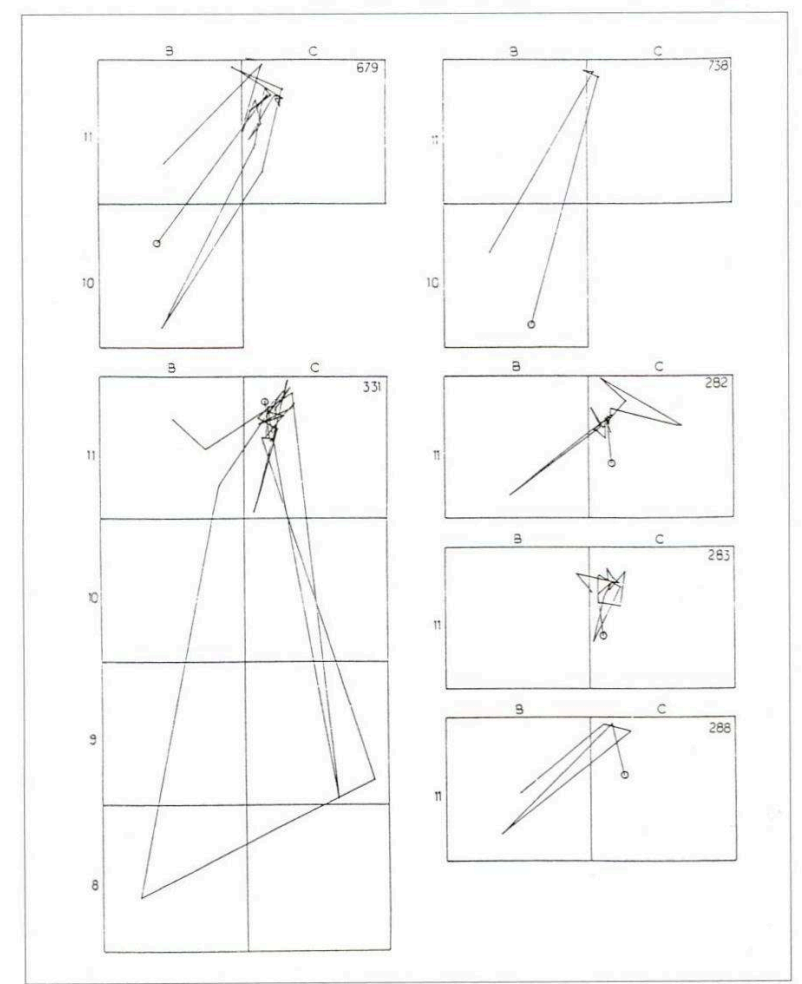

LAMAS A UNE FORME ALLONgÉE. AUCUN RACCORd N'A ÉTÉ TROUVÉ ENTRE CETTE CONCENTRATION ET LE MATÉRIEL SITUÉ AUX ALENTOURS. UNE ORIENTATION PRÉFÉRENTIELLE DES REMONTAgES,

PARALLÈle À LA PENTE, APPARAîT de MANIÈRE ÉVIDENTE. CET AMAS CORRESPOND PROBABLEMENT À UNE CONCENTRATION SECONDAIRE D'OBJETS DANS UNE RIgOLE

Simultanément, les remontages soulignent plusieurs faits remarquables, dont certains convergent avec les observations réalisées à Lunel-Viel. Les raccords entre pièces sont relativement peu abondants. Ils sont toujours parallèles à la pente ou légèrement obliques. Tous les remontages s'effectuent au sein de la concentration ou vers l'aval et il n'y a pas de relation avec les objets situés de part et d'autre de la concentration. Cet aspect unidirectionnel des raccords et le caractère totalement "intrusif» (bien qu'appartenant à la même occupation) de l'amas par rapport au matériel environnant suggèrent fortement un déplacement significatif des objets. L'hypothèse d'une concentration secondaire dans une rigole accompagnée d'un tri hydraulique des objets nous paraît la plus apte à rendre compte de l'ensemble des observations.

\section{Tri granulométrique}

Certains processus sédimentaires induisent un tri des particules transportées. Les mouvements individuels des particules (éboulisation, ruissellement) génèrent des tris longitudinaux, marqués selon le cas par une croissance ou au contraire une décroissance de la taille des débris de l'amont vers l'aval du versant. Le tri gravitaire des éboulis a fait l'objet de nombreuses observations (Francou 1991, Perez 1993), de même que le tri hydraulique lié au ruissellement sur les versants (Kirkby et Kirkby 1974, Coventry et al. 1978, Abrahams et al. 1984). 

longitudinal bien marqué et les talus dominés par ces mécanismes ne présentent pas d'évolution nette des paramètres de taille des débris avec la pente (Bones 1973, Albjär et al. 1979, Kotarba et Strömquist 1984). La situation est cependant souvent compliquée par l'existence de relais de processus sédimentaires, par exemple une sédimentation essentiellement gravitaire à l'amont, puis une zone médiane dominée par la solifluxion, enfin une zone distale où prévaut le ruissellement (Jahn 1960, Strömquist 1983). Des granoclassements longitudinaux complexes ont ainsi été décrits sur certains versants (Kirkby et Kirkby 1974, Albjär et al. 1979). Des tris verticaux, à l'origine de la stratification des dépôts, ont en revanche été quelquefois décrits, en particulier dans des dépôts de solifluxion (Francou 1988, Bertran, Francou et Texier 1995) et de flots de débris (Nieuwenhuijzen et Van Steijn 1990, Bertran et Texier 1994. Van Steijn et al. 1995). Ces tris sont provoqués par l'expulsion des débris grossiers à la surface des matériaux en mouvement sous l'action de différents mécanismes. L'action de la cryoexpulsion en milieu périglaciaire est assez bien documentée et a probablement joué un rôle important dans les sites paléolithiques. Les expériences ont notamment montré la rapidité de la ségrégation des débris grossiers engendrée par ce mécanisme (revue bibliographique in Washburn 1979).

Si d'assez nombreux travaux se sont attachés à rechercher des tris hydrauliques au sein de sites archéologiques en contexte fluviatile (Schick 1987, Petraglia et Potts 1994), peu de données concernent les sites de versant malgré l'intérêt que que l'on peut en attendre. Rick (1976) analyse la distribution des artefacts sur la pente qui se développe en avant d'un site péruvien (fig. 26). L'étude du matériel récolté le long de saignées longitudinales met clairement en évidence des tris ainsi qu'une corrélation significative entre certains paramètres (poids individuel des pièces, nombre de pièces par unité de ramassage, valeur de la pente). Les différents types d'artefacts (silex, os, céramique) suivent également des comportements distincts. L'interprétation proposée suggère que l'accumulation de déchets anthropiques était initialement localisée en sommet de talus sous le porche de la grotte, puis a été progressivement redistribuée sur la pente. Les. éléments les plus anciens (industrie lithique) ont subi un déplacement plus important que les témoins récents (céramique, os), car de plus longue durée. Fucks et al. (1977) décrivent également des tris longitudinaux, sans doute d'origine hydraulique, sur des sites épipaléolithiques d'Israël. 
26- Variation du poids moyen des pièces récoltées sur un talus devant la grotte de Ccurimachay (Pérou) (trait plein) comparé avec l'inclinaison du talus (trait pointillé)

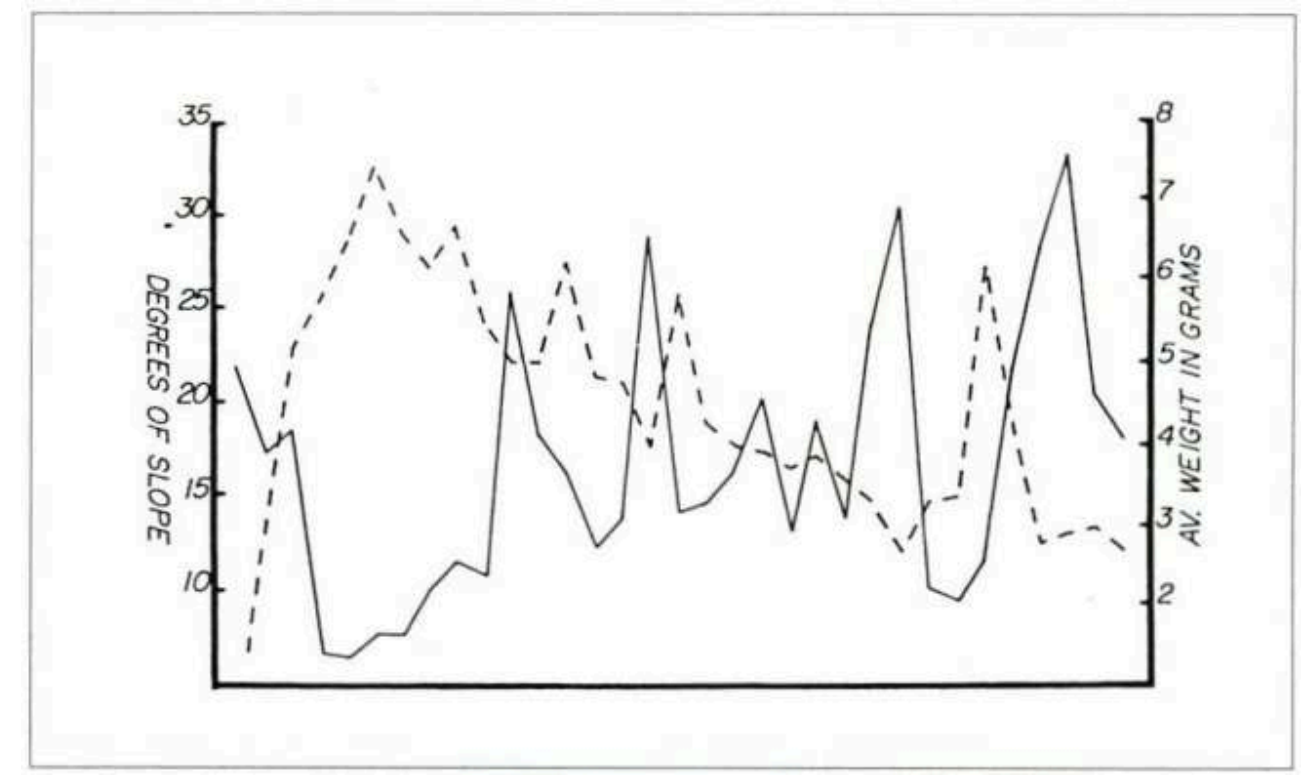

D'après Rick (1976)

Les courbes mettent en évidence un tri longitudinal net des objets et une forte corrélation entre le poids des objets et la valeur de la pente locale. Ces tris sont interprétés comme le résultat d'une redistribution du matériel archéologique sur le talus par des processus naturels

Kluskens (1990) détaille d'autres exemples de tri sur le site de Combe Capelle bas (Dordogne), à partir de mesures du poids des objets récoltés dans les différentes couches (fig. 27). Les assemblages lithiques montrent des variations très significatives de composition, les classes les plus grossières étant sur-représentées à l'intérieur de certains niveaux. Ces variations sont interprétées comme le résultat d'appauvrissements en éléments fins consécutifs à un lavage, en accord avec la présence de figures de ruissellement détectées sur le terrain.

27- VARIATION VERTICALE dU POIDS DES OBJETS RÉPARTIS EN 3 CLASSES DE TAILLE, SUR LE SITE DE COMBE CAPELLE BAS 


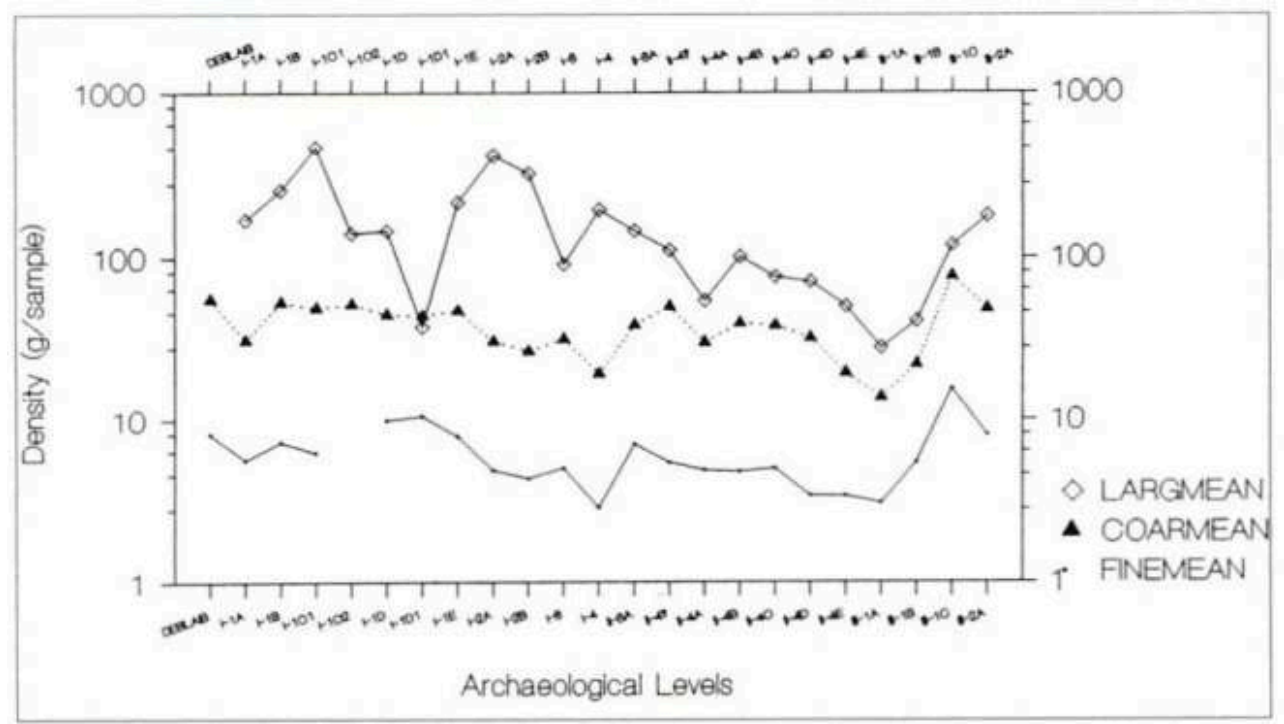

D'après Kluskens (1990)

Carrés : > $3 \mathrm{~cm}$, triangles : $1-3 \mathrm{~cm}$, points : 0,25 - $1 \mathrm{~cm}$. La base de la stratigraphie est située à gauche du diagramme. Les fluctuations des 3 courbes ne sont pas toujours parallèles, certaines couches montrant un enrichissement soit en éléments fins soit au contraire en éléments grossiers. Ces variations proviennent probablement de tris granulométriques liés au ruissellement

\section{Fabriques}

Le terme " fabrique " désigne la manière dont sont disposés des objets (cailloux, artefacts...) au sein du sédiment. Seuls l'orientation et le pendage du grand axe (axe d'allongement) des pièces sont généralement pris en compte. Quelques paramètres simples pour quantifier la distribution observée sont calculés selon les méthodes de Curray (Curray 1956) et de Woodcock (Woodcock 1977). L'étude des fabriques est une méthode introduite relativement récemment en archéologie, à la suite de Issac (Issac 1967) et Bar Yosef et Tchernov (Bar Yosef et Tchernov 1972), initialement dans le but de comprendre la génèse des sites du Paléolithique très ancien trouvés dans des terrains alluviaux en Afrique et au Proche-Orient.

De nombreux travaux de géomorphologie ont montré que des fabriques spécifiques se développent en fonction des processus sédimentaires mis en jeu. On dispose d'un référentiel bien documenté sur différents milieux, en particulier les dépôts fluviatiles (Potter et Pettijohn 1963, Sedimentary Petrology Seminar 1965, Rust 1972) et les dépôts de pente (revue bibliographique in Bertran et al. 1997). Quelques études concernent également du matériel archéologique expérimental (Isaac 1967, Schick 1987, Texier et al. sous presse).

Les données sur les fabriques générées par l'activité anthropique elle-même sont encore relativement peu nombreuses. Une première tentative (Bertran et Texier 1995a), réalisée à partir de plans d'objets sur des sites présentant des structures anthropiques évidentes, et donc supposés très peu perturbés, a montré une disposition aléatoire des artefacts sur pente nulle. Des applications de cette méthode à plusieurs sites paléolithiques en pied de paroi ou en abri-sous-roche dans le sud-ouest de la France ont en revanche mis en évidence la présence de fabriques non aléatoires, très 
comparables à celles rencontrées dans certains dépôts de pente périglaciaires (Kluskens 1990. Bertran 1994, Bertran et Texier 1995a et b).

L'exemple du site badegoulien de La Roche à Tavernat (Haute-Loire) (Bracco 1992) est brièvement détaillé ici (fig. 28). Le niveau archéologique est interstratifié dans la partie distale d'un petit cône détritique situé au pied d'une falaise. L'observation de terrain a mis en évidence des polygones triés, caractéristiques d'un environnement périglaciaire, dans une zone du site à peu près horizontale et localisée à proximité de la paroi. Sur la pente, les polygones s'étirent et passent à des coulées de solifluxion. Les mesures d'orientation des cailloux associés au niveau archéologique montrent un accroissement de l'orientation préférentielle avec la pente, qui témoigne de la déformation du niveau par la solifluxion. Parallèlement, les données de l'étude archéologique démontrent de manière éloquente une relation très nette entre l'organisation spatiale du matériel et le contexte sédimentaire (Bracco 1994). La zone centrale du site, qui n'a pas subi de déplacement sensible, présente un ensemble de structures anthropiques évidentes (cabanne, amas de débitage). Les remontages s'effectuent selon des directions aléatoires. Sur la pente en revanche, la dispersion verticale des objets s'accroît significativement et la structuration spatiale devient illisible.

28- Plan de la couche archéologique, projection verticale des objets et fabriques des cailloux associés au matériel archéologique sur le site de La Roche à Tavernat

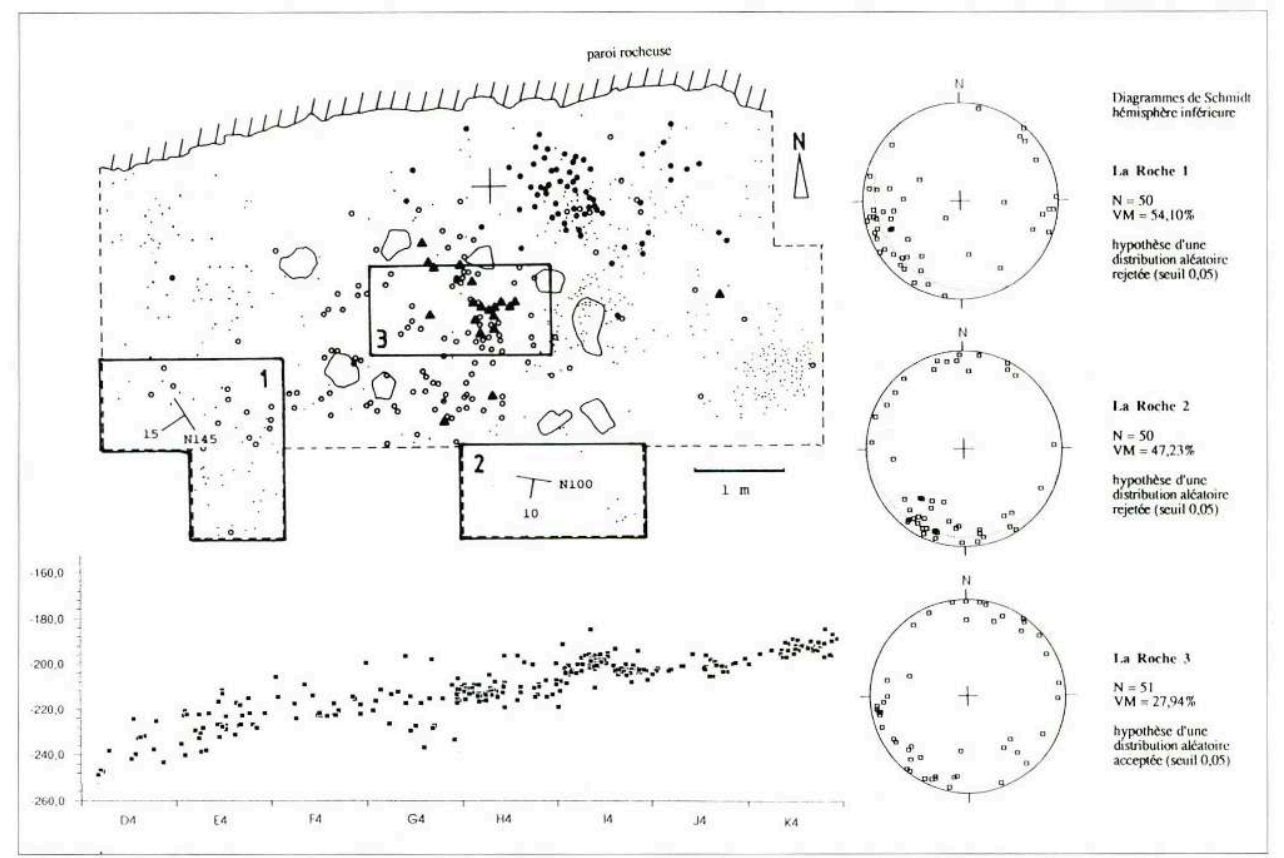

D'après Bertran (1994) et Bracco (1994)

La partie centrale du site, approximativement horizontale, montre une structuration anthropique claire de l'espace. Corrélativement, la fabrique des objets est aléatoire et le niveau d'occupation est relativement mince. Sur la pente en avant de l'abri, la dispersion verticale des objets s'accroît et les fabriques deviennent significativement orientées dans la pente. Ces phénomènes sont attribués à une perturbation du niveau par la solifluxion

Une compilation des données disponibles permet en première approche de différencier plusieurs types de fabriques rencontrées dans les sites archéologiques, par comparaison avec celles provenant des milieux naturels (fig. 29). Les sites inclus dans des dépôts alluviaux de débordement sur pente nulle ou faible ne présentent pas 
d'orientation préférentielle des objets. La disposition à plat des objets est en moyenne mieux marquée que pour les autres sites. Les sites provenant de dépôts de ruissellement ou de matériaux pédoturbés ont des caractéristiques voisines des précédents, avec en moyenne un pendage des objets plus variable. Une troisième catégorie s'isole assez bien des précédentes. Elle correspond aux sites provenant d'abris-sous-roche et de porches de grotte. L'orientation préférentielle des objets est forte et indique dans tous les cas analysés un remaniement des niveaux d'occupation sur la pente.

29- Fabrique comparée de quelques sites archéologiques, sur un diagramme rl/r2 (Woodcock 1977)

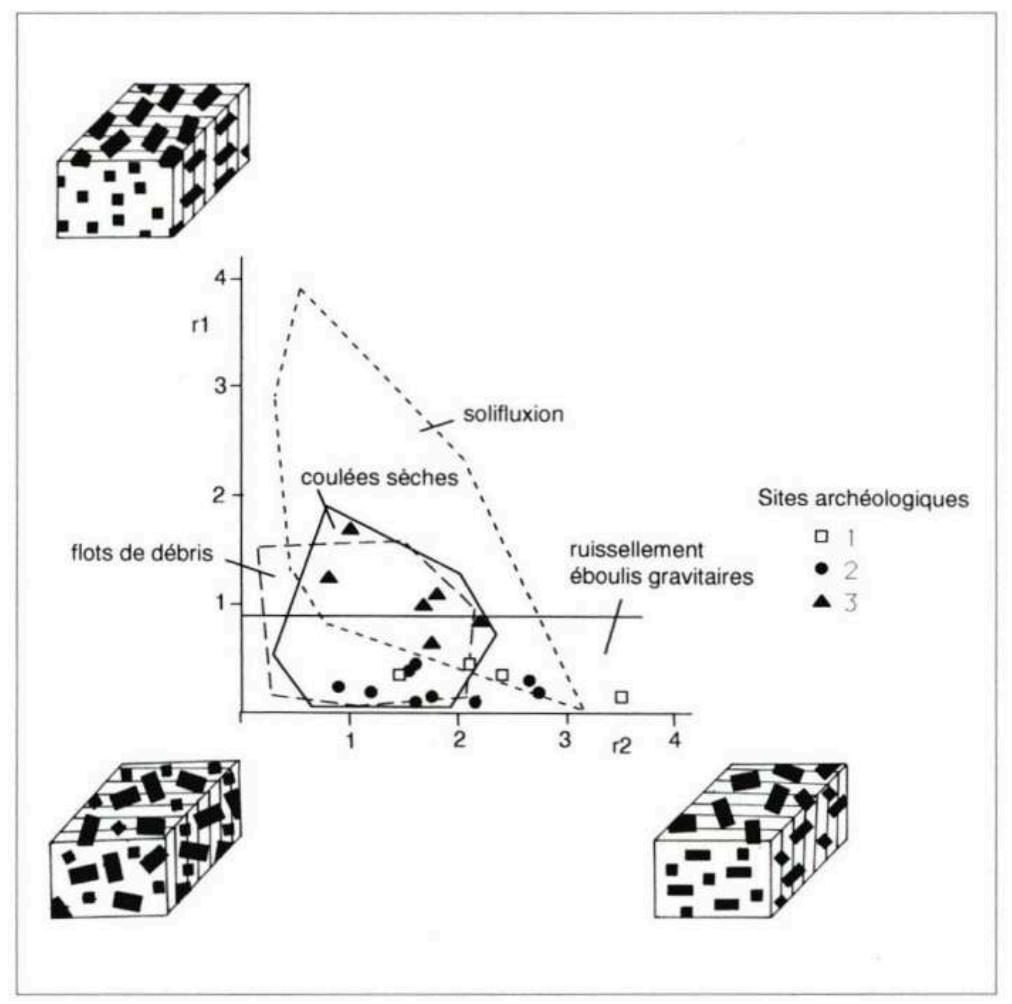

Les points situés à proximité de l'origine du diagramme correspondent à une distribution aléatoire de l'axe d'allongement des objets. Les points situés à proximité de l'axe $r 1$ traduisent une orientation préférentielle des objets suivant une direction déterminée (en général la pente), tandis que ceux localisés près de l'axe r2 reflètent une disposition à plat des objets. Les aires occupées par les fabriques de différents types de sédiments naturels sont indiquées pour comparaison. 1 - sites archéologiques inclus dans des dépôts limoneux de débordement, 2 - sites provenant de dépôts ruisselés, de niveaux perturbés par l'activité biologique ou par des phénomènes de retrait-gonflement (sols argileux), 3 - sites provenant de talus au pied d'abris-sous-roche ou de porches de grotte, constitués par des dépôts en masse (solifluxion, flots de débris). L'examen du diagramme montre que les fabriques relevées sur des sites très peu perturbés, comme par exemple la fabrique d'un petit amas de débitage paléolithique supérieur d'Etiolles ( $r 1=0,14 ; r 2=3,52$ ), sont caractérisées par une disposition à plat des objets. Les perturbations induisent soit une plus grande variabilité du pendage des objets (vers l'origine du diagramme), soit l'apparition d'une orientation préférentielle (vers les fortes valeurs de $\mathrm{r} 1$ )

Prises individuellement, les différentes méthodes décrites ne délivrent souvent pas une information suffisament claire pour permettre un diagnostic. Il faut alors prendre en compte un ensemble d'arguments archéologiques et géologiques convergents. Le cas du site mésolithique de Vaise (Rhône) illustre cette démarche. Ce site est situé au pied d'un versant dominant la vallée de la Saône à Vaise (Bertran, Nourissat, Best et Franc sous presse). Le matériel archéologique est inclus dans un sédiment limoneux. Il forme une 
nappe homogène d'une soixantaine de centimètres d'épaisseur dont la partie supérieure est mélangée à des fragments de céramiques néolithiques, associés à quelques fosses et amas de galets. Les décapages ont révélé plusieurs lobes de flots de débris composés de galets dans une matrice fine, qui avaient été dans un premier temps interprétés comme des empierrements d'origine anthropique (fig. 30). Plusieurs arguments conduisent à privilégier l'hypothèse d'une accumulation archéologique secondaire, d'origine sédimentaire. Le mélange d'objets épipaléolithiques et mésolithiques dans certains secteurs de la fouille, l'absence totale de remontages malgré la présence de matières premières facilement identifiables, joints à des arguments géologiques tels que la présence de pièces dans les flots de débris et localement, des niveaux d'artefacts d'épaisseur centimétrique interprétés comme des litages sédimentaires, suggèrent que le matériel ne représente qu'une fraction d'un site localisé plus haut sur le versant. Les dépôts ont ensuite servi de substratum à une occupation néolithique peu dense. Une date obtenue à partir de petits charbons de bois contenus dans un flot de débris indique que le remaniement est probablement lié à des essartages d'âge néolithique récent.

30- Relevé d'un « empierrement » de galets provenant du site mésolithique de Vaise et proposition d'interprétation

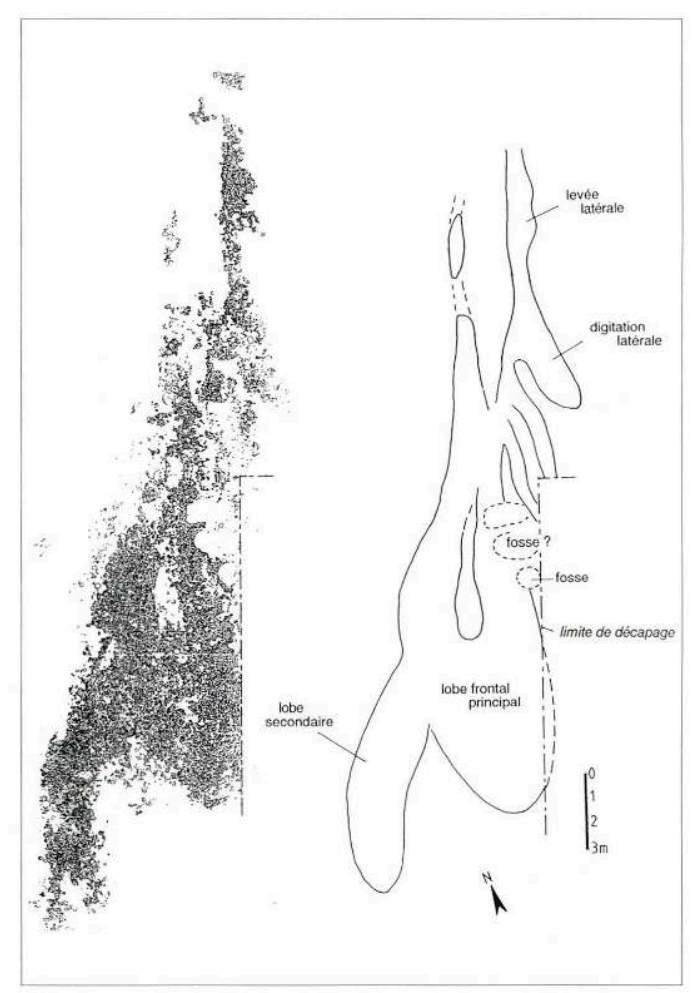

D'après Bertran, Nourissat, Best et Franc (sous presse)

Cette accumulation de galets colmatés par une matrice limoneuse et contenant des artefacts mésolithiques correspond probablement à un lobe terminal de flot de débris. Il est recoupé par des fosses d'âge néolithique ou bronze ancien 


\section{Conclusions}

Les dépôts de pente constituent l'un des principaux types de contexte sédimentaire auquel est confronté l'archéologue, ainsi qu'en témoigne l'abondante littérature consacrée aux talus formés au pied d'abris-sous-roche ou de porches de grotte. Les informations qui peuvent être déduites de leur étude détaillée concernent l'environnement sédimentaire local et, parfois, l'environnement climatique contemporain de l'occupation humaine, mais aussi la nature des perturbations subies par les niveaux d'occupation au cours de leur enfouissement. La dynamique de versant doit en effet être considérée comme un facteur essentiel de la formation des sites. Les nombreuses études sur des objets disposés à la surface de talus modernes ont toujours montré des déplacements plus ou moins importants précédent l'enfouissement, dont l'intensité varie largement suivant les mécanismes impliqués. Les cas d'enfouissement brutal, sans perturbation significative, sont en revanche relativement exceptionnels et sont associés à des milieux sédimentaires particuliers, comme dans la partie distale des accumulations de flots de débris ou d'éboulis gravitaires.

Censtatations montrent la nécessité dans le cadre de l'étude d'un site archéologique 1) d'identifier clairement les processus mis enjeu, 2) d'évaluer l'intensité des remaniements, de manière à comprendre la signification du matériel récolté. Différentes méthodes à la disposition des archéologues dans cette démarche sont décrites, notamment les remontages lithiques, la mise en évidence de tris granulométriques au sein des assemblages lithiques et l'étude de la disposition (fabrique) des objets. De nombreux progrès dans ce domaine peuvent être attendus de nouvelles simulations expérimentales en laboratoire ou en milieu naturel. Par ailleurs, bien que la majorité des exemples choisis ici soient paléolithiques, une démarche similaire peut être appliquée aux sites plus récents, les méthodes d'évaluation des remaniements devant être adaptées à d'autres matériaux comme la céramique.

D'une manière plus générale et en accord avec Bar Yosef (1993), la fossilisation sans altération significative de la disposition originelle des occupations est rare, quels que soient les milieux sédimentaires. Les contextes identifiés comme étant les plus favorables à un tel phénomène sont les dépôts d'inondation de rivières à forte charge en suspension, les dépôts lacustres et les dépôts loessiques. Dans la majorité des autres sites, si les études de l'organisation spatiale restent difficiles voire impossibles, un certain type d'information archéologique peut être néanmoins retiré après une étude approfondie des conditions de mise en place, concernant les caractères typologiques et technologiques de l'industrie, leur évolution chronologique (archéostratigraphie), le type de matières premières utilisées et leur provenance, la faune chassée... 


\section{Bibliographie}

Abrahams et al. 1984 : ABRAHAMS (A.D.), PARSONS (A.J.), COOKE (R.U.) et REEVES (R.W.). - Stone movement on hillslopes in the Mojave Desert, California : a 16year record. Earth Surface Processes and Landforms, 9, pp. 365-370.

Albjär et al. 1979 : ALBJÄR (G.), REHN (J.) et STRÖMQUIST (L.). - Notes on talus formation in different climates. Geografiska Annäler, 61 A, 3-4, pp. 179-185.

Allen 1992 : ALLEN (M.J.). - Products of erosion and the prehistoric landuse of the Wessex chalk. Past and Present Soil Erosion, Archaeological and Geographical Perspectives, M. Bell et J. Boardman, Oxbow Books, Oxford, monograph 22, pp. 37-52.

Ballandras 1993 : BALLANDRAS (S.) - Les crues torrentielles de l'été 1987 dans les Alpes françaises. Interprétations et enseignements. Revue de Géographie Alpine, 3, pp. 13-32.

Bar Yosef 1993 : BAR YOSEF (O.). - Site formation processes from a levantine viewpoint. Formation Processes in Archaeological Context, P. Goldberg, D.T. Nash et M. Petraglia, Prehistory Press, Monographs in World Archaeology n 17, pp. 13-32.

Bar Yosef et Tchernov 1972 : BAR YOSEF (O.) et TCHERNOV (E.). - On the palaeo-ecological history of the site of'Ubeidiya, Israel. The Pleistocene of the Central Jordan Valley, Publications of the Israel Academy of Sciences and Humanities, Jerusalem, pp. 5-35.

Benedict 1970 : BENEDICT (J.B.). - Downslope soil movement in a Colorado alpine region. Arctic and Alpine Research, 2, 3, pp. 165-226.

Berger 1995 : BERGER (J.-F.) - Facteurs anthropiques et naturels de l'évolution des paysages romains et protomédiévaux du Bassin valdainais (Drôme). L'Homme et la dégradation de l'environnement, XVe Rencontres internationales d'Archéolgie et d'Histoire d'Antibes, APDCA, Juans-les-Pins, pp. 79-114.

Bertran 1994 : BERTRAN (P.). - Dégradation des niveaux d'occupation paléolithiques en contexte périglaciaire : exemples et implications archéologiques. Paleo, 6, pp. 285-302.

Bertran 1996 : BERTRAN (P.). - Sédimentologie d'une avalanche rocheuse survenue en février 1995 à Claix (Alpes françaises). Quaternaire, 1, 2-3, pp. 75-83.

Bertran et Texier 1994 : BERTRAN (P.) et TEXIER (J.-P). Structures sédimentaires dans un cône de flots de débris (Vars, Alpes françaises méridionales). Permafrost and Periglacial Processes, 5, pp. 155-170.

Bertran et Texier 1995a : BERTRAN (P.) et TEXIER (J.-R). Fabric analysis : application to palaeolithic sites. Journal of Archaeological Science, 22, pp. 521-535.

Bertran et Texier 1995b : BERTRAN (P.) et TEXIER (J.-P). - The sedimentary deposits of CombeCapelle bas and their implications for site formation and paleoenvironment. In : The middle Paleolithic site of Combe Capelle Bas (France), H. Dibble et M. Lenoir, University Museum Monograph 91, Université de Pennsylvanie, p. 179-191.

Bertran, Francou et Texier 1995 : BERTRAN (P.), FRANCOU (B.) et TEXIER (J.-P.). - Stratified slope deposits : the stone-banked sheets and lobes model. Steepland Geomorphology, O. Slaymaker, Wiley, pp. 147-169.

Bertran et al. 1995 : BERTRAN (P.), COUTARD (J.-P), OZOUF (J.-C.) et TEXIER (J.-P.). - Dépôts de pente calcaires du nord de l'Aquitaine. Répartition stratigraphique et géographique des faciès. Zeitschrift für Géomorphologie N.F., 39, 1, pp. 29-54. 
Bertran et al. 1997 : BERTRAN (P.), HETU (B.), TEXIER (J.-P.) et VAN STEIJN (H.). - Fabric of subaerial slope deposits. Sedimentology, 44, pp. 1-26.

Bertran, Fabre, Franc, Limondin et Thiébault sous presse : BERTRAN (P.), FAVRE (L.), FRANC (O.), LIMONDIN (N.) et THIEBAULT (S.). - Evolution d'un versant au cours de l'Holocène à Vaise (France). Géographie Physique et Quaternaire.

Bertran, Nourissat, Best et Franc sous presse : BERTRAN (P.), NOURISSAT (S.). BEST (C.) et FRANC (O.). - Occupations épipaléolithique, mésolithique et néolithique de la Duchère à Vaise (Rhône) : rôle des processus naturels dans la constitution du site. Paleo.

Blikra et Nemec 1993 : BLIKRA (L.H.) et NEMEC (W.). - Postglacial avalanche activity in western Norway : depositional faciès sequences, chronostratigraphy and palaeoclimatic implications. Solifluction and Climatic Variations in the Holocene, B. Frenzel, European Science Foundation, Fisher, Stuttgart, pp. 143-162.

Bones 1973 : BONES (J.G.). - Process and sediment size arrangement on high arctic talus, southwest Devon Island, N.W.T., Canada. Arctic and Alpine Research, 5, 1, pp. 29-40.

Bonifay 1981 : BONIFAY (E.). - Les plus anciens habitats sous grotte découverts à Lunel-Viel (Hérault). Archéologia, 150, pp. 30-42.

Bracco 1992 : BRACCO (J.-R). - Le paléolithique supérieur du Velay et de ses abords. Recherches sur la dynamique des peuplements et l'occupation du sol dans une région volcanique de moyenne montagne. Thèse, Univ. de Provence, $229 \mathrm{p}$.

Bracco 1994 : BRACCO (J.-R). - Formation, déformations et informations d'une couche archéologique : La Roche à Tavernat, Locus 1. Préhistoire et Anthropologie Méditerranéennes, 3, pp. 25-37.

Brunsden et Ibsen 1993 : BRUNSDEN (D.) et IBSEN (M.L.). - The temporal causes of landslides on the south coast of Great Britain. Temporal Occurrence and Forecasting of landslides in the European Community, European Commission, Science and Research Development, R. Casale, R. Fantechi et J.C. Flageolet, Final Report, pp. 339-383.

Castex 1985 : CASTEX (J.-M.) - Effets des pluies des 25-26 sept. 1981 sur les aménagements des pentes au nord-ouest de Nice (Alpes-Maritimes). Méditerranée, 4, pp. 69-75.

Chandler 1973 : CHANDLER (R.J.). - The inclination of talus arctic terraces and other slopes composed of granular materials. Journal of Geology, 81, 1, pp. 1-14.

Cleveland 1973 : CLEVELAND (G.B.). - Fire + rain = mudflows. Big Sur 1972. California Geology, California Division of Mines and Geology, pp. 127-135.

Colas 1987 : COLAS (G.) - La crue torrentielle du Verdarel (Hautes-Alpes), 9 juill. 1981. Bull, de liaison des laboratoires des Ponts et Chaussées, 150-151, pp. 79-83.

Colcutt et al. 1990 : COLCUTT (S.N.), BARTON (N.R.E.) et BERGMAN (C.A.). - Reffitting in context : a taphonomic case study from a late Upper Paleolithic site in sands on Hengistburry Head, Dorset, Great Britain. The Big Puzzle, International Symposium on Reffitting Stone Artifacts, Cziesla E., Eisckhoff S., Arts N. et Winter D., Studies in Modern Archaeology, vol. 1, Holos, Bonn, pp. 219-235.

Corominas et al. 1993 : COROMINAS (J.), WEISS (E.E.J.) et MOYA (J.). - The use of dating techniques to assess landslide frequency, exemplified by case studies from european countries. Temporal Occurrence and Forecasting of landslides in the European Community, European Commission, Science and Research Development, R. Casale, R. Fantechi et J.C. Flageolet, Final Report, pp. 71-91. 
Coventry et al. 1988 : COVENTRY (R.J.), MOSS (A.J.) et VERSTER (E.). - Thin surface soil layers attribuable to rainflow transportation on low-angle slopes : an example from the semi-arid tropical Queensland, Australia. Earth Surface Processes and Landforms, 13, pp. 421-430.

Curray 1956 : CURRAY (J.R.). - Analysis of two-dimentional orientation data. Journal of Geology, 64, pp. 117-134.

Dibble et Lenoir 1995 : DIBBLE (H.) et LENOIR (M.). - The middle paleolithic site of Combe Capelle bas (France). University Museum monograph 91, University of Pennsylvania, 363 p.

Eisbacher 1979 : EISBACHER (G.H.). - Cliff collapse and rock avalanches (sturzstroms) in the Mackenzie Mountains, northwestern Canada. Canadian Geotechnical Journal, 16, pp. 309-334.

Faury 1990 : FAURY (O.). - L'érosion anthropique actuelle sur les hautes chaumes des Monts du Forez : mesures de suivi. Bull. Rhodanien de Géomorphologie, 25-26, pp. 45-65.

Francou 1988 : FRANCOU (B.). - Eboulis stratifiés dans les hautes Andes centrales du Pérou. Zeitschrift fiir Géomorphologie, 32, 1, pp. 47-76.

Francou 1991 : FRANCOU (B.). - Pentes, granulométrie et mobilité des matériaux le long d'un talus d'éboulis en milieu alpin. Permafrost and Péri glacial Processes, 2, pp. 175-186.

Fucks et al. 1977 : FUCKS (C.), KAUFMAN (D.) et RONEN (A.). - Erosion and artifact distribution in open-air epipaleolithic sites on the costal plain of Israel. Journal of Field Archaeology, 4, 1, pp. 171-179.

Gardner 1977 : GARDNER (J.). - High magnitude rockfallrockslide : frequency and geomorphic significance in the Highwood Pass area, Alberta. Great Plain-Rocky Mountain Geographical Journal, 6, pp. 228-238.

Gardner 1979 : GARDNER (J.). - The movement of material on debris slopes in the Canadian Rocky Mountains. Zeitschrift fiir Géomorphologie N.F., 23, 1, pp. 45-57.

Goguel et Pachoud 1972 : GOGUEL (J.) et PACHOUD (A.). - Géologie et dynamique de l'écroulement du Mont Granier dans le massif de la Chartreuse, en nov. 1248. Bull. BRGM, 2e série. III, 1, pp. 29-38

Govers 1987 : GOVERS (G.). - Spatial and temporal variability in rill development processes at the Huldenberg experimental site. Catena, supplement 8, p. 17-34.

Gray 1972 : GRAY (J.T.). - Debris accretion on talus slopes in the Central Yukon Territory. Mountain Geomorphohgy, Geographical Series, 14, Tantalus Press, Vancouver, pp. 75-84.

Grove 1972 : GROVE (J.M.). - The incidence of landslides, avalanches, and floods in western Norway during the Little Ice Age. Arctic and Alpine Research, 4, 2, pp. 131-138.

Guiresse et Revel 1995 : GUIRESSE (M.) et REVEL (J.C.). Erosion due to cultivation of calcareous soils on hillsides in south-west France. II. Effect of plouhing down the steepest slopes. Soil and Tillage Research, 35, pp. 157-166.

Harris et al. 1993 : HARRIS (C.), GALLOP (M.) et COUTARD (J.-P.). - Physical modelling of gelifluction and frostfrost-creep : some results of a large-scale laboratory experiment. Earth Surface Processes and Landforms, 18, pp. 383-398.

Hazelhoff et al. 1981 : HAZELHOFF (L.), VAN HOOF (P.), IMESON (A.C.) et KWAAD (J.P.M.). - The exposure of forest soil to erosion by earthworms. Earth Surface Processes and Landforms, 6, pp. 235-250.

Heim 1932 : HEIM (A.). - Bergsturz und Menschenleben. Fretz und Wasmuth, Zurich. 218 p. 
Hétu 1986 : HETU (B.). - L'influence du contexte géomorphologique quaternaire sur la dynamique postglaciaire des versants raides de la Gaspésie septentrionale. Thèse, Univ. de Montréal, 568 p.

Hétu et al. 1995 : HETU (B.), VAN STEIJN (H.) et BERTRAN (P.). - Le rôle des coulées de pierres sèches dans la génèse d'un certain type d'éboulis stratifiés. Permafrost and Periglacial Processes, 6 , pp. 173-194.

Hsü 1975 : HSU (K.J.). - Catastrophic debris streams (sturzstroms) generated by rockfall. Geological Society of America Bulletin, 86, pp. 129-140.

Isaac 1967 : ISAAC (G.L.). - Towards the interpretation of occupation debris : some experiments and observations. Kroeber Anthropological Society Papers, 37, pp. 31-57.

Jahn 1960 : JAHN (A.). - Some remarks on evolution of slopes on Spitzbergen. Zeitschrift für Géomorphologie, Supplement Band 1, pp. 49-58.

Johnson et Rodine 1984 : JOHNSON (A.) et RODINE (J.R.). - Debris flow. Slope Instability, D. Brunsden et D.B. Prior, Wiley, pp. 257-361.

Jonasson 1993 : JONASSON (C.). - Holocene debris flow activity in northern Sweden. Solifluction and Climatic Variations in the Holocene, B. Frenzel, European Science Foundation. Fisher, Stuttgart, pp. 179-196.

Jorda et Provansal 1996 : JORDA (M.) et PROVANSAL (M.) - Impact de l'anthropisation et du climat sur le détritisme en France du sud-est (Alpes du Sud et Provence). Bull, de la Société Géologique de France, 167, 1, pp. 159-168.

Kirkbv 1967 : KIRKBY (A.). - Measurement and theory of soil creep. Journal of Geology, 75, pp. 359-378.

Kirkby et Kirkby 1974 : KIRKBY (A.) et KIRKBY (M.J.). Surface wash at the semi-arid break in slope. Zeitschrift für Géomorphologie N.F., Supplement-Band 21, pp. 151-176.

Kluskens 1990 : KLUSKENS (S.L.). - Orientation and density analysis of stone artifacts at Combe Capelle bas, Périgord, France. Master Thesis, Univ. de Pennsylvanie, Philadelphie, 118 p.

Kotarba et Strömquist 1984 : KOTARBA (A.) et STRÖMQUIST (L.). - Transport, sorting and deposition processes of alpine debris slope deposits in the Polish Tatra Mountains. Geografiska Annàler, 66A, 4, pp. 285-294.

Kroll et Isaac 1984 : KROLL (E.M.) et ISAAC (G.L.). - Configurations of artifacts and bones at early Pleistocene sites in East Africa. Intrasite Spatial Analysis in Archaeology, Hietala H., New Directions in Archaeology, Cambridge University Press, Cambridge, pp. 4-31

Kvvaad 1977 : KWAAD (F.J.P.M.). - Measurements of rainsplash erosion and the formation of colluvium beneath deciduous woodland in the Luxembourg Ardennes. Earth Surface Processes, 2, pp. 161-173.

Kwaad et Mücher 1977 : KWAAD (F.J.P.M.) et MUCHER (H.J.). - The evolution of soils and slope deposits in the Luxembourg Ardennes near Wiltz. Geoderma, 17, pp. 1-37.

Laville 1975 : LAVILLE (H.). - Climatologie et chronologie du Paléolithique en Périgord. Etudes Quaternaires $\mathrm{n}^{\circ} 4$, Université de Provence, $442 \mathrm{p}$.

Le Grand 1994 : LE GRAND (Y.). - Processus de formation des dépôts archéologiques du Pléistocène moyen de LunelViel 1 (Hérault). L'utilisation des remontages. Préhistoire et Anthropologie Méditerranéennes, 3, pp. 57-63. 
Luckman 1977 : LUCKMAN (B.H.). - The geomorphic activity of snow avalanches. Geografiska Annäler, 59A, 1-2, pp. 31-48.

Martin 1993 : MARTIN (B.) - The role of landuse and rainfall in the triggering of landslides in Vars (Hautes-Alpes, France). Temporal Occurence and Forecasting of landslides in the European Community, European Commission, Science and Research Development, R. Casale. R. Fontechi et J.-C. Flageolet, Final report, pp. 235-319.

Matthews et al. 1986 : MATTHEWS (J.A.), HARRIS (C.) et BALLANTYNE (C.K.). - Studies on a gelifluction lobe, Jutunheimen, Norway : ${ }^{14} \mathrm{C}$ chronology, stratigraphy, sedimentology and palaeoenvironment. Geografiska Annäler, 68A, pp. 345-360.

Matthews et al. 1993 : MATTHEWS (J.A.). BALLANTYNE (C.K.), HARRIS (C.) et McCARROL (D.). Solifluction and climatic variations in the Holocene : discussion and synthesis. Solifluction and Climatic Variations in the Holocene, B. Frenzel. European Science Foundation, Fisher, Stuttgart, pp. 339-362.

Matthews et Berrisford 1993 : MATTHEWS (J.A.) et BERRISFORD (M.S.). - Climatic control on rates of solifluction : variations within Europe. Solifluction and Climatic Variations in the Holocene, B. Frenzel, European Science Foundation, Fisher, Stuttgart, pp. 363-382.

Meyer et al. 1995 : MEYER (G.A.). WELLS (S.G.) et JULL (A.J.T.). - Fire and alluvial chronology in Yellowstone National Park : climatic and intrinsic controls on Holocene geomorphic processes. Geological Society of America Bulletin, 107, 10, pp. 1211-1230.

Moeyersons et De Ploey 1976 : MOEYERSONS (J.) et DE PLOEY (J.). - Quantitative data on splash erosion, simulated on unvegetated slopes. Zeitschrift für Géomorphologie N.F., Supplement band 25, pp. 120-131.

Moss et Walker 1978 : MOSS (A.J.) et WALKER (P.H.). - Particle transport by continental water flows in relation to erosion, deposition, soils, and human activities. Sedimentary Geology, 20, pp. 81-139.

Nieuwenhuijzen et Van Steijn 1990 : NIEUWENHUIJZEN (M.E.) et VAN STEIJN (H.). - Alpine debris flows and their sedimentary properties. A case study from the French Alps. Permafrost and Periglacial Processes, I,PP-111-128.

Peiry 1990 : PEIRY (J.-L.) - Les torrents de l'Arve : dynamique des sédiments et impact de l'aménagement des bassins versants sur l'activité torrentielle. Revue de Géographie Alpine, LXXVIII, 1-2-3, pp. 26-58.

Petraglia 1993 : PETRAGLIA (M.D.). - The genesis and alteration of archaeological patterns at the Abri Dufaure : an Upper Paleolithic rockshelter and slope site in southwestern France. Formation Processes in Archaeological Context, P. Goldberg, D.T. Nash et M. Petraglia, Prehistory Press, Monographs in World Archaeology, n¹7, pp. 97-112.

Petraglia et Potts 1994 : PETRAGLIA (M.D.) et POTTS (R.). - Water flow and the formation of Early Pleistocene artifact sites in Olduvai Gorge, Tanzania. Journal of Anthropological Archaeology, 13, pp. 228-254.

Perez 1993 : PEREZ (F.L.). - Talus movement in the high equatorial Andes : a synthesis of ten years of data. Permafrost and Periglacial Processes, 4, pp. 199-215.

Ploux 1986 : PLOUX (S.). - Essai d'interprétation d'une concentration lithique : technologie et remontage. Couche VI du Flageolet 1 à Bézenac (Dordogne). Gallia Préhistoire, 29, 1, pp. 29-62. 
Poesen 1987 : POESEN (J.). - Transport of rock fragments by rill-flow - A field study. Catena, Supp. 8, pp. 35-54.

Potter et Pettijohn 1963 : POTTER (P.E.) et PETTIJOHN (F.E.). - Paleocurrents and Basin Analysis. New York Academic Press.

Raynal et Decroix 1987 : RAYNAL (J.-P.) et DECROIX (C.). - L'abri de Baume-Vallée (Haute-Loire, France), site moustérien de moyenne montagne dans son contexte régional. Arqueologia, Porto, 15, pp. 17-42.

Reading 1986 : READING (H.G.). - Sedimentary environments and fades. Blackwell Scientific Publications, Oxford, $615 \mathrm{p}$.

Rebiscoul 1994 : REBISCOUL (A.). - Le sanctuaire de ViuzFaverges (Haute-Savoie). Bull. d'Histoire et d'Archéologie des Amis de Viuz-Faverges, 34, pp. 13-30.

Reineek et Singh 1980 : REINECK (H.E.) et SINGH (I B.). Depositional sedimentary environments. Springer Verlag, Berlin, $551 \mathrm{p}$.

Rick 1976 : RICK (J.W.). - Downslope movement and archaeological intrasite spatial analysis. American Antiquity, 41, 1, pp. 133-144.

Rigaud 1982 : RIGAUD (J.-P.). - Le Paléolithique en Périgord : les données du Sud-Ouest Sarladais et leurs implications. Thèse, Univ. de Bordeaux 1.

Rust 1972 : RUST (B.R.). - Pebble orientation in fluvial sediments. Journal of Sedimentary Petrology, 42, pp. 384-388.

Ryder et al. 1990 : RYDER (J.M.), BOVIS (M.J.) et CHURCH (M.). - Rock avalanches at Texas Creek, British Columbia. Canadian Journal of Earth Sciences, 27, pp. 1316-1329.

Sala 1988 : SALA (M.). - Slope runoff and sediment production in two mediterranean mountain environments. Catena, Supp. 12, pp. 13-29.

Sauret 1987 : SAURET (B.). - Coulées boueuses, laves torrentielles, 1. Coulées de débris canalisées, compte rendu bibliographique. Bull, de liaison des Laboratoires des Ponts et Chaussées, 150-151, pp. 65-77.

Schick 1987 : SCHICK (K.D.). - Experimentally-derived criteria for assessing hydrologie disturbance of archaeological sites. Natural Formation Processes and the Archaeological Record, Nash D.T. et Petraglia M.D.. BAR International Series 352, pp. 86-107.

Schumm 1967 : SCHUMM (S.A.). - Rates of surficial rock creep on hillslopes in Western Colorado. Science, 55, pp. 530-561.

Sedimentary Petrology Seminar 1965 : SEDIMENTARY PETROLOGY SEMINAR. - Gravel fabric in Wolf run. Sedimentology, 4, pp. 273-283.

Smith et Gardner 1985 : SMITH (D.J.) et GARDNER (J.S). Geomorphic effects of ground squirrels in the Mount Rae area, Canadian Rocky Mountains. Arctic and Alpine Research, 17, 2, pp. 205-210.

Strömquist 1983 : STROMQUIST (L.). - Gelifluction and surface wash, their importance and interaction on a periglacial slope. Geografiska Annäler, 65A, 3-4, pp. 245-254.

Suwa et Okuda 1980 : SUWA (H.) et OKUDA (S.). - Dissection of valleys by debris flows. Zeitschrift für Géomorphologie N.F., Supplement Band 35, pp. 164-182.

Texier et al. sous presse : TEXIER (J.-P.), BERTRAN (P.), COUTARD (J.-P.), FRANCOU (B.), GABERT (P.), GUADELLI (J.-L.), OZOUF (J.-C.), PLISSON (H.), RAYNAL (J.-P.) et VIVENT (D.). - TRANSIT, un 
programme d'archéologie expérimentale en domaine périglaciaire : méthodologie, premiers résultats. Geoarcheology.

Varnes 1978 : VARNES (D. J.) - Slope movement. Types and processes. Landslides Analysis and Control. National Academy of Science, Washongton special report 176, pp. 11-33.

Vandaele et Poesen 1995 : VANDAELE (K.) et POESEN (J.). Spatial and temporal patterns of soil erosion rates in an agricultural catchment, central Belgium. Catena, 25, pp. 213-226.

Van Steijn et al. 1995 : VAN STEIJN (H.), BERTRAN (P.), FRANCOU (B.), HETU (B.) et TEXIER (J.-P). - Models for the genetic and environmental interpretation of stratified slope deposits. Permafrost and Periglacial Processes. 6, pp. 125-146.

Vérot-Bourrély 1995 : VEROT-BOURRELY (A.), ARGANT (J.), BRAVARD (J.-P.), CHAIX (L.) avec la coll. de BELLON (C.). PLANTEVIN (C.), BURNOUF (J.). - Le paléo-environnement du site de Gorgede-Loup (Lyon, ${ }^{9 e)}:$ Les signes matériels de la dégradation d'après l'étude interdisciplinaire du gisement. In : S. Van Der Leeuw (ed.) : L'Homme et la dégradation de l'environnement, Actes des XVe Rencontres internationales d'Archéologie et d'Histoire d'Antibes des 20-21-22 oct, 1994, APDCA, pp. 43-77.

Vidal et al. 1996 : VIDAL (N.). DE GOER DE HERVE (A.) et CAMUS (G.). - Déstabilisation de reliefs d'érosion en terrain volcanique. Exemples pris dans le Massif Central français. Quaternaire, 1, 2-3, pp. 117-128.

Villa 1982 : VILLA (P.). - Conjoinable pieces and site formation processes. American Antiquity, 47, 2, pp. 276-290.

Wainwright 1992 : WAINWRIGHT (J.). - Assessing the impact of erosion on semi-arid archaeological sites. Past and present soil erosion. Archaeological and geographical perspectives, M. Bell et J. Boardman, Oxbow Books, Oxford, monograph 22, pp. 227-241.

Washburn 1979 : WASHBURN (A.L.). - Geocryology. A survey of periglacial processes and environments. Edward Arnold, Londres, 406 p.

Wells II 1987 : WELLS II (W.G.). - The effects of fire on the generation of debris flows in southern California. Debris flows/Avalanches : Process, Recognition and Mitigation, J.E. Costa et Wieczoreck G.F., Geological Society of America, Reviews in Engineering Geology, 7, pp. 105-114.

Williams et Smith 1989 : WILLIAMS (P.J.) et SMITH (M.W.). - The frozen earth. Fundamentals of geocryology. Studies in Polar Research, Cambridge University Press, Cambridge, 306 p.

Wieczorek 1987 : WIECZOREK (G.F.). - Effects of rainfall intensity and duration on debris flows in central Santa Cruz Mountains, California. Debris flows/Avalanches : Process, Recognition and Mitigation, J.E. Costa et Wieczoreck G.F. (eds.), Geological Society of America, Reviews in Engineering Geology, 7, pp. 93-104.

Woodcock 1977 : WOODCOCK (N.H.). - Specification of fabric shapes using an eigenvalue method. Geological Society of America Bulletin, 88, pp. 1231-1236.

Yarnold 1993 : YARNOLD (J.C.). - Rock avalanche characteristics in dry climates and the effects of flow into lakes : insight from mid-Tertiary sedimentary breccias near Artillery Peak, Arizona. Geological Society of America Bulletin, 105, pp. 345-360.

Zimmermann et Haeberli 1992 : ZIMMERMANN (M.) et HAEBERLI (W.). - Climatic change and debris flow activity in high-mountain areas - A case study in the Swiss Alps. Catena, Suppl. 22, pp. 59-72. 


\section{Documents}

Caclin 1995 : CACLIN (C.). - Mongilbert Miette, A43 - Autoroute de Maurienne, Rapport de fouille de sauvetage. Service Régional de l'Archéologie Rhône-Alpes, Lyon, 30 p.

Legoupil et Bertran 1996 : LEGOUPIL (D.) et BERTRAN (P.). - Mission archéologique en Patagonie. Le gisement de Ponsonby. Rapport dactylographié, Université de Paris 1, 46 p.

Thieriot 1994 : THIERIOT (F.). - Autoroute A51 Grenoble-Sisteron. Rapport préliminaire de prospection-inventaire. Service Régional des Antiquités de Rhône-Alpes, Lyon.

\section{RÉSUMÉS}

Cet article présente 1) une revue des principaux processus sédimentaires impliqués dans la mise en place des dépôts de pente, 2) les potentialités de reconstructions paléoenvironnementales offertes par ces dépôts et 3) l'incidence des différents processus évoqués sur la formation des sites archéologiques. Des données assez précises sur les paléoenvironnements locaux et leur évolution peuvent être déduites d'une étude sédimentologique approfondie. En revanche, l'identification d'un signal climatique est plus problématique et requiert la prise en compte d'un grand nombre de dépôts datés et représentatifs de la zone étudiée. Les données acquises dans les milieux modernes permettent de penser que, dans la plupart des cas, les assemblages archéologiques trouvés dans les dépôts de pente ont subi des modifications plus ou moins importantes au cours de leur enfouissement. On décrit, à partir d'exemples pris dans des sites préhistoriques, différentes méthodes susceptibles de permettre une évaluation des remaniements subis par les niveaux archéologiques. 


\title{
Contexte morphodynamique et habitat humain de la moyenne vallée du Rhône au cours de la Préhistoire récente
}

\author{
Jacques-Léopold Brochier
}

\begin{abstract}
Les terrasses fluviatiles du Rhône et les vestiges préhistoriques associés ont d'abord été, de la part géologues du Quaternaire et des géographes, un objet d'étude destiné à étayer la chronostratigraphie du Quaternaire, principalement du Pléistocène (Bourdier 1962, Bornand 1972, 1976, Bravard 1986, Mandier 1988). Elles ont été considérées, par les archéologues fouillant les sites préhistoriques ou historiques présents à leur surface, comme des substrats géologiques sans histoire postérieure à la dernière glaciation. Leur caractéristique physiographique fondamentale est alors pour tous de présenter une surface plane, acquise dès leur origine. L'intérêt des préhistoriens ayant été retenu pendant un grand moment par les occupations en grotte, peu de sites en plaine avaient finalement fait l'objet de fouilles, avant ces dix dernières années. Il s'est agi, souvent, de simples ramassages de surface, ou de sondages très limités (Valette, Blanc 1955, Chapotat 1981). La fouille de fosses chasséennes était entreprise sur une terrasse wurmienne à Chateauneuf-du-Rhône La Roberte (Beeching et Thomas 1975). De façon par ailleurs quasi générale à la surface des terrasses fluviatiles, seules des structures en creux, fosses ou fossés, restaient concernées par les recherches.
\end{abstract}

\section{Évolution des idées : la variabilité du relief de la plaine rhodanienne}

2 La question de l'occupation humaine des terrasses rhodaniennes s'est posée de façon pointue avec les interrogations nées des nouvelles préoccupations archéologiques liées au besoin de comprendre un groupe culturel et sa façon d'occuper l'espace. Le programme «Culture et Milieu des Premiers Paysans de la Moyenne Vallée du Rhône - 
Archéologie-Biogéographie " s'est donné les moyens d'une investigation approfondie dans les domaines des sciences humaines, de la nature et des sciences (Beeching et al. 1986). Un premier examen du contexte morphodynamique de la vallée du Rhône à l'Holocène et des occupations du Mésolithique à l'âge du Bronze était réalisé (Beeching et al. 1989). Des opérations nouvelles: des fouilles de grande ampleur (Saint PaulTroisChateaux Les Moulins, Montélimar Gournier), des interventions programmées horssite comme les carottages de cônes détritiques alluviaux des affluents du Rhône (Drôme, Roubion), ont permis d'avancer dans la connaissance des conditions paléogéographiques de la vallée (Beeching, Brochier et col. 1989, 1990, 1994). Bien que centrés sur la période néolithique, ces travaux amenaient à prendre conscience de l'importance, de la rapidité, et de la fréquence des phénomènes morphodynamiques à l'Holocène et des liens étroits que ceux-ci entretiennent avec les sites archéologiques et leur conservation (Brochier 1991, Beeching, Brochier 1991). A la suite des fouilles de Montélimar Gournier, les terrasses rhodaniennes ne pouvaient plus être considérées comme de vastes étendues résolument planes n'autorisant pas l'existence de couches archéologiques, de stratigraphies, et de séquences chronoculturelles (fig. 1).

1- La moyenne vallée du Rhône de Valence à Orange

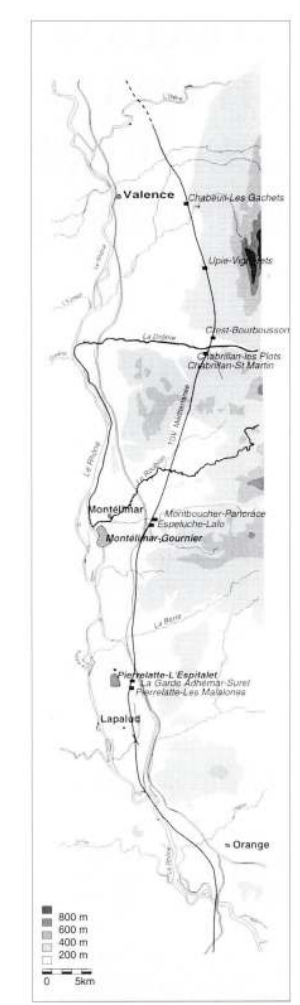

POSITION DES SITES de LA PRÉHISTOIRE RÉcente PIÉgÉs EN PALÉOVALLONS SUR TERRASSES ALLUVIALES (DESSIN BROCHIER ET JUNg)

3 Au nord, en amont de Lyon, une dynamique morphogénique holocène, propre au lit fluvial, était également mise en évidence (Bravard 1986, Nicoud et al. 1989). Au sud, en domaine méditerranéen, les études concernaient plus précisément le bas Rhône (Arnaut-Fasseta, Provansal 1993) ainsi que les zones palustres et les versants (Leveau, Provansal 1993). Dans le bassin Valdainais, adjacent à la vallée du Rhône au niveau de Montélimar, J.-F. Berger (Berger 1996) regroupe sous 20 phases de morphogénèses et 
pédogénèses l'histoire de l'Holocène. Plus récemment, les grandes opérations archéologiques de sauvetage préalables à la construction du TGV Méditerranée viennent d'apporter, par l'ampleur des investigations de terrain, une somme d'informations considérable, encore en cours d'exploitation et qui ne seront que succinctement abordées ici.

\section{La planation de la vallée du Rhône}

\section{Les acquis de la grande fouille de Montélimar Gournier}

Sans des travaux archéologiques de grande ampleur, la structure géomorphologique des sites de la Préhistoire récente des terrasses rhodaniennes serait restée méconnue. A Montélimar Gournier (fouille Beeching A., Cordier F.), l'évaluation archéologique, préalable à la construction d'une vaste zone industrielle de 100 ha, a conduit à la réalisation de 84 tranchées sub-parallèles (fig. 2), de 100 à $200 \mathrm{~m}$ de long, espacées de 20 à $50 \mathrm{~m}$, et de 1 à $2 \mathrm{~m}$ de profondeur jusqu'aux graviers de la terrasse (Beeching et al. sous presse). Le relevé exhaustif des stratigraphies, grâce à un codage précis des variations latérales de faciès sédimentaires, ténues et nombreuses, a permis de situer, avant la fouille, le contexte géologique des vestiges archéologiques. La terrasse rhodanienne, considérée au départ comme plane, telle qu'elle apparaitt aujourd'hui, s'est révélée présenter un paléorelief en longues gouttières surcreusées, base de la répartition des vestiges sur le site (fig. 3).

2- Vue aérienne du site de Montélimar Gournier au cours de l'évaluation par tranchées

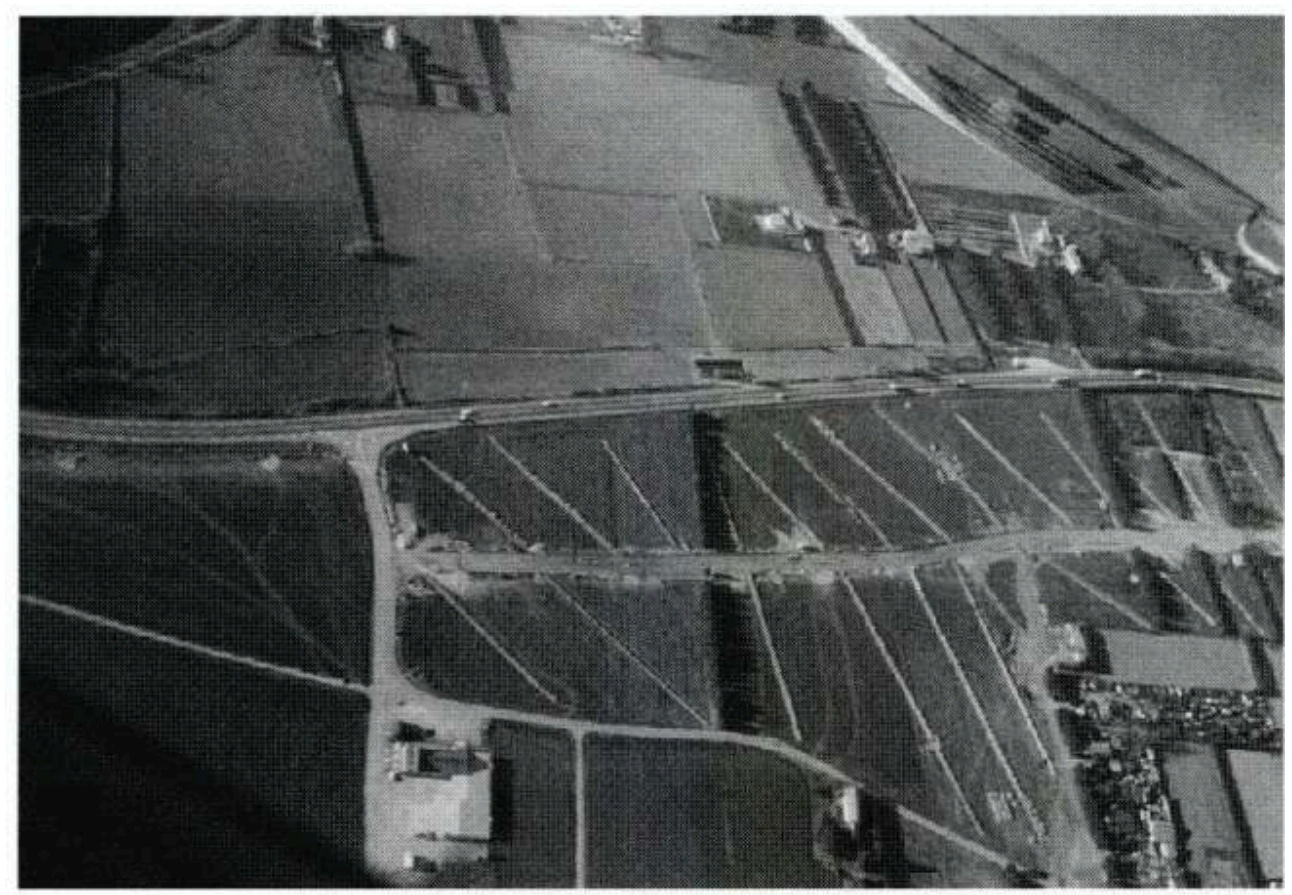

Cl. Beeching, CAP Valence 


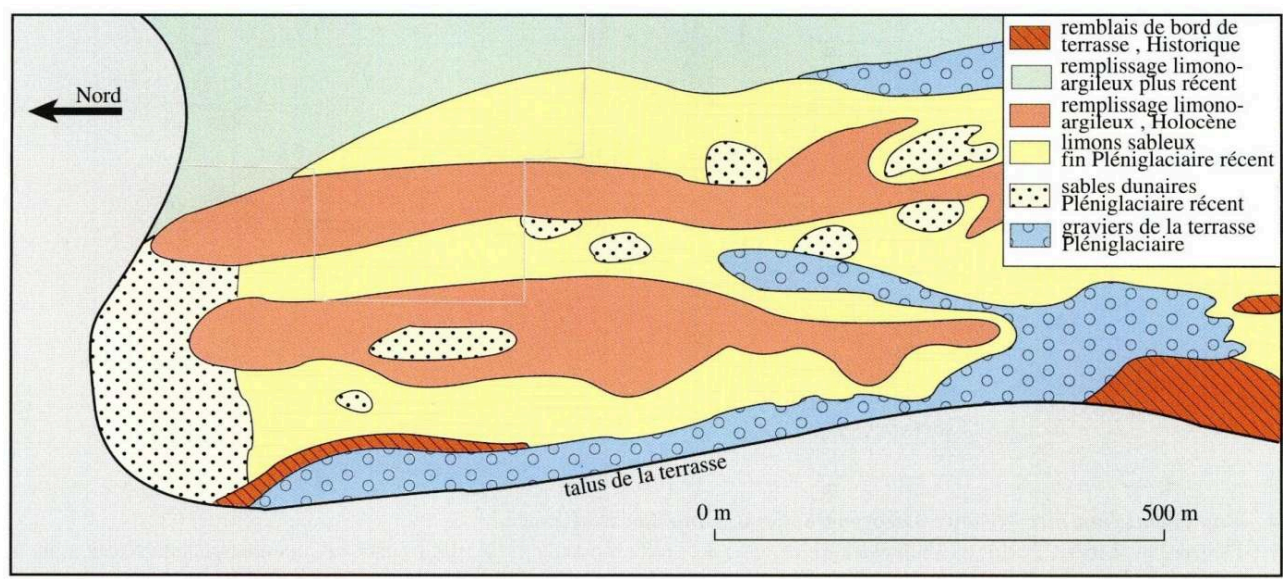

STRUCTURE gÉOMORPHOLOgIQUE DU SITE D'APRÈS LA CARTOGRAPHIE DES AFFLEUREMENTS SÉDIMENTAIRES À 60 CM DE PROFONDEUR (DESSIN BROCHIER ET JUNg)

Plusieurs sols d'occupation du Néolithique ancien, moyen, final, et de la fin de l'âge du Bronze, ont pu être fouillés sur plusieurs surfaces de l'ordre de $2000 \mathrm{~m}^{2}$. L'extension du Néolithique moyen chasséen sur les 100 ha, et l'importance des phénomènes funéraires et cultuels conduisaient à la théorie d'un site central au dispositif territorial chasséen (Beeching 1991, Beeching et al. sous presse).

6 L'état fossile actuel résulte d'une succession d'événements géomorphologiques et humains représentant 22 phases différentes que nous regrouperons en 9 épisodes principaux (fig. 4) :

1. Le creusement des talwegs d'origine, dans les graviers de la terrasse, s'effectue entre la fin du dépôt de celle-ci au Würm ancien (Mandier 1988) et le début du Würm récent (le fond est marqué par un réseau de fentes en coin).

2. Ces paléovallons sont comblés par des dunes sableuses, puis par des limons éoliens plus ou moins sableux à la fin du Pléniglaciaire récent (18000-16000 B.P. ?).

3. Dès l'interstade tradiglaciaire, puis dans l'Holocène ancien, ces limons subissent une pédogénèse et une profonde décarbonatation. Un site mésolithique d'une trentaine de $\mathrm{m}^{2}$ est piégé, et conservé dans un creux entre deux buttes sableuses.

4. Les limons argileux brun-rouge, pédosédiment colluvié des versants, où subsistent les racines du vieux sol antérieur. Les microcharbons sont nombreux, reflets de paléoincendies dans cette période juste antérieure au Néolithique ancien, ou déjà contemporaine.

5. Le paysage connu par les occupations du Néolithique ancien, moyen, final, est fait de vallonnements et de buttes interfluves (fig. 8a). Localement, et uniquement dans les fonds de vallons, où cette dynamique est possible, des colluvionnements limono-argileux diffus viennent ponctuellement recouvrir les sols d'occupations. Le rythme des recouvrements est très difficile à établir.

6. Entre le Néolithique final, Campaniforme, et l'âge du Bronze final, une phase de forte érosion en nappe vient tronquer les reliefs. Le tombant occidental de la terrasse est fortement érodé. Il n'y a pas d'incisions dans l'axe des talwegs.

7. Les paléotalwegs sont déjà en grande partie comblés au moment de l'occupation à l'âge du Bronze final. Des sols subsistent dans les zones les plus déprimées.

8. et 9. Du Bronze final à nos jours un arrasement des reliefs et un comblement des zones en creux conduisent à la surface plane actuelle. S'y ajoute un remblaiement sur le talus de la terrasse qui permet de gagner 2 ha de surface cultivable. Les travaux agricoles au cours de 
l'Antiquité et du Moyen Âge sont en grande partie responsables de cette planation qui est globalement acquise à ces périodes.

4- Montélimar Gournier. Histoire paléogéographique, simplifiée et résumée
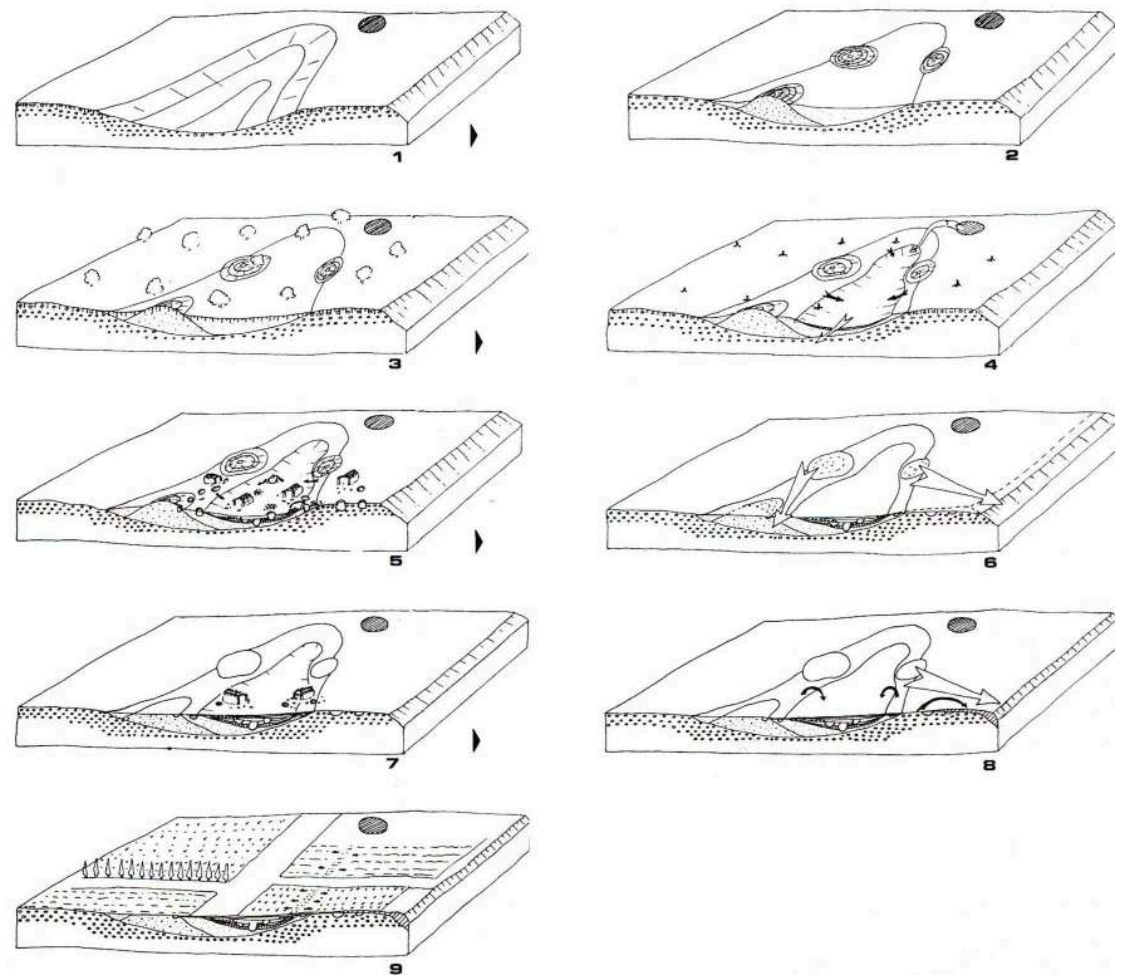

1 : PLÉISTOCÈne RÉCENT ; 2 : fin dU PLÉNIgLACIAIRE RÉCENT ; 3 : HOLOCÈNE ANCIEN ; 4 : 1 lère PHASE DE REMPLISSAgE ANTÉ-NÉOLITHIQUE À NÉOLITHIQUE ANCIEN ; 5 : OCCUPATIONS ET COLLUVIONNEMENTS, NÉOLITHIQUE MOYEN À FINAL ; 6 : TRONCATURE INTER NÉOLITHIQUE FINAL/ BRONZE fINAL ; 7 : OCCUPATION BRONZE fINAL $1-2 ; 8$ : ACTIVITÉS AgRAIRES, ET ARASIONS AU COURS DE L'ANTIQUITÉ ET DU MOYEN A

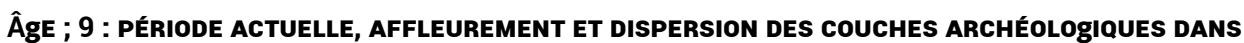
LES LABOURS (DESSIN BROCHIER ET JUNG)

\section{Pierrelatte l'Espitalet}




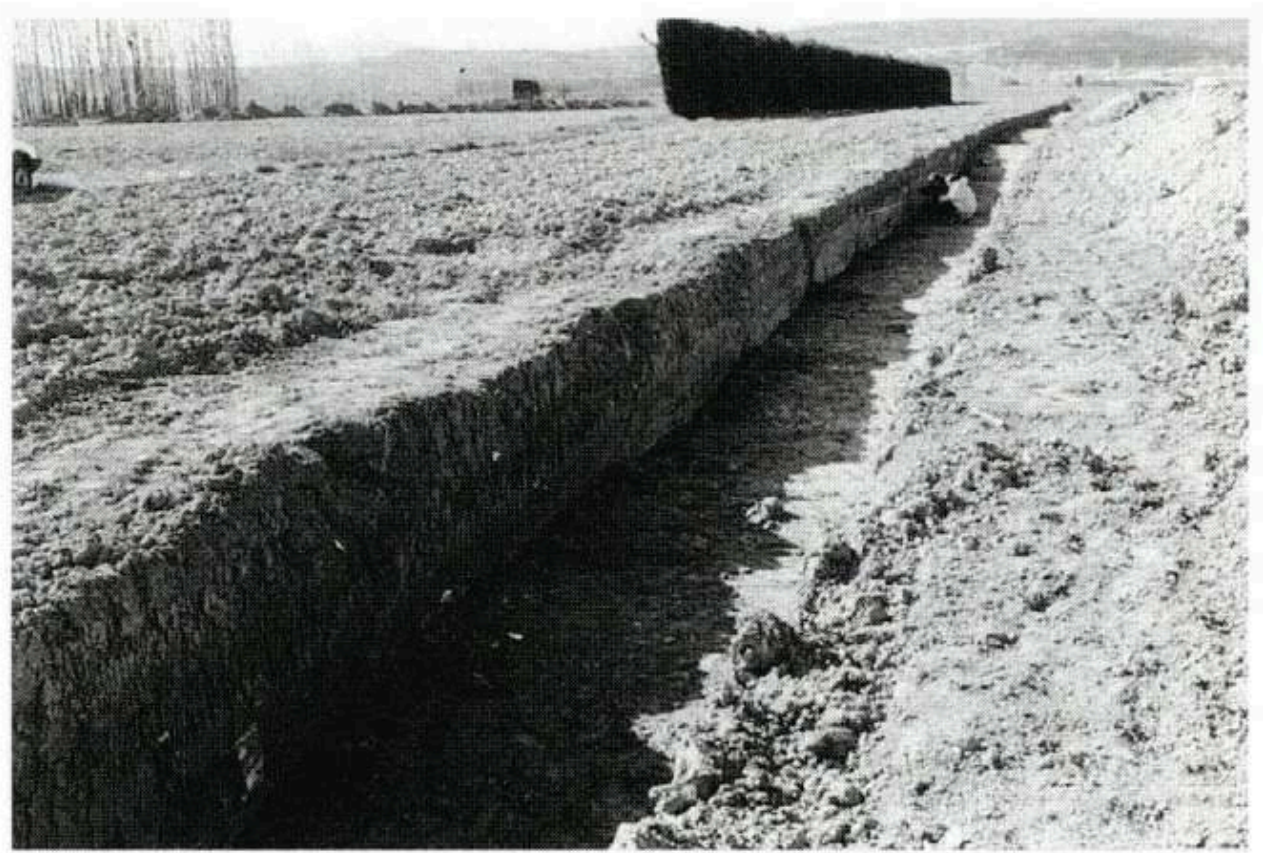

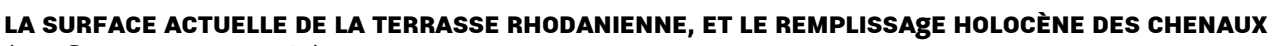
(PROfil dE LA TRANCHÉE)

Cliché : V. Savino, AFAN

7 Vingt kilomètres au sud de Montélimar, à Pierrelatte L'Espitalet, l'implantation d'une gravière du TGV Méditerranée sur une terrasse du Pléistocène récent a conduit à l'évaluation archéologique d'une surface de 30 ha (Savino 1995). De longues tranchées, totalisant $3900 \mathrm{~m}$, espacées de 100 à $150 \mathrm{~m}$, ont également mis en évidence une structure géomorphologique en gouttières subparallèles du même type que celle reconnue à Montélimar Gournier (fig. 5, 6). Cette évaluation aurait dû être complétée par des sondages ponctuels entre les tranchées, et des fenêtres fouillées sur de larges surfaces ce que l'échéancier de l'opération n'a pas permis de réaliser. L'étude du remplissage sédimentaire de ces chenaux est en cours; nous donnerons ici quelques repères de son histoire :

1. La terrasse rhodanienne du Pléniglaciaire récent est incisée de paléochenaux profonds de 3 à $4 \mathrm{~m}$, larges de 100 à $200 \mathrm{~m}$, pouvant s'anastomoser les uns aux autres. Ils représentent soit des sandurs abandonnés, soit des circulations plus récentes du Rhône, ou de la Berre, affluent voisin de rive gauche.

2. Les premiers dépôts sont constitués de sables fluviatiles alluviaux qui subsistent sur 0,50 à 2 $\mathrm{m}$ de puissance dans le fond des chenaux les plus profonds. Quelques branches et troncs d'arbre de la ripisylve s'y trouvent conservés, et datés de $6162+-52$ B.P. (5240-4945 cal. B.C. ; ARC 1345).

3. Ces sables sont incisés et en partie déblayés. Le remblaiement suivant est une alternance de sables et de limons d'origine fluviatile. La circulation d'eau reste de compétence faible. On assiste néanmoins au transport sur de faibles distances de quelques tessons, silex et charbons de bois. Ces derniers datent le site démantelé du Néolithique ancien et d'une période quasi-contemporaine (6060 +-65 B.P. ; 5210-4840 cal. B.C. ; ETH 14839) des bois flottés de la phase 2 , à moins qu'il ne s'agisse d'une seule et même phase. 
4. Des limons d'inondation, de la Berre ou du Rhône, viennent combler les zones en creux, sur des épaisseurs de 0,50 à $1 \mathrm{~m}$ 50. Il existe quelques vestiges néolithiques épars.

5. Ces dépôts peuvent être incisés dans l'axe des chenaux. Les phénomènes puissants de remplissage sédimentaire s'arrêtent. Une pédogénèse se développe. La décarbonatation consécutive conduit au concrétionnement des limons sableux sous-jacents qui commence probablement à ce moment.

6. Pendant trois à quatre millénaires vont se succéder des occupations humaines du Néolithique moyen chasséen à l'âge du Bronze final et à l'âge du Fer. Leur fossilisation s'effectue au sein d'un ensemble sédimentaire de 10 à $70 \mathrm{~cm}$ d'épaisseur. La matrice est de texture limono-argileuse, de couleur grise, brun sombre à noire. Cet ensemble complexe résulte d'une succession de pédogénèses, colluvionnements, passages humains, le tout repris et homogénéisé par des phénomènes d'hydromorphie dus à la présence de la nappe et à des mouvements vertiques $d u$ sol. Le mobilier archéologique se présente sous la forme d'épandages, de densité variable allant de 1 , à plusieurs dizaines de tessons, pour $4 \mathrm{~m}^{2}$. Des nappes plus denses peuvent être suivies sur quelques dizaines de mètres de longueur et servir ponctuellement de base à une chronostratigraphie. Comme il n'existe par ailleurs pas de repère lithostratigraphique au sein de cet ensemble, la séquence chronoculturelle n'est établie que sur des bases chronotypologiques. Sont présents sur le site avec des variations spatiales d'une période à l'autre (Beeching in Savino 1995) : le Chasséen, le Chasséen récent, final, la transition Chasséen/Néolithique récent post-Chasséen, la transition Néolithique récent post-Chasséen/Chalcolithique, le Chalcolithique, la transition Chalcolithique/Bronze ancien, le Bronze final 1-2. Le Néolithique final est la période la mieux représentée ; l'âge du Bronze moyen est absent, l'âge du Fer (Hallstatt à Tène finale) n'est présent que par quelques fragments.

7. À la fin de ce long épisode, les chenaux sont en partie comblés, et n'atteignent plus que 70 $\mathrm{cm}$ de profondeur au maximum. De nouvelles chenalisations peu profondes sont créées (divagations de la Berre ?), y compris dans les graviers des interfluves, dans une période précédant l'occupation gallo-romaine.

8. En certains points bas, mai drainés, se forment des zones humides que connaîtront les galloromains à leur arrivée sur le site.

9. Le site est mis en exploitation à l'époque romaine aux Ier et IIe s. ap. J. - C., construction de bâtiments et d'un réseau de fossés. Des remblaiements volontaires de zones en creux ont lieu. Ils s'accompagnent de déplacements de terre importants. Les points hauts graveleux sont tronqués et viennent combler les zones basses. L'aplanissement du relief, déjà commencé par les phases antérieures de remplissages, se poursuit activement. Il est quasiment achevé à l'époque romaine. Aucune morphogénèse active n'est repérable dans les périodes suivantes jusqu'à la surface régularisée que nous connaissons actuellement. 


\section{6- Pierrelatte L'Espitalet (fouille V. Savino)}

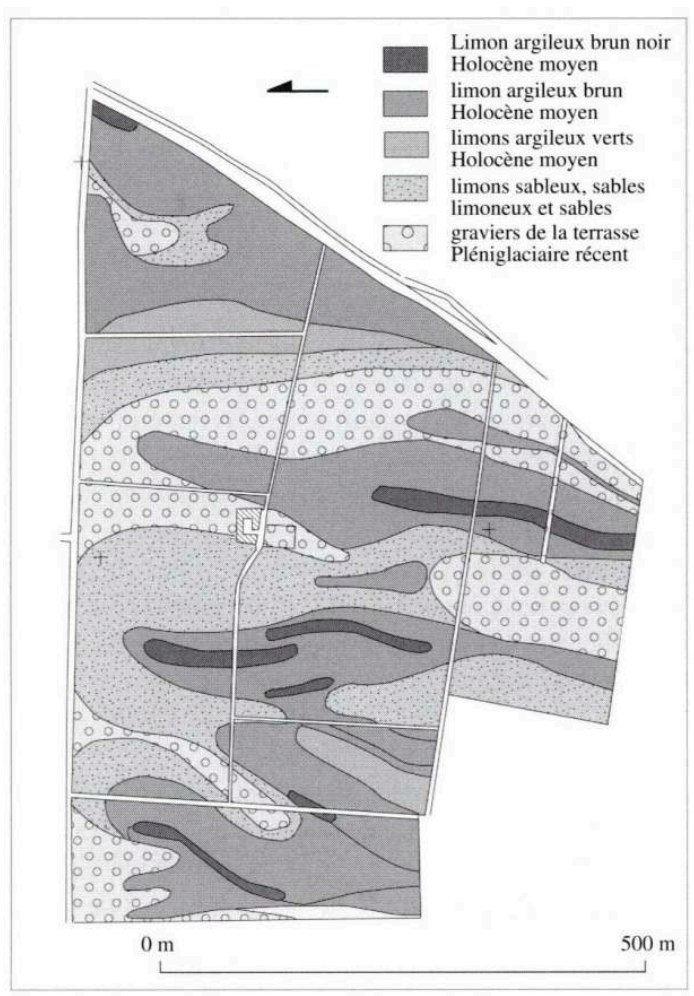

STRUCTURE gÉOMORPHOLOgIQUE DU SITE D'APRÈS LA CARTOgRAPHIE DES AFFLEUREMENTS SÉDIMENTAIRES À 60 CM DE PROFONDEUR

Dessin Brochier et Jung

8 Cette première approche du site, qui est restée insuffisante, nous permet d'avoir une vue globale de la structure taphonomique de l'ensemble sédimentaire ayant assuré la conservation des traces d'occupations néo à protohistoriques. Elle dépend entièrement de la structure géomorphologique en gouttières subparallèles allongées nord - sud. La «couche» s'épaissit et se trouve plus profondément enfouie dans l'axe des paléochenaux et s'amincit progressivement en s'en écartant (fig. 7a, 7b). Elle devient totalement érodée sur les interfluves graveleux où réapparaissent les graviers de la terrasse. Les vestiges sont conservés seulement dans les zones déprimées et concernent 18 ha 67 sur les 30 ha. Il n'existe, ou plutôt les tranchées n'ont mis au jour, que peu de fosses sur ce site. Elles sont localisées sur les flancs. En restituant la cinquantaine de centimètres, au moins, tronquée sur les buttes interfluves, le paléorelief connu par les hommes de la Préhistoire récente présentait des dénivelés de l'ordre de 1 à $2 \mathrm{~m}$ entre les points les plus hauts et les plus bas (fig. $\mathbf{8 b}$ ). 


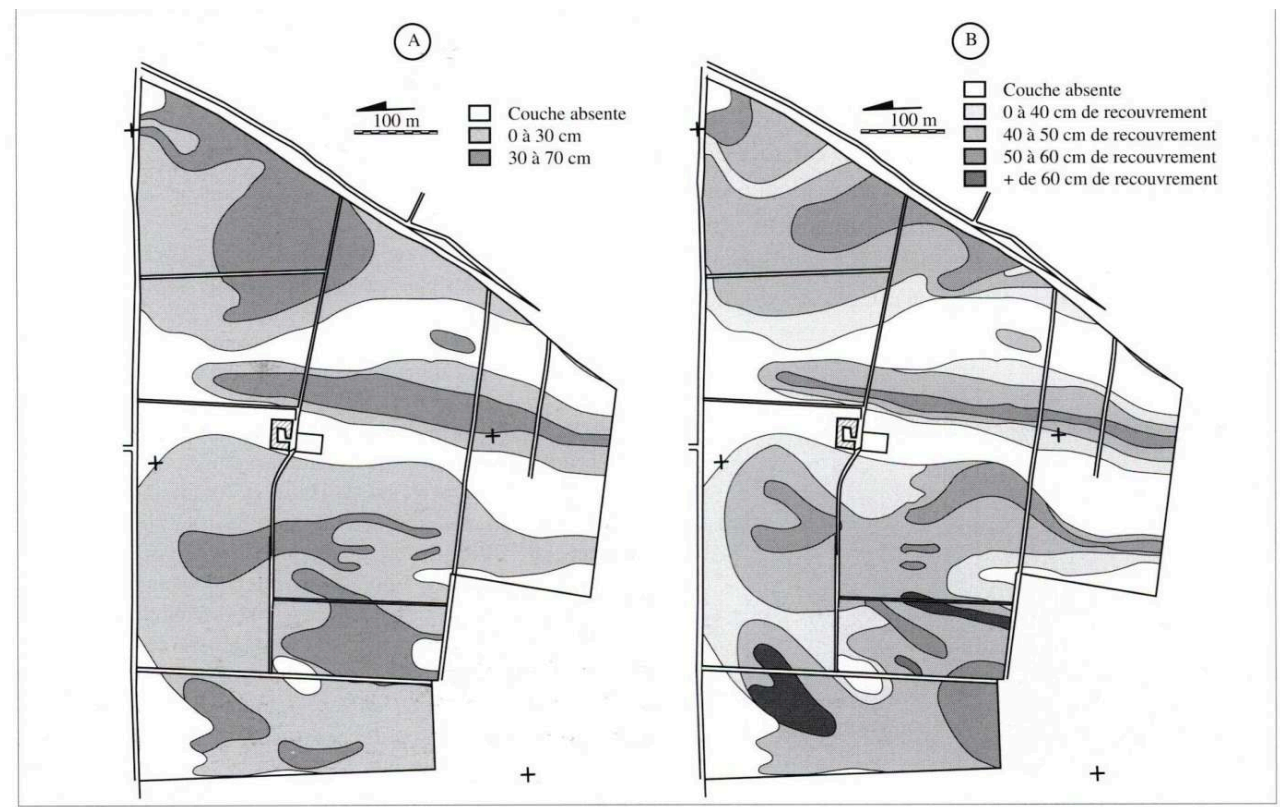

A) TAPHONOMIE DE L'ENSEMBLE SÉdIMENTAIRE NÉOLITHIQUE-PROTOHISTORIQUE. EPAISSEUR DE LA COUCHE.

B) TAPHONOMIE DE L'ENSEMBLE SÉdIMENTAIRE NÉOLITHIQUE-PROTOHISTORIQUE. PROFONDEUR D'ENFOUISSEMENT DE LA COUCHE

8a- Montélimar Gournier, 8b - Pierrelatte L'Espitalet

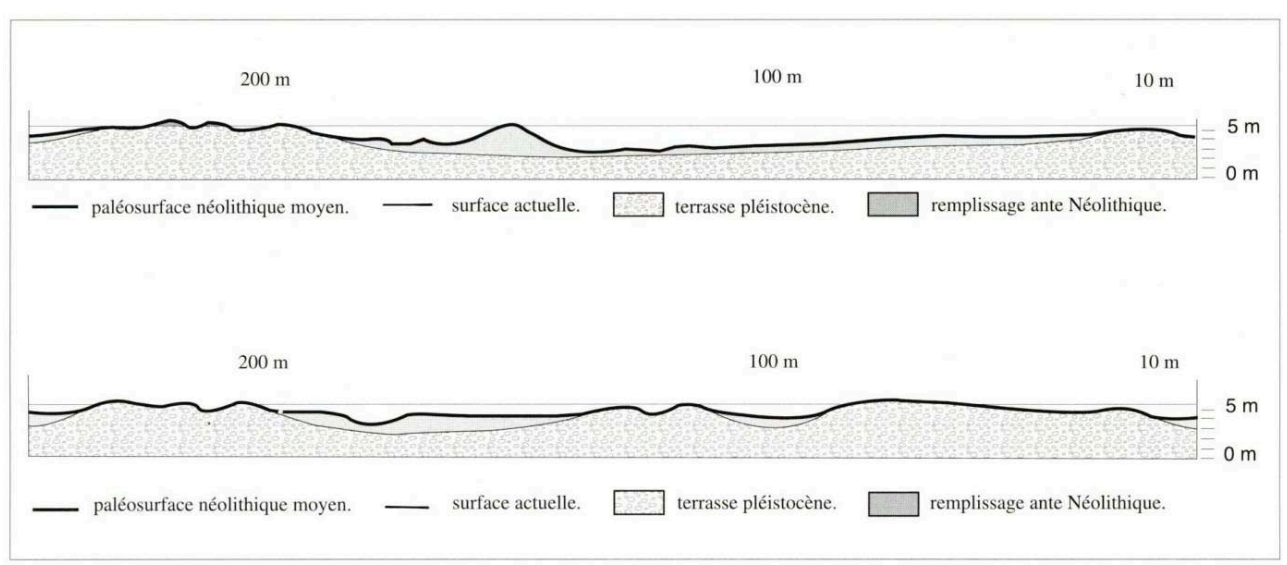

8.a- PALÉosurface topographIQUE EXISTANT AU NÉOLITHIQUE MOYEN. D'APRÈs LA TRANCHÉE DB, SUD DU SITE.

8.b- PALÉOSURFACE TOPOgRAPHIQUE EXISTANT AU NÉOLITHIQUE MOYEN. D'APRÈS TR2, TR3, SUD DU SITE (DESSIN BROCHIER ET JUNg).

\section{Importance des dynamiques sédimentaires, sur les terrasses du} Rhône et de ses affluents

Sur les terrasses pleistocenes

9 Les structures géomorphologiques en gouttières, décrites sur les deux sites de Montélimar Gournier et Pierrelatte L'Espitalet, gèrent l'enregistrement sédimentaire postglaciaire à la surface des terrasses rhodaniennes actuellement planes. Elles sont des 
formes relativement discrètes du paléorelief, tout en étant essentielles dans la conservation des sites préhistoriques. Elles ont été repérées en d'autres endroits des terrasses rhodaniennes : sur la terrasse mindélienne du plateau de Lautagne à Valence (fouilles A. Allimant), sur la terrasse wiirmienne recouverte du cône détritique de la rivière Drôme (Mandier 1988). Seuls quelques silex épars ont été découverts à Lautagne. Dans le haut bassin diois de la Drôme, sur une terrasse d'un de ses affluents, le Bez, les sondages, et les missions aériennes du Centre d'Archéologie Préhistorique de Valence ont montré que tout ce qui restait conservé du site néolithique de Menglon Terres Blanches l'était au sein d'un paléoréseau hydrographique formé depuis les versants.

Récemment, les travaux archéologiques du TGV Méditerranée (coordination AFAN/ TGV), ont bénéficié, en premier lieu dans la phase de prospection, des acquis des programmes de recherches précédents (Montélimar Gournier). Ils ont montré la généralisation de cette taphonomie pour les sites de la Préhistoire récente, du Mésolithique à la Protohistoire. Le tracé s'étant écarté de la vallée au nord de Pierrelatte, la connaissance acquise concerne surtout les versants et les terrasses des affluents rhodaniens. Ces sites sont actuellement en cours d'étude; nous citerons l'existence de paléovallons ayant piégé des traces d'occupation sur terrasses fluviatiles : sur les loess de recouvrement de la terrasse rissienne de la Drôme, en rive gauche (Chabrillan Saint-Martin 2-3, fouilles Billaud Y., Rimbault S.; Chabrillan Brégaud, fouille Defaux F. ; Chabrillan les Plots, fouille Vermeulen C.), en rive droite, sur la basse terrasse pléistocène récente de la Drôme (Crest Bourbousson 3, fouille Bastard F.), sur les cônes pléistocènes des pieds du Vercors (Upie les Vignarets, fouille Lurol J.-M.; Chabeuil les Cachets, fouille Billaud Y.). Plus au sud, sur les terrasses du Roubion et Jabron (étude géoarchéologique Berger J.-F.) on trouve les sites de Montboucher Pancrace (fouille Vermeulen C.), Espeluche Lalo (fouille Beeching A., Bouquin T.). Non loin de Pierrelatte, et de nouveau sur les terrasses rhodaniennes, nous citerons encore : La Garde Adhémar Surel, Pierrelatte Les Malalones (fouilles Linossier M.).

11 Cette configuration géomorphologique, "en tôle ondulée", n'est donc pas exceptionnelle, les paléoreliefs vallonnés se développant également sur les versants. Elle trouve son origine, soit dans les morphologies de fin de cycle glacaire, soit dans les épisodes de creusements généralisés qui caractérisent le Tardiglaciaire (des lits sableux plus anciens peuvent être alors déblayés). Nous parlerons plutôt de paléovallons que de paléochenaux : la circulation d'eau y reste occasionnelle, les versants sont largement ouverts. La forme en chenaux la mieux marquée se trouve à Pierrelatte L'Espitalet, avec des remplissages alluvionnaires au Néolithique ancien. Les remplissages sont généralement de type colluvial à alluvio-colluvial. Ce paléorelief vallonné est encore bien présent au Mésolithique et au Néolithique (fig. 8). Si l'on restitue quelques décimètres de plus aux zones en relief, tronquées plus tardivement, on obtient des amplitudes entre les creux et les bosses, allant de $50 \mathrm{~cm}$ à 2-3 $\mathrm{m}$, plus rarement 3-4 $\mathrm{m}$. Les vallons sont larges de 100 à $200 \mathrm{~m}$; les pentes sur les flancs sont de l'ordre de 2 à 5 $\%$, plus rarement $8 \%$. A la fin de l'âge du Bronze ces amplitudes sont déjà sérieusement diminuées par les phases de comblement successives; elles n'atteignent plus que $50 \mathrm{~cm}$ à $1 \mathrm{~m}$. Le " gommage » de ce paléorelief sera totalement réalisé par l'agriculture active au cours de l'Antiquité et du Moyen Âge. Il faut penser que des buttes, non naturelles, élevées dans la Préhistoire récente, comme les tertres tumulaires aient également pu être arasés et ne soient plus visibles dans le paysage. 


\section{Les recouvrements dus aux cônes détritiques alluviaux} détritiques alluviaux de ses affluents, Drôme et Roubion, couvre des surfaces de 20 à 30 $\mathrm{km}^{2}$, sur des épaisseurs de 2 à $15 \mathrm{~m}$. La sédimentation y est essentiellement fine, limono-argileuse. Ces accumulations commencent dans l'Holocène ancien, autour de 9500 B.P. ; comprises dans un cadre systémique, elles sont une image du bassin versant amont au cours de l'Holocène (Brochier et al. 1991, 1994). Peu de moyens ont jusqu'à présent permis l'exploration archéologique de ces cônes. La tranchée du gazoduc, de Livron à La Voulte, en bordure du cône de la Drôme, a révélé, à $2 \mathrm{~m}$ de profondeur, une occupation quasi continue de la vallée du Rhône à la fin de l'âge du Bronze (Brochier et al. 1983 ; Brochier 1988).

\section{Les recouvrements sédimentaires au sud de Lapalud} (Mandier 1988), n'avait pas encore reçu de base chronostratigraphique précise. L'importance de l'accrétion dans ce secteur, pour des raisons qui sont encore discutées (réponse eustatique, verrou, détritisme) explique la dilatation des séquences pédosédintentaires et l'enfouissement généralisé de la trentaine de sites découverts lors des travaux du TGV Méditerranée (géoarchéologie Berger J. F.). Les phases d'alluvionnement, tant du Rhône que de ses affluents, sont multiples. Dans la plaine d'Orange les niveaux néolithiques sont envisagés à 5-6 $\mathrm{m}$ de profondeur, les niveaux gallo-romains sont situés en moyenne à $3 \mathrm{~m} 50$.

Un phasage précis et une mise en corrélation de toutes ces dynamiques seront établis lors de la synthèse en cours des travaux du TGV Méditerranée. Nous retiendrons pour l'instant que le Tardiglaciaire est plutôt une phase de creusements généralisés, que les accumulations sédimentaires et les remplissages de paléovallons commencent à l'Holocène ancien, qu'ils sont sujets au cours de l'Holocène à plusieurs phases de remblaiements et de vidanges. Alors que les alluvionnements perdurent jusqu'à la période moderne sur les cônes alluviaux détritiques et au sud de Lapalud, les paléotalwegs sont comblés et la plaine acquiert, excepté quelques incisions ponctuelles, son aspect "fondamentalement» plan au cours de l'Antiquité et du Moyen Âge. L'homme, par ses travaux agricoles joue un rôle majeur, dans cette phase finale d'aplanissement.

\section{Structure géomorphologique et taphonomie archéologique}

\section{À l'échelle des sites}

La prise en compte de l'ensemble des sites du Néolithique moyen, dans le cadre du programme en archéologie spatiale sur la moyenne vallée du Rhône (Beeching, Brochier et col. 1989, 1990) nous conduisait à stipuler que plusieurs niveaux de lecture archéologique dépendaient de l'état de fossilisation des sites, que nous avons alors nommé "taphonomie», en empruntant ce terme aux zoologues (Brochier 1991). Il s'agit donc de prendre en compte les conditions de mort du site, et les dynamiques sédimentaires de recouvrement ou/et d'érosion qui ont conduit à sa fossilisation, ainsi 
que toutes les transformations pédosédimentaires, post mortem, qui ont pu intervenir jusqu'à nos jours. La carte archéologique est directement tributaire de la taphonomie des sites. L'étude de leur répartition spatiale doit se faire au travers d'un filtre correcteur qui intègre ces dynamiques d'enregistrement sédimentaires (Brochier 1991, Beeching, Brochier 1991).

Dans le cas de la vallée du Rhône, les zones à fort recouvrement sédimentaire holocène, cônes détritiques alluviaux des rivières préalpines, ennoiement sédimentaire au sud de Pierrelatte Lapalud, rendent tout à fait improbable la découverte de sites de la Préhistoire récente, ou même antiques. Seuls des travaux exceptionnels permettent d'avoir accès à cette information.

Sur les terrasses pléistocènes non recouvertes durant l'Holocène, la préservation des sites est largement déterminée par la présence de paléoreliefs en gouttières. Seuls les sites à nombreuses structures, en fosses, ou fossés, creusés dans les graviers fluviatiles peuvent apparaître dans les travaux agricoles de surface. Alors que les buttes des interfluves sont décapées de leurs sols archéologiques, ces derniers seront à rechercher dans les zones en creux jusqu'à 1 à 3-4 $\mathrm{m}$ de profondeur (fig. 9). La structure stratigraphique est en pelure d'oignon, et à développement latéral. Ces sites laissent apparaître, à la surface de la plaine actuelle, une forte hétérochronie spatiale des formations sédimentaires (fig. 3 et 6 ). L'arasion agriculturale, du fait de la paléomorphologie, peut amener à l'affleurement les graviers et limons pléistocènes, holocènes ancien à récent, les couches archéologiques, du Mésolithique aux périodes historiques (fig. 4). Ce contexte sédimentaire, quand il a pu être compris, n'est finalement pas très compliqué, mais pas toujours facile à mettre en évidence. Il implique des investigations de terrain de grande envergure.

9- Coupe schématique présentant les diverses situations taphonomiques à la surface des terrasses fluviatiles rhodaniennes

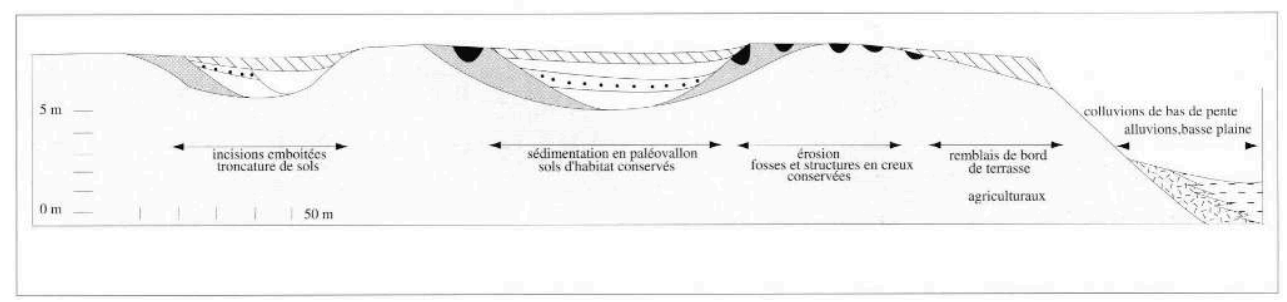

Dessin Brochier et Jung

La dimension des sites, du fait de l'ampleur de ces reconnaissances de terrain, a considérablement changé. Les surfaces marquées par l'occupation humaine sont de 100 ha à Montélimar Gournier, 30 ha minimum à Pierrelatte L'Espitalet en intégrant les interfluves érodés où les traces ne se sont pas conservées (100 ha par simple estimation et ramassages de surface autour du site). A la surface de ces terrasses, toutes les zones déprimées susceptibles de fossiliser des traces présentent des épandages plus ou moins denses, mais presque continus de fragments de tessons, de silex, de pierres (cette observation est surtout valable pour le Néolithique. La Protohistoire, aussi moins profondément enfouie, occupe des surfaces plus restreintes). De nouvelles questions se posent alors. Qu'est-ce qu'un site? Qu'elles en sont les limites, le statut? La question de l'existence possible d'amendements agricoles est également à éclaircir (étude en cours sur Pierrelatte L'Espitalet). Il est clair que les surfaces annoncées ne sont pas toutes 
occupées au même moment et que l'on a affaire à des superpositions d'occupations pas toujours aisées à distinguer même quand il s'agit de phases culturelles différentes. Au sein d'une même culture, il sera encore plus difficile de savoir si l'on est en présence d'un palimpseste de rapides passages successifs, ou d'une occupation plus pérenne. On rejoint là les questions relatives aux structurations intra-site et aux sols d'habitat.

\section{À l'échelle des sols d'habitat et structures intra-sites}

L'enregistrement sédimentaire des documents archéologiques mobiliers et immobiliers est directement fonction $\mathrm{du}$ contexte géomorphologique et des dynamiques sédimentaires en jeu. Ce contexte détermine trois zones de taphonomie différente (fig. 9,10):

1. Sur les points hauts, arasés, érodés, ne se retrouvent que les structures en creux, fosses et fossés, sans couche archéologique conservée. Le substrat de graviers ou de limons pléistocènes affleure en surface.

2. Dans le fond des paléovallons le piégeage des sédiments s'effectue au mieux, sous l'action de colluvionnements ou/et de ruissellements très diffus. La compétence reste faible; le matériel sédimentaire est fin, limono-argileux. Les pédogénèses et la présence de pédosédiments colluviés (sédiments déjà porteurs d'une pédogénèse antérieure) rendent la lecture stratigraphique difficile. C'est dans cette situation, où la vitesse de sédimentation est la plus rapide, que les niveaux archéologiques ont le plus de chance d'être distingués (fig. 10a). Les alluvionnements véritables sont rares. Le fond de certains vallons peut parfois être totalement déblayé.

3. Sur les versants, la sédimentation est réduite à nulle. Les fuseaux emboités de la structure en pelure d'oignon viennent pincer les uns sur les autres. Les différents niveaux d'occupation ne sont plus séparés que par des épaisseurs très faibles de sédiments, voire viennent même se superposer les uns sur les autres, constituant un palimpseste (11g. 10a). Une autre cause de superposition intempestive peut encore être due à une érosion en nappe, tronquant un niveau, créant un hiatus difficilement perceptible.

20 Cette variabilité spatiale de la vitesse de sédimentation gère la fossilisation de l'occupation humaine. Le rythme de sédimentation n'est jamais suffisamment rapide (alluvionnement saisonnier par exemple) et uniforme, pour que l'on puisse parler ici d'un sol d'habitat comme étant l'image intègre d'une occupation unique. Les sols, ou niveaux d'habitat individualisés à la fouille dans ces paléovallons sont marqués par des épandages plus denses de mobilier archéologique et par la présence de structures immobilières, empierrements, foyers, trous et calages de poteaux. Les termes de niveaux, ou sols, sont en fait des raccourcis qui cachent une réalité complexe. Les questions relatives à ces épandages se posent à deux niveaux.

21 D'une part, il s'agit de savoir si le mobilier a subi un déplacement. La dynamique de dépôt, colluviale à colluvio-alluviale, de faible compétence, ne permet pas un transport de tessons ou de pierres sur de longues distances (l'existence limitée dans l'espace et le temps de ruissellements forts n'étant pas exclue). Sur les pentes les plus fortes des versants qui ne dépassent guère 2 à $5 \%$ une partie du matériel a pu être déplacée vers le bas par colluvionnement (fig. 10e). Il faut néanmoins admettre que, dans le fond, du matériel est resté in situ, et a été recouvert par du matériel venu en dépôt secondaire. Il sera très difficile voire impossible d'en faire la distinction. Néanmoins, l'organisation d'origine peut, dans certains cas, rester perceptible. 
D'autre part il s'agit à la fouille de distinguer les différents niveaux, d'autant plus que de grandes surfaces doivent être fouillées, et que l'outil souvent utilisé est la pelle mécanique. Des brouillages sont dus à plusieurs situations taphonomiques :

- les nappes d'objets sont discontinues. Elles constituent des lentilles interstratifiées qu'il sera difficile de rattacher les unes aux autres (fig. 10b) ;

- la surface d'un sol d'habitat est rarement aussi plate qu'un décapage à la pelle mécanique. Il est quasiment impossible de suivre la topographie d'origine, des mélanges sont inévitables (fig. 10c) ;

- les niveaux interstratifiés, ne sont jamais totalement stériles; ils sont seulement moins denses, et brouillent l'individualisation des sols. Ce matériel peut provenir des phénomènes vertiques (mouvements de gonflements et rétractions des sols produisant des fentes) qui travaillent le sédiment (fig. 10d), ou encore des colluvions qui entraînent du matériel plus ancien arraché des versants ;

- des érosions en nappe peuvent tronquer des sols et conduire à des figures de discordance (fig. 10f) ;

- les sols vertiques ont un effet très destructeur à l'égard de ce qui pourrait rester conservé de murs en terre crue ou bois. Ils conduisent à une perception difficile des structures et de leur organisation.

10- Taphonomie des sols d'habitat et lecture archéologique de ces sols sur le terrain

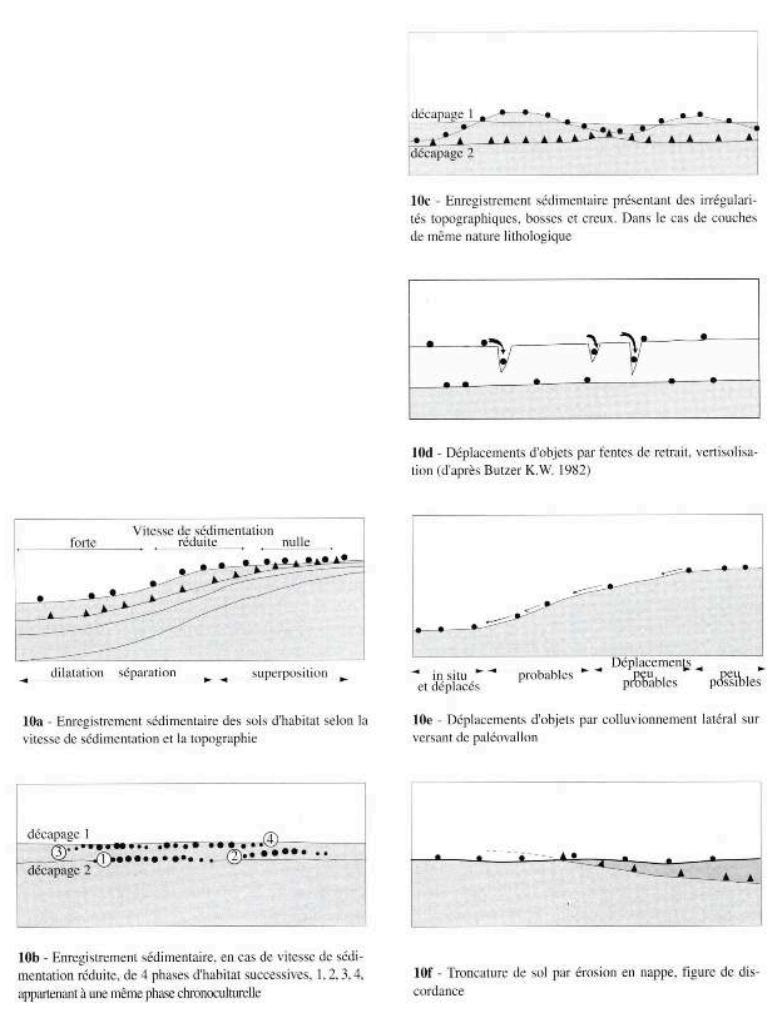

Dessin Brochier et Jung

Les terrasses alluviales ont donc fossilisé des "sols d'habitat». Les conditions de fossilisation sont loin d'y être les meilleures. De nombreux biais, qu'il s'agit de connaître, et reconnaître sur le terrain, sont apportés à l'information d'origine. Ces taphonomies en paléovallons sont trop souvent supposées être à l'origine de sites complètement détruits, en position secondaire, de ce fait discrédités et non fouillés. Or 
les fouilles montrent dans le fond de ces paléovallons des structures d'habitat in situ : trous et calages de poteaux (Montélimar Gournier, Chabrillan Les Plots), des empierrements, et foyers (Montélimar Gournier, Pierrelatte L'Espitalet, Chabrillan La Prairie, Chabrillan Les Plots). Des conditions très diverses peuvent coexister sur une même surface de décapage ; le mieux (recouvrement alluvio-colluvial de faible capacité de charge, sans déplacement des vestiges) peut voisiner avec le pire (alluvionnement ou colluvionnement fort avec transport). Le constat fait des problèmes liés à la conservation de ces sites, il convient également de constater, comme vient de le démontrer le long test du TGV en vallée du Rhône, que l'on ne trouvera pas de meilleure situation, les sites en taphonomie de limons d'inondation posent des problèmes équivalents. Le prétexte d'un état de conservation qui n'est pas excellent ne peut donc être retenu. L'éclairage de sujets essentiels de la Préhistoire récente passe par la fouille et l'étude de ces épandages : habitats étendus, sites centraux, successions rapides de passages de populations très mobiles, démographie, pastoralisme, amendements agricoles.

\section{Les ethnofaciès sédimentaires, les sédimentations anthropogènes}

Les fouilles en grands travaux, souvent conduites par grands décapages sur des surfaces qui peuvent aller de 1000 à plusieurs milliers de $\mathrm{m}^{2}$, mettent en évidence des vestiges mobiliers et immobiliers directement lisibles, relevés, et inventoriés. A côté de ces «structures évidentes " (LeroiGourhan 1972), il existe des traces beaucoup plus ténues de l'activité humaine. L'organisation du sédiment peut apparaître anormale (relatif alignement de ses éléments les plus grossiers par exemple), et sera notée comme anomalie sédimentaire (Vital, Voruz 1984). Nous proposons de prendre en compte l'ensemble de ces transformations du sol, même très minimes (variations de texture, plus ou moins argileuse, de couleur, etc), attribuables à l'homme et non à un agent naturel, sous le nom d'ethnofaciès sédimentaires (Brochier 1988, 1994). Un relevé exhaustif en sera réalisé, et la procédure suivante sera suivie pour leur étude :

\section{ETHNOFACIES SEDIMENTAIRES}

1 - Typologie des faciès sédimentaires Codage

Critères : texture, structure, couleur, composition La caractérisation doit pouvoir se faire à l'oeil nu, à la fouille

2 - Enregistrement spatial des faciès Cartographie

Sur calque appliqué aux relevés archéologiques

3 - Echantillonnage Analyses de laboratoire

Micromorphologie, sédimentologie, géochimie

4 - Première interprétation

Origine des faciès, hypothèses de travail

5 - Confrontation interdisciplinaire

Croisement des données venant de l'archéologie et de la géoarchéologie 
Cette stratégie a pu être mise en place sur la fouille du site de Montélimar Gournier. Notamment, une série de fossés, parallèles, peu profonds a été décrite (Beeching et al. sous presse, Berger 1991). Nous ne rentrerons pas dans le détail de ces structures qui restent encore d'une interprétation difficile. L'investigation archéologique sur le site de Pierrelatte L'Espitalet en est restée au stade de tranchées. L'urgence des fouilles de sauvetage n'est d'ailleurs pas le meilleur contexte pour cette stratégie de terrain. Selon les sites, le contexte pédosédimentaire fait que les ethnofaciès seront plus ou moins bien conservés. Phénomènes vertiques, bioturbation due aux vers de terre, colluvionnements, peuvent rendre ces derniers très difficilement lisibles.

Les constructions de terre et de bois de la Préhistoire récente ne laissent que peu de traces. L'exemple du site néolithique de Kovacevo, en Bulgarie (fouilles Démoulé J.P., Lichardus M.), démontre qu'en zone tempérée (à la différence des zones arides où il n'y a pas de vers de terre et de phénomènes vertiques) des maisons de terre crue bien constituées ne laissent dans le sol que des figures fossiles très difficiles à interpréter (Brochier 1994). Si l'on veut comprendre l'occupation humaine à travers les niveaux d'habitat précieusement piégés dans les paléovallons (lorsque les conditions taphonomiques l'autorisent), c'est une prise en compte de toutes ces traces ténues qu'il faut prendre en considération.

\section{Les relations géoarchéologie archéologie}

De la structure géomorphologique aux sols d'habitat, l'apport de la géoarchéologie est indispensable à la compréhension du contexte des documents archéologiques et à leur interprétation. La connaissance de ce contexte doit être un préalable à la fouille. Il faut qu'elle soit acquise auparavant, et que le géoarchéologue soit associé dès le début des travaux. Trop souvent encore, l'intervention n'a lieu qu'à un stade avancé de la fouille, et se résume à un échantillonnage rapide et partiel. On a pu dire que des sites, tels ceux évoqués plus haut, devaient être fouillés par des géoarchéologues. Les questions propre au terrain, et aux domaines des sciences de la terre sont suffisamment complexes, demandent du temps et un engagement, tout comme la fouille d'un niveau d'habitat requiert l'engagement et les compétences d'un archéologue. La solution est un va-etvient étroit entre l'archéologue et le géoarchéologue. Tout comme le géologue doit avoir conscience de ce qui se passe sur un terrain archéologique, l'archéologue de terrain, doit dans sa formation intégrer des connaissances issues des sciences de la terre. Le terrain ne doit pas être le domaine réservé du géoarchéologue. Les clés de compréhension résident autant dans un domaine que dans l'autre. La caractérisation géoarchéologique d'un site est nécessaire, mais restera insuffisante sans le regard de l'archéologue, comme dans le cas de l'opération non achevée de Pierrelatte L'Espitalet. La solution n'est pas non plus dans le tout analyse. Si la micromorphologie peut parfois préciser des apports colluviaux, ou alluviaux, la situation d'un « sol archéologique » ne sera jamais aussi claire que si le décapage met en évidence une certaine cohérence du matériel épandu, ou mieux des plans d'habitations, travail proprement archéologique.

Le terme de géoarchéologie tend à s'enraciner dans le sens de science ayant pour objectif essentiel de restituer les paléoenvironnements. Cet objectif reste important, car on ne fera pas une histoire de l'Homme sans faire l'histoire des paysages et des climats dans lesquels il a évolué. Nous avons plutôt voulu insister ici sur la place d'une lecture géoarchéologique d'un terrain archéologique, sur l'enregistrement 
sédimentaire du document archéologique (taphonomie), ou plus ponctuellement sur des structures anthropiques non évidentes (ethnofaciès sédimentaires). Dans ces derniers cas il y a imbrication totale entre géologie et archéologie. Dans le cas des restitutions paléoenvironnementales existe par contre une plus grande dualité. Le géoarchéologue, dans ce cas plutôt chronoécologue, utilise l'archéologie comme prestataire des données nécessaires à l'élaboration du cadre chronologique. Les vestiges humains ne sont alors considérés que comme des marqueurs biochronologiques. L'archéologue pourra utiliser les données environnementales dans ses discussions sur le paysage, les modes de vie, les relations de l'homme à l'environnement. Le rapport pourra se ressérrer dans le cadre de programmes orientés vers l'étude du territoire, de milieux aménagés, anthropisés. Il y a une géoarchéologie qui se pratique en dehors des sites d'habitat (Berger J.-F., ce volume). Dans l'approche des notions de territoire, de déforestations, d'agrosystèmes, on retrouvera des liens forts avec l'archéologie. Il s'agit là, comme dans le cas des études intra-site de formation de site et de taphonomie, de géoarchéologie au sens strict.

Depuis l'ouvrage, «la géologie de la Préhistoire» (Miskovsky J.C. dir. 1987), les méthodes de la géoarchéologie sont bien en place ; leur exploitation principale a été orientée vers l'élaboration d'un cadre chronoécologique et chronoclimatique du Quaternaire. Il reste encore beaucoup à faire dans ce domaine, en particulier pour la période holocène. Le cadre chronostratigraphique de l'histoire culturelle récente est à contruire. Mais la géoarchéologie doit aussi s'orienter de plus en plus vers la résolution de problèmes spécifiquement archéologiques. Sur des grandes fouilles, comme celles de Montélimar Gournier, Pierrelatte l'Espitalet, ou encore celles de l'opération TGV Méditerranée, on peut estimer qu'il y a une perte énorme d'informations de terrain parce que ni les archéologues, ni les géoarchéologues ne sont encore capables de l'enregistrer, de l'interpréter, de la lire. Des travaux ont lieu sur la formation des sites, la taphonomie (Goldberg et al. 1993, Berger, Brochier en préparation), sur les structures anthropiques intra-site (Courty et al. 1989, Wattez, Gé et al. 1993, Sordoillet ce volume), sur les ethnofaciès sédimentaires (Brochier 1991, 1994, Berger 1991); les travaux dans ce sens doivent se développer.

\section{Bibliographie}

Arnaud-Fasseta et Provansal 1993 : ARNAUD-FASSETA (G.) et PROVANSAL (M.) - Etude géomorphologique du delta du Rhône : évolution des milieux de sédimentation fluvatile au cours de l'Holocène récent, Méditerranée 3, 4, pp. 31-42.

Beeching 1991 : BEECHING (A.).-Sépultures, territoire et société dans le Chasséen méridional, l'exemple du bassin rhodanien. In : Colloque international de Nemours, Identité du Chasséen, mai 1989, Mémoire du Musée de Préhistoire d'Ile-de-France, 1991, 4, pp. 327-341. 
Beeching et Thomas 1975 : BEECHING (A.) et THOMASBEECHING (J.). - L'habitat chasséen de la Roberte à Chateauneuf-du-Rhône (Drôme). Etudes Préhistoriques, 1975, 12, pp. 23-32.

Beeching et Brochier 1989 : BEECHING (A.) et BROCHIER (J.-L.). - Archéologie spatiale entre Rhône et Alpes du Sud. L'exemple du Néolithique chasséen, Bull, du centre Genevois d'Anthropologie, $\mathrm{n}^{\circ}$ 2, 1989-90, pp. 57-70, 7 fig.

Beeching, Brochier et al. 1990 : BEECHING (A.), BROCHIER (J.-L.) et al. - Programme culture et milieu des premiers paysans de la moyenne vallée du Rhône après cinq années d'application. Entre choix stratégiques et réalités de la recherche. Xe Rencontres d'Archéologie et d'Histoire d'Antibes, Archéologie et espaces, octobre 1989, éd. APDCA, Juan-les-Pins, pp. 137-155.

Beeching, Brochier 1991 : BEECHING (A.), BROCHIER (J.-L.).-Quelle carte ? Carte de quoi ? Dossier carte archéologique, Les Nouvelles de l'Archéologie, n 45, éd. Errance, 1991, pp. 12-14.

Beeching et al. 1986 : BEECHING (A.), BROCHIER (J.-L. ) et MATTEUCCI (S.).-Espaces

archéologiques et géographiques dans l'analyse d'une culture préhistorique ; étude de la relation milieu-culture dans le Néolithique moyen de la moyenne vallée du Rhône. The Neolithic of Europe, Congrès international de Londres-Southampton, 1986, Préactes, 12 p. 1 fig.

Beeching et al. 1989 : BEECHING (A.), BROCHIER (J.-L.), MANDIER (P.), MATTEUCCI (S.) - La moyenne vallée du Rhône à l'Holocène : contexte morphodynamique, occupation et circulation humaines du Mésolithique à l'âge du Bronze. Actes du 112ème Congrès Nat. Soc. Sav., L'Homme et le fleuve. Lyon, 1987, CTHS, Paris, pp. 153-171.

Berger 1991 : BERGER (J.-F.).-Etudes géoarchéologiques sur le site de Montélimar-Gournier (Drôme). Mémoire de Maîtrise, Univ. de Paris 1, 1991, 1 vol.

Berger 1996 : BERGER (J.-F.). - Le cadre paléogéographique des occupations du bassin valdainais (Drôme) à l'Holocène. Thèse Archéologie et Environnement, Univ. de Paris I, 1996, 325 p.

Bornand 1972 : BORNAND (M.). - Etude pédologique de la moyenne Vallée du Rhône. Service d'Etude des Sols, $\mathrm{n}^{\circ}$ 152, INRA, 1972, 250 p., cartes.

Bornand et al. 1976 : BORNAND (M.), BOURDIER (F.), MANDIER (P.), MONTJUVENT (G.). - Les alluvions fluviatiles dans le bassin du Rhône. In : La Préhistoire Française, t.1, Paris, CNRS, 1976, pp. 89-94.

Bourdier 1962 : BOURDIER (F.). - Le bassin du Rhône au Quaternaire, géologie et préhistoire. Paris, CNRS, 3 vol., 363 p., 294 p., 297 fig.

Bravard 1986 : BRAVARD (J.-P). - Le Rhône du Léman à Lyon. La Manufacture, coll. L'Homme et la Nature, Lyon, 1986, 451 p., 122 fig.

Brochier 1988 : BROCHIER (J.-L.).-Les sédiments, documents archéologiques. Les Nouvelles de l'Archéologie, éd. Errance, 1988, n 31, pp. 15-17

Brochier 1991 : BROCHIER (J.-L.).-Environnement et culture : état de la question dans le Sud-Est de la France et principes d'étude autour du Chasséen de la moyenne Vallée du Rhône. Colloque international de Nemours, Identité du Chasséen, mai 1989, Mémoire du Musée de Préhistoire d'Ilede-France, 1991,4, pp. 315-326.

Brochier 1994 : BROCHIER (J.-L.).-Etude de la sédimentation anthropique. La statégie des ethnofaciès sédimentaires en milieu de constructions en terre. Site néolithique de Kovacevo (Bulgarie). Bull, de correspondance héllénique, 118, 1994, pp. 619-645. 
Brochier et al. 1991 : BROCHIER (J.-L.), MANDIER (P.), ARGANT (J.) - Le cône détritique de la Drôme : une contribution à la connaissance de l'Holocène du Sud-Est de la France. Quaternaire, 2, Paris, 1991, pp. 83-89.

Chapotat 1981 : CHAPOTAT (G.). - Vienne et sa région, plaque tournante de la Protohistoire du Rhône moyen. Nouvelles Archives du Museum d'Histoire Naturelle de Lyon, 1981, 19, pp. 21-28.

Courty et al. 1989 : COURTY (M.A.), GOLDBERG (P.), MACPHAIL (R.I.). - Soils and Micromorphology in Archaeology. Cambridge University Press, 1989, 344 p.

Goldberg et al. 1993 : GOLDBERG (P.), NASH (D.T.), PETRAGLIA (M.D.). - Formation Processes in Archaeological Context. Prehistory Press, Monographs on world archaeology n 17, 1993, 187 p.

Leroi-Gourhan, Brezillon, 1972 : LEROI-GOURHAN (A), BREZILLON (M.). - Fouilles de Pincevent. Essai d'analyse ethnographique d'un habitat magdalénien. VIIº supplément à Gallia Préhistoire, CNRS, Paris, 1972, 331 p.

Leveau et Provansal 1993 : LEVEAU (Ph.) et PROVANSAL (M.), dir. - Archéologie et environnement : de la Sainte Victoire aux Alpilles, ed. Univ. de Provence, Aix-enProvence, 1993.

Miskovsky 1987 : MISKOVSKY (J.C.) dir. - Géologie de la Préhistoire. Géopré, Paris, 1987, 1297 p.

Nicoud et al. 1989 : NICOUD (C.), THIEROT (F.), VITAL (J.). - Le site fluvial protohistorique des Barlières à Serrièresde-Briord (Ain). Actes du 112ème Congrès Nat. Soc. Sav., L'Homme et le fleuve, Lyon, 1987, CTHS, Paris, pp. 67-102.

Valette, Blanc 1955 : VALETTE (P.), BLANC (A.). - Quelques stations préhistoriques de la plaine de Valence. Cahiers rhodaniens, 1955, 2. pp. 3-6.

Vital, Voruz 1984 : VITAL (J.), VORUZ (J.L.).- L'habitat protohistorique de Bavois-en-Raillon (Vaud). Cahiers d'Archéologie Romande n² 28, Lausanne, 1984, 231 p.

\section{Documents}

Brochier et al. 1983 : BROCH1ER (J.-L.), BEECHING (A.), MATTEUCCI (S.). - Suivi archéologique des travaux du Gazoduc Allex-Livron-La Voulte par le Groupe Gazier Centre-Est. Rapport d'intervention de sauvetage, Centre d'Archéologie Préhistorique Valence, S.R.A. Rhône-Alpes, Lyon, 1983, 6 p., 10 fig.

Brochier et al. 1994 : BROCHIER (J.-L.), CLEMENT (P.), MANDIER (P.), ARGANT (J.), CHAIX (L.).-Le cône alluvial détritique du Roubion à Montélimar, à l'aval du bassin valdainais : un élément dans la restitution de l'espace. In : Beeching A., Brochier J.-L. : Archéologie spatiale en vallée du Rhône, le groupe néolithique et son territoire. Rapport final d'ATP Archéologie métropolitaine, multicop., Valence, 1994. pp. 44-50.

Savino 1995 : SAVINO (V.). - Emprunt de Pierrelatle-« Espialet-Nord », Drôme, TGV-Secteur II : AvignonValence. Rapport S.R.A. Rhône-Alpes, coordination AFAN TGV, Orange, 1995, 104 p. 


\title{
Géoarchéologie du Bassin Valdainais (Drôme)
}

\author{
Jean-François Berger
}

\section{NOTE DE L'AUTEUR}

Avec la collaboration de Thierry Odiot, Alain Beeching, Jacques-Léopold Brochier, Gérard Chouquer, Frédéric Magnin et Stéphanie Thiébault.

Je tiens à remercier l'ensemble des collègues impliqués dans les programmes collectifs sans lesquels ces études n'auraient pu aboutir. : l'ATP du CNRS du Centre d'Archéologie préhistorique de Valence: "Culture et milieux des premiers paysans en moyenne vallée du Rhône " (coordination A. Beeching et J.L. Brochier), le programme ARCHAEOMEDES (Understanding the Natural and Anthropogenic Causes of Soil Degradation and Desertification in the Mediterranean Basin) financé par le DG XII de la Commission européenne (coordination S. Van der Leeuw et $F$. Favory), l'opération de sauvetage archéologique sur le tracé du futur TGV Méditerranée, financée par la SNCF et coordonnée par T. Odiot, le programme H11 Rhône-Alpes: Occupation des sols de la conquête romaine au début du Moyen-Age en Tricastin coordonné par T. Odiot). Je n'oublierai pas L. Meignen qui a relu cet article, C. Jung avec qui je poursuis l'analyse des paysages antiques de la moyenne vallée du Rhône et le SRA Rhône-Alpes pour l'aide et les encouragements prodigués depuis le début de ces travaux.

1 Les recherches géoarchéologiques conduites dans le bassin valdainais (moyenne vallée du Rhône) apportent des résultats nouveaux sur les facteurs impliqués dans l'évolution des paysages holocènes. La démarche systémique mise en oeuvre permet une approche particulièrement fine des intéractions homme/milieu. Elle montre que la couverture pédologique a été constamment modifiée au cours des dix derniers millénaires par les processus d'érosion et de sédimentation et que la géodynamique a profondément affecté la conservation du patrimoine archéologique. Des corrections taphonomiques sont donc indispensables pour mener à bien une démarche en archéologie spatiale et en biogéographie. Quelques apports de la géoarchéologie à l'archéologie spatiale et à l'archéologie du paysage sont présentés dans le cadre de cet article. 


\section{Géoarchéologie, archéologie et paléoenvironnements}

\section{Définition et champs d'application de la géoarchéologie}

2 Pour mieux définir ce qu'est la géoarchéologie aujourd'hui, il est nécessaire de faire référence à l'école américaine qui, dans la lignée de K.W. Butzer (Butzer 1976 et 1982), a largement contribué à la publication de manuels de géoarchéologie et à la conceptualisation de cette discipline (Hassan 1978, Stein et Farrand 1985, Holliday 1985, Limbrey 1983, Waters 1992). «La géoarchéologie utilise les techniques et les approches de la géomorphologie (étude des origines et des formes du paysage), de la sédimentologie (étude des caractéristiques et de la formation des dépôts), de la pédologie (étude de la formation du sol et de sa morphologie), de la stratigraphie (étude des séquences, de la corrélation des sédiments et des sols) et de la géochronologie (étude du temps dans les séquences stratigraphiques)» (Waters 1992). On peut ajouter à ce tour d'horizon disciplinaire une véritable utilisation des sources archéologiques et une contribution importante aux modèles d'archéologie spatiale.

La géoarchéologie peut apparaître comme une discipline généraliste des Sciences de la terre, qui coordonne les études paléoenvironnementales sur une fouille archéologique ou dans des programmes de reconstitution des paléomilieux à l'écart des lieux d'occupation. Elle prend part aux réflexions et aux études sur les dynamiques de formation (formation processes) et d'évolution des sites archéologiques (taphonomie). Cette étude peut être localisée, à l'échelle du site, ou régionalisée à l'échelle d'un territoire d'étude (bassin-versant, lit majeur d'un cours d'eau, plateau...). Dans une démarche paléoécologique, l'interstratification de sites, de structures agraires ou de simples vestiges épars de la culture matérielle dans les séquences pédosédimentaires se révèle d'un grand intérêt puisqu'elle permet d'affiner le cadre géochronologique (fig. 1). Les vestiges de la culture matérielle peuvent être alors considérés comme des marqueurs biochronologiques précis (souvent plus précis qu'une date radiocarbone à deux sigmas). Les avancées récentes de la chronotypologie pour les périodes protohistoriques et antiques permettent souvent de raisonner à l'échelle du siècle, et dans le meilleur des cas à celle du demi-ou du quart de siècle (Lattara 6, Vital 1990). Ce constat lie fortement les études géoarchéologiques aux programmes en archéologie, car il est impératif de posséder une résolution chronologique aussi fine que possible lorsqu'on traite à la fois de l'intéraction entre l'homme et le milieu et de l'histoire du climat. 
1- Principes de corrélation et méthodes de datation des formations pédosédimentaires de la moyenne vallée du Rhône

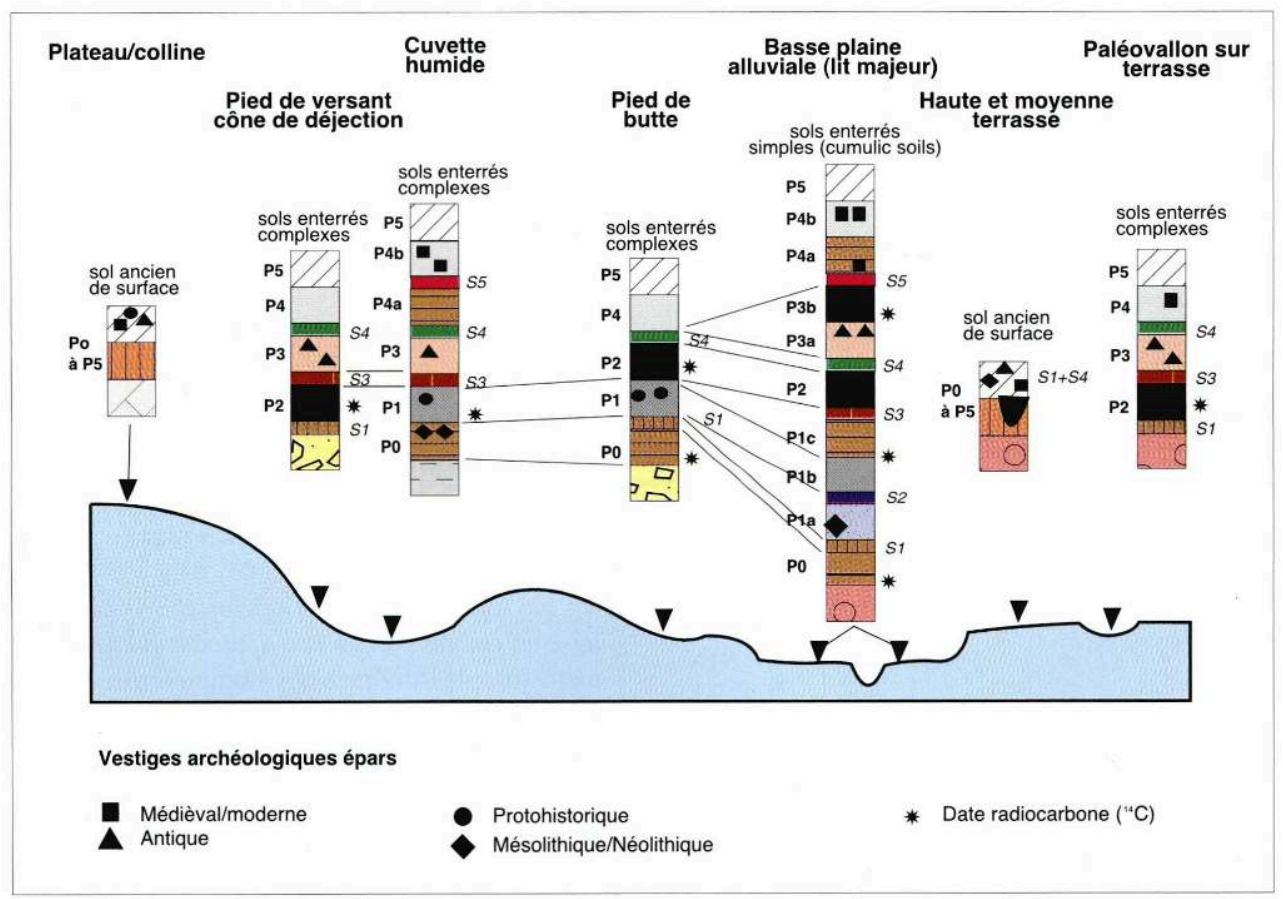

L'Âge DES UNITÉS PÉdologiques (PO À P5) EST ÉTABLI PAR RAPPORT AUX NIVEAUX ARCHÉologiques INTERSTRATIfiÉS DANS LES SÉQUENCES (DATATION LA PLUS PRÉCISE), ICI DE S1 À S5, PAR DES NAPPES D'OBJETS OU DES VESTIgES ISOLÉS OBSERVÉS DANS LES SÉqUENCES (DATATION RELATIVE À IMPRÉCISE, OU EN DERNIER RESSORT PAR DES DATATIONS ${ }^{14} \mathrm{C}$ OBTENUS APRÈS ÉCHANTILLONNAgE DE MATÉRIAUX ORgANIQUES PRÉSENTS DANS LE SÉDIMENT.

Les études géoarchéologiques sont aujourd'hui divisées en deux pratiques.

- Celle qui s'applique sur les sites archéologiques (géoarchéologie intra-site ou in-site analysis). Elle développe en étroite collaboration avec l'archéologue de terrain, sur la base d'analyses micromorphologiques, des problématiques relatives :

• ○ à la formation du site (Goldberg 1979, Butzer 1982, Rosen 1986, Courty et al. 1989, Gé et al. 1993, Sordoillet dans ce volume),

- au remplissage des structures en creux (fosses, fossés, foyers, Courty et Fedoroff 1982, Courty 1983, Macphail 1983),

- à la caractérisation de matériaux de construction,

- ou à la variation planimétrique des faciès sédimentaires générés par les activités humaines dans les habitats de plein air ou les grottes (ethnofaciès sédimentaires, Brochier 1983, Macphail 1983, Brochier 1991, Brochier J.-L 1994, Brochier 1994, Wattez et al. 1989, Courty et al. 1989).

- Celle qui s'applique en marge du site et/ou hors-site - à l'écart des lieux d'occupation (offsite analysis). Elle considère l'évolution des paysages entre des sites d'occupation contemporains. Cette dernière approche est plus tournée vers les paléoenvironnements et les paléoclimats. Ses supports sont des séquences alluviales, lacustropalustres ou colluviales. Elle prend ancrage parfois sur les lieux même des occupations (en considérant un avant et un après), dans le but d'obtenir un contexte chronologique performant, mais aussi et majoritairement dans les voisinages plus ou moins lointains des occupations, sur les lieux même de l'exploitation humaine ou simplement des terres de parcours (Bell 1983, Brochier 1991, Bravard et al. 1990, Magny 1993, Courty 1994, Berger 1996a). Cette approche se focalise 
parfois sur d'anciennes structures ou d'anciennes traces agraires qui peuvent se révéler fort ténues (Poupet 1994, Boissinot 1995, Berger et Jung 1996). Les processus d'anthropisation des paysages, les phases de recolonisation végétale synchrones d'une déprise humaine, les mutations agro-pastorales sont particulièrement recherchées dans le remplissage des structures agraires ou au sein des paléosols mis en culture. Les principaux interlocuteurs

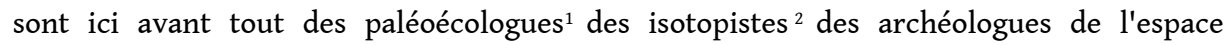
(archéologie spatiale) ou des photointerprètes. La mise en évidence de pratiques culturales ne repose plus uniquement sur la présence de meules à céréales, de faucilles, de lamelles de silex lustrées ou de silos. Les pôles terminaux du processus agropastoral sont complétés par une approche interdisciplinaire sur les lieux même de la production, dans le champ ou le pré.

\section{Concepts dans l'approche des paléomilieux}

5 L'Holocène, et surtout la période qui s'étend depuis le Néolithique, est caractérisé par la complexité des interrelations entre potentiel écologique (évolution des formes du relief, des sols, des cours d'eau, du climat), potentiel biologique (évolution de la végétation et de la faune) et actions anthropiques (pratiques agropastorales principalement). Ces rapports conditionnent les transformations paysagères qui s'opèrent de façon progressive ou brutale (théorie de la catastrophe). Il est communément admis que l'impact des activités humaines sur le milieu se fait sentir à partir du Néolithique, bien que certains auteurs conçoivent cet événement comme encore plus précoce, dès les périodes mésolithiques (Simmons et Innés 1987) ou au contraire ne l'imaginent pas véritable avant la fin de l'Age du Bronze ou la période romaine (Leveau 1993). Dès que la sphère sociale est intégrée dans le fonctionnement des paysages biophysiques, le concept d'agrosystème est sous-entendu. L'homme et ses activités sont alors introduits en tant qu'élément perturbateur dans le fonctionnement des écosystèmes.

6 Après une première longue période au cours de laquelle l'effort a porté sur la description des paysages anciens, la recherche s'est focalisée sur la compréhension de leur fonctionnement ainsi que sur la discrimination du rôle respectif des facteurs impliqués dans leur évolution. Les démarches en paléogéographie et en paléoécologie se sont alors voulues processuelles. C'est pourquoi les concepts et la nomenclature de la géographie et de l'écologie ont progressivement été introduits dans l'univers des paléoenvironnements. Les termes de géosystèmes, d'écosystèmes ou d'agrosystèmes (Bertrand 1975, Blandin et Lamotte 1988, Amoros et al. 1988, Brochier 1991) se révélèrent mieux adaptés à l'étude des paléomilieux car ils introduisent la notion d'espace et celle d'interactivité entre les différentes composantes d'une même entité géographique (paléobiogéographie, théorie des systèmes). La notion de site de référence se retrouve alors dépassée car elle apparaît trop restrictive compte tenu de la variabilité des enregistrements pédosédimentaires en milieu continental. 


\section{Démarche et méthodes}

\section{L'analyse systémique et les différents niveaux d'observation en paléogéographie}

7 L'étude de l'impact des facteurs socio-économiques et/ou climatiques sur l'évolution de l'environnement (modification du modelé, de la couverture pédologique, du fonctionnement hydrologique et du type de couverture végétale) nécessite donc une approche interdisciplinaire et concertée en amont, sur une aire préalablement bien délimitée comme un bassin-versant. On touche ainsi à la notion d'approche systémique d'une micro-région. Une telle démarche, centrée sur les paysages anciens, s'appuie sur l'identification et la hiérarchisation de signatures produites par des processus élémentaires, identifiables dans la mémoire du sol (Fedoroff sous presse). Ces signatures sont en fait des réponses à une action ou une série d'actions s'exerçant sur un milieu plus ou moins marqué par l'anthropisation. Elles peuvent être décelées à l'échelle macroscopique ou microscopique. Leur contexte de fossilisation ou de dépôt détermine la qualité de l'information (Berger 1996). Cette démarche est issue des méthodes de la paléogéographie traditionnelle (Boulin 1977). Elle a le plus souvent été employée sur de vastes secteurs géographiques, aux échelles des temps géologiques (très long terme). Les écologues et les géographes ont développé des démarches systémiques à de petites échelles paysagères, telles un bassin versant de rang inférieur ou un versant collinéen (Amoros et al. 1988), sur de courts laps de temps de l'ordre de la décennie ou du siècle (évolution à court terme). La période qui nous concerne est située entre les deux (moyen à long terme), elle est définissable à l'échelle du siècle ou du millénaire. L'objectif en paléogéographie est de traiter de la question des interactions complexes entre les différents compartiments des systèmes hiérarchisés afin de comprendre l'origine des signatures rencontrées. Elle est évaluable à différents pas de temps (selon la précision chronostratigraphique), (fig. 1) et à différentes échelles spatiales (selon la localisation de la séquence dans le géosystème, (fig. 2) ${ }^{3}$

\section{Méthodes et stratégies en paléoenvironnement}

8 L'enregistrement des événements pédo-sédimentaires et climatiques holocènes est sous l'étroite dépendance des phénomènes sédimentaires, guidés par une combinaison de facteurs climatiques et anthropiques. Les travaux récents en géomorphologie ont montré la nécessité d'analyser les enregistrements sédimentaires et pédologiques de façon globale, c'est-à-dire comme un système et non pas seulement à partir d'une ou deux coupes dites de référence, non représentatives de la variabilité des faciès et de l'activité d'ensemble des géosystèmes considérés (Macaire 1990, Amoros et al. 1988). "Chaque site, caractérisé par ses propres conditions stationnelles, a sa façon propre d'enregistrer le milieu qui l'entoure, ou seulement une fraction de ce milieu » (Brochier 1991).

9 Ainsi, pour travailler à une restitution la plus juste possible des paysages et des climats anciens, en tenant compte du caractère lacunaire et imprécis des enregistrements paléoenvironnementaux et archéologiques, il s'avère nécessaire de mettre au point une stratégie de terrain permettant de recueillir ces données sur l'environnement et sur 
l'homme de manière systématique, dans un cadre géographique restreint (Beeching et Brochier 1990, Brochier 1991, Berger et al. sous presse 1).

Le travail que nous avons développé en moyenne vallée du Rhône repose sur les principes de la paléogéographie. Cette dernière se fonde sur la multiplication des observations dans l'espace. Traditionnellement appliquée à de très grandes échelles spatiales et temporelles, cette approche est effectuée à une micro-échelle, celle d'un bassin-versant de rang inférieur. L'utilisation d'une approche systémique et déterministe permet théoriquement de comprendre la signification d'une signature, en fonction de sa fréquence et de son intensité. Les différentes phases paléogéographiques sont déterminées dans un premier temps par une étude combinée des processus géomorphologiques et pédologiques.

La classification des faciès corrélés à l'échelle de la région d'étude s'effectue grâce :

- aux observations de terrain,

- à la construction d'une typologie des faciès pédosédimentaires effectuée à l'échelle microscopique,

- à la maîtrise du contexte chronostratigraphique, qui dépend de la précision typochronologique lorsque l'on travaille sur les sites archéologiques ou à proximité immédiate, et de la répétition des datations radiocarbones lorsque l'on se situe à l'écart des lieux d'occupation (hors-site).

Elle nécessite de plus la mise au point d'une stratégie d'échantillonnage interdisciplinaire adaptée (fig. 2).

\section{2 - Multiscalarité et multiplicité des approches en paléoégéographie et en paléoécologie}

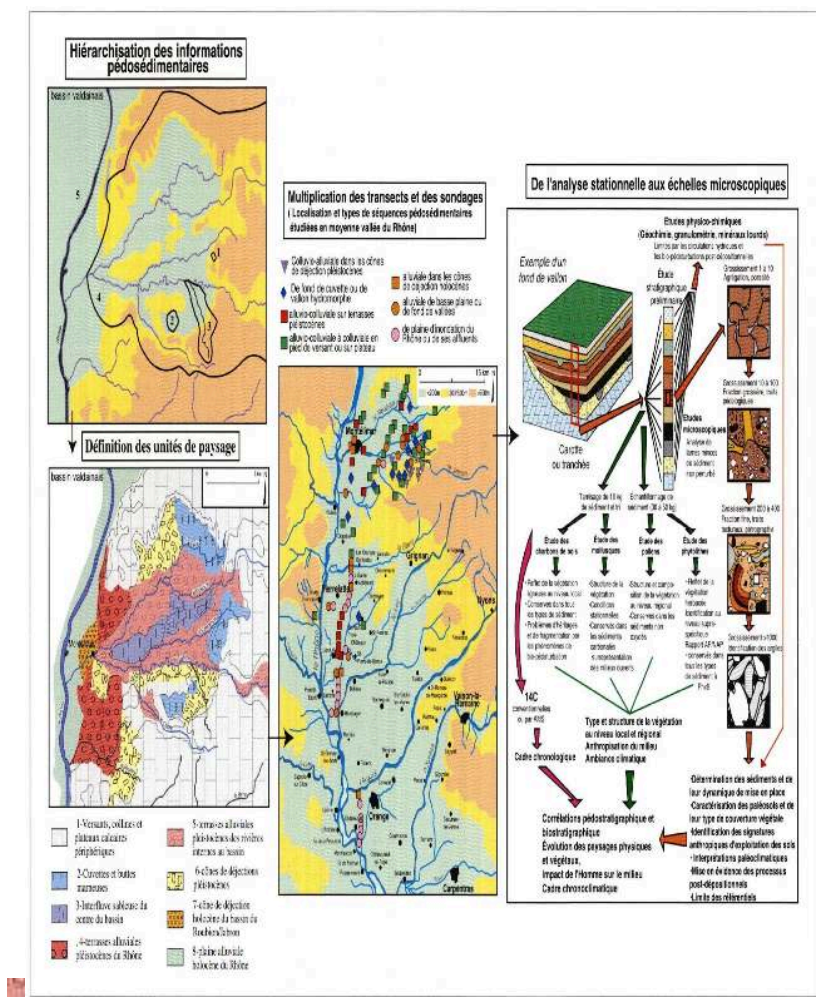

Niveaux d'observation, stratégies d'échantillonnage et analyses 


\section{Phasages de l'emprise et de la déprise humaine}

13 L'archéologie spatiale développe depuis une vingtaine d'années en France des prospections systématiques dans des micro-régions géographiquement homogènes. Cette pratique a pour objectif principal la reconstitution de la dynamique du peuplement humain au sein de l'espace géographique. Elle cherche à établir si toutes les unités de paysage d'une même région sont occupées au même moment, ou si des unités ou des positions particulières sont exploitées de manière préférentielle (choix culturels, contraintes historiques ou environnementales ?).

D'une manière générale, les données brutes de terrain sont peu discutées. Le problème de représentativité de l'échantillonnage n'est que rarement abordé de façon concrète même si les auteurs sont conscients des distorsions causées par l'évolution géomorphologique dans leurs cartes de répartition des sites archéologiques (Beeching et Brochier 1990).

Récemment, des études quantitatives en archéologie spatiale ont été tentées à partir d'un échantillonnage de surface pour analyser la dynamique du peuplement humain à l'époque romaine en moyenne et basse vallée du Rhône (Favory et al. 1995). Cette étude réalisée dans le cadre d'un programme européen fédérateur (ARCHAEOMEDES) a révélé de grandes fluctuations dans l'évolution du domaine rural, dont l'origine est à rechercher dans les dynamiques économique et historique.

16 À côté de ces approches, la matérialisation de l'emprise humaine sur le milieu est envisagée à partir :

- de multiples études sur les parcellaires anciens, grâce aux analyses en photo-et cartointerprétation (Chouquer 1983, Chouquer et Favory 1991) ;

- de fouilles de structures agraires dans le but de restituer la fonction des parcellaires et leur type de matérialisation au sol (Poupet 1994, Boissinot 1995, Berger et Jung 1996) ;

- de l'utilisation de sources épigraphiques comme les marbres du cadastre B d'Orange, qui nous renseignent sur les paléoréseaux hydrographiques, les axes parcellaires et la valeur des sols antiques (Piganiol 1962, Odiot 1994, Berger et al. sous presse 3);

- de la traduction des textes d'agronomes antiques (Pline, Columelle et Virgile) et de l'étude quantitative de leurs critères agrologiques (Favory et al. 1995, Berger et al. sous presse 3).

Ces nombreuses données complètent très utilement l'approche naturaliste. Elles nous renseignent sur l'organisation et le fonctionnement des agrosystèmes antiques et, à un degré moindre sur leur utilisation.

\section{Quelques applications géoarchéologiques et paléoécologiques au sud du bassin valdainais}

Deux axes complémentaires au sein d'un petit bassin versant ont été développés dans le cadre de cette étude :

- une prospection archéologique diachronique systématique suivie de fouilles ou de sondages sur des sites-tests pour reconstituer la fonction et l'organisation des implantations humaines dans l'espace (approche des systèmes économiques, techniques, sociaux) et estimer ainsi la charge potentielle de chaque phase culturelle sur le milieu ;

- une étude paléoenvironnementale interdisciplinaire à partir de multiples sondages géoarchéologiques « hors-sites », pour caractériser l'évolution des paysages dans le temps et 
dans l'espace. Elle intègre les recherches en géomorphologie, en pédologie, en anthracologie, en malacologie, en palynologie et sur les phytolithes.

\section{La micro-région étudiée}

La Valdaine appartient à la moyenne vallée du Rhône (fig. 3). Elle présente une forme de petit bassin de $300 \mathrm{~km}^{2}$ qui prend l'aspect d'un amphithéâtre dominé par des collines et des plateaux marno-gréseux et calcaires avec des dénivelés de 250 à $450 \mathrm{~m}$. Ce bassin s'ouvre à l'ouest sur la plaine du Rhône. La Valdaine est arrosée au nord par le Roubion et au sud par le Jabron qui confluent à Montélimar.

\section{3- Localisation du bassin valdainais et des principaux transects étudiés}

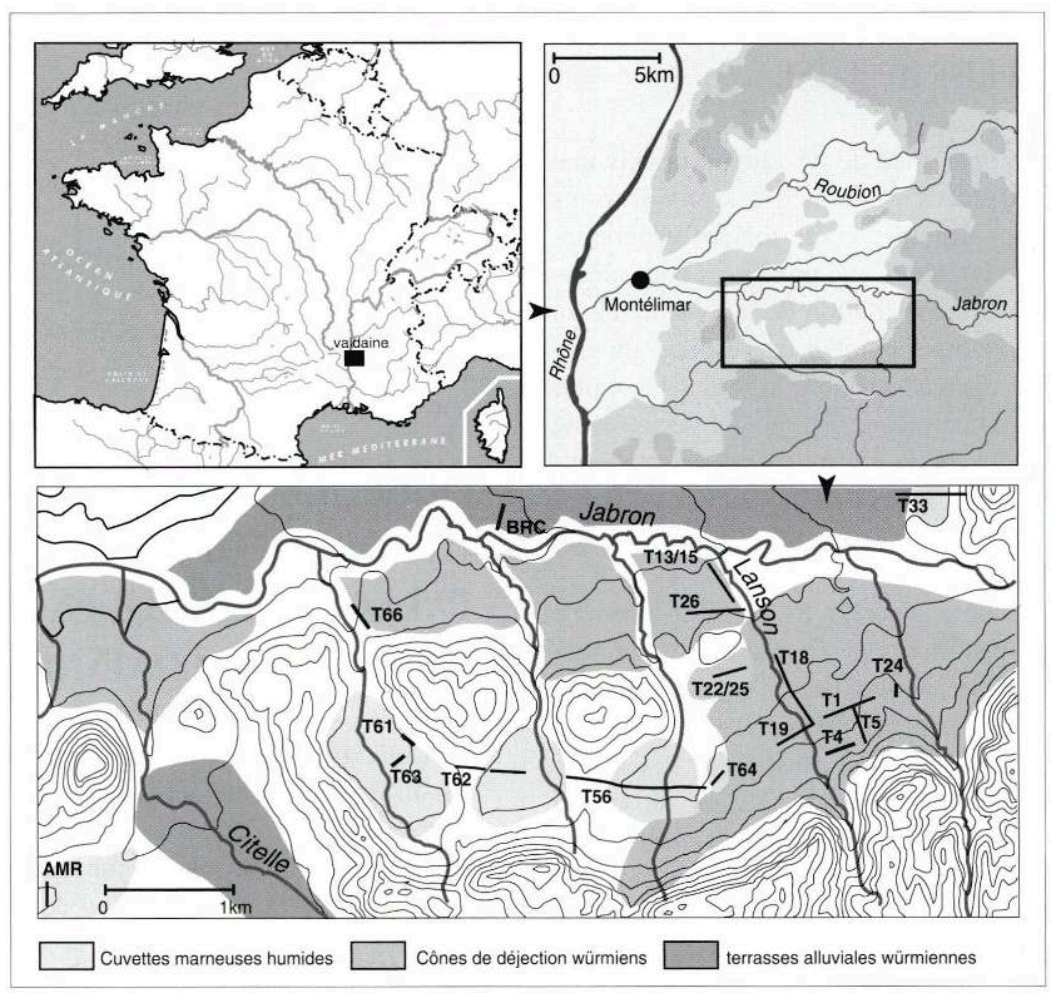

Ce bassin est subdivisé en huit unités de paysage sur la base de l'étude des composantes écologiques et humaines (lithologie, pédologie, morphologie, hydrologie, végétation et modes agropastoraux) et de leur dynamique (Berger 1996a). L'utilisation, l'évolution et le rôle de quatre d'entre elles seront discutés dans le cadre de cet article (fig. 3). Il s'agit des:

- cuvettes, vallons et buttes marneuses des piémonts collinéens,

- terrasses alluviales pléistocènes des rivières internes du bassin,

- cônes de déjection pléistocènes développés au pied des collines périphériques,

- plateaux et collines calcaires, gréseuses ou marneuses périphériques et leurs versants.

\section{Les types d'enregistrement disponibles}

21 Une centaine de séquences pédosédimentaires a été exploitée dans le bassin valdainais. L'étude de ces séquences nous a permis de corréler la répétition de certaines signatures morphopédologiques au cours de l'Holocène à travers l'ensemble du bassin (incisions, 
troncatures, progradations de la charge de fond grossière, colluvionnements ou pédogenèses) et de compléter les informations d'une coupe à l'autre lorsque des lacunes d'enregistrement étaient apparues, marquant des discontinuités flagrantes dans la perception de l'évolution environnementale holocène (Berger 1996).

Les deux tranchées présentées ici proviennent de levés stratigraphiques continus à travers des vallons et des cuvettes humides des piémonts du bassin valdainais (fig. 4). Leur étude révèle une morphogenèse très active à l'Holocène et une succession d'emboîtements dans l'axe des talwegs, sous l'effet de cycles d'incision/remblaiement. Les effets sur les paysages sont multiples, mais ils génèrent le plus souvent une importante sédimentation dans les points bas, dont l'origine est à rechercher dans l'ablation des sols dans les parties situées en amont. Ce phénomène provoque un empâtement des formes et un adoucissement de la topographie (nappes de bas de pente, comblement de paléovallons et de cuvettes). Le propos n'est pas ici de discuter l'origine de cette évolution continue des paysages de la moyenne vallée du Rhône au cours de l'Holocène (Brochier 1991, Brochier et al. 1991, Berger 1995 et 1996a et b), mais de montrer, par l'énoncé de quelques exemples, l'impact qu'elle peut avoir sur la pratique d'une archéologie spatiale axée sur la formulation de modèles de peuplement et sur la reconstitution des anciens biotopes exploités par l'homme. On rappellera simplement que la plupart des auteurs attribuent les causes de ces phénomènes à l'Homme mais aussi aux variations climatiques mineures enregistrées depuis la fin des temps glaciaires, à l'échelle de la planète. 
4 - Exemples de tranchées continues à travers des cuvettes, des vallons marneux et des cône de déjection pléistocènes
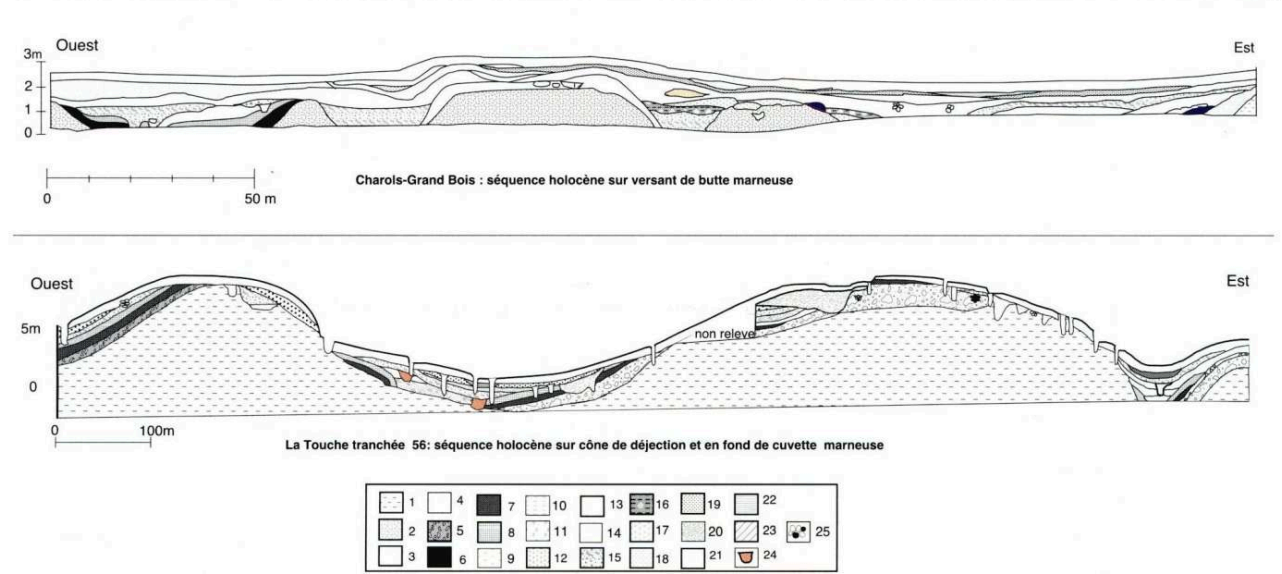

1 - MARNE APTIENNE gRISE, 2 - SOL BRUN CALCAIRE À RÉSEAU POLYgONAL TARDIgLACIAIRE SUR COLLUVION MARNO-gRÉSEUSE, 3 - SOL OU COLLUVION BRUN/VERT COMPACT, 4 - LENTILLES gRAVELEUSES RUISSELÉES TARDIgLACIAIRES INTERCALÉES DANS 3, 5 - SOL BRUN CALCAIRE À NODULES CARBONATÉS " STEPPIQUE » DU DÉBUT DE L'HOLOCÈNE ?, 6 - SOL BRUN-NOIR DÉCARBONATÉ À NOMBREUX PHYTOLITHES, HOLOCĖNE ANCIEN (7 400 À 7000 AV. J.-C), 7-SOL BRUN FONCÉ À BRUNNOIR " VERTIQUE " SUR COLLUVION DE SOL BRUN LESSIVÉ À NOMBREUX CHARBONS DE BOIS (NÉOLITIQUE MOYEN, PAR EXTENSION 5700 BP, EN COURS), 8 - SOL gRIS-JAUNE HYDROMORPHE DÉVELOPPÉ SUR COLLUVION DÉCARBONATÉE NÉOLITHIQUE MOYEN RÉCENT (3 700 À 3300 AV. J.-C.), 9 ET 10 - SOL PALUSTRE gRIS SOMBRE RICHE EN COQUILLES (NÉOLITHIQUE fINAL/CHALCOLITHIQUE ?), 11 - SOL BRUN CALCAIRE DE L'Âge dU BRONZE À NODULES CARBONATÉS, DÉVELOPPÉ SUR DES COLLUVIONS MIS EN PLACE AU COURS dU CHALCOLITHIQUE/BRONZE ANCIEN (2300 À 1900 AV. J.-C.), 12 - COUCHE D'OCCUPATION BRONZE FINAL, 13 - SOL HYDROMORPHE gRIS MOUCHETÉ DE ROUILLE DÉVELOPPÉ SUR DES COLLUVIONS dÉPOSÉES DURANT L'ÂgE dU FER (700/600 À 300 AV. J.-C.), 14 - SOL BRUN LA TÈNE/HAUT-EMPIRE ROMAIN, 15 - SOL CALCAIRE COLLUVIAL ROMAIN MIS EN PLACE AU MILIEU DE LA PÉRIOde ROMAINE, 16 - SOL BRUN de PRAIRIE HUMIDE (ANTIQUITÉ TARDIVE À HAUT MOYEN ÂgE) DÉVELOPPÉ SUR LES COLLUVIONS ROMAINES, 17 - PERTURBATIONS MÉdIÉVALES (XLLE S.), 18 ET 19 SOLS CALCAIRES COLLUVIAUX DÉVELOPPÉS SUR DES NAPPES COLLUVIALES SABLEUSES BASMÉdIÉVALES À MODERNES, 20 - ALLUVIONS gRAVELEUSES " TORRENTIELLES " MODERNES (XV-XIXE S.), 21 - HORIZONS AgRICOLES SUBRÉCENTS, 22 - COLLUVIONS LITÉES SUBRÉCENTES, 23 - HORIZON AgRicole ACTUEL, 24 - FOSSÉs de dRAINAgE dU hAUTEMPIRE ROMAIN (IER-IIE S.), 25 - DRAINS EN PIERRES MODERNES

\section{Une certaine utilisation des données géomorphologiques et pédologiques : la paléopédologie}

\section{Apport de la géoarchéologie à l'analyse du couvert pédologique Holocène}

\section{Constat préalable}

L'utilisation des cartes pédologiques actuelles à des fins paléogéographiques peut se révéler limitée sans une étude critique préalable, étant donné la variation de la couverture pédologique à l'Holocène. Malheureusement, dans la majorité des cas, la recherche des potentialités offertes par les paléomilieux s'effectue à partir de l'étude des caractères actuels de l'environnement, sans réflexion préalable sur l'évolution des paysages. Il s'agit donc de mettre en jeu les données de la géomorphologie, de la paléopédologie, de la phytosociologie et, à un moindre degré, des modèles 
d'exploitation agricole aux temps historiques (Borello 1982) pour tenter une plus juste restitution des paysages anciens. Cette démarche est bien souvent restée théorique et ne s'est que trop rarement appuyée sur de nécessaires études de terrain, à distance des lieux d'occupation. Aujourd'hui, les applications de la méthode dite "Site Catchment Analysis» (Higgs et Vita-Finzi 1972, Jarman 1972), qui cherche à établir les potentiels d'exploitation des sols dans un rayon donné autour des sites archéologiques, se fondent encore trop souvent sur les seuls caractères écologiques actuels (Dorioz In : Colardelle 1993, Coste et al. 1988), sans prendre en compte les profondes transformations qui ont inévitablement affecté les anciens écosystèmes.

\section{L'organisation de la couverture pédologique actuelle du bassin valdainais}

Les études paléogéographiques réalisées dans le bassin valdainais illustrent la fragilité d'interprétations reposant sur la documentation actuelle. Cette micro-région présente une grande diversité de sols liée à la variété des roches-mères, du relief et à son histoire polyphasée depuis le Pléistocène. La prédominance de roches marneuses et marnocalcaires, très sensibles à l'érosion, résulte des conditions paléogéographiques de l'ère secondaire. Les sols de la région valdainaise ont été abondamment étudiés, tant en ce qui concerne leur classification et leur distribution que leurs potentialités agricoles (Bornand 1967 et 1978). Dans le secteur présenté dans le cadre de cet article, les sols peuvent être regroupés en trois grandes catégories en fonction de critères topographiques, morphologiques et lithologiques d'une part, et de leur histoire au cours du Quaternaire récent d'autre part (cf. fig. 8).

1. Sur les terrasses pléistocènes des affluents préalpins du Rhône (ici le Jabron, la Citelle et à un degré moindre le Lanson), les sols rouges et bruns plus ou moins fortement lessivés sont les plus répandus (fersialsols et néoluvisols). Leur existence révèle une stabilité de ces unités au moins plurimillénaire. Des sols bruns calciques et bruns calcaires (calcosols) se regroupent surtout en rebord de terrasse. Leur présence est liée aux multiples troncatures alluviales qui ont marqué l'Holocène récent.

2. Dans les piémonts marneux et sur les cônes de déjection graveleux, les sols calcaires colluviaux (colluviosols), les sols bruns calcaires (calcosols) et les régosols d'érosion sont prédominants. Leur présence indique la forte instabilité des couvertures pédologiques dans ces unités de paysage. Très localement, des sols anciens, de type rouge faiblement lessivé (fersialsols), sont conservés. Ils marquent alors une certaine stabilité à l'échelle des temps holocènes.

3. Sur les versants périphériques, les collines et les plateaux calcaires, les lithosols, les rendzines grises et rouges décarbonatées (rendosols) dominent et révèlent le caractère résiduel des vieux sols.

Ce tour d'horizon des formations pédologiques montre que la majorité des sols du bassin valdainais sont jeunes, peu évolués, développés sur des formations sédimentaires subactuelles (colluvions et alluvions) ou sur des substrats géologiques récemment mis à nu. Seules les terrasses pléistocènes (mais de façon discontinue) et quelques glacis graveleux des piémonts présentent des sols anciens à l'échelle de la période holocène. Aucune indication chronologique n'est disponible pour la majorité de ces formations pédologiques, en dehors des repères chronostratigraphiques relatifs sur les terrasses quaternaires (Bornand et Icole 1984 et Mandier 1984). La carte des sols actuelle est donc peu adaptée à une utilisation paléopédologique (Site Catchment 
analysis) car plus des 3/4 de la surface pédologique du bassin ont varié au cours de l'Holocène sous l'impact des processus géomorphologiques.

\section{Modes de reconstitution des anciennes couvertures pédologiques}

L'analyse micromorphologique des différents types de sols reconnus dans le bassin valdainais permet d'identifier leur granulométrie, la pétrographie des fractions sableuses et limoneuses, leur état structural, leur complexe organo-minéral, l'état d'évolution de la matière organique et des charbons, l'activité de la faune du sol, la porosité, leur drainage et donc d'estimer leur aptitude à l'agriculture (fig. 5). Les quantifications sont par contre aléatoires. La géochimie pourrait apporter d'utiles compléments à l'étude de la valeur agrologique des sols fossiles. Elle est cependant limitée par les phénomènes de circulation hydrique dans les sols, postérieurement à leur enfouissement. Le $\mathrm{pH}$, la CEC (capacité d'échange cationique), la solution du sol, le calcaire libre et les principaux oligo-éléments peuvent être considérablement modifiés compte tenu des variations du fonctionnement hydrique des sols. Leur dosage se révélé donc délicat. Des analyses sur la teneur en phosphates, en matière organique total qui se minéralisent rapidement sous des formes identifiables sont plus fiables. Elles peuvent révéler la pratique de l'amendement.

5- Photographies des sols de la Valdaine aux échelles microscopiques

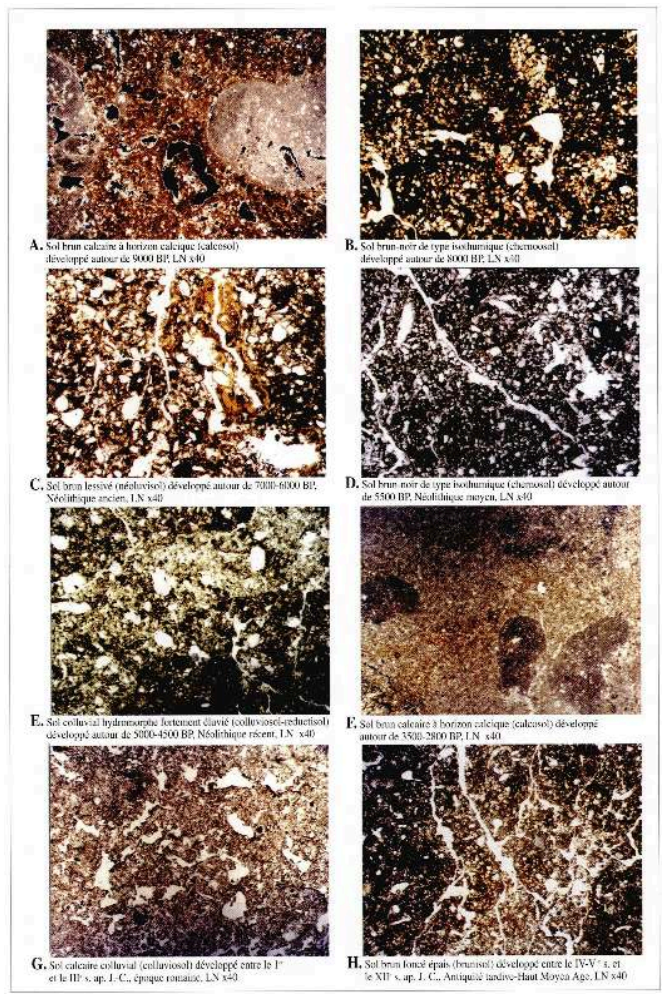

27 L'étude de nombreuses tranchées pédosédimentaires a montré que l'évolution géomorphologique a provoqué de profonds changements dans les paysages holocènes (cf. infra) (fig. 4). On peut ajouter que les caractères du climat, de la végétation et de l'anthropisation ont également varié au cours des dix derniers millénaires. Ces paramètres, en modifiant les processus pédologiques, transforment les caractères et les 
propriétés des sols anciens. L'approche en géoarchéologie spatiale démontre la complexité de l'extrapolation des sols actuels aux sols anciens. En Valdaine, les documents pédologiques actuels (fig. 7,8 ) apparaissent ainsi particulièrement inadaptés pour une étude historique de la valeur des terres.

\section{Élaboration de cartes pédologiques anciennes et discussion sur l'évolution des potentiels agrologiques}

Le principe de cartographie paléopédologique est identique à celui utilisé par les pédologues ou agronomes actuels. Il repose sur :

- une pratique de sondages multiples,

- une description détaillée sur le terrain,

- une analyse des composants et des traits pédologiques de chaque paléosol aux échelles microscopiques,

- une comparaison entre les différents types de sols reconnus (typologie des faciès pédologiques),

- un regroupement et une cartographie par unités de sol identiques.

La multiplication des observations dans la majorité des unités de paysage du bassin valdainais et leur calage chronologique au demi-millénaire, voire au siècle près, permet in fine de proposer une restitution de cartes paléopédologiques. Elles illustrent à la fois de profondes et constantes transformations dans les secteurs les plus sensibles aux phénomènes géomorphologiques et une certaine permanence des ambiances pédologiques dans les secteurs les moins sensibles, comme les moyennes et hautes terrasses quaternaires et certains glacis des piémonts collinéens (fig. 7).

Cette modification des types de sols a sans doute influencé les modes de mise en valeur des sols depuis la période néolithique. En effet, à des milieux diversifiés correspondent des possibilités de culture ou d'élevage fort différentes.

Certaines périodes ont été marquées par une homogénéité de la couverture pédologique (fig. 7), (Néolithique ancien, moyen). On observe ainsi la prédominance des sols bruns lessivés au cours du Néolithique ancien dans les unités marneuses et sur les cônes de déjection pléistocènes de la Valdaine. Ces sols argileux, décarbonatés, assez épais, ne sont pourtant pas très favorables à une mise en culture car les processus d'éluviation qui les ont marqués, ont provoqué une détérioration de leur stabilité structurale. Au cours de la majeure partie du Néolithique moyen, des sols brunnoirs de type isohumique ont remplacé les sols lessivés (fig. 5, 6 et 7). Très riches en matière organique et en particules charbonneuses, ils présentent une structure développée, une bonne épaisseur $(>50 \mathrm{~cm})$ et donc une bonne aptitude agrologique. Leur exploitation est, semble-t-il, uniquement pastorale (prairies permanentes?). Les indices micromorphologiques (porosité, microstructure, taux de phytolithes de graminées, formes des microcharbons...) et ponctuellement malacologiques, attestent une couverture herbacée durable (steppe). C'est d'ailleurs la permanence d'un couvert herbacé, parcouru par des feux de prairie récurrents, qui a favorisé la formation de ces types de sols aux caractéristiques proches des sols noirs d'Europe de l'Est ou d'Ukraine (chernozem et smolitsa). Le rôle du climat (continentalisation) ne peut être écarté dans le développement et l'extension de ces sols à l'ensemble de la moyenne vallée du Rhône et peut-être aussi à la Provence (Berger 1996a). Ces premières observations pédologiques sont en phase avec les indices archéologiques et sitologiques d'une société chasséenne 
tournée vers une économie pastorale (Beeching et Brochier 1990, Brochieret Beeching 1994).

$\mathrm{Au}$ cours de certaines périodes, l'importante remontée du niveau des nappes phréatiques dans les cuvettes des piémonts, en relation avec des fluctuations hydroclimatiques, a fortement marqué la dynamique de la pédogenèse. Des sols hydromorphes ou vertiques (pseudo-gleys, topovertisols) se substituent aux sols précédents qui présentaient un bon drainage jusque dans le fond des reliefs. Cette détérioration des conditions de drainage naturel favorise le développement de végétations palustres ou de prairies humides (Magnin, dans Berger 1996a). L'effondrement de la structure, la fermeture de la porosité des sols et la quasipermanence d'une nappe d'eau en fond de cuvette n'a pu que compliquer la mise en valeur de ces secteurs au cours des périodes qui ne connaissaient pas encore le drainage. Cette situation s'est répétée de manière cyclique au cours de l'Holocène moyen et récent. Elle a marqué les cultures du Néolithique récent, de la plus grande partie de l'âge du Fer et de l'Antiquité tardive et du Haut Moyen Âge.

6- Evolution des sols dans les piémonts collinéens de la Valdaine durant l'Holocène

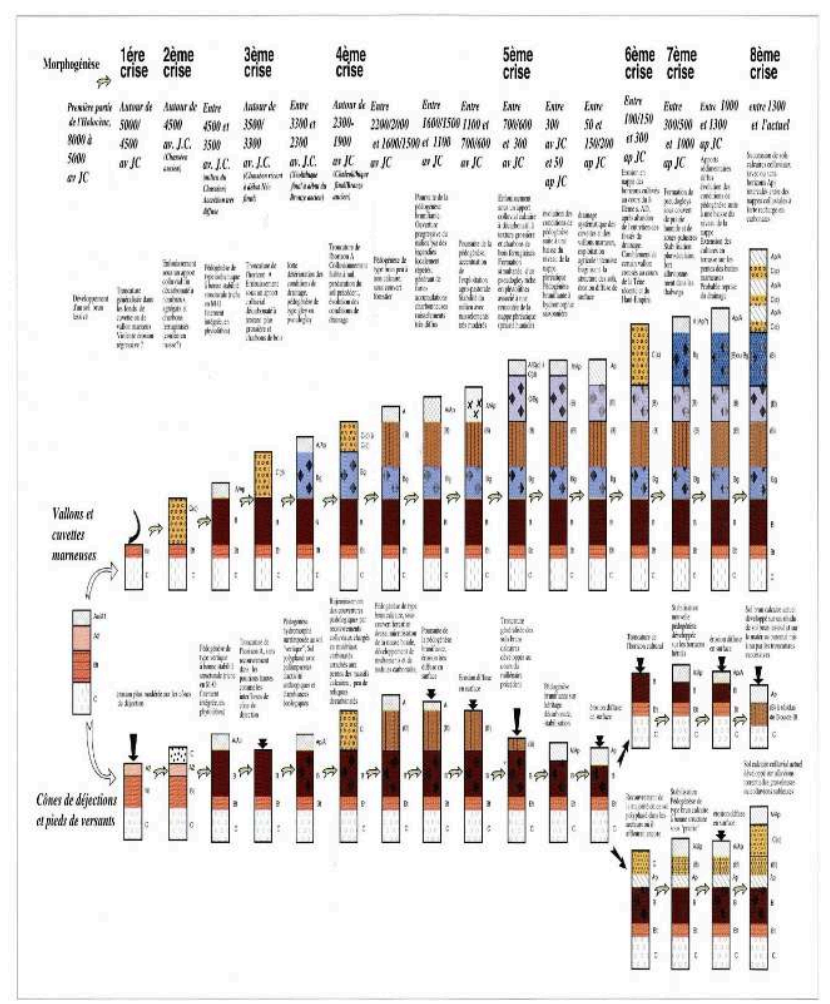

Pied de versant, cône de déjection, vallon et fond de cuvette marneuse

Les nombreuses études stratigraphiques réalisées dans la partie méridionale du bassin valdainais montrent aussi que des apports colluvio-alluviaux répétés ont nappé littéralement les piémonts collinéens au cours de l'Holocène. Ces phénomènes se sont accélérés à la fin du Néolithique. A partir de la période romaine, les sols évolués et décarbonatés formés au cours de la première moitié de l'ère postglaciaire ont quasiment tous disparu (fig. $5, \mathbf{6}$ ). Ils sont remplacés par des sols peu évolués, profonds et légers (prédominance des textures limoneuses et sableuses). Seul inconvénient pour une exploitation agricole optimale, ils sont pauvres en matière organique et peu 
structurés, donc sensibles à la battance et à l'érosion aréolaire (Berger 1995). La facilité du travail de la terre a sans doute primé dans l'Antiquité, puisque les sites galloromains se concentrent justement dans les piémonts (fig. 8 et 10). Ces couvertures peuvent néanmoins acquérir une bonne stabilité structurale et des taux de matière organique élevés, dès lors qu'ils sont stabilisés durant quelques siècles par un couvert végétal permanent, herbacé ou arboré. C'est le cas au cours de l'Antiquité tardive et jusqu'au Haut Moyen Âge (fig. 6), (Berger 1995, Berger et Jung 1996). Cette stabilité morphopédologique et cet enrichissement des sols a sans aucun doute profité à la société féodale entre les Xe et XIIIe s.

7- Evolution de la couverture pédologique dans la partie méridionale du bassin valdainais à l'Holocène
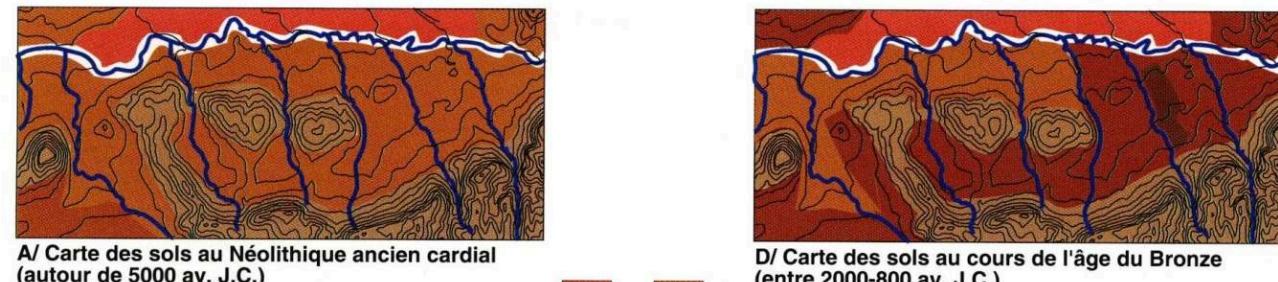
(autour de 5000 av. J.C.)

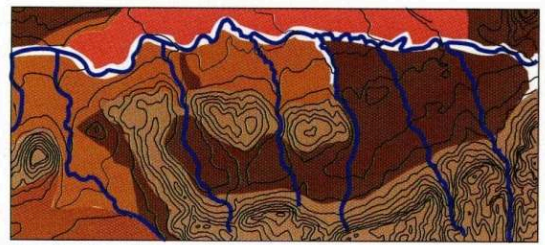

B/ Carte des sols au milieu de la période chasséenne (autour de 4000 av. J.C.)

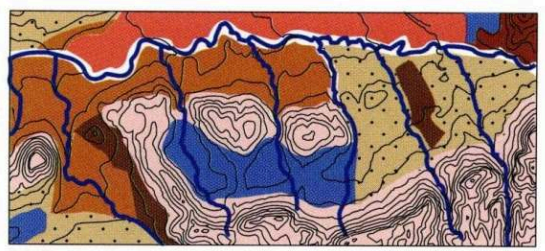

$\mathrm{C} /$ Carte des sols au milieu du Néolithique récent (autour de 3000 av. J -C
D/ Carte des sols au cours de l'âge du Bronze

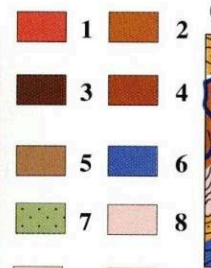
2000-800 av. J.C.)

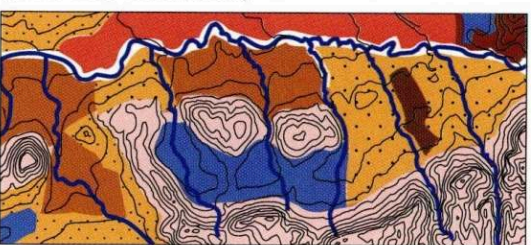

10 E/ Carte des sols au milieu de l'âge du Fer (autour de $600-500$ av. J.C.)

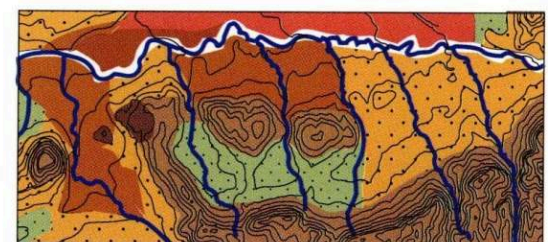

F/ Carte des sols actuels. Elle se présente sous la forme d'une mosaíque de sols complexe, héritage de la morphogenèse holocène

1 - SOL ROUgE FERSIALLITIQUE (FERSIALSOL), 2 - SOL BRUN LESSIVÉ (NÉOLUVISOL), 3 - SOL BRUN-NOIR DE TYPE ISOHUMIQUE À VERTIQUE DANS LES BAS FONDS (CHERNOSOL), 4 - SOL BRUN PEU ÉPAIS À ÉPAIS (BRUNISOL), 5 - RENDZINES ÉPAISSES ET SOLS BRUNS CALCAIRES (RENDOSOL ET CALCOSOL), 6 SOLS HYDROMORPHES (RÉDOXISOL), 7 - SOLS COLLUVIAUX HYDROMORPHES ÉPAIS (COLLUVIOSOLRÉDOXISOL), 8 - LITHOSOLS, RÉgOSOLS ET RENDZINES (LITHOSOL, RÉgOSOL ET RENDOSOL), 9 - SOLS JAUNES-gRIS COLLUVIAUX DÉCARBONATÉS ET FORTEMENT ÉLUVIÉS (COLLUVIOSOL ?), 10 - SOLS CALCAIRES COLLUVIAUX ET SOLS BRUNS CALCAIRE (COLLUVIOSOL, CALCOSOL)

Les études en paléogéographie menées en Valdaine révèlent que plus on se rapproche de l'actuel, plus la carte pédologique ressemble à une mosaïque variée, marquée par l'affleurement de nombreux sols d'âge différent. Cette variété pédologique est le fruit d'une interaction plurimillénaire complexe entre l'Homme et le climat, qu'il est nécessaire de comprendre pour ne pas formuler de modèles d'exploitation des sols trop hâtifs et peu ou non fondés. 


\section{L'apport de la géomorphologie et de la pédologie à la cartographie archéologique (analyse taphonomique)}

Les paysages se modifient sans cesse et cette évolution n'est pas sans incidence sur la pratique de l'archéologie spatiale. Il paraît ainsi encore difficile de saisir les rythmes de fréquentation des basses plaines, des pieds de versant et des cuvettes humides au cours de la période post-glaciaire, compte tenu :

- des profondes transformations morphologiques et de la forte destruction des archives alluviales ou palustres relatives à ces horizons dans les vallées préalpines de rang inférieur à dynamique torrentorrentielle ;

- du très fort recouvrement (jusqu'à $10 \mathrm{~m}$ ) dans les grandes plaines alluviales de rang supérieur, dans les vastes cônes détritiques des rivières préalpines et dans la plupart des piémonts marqués par les processus d'accrétion sédimentaire.

L'aspect de la carte archéologique actuelle est le résultat d'une évolution polyphasée (voire polycyclique) des paysages, sous l'étroite influence des variations paléohydrologiques (fig. 6). Les nombreux modèles d'occupation des sols établis depuis vingt ans n'ont pas toujours considéré cet aspect des choses et l'on est parfois arrivé à des interprétations réductrices de l'organisation dans l'espace des anciennes sociétés rurales. Réduire les communautés du premier Néolithique du sud-est de la France, de l'âge du Bronze (Berger et al. sous presse 2) au domaine karstique était, il n'y a pas si longtemps encore, monnaie courante. Regrouper l'habitat de l'âge du Fer dans le domaine collinéen, autour des oppida, faisait également partie de ces idées largement diffusées. La multiplication des opérations de sauvetage archéologique et l'interprétation des données contextuelles de terrain au sein d'une démarche géoarchéologique ont permis de nuancer les conclusions qui ne prenaient pas en compte l'impact des dynamiques pédo-sédimentaires sur l'enregistrement archéologique des systèmes d'occupation. Ainsi, très récemment, des gisements du Néolithique cardial, du Bronze ancien et du Bronze final, par exemple, ont été observés dans l'ensemble des unités de paysage qui compose la moyenne vallée du Rhône. Des occupations de La Tène sont aujourd'hui identifiées dans les très basses plaines alluviales ou dans les fonds de cuvettes. L'image du peuplement évolue donc, et l'on recherche maintenant activement à expliquer les causes et les processus impliqués dans la distorsion de l'image du peuplement initial. On regroupe tous les paramètres concernés dans l'évolution postdépositionnelle des gisements archéologiques sous le terme de taphonomie (cf. Brochier 1991).

En moyenne vallée du Rhône, un inventaire des types et des formes de conservation des sites holocènes a été réalisé grâce à une base de données importante. Quelques exemples sont présentés pour la période gallo-romaine (fig. 8). Un répertoire de formes taphonomiques est déjà disponible (fig. 9). Presque toutes les étapes ont été observées entre la conservation presque totale des gisements archéologiques, avec sols et structures d'habitat, et leur destruction complète suivie de leur dépôt au sein de formations sédimentaires (fig. 9). Certaines unités de paysage sont particulièrement sensibles à ces phénomènes de perturbation de la carte archéologique. Dans les cuvettes marneuses humides des piémonts, sur les cônes de déjection pléistocènes et dans les basses plaines alluviales (fig. 8), les sites sont souvent enterrés ou colluviés (près de $50 \%$ du corpus de sites de l'Antiquité). Le décapage généralisé des sols sur les pentes et la métamorphose des cours d'eau vers un style fluvial en tresse vers la fin du 
Ier s. ap. J.-C. explique en partie cette situation dans le bassin valdainais (Berger 1995 et 1996b). Les phénomènes géomorphologiques postérieurs sont également à considérer. Sur les terrasses pléistocènes à sols évolués (fersialsols) et sur quelques cônes de déjection stables depuis la fin des temps glaciaires, les sites romains apparaissent par contre régulièrement en surface, le plus souvent démantelés sur place par les labours postérieurs à l'abandon (fig. 8). On obtient donc alors une image presque correcte du paléopeuplement dans ces unités morphopédologiques, bien que des sites antiques puissent aussi être piégés en partie dans des paléovallons hérités de la morphogenèse tardiglaciaire sur ces vieilles terrasses, comme sur le site de Montélimar-Gournier (Beeching et al. 1994). La superposition des sites antiques, associés à leur forme taphonomique sur la carte pédologique actuelle, apporte également des informations intéressantes à exploiter dans le cadre d'une démarche taphonomique (fig. 8). Elle indique que les risques de retrouver des sites enterrés ou colluviés sont maximaux dans les secteurs à sol calcaire colluvial (colluviosol), à sol hydromorphe (colluviosol-reductisol) et à sol alluvial jeune (fluviosol) et minimaux dans les secteurs à sol rouge fersiallitiques (fersialsols) et à sol brun lessivé (néoluvisols). De tels résultats peuvent augurer de la création de modèles prédictifs pour l'archéologie spatiale ou l'archéologie préventive à partir de systèmes d'informations géographiques, pour orienter de futures investigations de terrain en moyenne vallée du Rhône. Ils montrent également que des documents cartographiques (géologie, géomorphologie et pédologie) actuels peuvent être exploités en amont de toute recherche archéologique, avec un regard dynamique sur les paysages, pour orienter les choix méthodologiques et techniques sur le terrain (recours à la pelle mécanique et au carottier seul, ou au contraire à la prospection aérienne et pédestre...). 
8- Représentation de la carte archéologique antique de la partie méridionale de la Valdaine après correction taphonomique

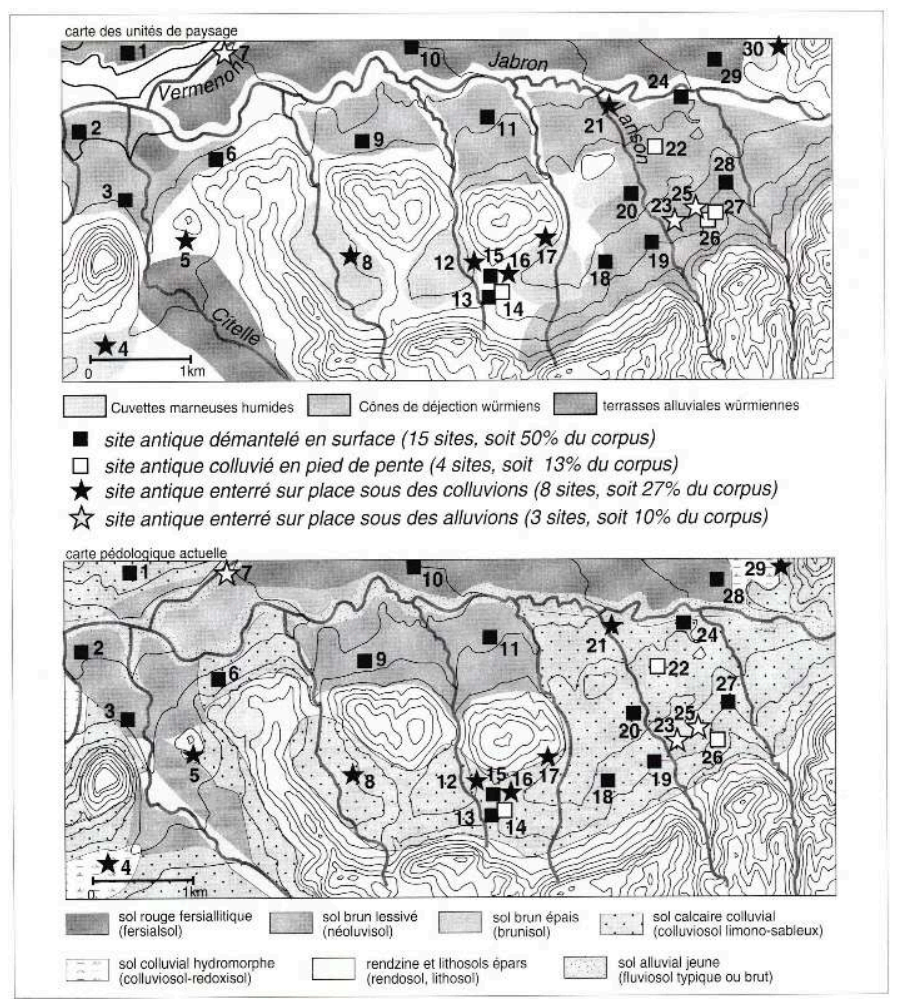

I. MONTBOUCHER-LE-PATY 2. MONTBOUCHER-LE-MONARD, 3. ESPELUCHE-SAINT-ROMAIN, 4. ESPELUCHEBEAUVOIR, 5. ESPELUCHE-PIRUGIER, 6. ESPELUCHE-ROTARY, 7. MONTBOUCHER-CONSTANTIN, 8.

ROCHEFORT-BOISSE, 9. PUYgIRON-ANDÉOL, 10. LA BÂTIE-ROLLAND-LE-JALIgNER, 11. PUYgIRON-LEPOULET, 12. ROCHEFORT-EN-VALDAINE-GOURNIER, 13. LA TOUCHE-LE ROUgE SUD, 14. LA TOUCHE-LE ROUgE NORD, 15. LA TOUCHE-LES FAURES OUEST, 16. LA TOUCHE-LES FAURES EST, 17. LA TOUCHE-N.-D. DE MASTAIZE, 18. LA TOUCHe-LA CHÊNUE, 19. PORTES-enVALdAINE-LE PRIEURÉ, 20. PORTES-EN-VALdAINEGRANDE GRANgE, 21. PORTES-EN-VALDAINE-LE MOULIN, 22. PORTES-EN-VALDAINE-LA TREILLE, 23. PORTES-EN-VALDAINE-CHÂTEAU, 24. PORTES-EN-VALDAINE-PRADAL, 25. PORTES-EN-VALDAINE-VINSON, 26. PORTES-EN-VALdAINE-LES ALLIERS, 27. PORTES-EN-VALdAINE-LE SERRE, 28. LA BÉgUde-de-MAZENCMANOTIÈRE, 29. LA BÉgUDE-DE-MAZENC-RATTIER, 30. LA BÉgUDE-DEMAZENC-LES MOULIÈRES 
9- Formes taphonomiques de sites antiques implantés dans les piémonts méridionaux du bassin valdainais, sur ou en pied de butte marneuse

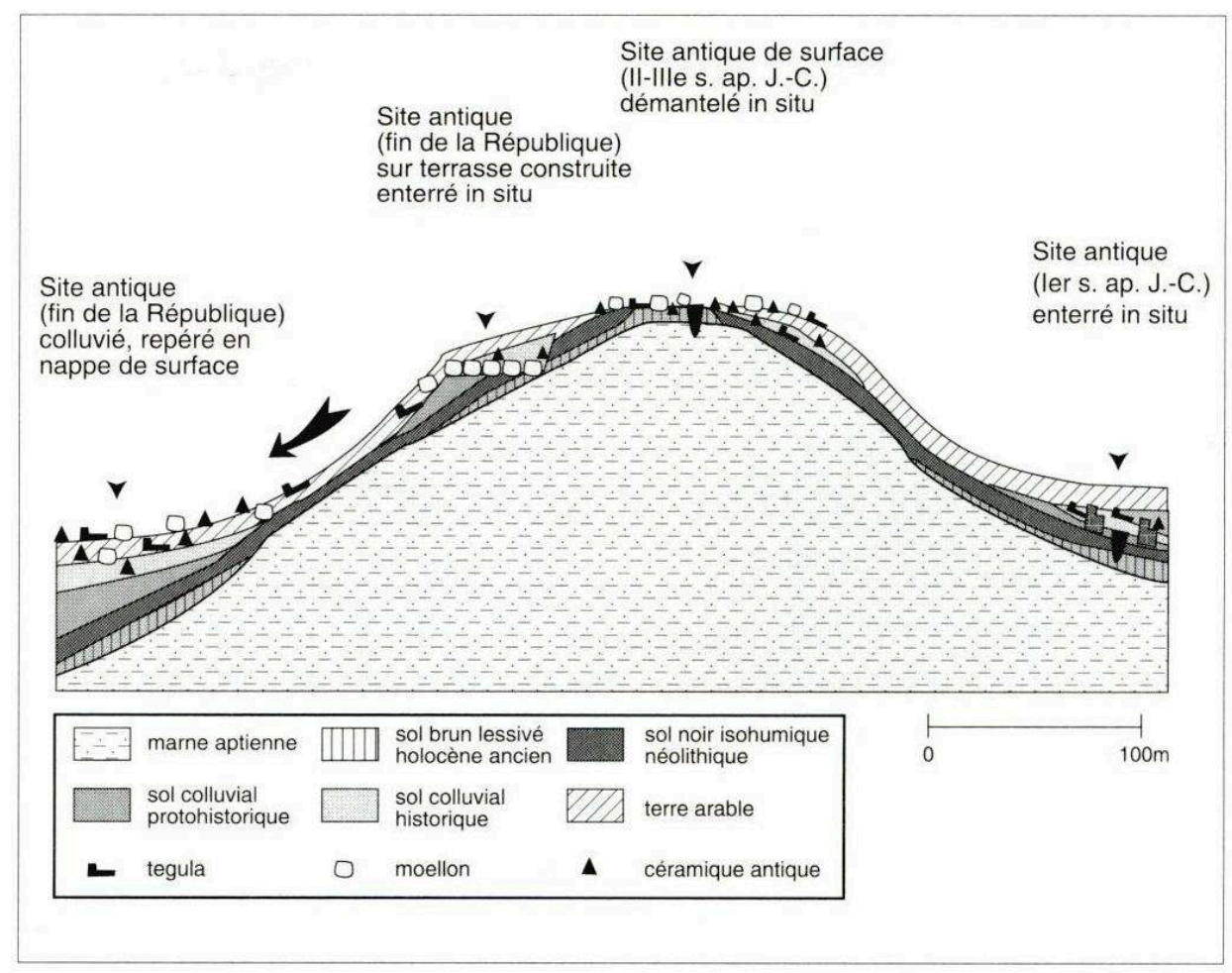

TRANCHÉE 56, COMMUNE DE LA TOUCHE

L'exemple de la période romaine présenté ici permet de mettre le doigt sur l'importance des destructions ou des dissimulations archéologiques liées à la géodynamique. Malgré l'importance des moyens développés pour prospecter la partie méridionale du bassin valdainais (prospections pédestres systématiques, prospections aériennes), une partie non négligeable de l'habitat antique n'aurait pu être découvert et utilisé dans l'élaboration de modèles d'occupation des sols. Il faut noter que pour certaines périodes comme l'âge du Bronze ou l'âge du Fer, l'impact de l'évolution géomorphologique sur les sites archéologiques apparaît encore plus fort (Berger 1996, Berger et al. sous presse 2, Bravard ce volume).

La répétitivité et l'extension spatiale des phénomènes géomorphologiques réduisent donc les possibilités d'évaluer à sa juste valeur la dynamique d'occupation des sols au cours de la période antique (comme au cours des autres périodes d'ailleurs) dans certaines unités de paysage. Le développement récent des grands travaux d'aménagement du territoire a révélé la richesse du patrimoine archéologique enfoui dans les zones à sédimentation active qui demeurent aujourd'hui encore relativement peu explorées. Seule une surveillance soutenue et durable de ces grands travaux permettra de restituer à moyen terme une meilleure image du peuplement humain dans ces secteurs particulièrement sensibles. 


\section{Les modèles d'évolution du paysage au premier millénaire ap. J.-C.}

40 À partir d'une intégration spatiale des données pluridisciplinaires (par l'utilisation des données en géomorphologie, paléopédologie, paléobotanique, malacologie et archéologie spatiale), les grands traits de la dynamique du peuplement galloromain et jusqu'à l'époque médiévale de la Valdaine sont dégagés et replacés dans un cadre paléogéographique et paléoécologique précis (au siècle près) (fig. 10).

La confrontation de ces trois approches permet de discuter de l'interaction entre l'homme et son environnement au cours du Ier millénaire ap. J.-C. et de proposer des hypothèses quant aux principales causes de l'évolution des paysages.

10- Evolution des piémons méridionaux de la Valdaine au cours du ler millénaire ap. J.C.

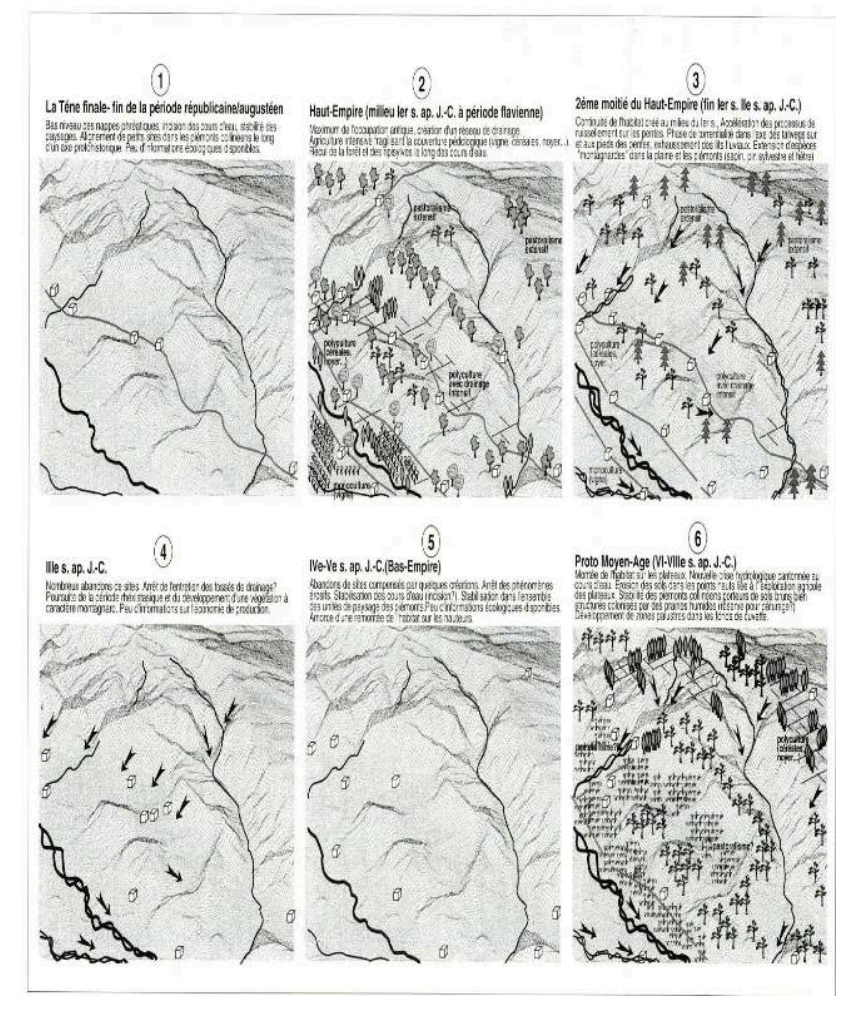

\section{La Tène finale - fin de la période républicaine/augustéen}

Cette phase d'occupation n'était pas connue dans les piémonts et les plaines de la Valdaine jusqu'aux débuts des prospections systématiques. Un premier bilan sur l'occupation de La Tène récente-finale avait été effectué par T. Odiot. Il mentionnait une série d'oppida implantés sur les plateaux calcaires périphériques au bassin valdainais et au Tricastin (Odiot 1985). En fait, les prospections-sondages ont révélé l'existence de petits sites ruraux, souvent enterrés sous des colluvions, à proximité des cours d'eau et dans les fonds de cuvettes humides. Ils s'alignent de façon régulière dans les piémonts collinéens de la Valdaine, le long d'un axe protohistorique (probablement créé au cours du Bronze final), sous la surveillance d'oppida régulièrement alignés sur les crêtes des massifs périphériques (fig. 10/1). Cette implantation des sites est rendue 
possible par le bas niveau des nappes phréatiques dans les cuvettes marneuses et l'incision de cours d'eau caractérisés par des écoulements à régime non torrentiel. La formation de sols calciques indique dans le même temps une augmentation des processus d'évaporation et d'évapotranspiration, sans doute liée à un réchauffement du climat (Berger 1996b). Les travaux du TGV-Méditerranée ont confirmé ces premiers résultats dans l'ensemble de la moyenne vallée du Rhône. Les rares données paléobotaniques révèlent une végétation méso-thermophile avec du chêne pubescent, du chêne vert et du filaire (Thiébault In : Berger 1996a, Rousseau en cours). En revanche, il existe encore peu de données sur les modes et les types d'exploitation des sols.

\section{Le Haut-Empire (milieu ler s. ap. J.-C. à période flavienne)}

En Valdaine, on assiste à un pic de création d'habitats ou de bâtiments agricoles à partir du milieu du premier siècle ap. J.-C. (fig. 10/2). De petite taille dans les piémonts (1 000 à $3000 \mathrm{~m}^{2)}$ et de taille moyenne à grande sur les terrasses et certains cônes pléistocènes $\left(5000 \mathrm{~m}^{2}\right.$ à 2 ha), ils semblent s'organiser en réseaux cohérents et hiérarchisés (fig. 11). Ces sites s'implantent en partie le long du vieil axe protohistorique et en partie le long des nouveaux axes orientés sur le cadastre $B$ d'Orange. Un décalage de près d'un demisiècle est observé avec le Tricastin et les régions plus méridionales de la Narbonnaise (Favory et al. 1995). Il est sans doute à mettre en relation avec l'avancée progressive du front colonial depuis les bords de la Méditerranée. Dans le même temps se met en place un réseau de drainage orienté sur le cadastre B d'Orange dans le but d'assainir systématiquement les cuvettes marneuses humides des piémonts. La maîtrise de l'hydraulique en moyenne vallée du Rhône à l'époque romaine est maintenant tout à fait démontrée par la combinaison entre les approches en carto-photo-interprétation et en géoarchéologie (Chartier et al. 1995, Berger et Jung 1996 et sous presse). Récemment, à plusieurs reprises, une hiérarchisation de réseaux de drainage ou d'irrigation cadastrés a été observée.

11- Modèle d'occupation des sols au cours du Haut-Empire romain dans les piémonts méridionaux de la Valdaine après correction taphonomique

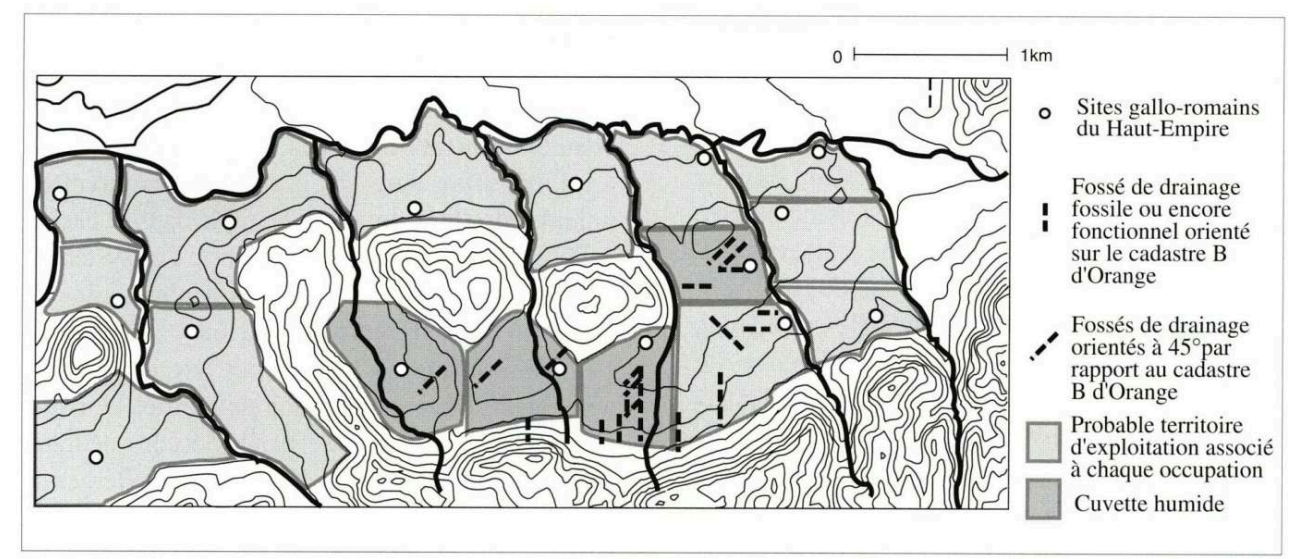

DES EXPLOITATIONS AgRiCOLES DE PETITE TAILLE (1000-3000M²) SE RÉPARTISSENT DE FAÇON RÉgULIÈRE AU SEIN D'UNITÉS gÉOgRAPHIQUES BIEN DÉLIMITÉES (INTERFLUVES OU CUVETTES MARNEUSES). LES TERRITOIRES D'EXPLOITATION REPRÉSENTENT UNE SURFACE ÉgALE À UNE CENTURIE EN MOYENNE (50HA) 
s. de notre ère correspond donc en moyenne et basse vallée du Rhône à la période du plein développement d'une viticulture spéculative dont la littérature agronomique latine se fait l'écho et dont l'archéologie et les études paléoenvironnementales confirment le dynamisme (Laubenheimer 1990, Odiot 1994, Favory et al. 1995, Odiot sous presse). Des informations récurrentes et pluridisciplinaires recueillies dans les formations alluviales, dans les paléosols et dans les structures fossoyées attestent de l'utilisation de la céréaliculture (carpologie et palynologie), de la viticulture (carpologie et anthracologie) et peutêtre de la culture du noyer (anthracologie et palynologie) dans des paysages exploités intensivement. Elles témoignent toutes d'un paysage très ouvert où la forêt semble résiduelle ou peu présente dans les plaines alluviales, dans lesquelles la majorité des ripisylves sont défrichées (Berger 1995 et 1996a, Thiébault In: Berger 1996a, Boubi en cours. Berger, Jung et al. en cours). Nos études spatiales ont démontré que le développement de la viticulture s'effectuait principalement sur les terrasses pléistocènes et sur certains cônes de déjection à sols fersiallitiques, que la polyculture était plutôt pratiquée dans les piémonts collinéens et peut-être sur les plateaux (Berger 1995, Berger et Jung en cours). Les analyses micromorphologiques affirment dans le même temps la pratique d'une agriculture intensive qui fragilise la couverture pédologique (fig. 5) (Berger 1995).

\section{La seconde moitié du Haut-Empire (fin le s. Ile s. ap. J.-C.)}

Cette phase est marquée par la continuité dans l'organisation de l'habitat créé au milieu du Ier s. et dans la gestion des sols (fig. 10/3). Des transformations s'opèrent par contre dans la dynamique des paysages. Une accélération des processus de ruissellement est observée sur les pentes suite à une augmentation des précipitations et à une concentration saisonnière de la pluviométrie (Berger 1995 et 1996b). Ce phénomène provoque le comblement répété des fossés de drainage (observation de nombreuses phases de curage), l'exhaussement des lits fluviaux suivi de leur métamorphose dans les plaines et les piémonts vers un style fluvial en tresse, et une activité torrentielle dans l'axe des talwegs sur et aux pieds des pentes. En fait, les pratiques agricoles intensives de la phase précédente ont favorisé, voire amplifié ces phénomènes géomorphologiques, en détruisant la stabilité structurale des sols (Berger 1995 et 1996b). Cette phase morphogénique active provoque la destruction ou le recouvrement des sites implantés dans le lit majeur des cours d'eau au cours de la période précédente. Les données paléobotaniques confirment l'impression d'une péjoration climatique, par la mise en évidence de l'extension d'espèces d'affinité « montagnarde » dans la plaine et les piémonts (sapin, pin sylvestre et hêtre) (Thiébault In : Berger 1996a). Les études anthracologiques et palynologiques menées sur les fossés cadastrés du Tricastin (à une vingtaine de kilomètres au sud du bassin valdainais) dans le cadre des travaux archéologiques du TGVMéditerranée révèlent les mêmes résultats (Rousseau et Farbos en cours).

Le Ille s. ap. J.-C.

Cette phase se distingue principalement par une modification dans l'organisation de l'habitat. De nombreux abandons de sites sont observés (fig. 10/4). Le niveau important des abandons ne constitue pas le signe d'une déprise rurale uniforme, mais celui d'une maturation des réseaux d'habitat passant par une réduction du nombre des 
unités de résidence et des locaux d'exploitation (Favory et al. 1995). Il faut tout de même signaler que cette restructuration des réseaux coïncide avec l'arrêt de l'entretien d'au moins une partie des fossés de drainage de la Valdaine, voire de la moyenne vallée du Rhône (Berger 1995, Berger et Jung sous presse). On peut noter l'existence de quelques créations de sites, notamment sur l'interfluve entre deux cuvettes des piémonts méridionaux (petit hameau), (fig. 10/4). Au niveau paléogéographique et paléoécologique, les phénomènes géomorphologiques et le développement d'une végétation à caractère montagnard se poursuivent. Il existe encore peu d'informations sur l'économie de production. Il est difficile de connaître quel a pu être l'influence de l'abandon d'une partie des réseaux de drainage au cours d'une période relativement humide sur la gestion des terres.

\section{Le Bas-empire et l'Antiquité tardive, IV e s. ap. J.-C. au début Vle siècle}

Le Bas-empire est marqué par quelques abandons de sites que compensent quelques créations (fig. 10/5).

Le bassin valdainais se démarque des autres régions de la Narbonnaise étudiées dans le cadre du projet ARCHAEOMEDES. Puisqu'il présente un second petit pic de création (Favory et al. 1995). Un changement important s'opère dans l'organisation des réseaux d'habitat puisque l'amorce d'une remontée de l'habitat sur les hauteurs est identifiée (Odiot et Berger 1995). Les phénomènes érosifs se ralentissent. Une stabilisation des cours d'eau (incision?) propice au développement de paléosols sur les berges fluviales et dans l'ensemble des unités de paysage des piémonts est observée (Berger 1995 et en cours). Il existe encore peu d'informations paléoécologiques disponibles pour cette période. Les études effectuées dans le cadre du TGV-Méditerranée devraient permettre de compléter les résultats de la Valdaine.

\section{Le Haut Moyen Âge (VI-VIIIe s. ap. J.-C.)}

Pour la fin de l'Antiquité et le début du Moyen Âge, la désorganisation des systèmes de drainage ou d'irrigation dans les plaines et les cuvettes humides des piémonts est identifiée dans le bassin valdainais et les régions limitrophes. Les systèmes fossoyés sont recouverts par des dépôts sédimentaires qui vont ensuite subir une longue période de pédogenèse, marquant une période de déprise agricole affirmée. L'extension de prairies de pâture est maintenant assurée par les études pédologiques et malacologiques (Berger 1995. Berger et Jung 1996, Magnin In: Berger 1996) (fig. 10/6). Ces observations témoignent donc d'une rupture nette dans la gestion des sols entre le début et la fin de l'Antiquité, fait confirmé par les analyses spatiales en archéologie qui identifient une montée de l'habitat aux cours du Bas-Empire et surtout de l'Antiquité tardive jusqu'au Haut Moyen Âge (Odiot et Berger 1995, Berger 1996a, Odes 1995). La stabilité des paysages est affirmée entre le VIe s. et le XIIe s., interrompue par une nouvelle crise hydrologique cantonnée au cours d'eau autour des VI-VIIIe s. Les analyses micromorphologiques d'alluvions des rivières situées dans les piémonts collinéens révèlent une érosion des sols dans les points hauts (domaine collinéen). L'alluvionnement de microfragments de terra rossa, de charbons de bois d'espèces de lisières et de pinèdes associées à la pratique de brûlis et à des graines de céréales 
carbonisées implique une forte responsabilité de l'homme et de ses pratiques dans l'exacerbation de ce phénomène alluvial. Cette érosion des vieux sols reliques du Pléistocène est en relation avec une exploitation agricole des plateaux, associée à la création de haies, en liaison avec la montée de l'habitat rural (fig. 10/6). On observe un fort contraste avec les piémonts marneux, recouverts par des prairies humides et des sols bruns bien structurés (réserve pour pâturapâturage?). Localement le développement de zones palustres peut être envisagé (fig. 10/6), (Magnin In: Berger 1996a). Encore une fois et de façon récurrente, cette phase morphogénique active provoque la destruction ou le recouvrement des sites implantés dans le lit majeur des cours d'eau au cours de la période précédente. La période qui suit cette péjoration hydroclimatique est à nouveau marquée par une forte stabilisation des paysages jusqu'à la fin du Haut Moyen Âge, dans laquelle des épisodes de fermeture du milieu sont envisagés à partir des données anthracologiques et malacologiques (Thiébault In : Berger 1996a, Magnin et Grosvallet corn. pers.).

\section{Conclusion}

La pratique d'une démarche géoarchéologique systémique sur les sites et à l'écart des lieux d'occupation, à l'échelle d'un petit bassin versant $\left(300 \mathrm{~km}^{2}\right)$, apporte de nombreuses informations sur la connaissance des processus responsables de l'évolution des paysages holocènes. Elle nécessite avant tout un investissement sur le terrain considérable, qui exploite de manière opportuniste les tranchées effectuées dans le cadre des grands travaux d'aménagement du territoire.

Dans le bassin valdainais, les recherches géoarchéologiques ont privilégié plusieurs approches :

- une étude de l'évolution des milieux de sédimentation par le biais de l'analyse sédimentaire et stratigraphique, qui permet d'analyser les variations du régime hydrologique et d'envisager les contraintes géodynamiques sur les implantations humaines et sur la conservation des vestiges archéologiques,

- une étude des couvertures pédologiques anciennes et actuelles, permettant de caractériser les différentes ambiances pédoclimatiques de l'Holocène, d'évaluer les conditions de mise en culture pour chaque phase culturelle et d'analyser les effets des pratiques agro-pastorales et des incendies sur les sols,

- une étude de l'évolution des paléovégétations, par l'analyse des résidus phytolithiques, anthracologiques, malacologiques et palynologiques contenus dans les sols (en collaboration avec des paléobotanistes), qui aide à comprendre les relations qu'elles pouvaient entretenir avec les variations morphopédologiques et culturelles,

- une étude de la répartition et de la densité des occupations successives à partir de prospections systématiques (en collaboration avec des archéologues), permettant d'établir une chronologie des phases d'emprise et de déprise humaine à comparer avec les données sur les paléoenvironnements.

La confrontation de l'évolution du peuplement à celle des environnements successifs montre la complexité des interrelations entre l'Homme et le climat, et la mobilité des paysages à l'Holocène. La nécessité de travailler avec un cadre chronologique précis (au demi ou au quart de siècle près) est impérative dans une démarche processuelle. Cet espoir est en passe d'être atteint au moins pour la période antique en moyenne vallée du Rhône. Il reste à l'étendre aux périodes plus anciennes, ou plus récentes qui ne 
présentent pas encore un potentiel de datation des événements environnementaux aussi précis.

\section{BIBLIOGRAPHIE}

\section{Bibliographie}

Amoros et al. 1988 : AMOROS (C.), BRAVARD (J.P.), REYGROBELLET (J.L.), PAUTOU (G.), et ROUX (A.L.) - Les concepts d'hydrosystème et de secteur fonctionnel dans l'analyse des systèmes fluviaux à l'échelle des écocomplexes, Bull. Eco/.,1988, 19, 4, 531-546.

Beeching, Brochier et al. 1990 : BEECHING (A.), BROCHIER (J-L.) - Programme culture et milieu des premiers paysans de la moyenne vallée du Rhône après cinq années d'applications. Entre choix stratégiques et réalités de la recherche. Xe Rencontres internationales d'Histoire et d'Archéologie d'Antibes, octobre 1989, Archéologie et Espace, éd. APDCA, Juan-les-Pins, 137-155.

Bell 1983 : BELL (M.) - Valley sediments as evidence of prehistoric land-use on the South Downs. Proceedings of the Prehistoric Society 49, 119-150.

Berger 1995 : BERGER (J.-F.), - Facteurs anthropiques et naturels de l'évolution des paysages romains et protomédiévaux du bassin valdainais (Drôme). In : S.E. Van der Leeuw éd., L'Homme et la dégradation de l'environnement. Actes des XVe Rencontres internationales d'Histoire et d'Archéologie d'Antibes, Juan-les-Pins 20-22 octobre 1994, éd. APDCA, 79-115.

Berger 1996a : BERGER (J-F.), - Le cadre paléogéographique des occupations du bassin valdainais (Drôme) à l'Holocène. Thèse Archéologie et Environnement, Université de Paris I, 325p.

Berger 1996b : BERGER (J-F), - Evolution des agrosystèmes et du climat, table ronde du GDR 954 sur les mutations du IIIe s. en Gaule Narbonnaise, Aix-en-Provence, éd. APDCA, 299-332.

Berger et Jung 1996 : BERGER (J-F.) et JUNG (C.) - Fonction, évolution et taphonomie des parcellaires en moyenne vallée du Rhône. Un exemple intégré en archéomorphologie et en géoarchéologie. Colloque Archéologie des parcellaires d'Orléans organisé par Ager et Archea, Orléans mars 1996, Errance éd., 95-112.

Berger et Jung 1997 : BERGER (J-F.) et JUNG (C.) - Developping a methodological approach to the Evolution of mid-Rhodanian Agro-systems during Historical Periods. Colloque du programme européen Populus organisé par K. Walsch et P. Leveau à Aix-en-Provence (sous presse, In Oxbow Monography 1997).

Berger et al. sous presse 1 : BERGER (J-F.), MAGNIN (F.), THIEBAULT (S.), ARGANT (J.), (sous presse) - Essais de paléoécologie d'un paysage : le bassin valdainais (Drôme, France) à l'Holocène, In : Ecologia Mediterranea 1997.

Berger, Magnin, Vital sous presse 2 : BERGER (J-F.), MAGNIN (F)., VITAL (J.) - Emprise et déprise humaine à l'âge du Bronze en moyenne vallée du Rhône, Paris, journées de la SPF. Ed. de la SPF (sous presse). 
Berger et al. sous presse 3 : BERGER (J-F.), ZANNIER (M.-P.), FAVORY (F.) et ODIOT (T.) - Les classifications des sols dans l'Antiquité et leur rapport avec les sols actuels. Colloque international d'Antibes « La dynamique des paysages protohistoriques, antiques, médiévaux et modernes ", (sous presse, éd. APDCA).

Bertrand 1975 : BERTRAND (G.) - Pour une histoire écologique de la France rurale. In : G. Duby (dir.) et A. Wallon, Histoire de la France rurale, Paris, Seuil, 1975, 37-113.

Blandin, Lamotte 1988 : BLANDIN (P.), LAMOTTE (M), - Ecologie des systèmes et aménagement : fondements théoriques et principes méthodologiques. In : Lamotte M. éd., Fondements rationnels de l'aménagement d'un territoire, Masson, Paris, 1988, 139-162.

Boissinot 1995 : BOISSINOT (P.) - L'empreinte des paysages hellénistiques dans les formations holocènes de Saint-Jean-du-Désert (Marseille). In : Morhange éd. -les origines de Marseille. Environnement et archéologie. Aix-en-Provence : institut de géographie. $\mathrm{n}^{\circ}$ spécial de Méditerranée, Revue géographique des pays méditerranéens, 82, 3-4, 33-40.

Bornand 1967 : BORNAND (M.) - Etude pédologique du bassin valdainais, vallées du RoubionJabron-région de Montélimar (Drôme). Service d'Etude des Sols, INRA, n 80, 1967, 83 p.

Bornand 1978 : BORNAND (M.) - Altération des matériaux fluvio-glaciaires. Genèse et évolution des sols sur terrasses quaternaires dans la moyenne vallée du Rhône. Thèse Doct. d'Etat, USTL Languedoc. Service d'Etude des Sols, INRA, Montpellier, 444, 329 p.

Bornand. Icole 1984 : BORNAND (M.), ICOLE (M.) - Les teintions « pédologie-géomorphologie-géologie du Quaternaire » Apports réciproques, Livre jubilaire du cinquantenaire AFES, 141-152.

Borrello 1982 : BORRELLO (M.A.) - « Site catchment analysis » d'Auvernier-nord (Bronze final), lac de Neufchâtel : note préliminaire. In :Jahrbuch der Schweizerischen Gesellschaft für ur-und Frühgeschichte, 1982, 83-91.

Boulin 1977 : BOULIN (A.) - Méthodes de la stratigraphie et géologie historique. Paris, Masson, 1977, $226 \mathrm{p}$.

Bravard et al. 1990 : BRAVARD (J.-P.), LE BOT-HELLY (A.), HELLY (B.), SAVAY-GUERRAZ(H.) - Le site de Vienne (38) Saint-Romain (69), Sainte-Colombe (69). L'évolution de la plaine alluviale, de l'âge du Fer à la fin de l'Antiquité : proposition d'interprétation. Xe Rencontres internationales d'Archéologie et d'Histoire, Antibes, 19-21 oct. 1989. Achéologie et Espace, éd. APDCA, Juan-les-Pins, 437-452.

Brochier 1983 : BROCHIER (J.-E.) - Bergeries et feux de bois néolithiques dans le Midi de la France. Caractérisation et incidence sur le raisonnement sédimentologique, Quartär, 33-34, 181-193.

Brochier 1991 : BROCHIER (J.-E.) - Géoarchéologie du monde agropastoral. In : J. Guilaine (ed.) : Pour une archéologie agraire. Paris, Armand Colin, 303-322.

Brochier 1991 : BROCHIER (J.-L.) - Environnement et culture : état de la question dans le Sud Est de la France et principes d'étude autour du Chasséen de la moyenne vallée du Rhône. Colloque international de Nemours, Identité du Chasséen, mai 1989, Mémoire du Musée Préhist. d'Ile de France $\mathrm{n}^{\circ} 4, .315-326$.

Brochier 1994 : BROCHIER (J.-L.) - Etude de la sédimentation anthropique. La stratégie des ethnofaciès sédimentaires en milieu de constructions en terre. Bull, de correspondance héllénique 118, pp. 619-645. 
Brochier, Mandier, Argant 1991 : BROCHIER (J.-L.)., MANDIER (P. ) et ARGANT (J.) - Le cône détritique de la Drôme : Une contribution à la connaissance de l'Holocène du Sud-Est de la France. Quaternaire, 2, 83-99.

Brochier, Beeching 1992 : BROCHIER (J.-L.). et BEECHING (A.) - Les grottes-bergeries d'altitude des Préalpes du Sud : début de l'élevage, premières transhumances au Néolithique. Rencontres internationales : l'Homme et le mouton dans l'espace de la transhumance, Die 1992.

Butzer 1976 : BUTZER (K. W.) - Géomorphology from Earth. Harper and row, New York.

Butzer 1982 : BUTZER (K. W.) - Archaelogy as Human Ecology. Cambridge Univ. Press. New York.

Chouquer 1983 : CHOUQUER (G.) - Localisation et extension géographique des cadastres affichés à Orange. In : Cadastre et espace rural, Approches et réalités antiques. Table ronde de Besançon, mai 1980, pp. 275-295.

Chouquer, Favory 1991 : CHOUQUER (G.) et FAVORY (F.) - Les paysages de l'Antiquité. Terres et cadastres de l'Occident romain, (IVe s. av. J.C. IIIe s. ap. J.-C.), éd. Errance, collection des Hespérides, Paris.

Coste, Guilaine, Revel 1988 : COSTE (N.), GUILAINE (J.) et REVEL (J.-C.) - Archéologie et pédologie : essai de reconnaissance des territoires d'exploitation autour des sites néolithiques, Bull. SPF, t. 85, 10-12, 390-411.

Courty 1983 : COURTY (M.-A.) - Interprétation des aires de combustion par la micromorphologie, Bull. SPF, 169-171.

Courty 1994 : COURTY(M.-A.) - Le cadre paléogéographique des occupations humaines dans le bassin du hautKhabur (Syrie du Nord-Est). Premiers résultats, Paléorient, 20/1, 21-59.

Courty, Fedoroff 1982 : COURTY (M. A.), FEDOROFF (N.) - Micromorphology of a Holocene Dwelling. P.A.C.T 7, II, Strasbourg 1981, 257-277.

Courty, Goldberg, Macphail 1989 : COURTY (M.-A.), GOLDBERG (P.) et MACPHAIL (R.I.) - Soils and micromorphology In : Archaeology. Cambridge University Press, 344 p.

Dorioz 1993 : DORIOZ (J.-M.) - Pédogénèse et potentialités agricoles. In : (sous la dir)de M. Colardelle et d'E. Verdel, Les habitats du lac de Paladru (Isère) dans leur environnement : la formation d'un terroir au XIe s. Maison des Sciences de l'Homme, D.A.F. $n^{\circ} 40$, pp. 59-63.

Favory et al. 1995 : FAVORY (F.), GIRARDOT (J.-J.) et RAYNAUD (C.), TOURNEUX (F.-P.) - Mobilité et résistance de l'habitat rural gallo-romain en vallée du Rhône : indicateurs de l'attraction ou de la répulsion exercée par le millieu ? In : S.E. Van Der Leeuw éd., l'Homme et la dégradation de l'environnement. Actes des XVe Rencontres Internationales d'Histoire et d'Archéologie d'Antibes, Juan-les-Pins 20-22 oct. 1994.

Fedoroff sous presse : FEDOROFF (N.) - L'apport de la micromorphologie des sols à la reconstitution des paléopaysages (Application au bassin méditerranéen pour la période $3000 \mathrm{av}$. J.-C./1800 ap. J.-C.). Colloque du programme européen Populus organisé par K. Walsch et P. Leveau à Aix-enProvence (sous presse, In : Oxbow Monography 1997).

Ge et al. 1993 : GE (T.), COURTY (M.A.). MATTHEWS (W.) et WATTEZ (J.) - Sedimentary Formation Processes of Occupation Surfaces. In : « Formation Processes in Archaeological Context ». P. Goldberg, D. Nash and MD Petraglia éd.. Monographs in World Archaeology 17, 149-163.

Godart et Legeay 1992 : GODART (O.) et LEGEAY (J.M.) - Entre discipline et réalité, l'artifice des systèmes. In : (sous la dir.) de M. Jollivet, Sciences de la nature, sciences de la société : Les passeurs de frontières. CNRS éd. 
Goldberg 1979 : GOLDBERG (P.) - Micromorphology of sediments from Hayonim Cave, Israel. Catena 6, 167-181.

Hassan 1978 : HASSAN (F.A.) - Sediments in Archaeology : Methods and implications for Palaeoenvironmental and cultural Analysis. Journal of Field Archaeology 5. pp. 197-213.

Higgs et Vita-Finzi 1972 : HIGGS (E.S.) et VITA-FINZI (C.) - Prehistoric economies : a territorial approach. In : Higgs e.S. éd., Papers in Economic Prehistory, Cambridge University Press, 27-36.

Holliday 1985 : HOLL1DAY (V.T.) - Morphology of late Holocene soils in the Lubbock late archaeological. Texas. Soil Sci. Soc. Am. J., Madison, USA, 49, 938-946.

Jarman 1972 : JARMAN (M.R.) - A Territorial Model for Archaeology : a behavioural and geographical approach. In : D.L. Clarke, Models in Archaeology, Londres, pp. 705-734.

Leveau et Provansal 1993 : LEVEAU (Ph.) et PROVANCAL (M.) dir. - Sociétés antiques et écologie des milieux montgnard et palustre, (la construction des paysages méditerranéens). Archéologie et environnement : De la Sainte-Victoire aux Alpilles, éd. Univ. de Provence, pp. 17-44.

Limbrey 1983 : LIMBREY(S.) - Archaeology and Palaeohydrology. In : Background to Palaeohydrology, ed by K.J. Gregory, J.Wiley \& sons, New York, p. 189.

Macaire 1990 : MACAIRE (J.) - L'enregistrement du temps dans les dépôts fluviatiles superficiels : de la géodynamique à la chronostratigraphie. Quaternaire, 1, pp. 41-49.

Macphail 1983 : MACPHAIL (R.I.) - The micromorphology of Dark earth from Gloucester, London and Norwich : an analysis of urban anthropogenic deposits from the Late Roman to Early Medieval periods in England. In : P. Bullock and C. P Murphy Ed., Soil Micromorphology, Academic publishers, Berkstamsted, pp. 245-252.

Macphail, Roman, Roberson 1987 : MACPHAIL (R.I.), ROMAN (J.C.), et, ROBERSON (L.) - The application of micromorphology to the understanding of Holocene soil development in the British Isles ; with special reference to Holocene cultivation. In : N. Federoff, L-M. Bresson et M.-A. Courty (eds), Micromorphologie des sols, AFES Plaisir, pp. 647-657.

Macphail, Courty, Gebhard 1990 : MACPHAIL (R), COURTY (M.A.) et GEBHARD (A.) - Soil micromorphological evidence of early agriculture in North West Europe. World Archaeology, 22, pp. 53-69.

Magny 1993 : MAGNY (M.) - Un cadre climatique pour les habitats lacustres préhistoriques ?.C. $R$. Acad. Sc. Paris, t. 316, série II, pp. 1619-1625.

Mandier 1984 : MANDIER (P.) - Le relief de la moyenne vallée du Rhône au Tertiaire et au Quaternaire. Essai de synthèse paléogéographique. Thèse de doctorat d'Etat présentée devant l'Univ. de Lyon II. 3 t. : 1-texte, 2 tab. et fig., 3-pl. et cartes.

Odes 1995 : ODES (B.) - « Saint-Saturnin : un site fortifié de l'Antiquité tardive », Recherches Donzéroises, $\mathrm{n}^{\circ} 21$.

Odiot 1985 : ODIOT (T.) - Occupations fortifiées de hauteuren Tricastin, Actes du colloque. Les Alpes à l'âge du Fer. Revue archéologique de Narbonnaise, supp. 22, 57-72.

Odiot 1994 : ODIOT (T.) - Habitat, sols et cadastres dans le Tricastin. In : F. Favory, J.-L. Fiches éd., Les Campagnes de la France méditerranéenne dans l'Antiquité et le haut Moyen Age, Paris, pp. 73-107.

Odiot sous presse : ODIOT (T.) - le site du mollard à Donzère. fiche Harur. 
Poupet 1994 : POUPET (P.) - Sols paléosols et prospections archéologiques. In : F. Favory, J.-L. Fiches éd., Les Campagnes de la France méditerranéenne dans l'Antiquité et le haut Moyen Age, Paris, pp. 311-324.

Piganiol 1962 : PIGANIOL (A.) - Les documents cadastraux de la colonie romaine d'Orange, XVIe suppl. à Gallia.

Rosen 1986 : ROSEN (A.M.) - Cities of Clay : The Geoarchaeology of Tells. Univ. of Chicago Press, Chicago.

Simmons, Innes 1987 : SIMMONS (I.G.) et INNES (J.B.) - Mid-Holocene adaptations and later mesolithic forest disturbance in Northern England. Journal of Archaeological Science, 14, 385-403.

Stein. Farrand 1985 : STEIN (J.K.), FARRAND (W.R.)., - Archaeology Sediments in Context. Peopling of the Americas. Center for the Study of Early Man, University of Maine, Orono.

Vital 1990 : VITAL (J.) - Protohistoire dans le défilé de Donzère. L'âge du Bronze dans la Baume des Anges (Drôme). Editions de la Maisons des Sciences de l'Homme D.A.F. nº 28, Paris, 152 p.

Waters 1992 : WATERS (M.R.) - Principles of Geoarchaeology : a North American Perspective, University of Arizona Press, 387p.

\section{Documents}

Beeching et al. 1994 : BEECHING (A.) et al., - Rapport de la fouille néolithique et protohistorique du site de Montélimar-Goumier (Drôme), 80p, 109 pl. de fig. (non publié).

Chartier et al. 1995 : CHARTIER (A.), CHOUQUER (G.)., JUNG (C.) et TSCHANTZ (X.), La gestion de l'eau. In : rapport ARCHAEOMEDES project, sous la direction de S. Van Der Leeuw, chap 15, pp. 283-296.

Favory, Girardot, Zannier 1995 : FAVORY (F.), GIRARDOT (J.J.), ZANNIER (M.P.), La perception des sols et des plantes chez les agronomes romains. In : rapport ARCHAEOMEDES project, sous la dir. de S. Van Der Leeuw, chap. 7, pp. 73-111.

\section{NOTES}

1. Palynologues, anthracologues, malacologues, carpologues et autres spécialistes des phytolithes.

2. Spécialistes des analyses du rapport 018/016, des fluctuations $d u{ }^{13} \mathrm{C}, \mathrm{du}{ }^{14} \mathrm{C}$ ou du méthane dans l'atmosphère.

3. - "D'un point de vue méthodologique, il est capital de travailler simultanément à plusieurs échelles, c'est-à-dire à plusieurs niveaux d'analyse correspondant à des objets de plus en plus complexes. A chaque échelle, l'unité systémique change, mais demeure le principe voulant qu'on l'étudié dans l'environnement formé par le niveau d'organisation supérieur" (Godart et Legay 1992). On peut par exemple citer la succession croissante : sol, unité de paysage, bassin-versant de rang inférieur (fig. 2). Ils sont autant de systèmes (pédo-bio-hydrologiques) emboîtés dont il faut caractériser le fonctionnement par une étude systématique de leurs composants et des processus qui les caractérisent. La variété des composants et la complexité de leurs relations augmentent lorsque la surface du système s'accroît et que les facteurs topographiques, hydrologiques et/ou lithologiques changent. 
Géoarchéologie des vallées et cours d'eau 


\title{
Géoarcheologie des vallées alluviales de Rhône-Alpes depuis le Tardiglaciaire
}

\author{
Jean-Paul Bravard
}

Agnès Vérot-Bourrély, Maurice Jorda et Michel Magny ont bien voulu faire une lecture critique et constructive de ce texte; qu'ils en soient sincèrement remerciés.

1 En moins de quinze ans la connaissance de l'archéologie et du paléo-environnement des fonds de vallée a connu un essor remarquable en Europe et dans le monde. La région Rhône-Alpes, riche de grands organismes fluviaux, fortement peuplée dans l'Antiquité, riche de sites urbains gallo-romains, a permis de réaliser une moisson d'observations. Celles-ci sont essentielles pour relier les acquis enregistrés depuis plus de vingt ans en Europe du Nord (Needham \& Macklin 1992 ; Starkel 1995) et dans l'Europe méditerranéenne (Pena Mone \& Sancho Marcen 1988; Leveau \& Provansal 1993 ; Lewin et al 1995), et construire à terme un ensemble cohérent à l'échelle de l'Europe occidentale.

2 En Rhône-Alpes, les vallées alluviales ont constitué et constituent des axes de peuplement et d'échanges majeurs dans une région aussi compartimentée par le relief. La complexité et la diversité spatiale de la mise en place des remblaiements alluviaux au Tardiglaciaire et à l'Holocène font que la taphonomie des sites archéologiques et le potentiel des milieux susceptibles de fournir des informations paléoenvironnementales méritent une approche clarificatrice préalable. L'occupation humaine a été dense à certaines époques et les villes gallo-romaines constituent des secteurs-clés pour la compréhension des relations entre les sociétés humaines et les cours d'eau. 


\section{Potentiel archeologique des vallées fluviales : principes de la taphonomie}

3 Une des préoccupations majeures de la politique archéologique concerne la sélection des sites à risque lorsque sont prévues des opérations d'aménagement du territoire de grande envergure, telles que la construction des autoroutes, de voies de chemins de fer, de zones industrielles ou de barrages-réservoirs. Des ouvrages mineurs, tels que des routes ou des bâtiments, sont susceptibles de poser des problèmes de même nature, même si l'ampleur des dégâts potentiels est plus limitée. Les vallées alluviales sont, à cet égard, des milieux tout à fait spécifiques.

4 En premier lieu, un des acquis des études réalisées depuis une quinzaine d'années réside dans le fait que les fonds de vallée ne peuvent plus être considérés comme des espaces homogènes dans lesquels le risque archéologique serait, en quelque sorte, inversement proportionnel au risque d'inondation. Certains fonds de vallée, considérés comme des lits majeurs aujourd'hui exposés, recèlent un patrimoine archéologique riche et diversifié, associant des sites du Paléolithique, du Néolithique, de l'âge du Bronze ou de l'époque médiévale ; les hiatus éventuels de l'occupation y sont davantage interprétés comme des phénomènes de vide culturel plutôt que comme des manifestations d'un déterminisme physique excluant l'implantation ou la fréquentation par les hommes. En revanche, d'autres fonds de vallée ont un patrimoine archéologique restreint dans la durée, comme si des segments de la Préhistoire ou de l'Histoire avaient seuls été enregistrés dans les dimensions horizontale et verticale de l'espace fluvial: vide total avant l'âge du Fer, densité de l'occupation gallo-romaine, vide médiéval etc... En fait, l'hétérogénéité du potentiel archéologique provient, dans la plupart des cas, d'une mise en place complexe qui fait largement appel aux données de la paléodynamique fluviale.

5 Pour la simplicité de l'exposé, il est préférable de ramener les vallées alluviales du bassin du Rhône à cinq types.

\section{Les vallées englacées au Würm : un patrimoine Holocène fossilisé}

$6 \mathrm{Au}$ Quaternaire, les périodes de refroidissement climatique se sont manifestées par la mise en place de masses glaciaires qui ont rempli et surcreusé les vallées alpines et débordé sur l'avant-pays. La limite maximum de l'avancée glaciaire du Würm et les modalités de la déglaciation sont bien connues depuis les travaux de F. Bourdier (1960-61), Y. Bravard (1963) ; elles ont été reprises et précisées par P. Mandier (1984 et 1988), G. Monjuvent et G. Nicoud (1988) puis Campy et al. (1990) : on situe cette limite notamment sur les amphithéâtres morainiques de Saint-Maurice-de-Gourdans (basse vallée de l'Ain), Grenay (haut-Rhône) et de Rives (Isère). Sauf exceptions, au nombre desquelles on peut compter des sites de grottes, les versants et les fonds de vallée ont fait l'objet de profonds remaniements par l'action des glaces et ont été des sites de dépôt de sédiments morainiques qui ont détruit ou, au mieux, oblitéré les traces d'occupations antérieures. Après la déglaciation, encore mal datée, mais qui s'est produite après le maximum de $18000 \mathrm{BP}$ et peut-être plus tardivement au cœur des Alpes, les fonds de vallées, surcreusés en ombilics glaciaires, sont devenus des cuvettes lacustres ; l'extension actuelle du lac Léman, des lacs d'Annecy et du Bourget ne donne qu'une image très réduite du paysage lacustre de la déglaciation (Monjuvent 1988), soit 
que ces cuvettes aient été comblées par des apports sédimentaires, soit que les seuils naturels qui contrôlaient l'exutoire aval aient été érodés par les émissaires lacustres, comme dans le cas du Rhône émissaire du Léman (Bravard 1986), de l'Arve (Peiry 1988 \& 1990) ou de l'Isère dans l'ombilic de Moirans (Salvador, 1991). La géométrie des cuvettes est restée la même lorsque l'émissaire n'a pas tranché le seuil contrôlant l'ombilic à l'aval ; c'est le cas du Rhône à l'amont de Sault-Brénaz, dans la petite région des Basses Terres. En revanche, lorsque l'incision du seuil aval a partiellement vidangé les cuvettes lacustres tardiglaciaires, les parties exondées ont subi une évolution subaérienne sous l'effet de processus propres aux versants ou aux basses terrasses (Peiry 1990) ; leur potentiel archéologique est, de ce fait, fonction de l'ancienneté de la vidange lacustre (fig. 1).

1- Le potentiel archéologique des vallées rhône-alpines

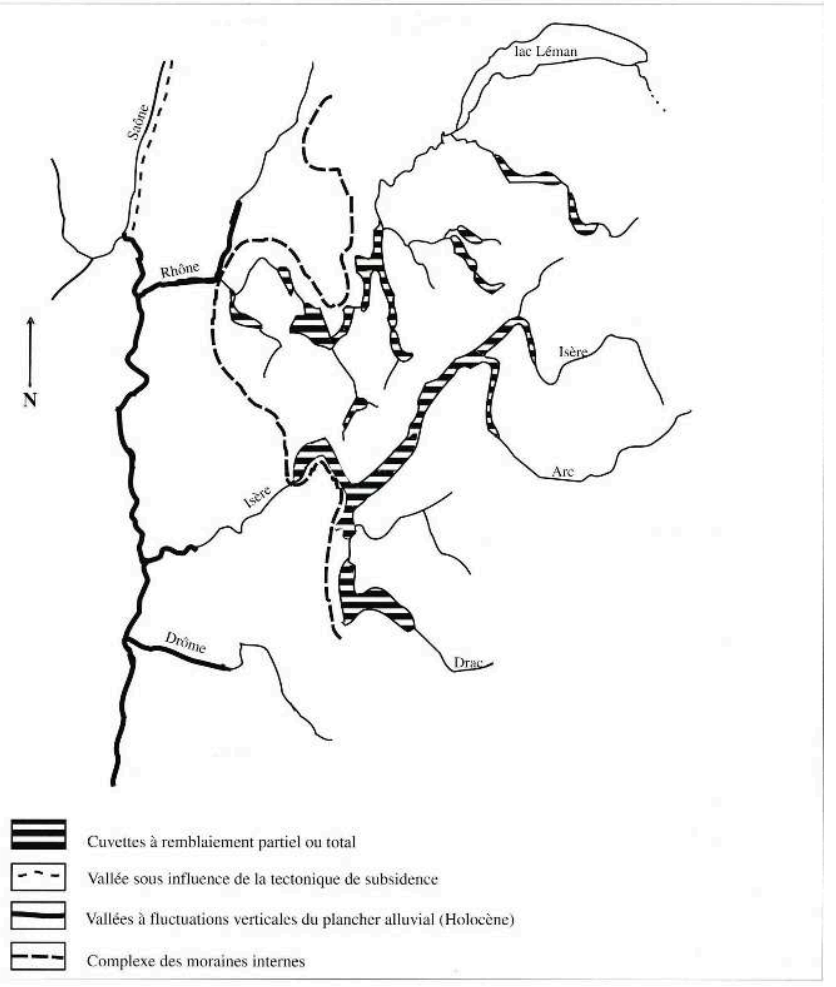

7 Ces vallées glaciaires, qu'elles soient occupées ou non par des cuvettes lacustres, encore en eau ou fossiles, présentent trois types de milieux susceptibles de détenir un patrimoine archéologique.

\section{Des milieux à très active dynamique fluviale et torrentielle tardiglaciaire et Holocène}

Ces milieux sont caractérisés par des apports sédimentaires de type «cônes de déjections » qui ont progressé vers l'aval et qui se sont exhaussés au fil des millénaires. Le plus bel exemple est la Chautagne qui est une cuvette pour laquelle on proposera l'expression de cuvette à " capitalisation sédimentaire et archéologique agradante » car le matériel découvert est fossilisé à différentes profondeurs en fonction de son ancienneté relative : troncs subfossiles à Anglefort (Lamouille et al. 1985) (fig. 2) et matériel du Bronze (Seyssel) à la base, stèles, atelier de céramique et appontement 
gallo-romains (Portout et Châtillon) à une profondeur d'environ $2 \mathrm{~m}$, site gallo-romain et du Haut Moyen-Age à Condate ; carrières romaines de Surjoux envahies par la charge de fond du Rhône (Savay-Guerraz 1985). Il est probable que le Grésivaudan recèle un potentiel analogue, comme la présence de très nombreux troncs subfossiles dans les derniers mètres du remplissage le laisse pressentir.

\section{2- Tronc subfossile à Anglefort}

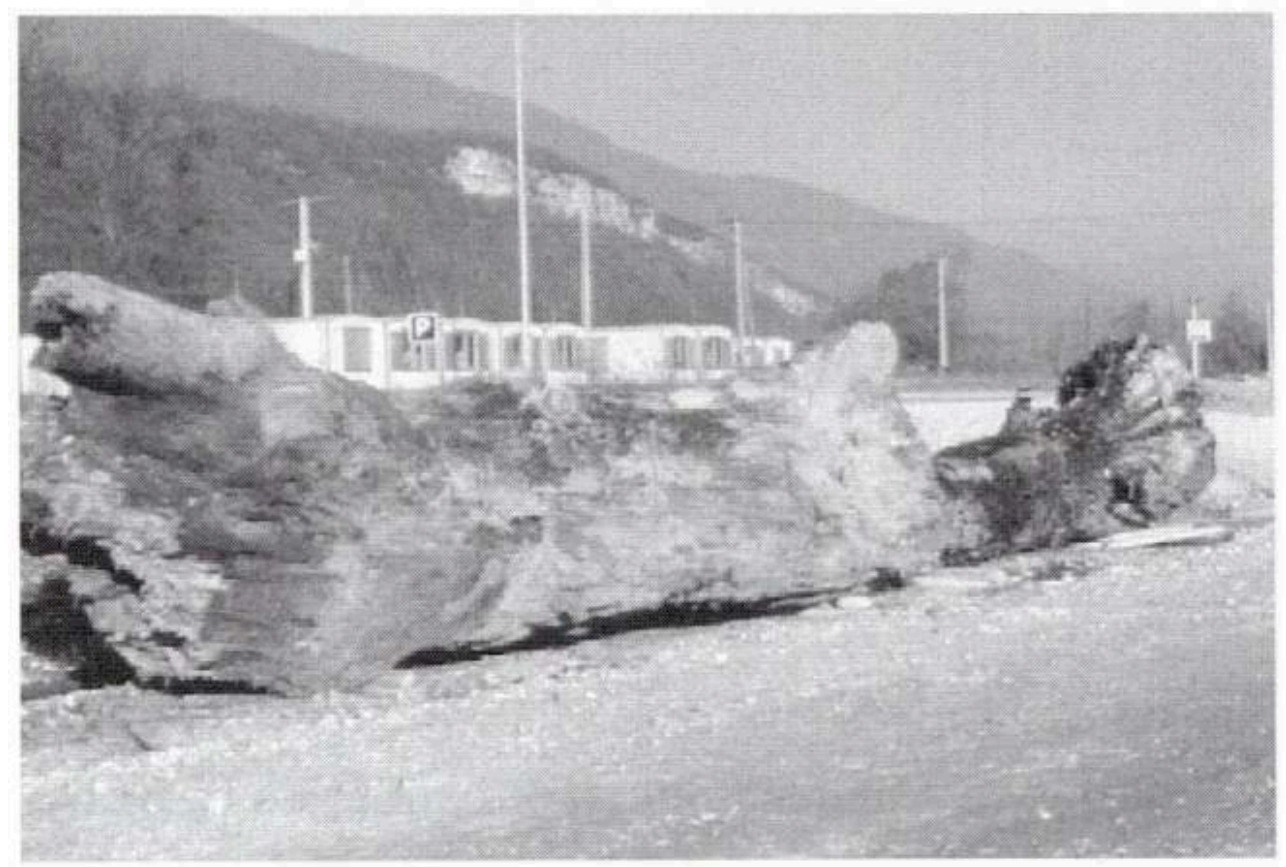

\section{Des milieux fluviaux à méandres mobiles}

9 La partie distale des cuvettes remblayées présente une morphologie de plaine à faible pente à la surface de laquelle se déplaçait un cours d'eau à méandres libres relativement actifs transportant une charge de fond de petit calibre. C'est la cas du Rhône contemporain dans les Basses Terres à l'aval d'Evieu et de l'Isère à l'aval de Saint-Quentin dans l'ombilic de Moirans. Ces plaines ont été favorables à des phénomènes de métamorphose fluviale, c'est-à-dire de substitution durable d'un style fluvial à un autre en réponse à des changements hydro-climatiques de grande ampleur. P.-G. Salvador (1991) a montré que l'Isère méandrait à l'époque galloromaine et que le balayage était tel que la rivière a abandonné des paléoméandres (recoupés) sur les marges de la plaine. Le Petit âge Glaciaire (début XIV e - fin XIX e s.), aux hivers froids et secs, a cependant été une période globalement favorable aux crues et aux processus érosifs du fait de printemps et d'étés frais et humides, voire orageux; cette période a provoqué la progradation d'une masse de cailloutis issue du bassin du Drac qui a détruit la partie axiale de la bande de méandrage galloromaine et médiévale. En revanche, dans les Basses Terres du Bas-Dauphiné (plaine du Bouchage), la présence conjointe de trains de méandres galloromains et de l'âge du Bronze laisse présager un potentiel riche (Bravard 1996). 


\section{Des milieux faiblement dynamiques à sédimentation organo-minérale}

10 Les cuvettes de surcreusement glaciaire sont aujourd'hui occupées par des bandes à activité fluviale ou torrentielle, à transport caillouto-sableux et à style en tresses. Du fait de leur extension et des hasards du travail de l'érosion glaciaire, ces cuvettes de surcreusement peuvent posséder des excroissances latérales. Ces marges sont favorables au dépôt de sédiments fins issus du dépôt par suspension dans des ambiances lacustres et fluvio-lacustres ; c'est le cas dans le Marais de Lavours en Bugey. Ces espaces, sans doute formés dès le Boiling, ont gagné en extension à l'Atlantique car les caractères climatiques de la période (forte évapotranspiration, remontée en altitude de la limite supérieure de la forêt) ont eu pour conséquences directes et indirectes de réduire l'activité des cours d'eau. Il en est résulté une contraction spatiale de la bande d'activité des cours d'eau montagnards à chenaux multiples et la formation de marais latéraux ou arrières-marais, comme ceux de Chautagne, Lavours et Champagneux sur le Haut-Rhône (Bravard 1986).

11 D'origine différente, puisqu'il s'est formé à la suite d'une défluviation de grande ampleur du Rhône, est le cas du Marais des Avenières qui a intrigué les archéologues du fait de la présence de fonds de cabanes et de matériels de pêche fluviale gallo-romains. Une tourbification post-fluviale remontant probablement au Haut-Empire a fossilisé jusqu'à nos jours le paysage de berges des méandres du Rhône (Bravard 1983).

\section{3- Tourbière au confluent du Giffre et de l'Arve}

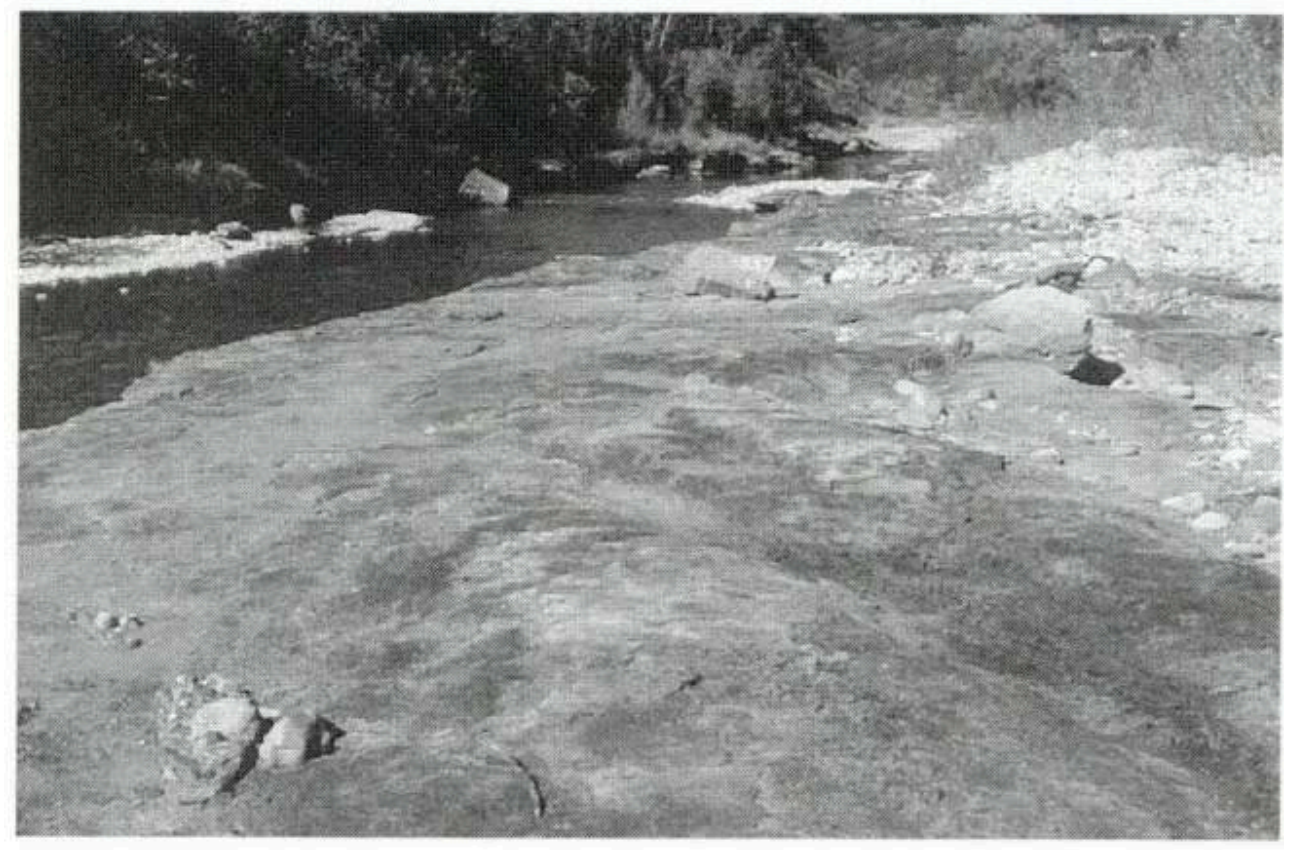

12 Il est enfin fort possible que, dans certaines vallées alpines, la dynamique érosive des versants et l'hydrologie de crue aient pu être assez réduites à l'Atlantique pour annihiler ou très fortement réduire le transport de la charge de fond. Ce pourrait bien être le cas de la moyenne vallée de l'Arve à l'aval de Cluses où J.-L. Peiry (1988) a reconnu une sédimentation organo-minérale entre $9760+/-100$ BP (Gif-7255) et 8570 +/-90 BP (Gif-7256). Il y a sans doute, dans cette vallée, un potentiel considérable enfoui sous plusieurs mètres de galets ; en témoigne la découverte de pieux du XIIIe s. plantés 
dans la tourbière d'âge boréal et fossilisés ensuite par une vague de sédiments caillouteux (fig. 3, 4). Cette découverte fut réalisée au confluent du Giffre et de l'Arve grâce à l'enfoncement des deux cours d'eau (Peiry 1986).

\section{Des milieux lacustres, sites archéologiques par excellence}

Soit que la masse d'eau ait été trop volumineuse par rapport aux apports sédimentaires entrants (cas du lac Léman, des lacs d'Annecy et d'Aiguebelette et d'une foule de petits lacs jurassiens), soit que la masse lacustre ait été isolée par sa localisation (cas du lac du Bourget que ses tributaires annexes n'ont pu combler), un certain nombre de cuvettes se sont maintenues. Nous n'aborderons pas ici l'analyse de ce type de milieu dans la mesure où il fait l'objet de développements dans ce volume par M. Magny. Signalons cependant le cas remarquable du lac du Bourget qui fut un excellent enregistreur de l'exhaussement du cours du Rhône à l'Holocène dans la mesure où le lac et le fleuve ont partie liée. Les sites archéologiques y sont à une profondeur décroissante du Néolithique à l'époque gallo-romaine; ceci traduit un exhaussement net même si ont existé de courtes phases de régression (Magny \& Richard 1985).

\section{4- Pieux plantés dans la tourbière d'âge Boreal au confluent du Giffre et de l'Arve}

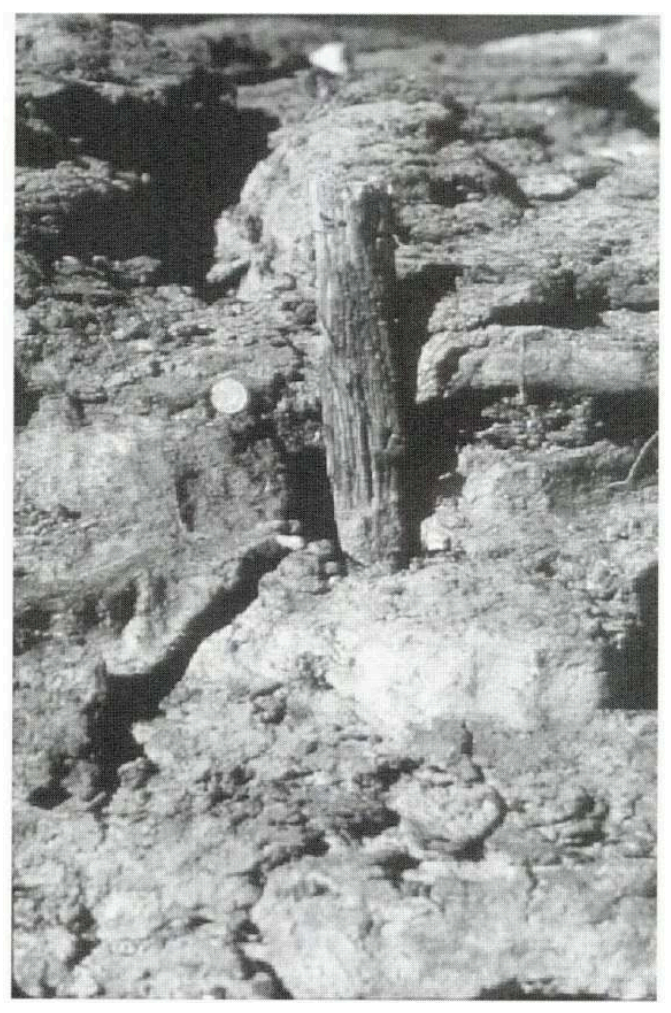

\section{Les vallées des piémonts non englacés : un potentiel difficile à évaluer}

Le phénomène majeur que les fonds de vallée non englacés ont connu est la succession d'une puissante phase d'épandage fluvio-glaciaire caillouto-sableux et d'une incision tardi-würmienne rapide qui amena les cours d'eau à un niveau proche du niveau moderne. Dans la vallée du Rhône, P. Mandier (1984) a interprété la phase 
d'enfoncement comme le résultat du recul et de l'abaissement des fronts glaciaires würmiens et du tarissement de la charge. Tous les fonds de vallée situés en contrebas de la dernière terrasse fluvioglaciaire y ont longtemps été interprétés comme des fonds de vallée holocènes tapissés des alluvions modernes des cartes géologiques. Cette phase d'incision doit affecter également les bassins non englacés, comme cela a été démontré dans certains bassins de la moyenne Durance, dans les Alpes du Sud (Jorda 1980 \& 1988 ; Rosique 1996).

15 C'est le travail interdisciplinaire réalisé à l'occasion des prospections archéologiques qui a permis de saisir en partie la complexité des remplissages sédimentaires de ce type de vallées, notamment du Rhône et du cours aval de quelques affluents comme l'Ain et la Drôme. Il faut en chercher l'explication dans l'histoire des fluctuations hydroclimatiques qui ont fait se succéder des phases de stockage et de déstockage sédimentaire sur le piémont alpin. Des processus comparables à ceux qui ont permis la mise en place des terrasses fluvio-glaciaires à l'échelle du Pléistocène ont joué à l'échelle de temps des quinze derniers millénaires, mais avec une ampleur verticale très atténuée du fait de la nature très différente des fluctuations hydro-climatiques enregistrées. Par ailleurs, les recouvrements fins déposés par les crues sur les lits majeurs ont fréquemment oblitéré les niveaux et donné une fausse impression de régularité topographique.

Les principales phases de déstockage sédimentaire ou vidange partielle des fonds de vallée ont été l'AllerØd (Brochier et al. 1991 ; Bravard 1997), le début de l'Atlantique et le Subboréal (Macé et al. 1989); des phases mineures ont été mises en évidence à la Tène sur le site de Vienne (Bravard et al. 1989d) et au X-XIIIe s. Ces constatations ont également été faites dans les Alpes du Sud et en Basse-Provence (Jorda 1992 ; Provansal 1992 ; Leveau \& Provansal 1993). Elles peuvent s'expliquer par l'existence de pulsations climatiques favorables à la phyto-stabilisation des versants et à leur protection vis-à-vis des processus d'érosion, notamment dans les montagnes, et à des bilans hydrologiques faiblement positifs. Pour expliquer l'enfoncement des cours d'eau, il convient d'admettre que les capacités de transport des cours d'eau excédaient les apports en sédiments grossiers formant la charge de fond, de sorte que le remplissage caillouteux des fonds de vallée a servi de source sédimentaire pendant les périodes concernées.

Pour l'ensemble des Alpes et de la vallée du Rhône, les principales phases de remplissage sédimentaire par apport de charge de fond (cailloutosableuse) sont le Dryas récent-Préboréal, la période de l'Atlantique, le Premier âge du Fer et le Petit âge Glaciaire (Jorda 1985 ; Bravard \& Evin 1989 ; Jorda et al. 1990 ; Berger 1995 ; Ballandras 1997; Bravard 1997). Elles peuvent s'expliquer par des périodes de péjoration climatique responsables d'un abaissement de la limite supérieure de l'arbre voisin de $200 \mathrm{~m}$ par rapport aux périodes plus chaudes et d'une réduction de la protection assurée par les formations végétales vis-à-vis des processus d'érosion sur versants. Les conditions hydrologiques, et en particulier le régime des précipitations, ont été d'autres facteurs favorables au transport d'importantes quantités de charge de fond. La réduction de la pente au débouché des massifs montagneux et la largeur des planchers alluviaux, en diminuant les forces tractrices, ont permis le dépôt de la charge de fond et un important stockage sédimentaire. Ces masses d'alluvions accumulées sont partiellement reprises lors de la phase de déstockage suivante de sorte que le transport de charge par les cours d'eau peut persister plusieurs décennies, même si les conditions phyto-climatiques réduisent les entrées de charge dans le système fluvial. 

processus paraglaciaires dans la fourniture en sédiments au Tardiglaciaire et à l'Holocène, c'est-à-dire la reprise durable de matériaux morainiques et fluvio-glaciaires par les processus torrentiels et fluviatiles. Il semble que dans la haute vallée du Doubs, les processus paraglaciaires soient restés actifs durant l'Allerød car le rythme de remplissage du lac de Chaillexon n'a pas faibli (Campy et al. 1994). L'essentiel de la charge de fond mise en mouvement dans la vallée du Rhône à l'aval du confluent de l'Ain provient de reprises aux dépens des terrasses fluvio-glaciaires de la Bienne et de l'Ain. L'épuisement progressif des sources de matériaux a cependant fait que les niveaux de remblaiement holocènes sont d'altitude décroissante mais l'étagement se fait dans une fourchette d'altitude inférieure à 2-3 $\mathrm{m}$ dans la plupart des cas. Il ne faut pas omettre d'impliquer les actions humaines dans la déstabilisation des versants pour expliquer la mobilisation de la charge de fond. L'intense activité d'élevage mise en évidence dans le haut bassin de la Drôme dès le Mésolithique expliquerait l'ampleur de l'accumulation enregistrée sur le cône de déjections de ce cours d'eau (Brochier et al. 1991).

19 Loin d'être homogène et formée d'un lit majeur lentement exhaussé par le dépôt de limons de débordement, comme le schéma classique le suggère, la surface des plaines alluviales est donc, en réalité, caractérisée par la présence d'une mosaïque d'unités géomorphologiques hétérochrones et dénivelées les unes par rapport aux autres de quelques décimètres à quelques mètres. Ces unités spatiales correspondent en général à des phases d'accumulation ou de légère incisionstabilité (Bravard et al. 1991; Berger 1995).

20 Les niveaux alluviaux correspondant aux phases d'incision-déstockage les plus marquées ne sont pas visibles en surface puisqu'ils sont fossilisés par des dépôts ultérieurs. Ainsi est-on en droit de penser que, dans la vallée du Rhône, le plancher alluvial d'âge Allerød et d'éventuelles industries associées sont entièrement fossilisés sous plusieurs mètres de cailloutis. La rareté des découvertes de matériel archéologique remontant à la Tène finale pourrait localement s'expliquer ainsi, ce qui n'exclut pas des découvertes en lit mineur (Chapotat et al. 1987). Par érosion régressive, les rivières affluentes ont pu connaître des rythmes semblables dans leur cours aval (Gadiolet et al. 1993 ; Berger 1995).

\section{La vallée de la Saône : un potentiel exceptionnel}

21 La vallée de la Saône est une terre d'élection de l'archéologie en milieu alluvial et fluvial. Depuis les découvertes de De Mercey et les travaux d'Arcelin dans les années 1870-1890, la Saône est une référence pour la Protohistoire et pour les périodes plus récentes : du Néolithique à l'époque gallo-romaine, des niveaux d'occupation séparés par quelques décimètres de limon de débordement se suivent avec régularité sur l'ensemble du linéaire de berge ; c'est là que fut mis au point le principe du chronomètre selon lequel la constance de l'épaisseur des lits de limons séparant ces niveaux permettait de dater les sédiments. En revanche, le fond paraît assez stable puisque les seuils naturels permettent la découverte d'artefacts appartenant aux différentes périodes préhistoriques et historiques. Cette superposition des périodes culturelles a permis de mettre en évidence le rôle de la tectonique de subsidence, en particulier entre Chalon et Mâcon (Journaux 1956 ; Bourdier 1960-61), suite au déplacement vers 
l'ouest de la zone de subsidence bressane active depuis la fin du Tertiaire (Petit 1993). Elle a également permis à $\mathrm{F}$. Bourdier et à ses prédécesseurs de souligner l'importance particulière de la sédimentation limoneuse en lit majeur, qui a été qualifiée d'anthropogène.

Les prospections et les fouilles réalisées dans le secteur de la plaine alluviale située entre Villefranche et Quincieux ont permis de nuancer les interprétations précédentes et de fournir une nouvelle clé de lecture. En effet les caractères originaux de la Saône ne s'expliquent pas seulement par le jeu de la tectonique; il convient de faire appel, en complément, à une évolution morphologique sous contrôle fluvial, le cours aval de la Saône influençant une partie importante du cours moyen. La position du niveau Allerød (les Argiles de la Caille que l'on rencontre de manière discontinue tout le long de la vallée) est due à la réalisation d'un profil d'équilibre en pente forte car la Saône rejoignait un cours du Rhône nettement plus bas que l'actuel. Il s'est probablement produit un phénomène de déstockage tardiglaciaire aux dépens des alluvions caillouteuses wurmiennes, avec mise en place d'un paysage de marais boisés sur le nouveau fond de vallée. Quant à l'accumulation progressive des limons dans lesquels les niveaux d'occupation sont interstratifiés, elle est favorisée par l'effet de barrage que l'importante charge de fond de l'Azergues a exercé à sa confluence avec la Saône, probablement dès le Dryas récent. De fait, on peut suivre à l'aval d'Anse une terrasse caillouteuse holocène qui se raccorde au plancher alluvial rhodanien sur le site de Lyon (Bravard 1997).

Cette interprétation a plusieurs implications :

- la présence d'une faune glaciaire dans les cailloutis du lit de la Saône ne signifierait pas que celui-ci ait été déprimé par le jeu de la tectonique. Le lit de la Saône serait un niveau d'érosion inscrit dans une nappe wiirmienne.

- l'effet de barrage par l'Azergues expliquerait l'épaisseur importante (5 à $6 \mathrm{~m}$ ) des sédiments fins à l'aval de Villefranche et le fait que la profondeur relative du niveau gallo-romain soit plus forte à l'aval que plus à l'amont. Ce fait, observé par C. Petit (1993), est en contradiction avec l'effet de la seule subsidence qui devrait au contraire avoir davantage déprimé le secteur entre Chalon et Mâcon.

- le secteur compris entre Anse et les abords de Lyon recèle un potentiel archéologique plus faible que l'amont, exception faite de Vaise. L'accumulation de nappes de gravier entre le Dryas récent et le Petit âge glaciaire a détruit ou fossilisé le niveau Allerød et d'autres niveaux éventuels.

\section{Les acquis de la recherche}

\section{Au carrefour de l'archéologie et des sciences de l'environnement}

Le fait le plus marquant dans le champ de la collaboration entre les sciences archéologiques et les sciences du paléo-environnement est probablement l'intégration de plus en plus poussée des approches de terrain. La coupe stratigraphique détaillée est le support commun d'une réflexion croisée sur la genèse d'une accumulation sédimentaire dans laquelle interviennent des éléments anthropiques et naturels. Les spécialistes convoqués. qu'ils soient géomorphologues ou géologues, palynologues ou malacologues, participent à la définition et à la délimitation des «unités 
stratigraphiques " qui sont les données de base de la confrontation ultérieure des hypothèses (Bravard et al. 1989).

Cette collaboration interdisciplinaire peut se mettre en place dès la phase préliminaire d'une opération de prospection, par exemple sur l'emprise d'une voie de communication. La recherche historique en archives et la géomorphologie fluviale ont servi conjointement à la délimitation des secteurs à potentiel archéologique dans la cuvette de Moirans, sachant que la bande de tressage fluvial moderne de l'Isère, identifiée et cartographiée avec précision en marge du cours d'eau aujourd'hui endigué, excluait toute découverte antérieure au XVIIIe s.

Dans le domaine de la géomorphologie et des sciences de la terre, l'adaptation de la méthode de Passega au paléo-environnement (Bravard et al. 1986) a permis de progresser dans l'interprétation des faciès granulométriques propres aux sédiments fins de recouvrement des lits majeurs et de remplissage des chenaux abandonnés. Moyennant des précautions, chaque faciès est indicateur de son appartenance à un type d'unité géomorphologique fluviale ou alluviale et descripteur du fonctionnement hydro-morphologique qui a permis sa mise en place (Salvador 1991a; Salvador \& Bravard 1995; Arlaud et al. 1994). L'emploi de la statistique a étendu le champ d'application à des milieux dont la stratigraphie n'est pas apparente, comme le remplissage de fossés médiévaux à Grenoble où différentes phases ont pu être mises en évidence (Peiry 1994).

La palynologie des sédiments alluviaux a donné des résultats prometteurs. Au confluent de la Drôme, une chênaie pourrait avoir été en place dès l'Allerød (11850 +/-400 BP ; Ly-4458) alors que le schéma classique décrit une forêt de pins dans la moyenne vallée du Rhône durant cette période ; la datation reste cependant à confirmer (Argant In : Brochier et al. 1991). Des sites de bras morts de la plaine alluviale lyonnaise ont été datés de l'Atlantique et de l'âge du Fer (Argant 1993). Dans le fond du vallon de Gorgede-Loup à Vaise (Lyon), la palynologie a permis de reconstituer des phases de défrichement agricole et d'abandon depuis la Protohistoire (Argant 1988; Vérot et al. 1995).

28 La malacologie a permis de préciser le degré d'ouverture du milieu dans le vallon de Gorge-de-Loup (Chaix In: Vérot-Bourrély et al. 1995). Signalons également l'intérêt potentiel d'autres méthodes relevant de la paléo-biologie, comme l'étude des cladocères fossilisés dans les sédiments des bras morts ou l'étude des diatomées; les populations de cladocères permettent de connaître l'évolution des conditions écologiques au fur et à mesure du remplissage, comme sur le site galloromain de la place Bellecour à Lyon (Bravard et al. 1986). On peut regretter que ces travaux très spécialisés et dépendant en général de travaux de doctorat, ne permettent pas une collaboration établie dans la continuité.

\section{Le sytème fluvial : un concept operationnel}

29 L'analyse du changement géomorphologique actuel et des transformations des paléoenvironnements est un thème à la mode. De fait, la sensibilité particulière des cours d'eau aux fluctuations hydro-climatiques et aux impacts anthropiques fait qu'ils sont de très bons marqueurs des perturbations à l'échelle des bassins versants. L'approche systémique fournit un cadre conceptuel commode à l'analyse des flux entrant dans le réseau hydrographique et permet d'expliquer les adaptations du fonctionnement 
géomorphologique en termes de réponses ou d'ajustements à la dynamique des flux hydriques et solides. Le concept de "système fluvial " (Schumm 1977), enrichi par la suite de sa composante écologique dans ce qui a été qualifié d'hydrosystème fluvial (Amoros \& Petts 1993), est un outil efficace d'analyse des interactions complexes à l'échelle des bassins versants. Le principe de base est que le réseau hydrographique accommode les flux hydriques reçus par le bassin versant et les flux de matières solides produits par les versants et/ou par le déstockage des sédiments des fonds de vallée. Le schéma synthétise trois modes d'approche complémentaires pour la compréhension du fonctionnement d'un système fluvial (fig. 5) :

1. A l'échelle des formes fluviales, l'étude géomorphologique enregistre les manifestations du fonctionnement ou du changement hydro-climatique. La forme et les dimensions de la section en travers, la sinuosité des méandres ou les formes des lits à fond caillouteux s'ajustent à des pas de temps courts alors que le type de style fluvial (tresses, méandres ou styles intermédiaires) et la pente de tronçons fluviaux ont un temps de réponse plus long, en général séculaire, les vitesses absolues dépendant de facteurs géographiques complexes.

2. Depuis les travaux de S. Schumm (1977) et de L. Starkel (1983), il est admis que les caractéristiques de forme (les variables libres) manifestent le mode d'ajustement du cours d'eau aux fluctuations des flux d'eau et de matière (la charge de fond) qui sont des variables externes. Les périodes durables de déséquilibre relatif de ces deux flux induisent l'ajustement des styles fluviaux. Par exemple, une phase pluridécennale de plus forte augmentation relative ou de moindre réduction des flux liquides par rapport aux flux solides induit un excès d'énergie dans le système fluvial. La dissipation d'énergie s'effectue par le biais d'un ajustement par réduction de la pente, ce qui peut se traduire par l'enfoncement et/ou une accentuation de la sinuosité d'un tronçon de cours d'eau. Dans l'autre sens, une forte augmentation de la charge de fond imposée au système fluvial par rapport aux flux d'eau susceptibles d'en assurer l'évacuation induit un exhaussement et/ou la tendance au tressage du tronçon fluvial concerné.

Il va cependant de soi que ce mode d'expression des flux est extrêmement rustique et que l'approche qualitative ne manifeste que des tendances évolutives en l'absence de données quantifiables. Ce mode d'approche présente cependant l'appréciable avantage de permettre un couplage complexe entre les processus et les réponses observables et de réaliser une modélisation sommaire. La démarche rétrospective qui part de l'observation des faits de terrain, c'est-à-dire des réponses, pour remonter aux causes des phénomènes et, en premier lieu, aux processus, peut ainsi procéder par analogie avec une certaine crédibilité.

3. Le dernier élément dans la démarche de compréhension du fonctionnement global du système est l'analyse des mécanismes de contrôle des flux entrants. Il est clair que les variables externes de contrôle des flux (la température et les précipitations) ne sont pas seules à commander les termes du bilan de l'eau dans les systèmes anthropisés. Les actions humaines sur les versants conditionnent l'état de la couverture végétale et des sols et, par voie de conséquence, l'évapotranspiration ainsi que le volume et les rythmes de fluctuation des réserves hydriques. Elles conditionnent également, par les types d'occupation et d'exploitation des terroirs, les modalités de la fourniture des matériaux des versants aux lits fluviaux ainsi que les possibilités de déstockage alluvial. 
5- Contrôles et réponses géomorphologiques

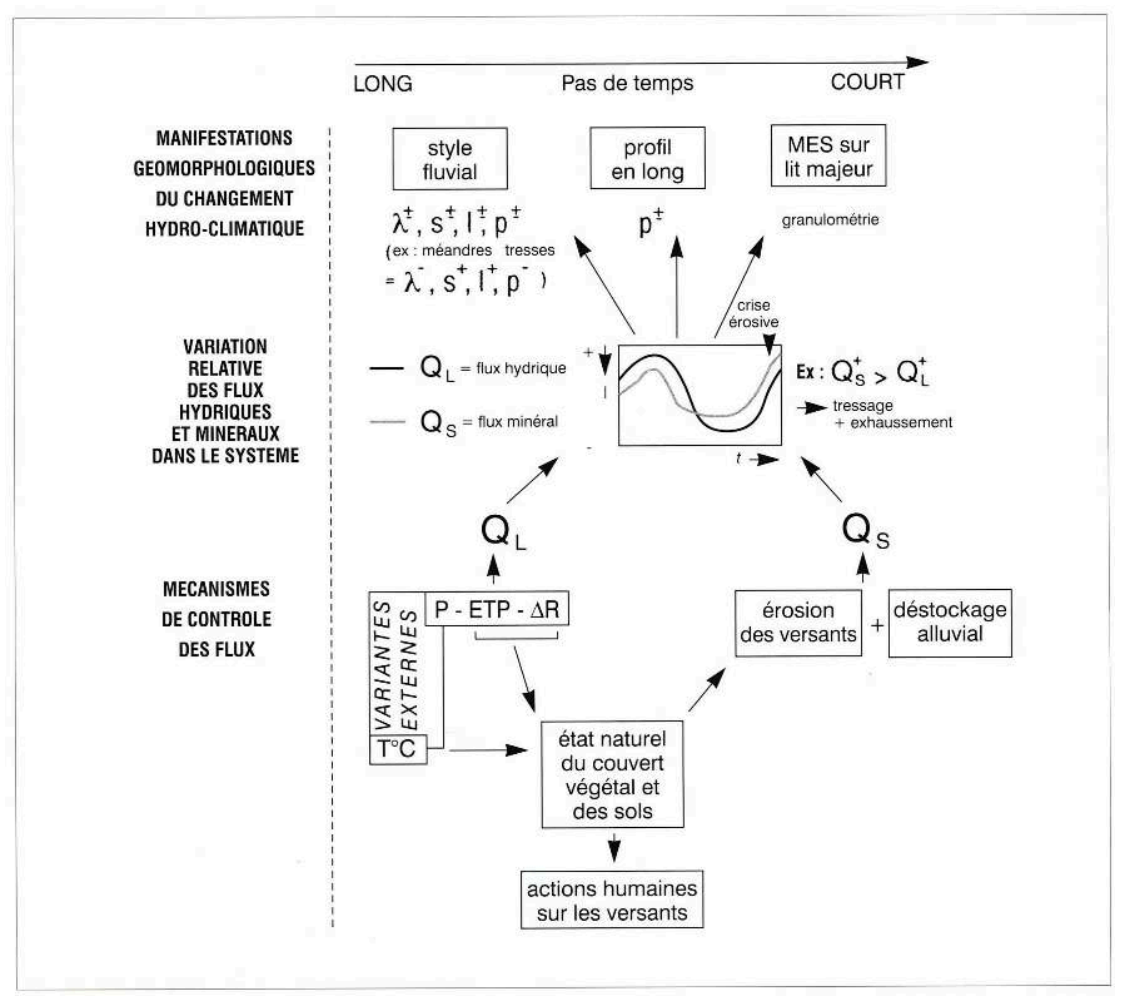
de fond grossier et des débits de crue morphogènes efficaces; seuls des changements forts à l'échelle des variables de contrôle sont susceptibles de produire une variation significative et durable des flux et des réponses géomorphologiques clairement identifiables à leur échelle. En revanche, les cours d'eau à fond caillouteux des piémonts de la France du Sud-Est sont des organismes fluviaux particulièrement sensibles aux fluctuations des flux hydriques et minéraux. Il faut sans doute voir dans ce caractère le fait que la forte pente des planchers alluviaux, la granulométrie relativement modeste des éléments constituant la charge de fond ainsi que l'augmentation de la fréquence des écoulements morphogènes consécutive aux défrichements, abaissent les seuils géomorphologiques de réponse des systèmes. En d'autres termes, la capacité de réaction des lits fluviaux à toute modification durable du volume de la charge de fond et des débits de crue est sans doute beaucoup plus forte que dans les cours d'eau de rang inférieur. Les variables libres, celles qui définissent la forme des chenaux, sont en équilibre précaire et donc en situation d'être ajustées en réponse à des stimuli de faible ampleur.

\section{Un bouleversement dans la connaissance des sites urbains gallo- romains}

Les connaissances ont sensiblement progressé sur les sites urbains de Rhône-Alpes. Certains quartiers des villes gallo-romaines de Lyon et de Vienne ont été construits en plaine alluviale ; c'est le cas de la presqu'île et du quartier Saint-Jean à Lyon, de SaintRomain-en-Gal et de la rive gauche du Rhône à Vienne. C'est le cas de la totalité du site de Grenoble, la Cularo gallo-romaine. L'apport essentiel des recherches réalisées depuis 
une dizaine d'années est la remise en cause d'une conception fixiste de l'environnement qui a longtemps fait juger des caractères négatifs des sites à l'aune des contraintes modernes.

\section{Des sites de plaine répulsifs?}

Les villes rhodaniennes ont durement souffert des crues au XVIIIe-XIXe s., en particulier en 1812, 1840 et en 1856, date à laquelle la digue en terre protégeant la rive gauche de Lyon lâcha, exposant le quartier de la Guillotière aux courants de débordement du Rhône. Lyon et Vienne aux époques moderne et contemporaine sont indubitablement des villes de lit majeur que les endiguements ne protègent qu'imparfaitement. Il en est résulté la croyance généralisée en la médiocrité pour ne pas dire la répulsivité des sites de plaine aux époques antiques.

Relisons A. Kleinclausz $(1925$, p. 5) à propos de Lyon: "pour qu'une ville puisse se constituer à l'abri de ce fleuve redoutable, dans ces vallées étroites et souvent inondées, sur ce sol incertain dominé par des collines abruptes, il faudra que l'homme parvienne à vaincre la nature ». Pour A. Desbats (1982, p. 29), « les difficultés du site interdisaient la traversée du Rhône à Lyon" avant la conquête romaine; pour J. Pelletier (1990, p. 18), « les implantations humaines ne pouvaient pratiquement pas se faire en bordure de fleuve » sur la rive gauche et « jusqu'à la fin du XVIIIe s., le Rhône est plutôt l'ennemi, une barrière peu franchissable et donc une frontière naturelle et politique ». A Vienne « le principal souci des architectes... fut de trouver des moyens de lutte contre l'humidité excessive du sol » (Leglay \& Tourenc 1971). Tel est également le cas de Grenoble bâtie au confluent de l'Isère et du Drac et sujette à de graves inondations en $1651,1711,1739,1740,1778,1812,1840,1843,1849$ et 1859 . Comme le soulignait Raoul Blanchard (1935), «il est difficile de trouver un site de ville plus exposé aux caprices de deux rivières irrégulières». La seule raison valable pour expliquer la création de Culciro dans le site "le plus plat de France» semblait être l'existence d'un tertre naturel «formant une plate-forme à peu près sèche, très rarement inondée par les eaux du Drac ou de l'Isère, et que nous avons vue épargnée par les grandes crues des XVIIIe et XIXe s. » (ibid., p. 63).

Jusqu'à une date récente, les historiens de l'Antiquité ont donc considéré que les villes galloromaines ont été construites en connaissance de cause dans un environnement particulièrement difficile, voire répulsif. Le même constat que celui-ci a été fait par $\mathrm{R}$ Leveau (1994) à propos du paysage d'Arles considéré comme marécageux à l'époque gallo-romaine par F. Benoit (1940). De même que les historiens et les archéologues ont «pris en otages » les géographes en considérant comme permanentes les contraintes naturelles des milieux, de même les naturalistes ont-ils érigé en postulat la «lutte séculaire de l'homme contre l'eau ». Les quartiers actuels qui ont succédé aux quartiers gallo-romains sont implantés dans le lit majeur moderne et contemporain du Rhône et ils ont subi, ou auraient pu subir sans les digues qui les protègent, des inondations très graves. Quelle aurait été la situation antique si l'on admet, qu'au surplus, ces quartiers ont connu un exhaussement de plusieurs décimètres à plusieurs mètres par des remblais urbains depuis l'Antiquité? 


\section{De très faibles contraintes naturelles à la Tène} inconsidérée et il ne faut pas juger de la qualité de ces sites à l'aune des contraintes modernes. A Lyon, les établissements de Saint-Jean et de la presqu'île se sont implantés sur une très basse terrasse caillouteuse mise en place au Premier âge du Fer (Macé 1990 ; Macé et al. 1992 ; Bravard et al. ce volume) ; ce niveau a subi un perchement relatif du fait d'une très probable incision à la Tène, comme ceci a été mis en évidence à Vienne (Bravard et al. 1989d). On peut également admettre que l'hydrologie du Rhône a été relativement calme dans la période sèche que fut la Tène et que les crues furent rares ; ce trait hydrologique pourrait même expliquer une implantation sur les berges mêmes du Rhône à Vienne, à l'époque augustéenne, soit en contre-bas de la très basse terrasse ( $n b$ : il ne faut cependant pas sous-estimer l'impact des aménagements postgallo-romains qui ont eu pour effet de resserrer le fleuve entre des digues ou sous des ponts et de relever les hauteurs atteintes par les crues). Quoi qu'il en soit, il n'a pas encore été possible de diagnostiquer la présence de couches d'inondation dans les niveaux d'occupation urbains antérieurs au 1er quart du 1er s. avant notre ère. L'interprétation du site de Grenoble faite par J.-L. Peiry et C. Féougier (ce volume) va dans le sens d'une installation gallo-romaine à la surface d'une plaine d'inondation régularisée par les alluvions de débordement de l'Isère, sans qu'il soit besoin d'invoquer la présence d'un môle naturel primitif pour la protéger des crues. $\mathrm{Ph}$ Leveau a fait le même constat pour l'Arles gallo-romaine où le cours du Rhône parait avoir été plus bas que l'actuel, comme en témoigne l'altitude du débouché des égouts antiques.

\section{La réactivation des contraintes fluviales et les politiques urbaines}

Les inondations réapparaissent au tournant de l'ère puisque quatre ou cinq niveaux de sédiments fins ont été repérés à Lyon au Ier s. ap. J.-C. Les anciens chenaux de tressage qui dilacèrent la presqu'île sont réanimés lors des crues; elles laissent des limons et abattent quelques murs, mais sans que l'urbanisation en soit découragée. Les entrepôts et autres éléments du bâti sont touchés, mais se maintiendront sans que la situation paraisse avoir été assez grave pour motiver la construction de digues. Une crue tous les 5 ou 10 ans pouvait être, après tout, jugée supportable ou ne pas justifier des investissements aussi lourds. La dynamique d'occupation urbaine est lancée et elle ne s'arrêtera pas, comme si la situation très favorable qui fut celle des premières années du site alluvial marquait à jamais les esprits ou que l'investissement réalisé ait nécessité un maintien sur place. On peut probablement considérer que la fréquence des inondations était très faible puisque les sites de plaine n'ont été inondés que quatre ou cinq fois en un siècle ; le risque de crue n'avait donc rien de dissuasif... Quoiqu'il en soit, des tentatives localisées d'exhaussement par remblaiement de la plaine alluviale ont été réalisées à Lyon; les tentatives recensées concernent des secteurs déprimés et sujets aux inondations ou à des vitesses de courant élevées, comme dans l'ancien bras Marsaux (Arlaud et al. 1994), sur les sites des places de la Bourse, de la République et des Célestins ; l'époque comprise entre les règnes de Claude et de Tibère parait avoir été une époque d'exhaussement artificiel et d'assainissement (Bravard et al, ce volume).

À Vienne, les bas quartiers des entrepôts sont décidément en situation trop risquée au Ier s. ap. J.-C. et on exhausse à l'aide de remblais jusqu'à atteindre la très basse terrasse 
dont subsiste un lambeau en rive gauche. L'effort consenti à Vienne parait être très supérieur à ce que l'on peut observer à Lyon. En revanche, le quartier de Saint-Romainen-Gal, sans doute bâti sur une ancienne île contemporaine de ce niveau, a été affecté par quelques épisodes de crue, mais sans que l'urbanisation paraisse s'en être ressentie. Reste la question de l'endiguement des zones inondables. Les fouilles réalisées à Lyon confirment leur présence, mais de manière très localisée sur trois sites de la presqu'île, soit sous les places Tolozan, A. Poncet et Gailleton (Vérot et al., ce volume). Il a pu s'agir de détourner les courants de crue mais rien ne prouve encore qu'une politique de protection contre les inondations ait été mise en œuvre à l'échelle de la presqu'île.

\section{Des espaces mobiles à l'échelle humaine}

Un des acquis les plus originaux concerne le site fluvial de Lyon. Les historiens et archéologues lyonnais ont toujours admis la quasi-stabilité spatiale des cours du Rhône et de la Saône, exception faite du déplacement de la confluence vers l'aval par Perrache au XVIIIe s., mais ont ardemment débattu de la possible existence d'un ou plusieurs bras du Rhône en travers de la presqu'île (on renverra à A. Desbats (1982) pour un résumé de ces scénarios). Il est de fait que l'iconographie actuelle privilégie une configuration, celle d'Amable Audin (Pelletier 1990; voir aussi la cartographie du Musée gallo-romain). Sans avoir encore fourni d'arguments définitifs sur ce point, les fouilles réalisées depuis 10 ans ont cependant renouvelé l'image du site lyonnais en apportant l'idée essentielle de l'instabilité géographique des lieux à l'échelle des quelque trois ou quatre siècles d'occupation.

43 Le bras Marsaux découvert par M. Audin (Russo et al. 1961) fut en réalité le cours principal de la Saône au Ier s. av. J.-C. Ce bras fut progressivement rempli de sédiments et de déchets urbains jusqu'à ne plus être fonctionnel au début du IIIe s. ap. J.-C. (Arlaud et al. 1994). Se pose alors la question de l'emplacement du cours actuel de la Saône dans l'Antiquité. Des arguments forts laissent penser que le tracé de la Saône actuelle s'est mis en place à l'époque gallo-romaine, peutêtre au Ier s. ap. J.-C. et qu'il a progressivement pris le dessus sur le Bras Marsaux jusqu'à s'y substituer complètement (Bravard et al. ce volume). Si cette hypothèse est exacte, la presqu't̂le avait une tout autre configuration puisqu'elle n'était séparée de la colline de Fourvière que par la Saône coulant à son pied.

Il est douteux que la presqu'île ait été coupée de manière permanente par un bras du Rhône, encore moins de la Saône. Les hypothèses évoquées dans la littérature ne se fondent que sur des arguments ténus et n'envisagent pas la possibilité de circulations éphémères en temps de crue. A l'emplacement de la place Bellecour (Vérot et al.1989), une dépression, sans doute un très vieux chenal, a servi lors des crues et a été particulièrement actif au Ier s. ap. J.-C. avant d'être remblayé et de ne plus subsister qu'à l'état de milieu humide. Les fouilles réalisées dans la presqu'île ont montré l'existence de chenaux fluviatiles peu profonds qui ont servi à l'occasion de crues du Rhône. La presqu'île était alors balayée dans le sens NE-SO par des flux d'eau et de sable.

\section{Marqueurs géomorphologiques et l'histoire hydro-climatique}

L'impossiblité de quantifier les flux solides et liquides du passé justifie le recours à une démarche qualitative. Les données n'étant pas disponibles pour une reconstitution du 
changement à l'échelle des trois derniers millénaires, l'accent a été mis sur l'analyse des manifestations géomorphologiques enregistrées et sur une simple hypothèse concernant le jeu relatif des variables de charge et de débit.

Deux périodes de tressage fluvial et degradation des lits fluviaux ont été clairement identifiées dans le bassin du Rhône (fig. 6).

6- Schéma simplifié représentant la variation relative des flux hydriques (OI) et des flux de charge de fond (Qs) des cours d'eau de la région lyonnaise depuis $\mathbf{3 0 0 0}$ ans

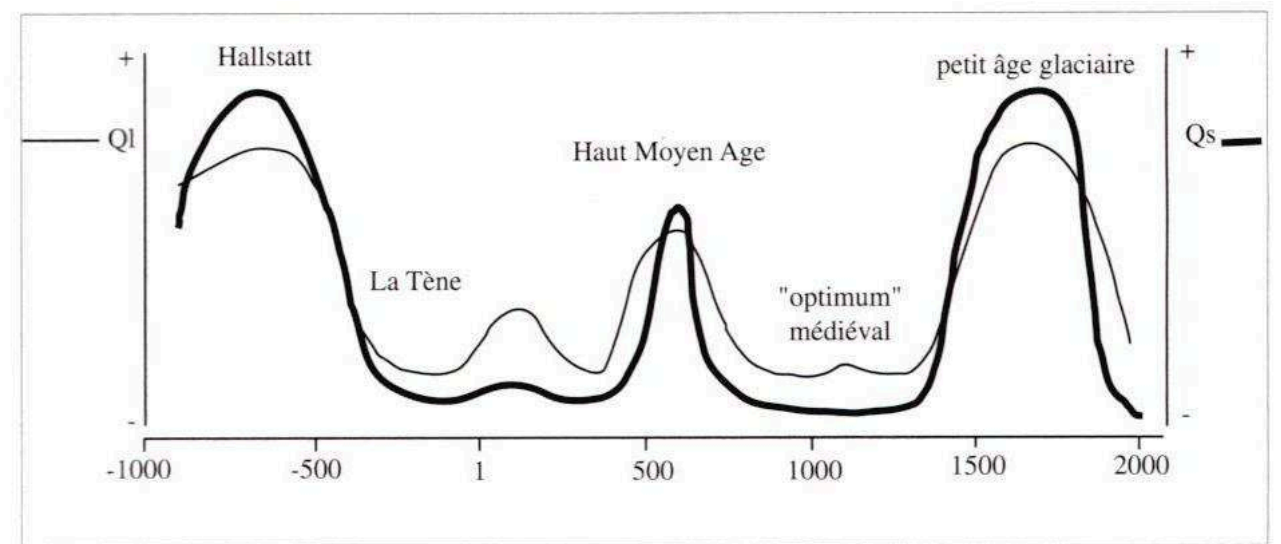

D'APRÈs BRAVARD et AL. 1992, (MODIfié)

LES VALEURS DONNÉES SONT INDICATIVES

Il s'agit du Premier âge du Fer qui est la période comprise entre environ les années 800 et les années $400 \mathrm{av}$. J.-C., sans que cette fourchette soit réellement calée dans le temps, et du Petit âge Glaciaire dont le début est vieilli au milieu du XIVe s. ap. J.-C. (Bravard 1989a) et qui s'achève à la fin du XIXe s. Ces deux crises majeures de très forte activité fluviale ont été décrites dans le bassin de la Durance (Jorda 1992 ; Provansal 1992), dans les Alpes du Nord et dans la région du Rhône moyen (Bravard et al. 1992). Elles sont interprétables par un changement durable (multiséculaire) des flux, de type $\mathrm{Qs}^{+}>\mathrm{Ql}^{+}$, l'excès de charge solide grossière se traduisant par l'impossibilité qu'avaient les cours d'eau d'assurer son évacuation. De là un raidissement de la pente de transport, un élargissement de la bande d'activité, une réduction de la profondeur des chenaux, une réduction de la sinuosité et une augmentation de la longueur d'onde des chenaux.

Il est à noter que la métamorphose fluviale ne peut s'exprimer à l'échelle du tronçon fluvial que si les deux flux liquide et solide sont altérés de manière synchrone. Autant il est clair que des tronçons montagnards réagissent avec rapidité aux injections d'eau et de charge solide, autant la réponse peut être différée sur les tronçons fluviaux éloignés des sources sédimentaires, ce qui est le cas dans les grandes vallées alpines et sur les piémonts. En effet les crues sont des événements enregistrés de manière immédiate sur l'ensemble du cours fluvial alors que la charge grossière se déplace de manière progressive et relativement lente vers l'aval. Une étude réalisée sur l'Isère en Grésivaudan a montré qu'à la fin du XVIIIe s. , la mégaforme constituée par la masse caillouteuse en cours de progradation depuis sans doute la fin du XIVe s. , associée à un style fluvial en tresse, atteignait les faubourgs de la ville de Grenoble où l'Isère continuait de méandrer (Bravard 1989). De là, la difficulté d'effectuer des corrélations entre les descripteurs du changement de l'environnement lorsque le temps de réaction des systèmes est fortement dépendant du paramètre spatial. 

le fait que ces fluctuations sont sous contrôle essentiellement climatique (Jorda 1980). Ces acquis géomorphologiques sont intégrés dans les synthèses paléoenvironnementales; en particulier, ils sont corrélés avec les développements récents des disciplines connexes que sont la paléo-limnologie (Magny 1995), la paléoglaciologie ( $c f$. la synthèse qu'en donne Grove 1987) et la paléo-climatologie. M. Magny a mis en évidence la très bonne corrélation qui existe entre d'une part le fort taux de ${ }^{14} \mathrm{C}$ résiduel et une faible activité solaire et d'autre part les phases de transgression lacustre; on peut sans doute y ajouter la très bonne corrélation avec les phases de progradation de la charge de fond et d'exhaussement des lits dans les systèmes fluviaux. Il est probable que le refroidissement climatique enregistré durant ces périodes s'est accompagné d'un déplacement vers le sud de la circulation zonale, d'une augmentation des précipitations estivales à caractère orageux et d'une réduction de l'évapotranspiration (Lamb 1995), cette évolution ayant eu pour effet d'augmenter les débits de crue. Il convient cependant d'admettre, pour expliquer la très forte augmentation des transports par charriage, que les entrées de sédiments dans les cours d'eau ont très fortement augmenté dans la même période. Dans les Alpes, à haute altitude, il est possible d'émettre l'hypothèse d'un abaissement de la limite supérieure des arbres ainsi que d'une recrudescence de l'activité glaciaire et de l'activité érosive (avalanches, mouvements de masse). M. Jorda (in litteris) doute cependant de l'influence de ces modestes variations climatiques holocènes (variations thermiques notamment) sur la limite supérieure de la forêt; en d'autres termes sur le détritisme et la morphogenèse fluviale: ces variations seraient, en effet, atténuées par l'inertie naturelle des groupements végétaux et des mécanismes régulateurs qui guident leur dynamisme. De fait, ces variations n'ont pas été mises en évidence dans les Alpes du Sud et en Basse Provence.

En revanche, il serait étonnant que les actions humaines n'aient pas eu leur part dans l'accélération des processus. Il convient en effet de remarquer que le Petit âge Glaciaire suit la période du Petit Optimum climatique médiéval, caractérisée par une forte colonisation des Alpes (Neboit 1983 ; Dufaure 1984). Il est probable - mais ceci serait à argumenter de manière détaillée - que l'extension de l'agriculture et des terroirs pastoraux en altitude a contribué à fragiliser les zones potentiellement productrices de sédiments. On a très peu d'informations sur ce qu'a pu être la colonisation des Alpes avant le premier âge du Fer, mais il est prouvé que les défrichements à but pastoral avaient sensiblement abaissé la limite supérieure des arbres à cette époque et fragilisé le milieu (De Beaulieu et al. 1989).

51 La période comprise entre le IVe s. av. J.-C. et la fin du XIIIe s. ap. J.-C. est en revanche caractérisée par des signes de faible activité géomorphologique. Il est quasiment certain que les grands cours d'eau ont adopté un style à méandres à l'époque romaine, comme le Rhône au débouché du Jura et l'Isère au débouché des Alpes, ou ont connu une phase d'incision à l'époque de la Tène (IVe-Ier s. av. J.-C.). Il est remarquable que les lits majeurs ne possèdent quasiment pas de dépôts d'inondation, soit que l'hydrologie ait été déficiente, soit que l'incision ait limité les débordements, soit probablement que les deux causes se soient cumulées. Fait exception la période romaine du Ier-IIe s. ap. J.-C. qui parait caractérisée par des crues débordantes relativement sérieuses sur les sites rhodaniens de Lyon et Vienne (Bravard et al. 1989; Macé et al. 1991) et/ou la période qui va de la fin du Ier s. ap. J.-C au IIIe s. inclus dans la 
moyenne vallée du Rhône (Berger 1995). Ces crues ne paraissent pas avoir remis en cause le style à méandres qui caractérise le Rhône à l'époque romaine; elles ont des signatures très nettes dans les fonds de vallée de la Valdaine qui connaissent un exhaussement des fonds de talwegs et des conditions d'hydromorphie. Une courte phase d'activité torrentielle paraît également avérée entre le Ve et le VIIIe s. ap. J.-C., mais ses manifestations sont rares et dispersées dans l'état actuel de la recherche.

\section{Les recherches à développer}

\section{La détermination du potentiel archéologique des sites de vallées}

Un des objectifs à mettre en oeuvre pourrait être une cartographie en trois dimensions du potentiel archéologique des fonds de vallées. Les cartes, réalisées à l'échelle du 1/25 000e, feraient apparaître :

1. des unités spatiales discriminées en fonction de l'ancienneté relative du substrat grossier du lit majeur. L'abandon d'un dépôt de charge de fond marque à la fois la destruction ou l'oblitération des sites plus anciens et le point 0 d'une nouvelle séquence évolutive caractérisée par le dépôt de sédiments fins issus de suspension et d'éventuelles périodes d'occupation ou de fréquentation par l'homme. Le niveau grossier inférieur donne en quelque sorte un terminus post quem à la possibilité théorique de rencontrer une installation humaine ou des artefacts en place.

2. des informations sur l'ampleur des fluctuations verticales du lit mineur à l'Holocène, en collectant des informations sur l'altitude des niveaux de creusement (l'Allerød. par exemple).

3. des données archéologiques telles que les sites les plus anciens découverts sur chaque unité de manière à vérifier la validité des hypothèses émises au stade de l'étude géomorphologique préliminaire.

Cette démarche est lourde, mais une programmation permettrait de formaliser la collecte des données et d'éviter des pertes d'information qui sont considérables à l'heure actuelle. La datation relative passe en outre par diverses techniques, dont l'emploi du radiocarbone. Un programme de datation assez systématique des troncs subfossiles ou de la matière organique (paléo-chenaux) découverts, couplé à un programme de recherche dans le domaine de la palynologie et de la dendrochronologie, permettrait de situer la recherche à un niveau comparable à ce qui se fait en Allemagne et au Royaume Uni (Schirmer 1988 ; Brown 1991 ; Needham 1992).

\section{Les rythmes climatiques et morphodynamiques}

\section{Quelques mises en garde méthodologiques}

La mise au point d'un phasage hydroclimatique relativement précis est un acquis séduisant. Il manifeste un retour en force de l'explication naturaliste après une période de doute qui domina les années 1970. Des progrès sont encore à réaliser car il est difficile de cerner le poids relatif de la période de péjoration du haut Moyen Age tant sur le plan chronologique que sur le plan de l'intensité relative des processus géomorphologiques concernés; de même, il est encore difficile de caractériser la période du Ier-IIème s. ap. J.-C. entre deux phases plus sèches. 
autant, il serait particulièrement dangereux de rechercher dans les rythmes hydroclimatiques un principe universel d'explication de certains caractères de la carte archéologique. Pour reprendre une interrogation formulée à propos de l'occupation de la presqu'île lyonnaise (Bravard et al. ce volume), le hiatus de l'occupation humaine que l'on a identifié entre le IVe et le XIIe s. est-il dû à une cause relevant de l'hydrologie ou bien à l'oblitération ultérieure des marques de l'occupation? Il est prudent de ne pas encore trancher, mais les faits d'ordre culturel doivent conserver toute leur place dans la recherche des explications, en particulier lorsqu'il s'agit de rendre compte des pleins et des vides dans l'occupation d'un territoire.

Par ailleurs, il serait regrettable de se contenter de cette nouvelle grille de lecture. La discipline géoarchéologique est trop jeune pour se replier sur elle-même et ne pas développer des collaborations multiformes, notamment du côté de la paléoclimatologie et de toutes les sciences permettant d'approcher la connaissance de l'état de l'épiderme de la terre aux diverses époques de la Préhistoire et de l'Histoire. La réussite de collaborations ne doit pas interdire d'explorer de nouveaux champs scientifiques aux marges des disciplines; il convient en effet d'éviter la reproduction de modèles alors que les sciences ne cessent d'évoluer.

\section{Quelles pistes de recherche?}

\section{L'adoption d'un schéma d'analyse systémique}

Faisant appel au principe des processus-réponses, ce schéma serait intéressant dans l'étude d'un système actuel ou subactuel car les données permettant la connaissance de chacune des étapes peuvent être acquises ou faire l'objet d'estimations réalistes. Il est possible d'analyser un changement complexe, de remonter à la dynamique des flux et, de là, à leurs mécanismes de contrôle. En revanche, la tâche est beaucoup plus délicate lorsqu'il s'agit d'interpréter les métamorphoses de paléo-systèmes. S'il est possible de déterminer avec une relative sûreté certaines manifestations géomorphologiques $d u$ changement, il serait hasardeux d'aller au-delà d'hypothèses concernant la variation relative de l'intensité des flux hydriques et minéraux. La reconstitution des mécanismes de contrôle de ces flux par l'emploi d'une simple démarche récurrente est trop aléatoire pour qu'il ne soit pas nécessaire d'acquérir dans le futur des données complémentaires concernant les paramètres climatiques et les modalités d'occupation du territoire par les sociétés humaines. Les interprétations des liens de causalité entre les réponses environnementales et les facteurs du déclanchement conduisent trop souvent, selon nous, à des choix prématurés et arbitraires entre déterminants climatiques et déterminants anthropiques. Faute d'arguments irréfutables, il apparait que la recherche en est réduite à des conjectures qui ne sont pas exemptes d'une soumission aux modes ou de considérations idéologiques inavouées ou explicites.

\section{L'échelle spatiale des réponses environnementales}

La question des réponses environnementales à des stimulus externes est un thème de recherche majeur. J.-F. Berger (1995) a insisté à juste titre sur l'importance de travailler sur la répétivité des signatures à l'échelle de la micro-région et dans des unités de paysage variées avant de se risquer à des généralisations. Il paraît en effet essentiel de faire la part réelle des facteurs anthropiques par rapport à une causalité privilégiant les 
faits de nature. Des études trop ponctuelles peuvent conduire à conclure de manière erronée à une surestimation du facteur hydro-climatique ou, inversement à celle du facteur anthropique. Globalement, on est en droit d'estimer que plus la perception est large sur le plan spatial, plus elle limite le poids l'artefact à l'échelle des sites.

\section{Climat et réponses environnementales}

Un des thèmes de recherche les plus prometteurs parait être celui de la spatialisation des réponses environnementales aux fluctuations hydroclimatiques. Cette question, présentée succinctement dans ce cadre, peut être envisagée à l'échelle de l'Europe occidentale et à l'échelle de la vallée du Rhône.

- Dans le premier cas, le déplacement en latitude de la position moyenne des zones de circulation cyclonale et des zones sous influence anticyclonique a affecté de manière inégale les péninsules méditerranéennes et la France moyenne. Une interprétation a été proposée par Ortolani et Pagliuca (1993) sous la forme d'une esquisse de déplacement latitudinal de la zonation de Koppen-Geiger (fig. 7). Il en ressort qu'en période froide et humide l'ensemble des péninsules méditerranéennes et de la France méridionale seraient incorporées dans la zone tempérée humide de type océanique ; en période chaude, les péninsules et la Provence seraient sous l'influence d'un climat semi-aride, le reste de la France connaissant un climat tempéré à été chaud et sec et à saison intermédiaires humides (type méditerranéen), ce qui est, peut être, proposer comme une extension excessive de ce dernier au détriment du climat de type océanique.

- La question de la variabilité des réponses environnementales à l'échelle de la vallée du Rhône ne se pose donc apparemment pas en période froide et humide puisque les signatures sont en principe assez homogènes à l'échelle de la vallée et de la frange méditerranéenne ; ceci est conforme aux faits d'observation. En revanche, si l'on admet ce principe, la moyenne vallée du Rhône pourrait connaître des précipitations de type méditerranéen en période sèche alors que la frange méditerranéenne pourrait être sous influence semi-aride dominante, exception faite de fluctuations mineures de pas de temps plus court. Ce caractère expliquerait, par exemple, que la période galloromaine, réputée uniformément sèche en Provence, ait connu un régime hydrologique différent aux premiers siècles de l'ère dans la moyenne vallée du Rhône. J.-F. Berger (1995) estime que le facteur climatique est prépondérant aux IIe et IIIe s. ap. J.-C. et traduirait dans la Valdaine «l'affirmation des influences méditerranéennes subhumides à fort contrastes saisonniers ». Cette influence, qui signifierait la descente vers le sud de l'anticyclone tropical et de la zone de circulation cyclonique d'ouest repoussés auparavant plus au nord, intercalerait un cycle à torrentialité marquée dans une longue période à faible hydraulicité (de la Tène au IVe s. ap. J.-C.). Elle pourrait avoir été plus précoce dans la région lyonnaise qui reçoit des cours d'eau alimentés par les Alpes et par le bassin de la Saône ; les crues sont en effet marquées dès le tournant de l'ère et jusqu'au IIe s. Reste à comprendre pourquoi les processus torrentiels du IIIe s. n'ont pas été repérés dans la région lyonnaise : s'agit-il de processus non encore identifiés? Ces processus sont-ils masqués par un fort contrôle anthropique en milieu urbain ou est-on trop au nord par rapport à la zone d'expression des processus torrentiels qu'est la moyenne vallée du Rhône? Quoi qu'il en soit, la courbe de variation $d u^{14} \mathrm{C}$ résiduel montre une variation légèrement positive entre la Tène et le IIIe s. (Magny 1995), ce qui est conforme à l'enregistrement de marques d'une certaine humidité dans la région et à l'existence d'une phase de transgression lacustre dans le Jura (Petit Maclu). 


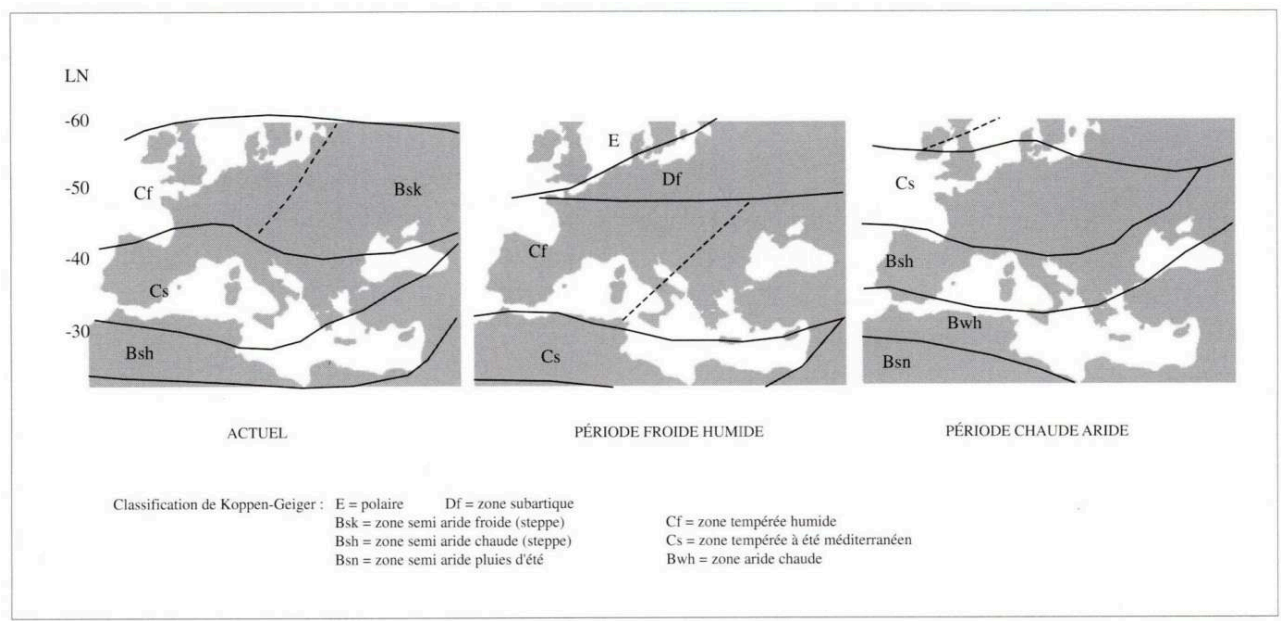

ORTOLANI ET AL. , 1994, MODIfiÉ

\section{BIBLIOGRAPHIE}

\section{Bibliographie}

Amoros 1993 : AMOROS (C.) PETTS (G.) - Hydrosystèmes fluviaux. Paris, Ed. Masson, 1993, (Collection d'écologie, 24) $295 \mathrm{p}$.

Argant 1988 : ARGANT (J.). - Climat et environnement au Quaternaire dans le bassin du Rhône d'après les données palynologiques. Lyon, Doc. Lab. Géol. Lyon n 111, Thèse de doctorat, Univ. Lyon I, 1988, $199 \mathrm{p}$.

Argant 1993 : ARGANT (J.). - Premières indications sur la végétation lyonnaise à l'Holocène d'après l'analyse pollinique. Palynosciences, 2, 1993, pp. 57-78.

Arlaud 1994 : ARLAUD (C.), BURNOUF (J.), BRAVARD (J.-P.), LUROL (J.-M.) et VEROT-BOURRELY (A.). - Lyon Saint-Jean. Les fouilles de l'îlot Tramassac. Lyon, Service régional de l'archéolgie, D A R A, $\mathrm{n}^{\circ} 10,1994,150 \mathrm{p}$.

Audin 1919 : AUDIN (M.). - Le confluent du Rhône et de la Saône. Lyon, Ed. Cumin et Masson, 1919, $113 \mathrm{p}$.

Ballandras 1997 : BALLANDRAS (S.). - Contribution à l'étude des bassins versants torentiels alpins. Stratigraphies, morphodynamique, paléoenvironnements de bassins versants depuis 15000 ans. Thèse de géographie, Univ. de Savoie, 2 t., 552 p.

Beaulieu 1989 : BEAULIEU (L. DE), EDOUARD (J.-L.), POMEL (P.), ROLANDO (C.), TESSIER (L.), THINON (M.), THOMAS (A.). - Timber line and human impact in the French Alps. In : MOE (D.) et HICKS (S.), dir. - Impact of Prehistoric and Medieval Man on the Vegetation : Man and the Forest Limit. Report of the meeting held in Ravello, 9-10 Déc. 1989, P.A.C.T., 1990, 31, pp. 63-81. 
Beeching 1987 : BEECHING (A.), BROCHIER (J.-L.), MANDIER (P.), MATEUCCI (S.). - La moyenne vallée du Rhône à l'Holocène : contexte morphodynamique, occupation et circulation humaines du Néolithique à l'âge du Bronze. In : La ville et le fleuve. Actes du 112e Congrès Nat. Soc. Sav., Lyon, 1987. Paris, éd. CTHS, pp. 153-171.

Benoit 1940 : Benoit (F.). - L'usine de meunerie hydraulique de Barbegal, Revue Archéologique, t. 15, 1940, p. 19-80.

Berger 1995 : BERGER (J.-F.). - Facteurs anthropiques et naturels de l'évolution des paysages romains et protomédiévaux du bassin valdainais (Drôme). In : L'Homme et la dégradation de l'Environnement, XVe Rencontres internationales d'Antibes, 1995. Ed. APDCA, Juan-les-Pins, 1996, pp. 79-114.

Berger 1996 : BERGER (J.-F.). - Le cadre paléogéographique des occupations du bassin valdainais (Drôme) à l'Holocène. Archéologie et Environnement, Univ. Paris I, 1996, 324 p.

Blanchard 1935 : BLANCHARD (R.). - Grenoble. Etude de géographie urbaine. Grenoble, Ed. Didier \& Richard, 3e éd., 1935, 234 p.

Bourdier 1960-61 : BOURDIER (F.). - Le Bassin du Rhône au Quaternaire, Géologie et Préhistoire. Thèse Sci., Paris, 2 vol., éd. CNRS, 1960-61, 658 p., 297 fig.

Bravard 1963 : BRAVARD (Y.). - Le Bas-Dauphiné. Recherches sur la morphologie d'un piedmont alpin. Genoble, Imp. Allier, $504 \mathrm{p}$.

Bravard 1983 : BRAVARD (J.-P.). - Une autocapture du Rhône par déversement dans les BassesTerres du BasDauphiné. Revue de Géographie de Lyon, 4, 1983, pp. 364382.

Bravard 1986a : BRAVARD (J.-P.). - Le Rhône, du Léman à Lyon. Lyon, Ed. La Manufacture, Lyon, 452 p.

Bravard 1986b : BRAVARD (J.-P.), DESBAT (A.), JACQUET (C.), LEBOT-HELLY (A.) et SAVAY-GUERZ (H.). - Observations géomorphologiques sur le site alluvial de Vienne (Isère) et Saint-Romain-en-Gal (Rhône) à l'époque gallo-romaine. IIIe Congrès Nat. Soc. Sav., Poitiers, 1986. Paris, éd. du CTHS, Archéologie, 1986, pp. 257-270.

Bravard 1986c : BRAVARD (J.-P.), AMOROS (C.) et JACQUET (C.). - Reconstitution de l'environnement des sites archéologiques fluviaux par une méthode interdisciplinaire associant la géomorphologie, la zoologie et l'écologie. Revue d'Archéométrie, 10, 1986, pp. 43-55.

Bravard 1989a : BRAVARD (J.-P.). - La métamorphose des rivières des Alpes françaises à la fin du Moyen Age et à l'époque moderne. Bull, de la Société de Géographie de Liège, 25, 1989, pp.145-157.

Bravard 1989b : BRAVARD (J.-P.), BURNOUF (J.) et VEROT-BOURRELY (A.). - Géomorphologie et archéologie dans la région lyonnaise : questions et réponses d'un dialogue interdisciplinaire. Bull. S.P.F., t. 10/12, 1989, pp. 429-440.

Bravard 1989c : BRAVARD (J.-P.) et EVIN (J.). - Datation du remblaiement holocène dans un secteur de la plaine alluviale du Rhône à Villeurbanne (69). Bull, du Laboratoire Rhodanien de Géomorphologie, $\mathrm{n}^{\circ} 23-24,1989$, pp. 2-10.

Bravard 1989d : BRAVARD (J.-P.), LEBOT-HELLY (A.), HELLY (B.) et SAVAY-GUERRAZ (H.) : Le site de Vienne (38), Saint-Romain (69), Sainte-Colombe (69). L'évolution de la plaine alluviale du Rhône, de l'âge du Fer à la fin de l'Antiquité : proposition d'interprétation. In : Archéologie et Espaces, Xème Rencontres internationales d'Archéologie et d'Histoire, Antibes, Oct. 1989. Juanles-Pins, Ed. APDCA, 1990, pp. 437-452. 
Bravard 1990 : BRAVARD (J.-R). - Observations nouvelles sur la dynamique fluviale de la Saône à l'Holocène, entre Villefranche et Anse (Rhône). Revue Géographique de l'Est, 1, 1990. pp. 57-76.

Bravard 1991 : BRAVARD (J.-P.), PEIRY (J.-L.) et GADIOLET (P.). - La formation de la plaine alluviale holocène du Rhône à l'amont de Lyon. Physio-Géo, n²2/23, 1991, pp. 167-172.

Bravard 1992 : BRAVARD (J.-P.), VEROT-BOURELY (A.) et SALVADOR (P.-G.). - Le climat d'après les enregistrements sédimentaires fluviatiles étudiés sur les sites archéologiques. Les Nouvelles de l'Archéologie, 50, 1992, pp.7-13.

Bravard 1996 : BRAVARD (J.-P). - Des versants aux cours d'eau, les implications des fluctuations paléohydrologiques à l'époque médiévale. In : Collardelle éd. : L'Homme et la Nature au Moyen Age, Paris, éd. Errance, 1996, pp. 171-179.

Bravard 1997 : BRAVARD (J.-P.). - Le profil en long de la Saône et du Rhône dans la région lyonnnaise au Tardiglaciaire et à l'Holocène : interférence de la tectonique et de la dynamique fluviale. Géographie Physique et Quaternaire.

Brochier 1991 : BROCHIER (J.-L.), MANDIER (P.), ARGANT (J.) et PETIOT (P.). - Le cône détritique de la Drôme : une contribution à la connaissance de l'Holocène du Sud-Est de la France. Quaternaire, vol. 2, 2, 1991. pp. 83-99.

Brochier sous presse : BROCHIER (J.-L.), CLEMENT (P.), MANDIER (P.), ARGANT (J.) et CHAIX (L.). - Le cône détritique du Roubion : une contribution à la connaissance de l'Holocène du Sud-Est de la France. Quaternaire.

Brown 1991 : BROWN (A.G.). - Hydrogeomorphological changes in the Severn basin during the last 15000 years : orders of change in a maritime catchment. In : Temperate palaeohydrology, Starkel (L.) éd., Chichester, Wiley, pp. 147169.

Campy 1990 : CAMPY (M.), LAMY au ROUSSEAU (R.) et NICOUD (G.). - Modalités de la déglaciation Wiirmienne dans le Nord-Ouest des Alpes (Nord Dauphiné, Savoie, Bassin lémanique). Geodinamica Acta (Paris), 4, 4, 1990, pp. 211225.

Campy 1994 : CAMPY (M.), BICHET (V.), DI GIOVANNI (C.), RICHARD (H.), RICHARD (J.) et OLIVE (P.). - Evolution des flux de matière depuis 12000 ans dans la haute vallée du Doubs (France). Bull. Soc. géol. France, t. 165, n 4.1994 , pp. 381-400.

Chapotat 1987 : CHAPOTAT (G.), EVIN (J.) et SAMUEL (E.). - Archéologie, datation radiocarbone et paléobotanique à l'ancien gué de Sérézin-du-Rhône. Bull. Mensuel Soc. Linéenne, 56, 5, 1987, pp. 164-176.

David 1964 : DAVID (L.) et VILAIN (H.). - Sur un bras du Rhône post-würmien à Lyon et sur les conditions climatiques au moment de son remblaiement. C.R. sommaire des Séances de la Soc. Géol. de France, 10, 1964, pp. 426-427.

Délaval et al. 1995 : DELAVAL (E.), BELLON (C.), CHASTEL (J.), PLASSOT (E.) et TRANOY (L.). Vaise, un quartier de Lyon antique. Lyon, Service régional de l'archéologie en RhôneAlpes, D A R A, $\mathrm{n}^{\circ} 11$, serie Lyonnaise $\mathrm{n}^{\circ}$ 5, 1995,291 $\mathrm{p}$.

Desbat 1982 : DESBAT (A.). - Lyon et ses fleuves dans l'Antiquité. In : Lyon au fil des fleuves, Lyon, Catalogue de l'exposition de l'ELAC, 1982, p. 29-37.

Dufaure 1984 : DUFAURE (J.-J.) éd. - La mobilité des paysages méditerranéens. Revue Géogr. Pyr. et du Sud-Ouest, Trav. II, $387 \mathrm{p}$. 
Gadiolet 1993 : GADIOLET (P.), MARTIN (S.) et BRAVARD (J.-P. ). - Données nouvelles sur le paléoenvironnement holocène de la bordure septentrionale des « Balmes viennoises » (Isère). Revue Géographique de l'Est, 4, 1993, pp. 267-279.

Grove 1987 : GROVE (J.). - The Little Ice Age. London, Methuen, 498 p.

Jorda 1980 : JORDA (M.). - Morphogenèse et évolution des paysages dans les Alpes de HauteProvence depuis le Tardiglaciaire. Facteurs naturels et facteurs anthropiques. Bull. Ass. Géogr. Français, 472, pp. 297-304.

Jorda 1985 : JORDA (M.). - La torrentialité holocène des Alpes françaises du Sud. Facteurs anthropiques et paramètres naturels de son évolution. Cahiers Ligures de Préhistoire et de Protohistoire, nlle série, 2, pp. 49-70.

Jorda 1988 : JORDA (M.). - Modalités paléoclimatiques et chronologiques de la déglaciation würmienne dans les Alpes françaises du Sud. Bull. AFEQ, 2-3, pp. 111-122.

Jorda 1992 : JORDA (M.). - Morphogénèse et fluctuations climatiques dans les Alpes françaises du Sud de l'âge du Bronze au haut Moyen Age. Les Nouvelles de l'Archéologie, 50, 1992, pp. 14-20.

Jorda 1990 : JORDA (M.), PROVANSAL (M.), ROYET (R.). - L'histoire « naturelle » d'un site de l'âge du Fer sur le piémont méridional des Alpilles. Le domaine de Servanne (Bouches-du-Rhône). Gallia, Al, pp. 57-66.

Journaux 1956 : JOURNAUX (A.). - Les plaines de la Saône et leurs bordures montagneuses. Etude géomorphologique. Thèse Univ. Paris, Ed. Caron, Caen, 529 p.

Kleinclausz 1925 : KLEINCLAUSZ (A.). - Lyon des origines à nos jours. La formation de la cité. Lyon, Imp. P. Masson, $429 \mathrm{p}$.

Lamb 1995 : LAMB (H.H.). - Climate, History and the Modern World. London, Routledge, 2e éd., 1995, $433 \mathrm{p}$.

Lamouille 1985 : LAMOUILLE (G.), SAMUEL (E.) et VILAIN (R.). - Les arbres fossiles et les alluvions holocènes du Rhône à « La Malourdie », commune d'Anglefort (Ain, France). Le Bugey, 72, 1985, pp. 1027-1062.

Leglay 1971 : LEGLAY (M.) et TOURENC (S.). - L'originalité de l'architecture domestique à Vienne après les découvertes récentes de Saint-Romain-en-Gal, C.R. Acad. Inscriptions et Belles Lettres, pp. 764-773.

Leveau 1994 : LEVEAU (P.). - L'histoire en otage : Arles, colonie romaine et les plaines du BasRhône, les enjeux d'un débat. In : L'Homme et la dégradation de l'environnement, XVe Rencontres internationales d'Antibes, 1995. Ed. APDCA, Juan-les-Pins, 1996, pp. 245-262.

Leveau 1993 : LEVEAU (PH.), PROVANSAL (M.). - Archéologie et environnement : de la Sainte-Victoire aux Alpilles. Publ. Univ. de Provence, Trav. Centre C. Jullian n 14, 551 p.

Lewin 1995 : LEWIN (J.), MACKLIN (M.G.), WOODWARD (J.C.). - Mediterranean Quaternary River Environment. Ed. Balkema, Rotterdam, 292 p.

Macé 1990 : MACE (S.). - La dynamique du confluent du Rhône et de la Saône à l'époque gallo-romaine. Mémoire de DEA, Univ. Lyon III, 29 p.

Macé 1992 : MACE (S.), VEROT-BOURRELY (A.) et BRAVARD (J.-P). - Genèse et fonctionnement holocène de la plaine alluviale du Rhône à Lyon. In : Archéologie et environnement des milieux aquatiques, Actes du 115 ème Colloque Nat. Soc. Sav., Préprotohistoire, Chambéry, 1991. Paris, éd. du CTHS, 1992, pp. 17-31. 
Magny 1995 : MAGNY (M.). - Une histoire du climat. Paris, éd.. Errance, 176 p.

Magny 1985 : MAGNY (M.) et RICHARD (H.). - Contribution à l'histoire holocène du lac du Bourget : Recherches sédimentologiques et palynologiques sur le site de Conjux-la-Chatière (Savoie, France). Revue de Paléobiologie, 4, n² 2, 1985, pp. 253-277.

Mandier 1984 : MANDIER (P.). - Signification dynamique et climatique des formations et terrasses fluviatiles quaternaires dans les Alpes et leur périphérie. Rapport. Bull. AFEQ, 1/2/3, pp. 113-118.

Mandier 1988 : MANDIER (P.). - Le relief de la moyenne vallée du Rhône au Tertiaire et au Quaternaire. Orléans, éd. BRGM, Doc. n 151, 3 t., 1988.

Monjuvent 1988 : MONJUVENT (G.) et NICOUD (P.). - Interprétation de la déglaciation rhodanienne au Würm, des moraines internes à la cuvette lémanique. Bull. AFEQ, 2/3, 1988, pp. 129-140.

Neboit 1983 : NEBOIT (R.). - L'Homme et l'érosion. Publ. Fac. Lettres, Univ. Clermont-Ferrand II, 1983 , fasc. $17,183 \mathrm{p}$

Needham 1992 : NEEDHAM (S.) et MACKLIN (M.G.). - Alluvial archaeology in Britain. Proc. Conf. British Museum, 1991. Oxford, Oxbow Books, Mon. 27, 1992, 277 p.

Ortolani 1993 : ORTOLANI (F.) et PAGLIUCA (S.). - Variazoni climatiche e crisi dell'ambiente anthropizzato. In : Una nuova geologia per l'ambiente, Atti Conv. AIQUA, Genova, relazione, $10 \mathrm{p}$.

Peiry 1986 : PEIRY (J.L.). - Dynamique fluviale historique et contemporaine du confluent GiffreArve (Haute-Savoie). Revue de Géographie de Lyon, 1, 1986, pp. 79-96.

Peiry 1988 : PEIRY (J.-L.). - Approche géographique de la dynamique spatio-temporelle des sédiments d'un cours d'eau intra-montagnard: l'exemple de la plaine alluviale de l'Arve (Hte Savoie). Thèse Lettres. Univ. Lyon III, 378 p.

Peiry 1990 : PEIRY (J.-L.). - Paléodynamique fluviale et chronologie de l'incision holocène de la basse vallée de l'Arve (Haute Savoie). Revue Géographique de l'Est, 1, 1990, pp. 77-92.

Peiry 1994 : PEIRY (J.-L.). - Application de l'analyse statistique multivariée et de l'image CM des dépôts fluviatiles à la reconstitution des paléoenvironnements fluviaux. L'exemple d'un bras mort du Rhône en amont de Lyon. Quaternaire, vol. 5,2, 1994, pp. 59-68.

Pelletier 1990 : PELLETIER (J.). - Le site de Lyon. In : Histoire de Lyon, Pelletier (A.) et Rossiaud (J.) éd., Le Coteau, Horvath, t. 1, pp. 13-19.

Pena Mone 1988 : PENA MONE (J.L.), SANCHO MARCEN (C.). - Correlacion y evolucion quaternaria del systema fluvial Segre-Cinca en su corso bajo (Provincias de Lerida y Huesca). quaternarioy Geomorfologia, 2, 1-4, pp. 77-83.

Petit 1993 : PETIT (C.) - Un bassin d'avant-pays de type pelliculaire, la Bresse au Plio-Pléistocène. Thèse de géologie, Université de Dijon, 335 p. et annexes.

Provansal 1992 : PROVANSAL (M.). - Le rôle du climat dans la morphogénèse à la fin de l'âge du Fer et dans l'Antiquité en Basse Provence. Les Nouvelles de l'Archéologie, 50, 1992, pp. 21-26.

Rosique 1996 : ROSIQUE (T.). - Morphogenèse et évolution des paléoenvironnements alpins de la fin des temps glaciaires au début de l'Holocène : l'exemple de la moyenne Durance (Alpes françaises du Sud). Thèse de géographie, Univ. d'AixMarseille I, 288 p.

Russo 1961 : RUSSO (Ph.) et AUDIN (A.). - Le site de Lyon. Panorama de son évolution. Revue de géographie de Lyon, pp. 295-346. 
Salvador 1991a : SALVADOR (P.-G.). - Le thème de la métamorphose fluviale dans les plaines alluviales du Rhône et de l'Isère (Bassin de Malville et Ombilic de Moirans). Thèse de Géographie, Univ. Lyon III. $498 \mathrm{p}$.

Salvador 1991b : SALVADOR (P.G.). - Une métamorphose holocène dans l'ombilic de Moirans (38, Isère). Physio-Géo, 22-23, pp. 173-178.

Salvador 1993 : SALVADOR (P.O.), BRAVARD (J.P.), VITAL (J.) et VORUZ (J.L.). -Archaeological evidence for Holocene floodplain development in the Rhône valley, France. In : Actes de la 2ème Conf. intern, de Géomorphologie, Berlin-Stuttgart, 1989. Zeitschrift für Géomorphologie, Suppl. Bd 88, pp.81-95.

Salvador 1995 : SALVADOR (P.-G) et BRAVARD (J.-R). - Holocene Archeological Cycles in Southern France. Journal of Coastal Research, Sp. Issue ${ }^{\circ}$ 17, pp. 93-94.

Savay-Guerraz 1985 : SAVAY-GUERRAZ (H.). - Recherches sur les matériaux de construction de Lyon et de Vienne antiques. Thèse 3e cycle, Univ. Lyon, 313 p. inédit.

Schirmer 1988 : SCHIRMER (W.). - Holocene valley development on the Upper Rhine and Main. In : Lake, Mire, and River Environments, Lang (G.) et Schlüchter (C.) éd., Rotterdam, Balkema, p. 153-160.

Schumm 1977 : SCHUMM (S.A.). - The Fluvial System. New York, Wiley, 338 p.

Starkel 1983 : STARKEL (L.). - The reflection of hydrologie changes in the fluvial environment of the temperate zone during the last 15,000 years. In : Background to Palaeohydrology, Gregory (K. J.) éd., Chichester, Wiley, p. 213-235.

Starkel 1995 : STARKEL (L.). - Changes of river channels in Europe during the Holocene. In : Changing River Channels, Gurnell (A.) \& Petts (G.) éd., Chichester, Wiley \& Sons, p. 25-42.

Vérot-Bourrély 1989 : VEROT (A.). BURNOUF (J.). JACQUET (C), AMOROS (C.) et BRAVARD (J.-P.). - Le site gallo-romain de la place Bellecour (Lyon, 2ème). Reconstitution interdisciplinaire du paléo-environnement. In : La ville et le fleuve, Actes du 112e Congrès Nat. Soc. Sav., Lyon, 1987. Paris, éd. CTHS, 3, 1989, pp. 147-155.

Vérot-Bourrély 1996a : VEROT-BOURRELY (A.), ARGANT (J.), BRAVARD (J.-P.) et CHAIX (L.). - Le paléoenvironnement du site de Gorge-de-Loup (Lyon 9e). In : L'Homme et la dégradation de l'environnement, XVe Rencontres internationales d'Antibes, 1995. éd. APDCA, Juan-les-Pins, 1996, pp. 43-78. 


\title{
Archeologie du lit mineur de la Saône : les recherches en chalonnais
}

\author{
Louis Bonnamour
}

1 Il convient d'observer qu'à l'échelle de l'Europe occidentale, nos connaissances relatives à l'archéologie fluviale restent grandement tributaires des découvertes fortuites réalisées à l'occasion de travaux d'aménagement ou d'extraction de matériaux. Il y a là une situation tout à fait paradoxale, en totale contradiction avec les impératifs de la recherche archéologique contemporaine et qui traduit un retard certain en ce domaine.

2 Pour nous en tenir aux publications parues depuis une trentaine d'années, que celles-ci portent sur des découvertes anciennes (Zapotocky 1969, Briard 1971, Torbrugge 1972, Mozsolics 1975, Wegner 1976, Mohen 1977, Warmenbol 1992, Wirth 1993), ou encore sur des travaux récents (Blanchet 1977, Monnet 1984, Schalles 1993, Künzl 1993, Briard 1995), on constate une caractéristique commune: tous les travaux à l'origine des découvertes sont totalement étrangers à l'archéologie et les auteurs se contentent d'étudier les trouvailles soit d'un point de vue purement typologique, soit avec une volonté de compréhension, mais en recourant à un ensemble d'explications traditionnelles, telles que combats sur les gués, naufrages, offrandes, destruction de sites de berge..., héritées du XIXe s. Il est évident que ce type de démarche ne risque pas de faire progresser nos connaissances concernant les raisons de la présence de ces vestiges dans le lit de nos fleuves et de nos rivières. Seule l'archéologie subaquatique est aujourd'hui en mesure de nous apporter des éléments de réponse.

3 En France comme à l'étranger (Italie, Pays-Bas, Grande-Bretagne, Pologne...), on note toutefois quelques timides et sporadiques initiatives individuelles dans le but de réaliser des prospections ou des récupérations de documents en plongée. L'exemple le plus caractéristique est sans doute celui de la grotte de Han-sur-Lesse en Belgique, où de spectaculaires récupérations de mobilier archéologique se poursuivent depuis 1959 (Marien s.d.).

4 En Allemagne, quelques rares opérations ont pu être réalisées à l'aide de caissons étanches en Mer du Nord, dans le lac de Constance, mais également sur d'anciens bras 
du Rhin (Kramer 1995). Sur ce dernier fleuve, l'étude du pont romain de Coblence a notamment pu être menée à bien grâce à l'utilisation du "Krokodil", vaste cloche à plongeurs de $7 \times 4 \mathrm{~m}$., construite en 1890 pour les besoins des services de la navigation du Rhin, et mise ici à la disposition des archéologues (Fehr 1981).

En milieu fluvial, le travail subaquatique est rendu complexe, tant du fait du courant que de la visibilité qui peut devenir totalement nulle au-delà d'une profondeur supérieure à quelques mètres. Toutefois, les travaux conduits par Eric Rieth sur des épaves et des sites portuaires médiévaux dans le lit de la Charente, ou les fouilles et prospections réalisées en Saône, ont apporté la preuve qu'avec des moyens relativement modestes, mais aussi avec une motivation certaine, il est possible de parvenir à des résultats scientifiquement non négligeables, dépassant de beaucoup le cadre de la simple récupération d'objets.

\section{Historique des recherches en Saône}

\section{Les dragages}

6 La prise de conscience de l'intérêt archéologique de la Saône est apparue de manière extrêmement précoce, sous l'influence d'un archéologue chalonnais, Jules Chevrier. Dès 1842-44 en effet, ce dernier avait suivi avec attention les travaux de dragage réalisés dans la traversée de Chalon pour l'amélioration de la navigation; il écrivait quelques années plus tard: "Un heureux privilège semble avoir été accordé à la Saône : c'est à elle qu'il était réservé de conserver au fond de ses eaux, des traces nombreuses de toutes les époques qui nous ont précédés. Depuis que de grands travaux sont venus violer le secret de ses eaux, nous avons pu recueillir de nombreux débris des temps passés. Par eux, nous pourrions presque écrire, en lettres de fer et de bronze, une histoire de tous les âges qui se sont succédés depuis la conquête de notre pays par les Romains jusqu'à nos jours" (Chevrier 1846, p. 236).

Le 5 avril 1843, un journal local, le "Patriote de Saône-et-Loire", relatait à la rubrique "Chalon" les découvertes archéologiques effectuées par la drague en plusieurs points de la rivière dans la traversée de la ville.

"Les machines à draguer qui fonctionnent devant nos quais amènent chaque jour quelques objets curieux et antiques. La machine qui était sous la première arche du pont a découvert une grande quantité de pièces de monnaies de cuivre et quelquesunes d'or ou d'argent, parmi lesquelles on a remarqué des Charles X (cardinal de Bourbon), devenues assez rares. Le nombre de ces monnaies est tel qu'un des ouvriers en montrait un plein sac de mille francs. Nous avons vu, sur une petite plaque d'airain, un Christ crucifié, avec des animaux symboliques aux quatre angles et des caractères gothiques indéchiffrables (pour nous) ; le tout d'une forme bizarre qui nous paraît devoir remonter loin dans le Moyen Age.

La drague qui est placée vis-à-vis le bastion, a fourni un grand nombre de tuiles et de fragments de tuiles romaines, des amphores et des urnes funéraires fort bien conservées, ainsi que quelques ustensiles en cuivre corrodés par l'oxydation. Mais la trouvaille la plus précieuse, est une admirable coupe en matière vitrifiée, transparente, et qu'on prenait de prime abord pour de l'écaillé. Cette coupe plate, évasée comme une grande assiette creuse, est ornée à l'extérieur par des guillochis en relief et en spirales. Elle est une nouvelle preuve, entre mille autres, que l'art de couler le verre était aussi commun dans l'antiquité que de nos jours. On peut voir cette coupe chez le gardien des travaux, dans la cour du bastion.

La machine a également amené beaucoup d'ossements d'animaux, et quelques ossements humains enfouis là depuis des siècles, sans doute, à la suite des 
nombreux désastres qui ont affligé nos historiques contrées.

La plus singulière de ces découvertes est une espèce de pierre, formée de sédiments superposés trouvée près de l'égout en aval du pont. L'intérieur de cette masse est rempli d'épingles et de hameçons agglomérés. Comment s'est opéré ce bizarre assemblage ? Est-ce le résultat d'un centre d'attraction magnétique ? est-ce l'effet d'un tourbillon de remous qui aurait entraîné sur un seul point les nombreuses épingles charriées par l'égoût et les hameçons perdus dans la rivière ? celà est assez difficile à expliquer. Ce qu'il y a de particulier, c'est qu'une brique de vase, trouvée près de l'égout du port St-Jean, offrait le même phénomène d'épingles adhérentes à la surface".

En 1853-54, puis à nouveau en 1869-70, de nouveaux dragages furent à nouveau réalisés à Chalon ; ces travaux donnèrent lieu à de très importantes découvertes aux environs de la Benne-la-Faux ou du Petit Creusot, cette dernière appellation étant liée à l'implantation, sur la rive gauche de la Saône, de chantiers de constructions navales, succursale des établissements Schneider du Creusot, et non, comme cela a été parfois écrit, à l'existence d'un toponyme d'origine celtique. Ces trouvailles, ou du moins une partie d'entre elles (Landa 1869 ; Bonnamour 1975), furent portées à la connaissance de Joseph Déchelette qui leur a consacré un travail tout à fait remarquable et n'a pas hésité à les comparer à celles du site éponyme de La Tène (Déchelette 1913).

Après Chalon, c'est la région nord de Mâcon qui. à l'extrême fin du XIXe s. et au début du siècle suivant, a livré de nombreux documents et en particulier près d'une centaine de petits objets métalliques datant de l'âge du Bronze (Jeanton 1917). Quelques années plus tard, Léonce Bidault de Grésigny publiait à son tour, sous forme d'un album photographique, le bilan de ses recherches entre Lyon et Chalon (Bidault de Grésigny 1920). Malheureusement, le manque absolu de précision quant à la localisation de la majeure partie des trouvailles enlève à cet ouvrage une bonne part de son intérêt documentaire.

Après quelques dizaines d'années de désintérêt pour les trouvailles de la rivière, souvent dispersées dans des collections publiques ou privées, parfois même sous de fausses provenances, Louis Armand-Calliat tentait, en 1957, de rattacher deux séries de trouvailles originaires d'Anse (69) et de Bougerot (71) à des sites de gués (Armand-Calliat 1957).

7 À partir de 1963 enfin, je me suis attaché à suivre systématiquement l'action des dragues travaillant en Chalonnais ainsi que dans la région de Verdun-sur-le-Doubs, afin d'essayer de comprendre les raisons de la présence d'une telle quantité de vestiges archéologiques, principalement galloromains et protohistoriques, dans le lit de la rivière. Assez rapidement, cette action a permis d'observer des concentrations de trouvailles totalement disparates et de noter d'étroites concordances entre les zones de découvertes et les hauts-fonds révélés par l'examen des documents du XIXe s. conservés dans les archives du service de la navigation de la Saône. Encore fallait-il apporter la preuve que nous nous trouvions bien là en présence de véritables gisements archéologiques, et non de simples accumulations accidentelles, comme n'hésitaient pas à l'affirmer et à l'écrire certains archéologues (Gaucher 1981, p. 31-36).

8 La découverte déterminante fut, à cet égard, celle réalisée au mois d'août 1973 par une puissante drague à godets, à une dizaine de kilomètres au sud de Chalon, sur la commune d'Ouroux-sur-Saône. Pour la première fois, nous avions le sentiment d'être en présence d'un gisement en place, en l'occurence un habitat incendié de la fin de l'âge du Bronze. En l'espace de quelques jours, sur une superficie d'une centaine de mètres carrés, la drague allait extraire du lit de la rivière quelques 300 pieux, plusieurs dizaines de meules, plusieurs tonnes de céramiques, ossements et bois brûlés, des objets en bois travaillé, des restes de vanneries, des objets de bronze... (Bonnamour 
1974). Même si elle ne marquait pas la fin des extractions de granulats dans le lit mineur (il faudra attendre près de 10 ans pour cela), la découverte d'Ouroux constituait un tournant puisqu'elle allait déclencher une série de travaux subaquatiques qui se poursuivent aujourd'hui encore.

9 Si le bilan d'un siècle et demi de dragages dans le lit mineur de la Saône apparaît extrêmement mitigé compte tenu de l'importance des destructions opérées, destructions très inégales comme l'attestent les recherches subaquatiques effectuées au sud de Chalon, il est également évident que ce sont les découvertes fortuites réalisées à l'occasion de ces mêmes dragages qui ont grandement contribué à la prise de conscience du potentiel archéologique de la Saône. Un autre apport non négligeable de ces travaux est l'enrichissement considérable de collections publiques, au premier rang desquelles il faut placer celles du musée de Chalon. Ces collections permettent aux chercheurs de disposer de documents relatifs à des périodes peu ou même non représentées sur les sites terrestres, ou encore présentant un caractère un peu exceptionnel, dans des domaines tels que l'armement ou la vaisselle antique en bronze ou en métal précieux.

\section{Les recherches subaquatiques}

Dès 1978, le Ministère de la Culture et la Ville de Chalon ont mis en place une infrastructure relativement importante, en vue de la réalisation de la fouille subaquatique de l'habitat du Bronze final d'Ouroux (Grandjean 1984) : une péniche de $38,5 \mathrm{~m}$. de long fut alors aménagée afin de servir de base logistique autonome à la fouille. En même temps, une vaste enceinte de palplanches métalliques, longue de $125 \mathrm{~m}$. et large de près de $50 \mathrm{~m}$., était implantée dans le lit mineur, à l'emplacement présumé du site (fig. 1). Parallèlement, un forage destiné à alimenter l'enceinte en eau claire était creusé au bord de la rivière. Après l'arrêt définitif de la fouille d'Ouroux en 1982, la péniche était restituée à la Ville de Chalon qui en confia l'usage à la section archéologie du musée Denon pour aider la poursuite des recherches. Base de travail fixe de premier ordre, la péniche est utilisée en même temps qu'un certain nombre d'embarcations légères motorisées; ces dernières, équipées de moto-pompes nécessaires au fonctionnement des engins de décapage ou de dévasage, permettent également d'assurer les opérations de prospection et, pendant les campagnes de fouille, les liaisons entre la péniche et le chantier. 
1- Ouroux-sur-Saône (71)

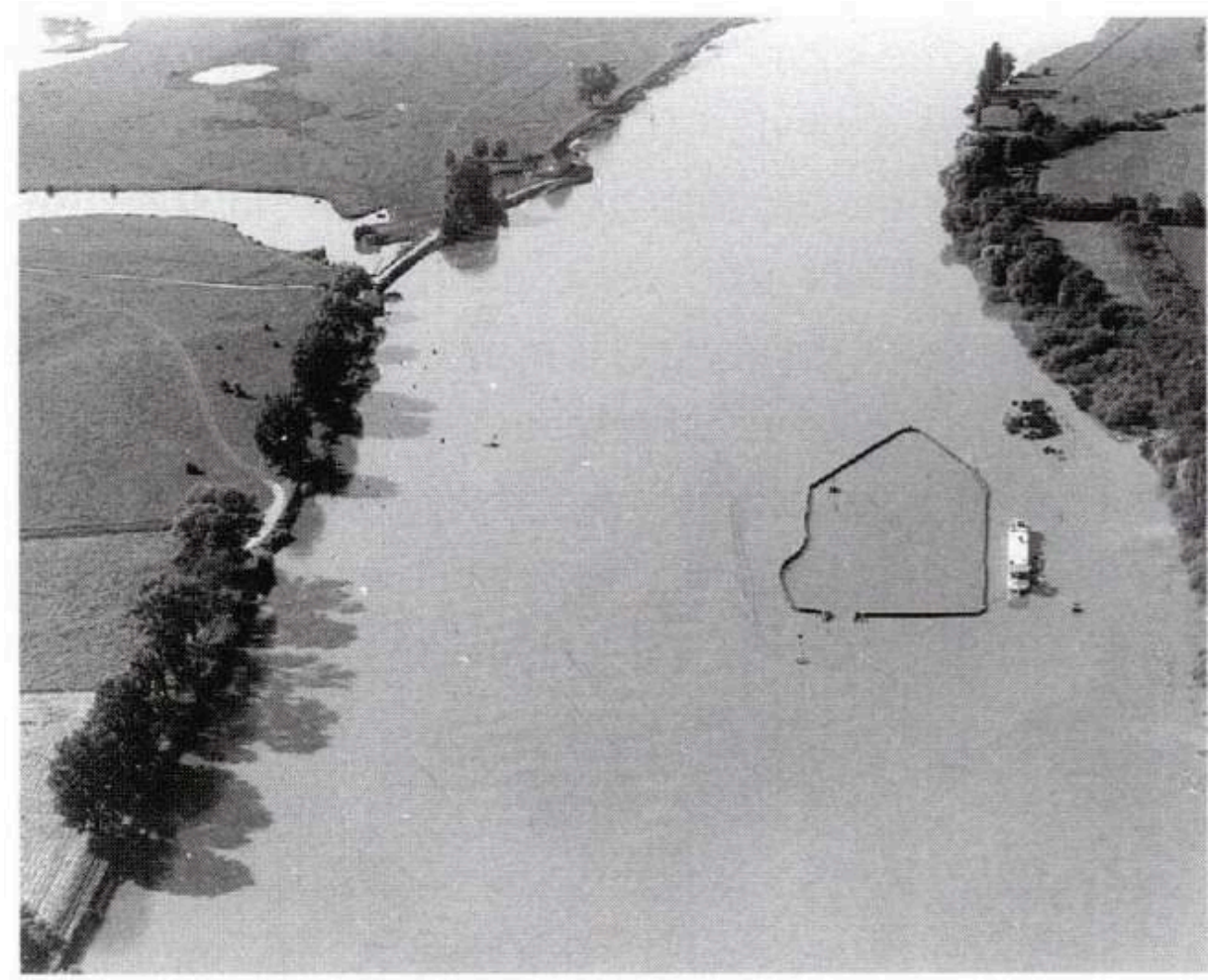

Vue aérienne du site pendant la campagne de fouille 1982

Cliché Musée Denon, archéologie

Pour l'essentiel, les recherches ont porté sur un secteur extrêmement limité, s'étendant sur une vingtaine de kilomètres du cours de la rivière entre les communes de Gigny/Saint Germain-du-Plain (71) et le nord de Chalon, soit entre les points kilométriques 125 et 144 (fig. 2). Très irrégulièrement atteinte par les extractions de granulats, cette portion de la "Grande Saône" a révélé un potentiel archéologique non négligeable. Nous nous trouvons dans un secteur du cours de la rivière large et rectiligne, présentant sa pente la plus faible, et, de ce fait, des conditions de conservation particulièrement favorables. Un autre élément déterminant qui entre en ligne de compte est que ce même secteur correspond à une zone de convergence de voies commerciales tout à fait exceptionnelle. Il sufit, pour s'en convaincre, d'observer la concentration des trouvailles sur les cartes de répartition de documents tels que les épées de la fin de l'âge du Bronze (Boulud 1995) ou encore de la vaisselle romaine en bronze (Baratte 1984 ; Nemeth 1993). Assez curieusement, l'extension des opérations de prospection au nord de la ville de Chalon s'est montrée particulièrement décevante, sans que nous soyons en mesure d'en expliquer les raisons.

A partir de 1982, sous l'impulsion d'une association de plongeurs bénévoles, les premières campagnes de prospection systématique débutèrent, à Chalon et au sud de l'agglomération. Dès la première année, ces travaux, conduits en association étroite avec la section archéologie du musée Denon, permirent de localiser une vingtaine de sites de diverses époques. En même temps que les prospections, une campagne de fouille d'une durée de 2 mois est depuis programmée chaque année. Outre l'étude de sites particulièrement intéressants ou menacés de destruction, cette action vise à établir un inventaire, aussi exhaustif que possible, des sites de toutes époques conservés sur cette portion de rivière...

En 1990-91, Annie Dumont et Jean-Michel Treffort, profitant de l'infrastructure technique existante, ont mené à bien deux campagnes de fouille à l'emplacement d'un site daté du Bronze final III sur la commune de Saint-Germain-du-Plain. Ce 
travail a notamment permis d'étudier une grande pirogue monoxyle protohistorique (Dumont 1994).

En 1992, une opération de prospection systématique fut réalisée sous la direction du CNRAS dans le cadre de travaux de mise au gabarit européen de la Saône entre Chalon et Saint-Symphorien (21). Les deux sites localisés à cette occasion (Chastel 1992), un site de gué ainsi qu'une pêcherie médiévale, ont fait l'objet d'une fouille en 1993, sous la direction de Michel Pichon. Ces sauvetages n'ont hélas donné lieu à la remise d'aucun document ni rapport.

\section{2- Carte de localisation des principaux sites mentionnés}

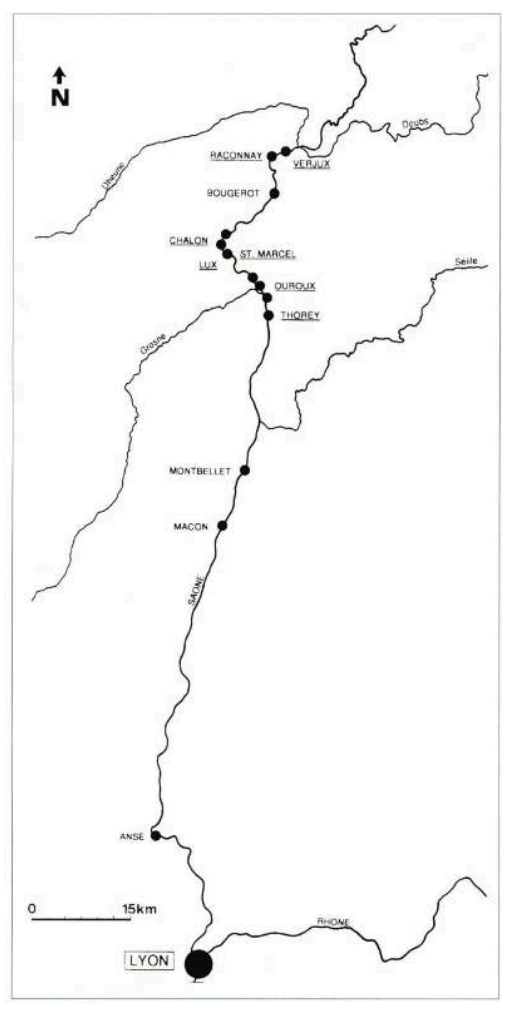

LES NOMS SOULIgNÉS CORRESPONDENT AUX LOCALITÉS AYANT DONNÉ LIEU À DES FOUILLES SUBAQUATIQUES

C. Michel, Musée Denon

\section{Les recherches en cours}

Un certain nombre de travaux réalisés dans le lit de la Saône depuis 1978 étant restés soit partiellement inédits, comme la fouille de l'habitat du Bronze final III d'Ouroux, voire même n'ayant fait l'objet d'aucun rapport de fouille tel le gué de Raconnay ou la pêcherie de la Vandaine à Verjux (cf. supra), je limiterai mon approche aux seuls travaux dont j'ai assuré la direction ou qui se sont déroulés en relation avec nous, entre 1982 et 1995.

11 Ces recherches ont principalement porté sur 6 grands thèmes que nous examinerons successivement :

- les passages à gué ;

- les habitats du Bronze final III ;

- l'évolution des bateaux de Saône ; 
- les sites portuaires gallo-romains et médiévaux ;

- les aménagements médiévaux ;

- le pont romain de Chalon.

\section{Les gués} l'archéologie de la rivière. Ces hauts-fonds naturels ont conditionné de multiples activités. En Chalonnais, un certain nombre d'entre eux sont bien connus par les données de l'archéologie, mais aussi par les documents d'archives du XIXe s. La plupart ont perduré du Néolithique Moyen-Final jusqu'à l'époque moderne ; ils figurent sur les documents antérieurs aux premiers bouleversements de la rivière, notamment sur le profil en long dressé en 1836, préalablement aux premiers travaux d'aménagement de la rivière. La continuité des découvertes sur les mêmes passages, durant cinq millénaires, semble montrer que la Saône avait atteint un profil d'équilibre qu'elle a su garder, sauf accidents ponctuels, tout au long de cette période.

La pérennité de la plupart des sites de gué peut sans doute s'expliquer par la nature de leur sous-sol :

- au Gué des Piles, les vestiges de l'âge du Bronze reposaient sur un niveau d'argile compacte épais plus de $2 \mathrm{~m}$ (possible affleurement des marnes de Bresse). Les vestiges archéologiques avaient en outre été protégés de l'érosion par la présence de nombreux troncs d'arbres couchés ;

- dans un certain nombre d'autres cas, comme les gués de Raconnay, de la Casaque, du Port de Grosne ou du pont de Seurre, le passage était établi sur une couche particulièrement compacte, constituée de sable et de gravier agglomérés par de l'oxyde de fer. possibilité de déplacement (cf. la Loire : Dion 1961).

Dans d'autres cas en revanche (Chalon : grand pont de Saône ; Port Guillot), le hautfond est constitué de sédiments meubles et sa stabilité se trouve de ce fait plus aléatoire. Au Port Guillot, le passage du Ier s. ap. J.-C. semble bien avoir été bouleversé et le matériel archéologique entrâné, avant que n'intervienne un réaménagement du passage au IIIe s., réaménagement qui figera l'évolution du site quasiment jusqu'à nos jours...

16 Il n'est pas impossible que la "disparition", sur les profils du XIXe s. (mais nous ne possédons que des profils postérieurs aux premiers travaux de dragage), du haut-fond de Jean de Saône à Montbellet (71), et par voie de conséquence du gué, dont l'existence est attestée par la découverte de plusieurs centaines de découvertes archéologiques, trouve son explication dans la nature du substrat. Il est également probable que les travaux réalisés à l'amont (clayonnages et dragages de l'ile de la Mothe) comme à l'aval (pont suspendu de Fleurville) ont eu pour conséquence un arasement du haut-fond... Au Port Guillot, la construction du Pont de Bresse, achevé en 1974, a été à l'origine d'un phénomène d'érosion régressive que nous avons pu suivre de 1982 à 1995, à l'occasion de multiples prospections subaquatiques.

Cet élément capital de l'archéologie de la Saône, après avoir donné lieu à un DEA (Dumont 1992), fait actuellement l'objet d'une thèse de doctorat (Dumont 1997) ; nous 
n'aborderons ici que les divers cas sur lesquels des recherches approfondies ont été réalisées : le gué du Port Guillot et celui de la Casaque.

\section{Le gué du port guillot}

Situé à la limite sud de Chalon, le secteur du Port Guillot a livré de très importantes découvertes fortuites aux environs de 1930, à l'occasion des travaux de construction d'une centrale thermique en bordure de la rive gauche de la rivière. Les prospections subaquatiques conduites dans cette même zone, de manière intense et régulière à partir de 1982, ont confirmé l'exceptionnelle richesse du site. Des indices d'ordre géographique et toponymique nous avaient laissé supposer l'existence d'un passage à gué (fig. 3). Son existence a été confirmée, et son tracé établi de façon précise grâce à la réalisation, à notre demande, d'un levé bathymétrique effectué par le laboratoire des Ponts et Chaussées de Blois (fig. 4). Sur une superficie de 14 ha, ce levé a nécessité quelques 12000 points de mesure. Outre un rendu en courbes de niveau ainsi qu'en trois dimensions, ce travail a permis la réalisation d'une maquette qui constitue un élément visuel et muséographique important. Une fouille de contrôle a également permis de localiser et de topographier une partie du pavage mis en place au début du IIIe s. ap. J.-C.

3- Chalon/Saint-Marcel/Lux (71). Gué du Port Guillot

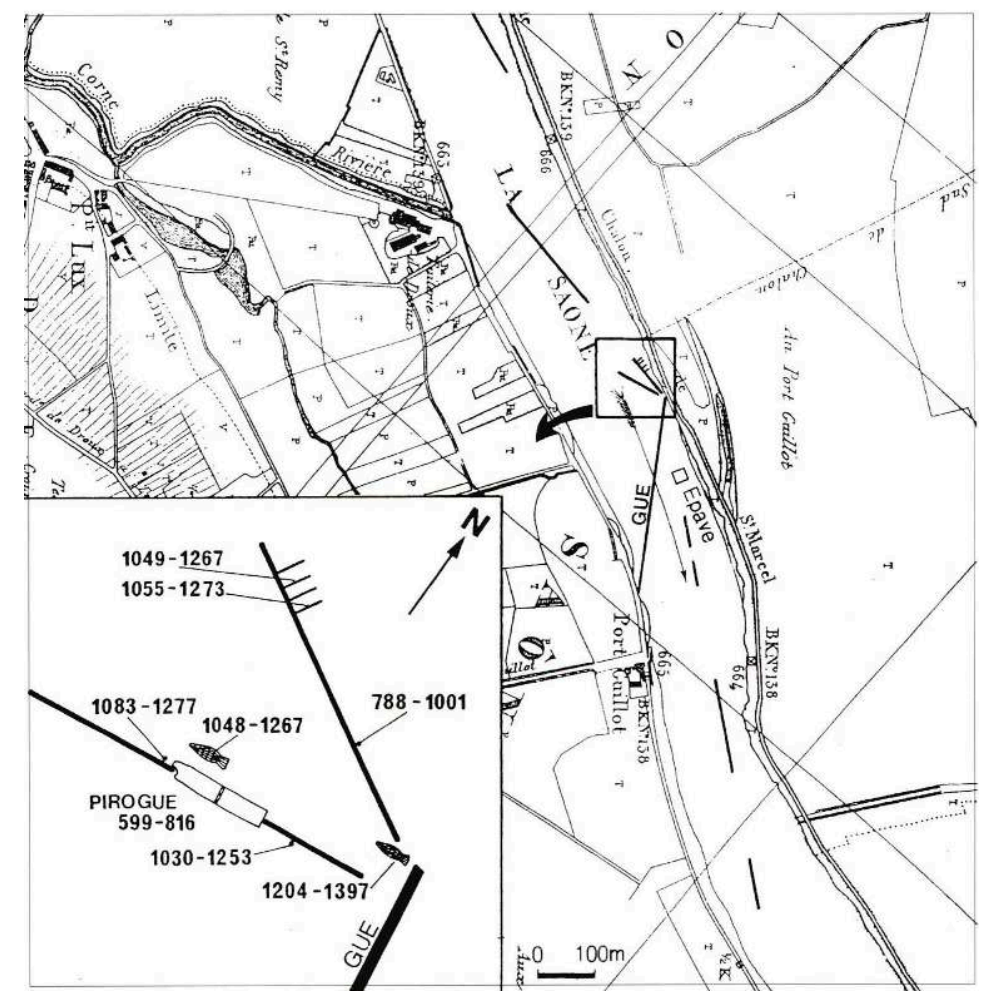

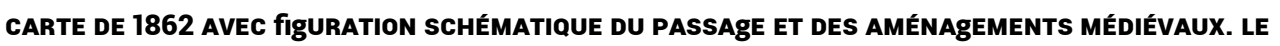
TOPONYME “PORT GUILLOT “SE RETROUVE SUR L'UNE ET L'AUTRE RIVE, AUX DÉBOUCHÉS DU gUÉ. RIVE gAUCHE, L'ACCÈS AU PASSAgE CORRESPOND EN OUTRE À LA LIMITE DE COMMUNES ENTRE CHALON ET SAINT-MARCEL 
4- Le Port Guillot. Bathymétrie du fond de la rivière réalisée par le laboratoire des Ponts et Chaussées de Blois

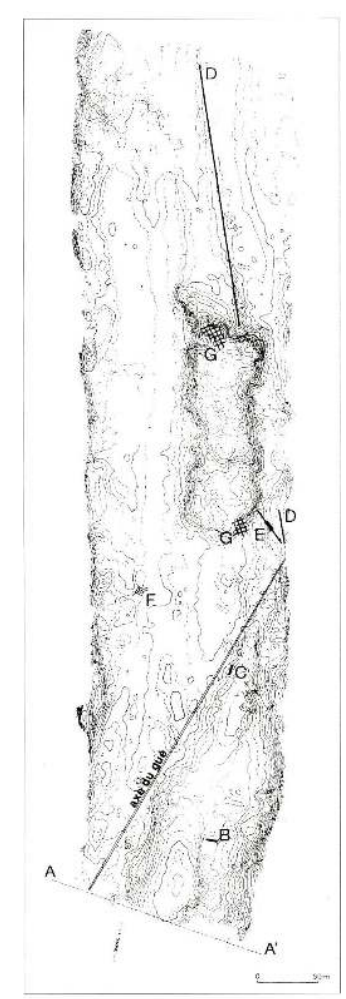

SUR LE FOND DE CARTE ONT ÉTÉ POSITIONNÉS : AA' : AXE DU PONT DE BRESSE. B : ÉPAVE DU XIIIE S. C : PIROgUe MONOXYLE DE L'Âge dU BRONZE. D : AMÉNAgEMENTS MÉdIÉVAUX (XE-XIIIE S.), INTERROMPUS PAR UN TROU DE DRAgUE. E : PIROgUE MÉROVINgIENNE. F : FOUILLE 1987 À L'EMPLACEMENT D'UNE ZONE DE CHARgEMENT DE VASES DE SEVREY DES XVIE - XVIIE S. G : CONCENTRATIONS DE CÉrAMIQUES MÉDIÉVALES.

Une prospection au sonar latéral, en revanche, conduite en même temps que le levé bathymétrique, s'est révélée beaucoup moins positive et d'interprétation plus complexe. Par ailleurs, la localisation en plongée et l'identification des anomalies repérées se sont révélées particulièrement fastidieuses et ont essentiellement conduit à la découverte d'épaves métalliques modernes, comme des barques de pêche. Basée sur le principe du balayage du fond de la rivière par ondes ultrasonores, cette méthode ne permet de détecter que les obstacles dépassant, au moins partiellement, le fond de la rivière, donc immédiatement appréhendables par des plongeurs dans le cadre d'une opération de prospection classique "à vue".

\section{Le gué de la casaque}

Situé à une dizaine de kilomètres au sud de Chalon et assurant la jonction entre les communes d'Ouroux (rive gauche) et Varennes-le-Grand (rive droite), ce passage a été mis en évidence fortuitement par les travaux de dragage menés en 1990. Les plongées de contrôle effectuées pendant les travaux montrèrent la présence d'un pavage romain en place en bordure du trou de drague, à une profondeur moyenne de $6,50 \mathrm{~m}$., recouvert par une épaisse couche de gravier. Une étude de résistivité électrique à grande profondeur, réalisée par le laboratoire des Ponts et Chaussées de Blois a montré l'existence ponctuelle d'un compartiment affaissé correspondant à une partie de la trajectoire du gué antique. La présence, dans les sédiments grossiers déposés après 
l'affaissement, d'une nasse en osier datée du XIVe s. par le radiocarbone, laisse supposer que ce phénomène local de tectonique pourrait être mis en relation avec le tremblement de terre de Bâle de 1356 ( ?). Observons en outre qu'un document de la fin du XIXe s., retrouvé dans les archives du Service de la navigation, fait état d'un nouveau passage à gué recoupant le passage antique, et implanté sur des sédiments déposés après l'affaissement du gué initial. Ici, contrairement au gué du Port Guillot, la bathymétrie ne s'est pas révélée d'un grand secours pour retrouver le tracé du passage. Les perturbations subies par le site expliquent fort probablement le fait (fig. 5).

5- Ouroux/Varennes-le-grand (71)

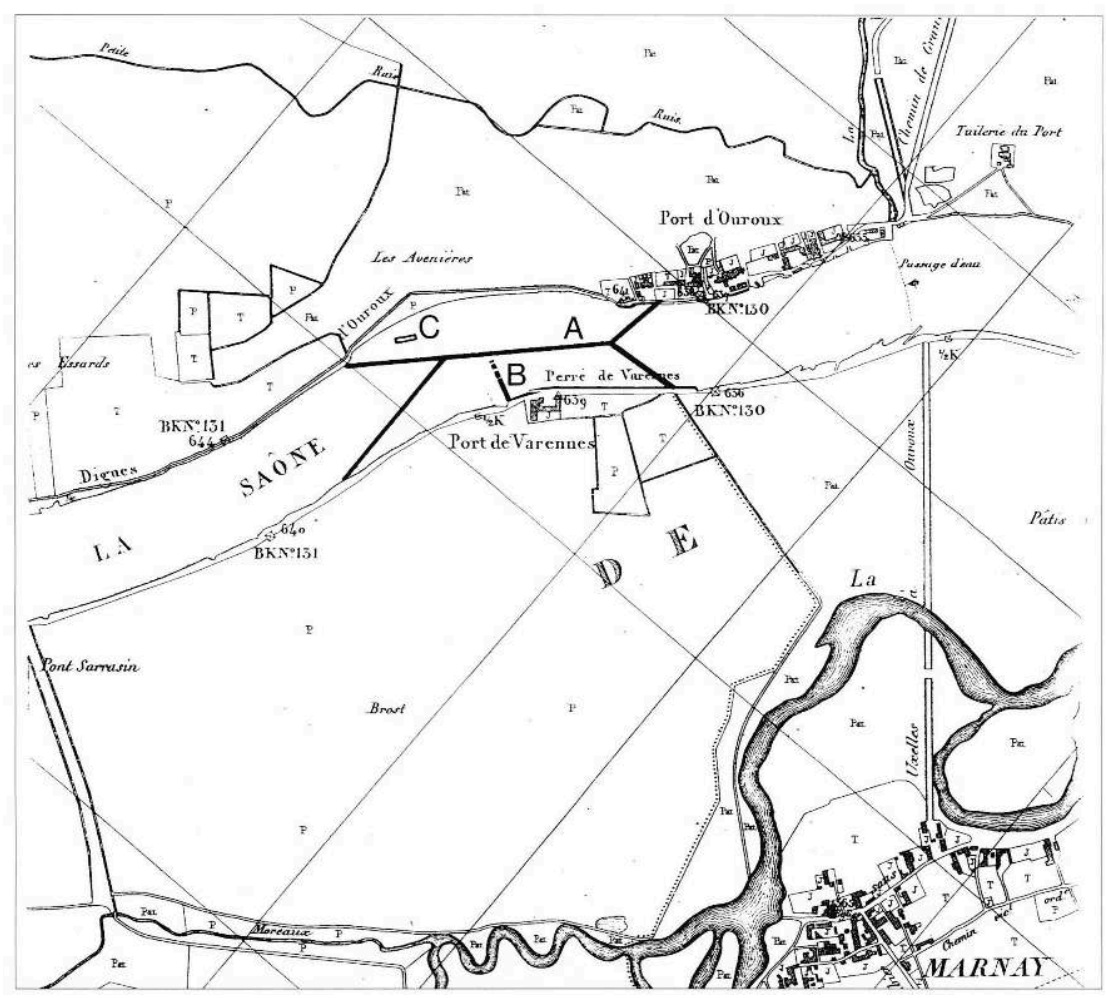

LES gUÉS dE LA CASAQUE POSITIONNÉS dE MANIÈRE SCHÉMATIQUE SUR UN FOND DE CARTE DE 1862. LE PASSAgE MODERNE RECOUPE LES TRACÉS ANTIQUES

21 L'étude de l'environnement du gué de la Casaque a été pour nous l'occasion de tenter de localiser une épave antique chargée d'amphores, repérée par dragage en 1970. Dans ce but, une étude à l'aide d'un pénétrateur de sédiments a également été effectuée ; elle a révélé la présence d'un certain nombre d'anomalies superficielles, donc récentes. La nature même des sédiments déposés après l'affaissement (galets et gros graviers) interdisait tout espoir de détection de vestiges profonds. Des sondages préalables auraient été susceptibles de nous montrer l'inanité de l'emploi d'une telle technique dans ce cas précis : seuls en effet des sédiments fins tels que des couches de vase ou de sable sont susceptibles de permettre l'application, avec succès, d'une telle méthode.

Au gué de la Casaque, nous avons eu la chance de pouvoir suivre, de manière continue, le pavage du gué sur une longueur de $200 \mathrm{~m}$. à l'aval de la zone affaissée. La découverte fortuite d'une casserole en bronze, visiblement placée intentionnellement entre les dalles du pavage, nous a conduits à nous poser la question de la présence d'éventuels dépôts votifs, sous forme d'offrandes "jetées" à la rivière ou symboliquement enfouies... 
(Le Gall 1953). Après topographie, la prospection systématique de l'ensemble du pavage à l'aide d'un détecteur électro-magnétique nous a permis de localiser l'ensemble des objets métalliques, aussi bien superficiels que profonds, en relation fortuite ou volontaire avec le passage. Si, pour un certain nombre d'objets antiques, visiblement déplacés, il n'est pas possible de se montrer catégorique, il n'en va pas de même pour d'autres, et notamment pour un glaive de type Pompéi et pour une des deux pointes de lance romaines mises au jour, ainsi que pour plusieurs outils, hache et ascia notamment, découverts, tout comme la casserole en bronze, enfouis entre, voire sous les dalles. L'utilisation d'un matériel particulièrement performant s'est donc révélée ici positive, et nous a permis de faire un pas décisif dans la compréhension de la présence d'une partie des trouvailles antiques, vaisselle de bronze, armes et même outils, en milieu fluvial (Bonnamour à paraître, a).

\section{Les habitats du bronze final III}

Nos observations ont porté sur une dizaine d'habitats implantés dans l'actuel lit mineur (Bonnamour et al. 1990, fig. 1). Seul toutefois le site du Gué des Piles à Chalon a donné lieu à une fouille étendue. Quatre campagnes de recherches et quelques 2500 heures de travail subaquatique ont été consacrées à l'étude de ce gisement (Bonnamour 1989b). Sans revenir de manière approfondie sur des résultats déjà exposés, il convient de noter que tous les sites chalonnais sur lesquels ont porté nos travaux sont situés à une profondeur constante, entre 5 et $5,50 \mathrm{~m}$. sous le niveau de l'eau actuel. Or les observations réalisées à l'occasion de la fouille du site du Gué des Piles, confortées par les analyses carpologiques et palynologiques, ont apporté la preuve que l'habitat installé sur des plateformes supportées par des pieux, était implanté à l'origine non pas au-dessus de l'eau, mais sur un îlot dans la rivière. L'explication par le recours à un phénomène de subsidence paraît d'autant plus plausible que nous avons parallèlement pu observer, sur une série d'autres sites proches, que la plupart des vestiges galloromains reposaient à une profondeur voisine de $4,50 \mathrm{~m}$., alors qu'un certain nombre de structures médiévales se rencontraient à une profondeur variant entre $3 \mathrm{~m}$ et $3,50 \mathrm{~m}$. sous le niveau de l'eau actuel, artificiellement surélevé de quelques 2,50 m. par la construction du barrage de Gigny à la fin du XIXe s. Il convient toutefois de préciser, pour une meilleure compréhension du phénomène, qu'aucune comparaison ne peut être établie avec les stratigraphies terrestres; en effet, si les vestiges les plus anciens rencontrés sous l'eau sont aussi les plus profonds, il faut rappeler que quelle que soit leur datation, et la profondeur à laquelle on les rencontre, les sites repérés en place sont souvent peu ou pas recouverts de sédiments. Sur les $840 \mathrm{~m}^{2}$ du site ayant fait l'objet d'un travail de topographie, près de 500 pieux ont pu être localisés. L'extraction d'un certain nombre d'exemplaires nous a montré qu'ils pouvaient être enfoncés de plus de $2 \mathrm{~m}$. dans une couche d'argile grise, très compacte, constituant le noyau du haut-fond sur lequel était implanté l'habitat. L'étude de 119 rondelles prélevées sur des pieux en chêne a permis à $G$. Lambert et $C$. Lavier, en dépit du nombre relativement faible de cernes des bois utilisés, d'obtenir une séquence dendrochronologique moyenne de 134 ans, et de dater de l'année 956 av. n. è. la dernière phase d'abattage de bois sur cet habitat Bronze final III. L'existence d'une série d'habitats implantés sur des hauts-fonds dans le lit mineur de la Saône à cette époque, et exclusivement à celle-ci, pose de multiples problèmes que l'archéologie est incapable de résoudre à elle seule. Dans ce cas précis, plus encore que dans les autres que nous aurons l'occasion 
d'aborder, il est évident que les données d'ordre géologiques, géomorphologiques ou climatiques s'avèrent capitales pour la compréhension du phénomène (fig. 6).

6- Ouroux-sur-Saône (71)

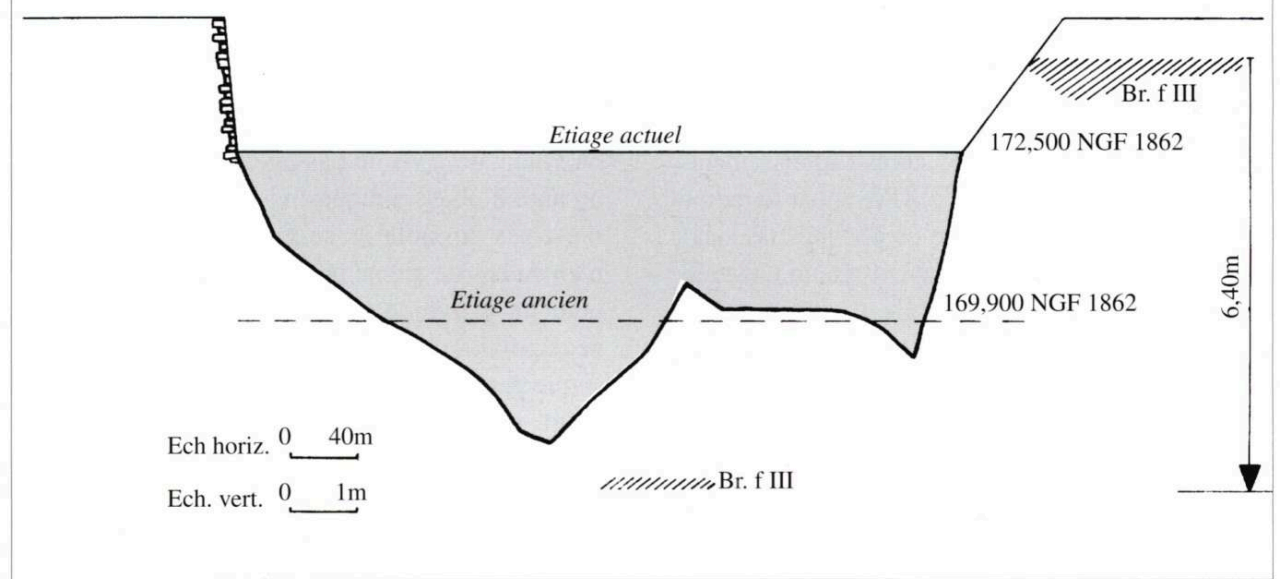

POSITIONNEMENT DES HABITATS BRONZE FINAL SUR LA BERgE ET DANS LE LIT MINEUR, SUR UN PROfIL TRANSVERSAL DATÉ DE 1862. L'IMPORTANCE EXCEPTIONNELLE DE LA SÉDIMENTATION RECOUVRANT LES VESTIgES MIS EN ÉVIDENCE PAR LA DRAgUE, EST dUE AUX ALLUVIONS dÉPOSÉES PAR UN AFFLUENT, LA GROSNE.

C. Michel, Musée Denon

\section{L'évolution des bateaux de Saône de la fin de l'âge du Bronze à l'époque moderne}

Si l'étude des anciens bateaux de bois ne constituait pas, a priori, un pôle majeur de nos recherches, force est de constater qu'au fur et à mesure des découvertes, leur intérêt s'est progressivement imposé à nous. Depuis 1983, date de la première trouvaille fortuite d'une épave, à l'occasion d'une prospection subaquatique au sud de Chalon, 6 bateaux, échelonnés de la fin de l'âge du Bronze au XVIIe s., ont ainsi été découverts et ont pu faire l'objet d'un relevé, voire d'une étude plus approfondie (Bonnamour, à paraître b). Assez curieusement, la période gallo-romaine est absente de cette série ; heureusement, la fouille d'une pile du pont romain de Chalon, et l'étude du caisson étanche mis en place autour de cette pile afin de permettre sa construction, nous ouvrent d'intéressantes perspectives sur des techniques visiblement inspirées de la charpenterie navale antique.

Le suivi des dragages, comme les découvertes faites en plongée ces années dernières, ont montré que les épaves étaient souvent concentrées aux abords des gués. S'il est évident qu'en période de basses eaux, un haut-fond peut constituer un piège naturel pour un bateau, il ne faudrait toutefois pas penser qu'une épave est obligatoirement associée au site sur lequel on la découvre. Des documents modernes, antérieurs aux grands travaux d'aménagement de la rivière, montrent en effet qu'après son naufrage, un bateau peut soit demeurer sur place, notamment lorsqu'il est lourdement chargé, soit être entraîné vers l'aval, sur une distance qui peut atteindre plusieurs dizaines de kilomètres. Lorsqu'une épave est découverte sur un site, on ne peut donc a priori présumer du fait qu'elle est bien contemporaine de celui-ci. La réalisation d'une ou 
plusieurs datations radiocarbone va alors nous apporter une première approximation, avant qu'un éventuel recours à la dendrochronologie ne permette de préciser la datation. L'obtention d'une datation dendrochronologique à partir d'un échantillon unique, dans le cas d'une pirogue monoxyle par exemple, est parfois aléatoire et ne devrait être recherchée que parallèlemement à une datation radiocarbone.

Il est intéressant, du fait de leur diversité, et afin d'illustrer notre propos, de passer très rapidement en revue les diverses épaves découvertes dans le lit de la Saône ces années dernières : sur un total de 6 exemplaires, 2 apparaissent comme isolés, 1 n'appartient pas au site sur lequel il a été mis au jour, et les 3 derniers montrent une relation possible ou certaine avec le gisement sur lequel ils ont été identifiés.

\section{Les épaves isolées}

27 La plus caractéristique à cet égard est une grande "Savoyarde" de la fin du XVIIe s.; ce bateau à fond plat, nez relevé et bordés fortement évasés, destiné au transport des marchandises, a été découvert et fouillé à Ouroux, au débouché amont du gué de la Casaque. Peu après la trouvaille de ce bateau en 1991, deux échantillons prélevés sur des planches de chêne provenant d'un bordé disloqué, et présentant chacun plus de 100 cernes, ont été soumis à une analyse dendrochronologique. La synchronisation des courbes établies à partir de ces deux échantillons s'est révélée impossible; seule une étude plus complète, à la suite d'une campagne de fouille et du prélèvement d'une quinzaine d'échantillons sur l'épave a permis de parvenir à un résultat fiable. $\mathrm{Ne}$ perdons pas de vue en effet que dans une région comme la vallée de la Saône, les bois utilisés pour la construction navale pouvaient certes être de provenance locale, mais qu'il pouvaient également aussi avoir été acheminés par radeaux, et avoir des origines aussi diverses que les Vosges, le Jura ou la Franche-Comté, avec toutes les conséquences susceptibles d'en découler au niveau d'une analyse dendrochronologique.

Datée du XIIIe s. par le radiocarbone, l'épave découverte en 1983, légèrement en aval du gué du Port Guillot, sur la commune de Saint Marcel, se présentait également comme une trouvaille isolée. Entre la berge et l'épave, à quelques mètres de cette dernière, une vingtaine de pots médiévaux en terre pourraient toutefois avoir appartenu au chargement du bateau. Par ailleurs, nos recherches nous ont permis de localiser, à une centaine de mètres en amont, une zone de chargement de vases médiévaux originaires des ateliers de Sevrey, et contemporains de ceux découverts au voisinage de l'épave. Il n'est donc pas interdit de penser que le bateau naufragé pourrait provenir de là...

\section{Les épaves en contexte}

29 Toujours dans ce même secteur, l'étude d'un aménagement médiéval sur lequel s'est greffée une pêcherie (Bonnamour 1991 et 1992) a amené la découverte d'un fragment de pirogue visiblement réutilisé lors de la mise en place de l'aménagement. La datation radiocarbone de la pirogue, ainsi que de bois prélevés sur la pêcherie, a permis de confirmer les observations archéologiques et d'attribuer la pirogue à l'époque mérovingienne, alors que la pêcherie semble avoir été installée deux à trois siècles plus tard.

En 1989. des prospections en bordure de la rive gauche de la Saône, sur la commune de SaintGermain-du-Plain, à hauteur de l'habitat du Bronze final III des Rives, avaient permis d'observer la présence de nombreux vestiges osseux ainsi que de céramique. 
Une grande pirogue monoxyle avait également été localisée dans cette même zone, sans qu'une relation éventuelle entre ces différents vestiges puisse être clairement établie. Une fouille subaquatique réalisée par A. Dumont et J.-M. Treffort a montré que les vestiges archéologiques ne se trouvaient pas en place, mais provenaient de l'habitat établi sur la berge. Les deux datations radiocarbone effectuées sur la pirogue (Dumont 1994) ne paraissent absolument pas convaincantes quant à la relation possible avec l'habitat de berge, et sembleraient plutôt se rapporter au premier âge du Fer.

31 Moins problématique en revanche parait être la datation de la pirogue monoxyle découverte à proximité du débouché, rive gauche, du gué du Port Guillot à Saint Marcel. Datée de 570 à 987 av. n. è. (Bonnamour à paraître b), cette pirogue reposait au contact d'une couche d'argile renfermant des végétaux ainsi que de nombreux éléments archéologiques attribuables au Bronze final III. Il semble donc bien qu'elle'soit restée en place dans son environnement.

\section{7- Ouroux-sur-Saône (71)}

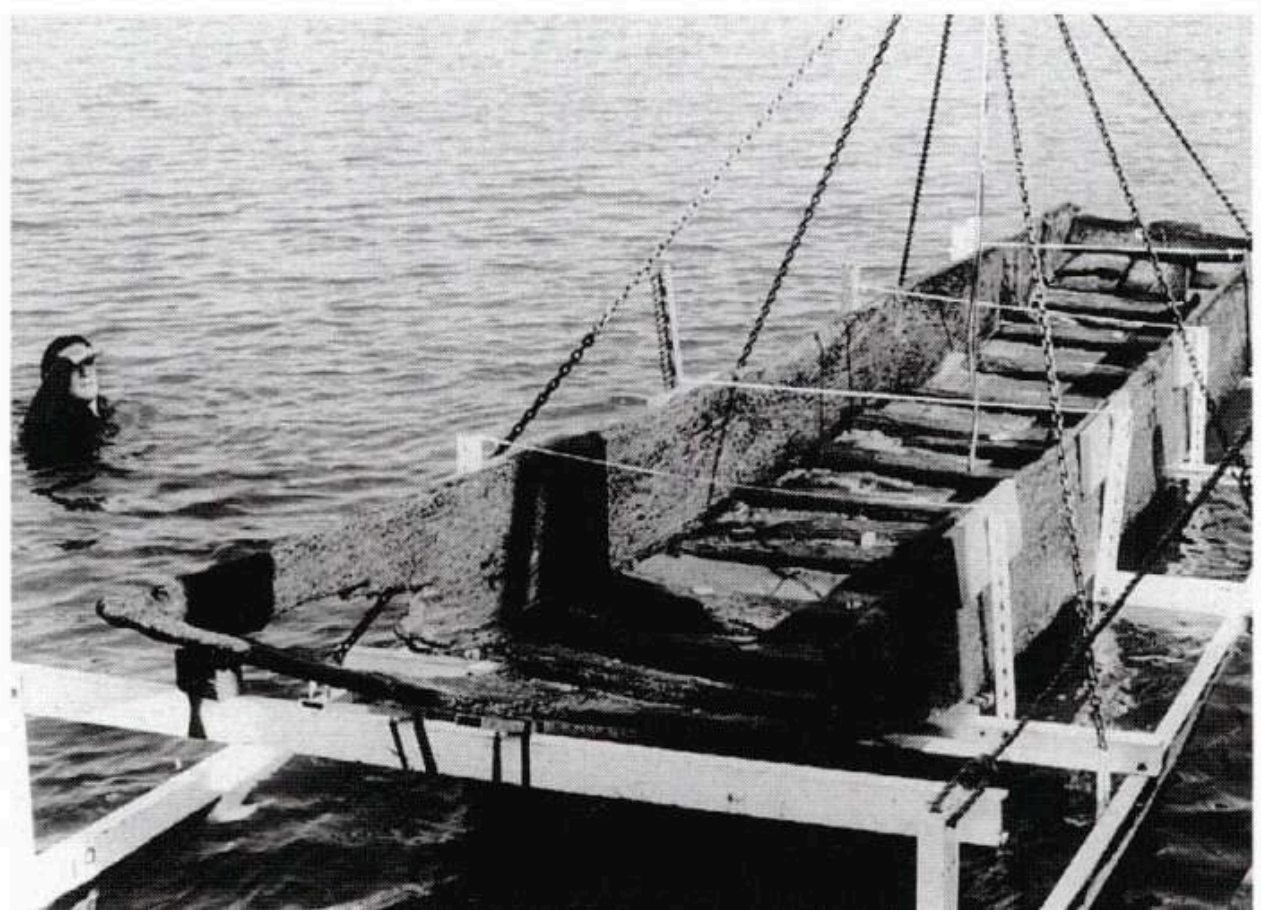

FOUILLE d'UNE ÉPAVE MÉdIÉVALE DE TYPE “MONOXYLE-ASSEMBLÉ “

Cliché Musée Denon, archéologie

Plus évidents encore paraissent être les rapports existant entre le bateau de type "monoxyle assemblé" fouillé à Ouroux en 1990 et l'aménagement avec pêcherie aux abords duquel il a été retrouvé (fig. 7). La similitude des résultats obtenus lors d'une série de datations radiocarbone montre que nous nous trouvons là très vraisemblablement en présence du bateau de service utilisé pour le fonctionnement de la pêcherie au cours du XIVes.

\section{Le port Guillot : un site portuaire antique, médiéval et moderne}

33 Outre la présence d'un passage à gué et celle de trois épaves répertoriées, ce site, à la limite sud de Chalon, présente l'intérêt d'avoir connu des activités portuaires quasi 
ininterrompues depuis la fin du Ier s. jusqu'à la période moderne. Cette pérennité s'explique par la présence, à quelques kilomètres en retrait de la rivière, d'un important centre de production de céramique, les ateliers de Sevrey-La Charmée, connus jusqu'à présent surtout pour leurs productions médiévales (Renimel 1974).

En réalité, la production de ces ateliers semble remonter à l'Antiquité, comme le prouvent l'abondance et la spécificité de vases retrouvés sur le site du Port Guillot, telle la série de 5 plats à couverte micacée, retrouvés empilés au fond de la rivière (fig. 8). Dès les premières prospections, nous avions été particulièrement frappés d'observer, dans la zone du Port Guillot, la présence de nombreux points de trouvailles d'une superficie très restreinte, mais présentant pour la plupart une relative homogénéité chronologique. La réalisation de la bathymétrie du secteur, et la mise en évidence du tracé du gué à partir de 1988 nous ont permis de commencer à comprendre l'organisation du site, et de discerner les relations ayant pu exister entre le passage et ce qui apparaissait comme différentes zones de chargement. Tant à l'époque romaine, mérovingienne qu'au bas Moyen Age, le pavage du gué, au voisinage des deux rives de la rivière, a visiblement servi de rampe de chargement, selon une technique élémentaire qui demeurera en usage sur la Saône jusqu'au début du XXe s. Curieusement, la période axée sur les Xe-XIIIe s. échappe à cette règle, puisque l'ensemble des opérations de chargement de vases se concentre sur la rive gauche, rive opposée à celle sur laquelle étaient situés, à l'intérieur des terres, les ateliers de production. A cette époque, on constate la présence, au débouché du gué, d'un aménagement sommaire sous forme de lignes de piquets disposés perpendiculairement à la rivière, et dont on peut supposer qu'elles ont servi d'armature à un quai en fascines (Bonnamour 1992, p. 360). L'abandon des activités portuaires sur la rive droite et leur report sur la rive opposée est incontestablement à mettre en relation avec des conditions de navigation particulièrement défavorables; c'est en tout cas la conclusion vers laquelle nous a orientés l'étude d'un aménagement long de $1300 \mathrm{~m}$., intégrant également une pêcherie, et destiné à faciliter la navigation au passage du haut-fond (fig. 3). 


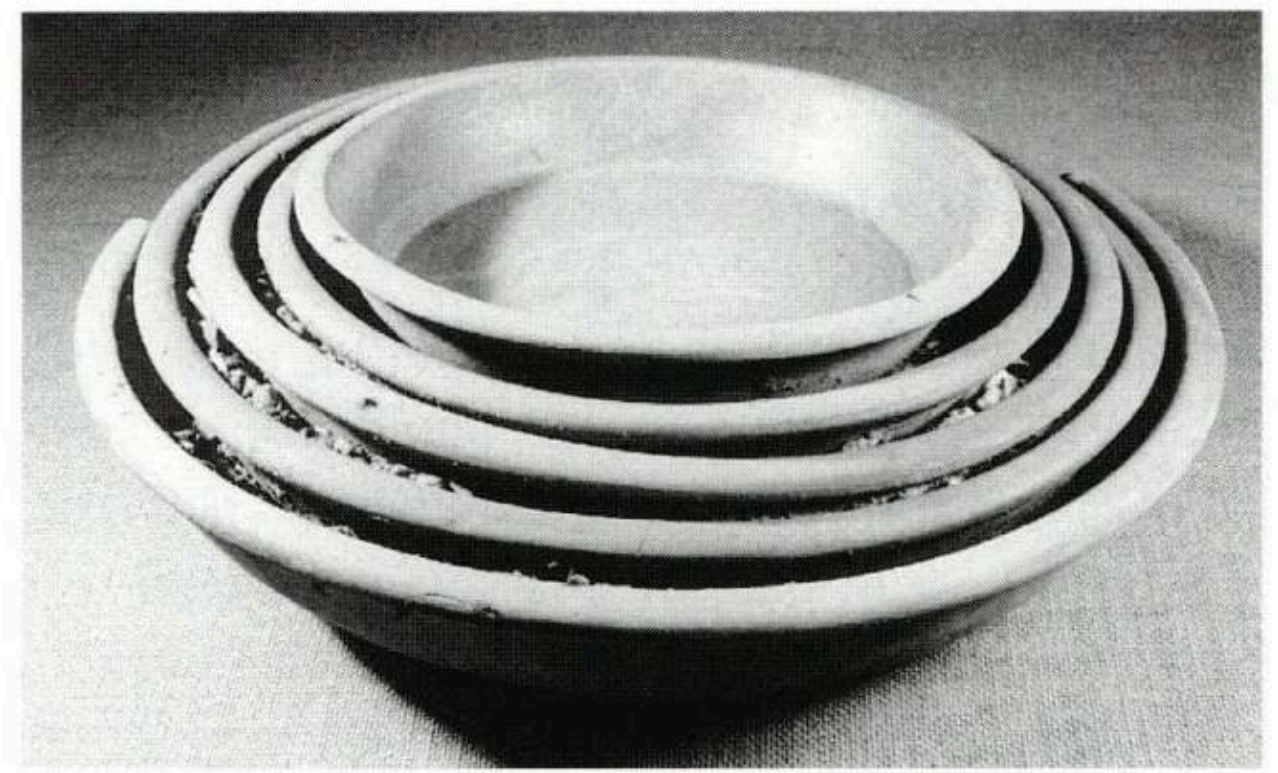

FOUILLE DU SITE PORTUAIRE gALLO-ROMAIN DU PORT GUILLOT : CINQ PLATS EMPILÉS, TELS QU'ILS FURENT DÉCOUVERTS

Cliché Musée Denon, archéologie

Entre le XIVe et le XVIe s., voire le début du XVIIe s., les conditions de navigation paraissent s'améliorer, et les points de chargement se multiplient le long des berges, sur toute la longueur du gué et même en amont, en bordure d'un bras secondaire révélé par la bathymétrie. Là, la fouille en 1987 d'une petite zone de chargement nous a montré l'absence totale d'installation fixe, à l'exception de quelques piquets d'amarrage. Sur les $20 \mathrm{~m}^{2}$ étudiés, 57 pots archéologiquement complets ont été retrouvés, partiellement enfoncés dans la vase sur deux épaisseurs, et recouverts par une épaisse couche de gravier, qui atteste l'importance de la sédimentation en rive droite, en aval de la confluence avec la Raie de Droux. Le suivi d'une série de sites portuaires échelonnés sur une aussi longue période et sur une zone géographique restreinte présente un intérêt certain pour la compréhension de l'évolution de la rivière. La bathymétrie, les datations radiocarbone, la climatologie constituent des apports essentiels pour l'approche du phénomène.

\section{Les aménagements médiévaux}

C'est une fois encore le site du Port Guillot qui a livré les premiers éléments ayant permis la prise en compte d'un phénomène jusqu'alors insoupçonné sur la Saône, et dont l'ampleur nous apparaît aujourd'hui à la lumière des découvertes archéologiques autant que des recherches d'archives (Canat 1992). Dès 1982, des alignements ou des groupes de piquets en bois blanc avaient été observés sans que nous leur ayons porté une attention particulière. Toutefois, la découverte, quelques années plus tard, de céramiques médiévales et d'un tronçon de pirogue visiblement associés à ces piquets, nous a conduits à organiser la fouille systématique du secteur le plus sensible de ce vaste aménagement, en bordure amont du haut-fond guéable, et à étendre les prospections à l'ensemble du dispositif. 
La fouille a porté sur trois aménagements distincts, étroitement imbriqués et chronologiquement proches, comme l'a montré la série de datations radiocarbone réalisée à partir des bois prélevés sur l'ensemble de la structure (Bonnamour 1992, p. 360). Long de $1300 \mathrm{~m}$., l'aménagement principal, disposé de part et d'autre du hautfond, est constitué par un vaste "clayonnage" ; il est destiné à canaliser le cours de la rivière, afin, dans un premier temps, de rejeter le courant en direction de la passe navigable de rive gauche, avant de le renvoyer ensuite au large pour éviter qu'il ne sape la berge. Sur le haut-fond, là où la hauteur d'eau est la plus faible, et, en contrepartie, le courant le plus fort, ont été implantés une pêcherie ainsi que le petit quai de chargement auquel il a été fait allusion précédemment (fig. 9). La douzaine de datations radiocarbone réalisées permet de soupçonner une antériorité, de l'ordre d'un siècle, de la stucture principale par rapport à la pêcherie et au quai, qui seraient venus se greffer sur l'aménagement initial vers le début du XIe s. L'ensemble a ensuite fait l'objet de réparations et de travaux d'entretien au moins jusqu'à la fin du XIIIe s. Bien que nous nous trouvions systématiquement, dans le cas des multiples aménagements médiévaux qui jalonnent le cours de la Saône, en présence de bois blancs de faible diamètre, des analyses dendrochronologiques seraient probablement susceptibles de préciser la chronologie relative de l'ensemble. Un tel travail suppose une topographie et des prélèvements systématiques, ainsi que des moyens dont nous ne disposons bien évidemment pas.

\section{9- Saint-Marcel (71)}

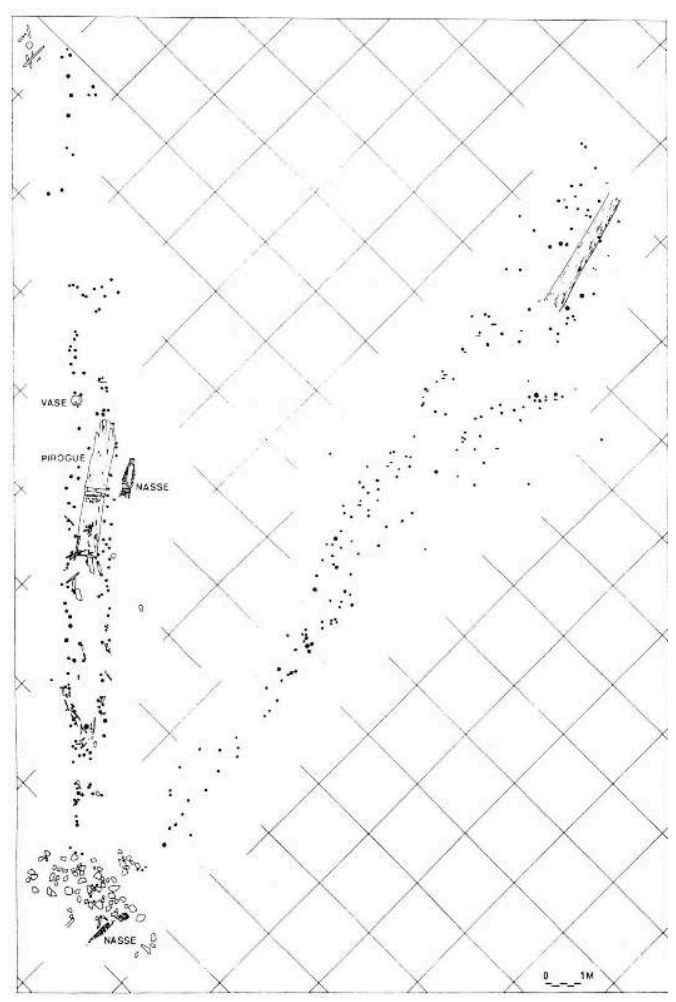

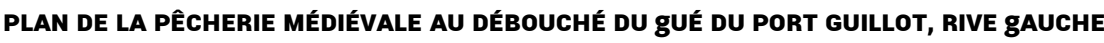

C. Michel, Musée Denon

En 1991, à la suite de l'aménagement du Port Guillot, nous avons été amenés à travailler sur un autre site, d'apparence assez semblable, à Ouroux-sur-Saône. Ce site, en cours de 
destruction rapide, suite à des travaux d'extraction de granulats et à l'érosion consécutive à ces derniers, comportait les restes d'un grand clayonnage longitudinal, en bordure de la rive gauche de la Saône, ainsi que les vestiges d'une pêcherie. Cette dernière avait de toute évidence été l'objet d'une destruction brutale peu après sa mise en place, puisqu'elle se présentait sous la forme d'un enchevêtrement de grands pieux en bois blanc, conservés sur toute leur longueur. La datation radiocarbone des piquets du clayonnage, des pieux de la pêcherie ainsi que de l'épave retrouvée à proximité a montré d'une part la contemporanéité des ces divers éléments, et d'autre part leur remarquable homogénéité chronologique, axée sur le XIVe s. (Bonnamour 1992, p. 374). Outre le problème posé par la destruction brutale de la pêcherie, imputable à un événement naturel ou à l'action de l'homme (?), on remarque une différence importante dans le positionnement de l'aménagement : il est placé non pas à cheval sur le haut-fond, comme c'était le cas au Port Guillot, mais en aval de ce dernier, dans un secteur où la berge, particulièremement escarpée, est soumise à une érosion importante. En période de forte activité hydrologique, on peut donc y voir un ouvrage analogue aux "turcies" de la Loire (Dion 1961), sorte de digue de protection immergée destinée à briser le courant. La poursuite des prospections subaquatiques nous a montré l'extrême abondance des aménagements de ce type, qui ont survécu jusqu'à la fin du XVIIIe s. sous la forme de "bennes" ou "bannes" destinées au fonctionnement des moulins à nefs. Pour la période médiévale, la multiplication des datations radiocarbone à partir d'échantillons prélevés systématiquement lors des prospections, semble indiquer deux grandes phases de construction, l'une centrée sur la période X - XIIIe s., l'autre sur les XIVe - XVe s. Pêcheries et aménagements de moulins exceptés, il semble bien que leur finalité ait été totalement différente, adaptée à des changements du régime hydrologique. La poursuite des recherches et la multiplication des datations absolues devraient également permettre la mise en évidence d'ouvrages analogues, et notamment de pêcheries d'époques antérieures, mérovingiennes, galloromaines, voire même protohistoriques. L'exemple, maritime il est vrai, de la baie du Mont SaintMichel (L'Homer 1995) est, à cet égard, particulièrement encourageant.

\section{Le pont romain de Chalon}

Vraisemblablement construit au début du IIe s., le "grand pont de Saône" est resté en usage jusqu'à sa destruction brutale par fait de guerre, le 5 septembre 1944. Les travaux de démolition qui ont suivi amenèrent un certain nombre d'observations archéologiques qui ont permis à Louis Armand-Calliat de soupçonner l'antiquité de l'ouvrage (Armand-Calliat 1952). En 1990, des travaux d'approfondissement du chenal navigable ont porté sur l'emplacement des piles $\mathrm{n}^{\circ} 3$ et 4 du pont antique et médiéval, et eu pour conséquence l'extraction d'environ un millier de grands blocs de calcaire et de grès. C'est cette dernière découverte qui a motivé notre intervention et la fouille en cours depuis 1994 à l'emplacement de la pile $n^{\circ} 3$.

Les plans et profils des XVIIIe et XIXe s. dont nous disposions jusqu'alors montraient des piles posées directement sur le fond de la rivière ou assises sur des pieux. Les travaux des années 1950 avaient, grâce à la découverte de grands sabots métalliques, attesté la réalité de ces derniers à l'emplacement des piles antiques. Les premiers travaux de décapage nous ont apporté la preuve que la base de la pile $n^{\circ} 3$, construite à l'aide de gros blocs de grès liés par du mortier et des crampons métalliques noyés dans le plomb, avait été assez profondément enfouie dans le sol et se trouvait, de ce fait, 
conservée sur une hauteur de près de $2 \mathrm{~m}$. Les sondages géologiques réalisés préalablement aux travaux de reconstruction du pont apportent une explication logique à cette particularité : il faut en effet descendre à environ $6 \mathrm{~m}$. sous la première assise de blocs, à travers des couches de gravier et de sable, avant d'atteindre un épais niveau argileux susceptible d'assurer une stabilité suffisante à l'ouvrage. Logiquement donc, les pieux de fondation supportant le platelage et la pile devraient être implantés jusqu'à ce niveau: nous nous efforcerons de le confirmer lors de la campagne 1996. Cette particularité du pont de Chalon, liée à la présence d'une épaisse couche de sédiments superficiels instables, a rendu plus complexe la tâche des bâtisseurs romains, et interdit l'usage des batardeaux classiques du type de ceux employés pour la construction du pont de Trêves (Clippers 1969). A Chalon, l'assèchement du chantier a dû être réalisé en deux temps : en premier lieu, une digue sommaire, avec armature de pieux, a été construite tout autour de l'emplacement de la pile ; cet espace a alors pu être vidé à l'aide d'une puissante pompe à roue, puis excavé. Au fond du "polder" ainsi créé a été construit un caisson étanche, très soigneusement assemblé selon des principes s'apparentant fort à ceux de la construction navale. Ce caisson achevé et maintenu à sec à l'aide d'une simple pompe à piston, le travail a pu alors commencer : enfoncement et recépage des pieux, mise en place du platelage, puis de quatre premières assises de grès. Le chantier, dépassant alors le niveau d'étiage, a ensuite pu être poursuivi de manière traditionnelle.

41 Parmi les problèmes nombreux et complexes posés par la fouille d'un tel ouvrage, relevons la présence, à l'aval de la pile, d'une vaste enceinte de pieux creusée plus profondément que la base de la pile, et remplie de pierrailles et de blocs de remploi, sur une hauteur de $3 \mathrm{~m}$. Le rôle initial de cette "enceinte" est certes d'assurer la protection de la pile contre une érosion prévisible, du fait de l'instabilité du substrat. En réalité, cette "crêche" de protection a répondu à un autre objectif : au cours des premières phases de construction, elle a en effet servi d'aire de travail pour la mise en place des pompes ainsi que des engins de levage, avant d'être remblayée jusqu'à un niveau supérieur à celui de l'eau afin de pouvoir à nouveau être utilisée comme plateforme de travail pour la suite du chantier. Il nous a par ailleurs été possible d'identifier de manière précise le niveau d'étiage antique, marqué par un épais concrétionnement de carbonate de chaux au sommet de la troisième assise de grès, à une profondeur de 4,50 $\mathrm{m}$. sous le niveau actuel de l'eau de la rivière. Un autre point intéressant est la présence, autour des piles, d'importants enrochements. Nos observations au niveau de l'avant-bec de la pile $\mathrm{n}^{\circ} 3$, appuyées sur des trouvailles notamment de monnaies, montrent que le pourtour de la pile est resté vide, protégé par le seul caisson de construction laissé en place à l'issue des travaux, durant un laps de temps supérieur à un siècle. Au cours du IIIe s., à une date que nous ne pouvons préciser actuellement, on a procédé au démontage systématique d'une partie du caisson, avant de mettre en place les enrochements constitués de matériaux de remploi. A ce stade de la recherche, la question se pose de savoir si l'installation de ces enrochements est liée à la disponibilité de masses importantes de matériaux, issus de la destruction de monuments liée à des événements politiques, ou à des raisons d'ordre hydrologique ayant mis en danger la stabilité de l'ouvrage. La conjonction des deux explications est également plausible; il est tentant ici d'établir un rapprochement avec le réaménagement, vers le milieu du IIIe s., du pavage du gué du Port Guillot, suite à un bouleversement complet du passage, mais il convient de se montrer prudent en ce domaine, car nous ne disposons que d'éléments isolés, d'interprétation trop aléatoire. 


\section{Conclusion}

En dépit de l'ampleur des destructions opérées pendant un siècle et demi de dragages et d'extractions incontrôlées de matériaux alluvionnaires dans le lit mineur de la Saône, l'expérience chalonnaise montre que l'inventaire, la protection et l'étude des sites doivent être poursuivis. Le travail réalisé est loin d'être satisfaisant; il demande à être approfondi dans un esprit pluridisciplinaire, en fonction de thématiques précises. Pour ponctuelle qu'elle ait été, cette action a cependant non seulement apporté la preuve évidente de l'existence de véritables gisements archéologiques, mais a aussi montré leur variété et la richesse des informations qu'ils sont susceptibles de livrer, tant en ce qui concerne l'histoire des hommes que celle, indissociable, de la rivière.

\section{BIBLIOGRAPHIE}

\section{Bibliographie}

Armand-Calliat 1952 : ARMAND CALLIAT (L.) - Le pont romain de Chalon. Mémoires de la Société d'Histoire et d'Archéologie de Chalon, 33, 1952, p. 53-63.

Armand-Calliat 1957 : ARMAND CALLIAT (L.) - Trouvailles archéologiques dans la Saône à Anse (Rhône) et aux abords de Chalon. Gallia 15, 1, p. 128-144.

Baratte et al. 1984 : BARATTE (F.) et al. - Vases antiques de métal au Musée de Chalon-sur-Saône. Ve suppl. à la R.A.E., Dijon, 1984.

Bidault de Grésigny 1920 : BIDAULT DE GRESIGNY (L.) - Recherches archéologiques dans la vallée de la Saône entre Lyon et Chalon-sur-Saône de 1875 à 1920. Chalon, 1920. (album de planches photographiques).

Blanchet 1977 : BLANCHET (J.-C.), LAMBOT (B.) - Les dragages de l'Oise de 1973 à 1976. Cahiers Archéologiques de Picardie, 4, 1977, pp. 62-88.

Bonnamour 1974 : BONNAMOUR (L.) - Trouvailles de la fin de l'âge du Bronze dans la Saône sur le site d'OurouxMarnay (S.-et-L.). Bull. S.P.F., 71, CSRM 6. 1974, pp. 189191.

Bonnamour 1975 : BONNAMOUR (L.) - La port gaulois et gallo-romain de Chalon. Etat de la recherche. Mémoires de la Société d'Histoire et d'Archéologie de Chalon, 45,1975, pp. 761-71.

Bonnamour 1989 : BONNAMOUR (L.) - L'habitat Bronze final du Gué des Piles à Chalon-sur-Saône (S.-et-L.). Etude archéologique. Gallia Préhistoire, 31, 1989, pp. 159-189.

Bonnamour 1989a : BONNAMOUR (L.) - Nouvelles découvertes archéologiques en Saône sur le site du gué de Gigny-Thorey (S.-et-L.). R.A.E., 40, 1989, pp. 47-60.

Bonnamour et al. 1990 : BONNAMOUR (L.), MARINVAL (P.) et al. - Les habitats du Bronze final III dans la moyenne vallée de la Saône au sud de Chalon et le gué des Piles. In : Colloqe de Lons-le- 
Saunier : Un monde villageois, habitat et milieu naturel en Europe de 2000 à 500 av. J.-C., Lons-le-Saunier, 1990, pp. 97-111.

Bonnamour 1991 : BONNAMOUR (L.) - Recherches subaquatiques en Saône : mise en évidence d'aménagements médiévaux. In : 116e Congrès Nat. Soc. Sav., Chambéry, 1991, pp. 165-177.

Bonnamour 1992 : BONNAMOUR (L.) - Fouille d'aménagements médiévaux dans le lit de la Saône au sud de Chalon. R.A.E., 43, 1992, pp. 353-378.

Bonnamour à paraître a : BONNAMOUR (L.), DUMONT (A.) - Les armes romaines de la Saône. Etat des découvertes et données récentes de fouilles. In : IXe International Roman Military Equipment Conference, Leyden, Netherlands, 1994.

Bonnamour à paraître $\mathbf{b}$ : BONNAMOUR (L.)-Bateaux de Saône : 3000 ans d'évolution. In : 7e colloque international d'archéologie navale, Tatihou, 1994, à paraître dans Archaeonautica.

Boulud 1995 : BOULUD (S.) - Les épées de l'âge du Bronze dans la vallée de la Saône. Mémoire de Maîtrise, Univ. de Bourgogne, 1995.

Briard 1971 : BRIARD (J). - Epées de Bretagne et d'ailleurs jetées dans les rivières à l'âge du Bronze. Annales de Bretagne, 1971, pp. 47-58.

Briard 1995 : BRIARD (J). et alii - Le Néolithique et l'âge du Bronze du site à gué de la Vilaine entre Massenac (LoireAtlantique) et Langon (Ille-et-Vilaine). Bull. S.P.F., 92, 1, 1995, pp. 109-122.

Chevrier 1846 : CHEVRIER (J.) - Notice sur un vase byzantin trouvé dans la Saône en 1843. Mémoires de la Société d'Histoire et d'Archéologie de Chalon, 1, 1846, $\rho$ p. 235-240.

Cüppers 1969 : CÛPPERS (H.) - Die Trierer Romerbrücke., Mainz, 1969. (Trierer Grabungen und Forschungen 5).

Déchelette 1913 : DECHELETTE (J.) - La collection Millon. Antiquités préhistoriques et gallommaines.Paris, 1913,pp. 155-282.

Dion 1961 : DION (R.) - Histoire des levées de la Loire, Paris, 1961, pp. 14-22.

Dumont 1992 : DUMONT (A.) - Les gués de la Grande Saône (de Verdun sur le Doubs à Lyon) Inventaire et problématique. Mémoire de DEA, Univ. Lumière Lyon 2, 1992.

Dumont 1994 : DUMONT (A.), TREFFORT (J.-M.) - Fouille d'une pirogue monoxyle protohistorique à Saint-Germain-du-Plain (S.-et-L.). R.A.E., 45, 2, 1994, pp. 305-319.

Dumont 1997 : DUMONT (A.) - Les passages à gué de la Grande Saône. Thèse de doctorat. Univ. Lumière Lyon 2.

Fehr 1981 : FEHR (H.) - Römische Rheinbrücke Koblenz. In : Bonner Jahrbücher 181, Bonn, 1981, pp. 283-354.

Le Gall 1953 : LE GALL (J.) - Recherches sur le culte du Tibre. Thèse complémentaire pour le doctorat ès lettres, Univ. de Paris. PUF, 1953, 112 p.

Gaucher 1981 : GAUCHER (G). Sites et cultures de l'âge du Bronze dans le Bassin Parisien. XVe supp. à Gallia Préhistoire, 1981, p. 31-36.

Grandjean 1984 : GRANDJEAN (P.) - L'habitat Bronze final d'Ouroux-sur-Saône. In : Archéologie des lacs et des rivières, 20 ans de recherches subaquatiques en France, Musée-Chateau d'Annecy, 1984, s. p.

L'Homer 1995 : L'HOMER (A.) - Les vestiges de la pêcherie en bois de Saint-Jean-le-Thomas datant de l'âge du Bronze, baie du Mont-Saint-Michel et marais de Dol. In : Milieux naturels et peuplements dans le passé, Centre régional d'archéologie d'Alet, Saint-Malo, 1995, pp. 119-124. 
Jeanton 1917 : JEANTON (G.), LAFAY (G.) - Nouvelles découvertes archéologiques faites dans la Saône en aval de l'île Saint-Jean, près de Mâcon. Bull. S.P.F., 14, 1917, pp. 161-176 et 191-204.

Kramer 1995 : KRAMER (W.), SCHLICHTHERLE (H.) - Unterwasser Archäologie in Deutschland. Antike Welt, 26, 1, 1995, pp. 3-16.

Künzl 1993 : KÜNZL (E.) - Die Alamannenbeute aus dem Rhein bei Neupot., Mainz, RomischGermanischen Zentralmuseum, 1993, 4 vol.

Landa 1869 : LANDA (L.) - Promenade archéologique aux environs de Chalon. Matériaux d'Archéologie et d'Histoire, 1, 1869, pp. 108-112 et 150-152.

Mariën s. d. : MARIËN (M.-E.) - Découvertes à la grotte de Han. Han-sur-Lesse, s. d.

Mohen 1977 : MOHEN (J. P.). L'âge du Bronze dans la région de Paris : catalogue synthétique des collections conservées au Musée des Antiquités Nationales, Paris, Editions des Musées Nationaux, 1977.

Monnet 1984 : MONNET (R.), THEVENIN (C.) - Dragages récents dans l'Ognon à Marnay (HauteSaône). R.A.E. 34, 1984, pp. 366-374.

Mozsolics 1975 : MOZSOLICS (A.) - Bronzkori Kardok Folyokbol. Kiilonlenyomat Az Archaeologiai Estesito 102, 1975, pp. 3-24.

Nemeth 1993 : NEMETH (O.) - Vases antiques de métal dans la moyenne vallée de la Saône. Mémoire de maîtrise d'Archéologie, Univ. de Bourgogne, 1993.

Renimel 1974 : RENIMEL (S.) - L'atelier céramique de Sevrey (IXe-XIXe s.), Un millénaire de tradition céramique en Chalonnais. Chalon, 1974, Société d'Histoire et d'Archéologie de Chalon, 1974.

Schalles 1993 : SCHALLES (H. J.), SCHREITER (C.) - Geschichte aus dem Kies, Neue Funde aus dem alten Rhein bei Xanten. Xantener Berichte 3, 1993, $269 \mathrm{p}$.

Torbrügge 1972 : TORBRÜGGE (W.) - Vor-und Frühgeschichtliche Flussfunde. Zur Ordnung und Bestimmung einer Denkmälergruppe. Bericht der RömischGermanischen Komission, 51-52, 1972, 146 p.

Warmenbol et al. 1992 : WARMENBOL (E.) et al - La collection Edouard Bernays. Néolithique et âge du Bronze, époques gallo-romaine et médiévale. Bruxelles, 1992.

Wegner 1976 : WEGNER (G.) - Die vorgeschichtlichen Flussfimde aus dem Main und aus dem Rhein bei Mainz. 1976, 197 p. (Materialhefte zur Bayerischen Vorgeschichte A 30).

Wirth 1993 : WIRTH (S.) - Flussfunde aus Augsburg. Acta Praehistorica et Archaeologica, 25, 1993, pp. 211-242.

Zapotocky 1969 : ZAPOTOCKY (M.) - Kvyznamu Labe Yako Spojovaci a Dopravni Cesti (Zur Bedeutung der Elbe als Verbindungs-und Transportweg). Pamatky Archeologicke 60, 1969, pp. 277-366.

\section{Documents}

Canat 1992 : CANAT (C.) - Recherches en archives, In : CHASTEL 1992, pp. 27-46.

Chastel 1992 : CHASTEL (J.) - Aménagement de la Saône entre Chalon-sur-Saône (71) et SaintSymphorien-sur-Saône (21). Rapport de prospection archéologique subaquatique. Service Régional de l'Archéologie de Bourgogne, 1992. 


\title{
À propos de la fondation de Grenoble : un réexamen de l'hypothèse d'une installation primitive sur un môle alluvial
}

\author{
Jean-Luc Peiry et Cyril Féougier
}

\begin{abstract}
À la suite des travaux de R. Blanchard (1911) et de H. Müller (1930), lorsque l'on demande à un archéologue ou à un géographe grenoblois les raisons de l'implantation de la ville entre l'Isère et le Drac, l'un des éléments qui revient invariablement est l'existence hypothétique d'un "môle alluvial" à l'emplacement de la ville ancienne. Il y a vingt siècles, un point haut, protégé des inondations, aurait servi à fixer les premières implantations humaines. Depuis la formulation de cette hypothèse, la connaissance des processus fluviatiles dans les plaines alluviales intramontagnardes a notablement progressé. C'est tout particulièrement le cas dans les vallées de l'Isère et du Drac aux abords de Grenoble, où plusieurs études permettent d'avoir une idée relativement approfondie du mode de fonctionnement de ce site de confluence depuis le XIIIe ou XIVe s. (Bravard 1989; Salvador 1991). Des investigations complémentaires sur la topographie du cône alluvial du Drac et son contact avec l'Isère ont été récemment menées à partir de la synthèse des sondages réalisés dans Grenoble (Féougier 1994). L'objectif de cet article est de présenter les résultats de cette étude et de réexaminer l'hypothèse d'un môle alluvial comme point d'ancrage des premiers indices d'occupation humaine en rive gauche de l'Isère.
\end{abstract}

\section{L'hypothèse d'un môle alluvial en rive gauche de l'Isère}

2 En 1911, dans la première édition de son ouvrage intitulé « Grenoble, essai de géographie urbaine ", Raoul Blanchard indiquait que la construction des premières infrastructures grenobloises était liée à trois facteurs favorables : 1) un site de confluence, localisé à la jonction de deux cours d'eau alpins d'importance, le Drac et l'Isère ; 2) un carrefour de vallées où convergeaient trois routes majeures (ceci correspond à la traditionnelle 
image de l'Y grenoblois ouvrant sur le sillon alpin et l'Italie, le sud de la France et la vallée du Rhône) (fig. 1) ; 3) un point de franchissement privilégié de l'Isère, la rivière repoussée par le Drac étant calée contre le flanc sud du massif de la Chartreuse. R. Blanchard émet l'hypothèse qu'il existe un site favorable sur la rive gauche de l'Isère, lequel, selon son expression, «présente des avantages pour la défense et (...) est à peu près gardé contre les inondations"; selon lui, ce site topographiquement surélevé prend la forme d'un tertre s'élevant entre deux bras du Drac. Cette zone plus élevée aurait fourni par le passé un refuge face aux inondations de l'Isère. Il en voulait pour preuve une série de grandes inondations ayant marqué la ville : la crue d'août 1525 laissa hors d'eau le coeur actuel de la vieille ville (place aux Herbes); la crue généralisée de 1733, dont on retrouve l'empreinte sur tous les grands cours d'eau des Alpes du Nord, n'inonda pas la place aux Herbes et la place Claveyson, les rues Brocheries et Pérollerie; la crue d'octobre 1778, appelée "Déluge de la Saint Crespin », épargna la même zone ; puis enfin, la fameuse crue de novembre 1859, qui sert encore aujourd'hui de référence pour délimiter les zones inondables grenobloises, n'inonda pas ce même quartier (Pilot 1859).

\section{1- Carte de localisation}

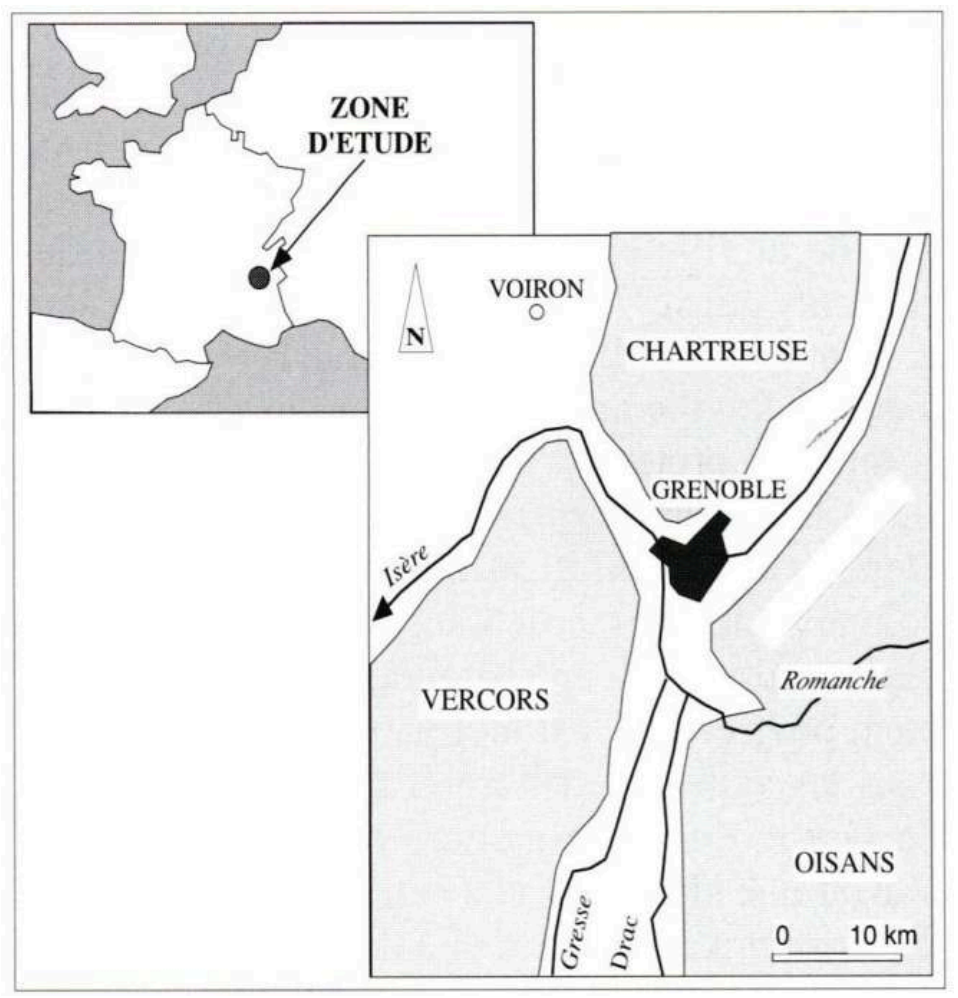

En 1930, H. Müller, Conservateur du Musée Dauphinois, dans un article sur les origines de Grenoble paru dans la Revue de Géographie Alpine, citant R. Blanchard, reprenait la proposition d'un point haut pour l'installation du site de Cularo, un peu avant l'ère chrétienne. C'était, selon lui, sur les graviers du Drac que se seraient installés les premiers occupants. Il émettait même l'hypothèse d'un "rocher surgissant de la plaine ancienne (...) et actuellement enfoui sous 8 à 10 mètres d'alluvions, et plus ». L'examen de la topographie de surface de la vieille ville montre qu'il existe effectivement une proéminence de l'ordre d'1 mètre à 1,50 mètre par rapport à la topographie alentour (fig. 2). Cette différence d'altitude a effectivement pu suffire à maintenir hors d'eau le 
quartier situé autour de la place aux Herbes. Les textes et articles anciens ne permettent cependant pas de déterminer si cette proéminence est effectivement liée à la présence d'un point haut dans la plaine alluviale ou s'il s'agit d'un secteur où le remblaiement urbain est plus épais qu'ailleurs.

2- Topographie de la surface du Grenoble ancien

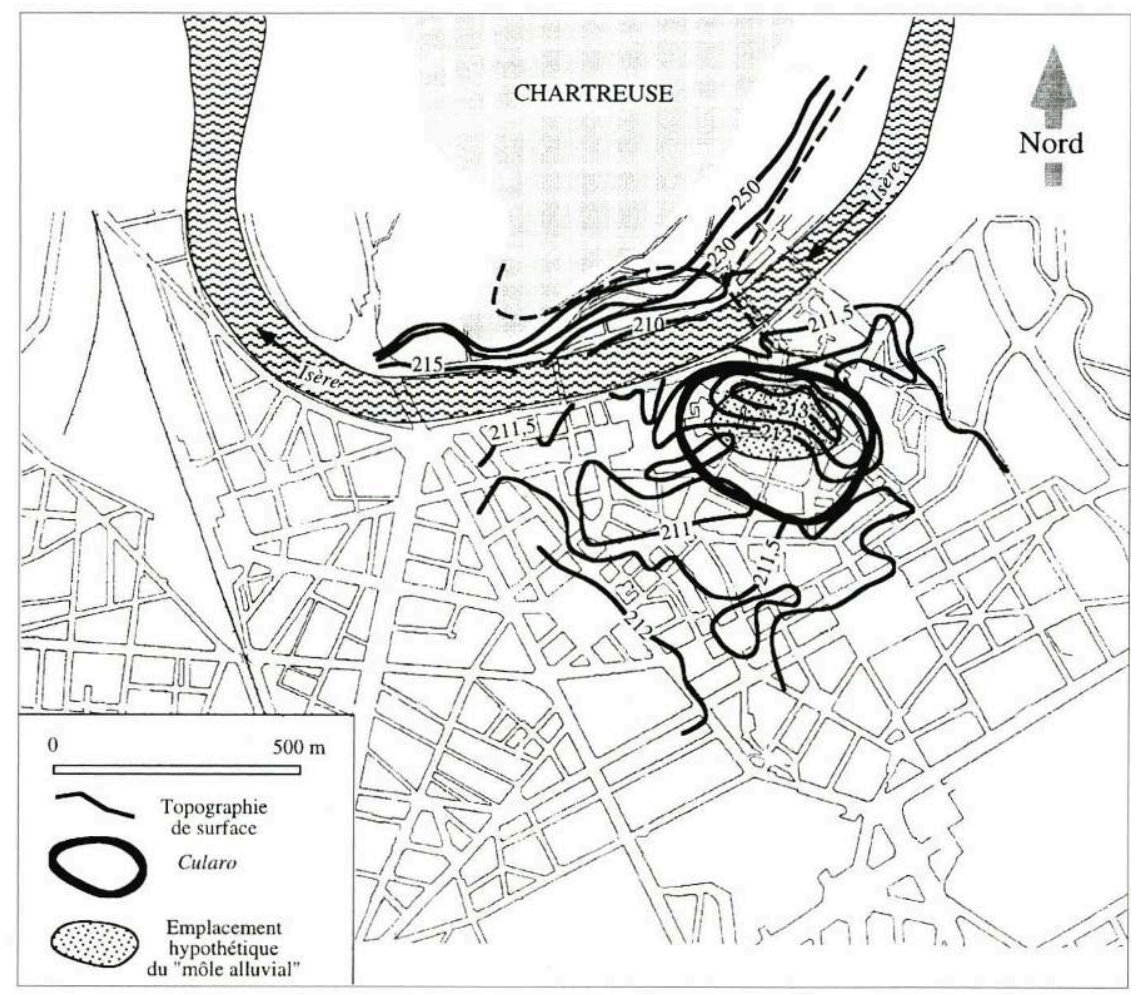

LE COEUR DE LA VIEILLE VILLE EST LÉgèrement EXHAUSSÉ PAR RAPPORT AU RESTE DE LA CITÉ, CE QUI EXPLIQUE QUE L'INONDATION DE 1859 AIT LAISSÉ CERTAINES RUES EXONDÉES

source : A. de Montjoye, 1990, modifié

\section{La reconstitution de la topographie de l'alluvium de graviers et galets}

\section{Sources et méthode}

La vérification de l'existence d'un môle alluvial a été faite à partir de la synthèse des connaissances portant sur le sous-sol grenoblois, en recueillant l'information sur l'altitude à laquelle est localisé le sommet du remblaiement de gravier. En effet, les matériaux grossiers constituant l'alluvium témoignent de phases fonctionnelles actives d'un ou de plusieurs chenaux du Drac qui a progressivement édifié le cône de déjection de ce cours d'eau au cours de l'Holocène. La constitution de cette base de données topographiques résulte de la collecte de 51 sondages localisés dans la partie nord de la ville. Ces sondages proviennent de trois sources principales : 1 ) des études géologiques réalisées pendant la construction du tramway ; 2) d'entreprises de géotechnique ayant une longue pratique du sous-sol grenoblois ; 3) d'un certain nombre d'observations réalisées par nous-mêmes, à l'occasion d'opérations de fouille, notamment sur les sites 
de Sainte-Claire, Notre-Dame, de l'Ancien Évêché et de la place Verdun. L'exploitation des sondages a consisté à relever l'altitude du sommet du remblaiement de graviers et galets. Chaque sondage a été repéré en plan par sa latitude et longitude. Un fichier informatique a été constitué puis traité par un logiciel de cartographie traçant des courbes de niveaux (SURFER ${ }^{\mathrm{TM}}$ ) de manière à reconstituer la topographie du cône alluvial du Drac (fig. 3).

3- Reconstitution de la topographie de la surface des graviers et galets par les sondages

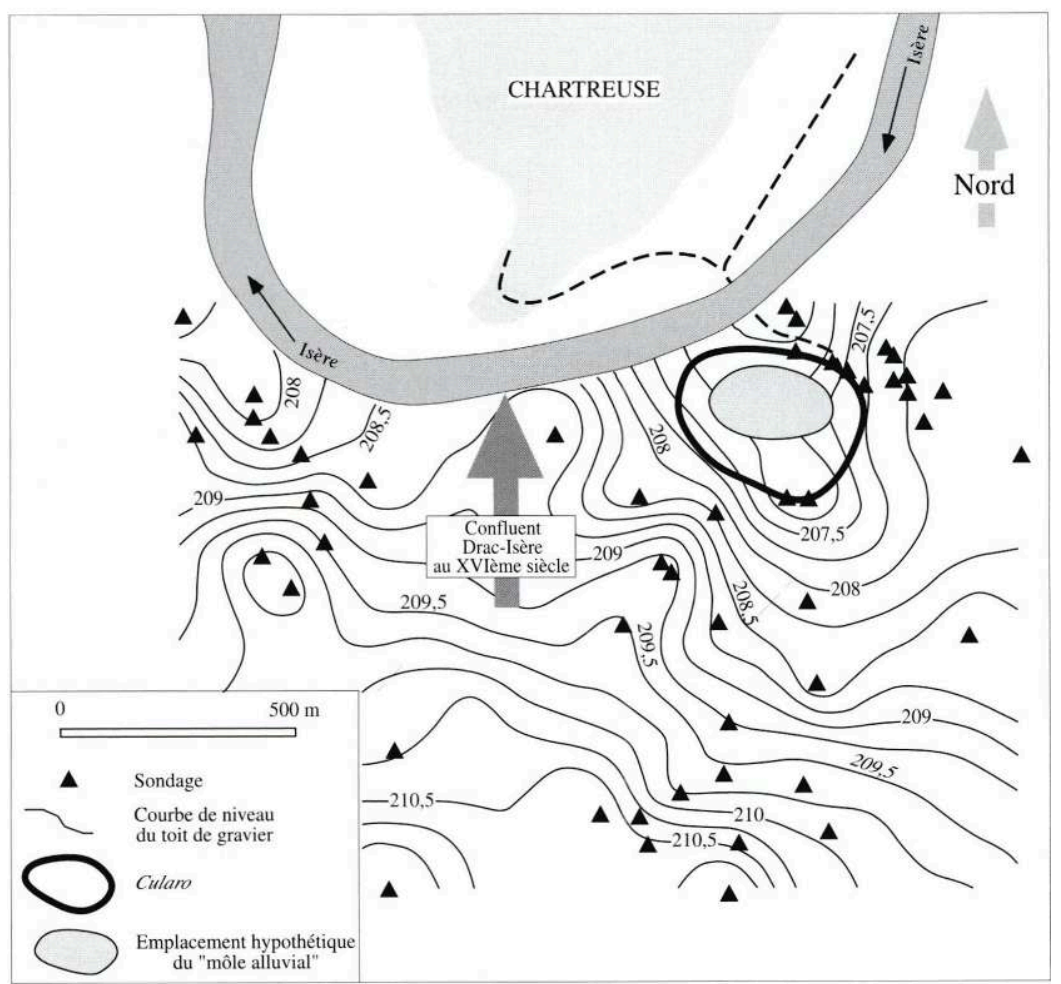

Le coeur de la vieille ville localisé sur les marges du cône alluvial du Drac apparaît clairement en situation déprimée

\section{Résultats}

5 En raison du nombre relativement limité de sondages et de leur très inégale distribution spatiale, la restitution cartographique en courbes de niveaux de la surface du gravier donne une image probablement très imparfaite de la réalité. Cependant, la précision du document est suffisante pour que l'on reconnaisse sans ambiguïté possible que Grenoble est implantée sur le cône alluvial du Drac. Ce cône alluvial est clairement identifiable jusqu'au pont Marius Gontard qui correspond à la zone de confluence DracIsère au XVIe s. (voir infra) ; il s'atténue rapidement vers l'Est, comme en témoignent des courbes de niveau parallèles et fortement rapprochées. Le site de la vieille ville est donc implanté sur la marge orientale de ce cône ; l'altitude du toit de gravier y est inférieure à 207,50 mètres NGF. Contrairement à ce qu'imaginait R. Blanchard (1911), la ville ancienne n'est pas localisée sur un point haut mais dans une zone topographiquement déprimée par rapport au reste de la plaine. Les éléments figurant sur la carte géomorphologique de Grenoble (Chardon et al. 1980) confirment les résultats des sondages ; dans le méandre de l'île-Verte, la ville s'est développée sur un remblaiement 
alluvial essentiellement composé de sédiments fins mis en place par les débordements de l'Isère ; cette zone paraît donc être restée en dehors de l'influence directe du Drac et de ses apports de sédiments grossiers. A ce stade de la réflexion, une première conclusion s'impose : le point haut actuellement observé au coeur de la ville ancienne n'est aucunement d'origine naturelle. Il résulte plus simplement d'une accumulation de remblais anthropiques plus épaisse qu'ailleurs; cette surépaisseur remonte au moins au XVIe s., l'inondation d'août 1525 ayant épargné le quartier de la place aux Herbes.

\section{Interprétation et discussion des résultats}

\section{Un exhaussement progressif du cône alluvial du Drac par apport de charge grossière à l'époque moderne}

6 Pour mieux comprendre les raisons de cette distribution spatiale des sédiments grossiers, il est nécessaire de reconstituer la dynamique du Drac au cours des 700 dernières années (fig. 4) :

a. En 1925 après une minutieuse étude des archives disponibles, A. Bouchayer écrivait qu'au XIIIe s., le Drac portait des bateaux et des moulins ; ces éléments attestent un cours d'eau au chenal probablement stable et fixe, à la dynamique modérément active. Jusqu'au XVe s., le Drac confluait avec l'Isère dans le Grenoble actuel, approximativement au droit du pont Marius Gontard.

b. Au XVe s., le Drac connaît progressivement une recrudescence de son activité morphologique : le lit va rapidement s'élargir, se complexifier et se diviser en de multiples bras et, fait très important, le lit va progressivement s'exhausser. Bouchayer (1925) a recueilli dans les archives de très nombreux témoignages qui attestent de l'élévation progressive du plancher alluvial sous l'effet d'une recrudescence des apports de charge de fond. L'instabilité marquée de la rivière devient alors incompatible avec le maintien de la zone de confiance Drac-Isère à l'aval immédiat de la ville; à partir de cette période, les Grenoblois n'auront de cesse que d'éloigner le Drac de la ville et de le repousser vers l'Ouest en direction du Vercors.

c. En 1732, le Drac très nettement déplacé vers l'Ouest est endigué sur une grande partie de son cours. Le système de correction va progressivement être renforcé et complété pendant les décennies suivantes jusqu'à arriver à la situation actuelle d'un cours d'eau corseté par des digues longitudinales insubmersibles. L'exhaussement entre les digues s'accélère, à tel point qu'en 1787 l'accumulation de matériaux aurait atteint une épaisseur de 7,70 à 8,10 mètres dans la partie inférieure du cône de déjection (cité par Savaldor 1991, p. 303). 


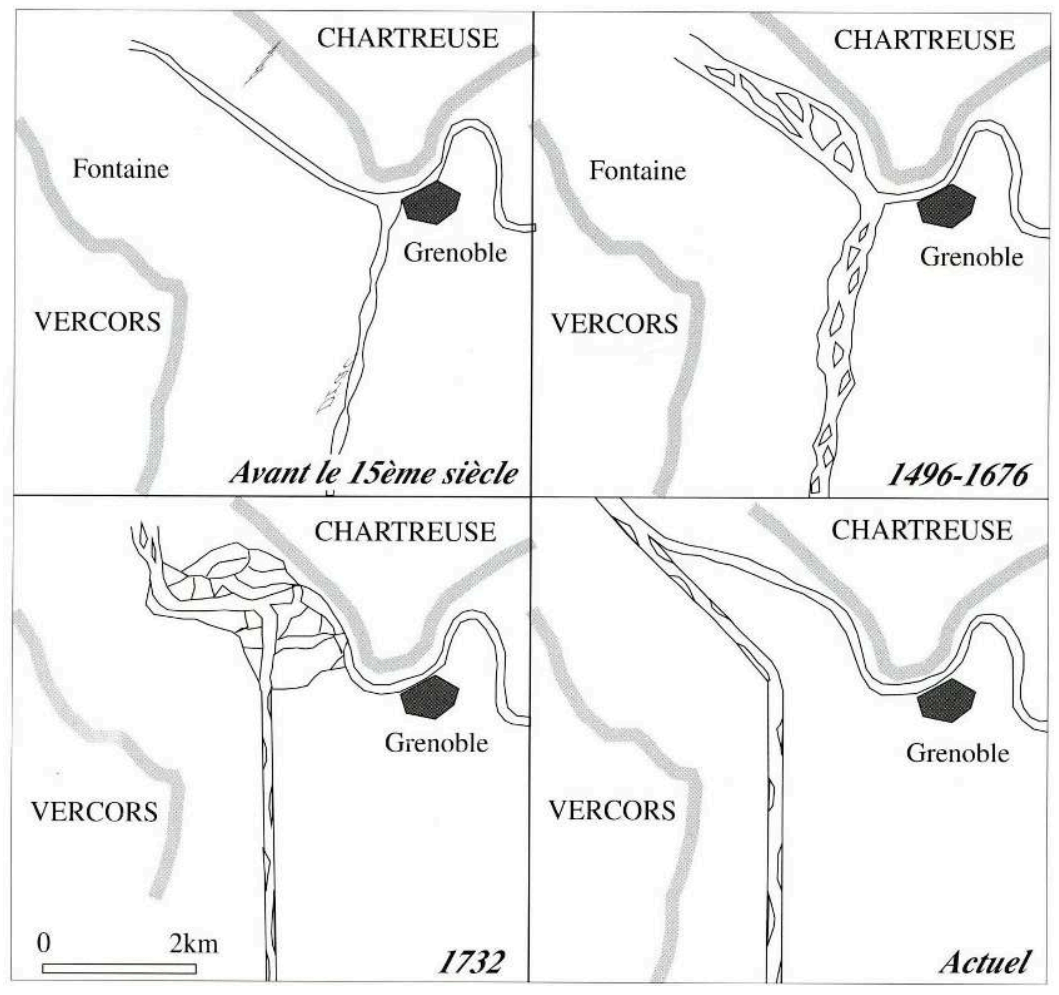

source : P.G. Salvador, 1991, modifié

\section{Un exhaussement de la plaine de l'Isère contrôlé par l'édification du cône alluvial du Drac}

7 Dans la plaine de l'Isère en amont du confluent Drac-Isère, un exhaussement s'est également produit, mais de nature différente :

1. Dans l'enceinte de la ville gallo-romaine et médiévale, le remblaiement urbain constitue l'essentiel de l'exhaussement. Les études réalisées place Notre-Dame et place Sainte-Claire ont montré que l'installation gallo-romaine s'était produite à la surface d'une accumulation fine de crues préromaine, surmontant d'environ deux mètres le toit des galets. Au moment de la construction du rempart, à la fin du IIIe s., les niveaux d'occupation étaient compris entre les cotes 209,10 et 210,00 mètres NGF, soit environ 3 à 4 mètres sous les plus hauts niveaux actuels. Le niveau d'occupation du baptistère construit au Ve s. (210,40 NGF) serait resté inchangé au moins jusqu'au Xe s. (L. Baucheron comm. perso.). L'essentiel du remblaiement urbain conduisant à la mise en place de la topographie actuelle semble donc dater du dernier millénaire.

2. À l'Est de la ville médiévale, dans le quartier de l'île-Verte, des indices d'habitat disséminé et de mise en culture sont présents dans les textes depuis la première moitié du XIIe s. Des tombes provenant d'une nécropole associée à un hôpital au début du XVe s. auraient été trouvées à une profondeur importante de 1,80-2,00 mètres (A. Bouvier, comm. perso.). Dans cette zone, les dépôts sont constitués pour l'essentiel de limons de débordement de l'Isère résultant d'une sédimentation forcée sous le contrôle du cône alluvial du Drac (Lourneaux, 1976 ; Hannss, 1983). 


\section{Premiers éléments d'une chronologie morphodynamique}

8 Entre le IIe-IIIe s. et le XIVe s., l'activité de la dynamique fluviale ne paraît pas avoir constitué une gêne majeure pour le développement des activités humaines sur le site de Grenoble : le fait que les niveaux d'occupation paraissent avoir peu changé jusqu'au Xe s. au moins est un premier argument en faveur de cette thèse ; le fait que le Drac porte des ouvrages hydrauliques et soit stable au XIVe s. en est un second. Pendant toute cette période, l'activité morphodynamique du Drac est probablement restée insuffisante pour engendrer une phase de construction et d'exhaussement significative du cône alluvial du Drac. Cela ne signifie pas que le plancher alluvial ne subissait pas des variations d'altitude (incision et exhaussement), mais plus probablement qu'elles restaient d'ampleur insuffisante pour marquer profondément la morphologie du cône alluvial du Drac. Il est vraisemblable également que la ville était épisodiquement inondée par les fortes crues. Une recrudescence de l'activité des crues du Drac paraît s'amorcer à la fin du XIVe s. (Bouchayer 1925 ; Bravard 1989); elle aurait précédé la crise morphodynamique de l'Époque Moderne marquée par la métamorphose du chenal unique en lit tressé, l'exhaussement du chenal et la reprise de construction du cône alluvial.

Les données recueillies sur les sondages localisés à l'extrémité aval du cône alluvial du Drac indiquent une différence d'altitude d'environ 1,50 mètre entre le toit des galets sous la ville galloromaine et la zone de confluence au XVIe-XVIIe s. (pont Marius Gontard). Il semble donc que la forte activité de la dynamique fluviale et les volumineux apports de charge grossière qui l'ont accompagnée aient produit un exhaussement différentiel significatif, mais cependant sans commune mesure avec ceux annoncés par les ingénieurs du XVIIIe s. (7 à 8 mètres). Cet exhaussement différentiel pourrait avoir été renforcé par deux phénomènes : 1) le contrôle progressif du champ de divagation du Drac par les travaux de correction dès le XVIe s.; l'exhaussement a été accéléré entre les digues en raison de la réduction des surfaces d'épandage de la charge ; 2) le fait que la ville de Grenoble fût enfermée dès le IIIe s. dans ses remparts successifs (fig. 5) ; ces remparts ne protégeaient pas contre l'inondation, notamment lors des débordements du Drac, mais empêchaient les bras vifs d'entrer dans la ville et d'y déposer leur charge de fond. Sur la marge orientale du cône alluvial du Drac, dans le quartier de l'îleVerte, l'exhaussement du cône alluvial est également enregistré par la sédimentation de limons provenant de débordements de l'Isère; les vestiges archéologiques semblent indiquer qu'une épaisseur de sédiments fins de 1 mètre pourrait s'être déposée entre le XVIe s. et le début du XXe s. $(0,25 \mathrm{~m}$ par siècle), confirmant ainsi d'une manière indirecte que le cône alluvial du Drac était dans une phase de construction active. 


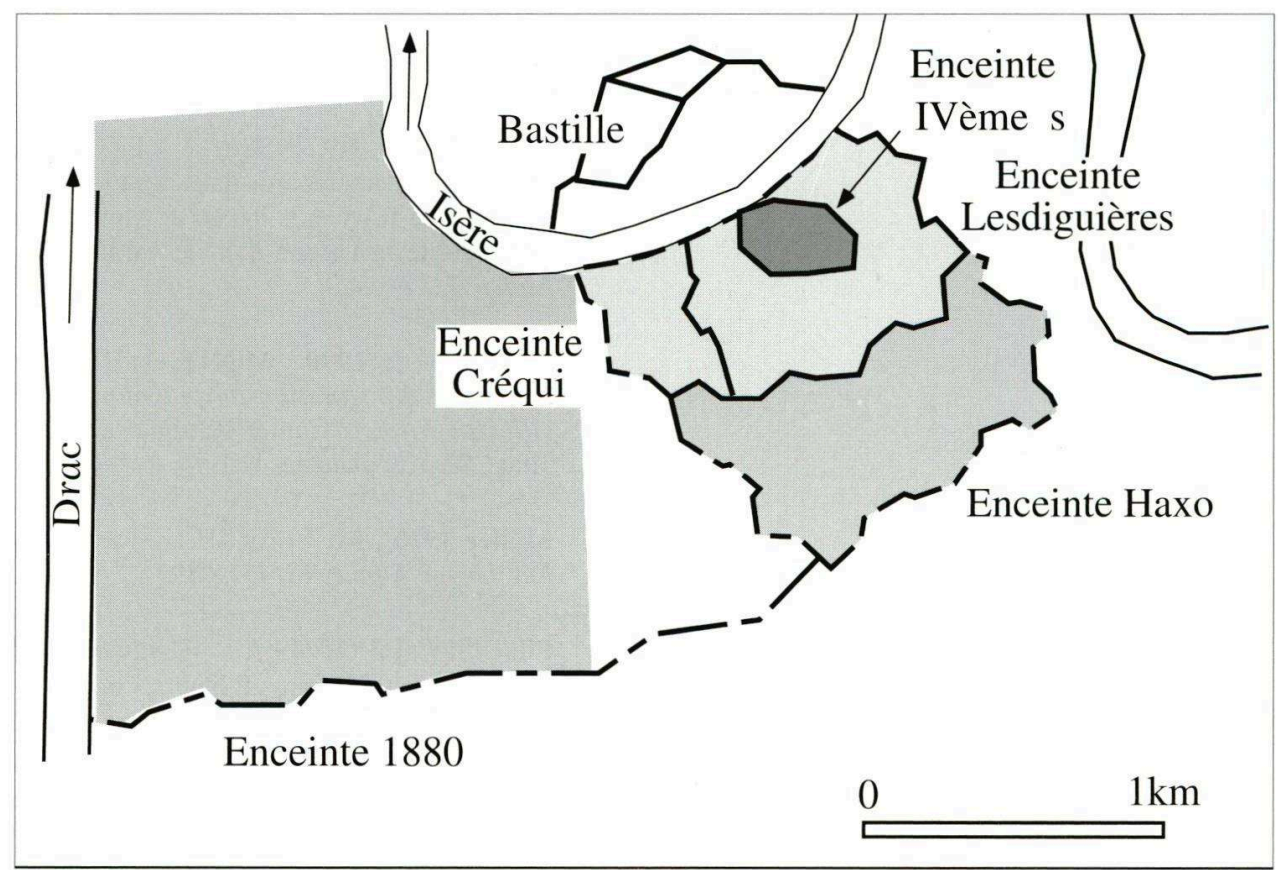

ELLES MARQUENT LE DÉVELOPPEMENT PROgRESSIF DE LA VILLE EN DIRECTION DU SUD, PUIS DE L'OUEST AVEC LA RÉUSSITE DU PROgRAMME D'ENDIgUEMENT DU DRAC

source : V. Chomel, 1976 modifié

\section{Conclusion}

10 L'hypothèse d'un môle alluvial comme site d'ancrage des premières infrastructures grenobloises a été fondée sur l'existence d'un point haut au coeur de la ville ancienne, unique zone exondée lors des grandes crues ayant submergé Grenoble entre le XVIe et le XIXe s. L'étude de la topographie du toit de gravier par les sondages permet de démontrer que la ville ancienne se trouve en fait au coeur d'une zone déprimée; le niveau des graviers et galets au confluent DracIsère au XVIIe $s$. serait environ 1,5 mètre plus haut que celui relevé au centre de la ville ancienne. Le «môle alluvial » supposé par Blanchard et Müller est en fait une zone où le remblaiement urbain est d'épaisseur plus forte qu'ailleurs, et ce dès le XVIe s.

11 L'exhaussement différentiel du toit de gravier trouve son origine dans la recrudescence d'activité du Drac à partir du XIVe s.; elle a engendré l'exhaussement progressif du cône alluvial du Drac, ce qui ne s'est pas produit dans la ville protégée des incursions du chenal par une enceinte depuis la fin du IIIe s. À partir du XVIIe s., cet exhaussement a été combattu par les Grenoblois qui ont progressivement éloigné le Drac des remparts protégeant la ville. L'exhaussement du cône alluvial du Drac a exercé un contrôle aval sur la dynamique fluviale de l'Isère et provoqué l'exhaussement de sa plaine d'inondation par dépôt de sédiments fins de débordement. La profondeur anormale de tombes datant du XVIe s. laisse penser que l'exhaussement pourra être de 1 mètre depuis cette période, ce qui est en accord avec les observations faites sur les dépôts de gravier du Drac. Le faible rehaussement des niveaux d'occupation entre le IIe-IIIe s. et le Xe s. au moins permet d'émettre l'hypothèse d'un exhaussement altitudinal non 
significatif du cône alluvial du Drac jusqu'à la fin du Moyen Âge, la crise morphogénique se manifestant après le XIVe $s$.

Cette étude, si elle permet d'affirmer que les arguments utilisés au début du siècle pour émettre l'hypothèse d'un tertre en rive gauche de l'Isère sont erronés, ne permet pas de conclure définitivement sur l'existence ou non d'un môle alluvial, il y a 2000 ans. La crise morphodynamique du Drac à partir du XIVe s. a profondément modifié la topographie de son cône alluvial et il n'est actuellement pas possible d'avoir une idée de ce qu'elle était au début de l'ère chrétienne.

\section{BIBLIOGRAPHIE}

\section{Bibliographie}

Blanchard 1911 : BLANCHARD (R.). - Grenoble, étude de géographie urbaine. Didier et Richard Ed., Grenoble, $234 \mathrm{p}$.

Bouchayer 1925 : BOUCHAYER (A.). - Le Drac dans la plaine de Grenoble. Rev. Géogr. Alpine, 13, $115-172,287-358$ et $549-621$.

Bravard 1989 : BRAVARD, (J.-R). - La métamorphose des rivières des Alpes françaises à la fin du Moyen Age et à l'Epoque Moderne. Bull. Soc. Géograph. Liège. 25, 145-157.

Chardon, Marnezy et Montjuvent 1980 : CHARDON (M.). MARNEZY (A.) ET MONTJUVENT (G). Carte géomorphologique détaillée de la France à $1: 50000$; feuille de Grenoble XXXII-34., Paris CNRS éd., Carte couleur H.T. et notice explicative, $47 \mathrm{p}$.

Chomel 1976 : CHOMEL (V.). - Histoire de Grenoble. Privat éd., Toulouse, 466 p.

Dangreaux 1985 : DANGREAUX, (B.). - Recherche sur les origines de Grenoble. Mémoire de T.E.R. d'histoire, Univ. d'Aix-Marseille 1,146 p. et planches hors texte.

Féougier 1994 : FÉOUGIER (C.). - A propos de la fondation de Grenoble : reconstitution du paléoenvironnement fluvial sur les sites d'archéologie urbaine. Mémoire de Maîtrise, Institut de Géographie Alpine, 96 p.

Fourneaux 1976 : FOURNEAUX (J.-C.). - Les formations quaternaires de la vallée de l'Isère dans l'ombilic de Grenoble. Géologie Alpine. 52, 31-72.

Hannss 1983 : HANNSS (C.). - La constitution des plaines alluviales et leurs rebords dans la vallée de l'Isère entre l'embouchure de l'Arc et le bassin de Moirans, ainsi que la plaine alluviale de la Leysse dans le val du Bourget. Rev. Géog. Alpine, 72, 439-456.

Montjoye de 1990 : MONTJOYE DE (A.). - Grenoble, document d'évaluation du patrimoine archéologique des villes de France. Centre National d'Archéologie Urbaine, Tours, 92 p. et planches H.T.

Müller 1930 : MÜLLER (H.). - Les origines de Grenoble. Rev. Géogr. Alpine, 18, 451-489. 
Pilot 1859 : PILOT (J.J.A.) - Grenoble inondé. Maisonville et fils et Jourdan, Libraires-Editeurs, Grenoble, $112 \mathrm{p}$.

Salvador 1991 : Salvador (P.-G.). - Le thème de la métamorphose fluviale dans les plaines du Rhône et de l'Isère. Thèse Géographie et Aménagement, Univ. Lyon 3, 498 p. 


\title{
Paléodynamique du site fluvial de Lyon depuis le Tardiglaciaire
}

\author{
Jean-Paul Bravard, Agnès Vérot-Bourrely et Odile Franc
}

\section{NOTE DE L'AUTEUR}

Avec la collaboration de Catherine Arlaud

Les auteurs tiennent à manifester leur reconnaissance aux archéologues de l'AFAN qui leur ont permis d'avoir accès aux résultats obtenus sur les chantiers de fouilles, au Service Municipal d'Archéologie de Lyon ainsi qu'au Service Régional de l'Archéologie de Lyon. Une partie des dates ${ }^{14} \mathrm{C}$ mentionnées dans le texte a été financée par le Conseil Régional du Rhône; les analyses ont été réalisées au laboratoire de Radiocarbone de l'Université Lyon 1 ainsi qu'à Archéolabs et au laboratoire de Gif-sur-Yvette. Une lecture critique d'A. Desbats et de P-G. Salvador a permis d'améliorer la première version du texte.

1 Les Lyonnais manifestent un véritable intérêt pour l'histoire de leurs cours d'eau. La première découverte pour l'époque contemporaine fût celle d'un quai romain signalée en 1846 par l'archéologue Artaud (p. 175). Un souci constant depuis le milieu du XIXe s. a été de reconstituer le dessin du réseau hydrographique à l'époque romaine au pied des collines de Fourvière et de la Croix Rousse. Les grandes questions étaient de localiser l'emplacement de la confluence de la Saône et du Rhône et de préciser le dessin d'anciens bras fluviaux ouverts en travers de la presqu'île. Dans la synthèse qu'il a proposée, A. Desbat (Desbat 1982) fait état des découvertes et des hypothèses concurrentes: la solution suggérée par Ph. Russo et A. Audin (1961 et 1964), qui dessinent un bras du Rhône à hauteur des Jacobins, est alors la version « consacrée par l'usage " mais elle reste une "supposition ». En effet, les fouilles réalisées à la fin des années 1970 n'avaient encore apporté aucune preuve déterminante et faisaient au contraire douter de la présence d'un bras fluvial actif en travers de la presqu'île, à l'époque romaine. 


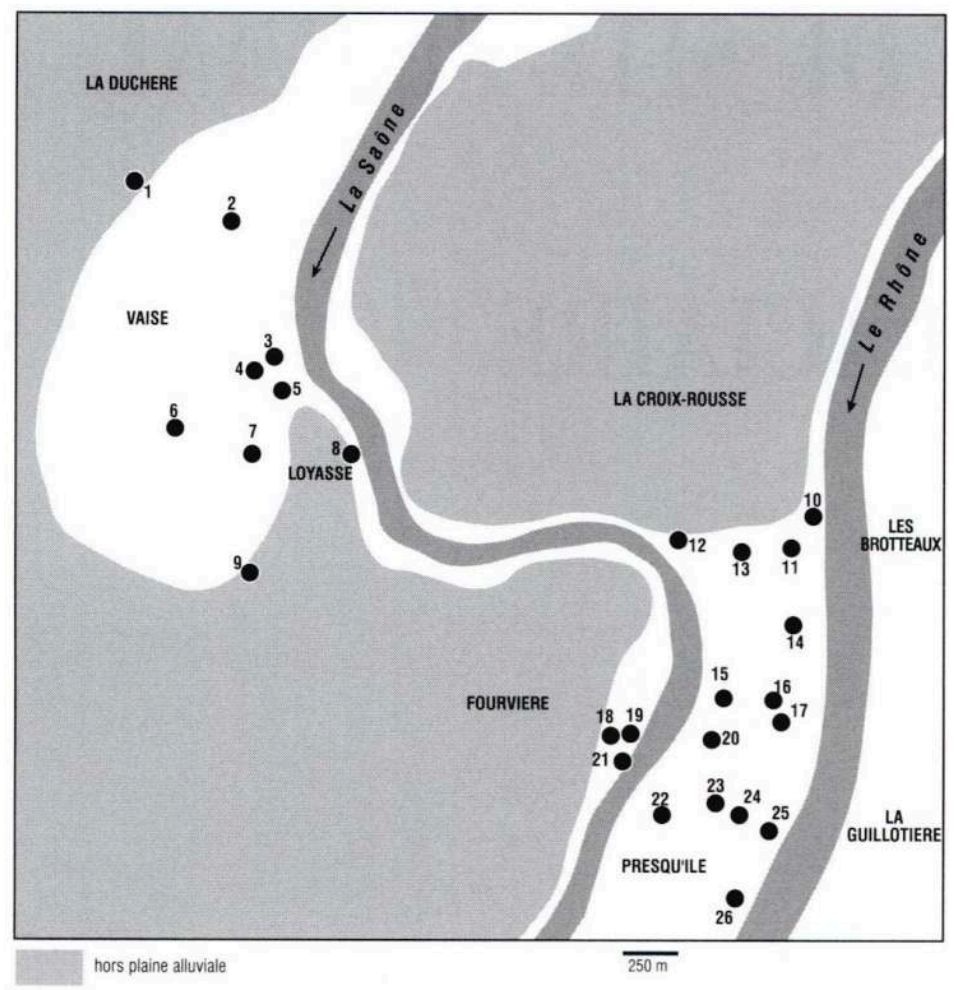

1 : PÉRIPHÉRIQUe NORD (A. SPELLER), 2 : PLACE de PARIS (J.-L. JOLY), 3 :10, RUE MARIETTON (M. MONIN). 4 : PLACE VALMYMÉTRO (M. LE NEZET-CÉLESTINS), 5 : ZAC CHARAVAY (J.-P. LASCOUX), 6 : RUE DU DOCTEUR HORAND (C. BELLON), 7 : RUE SERgENT BERTHET-MÉTRO (O. FRANC), 8 : QUAI ARLOINg (L. TRANOY), 9 : STATION DE MÉTRO GORgE-DE-LOUP (J. BURNOUF), 10 : PLACE TOLOZAN (C. BECKER), 11 : OPÉRA (F. REYNAULT), 12 : ZAC SAINT-VINCENT (J.-P. LASCOUX), 13 : TERREAUX-LPA (C. ARLAUD), 14 : BOURSE-LPA (C. ARLAUD), 15 : ILÔT 24-RUE DE LA MONNAIE (L. JACQUIN), 16 : RUE PALAIS GRILLET (G. AYALA), 17 : RÉPUBLIQUE-CHILDEBERT L.P.A (C. ARLAUD), 18 : TRAMASSACMÉtro (J. BURNOUF), 19 : AVENUE ADOLPHE MAX-MÉtRo (F. VILLEDIEU), 20 : CÉleSTINS-L.P.A. (C. ARLAUD), 21 : ILÔT CLÉMENT V (V. MONNOYEUR), 22 : FACULTÉ CATHOLIQUE (M. MONIN), 23 : KIOSQUE BELLECOUR (C. BECKER), 24 : PLACES BELLECOUR-ANTONIN PONCET - MÉTRO (J. BURNOUF), 25 : PLACE ANTONIN PONCET-L.P.A. (C. BECKER), 26 : PLACE GAILLETON (D. MARCHIANTI).

2 Si le site primitif de Lyon est en général associé à la colline de Fourvière, les plaines alluviales de la Saône et du Rhône ont constitué des espaces essentiels pour le développement de la ville historique puis de l'agglomération contemporaine.

Dès l'époque romaine, les bords de la Saône étaient occupés et la presqu'île connaissait un début d'urbanisation dans un environnement de lônes et de brotteaux réputés peu hospitaliers, voire répulsifs, par l'historiographie lyonnaise ; il faudra attendre la fin du XVIIIe s. pour que la rive gauche du Rhône connaisse un développement rapide, même si des têtes de pont avaient été établies sans doute dès l'époque romaine. Quant à la plaine de Vaise, jusqu'à une date récente, on ne considérait pas qu'elle fasse réellement partie du site urbain de Lyon.

4 La compréhension des conditions de formation des plaines alluviales et de leur occupation à Lyon même, s'est depuis peu élargie aux environs de la cité. La tâche est délicate car le lit majeur du Rhône est une surface topographique très peu différenciée. Du confluent de l'Ain à Lyon, soit sur une distance de plus de $30 \mathrm{~km}$, les dénivellations transversales n'y excèdent pas 2-3 $\mathrm{m}$ pour une largeur de plusieurs kilomètres. Des talus ont été identifiés là où les divagations ont pu retailler des niveaux anciens à la 
faveur du resserrement du lit majeur ; ailleurs, la confusion entre les niveaux est due à l'égalisation de la surface topographique par les dépôts successifs de limons de débordement. A la fin du XVIIIe s., cependant, un niveau inondable par les "grandes crues " était distingué des "surfaces inondées lors des crues ordinaires» en rive gauche du Rhône sur les communes de Villeurbanne et Lyon (Bravard, 1987). Un document fiable, l'Atlas du Cours du Rhône au 1/10000e (Ponts et Chaussées, 1857-1866), représente les surfaces touchées par la crue centennale de 1856 et les surfaces épargnées dans la plaine alluviale formée des "alluvions modernes » de la carte géologique. Avant que les grands travaux de génie civil aient affecté la morphologie et les écoulements, le lit majeur était une surface inégalement soumise aux débordements fluviaux. Il faut chercher l'origine de cette complexité dans l'histoire de la mise en place du remplissage sédimentaire.

Depuis 1982, les opérations de prospection et de fouille archéologiques réalisées à Lyon ont intégré de simples observations géomorphologiques ou des études détaillées (fig. 1); d'autres spécialités ont été d'ailleurs associées sur certains sites, comme la palynologie et la malacologie. Les travaux de percement du métro, de construction de parkings souterrains et le chantier du Périphérique Nord ont donné des moyens matériels très appréciés mais des opérations de rénovation urbaine plus modestes, en particulier à Vaise, ont apporté une moisson de faits et permis de couvrir un territoire plus vaste dans les périmètres comportant un risque archéologique identifié. Par ailleurs, une prospection géomorphologique soutenue par le Service de l'Archéologie a été réalisée dans la plaine alluviale du Rhône entre le confluent de l'Ain et les quartiers de la rive gauche à Lyon; elle a permis d'obtenir des informations précieuses pour la compréhension de la mise en place du remplissage sédimentaire de la plaine alluviale.

6 Nous présentons ci-dessous les données collectées depuis une quinzaine d'années en réactualisant une première ébauche de la question (Macé et al. 1993). Le plan diachronique a été retenu car il permet de présenter une reconstitution des étapes successives de la mise en place des plaines depuis environ 15000 ans sans donner un poids excessif à des observations détaillées mais encore trop ponctuelles.

\section{La dynamique des plaines du Rhône et de la Saône au Tardiglaciaire et au début de l'Holocène}

\section{La fin des temps glaciaires : un enfoncement majeur du Rhône et de la Saône}

\section{Les terrasses fluvio-glaciaires du Rhône et de la Saône}

7 Les étapes de la dernière déglaciation dans l'Est lyonnais, présentées de manière détaillée par P. Mandier (Mandier 1988), sont matérialisées par une série de terrasses fluvio-glaciaires emboîtées. Elles sont expliquées par trois «pulsations majeures » du glacier du Rhône au Würm récent dans la région du confluent Ain-Rhône et de l'arc de Grenay, à une trentaine de kilomètres à l'amont de Lyon; ce sont :

- le stade d'avancée B correspondant au maximum du Würm (culminant sans doute vers 20 000-18 000 B.P.). 
- les stades C et D (Charvieu - La Valbonne) qui ont produit des ensembles de moraines et terrasses fluvio-glaciaires de récession, comme la terrasse caillouteuse de la Guillotière à Lyon (stade C).

- la phase de décrépitude glaciaire, ou stade E, a donné la terrasse de Chesne (dans l'ombilic de la Verpillière) que $P$. Mandier prolonge par les couloirs de creusement de la terrasse de la Valbonne (aval du confluent de l'Ain, en rive droite) à 192-190 m. Il n'existe, à ce jour, aucun élément de datation de la terrasse de Chesne, mais $\mathrm{P}$. Mandier la corrèle avec prudence avec la «très basse terrasterrasse » de la gare de triage de Chasse-sur-Rhône, à l'aval de Lyon, l'argument étant qu'il s'agit du dernier niveau au-dessus de la plaine holocène ; la datation radiocarbone d'os de bisons découverts dans cette dernière a donné 14350 +/-290 B.P (Ly 653 ) et $12120+/-180$ B.P. (Ly - 723).

Dans la plaine de la Saône aval, les prospections géo-archéologiques récentes ont permis de dater la basse terrasse sableuse qui ceinture la plaine de Vaise à une altitude relative de 6 à $12 \mathrm{~m}$ par rapport à la plaine actuelle (fig. 2). L'inégale altitude du sommet de cette terrasse (entre $170,50 \mathrm{~m}$ et $176,50 \mathrm{~m}$ ) est due à l'altération de sa morphologie par l'érosion latérale de la Saône et par les écoulements issus du versant au Tardiglaciaire et à l'Holocène. Des fragments de bois flottés, découverts à une profondeur de $10 \mathrm{~m}$ (163,20 m NGF) dans la basse terrasse, rue du Sergent Berthet, ont été datés 17560 +/-180 B.P. (Ly - 26, OxA - 4406) (Franc, 1993a). Par ailleurs, des coquilles de malacofaunes ont été datées de 15265 +/-125BP (Ly - 197) à l'altitude de 174,98 $\mathrm{m}$ sur le site d'anciens bassins de la SNCF. En accord avec cette datation, la malacofaune présente une "association à Pupilla» représentative du Pléniglaciaire supérieur (Limondin In : Franc 1996). La stratigraphie et la pétrographie permettent d'associer ces deux formations distantes de $1,5 \mathrm{~km}$.

\section{Coupe nord-sud dans le remplissage sédimentaire de la plaine de la Saône à Vaise}

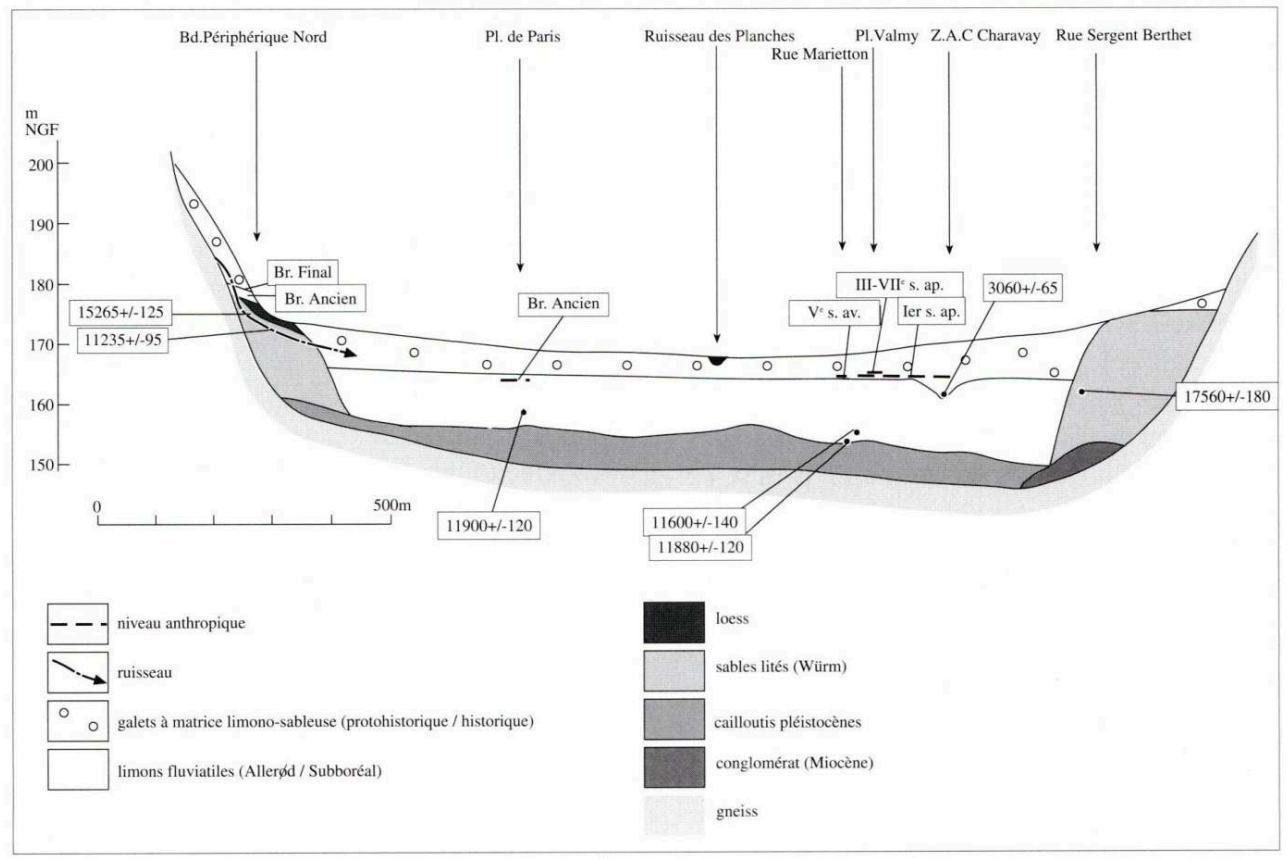

Ces deux dates suggèrent une accumulation sableuse considérable vers 18000 - 15000 B.P., soit à une période correspondant au Pléniglaciaire supérieur et au début de la récession si l'on accorde foi à la datation sur coquilles qui rajeunit peut-être la 
formation. L'hypothèse la plus plausible est que l'accumulation fluvio-glaciaire du Rhône (terrasse de la Guillotière) faisait barrage aux écoulements de la Saône ; celle-ci accumulait dans un environnement fluvio-lacustre à une période que l'on peut corréler avec les stades C et D de P. Mandier (op. cit.), si l'on se fie aux dates radiocarbone; comme il est logique que les mêmes processus aient joué durant le maximum du Würm (stade B), on est tenté de vieillir la terrasse de la Guillotière et de la rattacher ellemême au stade B.

\section{Des lits fluviaux très bas au Bölling et à l'Allerød}

10 La période comprise entre le Bölling inclus et le début de l'Holocène était mal connue jusqu'à une date récente. Des prospections réalisées dans la plaine de Vaise ont apporté des éléments déterminants pour dater des niveaux de la Saône situés sous le lit majeur actuel (fig. 1,2).

1. Au $n^{\circ} 10$ de la rue Marietton, une date a été obtenue sur un niveau organique reposant sur un cailloutis qui représente le plancher alluvial de la Saône à 161,15 m: 12215 +/-210 B.P. (Lyon - 219 OxA) (Monin et al. 1995).

2. Le plancher caillouteux a aussi été atteint entre $157,70 \mathrm{~m}$ (Place de Paris) et 155,30 m (Place Valmy) sous la plaine de Vaise. La base des alluvions fines sus-jacentes a pu être datée grâce à la présence de matière organique :

- $\circ$ Place de Paris : 11900 +/-120 B.P. (Ly - 6107) à la cote 159,40 m. Le niveau sableux daté a livré une malacofaune de bord de rivière à espèces de milieux lénitiques et lotiques (Mouthon In litteris) (Franc 1993b) ;

- Place Valmy : $11880+/-120$ B.P. (Ly - 6544) à la cote 155,60 m et $11600+/-140$ B.P. (Ly 6545) à la cote 156,40 m. Le cailloutis est ici surmonté par $4 \mathrm{~m}$ d'argiles noires à feuillets de débris organiques et minces lits de sable fin (Le Nezet-Célestins et al 1993).

11 Ces dates et les altitudes des dépôts permettent de proposer l'hypothèse d'un enfoncement progressif de la Saône qui aurait atteint $161 \mathrm{~m}$ à la fin du Bölling (vers 12200 B.P), puis 159, 40/155,60 m au début de l'Allerød (vers 11 900-11 600 B.P). La dénivellation de $3 \mathrm{~m}$ existant entre les cotes des dépôts datés de l'Allerød peut s'expliquer par l'existence d'irrégularités topographiques modelées par la dynamique de la Saône (chenaux et bancs).

L'Allerød (12000 - 11000 B.P.) est une période de calme hydrologique et morphodynamique réputée favorable à une sédimentation fluviale à dominante de fines et de matière organique.

13 Des dépôts analogues sont identifiés depuis 1865 dans la vallée de la Saône puisque Falsan et Locard récoltèrent à la Caille, dans le quartier de Vaise (à $2 \mathrm{~km}$ à l'amont de l'ancienne Ecole vétérinaire), une série de mollusques dans des argiles dites «lacustres». En 1880, Locard localise cette couche en rive gauche de la Saône, vers l'octroi du quai de Serin. En 1882, il la retrouve sous les sables et graviers du « cirque » de Vaise avec sa faune malacologique "si caractéristique ", des restes de mammifères et des débris végétaux. Dans la vallée de la Saône, mais plus à l'amont, ces argiles furent également repérées par A. Arcelin (Arcelin 1870) à Fleurville, leur malacofaune, de type "moderne", lui permettait de leur attribuer une origine fluviatile dans un environnement climatique cependant "assez sévère ». Des argiles semblables ont pu être datées de l'Allerød à Varennes-les-Mâcon (Ayroles et Combier, 1969; Combier et Floss, 1994). 

mais n'ont jamais fait l'objet de datation radiocarbone. Citons les observations faites par Locard (1882) à la faveur du creusement de puits. Aux Brotteaux et à la Guillotière, au Parc de la Tête d'Or (sur le site de l'Exposition internationale), cet auteur note l'existence d'une couche d'argile grise plus ou moins bleuâtre, renfermant des coquilles blanchâtres. Intercalée dans les graviers, cette couche discontinue est signalée à une profondeur constante de 10 à $12 \mathrm{~m}$, ce qui la situerait aux alentours de 152-154 m NGF, cotes compatibles avec les découvertes de Vaise. Locard (1882) note que la couche d'argile fait défaut sous la presqu'île mais des marnes blanches se retrouvent à partir d'une profondeur de 12,50 $\mathrm{m}$ et avec une épaisseur de $4 \mathrm{~m}$ à $4,50 \mathrm{~m}$ sur le site de l'Arsenal. Grâce à Locard, ces argiles sont également connues à Gerland et à Ban (Givors). Leur faune, qui appartient à des "eaux douces, claires et limpides", est semblable à l'actuelle. Par la suite, L. Germain (Germain 1911) a étudié la malacofaune des «terres de losne » de la Mouche et Gerland utilisées dans les tuileries : compactes à la base et pouvant atteindre une épaisseur de $4 \mathrm{~m}$, elles s'enrichissent en sable vers le haut ; la faune est celle d'eaux « froides, calmes et vaseuses » et correspond à un climat "plus clément que celui contemporain de la faune du loess".

\section{Une hypothèse : I'incision du talweg des grands cours d'eau au Tardiglaciaire} niveau de son lit majeur actuel ; cette évolution affecta la Saône aval, probablement par érosion régressive (Bravard, 1997). Il est à noter que la vidange sédimentaire de la plaine de Vaise a été facilitée par le caractère affouillable des matériaux sablolimoneux stockés au Würm. Tout comme la Saône, qui suit le niveau de base rhodanien, les ruisseaux qui descendent des versants de La Duchère (Vaise) ajustaient, par érosion régressive, leur profil en long au niveau de remplissage de la plaine. Ainsi les alluvions d'un talweg ancien sont-elles datées, sur le site du Périphérique Nord, de 11235 +/-95 B.P. (Ly - 196, OxA) à $4 \mathrm{~m}$ sous le niveau supérieur de la terrasse.

Un argument supplémentaire en faveur de l'enfoncement du Rhône et de la Saône est la présence d'une épaisse séquence de sable et gravier de Saône sous la presqu'île à Lyon : le sommet de cette accumulation est coté entre 157 et 155,50 m sous le quartier SaintJean et entre 156 et 152,50 sous la place Bellecour ; le dépôt n'a pu être réalisé que par des cours d'eau coulant à un niveau sensiblement plus bas que de nos jours. Comme le toit de cette formation s'abaisse plus rapidement vers l'est qu'il est de règle dans une plaine alluviale (la dénivellation moyenne serait de 3 à $4 \mathrm{~m}$ en $1 \mathrm{~km}$ selon les données 
de sondages de la SEMALY), la surface sommitale de cette accumulation doit correspondre à un ravinement par les cailloutis rhodaniens déposés ultérieurement.

Ce scenario est cependant en contradiction avec la date de $12120+/-180$ B.P. obtenue pour la très basse terrasse de Chasse qui se situe en contre-haut du lit majeur du Rhône actuel. Il convient peut-être de vieillir quelque peu ce niveau ou de ne prendre en compte que la datation à 14300 B.P. (il est tentant de corréler cette terrasse de Chasse avec le stade D de P. Mandier et d'en faire un jalon dans le processus d'incision conduisant au talweg en place à la fin du Bölling et à l'Allerød; dans ce cas les terrasses à forte pente du stade $\mathrm{E}$, présentes à $30 \mathrm{~km}$ à l'amont de Lyon, seraient à rattacher au Boiling, donc à un niveau présent sous le lit majeur du Rhône à Lyon).

Quant aux causes de l'incision des talwegs fluviaux, il convient de faire référence aux explications qui ont été avancées ailleurs pour expliquer le même phénomène. Dans les Alpes du Sud, la reconquête forestière par les pinèdes se fait au Boiling (Jorda, 1980), la période Bölling - Allerød constituant un interstade tardiglaciaire fortement apparenté au Post-glaciaire classique (Jorda, 1988). La couverture des versants réduit l'intensité des flux minéraux grossiers et favorise l'incision des talwegs ainsi qu'une sédimentation à dominante organique (Rosique, 1996). Cette situation n'est qu'en apparence contradictoire avec les observations de Campy et al. (1994) qui caractérisent la période 12000 - 9000 B.P. dans le HautJura par l'importance assez constante des processus mécaniques et du détritisme grossier : comme le notent les auteurs, c'est que la proximité géographique des sources sédimentaires mobilisables que constituent les moraines würmiennes fraîches ne permettrait pas à la colonisation forestière en cours de contrôler efficacement la fourniture sédimentaire dans les hauts bassins.

\section{La réaccumulation sédimentaire de la charnière Tardiglaciaire - Holocène (11 $000-8000$ B.P.)}

Une réaccumulation grossière par les cours d'eau a été identifiée au Dryas final. Bien connue dans d'autres régions, elle a été attribuée à une phase brutale de refroidissement climatique. Celui-ci s'est traduit par l'abaissement de la limite supérieure des arbres de $200 \mathrm{~m}$ dans les Alpes et le Jura et par l'ouverture de la couverture forestière au profit des pelouses. La morphogenèse était alors plus active et les flux détritiques, intenses, ont permis une réaccumulation dans les fonds de vallées (Jorda, 1985 ; Rosique, 1996). 


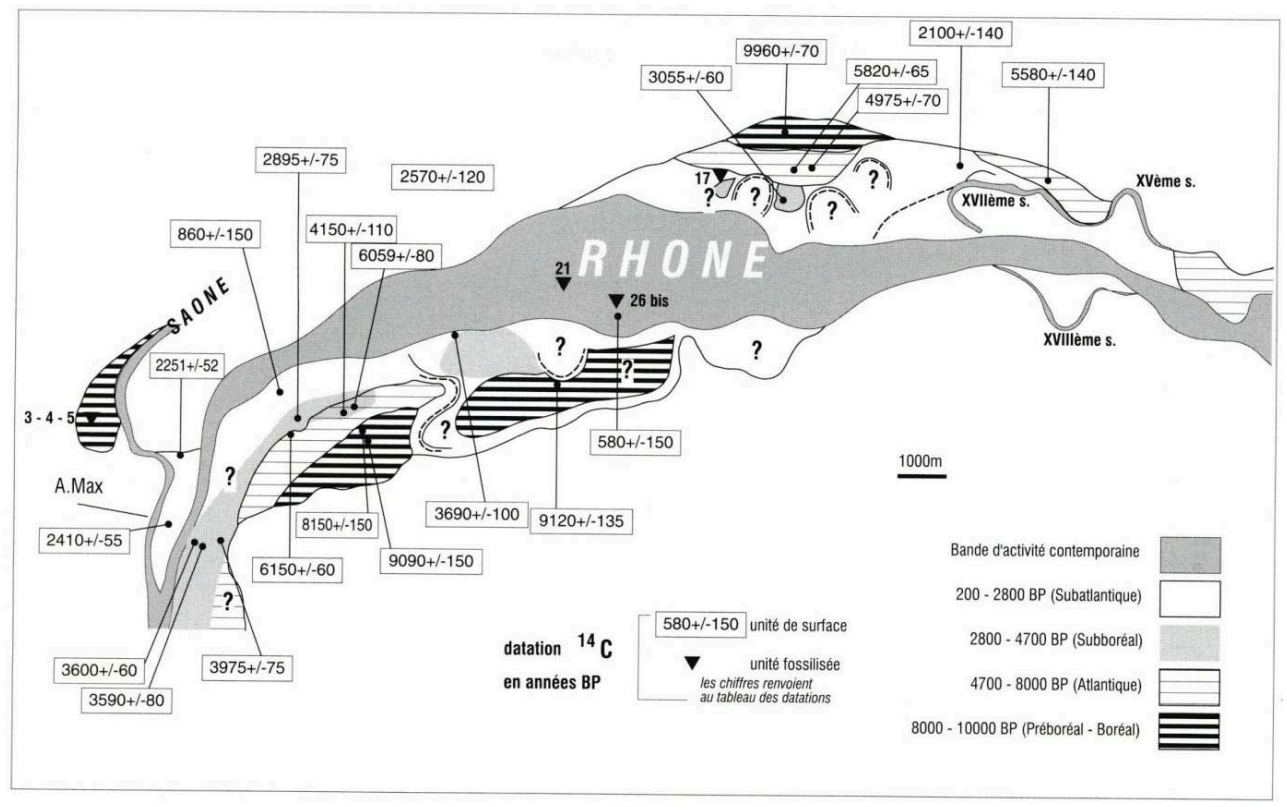

Dans la plaine du Rhône à l'amont de Lyon, des datations aussi systématiques que possible ont été réalisées sur le matériel organique trouvé dans les excavations ouvertes dans la plaine alluviale à l'occasion de l'exploitation de carrières, de l'ouverture de tranchées, de fouilles préalables à la construction d'immeubles, de campagnes de prospection et de fouilles archéologiques (tableau 1 et fig. 3). Une petite partie de l'information a pu être sauvée, mais elle permet d'opérer un constat, celui d'une réaccumulation acquise au Préboréal à un niveau supérieur à ce que furent, par la suite, les niveaux fluviatiles holocènes. Ce bas niveau a été repéré et daté sur trois sites :

- À la Boisse (lieu-dit Pré Rands), un tronc de sapin a été découvert à la cote $179 \mathrm{~m}$ dans un chenal de tressage remblayé par des sables graveleux à stratification entrecroisée ; ce chenal est localisé sur la marge nord de la plaine au pied de la

- des Dombes. Il a été daté 9960 +/-70 B.P. ou 9875-9040 cal B.C. après calibration (ARC - 484).

- À Meyzieu (lieu-dit La Rubina), un tronc a été découvert dans les cailloutis, enfoui à une profondeur de 1-2 $\mathrm{m}$, à l'occasion de la prospection archéologique réalisée avant la construction de l'autoroute A 46 Nord. Ce tronc date à 9120 +/-135 B.P. (Ly - 5439) un niveau perché de +2,5 $\mathrm{m}$ par rapport à la plaine moderne.

- À Villeurbanne (lieu-dit Grand'Poste), un tronc, récolté dans les alluvions caillouto-sableuses d'un banc dont le toit cote $164 \mathrm{~m}$, a été daté 9090 +/-150 B.P. (Ly - 3746). Un chenal voisin, remblayé sur 2,5 $\mathrm{m}$ par des lits minéraux (limono-argileux) et organiques (feuilles) a fourni un âge de 8150 +/-150 B.P. (Ly - 3747). Ce dernier élément nous assure que le tronc précédent a été fossilisé avant la fin du Boréal et qu'il ne s'agit pas d'un remaniement holocène postérieur. Si l'arbre est mort à la fin du Préboréal, il a cependant pu être repris et redéposé au Boréal. 
Tableau 1 - Liste des dates radiocarbone obtenues dans la plaine alluviale Rhône (du confluent de I'Ain à Lyon) et de la Saône (Vaise)

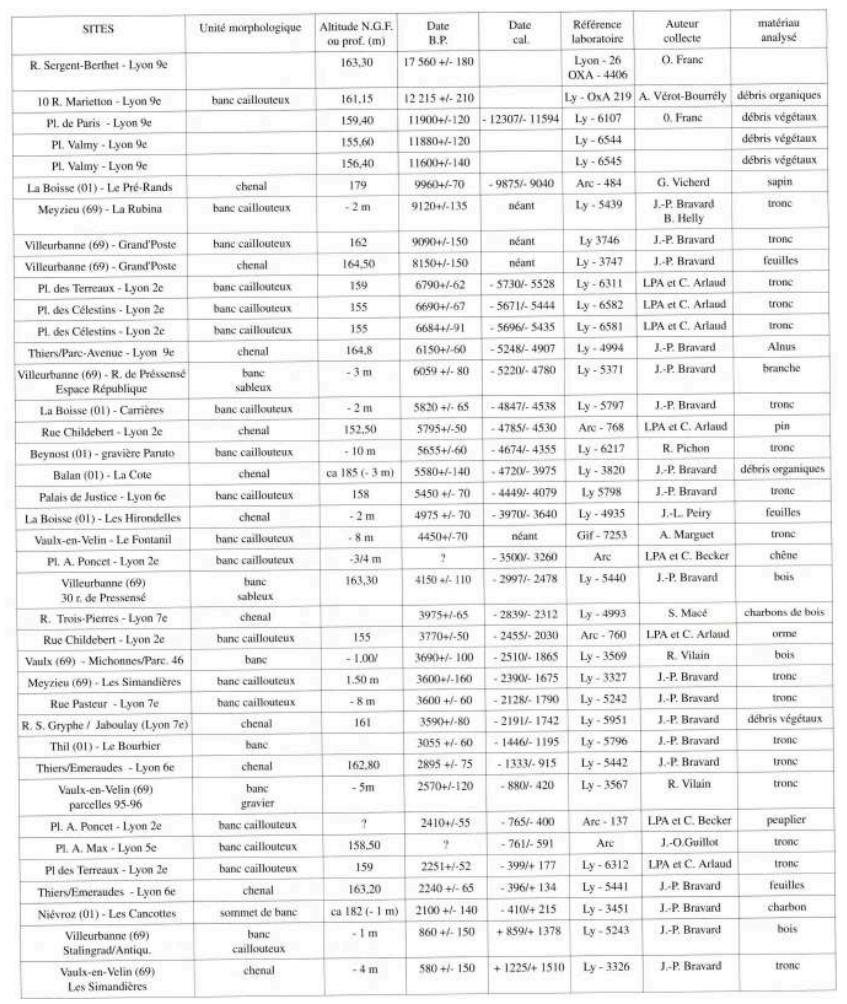

Quoiqu'il en soit, ces trois dates démontrent qu'un important remblaiement alluvial est acquis au Préboréal ou au plus tard à la fin du Boréal à l'amont de Lyon. Une épaisseur minimum de 5 à 6 mètres de cailloutis sur une largeur moyenne de $3 \mathrm{~km}$ signifierait qu'un volume minimum de 15 à $20106 \mathrm{~m}^{3} / \mathrm{km}$ se serait déposé dans la plaine alluviale entre l'Allerød et la fin du Boréal. Ce remblaiement a très probablement débuté au Dryas final en rive droite. Les deux sites de rive gauche sont plus récents et très certainement d'âge préboréal-boréal. Ces trois sites se raccordent assez bien et forment un niveau d'une altitude relative de $+2 \mathrm{~m}+/-1 \mathrm{~m}$ par rapport au sommet des bancs caillouteux du Rhône moderne. Si le maximum du remblaiement a été acquis dès le Dryas final (ce que rien ne démontre), les niveaux préboréaux manifesteraient déjà une tendance à la réincision; on peut aussi bien admettre un fonctionnement du Rhône dans le plan d'un niveau à peu près constant entre ca 11000 B.P. et 9000 B.P. Le paléochenal boréal de la Grand'Poste de Villeurbanne parait correspondre à un fonctionnement résiduel du niveau préboréal-boréal car son remblaiement est postérieur à un exhaussement sableux du banc caillouteux et possède un remplissage traduisant également un faible dynamisme des flux (Bravard et Evin 1989). Ce chenal peut être rapproché de celui qui fut étudié à proximité par David et Méon-Vilain (1964); comme le précédent, il fut attribué au Boréal sur la foi des analyses polliniques. 


\section{La dynamique fluviale de l'Atlantique à l'époque moderne}

\section{Une probable phase de faible activité fluviale à l'Atlantique ancien (6 800-6 700/5 800 B.P.) suivie d'une phase de forte activité à l'Atlantique récent (5 $800-5400$ B.P.)}

\section{Les éléments datés}

Une série de dates groupées dans l'Atlantique récent est maintenant disponible mais leur interprétation doit être maniée avec prudence. Il s'agit de dates authentifiant le fonctionnement résiduel de bras fluviaux entaillant une paléoterrasse et de dates portant sur des troncs subfossiles découverts dans le corps du remplissage caillouteux et emboîtés dans ces niveaux. Nous distinguerons deux ensembles géographiques, le secteur de la plaine alluviale à l'amont de Lyon et le site de Lyon-Villeurbanne.

Au premier ensemble appartiennent les sites suivants :

1. La Cote (Balan, Ain) où la matière organique de remplissage d'un bras mort est datée 5580 +/-140 B.P. ou 4 720-3 975 cal. BC (Ly - 3 820). Il s'agit d'une basse terrasse perchée d'environ $2 \mathrm{~m}$ par rapport à la plaine moderne.

2. Les carrières (La Boisse, Ain) où un tronc a été daté 5820 +/-65 B.P. ou $4847-4538$ cal. BC (Ly - 5 797).

3. La gravière Paruto (Beynost, Ain) où un fragment de tronc remonté d'une profondeur de 10 $\mathrm{m}$, selon l'auteur du prélèvement, a été daté 5655 +/-60 B.P. ou $4674-4355$ cal. BC (Ly 6 217).

Ces deux derniers sites sont dans le plan d'un lit majeur très peu incliné du nord (niveau préboréal) vers le sud (le lit moderne); la topographie ne permet pas de distinguer deux niveaux, l'un Dryas final - Préboréal, l'autre Atlantique.

4- Coupe est-ouest dans le remplissage sédimentaire de la plaine du Rhône à Lyon, au niveau de la presqu'île
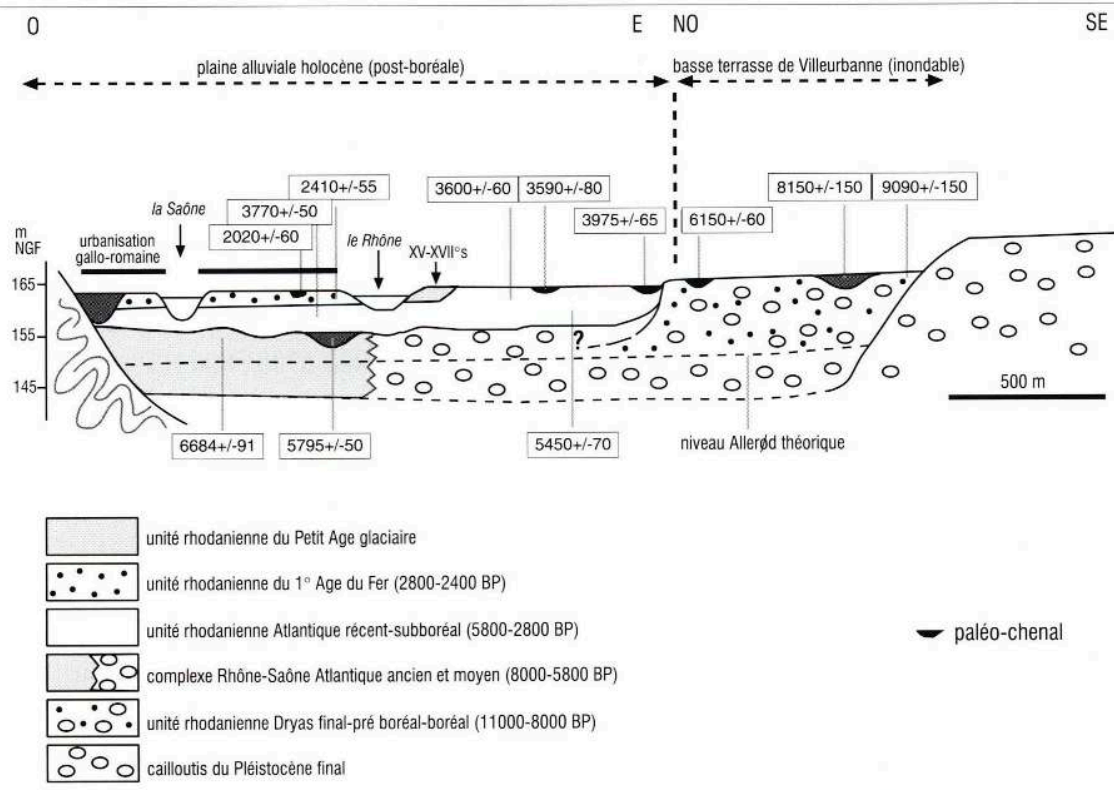

permettent de proposer prudemment l'hypothèse de fluctuations hydromorphologiques au sein de la période atlantique, à savoir :

- une phase d'incision du Rhône dans le remblaiement caillouteux mis en place au Préboréal et dont on sait qu'il est encore atteint par les crues au Boréal. Cette incision ravine le remblaiement sableux sous-jacent mis en place par la Saône vers 5800 B.P. (4 800-4 500 av. J.-C.) sous la place de la République. Il n'est pas certain qu'il y ait eu permanence d'un bas niveau fluvial entre 6800 et 5800 B.P. dans la mesure où les dépôts organominéraux fins datés sur la marge de la terrasse préboréale-boréale de Villeurbanne se mettent en place vers 6 150-6 050 B.P. (5 250-4 800 cal. BC) à une altitude relativement élevée (163 m). Il peut alors s'agir de dépôts de crues exceptionnelles déposés par le Rhône en position déprimée ou de dépôts sur le paléo-niveau facilités par une aggradation du talweg vers 6 150-6 050 B.P. Cette phase pourrait éventuellement être corrélée avec la dernière phase de transgression lacustre de Cerin (Magny 1995) ;

- une phase de forte activité est possible sur le site de Lyon vers 5450 B.P., portant l'altitude de la bande caillouteuse du Rhône aux alentours de $158 \mathrm{~m}$ ou plus haut sur le site du Palais de Justice, mais le tronc daté pourrait être remanié. Les découvertes faites dans la plaine alluviale du Rhône à l'amont de Lyon (Bravard et al. 1991) apportent cependant du crédit à l'hypothèse d'une phase d'aggradation puisque les dates obtenues (5 800-5 600 B.P.) sont 
contemporaines de celle du Palais de Justice. La phase d'aggradation/forte activité de 5 800-5 450 B.P. pourrait être corrélée avec la phase de transgression lacustre du Grand Maclu correspondant à l'avancée glaciaire de Rotmoos I datée 5 800-5 300 B.P. (Magny op. cit.) mais n'a, semble t'il, pas d'équivalent en Valdaine, dans la moyenne vallée du Rhône (Berger 1996).

\section{Le subboréal (4 700-2 700 B.P.) : une stabilisation relative?}

34 Les datations effectuées dans la plaine alluviale du Rhône pour cette période portent sur des troncs extraits à une profondeur de 4 à $5 \mathrm{~m}$ ainsi que sur de la matière organique collectée dans des bancs caillouteux à faible profondeur et dans le remplissage de chenaux. Rien ne permet de mettre en évidence l'existence de fluctuations hydromorphologiques (exhaussement/incision, alternance de phases de faible et forte activité) au sein de la période.

Dans les îles de Miribel-Jonage, des troncs subfossiles reposant sur un niveau de gros galets ont été découverts à un bas niveau (profondeur de $8 \mathrm{~m}$ ) dans des ballastières. Ils sont datés 4450 +/-70 B.P. (Gif - 7253) au Fontanil (Vaulx-en-Velin) et $3600+/-160$ B.P. (Ly - 3 327) aux Simandières (Meyzieu). Ils peuvent correspondre à une mise en place dans des mouilles ou à de bas niveaux fluviaux. La première hypothèse est cependant à privilégier dans la mesure où de la matière organique contemporaine a été découverte dans des bancs caillouteux et/ou des remplissages sédimentaires de chenaux. Citons le site de la rue de Préssensé à Villeurbanne daté 4150 B.P. +/-110 (Ly - 5440$)$; un orme daté 3770 +/-50 B.P. ou 2 455-2 030 cal. BC (ARC - 760) a été découvert sur le site du parking République (Lyon 2e), à $155 \mathrm{~m}$ d'altitude au sommet du remplissage du chenal du Rhône. Un banc caillouteux contemporain a été daté sur la rive gauche du Rhône à Lyon. Il s'agit d'un banc situé rue Pasteur (Lyon 7e) daté 3600 +/-60 B.P. (161 m). Ce banc est de peu postérieur au chenal de la rue des Trois Pierres (Lyon 7e) situé au pied de la terrasse de la Guillotière, qui a été daté 3975 +/-65 B.P. (Ly - 4993). Le remplissage d'un autre chenal situé rue Sébastien Gryphe (Lyon 7e) a été daté 3590 +/-80 B.P. (Ly 5951). A l'amont, citons un banc situé au Bourbier (Thil, Ain), postérieur aux unités morphologiques précédentes et daté 3055 +/-60 B.P. (Ly - 5 796), ainsi que le site des Michonnes-Parc 46 daté 3690 +/-100 (Ly - 3 569).

Des niveaux de fréquentation datant du Bronze Final confirment la stabilisation de la plaine alluviale à cette époque et fixent le niveau d'exhaussement sableux de celle-ci à $164 \mathrm{~m}$ au 44 rue de la Madeleine (Monin 1988) et à 163,70 $\mathrm{m}$ à l'angle des mes Père Chevrier et Saint Jérôme (ce dernier niveau est daté du Bronze Final I ou IIa par Rahatsoz et al. 1997). Un niveau à débris de bois, trouvé à 162,25 m sur le site de l'îlot Charavay, donne la cote du remplissage alluvial de la plaine de Saône à Vaise à la date de $3060+/-65$ BP (Ly - 7 556).

Cette phase paraît donc matérialisée par des bancs situés à une altitude voisine de 160-162 m et des chenaux cotant 155-159 m dans la presqu'île. Elle est contemporaine d'une phase de régression lacustre dans le Jura, placée entre les phases de transgression de Chalain et de Pluvis (Magny op. cit.). Il peut s'agir d'une phase d'activité fluviale modérée dans les vallées du Rhône et de la Saône. Pour sa part, J.-F. Berger (op. cit.) a identifié des phases de torrentialité vers 5 000-4 700 et 4 000-3 700 B.P en Valdaine. 


\section{La nappe alluviale grossière du premier âge du Fer (2 800-2 400 B.P.)}

Des preuves d'une forte activité fluviale au Premier âge du Fer ont été découvertes dans trois secteurs de la plaine alluviale de Lyon.

A. À l'Ouest, sur le site A. Max (quartier SaintJean), un vaste banc caillouteux rhodanien culminant à $163 \mathrm{~m}$ a été daté par un tronc découvert à la cote $158,50 \mathrm{~m}$; son âge, obtenu par dendrochronologie, est compris entre 761 et 591 cal. BC (Arlaud et al. 1994a). La présence de ces alluvions du Rhône au pied de la colline de Fourvière (sites archéologiques du métro et îlot Clément V; (Monnoyeur et al. 1992) démontre que la dynamique du fleuve, très puissante, avait plaqué la Saône contre la colline: au cours de l'âge du Fer, le Rhône confluait donc avec la rivière dans le quartier Saint-Georges (Arlaud et al. op. cit.) (fig. 5).

5- Les alluvions de la Saône (en clair) et du Rhône à l'époque gallo-romaine - îlot Clément V

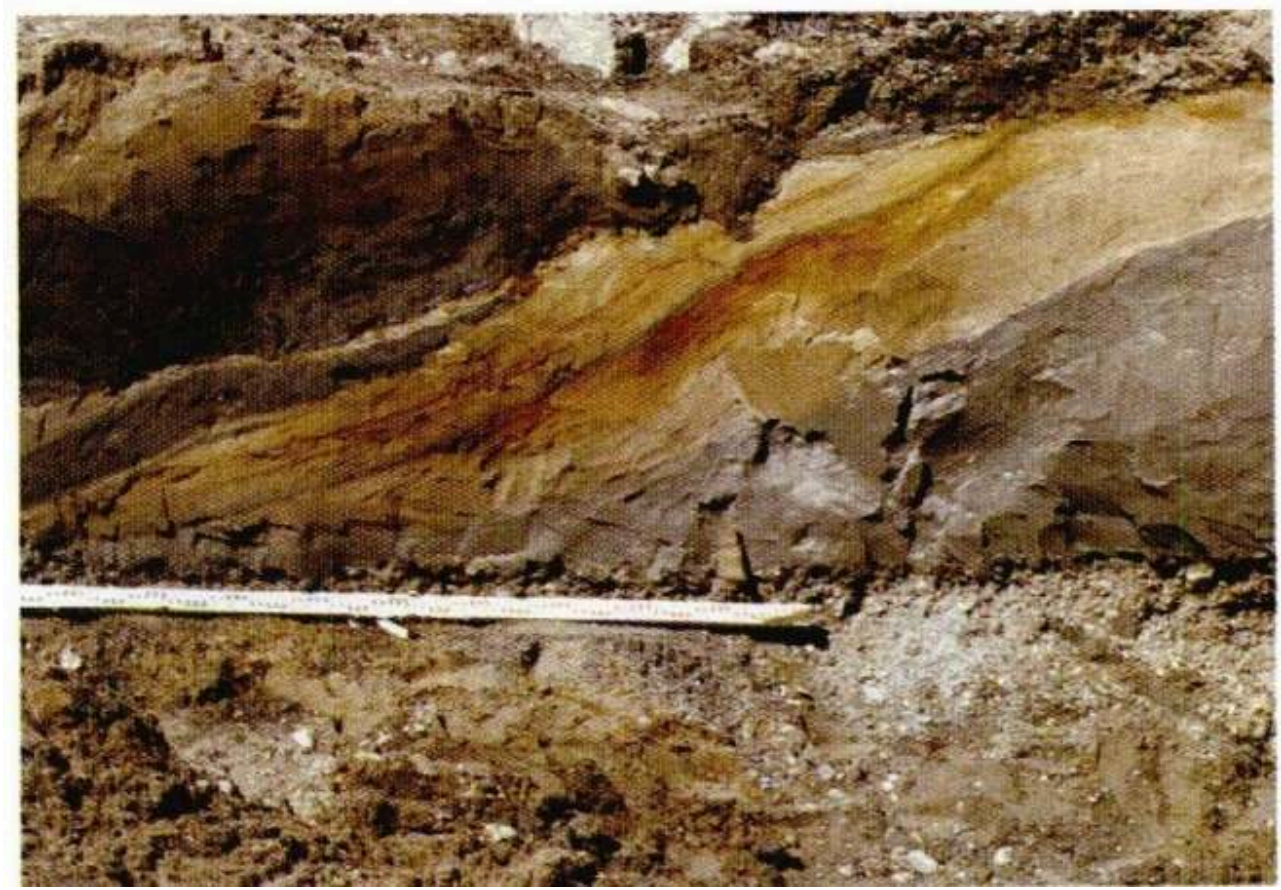

CL. O. FRANC

A. Dans la Presqu'île, sur le site de la place Antonin Poncet, un tronc de peuplier a été daté 2410 +/-55 B.P. ou 765-400 cal. BC (Arc 137, In: Becker et al. 1989); il serait contemporain de la mise en place d'un banc rhodanien culminant à $162 \mathrm{~m}$. Cette phase de construction par le dépôt de charge de fond a pu perdurer jusqu'au début de la Tène, comme en témoigne la découverte, à $159 \mathrm{~m}$ NGF sous la place des Terreaux, d'un tronc daté 2251 +/-52 B.P. ou 399-177 cal. BC (Ly - 6312) (Arlaud et al. 1994b). Ces dates donnent la fin de la mise en place d'une morphologie de tressage remontant pour l'essentiel au Ier âge du Fer (fig. 4). De vastes bancs caillouteux séparés par des chenaux larges de 10 à $20 \mathrm{~m}$ et profonds de 1 à $3 \mathrm{~m}$, orientés NE/SO, ont été repérés à l'occasion des fouilles archéologiques. Les bancs culminent à $164 \mathrm{~m}$ au Terreaux et à $162 \mathrm{~m}$ au Sud de la place Bellecour. Cet espace correspond à une bande alluviale active remaniée par les fortes divagations du Rhône. Trois grands axes de chenalisation N.E/S.O. ont été mis au jour du nord au sud :

- un chenal place de la Bourse, large d'une quinzaine de mètres, il cote à 161,60 m 
- une zone de tressage large d'une centaine de mètres, sous la place de la République, dont les talwegs cotent à $162,30 \mathrm{~m}$

- un chenal place Bellecour dont le fond atteint $160 \mathrm{~m}$ NGF (fig. 6)

A. À la limite de Lyon et Villeurbanne, la construction de l'immeuble «Les Emeraudes » (Place Ch. Hernu), a permis d'observer un chenal du Rhône entaillé dans le rebord de la terrasse d'âge atlantique cotant à $164-165 \mathrm{~m}$. Le fond du chenal $(162,8 \mathrm{~m})$ a été daté grâce à un fragment de tronc à $2895+/-75$ B.P. ou $1333-915$ cal. B.C. (Ly 5 442) et la partie médiane de son remplissage à $2240+/-65$ B.P. ou 396-134 cal. B.C. (Ly - 5 441). L'analyse palynologique réalisée par J. Argant (Argant 1993) a montré que le secteur faisait l'objet d'une exploitation céréalière peu marquée. Le banc de convexité attenant au bras mort est un élément de la plaine alluviale construite à l'âge du Fer dont il reste des éléments très étendus dans la presqu'île ; c'est la première fois que l'on identifie son pendant en rive gauche à une altitude voisine de 163-164 m. A Vaulx (Parcelles 95-96), J. Vilain a obtenu une date à $2570+/-120$ B.P. (Ly - 3567) dans un banc situé à une profondeur de $5 \mathrm{~m}$ (Archives du laboratoire de Radiocarbone).

\section{6- La Saône et le Rhône autour de l'an 1 à Lugdunum}

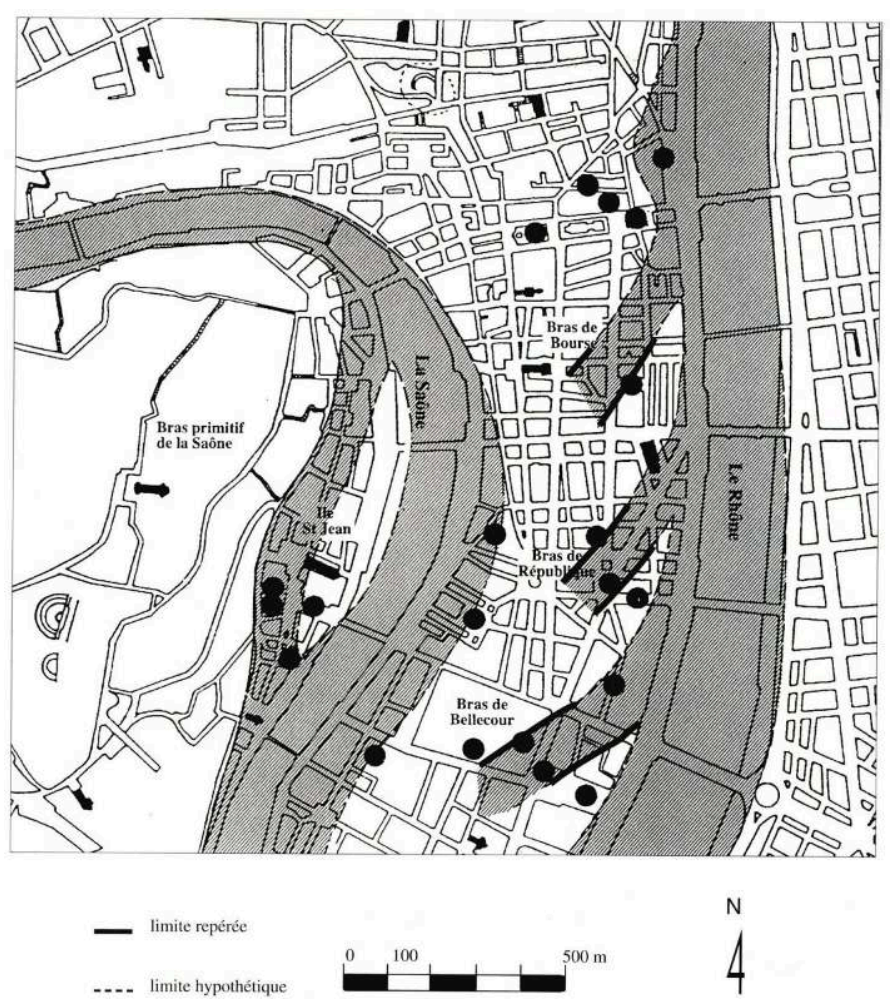

À Vaise, rue du docteur Horand, le talweg du Bronze Ancien est comblé, mais un fond humide subsiste lorsque s'installe le groupe humain entre le dernier quart du VIe s. et le premier quart du Ve s. av. J.-C. Puis l'occupation est ruinée par une phase de ravinement peu intense ; le talweg qui en est issu est enfin comblé à la fin du Ier âge du Fer (Bellon et al. 1994).

\section{La Tène (2 400-2 000 B.P.) : une période de stabilité}

À la fin du Ier âge du Fer, la dynamique du Rhône faisait donc de la plaine, sous Fourvière, un espace sans doute impropre à la colonisation humaine. Seul le site de 
Saint-Vincent, localisé en rive gauche de la Saône, au pied du plateau de la CroixRousse, révèle une occupation qui se traduit par la présence d'un four daté du Hallstatt (Moyen à Final), voire de la Tène. La position topographique de ce site à l'abri des fluctuations du Rhône explique cette installation humaine. De même, il connaît une occupation de la Tène qui se traduit par les témoins d'une activité artisanale datée de 40-20 av. J.-C. (Lascoux et al. 1994) ou de 40-30 av. J.-C. (Desbat,1996), mais A. Desbats (in litteris) estime que le mobilier, dont l'étude est en cours, montre une occupation durant la première moitié du Ier s. av. J.-C.

$41 \mathrm{Au}$ cours du IIe âge du Fer, les différentes fouilles archéologiques révèlent un changement de la dynamique fluviale qui conduit à une relative stabilité de la presqu'île. Le site devient une plaine d'inondation régulièrement exhaussée par des limons de débordement plus ou moins sableux et épais de quelques décimètres; la plaine s'exhausse jusqu'à une altitude moyenne de 163-164 m tandis que des chenaux obliques se remblayent peu à peu. Le Rhône se retire vers l'est de la plaine actuelle ; l'activité fluviale se réduit et le lit s'encaisse tout en évoluant vers une morphologie simplifiée. Cette chronologie est précisée par la présence d'un squelette humain fossilisé dans ces alluvions sableuses sous le site de la rue PalaisGrillet : il est daté par radiocarbone de 2015+/-150 B.R (Ly - 5659) (Ayala et al. 1992). La datation d'un lit de feuilles mortes piégées dans les premiers niveaux de remblaiement du chenal de la place de la Bourse à $161,90 \mathrm{~m}, 2020+/-60$ B.R ou $179 \mathrm{cal}$. BC/88 cal. AD (Ly - Oxa 3945) confirme la précédente datation obtenue à quelques dizaines de mètres. Cette fourchette chronologique est resserrée par la présence d'un aménagement d'amphores au sommet du remplissage, ce qui lui donne un terminus augustéen (Arlaud et al soumis).

42 Au cours de cette période, le Rhône, en se repliant vers l'est, va permettre à la Saône de se dilater sur sa rive gauche de sorte que le site de confluence va se décaler à l'est. Abandonnant son chenal primitif au pied de la colline, la rivière s'ouvre un nouveau tracé, sensiblement identique à l'actuel, dès le début de notre ère. Elle va édifier peu à peu sa berge de rive gauche dont les phases de construction ont pu être observées sur le site de la place des Célestins; la fouille de l'îlot 24 (Jacquin et al. 1984) montre que cette rive est pratiquement fixée au milieu du Ier s. ap. J.-C. La rivière délimite alors ce que l'on appelle aujourd'hui la presqu'île ; la Saône participe dès lors, comme le Rhône, à l'alluvionnement de cette unité nouvellement formée ; des alluvions de débordement ont été relevées place des Terreaux (Arlaud et al. 1994b) et au niveau de la place Bellecour (Faculté Catholique) (Monin et al. 1986).

Ces différents éléments permettent d'imaginer un paysage en totale mutation lors de l'arrivée de la colonie romaine sur le site de Lyon au milieu du Ier s. av. J.-C. Les lônes partiellement remblayées ne sont probablement en eau que lors des hautes-eaux ou des crues. La plus importante, qui doit être le témoin de la Saône primitive, délimite « l'île Saint Jean ", bordée à l'est par la nouvelle Saône. Sur la presqu'île, les terres basses sont encore instables, mais à l'étiage elles présentent enfin de nouveaux espaces à conquérir en bordure d'un Rhône moins contraignant. A Vaise, le IIe âge du Fer présente une lacune sédimentaire et, dans une large mesure, archéologique pour la période couvrant la fin du Ve s. à la fin du IIe s. av. J.-C., sur tous les sites observés ; l'occupation y serait attestée entre la fin du IIe et le début du Ier s. av. J.-C. sur les sites Rue du Souvenir, ZAC Charavay et Marietton (A. Desbats in litteris). 


\section{La crise hydrologique du début de notre ère}

Autour de l'ère, les populations riveraines, principalement installées sur les collines de Fourvière et de la Croix-Rousse, ont vu le site de confluence se modifier. Sur ces terres basses, de nouveaux espaces se sont stabilisés dans la plaine et offrent des sites d'installation. Néanmoins, cette évolution vers la stabilité est interrompue par le retour de flux tractifs du Rhône sur la presqu'île. Plusieurs chenaux du Rhône vont à nouveau drainer des crues et les hautes eaux, plus particulièrement de la fin du Ier s. av. J.-C. au Ier s. ap. J.-C. Cette période enregistre effectivement des épandages de sables grossiers dûs aux inondations et témoins d'une hydrologie accrue par rapport à la période de la Tène. Ces chenaux vont être finalement comblés au cours du Ier s. ap. J.-C.

Plusieurs sites démontrent la fossilisation des niveaux d'occupation antiques par des dépôts alluviaux issus de balayages de crues ou de débordements lents. Les flux s'écoulent encore par les chenaux fonctionnels à la fin du Ier âge du Fer. La chronologie de leur remplissage et des dépôts d'inondation ont permis d'émettre une hypothèse concernant la paléohydrologie au début de notre ère.

\section{Les dépôts de crues du Rhône datés par les installations humaines}

Sur les sites de Bourse, République, Palais-Grillet, les premiers vestiges sont ceux d'installations précaires (foyer, fosses, trous de poteaux,...) datées du règne d'Auguste. Ils sont fossilisés par les dépôts d'inondation, qui eux-mêmes portent des témoins d'une occupation datée du règne de Tibère. Malgré le caractère inondable des lieux, les GalloRomains persistent à s'installer sur la presqu'île. Cette occupation est à son tour fossilisée par des dépôts de crue. Sous le règne de Claude, le terrain est exhaussé par un remblai caillouteux de près de $50 \mathrm{~cm}$, ce qui assure une installation plus durable dans cet espace à risque. Sur le site de l'opéra, une couche de sables et limons remblaie un puits daté par dendrochronologie de 80 ap. J.-C. (Raynault 1991).

\section{Les remplissages de bras du Rhône}

Le bras observé place de la Bourse est remblayé par plusieurs séquences à dominante sableuse atteignant 1,90 $\mathrm{m}$ d'épaisseur. Les caractères de la sédimentation suggèrent un chenal sinueux avec banc de convexité et mouille de concavité. Les amphores augustéennes, qui scellent le comblement du chenal, étaient surtout concentrées dans la convexité, ce qui traduit l'intention d'assainir cette zone humide en aménageant la berge la plus stable (Arlaud et al. soumis).

La bande de tressage de la Place de la République draine des flux jusque dans la deuxième moitié du Ier s. ap. J.-C. et rend impossible toute occupation à l'exception de ses rives à l'abri des courants turbulents. Au cours des siècles suivants, ce secteur à topographie déprimée enregistre encore quelques dépôts fins d'inondation (Arlaud et Lurol et al. 1992).

La fouille liée à la construction du métro, place Bellecour, est venue confirmer l'hypothèse de A. Steyert (1895) qui proposait un bras du Rhône traversant la presqu'île d'est en ouest. L'analyse a permis d'observer l'exhaussement d'un banc caillouteux, à l'emplacement de la place A. Poncet, et le remblaiement du chenal en 6 séquences successives. On note que la levée du chenal, renforcée par un aménagement 
d'amphores flaviennes, est réactivée par des flux de débordement du Rhône à la fin du Ier s. ap. J.-C. (Vérot et al. 1989).

\section{Les fluctuations de la Saône}

Dans la partie sud de la plaine de Vaise, la Place Valmy (Le Nezet-Célestin et al. 1993) et la ZAC Charavay (Lascoux 1994) ont reçu peu d'apports sédimentaires. La Saône, si elle a débordé dans la plaine, n’a pas laissé de sédiments ou, du moins, ils n'ont pas été encore découverts. Les processus responsables de l'exhaussement sont des ruissellements diffus en provenance des versants mais ils semblent avoir été maîtrisés durant les phases d'occupation. Place Valmy, l'occupation est attestée jusqu'au milieu du VIIe s. ap. J.-C., mais l'intercalation de témoins naturels dans la stratigraphie ne se produit qu'au milieu du Ier $\mathrm{s}$. de notre ère. Dans la plaine de Vaise, les ruisseaux qui descendent des versants sont très actifs et détruisent en partie les occupations des Ier et IIe s. sur les sites de Gorge-de-Loup (VérotBourély et al. 1995), de Horand (Bellon et al. 1994) et du Périphérique Nord de Lyon (Franc 1996).

51 Sur la rive droite de la Saône, sous Fourvière, l'analyse du remplissage sédimentaire et anthropique du chenal primitif du site de Tramassac précise la chronologie de l'activité hydrologique de la Saône. De la deuxième moitié du Ier s. ap. J.-C. à la première moitié du IIIe s. ap. J.-C., se succèdent des épisodes de crue et de décrue qui contribuent peu à peu à raffinement vers le haut de la dernière séquence de remblaiement. Jusqu'au milieu du IIIe s. ap. J.-C., des chenaux résiduels de crue se maintiennent et sont ensuite comblés par des sables grossiers, témoins d'un courant encore assez vif, et par des remblais anthropiques (Arlaud et al. 1994).

Des dépôts de crue liés à la rivière ont été identifiés en amont, sur la rive droite (site du Quai Arloing), où ils fossilisent un sol du Ier s. ap. J.-C. (Vérot-Bourrély 1995). De même, à l'emplacement du kiosque de la place Bellecour, un dépôt de crue de la Saône s'intercale entre des niveaux datés 40 et 60 ap. J.-C. (Becker 1982).

Ces données permettent de décrire la plaine de Lyon entre Rhône et Saône au début de l'Antiquité, comme un espace parcouru par des chenaux divagants et peu profonds, où seuls les bancs caillouteux émergés et exhaussés d'un remblai sont fréquentés dès le début de notre ère. Cette période est caractérisée par un retour des crues après celle de relative stabilité de la Tène (Bravard et al. 1992). Dès la fin du Ier s., la plaine alluviale de Lyon ne conserve quasiment plus de témoignages d'inondations, à l'exception de minces dépôts dans les zones à topographie déprimée comme sur les sites de République et Célestins. Plusieurs facteurs peuvent expliquer cette absence : tronquage des dépôts, activité hydrologique apparemment en diminution, volonté des GalloRomains de maîtriser l'espace en exhaussant la surface de circulation par rapport au niveau des inondations.

\section{Des éléments sur la dynamique sédimentaire de la presqu'île au Moyen Âge et à l'époque moderne}

Les données sont encore isolées mais elles permettent de proposer des hypothèses sur la paléotopographie de la presqu'île. Elles démontrent surtout que la lecture géomorphologique doit s'effectuer dans tous les niveaux sédimentaires jusqu'à l'époque moderne. Les textes sont riches en enseignements sur la description des phénomènes 
naturels contraignants. Un travail en étroite collaboration entre géomorphologues et archivistes reste à réaliser car seule une double lecture peut permettre d'isoler le fait anecdotique de l'événement à signification paléoclimatique.

Des dépôts d'inondation entre la fin du IVe s. ap. J.-C. et le début du Haut-Moyen Âge

Ils ont été mis en évidence sur le site de la place des Célestins (Arlaud et Lurol 1994) et ils semblent provenir des débordements de la Saône et du Rhône. Le site de République conserve une zone déprimée à l'emplacement de la bande de tressage antique et il enregistre des dépôts d'alluvions rhodaniennes dans la période comprise entre le IIIe et le XIIe s.

L'ouverture d'une lône entre la fin de l'antiquité et le début du XIIle s. sur la place des Terreaux

Une dépression localisée dans ce site a été interprétée comme le tracé d'une ancienne lône ouverte par une crue (Arlaud et al. 1994b). Cet épisode pourrait éventuellement être rattaché à une péjoration climatique contemporaine du fonctionnement de cônes de déjection entre les VIeVIIIe s. (Bravard 1996). Ce chenal réactualise la crue de 580 décrite par Grégoire de Tours, laquelle était, pour Ph. Russo et A. Audin (1961 et 1964), le point de départ de l'ensablement d'un grand bras place des Jacobins et d'une nouvelle confluence Rhône-Saône au niveau des Terreaux.

57 À proximité, le site République - ancienne rue de l'Hôpital - conserve des dépôts fins d'inondation datés du XIIIe s. (Arlaud et Lurol et al. 1992).

\section{Des événements en relation avec le Petit Âge Glaciaire?}

Le site de la Place des Terreaux a enregistré le dépôt d'alluvions caillouteuses du Rhône dans la partie est du premier fossé des Terreaux, avant l'agrandissement du fossé des fortifications, au XVe s. Cet événement, sans doute survenu au XIVe s., a peut être contraint à modifier la conception du fossé. Au cours de l'époque moderne, de nombreux témoignages citent des inondations catastrophiques dans la ville: 1570, 1602, 1711, 1840, 1845 et surtout Mai 1856 qui conduit à la protection définitive de la ville (Bravard 1987). Le site de République enregistre le dépôt de limons de débordements dans des niveaux anthropiques datés des XVIe, XVIIIe et XIXe s.

\section{Potentiel archeologique des plaines alluviales}

\section{La plaine du Rhône}

Les développements précédents montrent que la paléogéographie de la plaine du Rhône à l'amont de Lyon et à la traversée de la ville actuelle est commandée par l'adaptation complexe du profil en long et du dessin en plan aux fluctuations hydro-climatiques tardiglaciaires et holocènes. Le potentiel archéologique doit donc être pris en compte dans les trois dimensions de l'espace. 


\section{La mobilité verticale du Rhône et du toit caillouteux de la plaine alluviale}

60 Il est probable que la réaccumulation sédimentaire rhodanienne consécutive au bas niveau Allerød a une épaisseur d'environ 7 à $9 \mathrm{~m}$ à Lyon. Elle est pour l'essentiel de nature cailloutosableuse, exception faite de lentilles sableuses correspondant à des bancs latéraux ou de remplissages de paléo-chenaux sablo-limoneux et organiques. Le calibre des particules caillouteuses de la nappe de réaccumulation fait que leur reprise a été possible durant l'Holocène. Cette reprise n'a pas été le fait de " processus-relais » équilibrés, les apports de l'amont par les crues étant compensés par le départ d'une quantité équivalente de matériaux vers l'aval. En effet, suivant les périodes de l'Holocène, la relation entre la capacité de transport (donnée par l'hydrologie des crues) et la charge à transporter (provenant du Jura, de l'érosion des berges fluviales ou de l'érosion du fond du lit) s'est modifiée à plusieurs reprises.

61 Les périodes pendant lesquelles la charge a excédé la capacité de transport ont, en principe, été favorables au développement d'un style fluvial en tresse (nombreux chenaux de faible profondeur, nombreux bancs de galets instables), à une grande mobilité latérale et à l'exhaussement de la plaine alluviale qui stockait l'excédent de matériaux que le Rhône ne pouvait emporter. Ces périodes, défavorables à l'installation humaine, ont aussi eu pour effet de fossiliser les niveaux antérieurs ou de les détruire. $\mathrm{Au}$ nombre de ces phases d'exhaussement, citons celle du Dryas final-Préboréal (11 000-9 000 B.P.), celle de l'Atlantique (5 800-5 400 B.P.), qui est probable, et celle du Premier âge du Fer. Il est remarquable que le sommet des bancs caillouteux de la plaine lyonnaise se tienne aux environs de 163-165 m à l'amont (Villeurbanne) et 162-163 m à l'aval pendant les pulsations verticales de l'Holocène. Le fond reconnu des chenaux alluviaux se tient, durant ces phases d'accumulation, à une altitude voisine de $162 \mathrm{~m}$ à l'amont (Villeurbanne) et $160 \mathrm{~m}$ à l'aval (Place Bellecour).

62 En revanche, les phases de déficit sédimentaire se sont traduites par un déstockage alluvial de la plaine du Rhône sous l'effet de l'incision et de la divagation fluviale. En général, ces périodes sont caractérisées par un tressage peu actif (une partie des chenaux anciens semble encore fonctionnels) ou par un style à chenal unique (en principe le méandrage). Le profd en long est modifié par un enfoncement généralisé et les chenaux ajustent probablement leur géométrie en adoptant un faible rapport largeur/profondeur : plus étroits, les chenaux sont aussi plus profonds et développent des mouilles pouvant avoir une profondeur de 5 à $6 \mathrm{~m}$ ou davantage. Le ravinement des sables de Saône sous la presqu'île durant l'Atlantique pourrait s'expliquer par la conjonction de deux causes, un talweg incisé et la mobilité de mouilles surcreusées. Ces périodes laissent peu de témoignages sous forme de dépôts puisqu'elles correspondent à des phases de déstockage sédimentaire. Les ravinements de formations anciennes sont aussi difficiles à observer. Il est très probable que le Rhône s'est enfoncé durant la Tène et jusqu'à la fin du Moyen Âge mais les occasions de rencontrer ses berges et de définir sa géométrie ont été très rares (Place Tolozan), d'autant que la réaccumulation du Petit Age Glaciaire a oblitéré les formes. Pendant ces périodes de bas niveau des talwegs, les crues devaient être faiblement débordantes de sorte que l'épaisseur des dépôts de recouvrement fins sur les bancs caillouteux est limitée. 


\section{La mobilité spatiale du Rhône}

63 schéma de l'extension spatiale maximale de la bande soumise à l'activité fluviale depuis la réaccumulation du Préboréal (fig. 7). On s'est efforcé de distinguer l'extension de la zone soumise à l'activité de la Saône de celle soumise à l'activité du Rhône, tout en sachant qu'il pouvait subsister des lambeaux de plaine alluviale hérités des épisodes antérieurs au coeur des bandes actives délimitées.

7- Espaces d'activité de la Saône et du Rhône à Lyon depuis le Tardiglaciaire

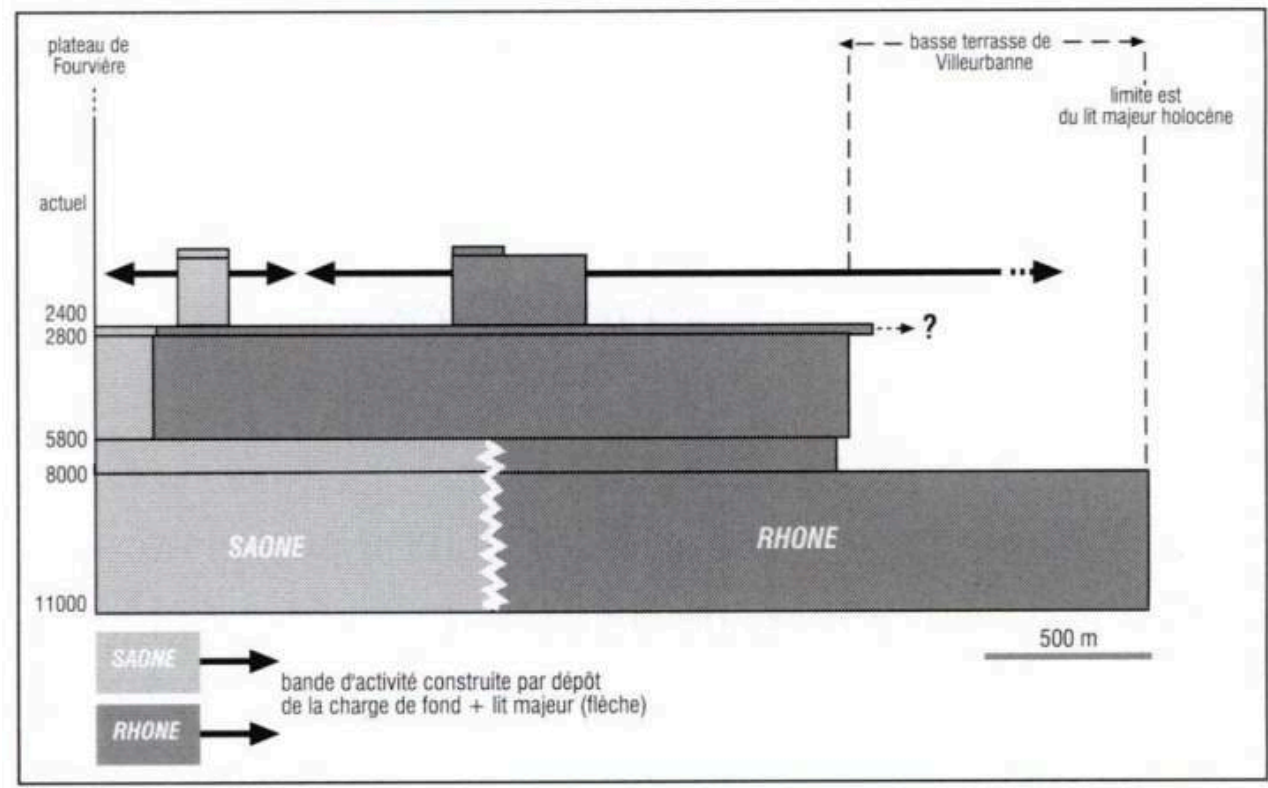

On sait que le maximum d'extension de la bande d'activité fluviale vers l'Est a été acquis au Préboréal-Boréal avec la construction de la basse terrasse de Villeurbanne. On ne sait si l'accumulation sableuse de la Saône, rencontrée sous la Presqu'île, atteignait une cote sommitale équivalente $(164-165 \mathrm{~m})$ ou si les sables de la Saône étaient fossilisés par l'accumulation caillouteuse rhodanienne; en l'absence de dépôts rhodaniens attestés, on émettra l'hypothèse, prudente, d'une extension des dépôts de la Saône jusqu'au Rhône actuel pendant le début de l'Holocène, celui-ci étant décalé vers l'Est par rapport à la situation actuelle. Rien n'est cependant certain car les apports sédimentaires de la Saône devaient être modestes par rapport à ceux du fleuve.

L'Atlantique inaugure une phase de déplacement vers l'Ouest et d'élargissement de la bande d'activité rhodanienne. Ce glissement se manifeste par un abandon de la basse terrasse de Villeurbanne, par le ravinement puis la fossilisation des sables de la Saône sous la presqu'île. On connaît fort mal le comportement respectif des deux cours d'eau au Subboréal mais on sait que cette phase d'expansion culmina au Ier âge du Fer avec une paléo-Saône plaquée au pied de Fourvière et une érosion latérale qui s'effectua au détriment de la basse terrasse de Villeurbanne.

La phase d'incision fluviale de la Tène inaugura une période de contraction spatiale de la bande active. Elle se manifesta par la stabilisation du cours de la Saône sur son tracé actuel et par un retour vers l'Est de la bande d'activité fluviale du Rhône qui délaissa la presqu'île, exception faite de courtes phases de crues. Le Rhône a néanmoins épargné 
des secteurs anciennement construits en rive gauche, comme en témoigne les reliques de bancs et de chenaux découverts à la Guillotière et à Villeurbanne.

Le Petit Âge Glaciaire n'a pas remis en cause ce schéma malgré une tendance nette à l'expansion de la bande active. C'est que la ville défend alors la presqu'île par de puissants endiguements ainsi que les abords du Pont de la Guillotière puis la Tête d'Or (XVIIIe s.) ; le Rhône s'est cependant élargi sur sa rive gauche qui demeure l'espace de débordement jusqu'au milieu du XIXe s. Toutefois, sur la rive droite, la partie orientale du fossé des fortifications des Terreaux enregistre vers les XIVe-XVe s., un dépôt caillouteux rhodanien, épais de $50 \mathrm{~cm}$, qui culmine vers $162,50 \mathrm{~m}$ : cet alluvionnement a d'ailleurs pu contribuer à l'élargissement du fossé et à la mise en place de murs le long du fleuve (Arlaud et al. soumis).

\section{Le potentiel archéologique de la plaine du Rhône}

Les principes de base de la taphonomie des sites lyonnais situés dans la plaine alluviale du Rhône sont les suivants :

- les phases d'accumulation caillouteuses sont favorables à la destruction des sites ou traces d'occupations antérieures du fait de la vitesse des courants; au mieux elles permettent une fossilisation partielle, à condition que les structures aient résisté. Des découvertes ont été faites de sites archéologiques fossilisés sous une nappe caillouteuse mais il faut considérer ici l'échelle des processus : le long remaniement par le fleuve se fait avec une autre ampleur. Les découvertes sont alors fréquemment en position secondaire (blocs taillés, cargaisons de bateaux des îles de Miribel).

- la datation de secteurs de la plaine alluviale par les bancs caillouteux donne un terminus a c/ uo à la fréquentation humaine ou à des installations d'autant plus durables que l'érosion fluviale n'est pas venue les perturber par la suite.

- les limons de recouvrement déposés par les crues et postérieurs à l'abandon des bandes d'activité fluviale fossilisent des sites et sont euxmêmes des milieux de découvertes potentielles.

On est maintenant en mesure de proposer les conclusions suivantes :

- la basse terrasse de Villeurbanne a pu être un support d'activités humaines non perturbé par l'érosion fluviale depuis environ 9000 B.P. ; le reste de la rive gauche a conservé des secteurs épargnés depuis environ 6 000-5 000 B.R mais cet est une sorte de mosaïque encore mal connue sur ce plan. Il conviendrait de développer les prospections entre les Brotteaux et la Guillotière et d'explorer systématiquement le dernier secteur qui possède un fort potentiel. L'ensemble de la rive gauche possède donc le potentiel archéologique le plus diversifié des plaines alluviales régionales si l'on considère le critère durée, ce qui ne préjuge pas de l'occurrence des occupations humaines.

- la presqu'île et le quartier Saint-Jean ont une occupation potentielle postérieure au Ier âge du Fer; cependant le balayage par des courants de crue actifs a été facteur de destructions localisées aux chenaux hérités de la phase de construction précédente.

\section{La plaine de Vaise}

70 L'évolution holocène et le potentiel d'occupation de la plaine de Vaise sont fondamentalement différents de ceux de la plaine du Rhône. La géométrie du lit majeur 
de la Saône est en effet contrôlée par la double stabilité verticale et spatiale du cours d'eau.

\section{La stabilité de la Saône et de sa plaine alluviale}

Il est logique d'admettre que la période DryasPréboréal a permis une réaccumulation sédimentaire fluviale généralisée à l'ensemble de la cuvette de Vaise, le profd en long de la Saône étant contrôlé par la réaccumulation du Rhône jusqu'à une cote voisine de 164-165 m; compte tenu de la distance existant entre Vaise et le quartier Saint-Paul $(1,5 \mathrm{~km})$ mais d'une pente aval de la Saône probablement faible à cette époque, la cote de la plaine alluviale devait être à une altitude à peu près équivalente. La vitesse du processus de réaccumulation, que l'on ignore, a pu favoriser la mise en place soit de formations fluviales dans le cas d'une remontée lente, soit de formations fluviolacustres dans le cas d'une remontée soudaine; ce sont les 7 à $8 \mathrm{~m}$ de dépôts limonosableux lités qui forment le revêtement des cailloutis présents sous la plaine.

L'absence de traces d'érosion ou de dépôts fluviaux holocènes dans la plaine de Vaise plaide en faveur d'une stabilité en plan de la Saône pendant l'Holocène. Les phases de déstockage et de stockage sédimentaire rencontrées dans la plaine du Rhône n'ont donc pas existé dans la basse plaine de la Saône. Tout au plus peut-on admettre avec vraisemblance que l'altitude du talweg de la Saône a fluctué en relation avec les phases d'incision-exhaussement du talweg du Rhône. Comme la plaine alluviale a été édifiée au Dryas-Préboréal, période d'accumulation maximale, toutes les fluctuations verticales postérieures se sont inscrites en contrebas de ce niveau, sans que ce principe exclue néanmoins la possibilité de découvrir des traces d'inondation modérées.

Une autre caractéristique de la plaine de Vaise est d'être entourée de versants raides et entaillés par des vallées drainées par de petits cours d'eau. Il en résulte que les apports sédimentaires de ces tributaires ont eu la possibilité de se déposer sur le plancher alluvial de la Saône en formant des cônes de déjections aplatis. Ceux-ci sont localisés à l'exutoire des tronçons encaissés ; ils se prolongent par des nappes alluviales remaniées par des chenaux divagants à charge caillouto-sableuse qui déposaient des limons fertiles d'origine loessique. L'épaisseur de ces nappes, qui se superposent aux limons de la Saône ou les ravinent faiblement, n'excède pas 1 à $2 \mathrm{~m}$. En découle une faible pente de la base des versants en direction de la Saône, favorable à l'évacuation des eaux affluentes, mais défavorable à l'extension des crues de la Saône. On suggérera également que la fertilité de la plaine de Vaise était sans doute meilleure que celle de la plaine du Rhône dont le recouvrement est plus sableux; des rétentions d'eau pluviale étaient cependant possibles à certaines périodes de l'année dans la plaine de Vaise du fait de la faible perméabilité du recouvrement limono-argileux.

\section{Le potentiel archéologique de la plaine de Vaise}

Ce potentiel concerne deux périodes privilégiées.

- L'Allerød, puisque la bonne conservation des niveaux fluviaux limono-organiques, contemporains des Argiles de la Caille, permet de ne pas exclure des découvertes archéologiques à des cotes voisines de 156-160 m.

- La période qui va du Mésolithique au Moyen Âge. puisque la réaccumulation alluviale préboréale donne un terminus a quo aux possibilités d'occupation humaine. De fait les découvertes se font nombreuses... 


\section{La plaine alluviale de Lyon : un cadre peu hospitalier pour les populations riveraines}

75 La reconstitution de la paléodynamique fluviale dans le lit majeur du Rhône actuel montre combien ce site est resté contraignant pour les populations riveraines. La colonisation humaine a dû adopter différents comportements face aux fluctuations hydrologiques afin de maîtriser un espace inhospitalier. L'approche interdisciplinaire a permis d'interpréter la relation milieu-société et d'expliquer les différentes formes de développement des activités humaines.

\section{La protection contre les crues par des digues}

Ce premier type de comportement, de nature défensive, s'est traduit par la construction d'édifices assimilés à des digues protégeant les zones occupées.

Pour la période antique, nous pouvons citer :

- le mur-digue de l'Ilot Vieille Monnaie séparant un espace protégé, où se développe un habitat daté 40-60 ap. J.-C., alors que la partie ouest proche de la Saône est exhaussée par des limons de débordements (Jacquin et al 1984) ;

- sur le chantier de l'Avenue A. Max, un mur a proximité d'un chenal résiduel de crue semble avoir servi de digue protectrice au cours de la fin du IIe - début IIIe s. ap. J.-C. (Arlaud et al. 1994a, p.37);

- un fragment de mur a pu jouer un rôle protecteur à l'extrême sud-est du site des Célestins au cours de l'époque flavienne. De même, la mise en place d'un long mur partageant le site en deux à la fin du IIe-début IIIe s. a pu avoir le même objectif (Arlaud et Lurol et al. 1994);

- la découverte, par $\mathrm{F}$. Artaud, d'éléments de construction interprétés comme les témoins d'un quai-digue (Artaud 1846) n'a jamais été confirmée.

En ce qui concerne l'époque moderne, trois sites permettent de localiser des fragments de digues sur le rive droite du Rhône :

- au nord, l'étude du site de Tolozan a mis en évidence une digue maçonnée fondée sur des pieux datés par dendrochronologie de 1624 (Becker et al. 1991);

- sur le site d'A. Poncet, un mur nord-sud avec un batardeau au pied et des pieux de bois en fondation provoque une coupure stratigraphique entre des fondations modernes sur la plaine d'inondation et, côté Rhône, des remblais interstratifiés avec des limons de débordement (Becker et al. 1989) ;

- les sondages de la Place Gailleton ont révélé un mur fondé dans le cailloutis qui aurait pu servir de digue. Il est surmonté par des dépôts d'inondation du Rhône, mais sa chronologie n'est malheureusement pas connue (Marchianti et al. 1992).

\section{La protection par des remblais artificiels}

Le retour des crues débordantes au cours du Ier s. ap. J.-C. et le fonctionnement de chenaux de crues a rapidement conduit les populations à en accélérer le remblaiement naturel. Plusieurs exemples illustrent ce phénomène.

- lors du changement de tracé de la Saône autour de l'ère, une île s'est formée entre le bras primitif et le nouveau chenal. Ce nouvel espace était intéressant à coloniser mais le chenal résiduel entravait l'installation. Aussi le bras primitif de la Saône, plaqué contre la colline de Fourvière, est-il devenu une zone-dépotoir dès le Ier s. ap. J.-C. Remblaiements naturels et 
archéologiques se sont succédé jusqu'à l'assèchement définitif qui a enfin permis l'occupation de la rive droite de la Saône, nouvellement formée, à la fin du IIIe s. ap. J.-C

(Arlaud et al. 1994b) ;

- sur la place Bellecour, la levée de berge du bras du Rhône a été renforcée par un épais remblai formé de galets et d'amphores flaviennes; il fournissait probablement un axe de circulation privilégiée (Vérot et al. 1989);

- place de la Bourse, la phase terminale de remblaiement naturel du paléochenal a été accélérée par la mise en place d'une couverture d'amphores augustéennes retournées (Arlaud et al soumis) ;

- place de la République - rue Childebert, une zone à topographie déprimée et assujettie aux inondations présente un aménagement d'amphores augustéennes imbriquées en quinconce ; ce dispositif peut correspondre à un gué (Arlaud et Lurol et al 1992) ;

- la plupart des sites de la presqu'île présentent entre les traces d'occupation datées du règne de Tibère et l'occupation claudienne, un remblai caillouteux épais de 30 à $50 \mathrm{~cm}$ qui contribuait probablement à assainir les terrains régulièrement inondés mais aussi à les exhausser afin de les mettre hors de portée du niveau des crues ;

- la partie nord du site des Célestins a connu des inondations tardives. Elle a été remblayée au IIIe s. par un épais dépôt de démolition contenant un important mobilier archéologique, principalement amphorique. De même dans les niveaux d'habitats de la partie sud, plusieurs fosses ont été remblayées avec des amphores et semblent correspondre à des travaux d'assainissement (Arlaud et Lurol, et al 1994).

\section{L'utilisation de la topographie naturelle}

La relative rareté des aménagements réalisés pour lutter contre les inondations dans l'Antiquité peut conduire à relativiser le risque perçu par les habitants ou à considérer que la valeur des biens à protéger ne justifiait pas des travaux coûteux. Les travaux d'exhaussement de la plaine du Rhône à Vienne furent en effet d'une autre ampleur (Bravard et al. 1989). Cependant la proximité des deux cours d'eau offre aussi un potentiel de ressources et des axes de circulation qui ont été valorisés.

- le site de Tolozan en bordure de la rive droite du Rhône a été l'objet d'un enrochement servant d'abri pour bateaux avant la fin du règne de Tibère. Partiellement détruit, il fut renforcé et protégé par des pieux dans la deuxième moitié du Ier s. ap. J.-C. (Becker et al., 1991);

- le fossé des fortifications médiévales est installé sur une topographie naturelle intéressante : une zone déprimée entre Rhône et Saône résultant d'une ancienne lône, au pied du plateau de la Croix-Rousse (Arlaud et al. 1994b) ;

- plus au sud, le pont de la Guillotière, axe privilégié de circulation, fut détruit plusieurs fois par le Rhône, mais reconstruit inlassablement au même endroit (Burnouf et al. 1991).

81 De même, la mise au jour de différents petits aménagements démontre l'utilisation de la ressource en eau: bassins dans l'ancien bras de l'Avenue A. Max (Villedieu, 1990), puits perdus de la place de la République (Arlaud et Lurol et al 1992), etc...

\section{Perspectives et conclusion}

Les contraintes liées aux cours d'eau sont très fortes sur le site de Lyon. Lorsque dans les années 1980, l'archéologie urbaine s'est orientée vers une vision diachronique de la ville, la géomorphologie et les autres disciplines du paléoenvironnement ont trouvé 
une place dans cette perspective en étudiant les processus naturels à l'échelle des sites pour les périodes où des témoignages archéologiques étaient sauvegardés. A une échelle plus vaste, ces études interdisciplinaires ont montré qu'elles pouvaient apporter des informations sur les fluctuations hydroclimatiques à l'Holocène.

Bien que nous n'ayons pu dresser ici le bilan complet des connaissances acquises, nous aimerions ouvrir quelques perspectives sur ce qui reste à réaliser.

- Il manque encore des éléments du puzzle pour restituer les paléotracés du Rhône et de la Saône et leur chronologie. La poursuite des prospections en rive gauche du Rhône, en particulier aux abords du pont de la Guillotière et le long de la voie vers l'Italie.

- Une grande question reste en suspens : tous les sites de la presqu'île, sauf celui des Célestins qui a conservé les traces d'une occupation presque continue, présentent un hiatus dans l'occupation humaine entre les IVe et le XIIe s. Ce hiatus est-il lié à une activité hydrologique trop contraignante qui aurait découragé l'installation du bâti ou à des facteurs purement historiques ? Cette période fut plutôt une période de calme hydrologique entre le Ville et le XIIe s. L'absence de sédimentation naturelle durant 8 à 10 siècles paraissant cependant peu vraisemblable, on n'écartera pas l'hypothèse selon laquelle l'absence de niveaux d'occupation du Haut Moyen Âge pourrait s'expliquer par leur arasement durant l'époque médiévale ; cet arasement aurait aussi affecté les dépôts naturels.

- Les études écologiques faisant appel à l'analyse des pollens, des charbons, des macrorestes sont encore peu développées. Il serait souhaitable qu'à l'avenir elles soient davantage intégrées dans la démarche de reconstitution paléoenvironnementale.

- Un travail en collaboration entre naturalistes et archivistes devrait fournir de nouvelles clés d'interprétation en ce qui concerne l'impact des facteurs naturels sur les comportements humains à partir du Moyen Âge.

Comme on le voit, de nombreuses questions restent encore en suspens, mais l'intégration des problématiques géomorphologiques et archéologiques se renforce et fait évoluer les questions posées. À Lyon comme ailleurs, leur renouvellement sera un des enjeux de la recherche interdisciplinaire des années à venir.

\section{BIBLIOGRAPHIE}

\section{Bibliographie}

Arcelin 1870 : ARCELIN (A.). - Appendice. In : Ferry (H.) (de) : Le Maçonnais préhistorique. Paris, Reinwald éd.

Argant 1993 : ARGANT (J.). - Premières indications sur la végétation lyonnaise à l'Holocène. Symposium Ass. Pal. Langue Fr., sept. 1991, Palynosciences, 2, 57-78.

Arlaud et al. 1994a : ARLAUD (C.), BURNOUF (J.), BRAVARD (J.-R), LUROL (J.-M.), VEROTBOURRELY (A.) et coll. - Lyon Saint-Jean : les fouilles de l'îlot Tramassac, Lyon, Service régional de l'Archéologie, D A R A, n 10, série lyonnaise n 4, 1994, 151 p. 
Arlaud et al. soumis pour publication : ARLAUD (C.) (dir.) en coll. avec LUROL (J.-M.) et VEROTBOURRELY (A.), avec la participation de AUGER-RAHATZOS (M.), AYALA (G.), BERNARDI (B.), BONNET (C.), CECILLON (C.), FOREST (V.),HORRY (A.), LE NEZET-CELESTINS (M.), PLANTEVIN (C.), ROLLAND (M.), SAVAY-GUERRAZ (S.), VICARD (T.) Bourse - République - Célestins - Terreaux, chantiers archéologiques parkings L.P.A., Lyon, D A F, soumis pour publication.

Artaud 1846 : ARTAUD (F.) - Lyon souterrain, ou observations archéologiques et géologiques faites dans cette ville depuis 1794jusqu'en 1836. Lyon, 1846, $259 \mathrm{p}$.

Ayala et al. 1992 - AYALA (G.) avec la coll. de VEROTBOURRELY (A.) - Rue Palais-Grillet : une intervention archéologique au coeur de la presqu'île lyonnaise, R.A.E., Ed. du CNRS, 43, 1992.

Ayrolles et Combier 1976 - AYROLLES (P.) et COMBIER (J.) - Gisement épipaléolithique de Varennes-Lès-Mâcon. LivretGuide de l'excursion A8, Bassin du Rhône, Paléolithique et Néolithique, IXe Congrès UISPP, Nice, pp. 129-133.

Becker et al. 1989 : BECKER (C.) avec la coll. de MACE (S.), MANDY (M.-O.), VICARD (T.), AUGER (M.) - Fouille de la place Antonin Poncet à Lyon «Archéologie du Midi Médiéval II pp. 137-186.

Berger 1996 : BERGER (J.-F.) - Le cadre paléogéographique des occupations du bassin valdainais (Drôme) à l'Holocène. Thèse d'Archéologie, Univ. de Paris I.

Bourdier 1961 : BOURDIER (F.) - Le Bassin du Rhône au Quaternaire, Géologie et Préhistoire. Thèse Sci., Paris, 2 vol., éd. C.N.R.S., 658 p., 297 fig.

Bravard 1987 : BRAVARD (J.-P.) - Le Rhône, du Léman à Lyon. Lyon, La Manufacture éd. 452 p.

Bravard 1996 : BRAVARD (J.-P.) - Des versants aux cours d'eau, les implications des fluctuations paléohydrologiques à l'époque médiévale, ln : L'homme et la nature au Moyen Age, Actes du V ${ }^{\circ}$ Congrès international d'Archéologie Médiévale (Grenoble), sous la dir. de M. Colardelle, Errance, pp. 171-179.

Bravard, 1997 : BRAVARD (J.-P.).-Tectonique et dynamique fluviale postglaciaires à la confluence Saône-Rhône (France). Géographie Physique et Quaternaire, sous presse.

Bravard et Evin, 1989 : BRAVARD (J.-P), EV1N (J.) - Datation du remblaiement holocène dans un secteur de la plaine alluviale du Rhône à Villeurbanne (69). Bull. Labo. Rhod. de Géom., n²3-24, pp. $2-10$.

Bravard et al. 1991 : BRAVARD (J.-P). PEIRY (J. L.), GADIOLET (P.) - La formation de la plaine alluviale holocène du Rhône à l'amont de Lyon. Physio-Géo, n² 22/23, pp. 167-172.

Bravard et al. 1992 : BRAVARD (J.-P.), VEROT-BOURRELY (A.), SALVADOR (P-G.). - Le climat d'après les informations fournies par les enregistrements sédimentaires fluviatiles étudiés sur des sites archéologiques. In : Le climat à la fin de l'âge du Fer et dans l'Antiquité (500BC-500AD), méthodes d'approches et résultats. Les Nouvelles de L’Archéologie, n 50, Hiver 1992, pp. 7-13.

Burnouf et al. 1991 : BURNOUF (J.), GUILHOT (J.O.), MANDY (M.-O.), ORCEL (C.) - Le Pont de la Guillotière. Franchir le Rhône à Lyon. DARA n 5, Série Lyonnaise n 3, Lyon, S.R.A. en Rhône-Alpes, $196 \mathrm{p}$.

Campy et al. 1994 : CAMPY (M.), BICHET (V.), DI GIOVANNI (C.), RICHARD (H.), RICHARD (J.), OLIVE (P.) - Evolution des flux de matière depuis 12000 ans dans la haute vallée du Doubs (France). Bull. Soc. Géol. France, t. 165, n 4, pp. 381-400.

Combier et Floss, 1994 : COMBIER (J.), FLOSS (H.) - Nouvelles recherches sur le Paléolithique final de Varennes-Lès-Mâcon (Saône-et-Loire). Travaux de l'Institut de Recherche du Val de SaôneMâconnais, nº 1, pp. 77-99. 
David, Méon-Vilain, 1964 : DAVID (L.), MEON-VILAIN (H.) - Sur un bras du Rhône post-würmien à Lyon et sur les conditions climatiques au moment de son remblaiement. C.R. Somm. Soc. Géol. France, 10, pp. 426.

Desbat 1982 : DESBAT (A.) - Lyon et ses fleuves dans l'Antiquité. In : Lyon au fil des fleuves, Catalogue ELAC, 1982, pp. 29-37.

Desbat 1996: DESBAT (A.) - Les productions des ateliers de potiers antiques de Lyon, les ateliers précoces. Gallia, 53,1996, 249 p.

Germain 1911 : GERMAIN (L.). - Etudes sur les mollusques terrestres et fluviatiles de quelques formations quaternaires des bassins du Rhône et du Rhin. Lyon, H. Georg éd., 194 pp.

Jorda 1980 : JORDA (M.). - Morphogenèse et évolution des paysages dans les Alpes de Haute Provence depuis le Tardiglaciaire : facteurs naturels et facteurs anthropiques. Bull. Assoc. Géog. Franc., n 472, 1980, pp. 295-304.

Jorda 1985 : JORDA (M.). - Le Dryas récent : une crise morphoclimatique majeure dans les Alpes françaises du Sud, Studio Geomorphologica Carpatho-Balcanica, pp. 11-28.

Jorda 1988 : JORDA (M.). - Du Pléniglaciaire supérieur au Postglaciaire : le concept de Tardiglaciaire européen et son évolution récente. Géologie Alpine, pp. 241-249.

Lascoux 1994 : LASCOUX (J.-P.). - La TAC Charavay. Mémoire de Maîtrise, sous la dir. de Y. Le Bohec, Univ. Lyon II, 1994.

Locard 1882 : LOCARD - Notice sur la contribution géologique du sous-sol de la ville de Lyon considéré du point de vue du régime hydrographique. Lyon, H. Georg éd., 24 p.

Macé et al. 1991 : MACE (S.), VEROT-BOURRELY (A.), BRAVARD (J.-P.). - Genèse et fonctionnement holocène de la plaine alluviale du Rhône à Lyon. Actes du 115è Congrès. Nat. Soc. Sav., Chambéry, éd. du C.T.H.S., 1991, pp. 17-31.

Magny 1995 : MAGNY (M.). - Une histoire du climat. Paris, Errance, 176 p.

Mandier 1988 : MANDIER (P.). - Le relief de la moyenne vallée du Rhône au Tertiaire et au Quaternaire. Doc. du B.R.G.M. $\mathrm{n}^{\circ} 151,3$ tomes.

Rosique 1996 : ROSIQUE (T.). - Morphogenèse et évolution des paléoenvironnements alpins de la fin des Temps glaciaires au début de l'Holocène : l'exemple de la moyenne Durance (Alpes françaises du Sud). Thèse de Géographie, Univ. de Provence, 288 p.

Russo et Audin 1961 : RUSSO (Ph.) et AUDIN. (A.). - Le site de Lyon. Panorama de son évolution. Revue de Géographie de Lyon, pp. 295-346.

Russo et Audin 1964 : RUSSO (Ph.) et AUDIN. (A.). - Histoire ancienne de Lyon. Lyon. Audin, 1964. $64 \mathrm{p}$.

Steyert 1895 : STEYERT (A.). - Nouvelle histoire de Lyon, tome 1 "L’Antiquité", Lyon, 1895.

Vérot et al. 1989 : VEROT (A.), JACQUET (C.), BURNOUF (J.), AMOROS (C.), BRAVARD (J.-P.) - Le site galloromain de la place Bellecour (Lyon 2ème) : reconstitution interdisciplinaire du paléoenvironnement, La ville et le fleuve, Actes du 112e Congrès Nat. Soc. Sav., pp. 147-155, Lyon, avril 1987, Paris, éd. du C.T.H.S.

Vérot-Bourrély 1995 : VEROT-BOURRELY (A.) : Aspects du paléo-environnement In : DELAVAL (E.), BELLON (C.), CHASTEL (J.), PLASSOT (E.), TRANOY (L.) : Vaise, un quartier de Lyon antique. D.A.R.A. $\mathrm{n}^{\circ}$ 11, série lyonnaise $\mathrm{n}^{\circ}$ 5, Lyon, S.R.A. en Rhône-Alpes, pp. 257-259. 
Vérot-Bourrély 1995 : VEROT-BOURRELY (A.), ARGANT (J.), BRAVARD (J.-P), CHAIX (L.) avec la coll. de BELLON (C.), PLANTEVIN (C.), BURNOUF (J.). - Le paléo-environnement du site de Gorgede-Loup (Lyon, $9^{\mathrm{e})}$ : Les signes matériels de la dégradation d'après l'étude interdisciplinaire du gisement. In : S. VAN DER LEEUW (ed.) : L'Homme et la dégradation de l'environnement, Actes des XVe Rencontres internationales d'Archéologie et d'Histoire d'Antibes des 20-21-22 oct, 1994, APDCA, Sophia Antipolis, pp. 43-77.

Villedieu 1990 : VILLEDIEU (F.) - Lyon, Saint-Jean, les fouilles de l'avenue Adolphe Max, DARA n 3, Archéologie et Métropolitain, série lyonnaise n² 2. Lyon, S.R.A.en RhôneAlpes,.

\section{Documents}

Arlaud et al. 1994b : ARLAUD (C.) (dir.), Le NEZETCELESTINS (M.), ROLLAND (M.), SAVAYGUERRAZ (S.), VEROT-BOURRELY (A.), VICARD (T.) avec la coll. de AUGER-RAHATZOS (M.), BONNET (C.), CECILLON (C.), DAGUIN (P.), FOREST (V.), HALITIM (N.), HAMMACHE (M.), KOVATCHEVITCH (C.), PLANTEVIN (C.), PONSERO (C.), PONT (F.), REYNAUD (C.) - Place des Terreaux, Lyon 1991-1994, Document Final de Synthèse, S.R.A.en Rhône-Alpes, AFAN, Lyon Parc Auto, 1 vol. texte, 1 vol. planches, 1 vol. annexes, 1 vol. archives de fouilles et inventaires.

Arlaud et Lurol et al. 1991 : ARLAUD (C.) (dir.) et LUROL (J.-M.) avec la coll. de : AUGERRAHATZOS (M.), AYALA (G.), CECILLON (C.), FOREST (V.), HAMMACHE (M.), HORRY (A.), PLANTEVIN (C.), R1CORDEAU (Y.), SAVAY-GUERRAZ (S.), VEROT-BOURRELY (A.), WAVRIN (L.) et la contribution de AUDRA (A.), CLARET (B.), MATHEY (P.) et POISSON (J.-M.) - Chantier Archéologique. Place de la Bourse, Lyon 1990. Rapport de fouille de sauvetage, S.R.A. en Rhône-Alpes, AFAN, Lyon Parc Auto.

Arlaud et Lurol et al. 1992 : ARLAUD (C.) (dir.) et LUROL (J.-M.) avec la coll. de : AUGERRAHATZOS (M.), AYALA (G.). BERTRAND (E.), CECILLON (C.), FOREST (V.), HAMMACHE (M.), HORRY (A.), PLANTEVIN (C.), SAVAY-GUERRAZ (S.), VEROT-BOURRELY (A.) - Chantier Archéologique. Place de la République, Lyon 19911992, Document final de synthèse, S.R.A., AFAN, Lyon Parc Auto.

Arlaud et Lurol et al. 1994 - ARLAUD (C.) (dir.) et LUROL (J.-M.) avec la coll. de : AUGERRAHATZOS (M.), BONNET (C.), CECILLON (C.), FOREST (V.). HAMMACHE (M.), HORRY (A.), PLANTEVIN (C.), ROLLAND (M.), BERNARDI (B.) et VEROT-BOURRELY (A.) - Chantier Archéologique, Place des Célestins, Rapport de fouille de sauvetage, S.R.A. en Rhône-Alpes, AFAN.

Becker 1982 : BECKER (C.). - Sondages du kiosque Bellecour. Lyon 2ème. Rapport du S.A.M. de la ville de Lyon.

Becker et al. 1991 : BECKER (C.), MACE (S.). - Fouille de la place Tolozan. Rapport du S.A.M. de la ville de Lyon.

Bellon et al. 1994 : sous la dir. de BELLON (C.), FRANC (O.), GENIN (M.), PERRIN (F.), DE SURY (B.), THEVENIN (E.), FELLMANN (D.). - « Horand II, 93 », lot 5 immeuble A et B. Document final de synthèse, S.R.A., Lyon, Rhône-Alpes, 1994.

Franc 1993a : FRANC (O.). - Extension métro ligne D, suivi géomorphologique des terrassements rue Sergent Berthet. S.R.A.en Rhône-Alpes, S.A.M. de la ville de Lyon, Centre de Recherche en Géographie et Aménagement (Lyon III). S.R.A., Lyon. Rhône-Alpes, 1993.

Franc 1993b : FRANC (O.). - Place de Paris, extension métro ligne D, suivi géomorphologique du décapage des couches sédimentaires profondes. Centre de Recherche en Géographie et Aménagement, 
Université J. Moulin (Lyon III). 12 p. S.A.M. de la ville de Lyon et S.R.A.en RhôneAlpes, Janvier 1993.

Franc 1996 : FRANC (O.). - Histoire sédimentaire d'un versant occupé par l'homme à l'Holocène à Vaise (Lyon-9e are). Document final de synthèse, S.R.A., Lyon, RhôneAlpes, 70 p., fig., ann., tome 1 \& 2, 1996.

Jacquin et al. 1984 : JACQUIN (L.), BECKER (C.), MONIN (M.) avec la coll. de BRAVARD (J.-P.). Ilôt 24, 7-911 rue de la Monnaie. S.R.A. en Rhône-Alpes, S.A.M. de la Ville de Lyon.

Lascoux et al. 1994 : LASCOUX (J.-P.), JACQUET (P.), NOURISSAT (S.), WIDLACK (W.).-ZAC SaintVincent Lyon. Document final de synthèse. Vol. 1-Synthèse, vol. 2 - Corpus, S.R.A. en Rhône-Alpes., A.F.A.N.

Le Nezet-Célestin 1993 : LE NEZET-CELESTINS (M), MONNOYEUR-ROUSSEL (V.), PLASSOT (E.). Avec la participation de : AUDRA (A.), BILLARD (M.), BONNET (C.), BROUILLAUD (S.), FRANC (O.), GISCLON (J.-L), HAMMACHE (M.), KOVATCHEVITCH (C.), MATHEY (P.), PLANTEVIN (C.), ROLLAND (M.), RUF (D.). - Place Valmy fouille de la future station de métro Lyon-Vaise. S.A.M. de la Ville de Lyon, S.R.A., AFAN, SYTRALSEMALY. Rapport déposé au S.R.A., Lyon, Rhône-Alpes, 1992-1993. 303p.

Marchianti et al. 1992 : MARCHIANTI (D.) avec la coll. de FRANC (O.).-Sondages archéologiques Place Gailleton, Lyon 2ème, S.R.A.en Rhône-Alpes, S.A.M. de la Ville de Lyon. 34 p.

Monin, 1988 : MONIN (M.).-44, rue de la Madeleine, îlot du Repos. Rapport déposé au S.A.M. de la Ville de Lyon., 8 p.

Monin et al. 1986 : MONIN (M.) avec la collaboration de BRAVARD (J.P.) - Facultés catholiques, 25 rue du Plat, Lyon. Rapport du S.A..M. de la Ville de Lyon.

Monin et al. 1995 : MONIN (M.), AYALA (G.), HORRY (A.), avec la participation de ARGANT (J.), AUDRA (A.), PLANTEVIN (C.), VEROT-BOURRELY (A.). - 10, rue Marietton, 69009 Lyon, Document final de synthèse, site n²7097, S.R.A. en Rhône-Alpes, S.A.M. de la Ville de Lyon, AFAN.

Monnoyeur et al, 1992 : MONNOYEUR ROUSSEL V. (dir.) avec la collaboration de AUDRA (A.), AYALA (G.)., BERNARDI (P.), BRAVARD (J.-P), CLARET (B.), FRANC (O.) POISSON (J.-M.), VEROTBOURRELY (A.), - Lyon, Ilot Clément $V$, Rapport de fouille de sauvetage, S.A.M. de la Ville de Lyon et S.R.A. en Rhône-Alpes, 1 vol. texte, 1 vol. doc..

Raynaud 1991 : RAYNAUD (F.), HAMMACHE (M.), MACE (S.), PICLET (C.), TISSOT (C.) - Fouilles de sauvetage programmé. Opéra de Lyon, Rapport du S.A.M. de la Ville de Lyon. 


\title{
Milieu et sociétés dans la vallée des Baux
}

\author{
Philippe Leveau
}

1 Les travaux de géoarchéologie dans la vallée des Baux ont leur origine dans une collaboration nouée en 1986 à Aix-en-Provence entre archéologues travaillant sur la période historique et environnementalistes. Elle avait débuté dans le cadre de l'Action Thématique Programmée, «Histoire de l'environnement et des Phénomènes Naturels »: deux contrats ont ainsi été successivement obtenus dans la région de l'Etang-de-Berre. Des programmes de Prospections/Inventaire ont été conduits en collaboration avec le Service Régional de l'Archéologie de PACA (Leveau 1993a). Ces programmes ont toujours été conçus en relation avec une réflexion sur l'archéologie de sauvetage. De ce fait notre équipe est intervenue dans la vallée des Baux, à partir de 1989, à l'occasion d'une opération d'archéologie de sauvetage occasionnée par la construction d'un golf à Mouriès. Cette collaboration s'est poursuivie dans le cadre d'une fouille programmée au vallon des Arcs à Fontvieille puis aux pieds des Moulins de Barbegal. Très logiquement ces deux expériences ont débouché sur un programme de recherche sur l'Holocène englobant tout le bassin versant. La vallée des Baux présentait l'avantage d'offrir un schéma de fonctionnement bien renseigné ; ses caractéristiques de dépression fermée laissait espérer l'existence de séquences lisibles couvrant l'Holocène; des faits culturels et des événements majeurs du point de vue historique permettaient d'établir une relation précise entre la "pression anthropique » et la constitution des dépôts. Enfin, dans la mesure où la dépression fermée est une unité paysagère caractéristique du milieu méditerranéen, il était possible de donner à cette recherche une dimension plus large, pour y réaliser la combinaison des approches archéologique et environnementaliste. 


\section{La vallée des Baux, le cadre naturel et l'histoire récente}

\section{Le milieu}

Proche d'Arles, la vallée des Baux est une micro-région de la Provence rhodanienne qui appartient à la série des dépressions fermées qu'a étudiée Paul Ambert (Ambert 1992) (fig. 1, 2). Par ailleurs cette cuvette et son bassin d'alimentation juxtaposent trois unités paysagères caractéristiques du milieu méditerranéen. Au nord, en position dominante, les Alpilles, petit massif calcaire, constituent un château d'eau dont les ressources ont été largement exploitées dans l'Antiquité. Les collines en roches tendres du versant sud. les sols et les formations pléistocènes hérités nourrissent des apports sédimentaires qui aboutissent dans la dépression. Au sud, s'étend le plateau de Crau formé par des épandages pléistocènes d'une paléo-Durance. Les cailloutis perméables qui le constituent sont à l'origine d'un paysage désertique et d'un mode de mise en valeur longtemps essentiellement pastoral. Au centre, la vallée des Baux, elle-même, communique mal avec la vallée du Rhône et la zone deltaïque située immédiatement à l'aval; elle en est séparée par un étroit goulet. Définie par la topographie comme une forme en creux, située très approximativement en dessous de la courbe de niveau des $20 \mathrm{~m}$, l'érosion quaternaire y a déblayé une série de rides et de multiples cuvettes; l'alluvionnement les a partiellement comblés et les parties les plus basses se situent encore entre 1 et $3 \mathrm{~m}$ au dessus du 0 NGF. En l'absence de réseau hydrographique organisé, on observe une multitude d'écoulements plus ou moins diffus.

1- Localisation de la zone d'étude

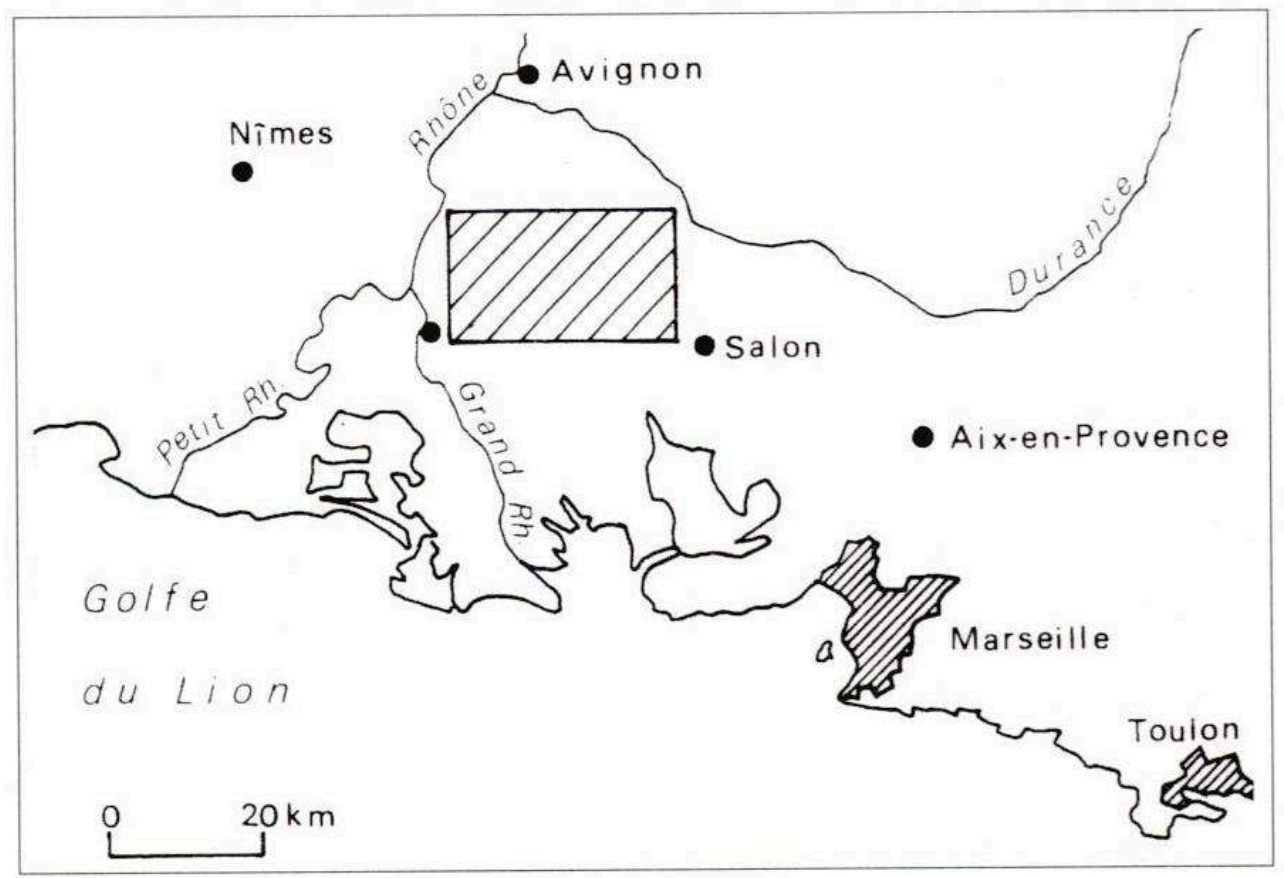


2- Les cuvettes endoréiques du pourtour du Golfe du Lion (d'après Ambert 1992)

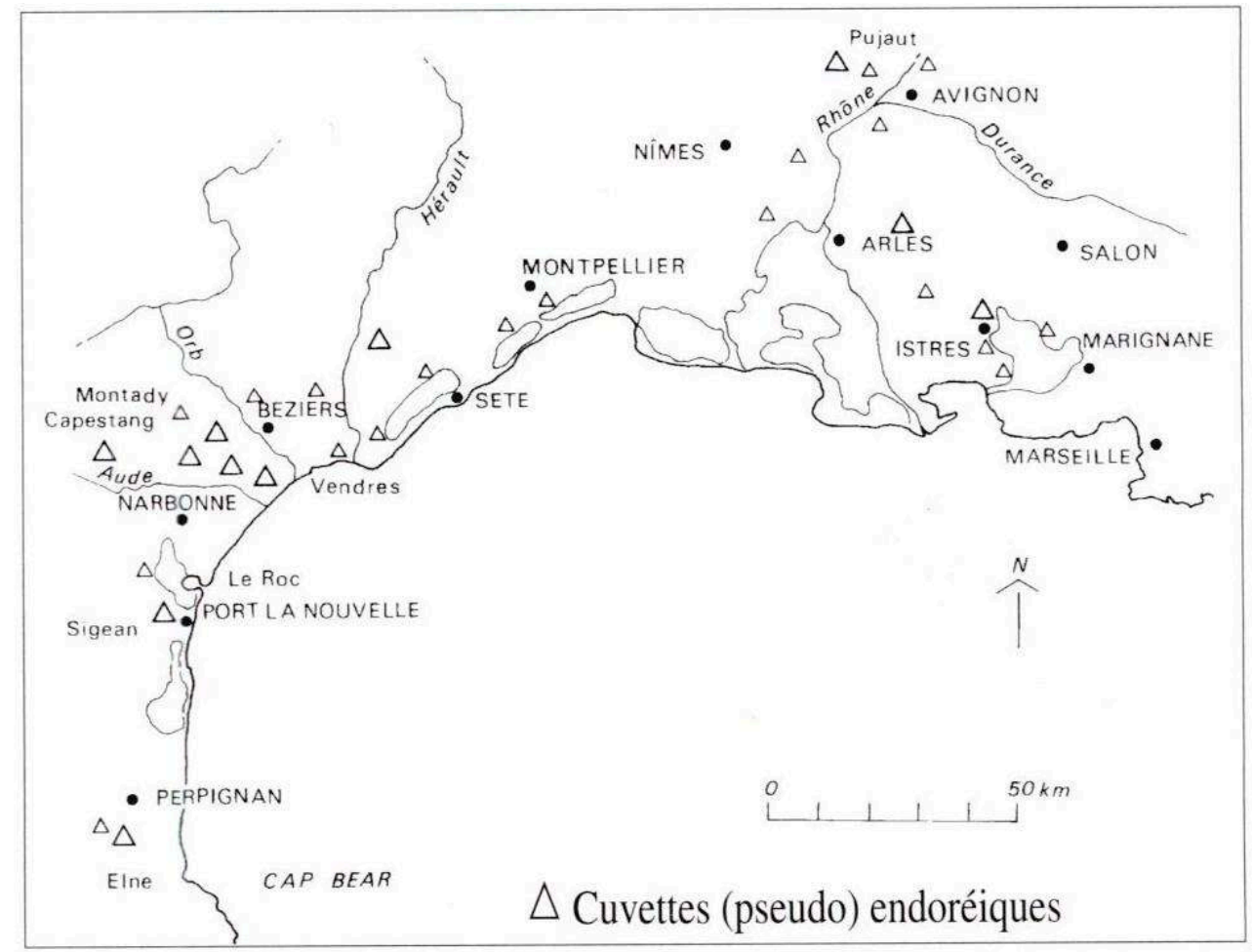

LA CUVETTE DES BAUX SE TROUVE AU NORD D'ARLES

\section{Le problème hydrologique dans la vallée des Baux}

3 La vallée des Baux est actuellement couverte de cultures, mais une nappe d'eau en occuperait le fond si les eaux n'étaient pas évacuées par pompage dans un canal qui rejoint la mer après un parcours parallèle au Rhône. L'aménagement actuel des marais des Baux en "polder» est considéré comme une application heureuse en zone méditerranéenne d'un mode de mise en valeur plus largement développé dans les régions septentrionales (fig. 3). Actuellement avec des précipitations se situant aux environ de 500 à $600 \mathrm{~mm}$ par an et une évaporation qui atteint le double (1 $200 \mathrm{~mm}$ par an), le bilan hydrique est négatif. La tendance naturelle serait donc l'assèchement du bassin. La présence d'une nappe d'eau affleurante est due à sa position en contrebas des eaux de ruissellement du massif des Alpilles et à l'apport de la nappe de Crau (que grossissent les apports du canal de Craponne) et aux difficultés du drainage naturel vers le Rhône. 


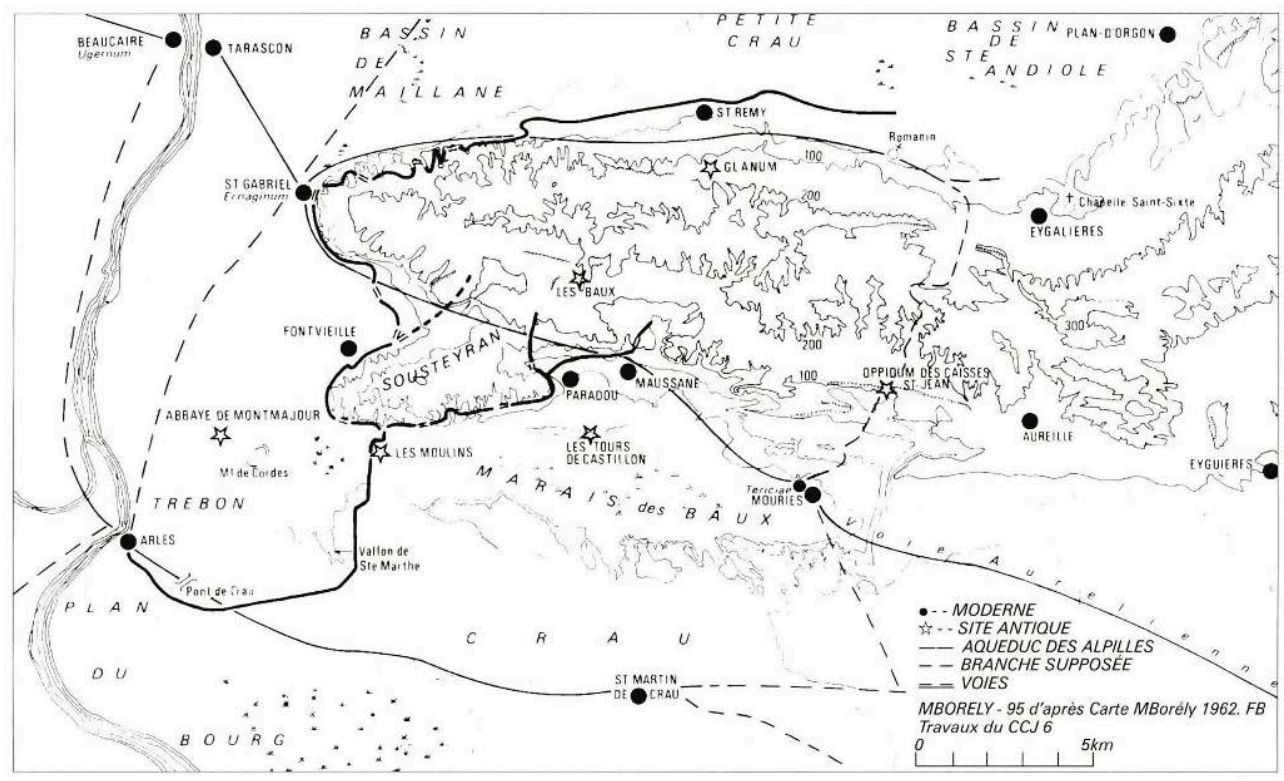

SITUÉ ENTRE LA PLAINE DE CRAU AU SUd ET LE CHAÎNON DES ALPILLES AU NORD, LE MARAIS DES BAUX OCCUPE UNe ZONE dÉPRIMÉE dont les POINTS Les PLUS BAS SE SITUENT À PEINE AU-DESSUS DU 0 NGF. TOUT AU NORD, LES ALPILLES DOMINENT LA PLAINE DE LA DURANCE. LES DEUX ZONES MARÉCAgEUSES de MAILlANE ET DE SAINT-ANDIOL SONT SÉPARÉES PAR LA PETITE-CRAU

4 Les aménagements jouent un rôle important: l'été, l'inondation est entretenue artificiellement par les irrigations : depuis le XVIe s., le canal de Craponne et, depuis la fin du XVIIIe s., celui de Boisgelin conduisent de la Durance vers Arles des eaux d'irrigation chargées de sédiments ; elles irriguent le piémont sud des Alpilles et la Crau et sont en partie récupérées dans le fond de la vallée. Ces canaux ont complètement modifié un hydrosystème dont les prolongements doivent être cherchés, au-delà de la Crau, jusque dans le bassin de la Durance. Déjà, à l'époque romaine, des aqueducs réalisaient des transferts d'eau dont l'importance n'était pas négligeable (Vaudour 1991). Les principales sources du versant sud et des venues d'eau artésiennes (Mas de la Dame) étaient captées par les hydrauliciens romains.

\section{Occupation du sol et carte archéologique}

5 Le choix de cette micro-région pour une recherche pluridisciplinaire s'explique par la richesse de son patrimoine archéologique et historique. Une série de sites importants y constituent autant de "marqueurs" pour l'étude des différentes phases de son histoire : ce sont les monuments funéraires dits « hypogées» de Fontvieille dont le plus récent est daté du Chalcolithique, les moulins romains de Barbegal et le château des Baux. Mais les recherches bibliographiques et les premières vérifications de terrain en cours ont montré qu'à côté de ces sites majeurs existaient une série de sites qui, en plus grand nombre que l'on pouvait espérer, jalonnaient l'histoire de l'occupation de la vallée des Baux durant l'Holocène. Une enquête a permis à M. Gazenbeek de proposer une carte archéologique qui, déposée au Service régional de l'Archéologie de PACA, a servi au fichier DRACAR (Gazenbeek 1995).

L'ensemble des monuments funéraires de la fin du Néolithique et du Chalcolithique que l'on regroupe sous la dénomination impropre mais consacrée d'hypogées de Fontvieille 
comprend en réalité des monuments mixtes constitués de longues tranchées couvertes d'énormes dalles. Au sein d'un mégalithisme provençal qui appartient à la même «province » que celui du Languedoc, ils se distinguent par leur taille : la centaine de sépultures connues ailleurs sont pour la grande majorité de petites dimensions. Distincts des deux autres types de dolmens qu'a définis G. Sauzade (Sauzade 1990), les dolmens de type alpin et les dolmens à couloir de Provence orientale -, ils se caractérisent par une longue chambre funéraire, à parois latérales en pierre sèche, de forme trapézoïdale, aménagée dans une fosse creusée préalablement. A l'intérieur de cette série, les hypogées du Castellet sont remarquables par leur gigantisme : creusé dans la molasse, celui de la grotte des Fées (dite aussi Épée de Roland) est un ensemble complexe dont la longueur atteint $44 \mathrm{~m}$. Pour expliquer cet ensemble, on a invoqué des facteurs écologiques: la présence de petites éminences rocheuses, la nature et la qualité de la roche (molasse). Depuis le siècle dernier, on les imaginait dans un paysage noyé par les eaux d'où émergeaient les quelques reliefs sur lesquels ils sont situés, cet isolement géographique et une situation de «bout du monde » servaient d'explication : dans de nombreuses sociétés, l'isolement géographique et donc la faiblesse des apports extérieurs, - l'insularité à Malte, en Sardaigne et aux Baléares - auraient favorisé l'apparition de créations architecturales mégalithiques originales.

7 D'une manière générale, les cartes de répartition des sites du Néolithique moyen et final, du Chalcolithique et de l'âge du Bronze privilégiaient évidemment les marges de la zone endoréique actuelle des marais des Baux et les bas de pente. Mais, à partir du moment où les résultats de nos recherches remettaient en question la permanence de l'inondation, il devenait indispensable de reprendre les prospections dans les zones basses afin de vérifier l'absence de l'habitat préhistorique. L'accumulation de sédiments postérieurs masquait les vestiges préhistoriques. Or les prospections réalisées par M. Gazenbeek lui ont montré qu'il n'en était rien: d'une part les recouvrements actuels masquaient une topographie différenciée; d'autre part, les sites funéraires s'intègrent à une série longue et nourrie de gisements appartenant au Néolithique et à la Protohistoire ancienne.

8 La richesse des séries archéologiques concernant l'âge du Fer et la période galloromaine n'est pas moins grande. La trentaine de sites connus se répartit sur l'ensemble de la région, mais là encore il faut observer que seuls certains secteurs ont été prospectés de façon systématique. Comme dans le reste du Midi Méditerranéen, la période de l'âge du Fer est caractérisée par la présence d'agglomérations de hauteurs, les oppida : à l'ouest, le Mont des Cordes qui est doté d'un rempart (Bourilly 1911) et le Castellet où les premières installations étendues remontent peut-être au premier âge du Fer (VIIe au VIe s. av. J.-C.) et se poursuivent jusqu'à l'abandon au IIe s. avant notre ère (Poumeyrol 1953); au centre, les Tours-deCastillon (Tréziny 1987-1988) ${ }^{1}$ et le Castellas de Maussane (Treziny 1990) qui encadrent le bassin de Maussane/Paradou ; à l'est, les Caisses de Mouriès, site occupé dès le premier âge du Fer (l'oppidum des Caisses et le site de Servanne en bas de pente). Il existe en outre un ensemble funéraire et cultuel du Ier s. avant notre ère à la fontaine de l'Arcoule, une des sources captées par l'aqueduc romain au sud des Al pilles entre Paradou et les Baux.

9 À l'époque romaine, la vallée des Baux est dans la dépendance de la colonie romaine d'Arles fondée dans les années 40 av. J.-C. A son extrémité occidentale, la vallée était franchie par le grand pont de l'aqueduc qui, à l'époque augustéenne sans doute, amena à Arles l'eau des Alpilles. A proximité de ce point de franchissement se trouvent les 
célèbres moulins romains de Barbegal que l'on, datait de la fin de l'Antiquité, jusqu'aux fouilles récentes (Leveau 1995a). Le grand itinéraire de liaison, la Voie Aurélienne, passait au nord, entre les Alpilles et la vallée. D'après une tradition dont $\mathrm{F}$. Benoit s'est fait l'écho (Benoit 1940), tout le pays autour d'Arles était inondé et les relations étaient assurées par des radeaux. A proximité de la chapelle Saint-Gabriel, où est localisé le site à'Ernaginum, on montre l'endroit où abordaient des embarcations légères. Cette vision a été complètement remise en question par les fouilles qui ont montré d'une part que les moulins dataient vraisemblablement de l'époque d'Hadrien (IIe s.) et avaient fonctionné comme établissement à caractère industriel jusque dans les années 270 et qui d'autre part - nous l'avons vu - ont remis en question l'image que l'on avait du paysage antique. Pas plus qu'aux temps préhistoriques, la vallée des Baux n'était un bout de monde à l'époque romaine. A proximité des moulins existait un habitat important : des monuments funéraires ont été démontés pour consolider les aqueducs dans la dernière période de leur utilisation; au second siècle, une villa contemporaine des moulins était implantée à proximité du mas de la Mérindole, quelques centaines de mètres à l'est des moulins. Elle devait comporter une partie résidentielle, mais surtout une de ses annexes appartient à la série des entrepôts à dolia des villae viticoles connue en Provence. A proximité, les fouilles réalisées par Peter Bellamy et Bruce Hitchner ont révélé la présence d'un cimetière daté des VIIe-VIIIe s. (Bellamy 1996). Le site de la Mérindole n'est pas isolé : les prospections réalisées par M. Gazenbeek ont confirmé la présence de traces d'une occupation antique de la vallée: elle n'avait fait l'objet d'aucune recherche dans la mesure où la permanence de l'inondation la rendait invraisemblable.

Au-dessus de la vallée, au pied du massif des Défends de Sousteyran et d'une manière générale des collines du piémont sud des Alpilles, les prospections réalisées le long de l'aqueduc romain avaient montré l'apparition de nouveaux sites durant le IVe s. et la réoccupation de certains sites abandonnés à la fin de la période protohistorique. A quelques kilomètres de là, près de l'église paroissiale de Paradou, Saint-Martin, mentionnée depuis la fin du Xe s. dans les textes, une série de fouilles d'urgence ont permis de suivre la continuité de l'occupation du sol depuis l'époque où fut créée la piste qui précéda la voie Aurélienne, jusqu'à la fin de l'Antiquité et durant le haut Moyen Âge.

11 La période médiévale est connue grâce à plusieurs sources écrites majeures: les cartulaires des abbayes de Saint-Paul-de-Mausole, de Montmajour et de Saint-Victor de Marseille ainsi que les recueils de Gallia Christiana Novissima pour les diocèses d'Arles et d'Avignon et le recueil des chartes de la Maison des Baux. Malgré leur caractère lacunaire, ces documents permettent d'étudier la répartition spatiale des églises et des chapelles rurales puis des villae (au sens pris par le mot à l'époque médiévale) qui structurent le paysage. Cependant les textes ne sont suffisamment nombreux qu'à partir du IXe s., voire du Xe s. Grâce à l'identification des céramiques à cuisson réductrice, essentiellement kaolinitiques, la prospection a commencé à apporter d'utiles indications sur la présence d'habitations durant le Haut Moyen Âge près de chapelles rurales, en des lieux isolés, mais aussi et d'abord sur les sites à'oppida protohistoriques ou à leurs abords (Castellet, Tours-de-Castillon, Mont des Cordes). La présence de lieux habités au Moyen Âge est également révélée par la présence d'un parcellaire concentrique fossile, ainsi autour de Barbegal et sans doute ailleurs dans la vallée. A côté des occupations médiévales bien attestées sur les sites fortifiés des Baux ou du Montpaon. on en connaît en zone basse (Saint-Martin à Paradou, Saint-Roman à 
Fontvieille), autour du marais ou plus rarement sur des points élevés au milieu de celuici. Au Moyen-Age, le marais n'était pas en effet un lieu désert: il était parcouru de canaux, on y péchait et on y ramassait des plantes; les troupeaux y descendaient durant la saison sèche et ses parties les plus hautes étaient alors mises en culture ${ }^{2}$.

Les premières grandes tentatives de drainage débutent aux Temps Modernes; elles sont liées à la pénétration du pouvoir royal : une délégation de la ville d'Arles vint rencontrer Louis XIII à Lunel et obtint l'envoi de l'ingénieur hollandais Van Ens. Le pouvoir royal était seul en effet en mesure de vaincre la force de résistance des pouvoirs locaux et de financer l'opération. Les travaux qui débutèrent dans la région d'Arles, durent tenir compte des intérêts divergents des trois communautés politiques qui se partageaient la région : au nord, la ville de Tarascon qui voulait évacuer les eaux arrivant des Alpilles par le bassin de la Duransole, au sud ; la vallée des Baux qui voulait se débarrasser des eaux reçues d'un bassin versant incluant le versant sud des Alpilles ; à l'ouest, la ville d'Arles qui souhaitait protéger ses terroirs agricoles contre ces arrivées d'eau et contre les inondations du Rhône. L'oeuvre de Van Ens a été louée à juste titre: les marais d'Arles et de Tarascon furent asséchés (Waton-Chabert 1963). Mais l'oeuvre de l'ingénieur fut éphémère. Dès la fin du XVIIe s., ses travaux se dégradèrent. Le dessèchement de la vallée des Baux fut le premier abandonné et les ouvrages réalisés détruits lorsque le Prince de Monaco, qui avait reçu la seigneurie des Baux, annula les privilège consentis à Van Ens.

\section{Sites archéologiques et évolution du milieu}

13 Les problématiques "paysagères" et géoarchéologiques qui ont pris une place essentielle dans les recherches sur la vallée des Baux ont commencé à émerger il y a une dizaine d'années: le problème de l'enfouissement des structures archéologiques fut posé à l'occasion d'une fouille de sauvetage dont les résultats avaient incité à développer la collaboration entre archéologues et environnementalistes.

\section{Les caisses de Servanne à Mouriès et l'érosion dans les Alpilles}

14 La première intervention conjointe entre archéologues et géomorphologues a porté sur le site de Servanne à Mouriès. Situé au pied d'une crête calcaire portant l'important oppidum des Caisses, le vallon de Servanne faisait l'objet d'un aménagement pour un golf. Une fouille de sauvetage dirigée par R. Royet avait mis au jour un petit groupement de maisons en pied de pente. Daté de l'Age du Fer, ce site (un hameau ?) avait connu deux périodes d'occupation, l'une du VIe au Ve s. av. J.-C. et l'autre aux IleIer s. av. J.-C. Or sous une topographie d'apparence régulière, des tranchées avaient révélé l'existence d'un paléotalweg profond de plusieurs mètres, fossilisé par des dépôts torrentiels puis colluviaux. Dans le remplissage, le matériel archéologique contenu avait permis de distinguer deux dépôts torrentiels dont le premier correspondait à la période située entre les deux occupations. Le village de la fin de l'âge du Fer s'était installé sur un talweg qui ne fonctionnait plus. Le comblement de la gouttière subsistante avait été achevé par une nouvelle arrivée torrentielle, postérieure à la période antique.

15 L'interprétation de ces données en terme de géomorphologie avait été réalisée par M. Jorda et M. Provansal (Jorda 1991). La formation torrentielle suggérait qu'à l'âge du Fer, 
les conditions climatiques étaient différentes de celles d'aujourd'hui: un régime pluviométrique caractérisé par des précipitations plus intenses provoquait des écoulements à forte compétence. Cette situation climatique n'était susceptible d'engendrer les modifications visibles du modelé que parce qu'elle s'exerçait sur des sols fragilisés par une exploitation agricole liée à la présence d'une agglomération paysanne importante et sans doute en croissance démographique. Ils observaient d'autre part que l'occupation d'époque romaine, bien que vraisemblablement plus intense, n'avait pas engendré de crise érosive comparable : on ne pouvait lui attribuer que des effets limités dus à des ruissellements diffus mobilisant des colluvions. Il convenait donc de rechercher la cause première de la réduction des écoulements torrentiels dans une moindre abondance et une meilleure répartition des pluies.

16 Cet exemple qui montrait assez clairement l'intérêt d'une réflexion sur l'évaluation des paramètres bioclimatiques et des pratiques sociales, fut vérifié et complété par d'autres interventions parmi lesquelles on retiendra celle qui fut réalisée sur le site galloromain de la Grande-Terre à Maussane.

\section{Les fouilles de Barbegal et la question de la paludification (lac, marais et paluds)}

17 La fouille de sauvetage des Caisses de Servanne à Mouriès attirait l'attention sur les origines climatiques et anthropiques des changements du modelé sur le versant sud des Alpilles. Quelques années plus tard, les fouilles de Barbegal apportèrent des nouveautés sur l'évolution de la dépression elle-même. L'opération avait eu pour origine le souhait manifesté par les collectivités locales en faveur d'une reprise des activités archéologiques sur le site prestigieux des Moulins de Barbegal. L'un de ses objectifs était de dater le monument en effectuant des sondages dans une zone épargnée par la fouille de F. Benoit. Lorsque dans les années 1940 en effet, celui-ci avait dégagé le monument, il avait fait porter son effort sur le dégagement des chutes qui s'étageaient sur le flanc sud du chaînon de la Pêne et avait arrêté ses investigations au niveau du chemin qui longeait le pied de pente. On pouvait espérer que, dans le fossé d'écoulement des eaux des moulins, seraient conservés des dépôts correspondant à la dernière période de fonctionnement de l'usine et que le matériel céramique charrié permettrait de préciser la chronologie du monument.

Menée en 1992 et 1993, l'opération amena les résultats attendus. Mais elle conduisit aussi à revoir complètement l'histoire de la dépression. Elle mit en évidence la superposition de trois couches constituées de dépôts correspondant à trois phases de fonctionnements de la vallée des Baux dans ce secteur (Leveau 1995a). La constitution de la couche supérieure nous renvoyait à l'histoire la plus récente de la dépression. Par leur couleur, leur texture et leur malacofaune, les sédiments qui la constituent montraient qu'elle s'était déposée dans une nappe d'eau permanente, celle qui occupait le fond de la vallée à la fin du Moyen Âge et aux débuts des Temps Modernes quand, à la suite des conflits évoqués plus haut, un barrage fut édifié pour éviter que, lors des grandes pluies, le marais de Barbegal ne déborde vers la plaine d'Arles. La couche intermédiaire, déposée après l'abandon des moulins, était constituée de colluvions déposées entre la fin de l'Antiquité et la fin du Moyen Âge. Ses caractéristiques sédimentologiques montraient que l'inondation n'était pas alors permanente : la nappe phréatique affleurait seulement à certains moments. Le faciès et la géométrie de la 
couche inférieure, déposée lorsque les moulins fonctionnaient, montraient que l'eau qui avait servi à actionner les roues, sortait à un niveau proche de $1 \mathrm{~m}$ NGF. Les caractéristiques des galets roulés déposés sur le substrat attestaient l'absence d'une nappe d'eau à cet endroit.

L'étude de l'encaissant des structures archéologiques prouvant que le monument était implanté sur des sédiments mis en place durant une période d'inondation, M. Jorda et M. Provansal montrèrent que la lente montée des eaux dans la dépression durant l'Holocène n'avait pas été un mouvement linéaire. La dépression avait connu des phases de régression - dont précisément celle qui avait été mise en évidence pour l'époque romaine. La période d'utilisation des moulins (IIe-IIIe s.) est contemporaine d'un drainage (partiel ?) de la cuvette (Provansal à paraitre). Le raisonnement tenu à propos du site de Servanne trouvait son application ici: là aussi, la situation de l'époque romaine résultait de la combinaison d'une évolution naturelle et d'une intervention humaine, cette fois dans la mise en valeur du milieu humide.

La suite des opérations qui, en 1993 et 1994, marquèrent l'achèvement de cette phase du programme archéologique, confirma le bien fondé de l'hypothèse proposée sur le caractère progressif et en définitif tardif de l'inondation dans la vallée des Baux (fig. 4). En 1993, la découverte et la fouille du petit cimetière situé près de la ferme de la Mérindole, au débouché d'un vallon actuellement sec, à quelques centaines de mètres à l'est des moulins, donna une première confirmation de la réalité du peuplement de la vallée à la fin de l'époque mérovingienne. L'année suivante en déplaçant les déblais de fouilles de F. Benoit, on découvrit au pied même des moulins quelques inhumations datées des IVe-Ve s. Il devenait ainsi certain que, contrairement à ce que l'on écrivait depuis F. Benoit, l'occupation humaine ne s'était pas précocement repliée vers le nord abandonnant le fond de la vallée devant la montée de l'eau : la vallée restait occupée. Cette vision nouvelle permettait de revoir la situation de sites médiévaux qui se trouvent plus à l'est, les Tours de Castillon et le château des Baux.

4- Evolution du plan d'eau dans la vallée des Baux durant les deux derniers millénaires

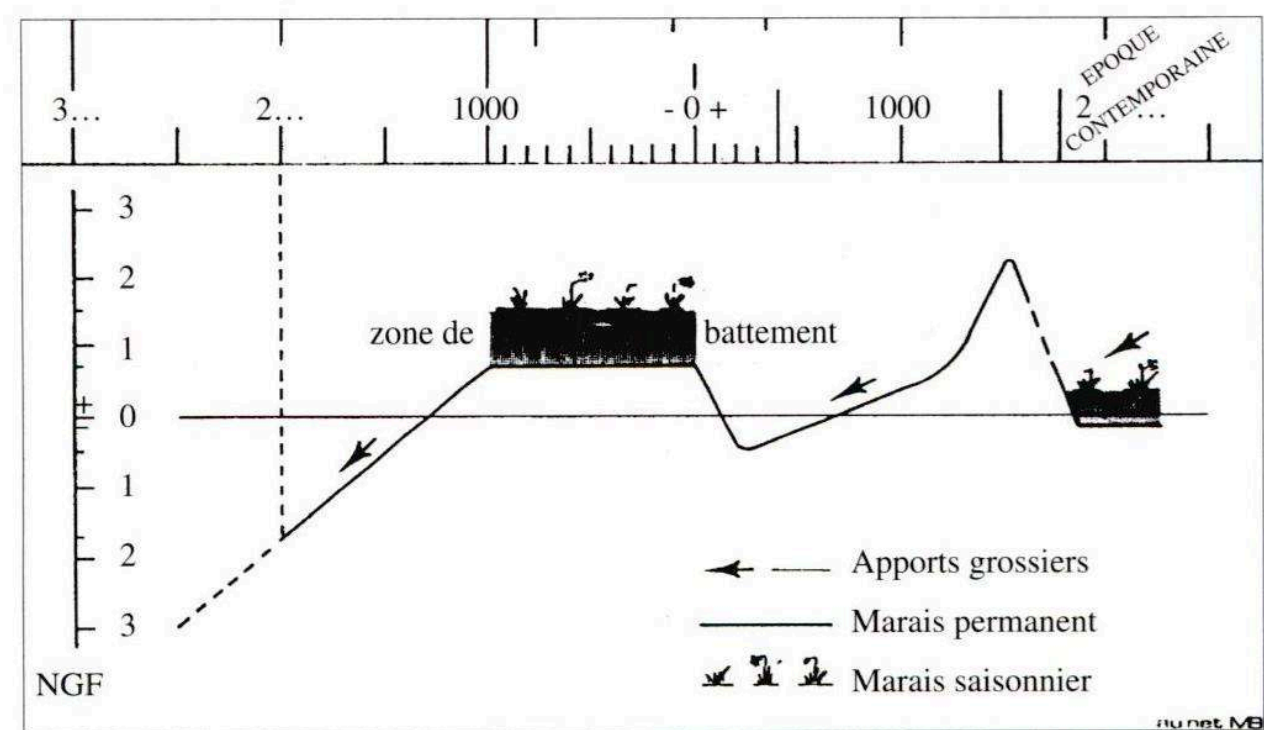

D'APRÈs PROVANSAL À PARAître 
21 Il n'est évidemment pas question de nier l'importance de l'eau dans le paysage médiéval de la région: l'abbaye de Montmajour apparaît comme une île au milieu de marais (Stouff 1993), au maintien desquels les moines sont attachés. Dans les textes qu'a étudié 0 . Maufras, les mentions de terres en eau dans la vallée des Baux sont fréquentes. Il convient seulement de relativiser cette donnée ou plutôt de lui rendre une dimension historique occultée pour rétablir les conditions d'une approche scientifique dans l'étude des paysages du passé. On a proposé des images contradictoires et tout aussi peu fondées des paysages du Bas Rhône à l'époque romaine. Prenons un exemple : en 1674, une crue, à la suite de laquelle la Durance inonda les zones basses comprises entre la Montagnette et les Alpilles accrédita l'hypothèse d'un passage de la Durance dans cette trouée encore à l'époque antique. Cette théorie a été abandonnée mais lui en a succédé une autre dans laquelle les Romains n'en jouent pas moins un rôle excessif. Citons la présentation de la dépression de Graveson et de Maillane par une géographe : «Partant de Laurade et recevant les eaux d'Eyrargues et de Graveson, (la Duransole) finissait par constituer un gros cours d'eau qui aboutissait par Saint-Gabriel à la région d'Arles. Les Romains asséchèrent, drainèrent, canalisèrent et amenèrent aussi vers ce fleuve les eaux des marais de Rognonas, créant la Laune, affluent de ce que l'on appelait le fleuve de Saint-Gabriel. Les mêmes Romains le mirent aussi en communication avec la vraie Durance par un canal dit le Réal, par l'Aiguillon, affluent de la Durance. Ce rialis Durentiae est attesté en 1327 et 1469, d'où la confusion » (Hayez 1978). En l'absence de fouilles de carottages ou d'observations de terrain ces affirmations fondées sur la seule utilisation de textes demeurent de pures hypothèses.

\section{Taphonomie des sites et des parcellaires : les forages et l'histoire des dépôts}

La spatialisation des données archéologiques suppose une étude de la sédimentation dans la vallée des Baux. Envisagée ici du point de vue de l'archéologue, - de ce fait, on parlera de taphonomie-, l'analyse géomorphologique est en effet essentielle pour la compréhension des processus d'enfouissement des sites et des parcellaires.

Actuellement nous pouvons nous appuyer sur une récente synthèse collective publiée par J.-L. Ballais, M. Jorda, M. Provansal et Covo (Ballais 1993). Elle dresse un bilan du remblaiement de la dépression à partir de données issues des observations faites sur le site archéologique de Barbegal, complétées par des sondages à la pelle mécanique au pied et en aval des moulins et légèrement plus à l'est sur le cône du torrent des Crottes d'Aubert. Ces sondages avaient atteint surtout des dépôts holocènes, en plus grande partie d'âge protohistorique ou historique. Antérieurement deux carottages avaient été réalisés par Hélène Laval dans la partie nord-est de la dépression (probablement au sud immédiat des rochers de la Pêne) (Trial-Laval 1979) et plusieurs sondages avaient été pratiqués au pied des moulins. Ils ont été complétés en mars 1995 par seize sondages à la tarière hélicoïdale dont les emplacements ont été choisis en fonction d'une double problématique géomorphologique (comprendre la dépression dans l'espace et saisir l'histoire des flux détritiques et hydriques) et archéologique (appréhender les modes d'occupation du sol). 

goulet de Barbegal, où deux séries de forages ont été réalisées, au nord du pointement rocheux du Mas d'Agard et au sud des Moulins de Barbegal, dans la partie orientale de la dépression, le secteur traversé par la chaussée fossile et la route actuelle au sud des Tours de Castillon où deux sondages distants de $2 \mathrm{~km}$ ont été pratiqués. La nouveauté principale est la mise en évidence d'une topographie surcreusée à l'est de la cuvette. Les analyses géomorphologiques réalisées jusqu'ici n'avaient envisagé qu'une seule situation, celle d'un écoulement vers l'ouest. Désormais la question de l'écoulement des eaux et du drainage se pose en termes nouveaux. Le fonctionnement de la cuvette a varié. Dans une première synthèse, $\mathrm{H}$. Bruneton propose le schéma évolutif suivant (Bruneton 1995): dès le début de l'Holocène, un remplissage sans doute quasi exclusivement d'origine locale aurait gommé la plupart des irrégularités topographiques. Cependant, la zone orientale nettement déprimée et lacustre se serait très tôt opposée à une zone occidentale peut-être palustre, très rarement inondée. Il est en tout cas certain que la montée de l'eau a été lente et continue avec de brèves épisodes régressifs et qu'en particulier le niveau était redescendu de manière sensible à l'époque romaine après un maximum durant l'époque protohistorique; ce maximum serait en tout cas resté bien inférieur aux niveaux atteints durant les Temps Modernes. Malgré l'extension régulière de la zone palustre la différence entre les deux parties de la dépression aurait subsisté jusqu'à l'uniformisation récente du bassin à la suite des aménagements: formation d'un plan d'eau continu au XVIe s. puis assèchement complet achevé dans les années 1950. Parmi les éventualités, il faut envisager celle d'un écoulement naturel d'une grande partie des eaux de surface vers l'est et non vers le Rhône et du creusement à l'époque romaine d'un exutoire remettant en fonctionnement le goulet.

Des profils polliniques avaient été étudiés par $\mathrm{H}$. Triat-Laval seule puis en collaboration avec J. Médus (Triat-Laval 1979 et Laval 1994). Les carottages réalisés ont permis à V. Andrieu de reprendre l'étude avec une maille serrée d'échantillonnage en bénéficiant des progrès réalisés dans le traitement des sédiments. Au mois de mars 1996, trois carottes avaient été ainsi analysées, deux prélevées au centre du marais donnaient un enregistrement de l'histoire de la végétation depuis le début de l'Holocène, la troisième prélevée au pied des moulins était caractérisée par un profil très segmenté. Moins intéressante en terme d'histoire de la végétation, cette carotte présente le grand intérêt d'offrir un enregistrement d'une période de défrichement et d'activités pastorales associées à une phase d'apaisement du niveau de l'eau du marais. Zone humide susceptible d'avoir accueilli des troupeaux, la vallée des Baux a pu également constituer à l'époque antique une zone de production céréalière... Ainsi s'esquisse la possibilité de mieux saisir le phénomène agricole à partir d'une recherche sédimentologique.

\section{Milieu naturel, exploitation des sols et systèmes spatiaux}

L'étape suivante de la recherche consiste à intégrer les données environnementales et archéologiques collectées sur des sites précis (Servanne, Barbegal) dans un espace régional diversifié réunissant outre la vallée, le massif calcaire des Alpilles, le plateau de Crau et la zone deltaïque du Bas Rhône. C'est l'approche par ce que les géographes appellent le système spatial ${ }^{3}$ Une identification correcte des systèmes spatiaux successifs est en effet indispensable pour écrire l'histoire d'une société régionale : les 
établissements se sont répartis dans un espace, ils ont généré leurs ceintures de champs que des chemins ont desservis, qu'ont traversés des axes déterminés par l'intégration de cette micro-région dans un espace aux horizons plus vastes. Ces établissements se sont agrégés entre eux pour former des unités politiques ou ethniques dont les limites regroupent les terroirs et des ensembles paysagers...

Dans la région envisagée, la mise en valeur agricole actuelle commande la dispersion de l'habitat en gros mas, centres d'exploitations agricoles qui coexistent avec des bourgades (Maussane, Mouries, Paradou,...) où les fonctions de service sont essentielles. Cette forme d'habitat liée à l'intégration de la région dans une économie agricole orientée vers la commercialisation n'est pas nouvelle: un rapprochement s'impose avec la période romaine durant laquelle - prospections et fouilles le prouvent - se développe le système de la villa. A l'époque romaine puis à partir des Temps Modernes (pour le Moyen Âge, la question est posée) ces formes d'occupation du sol ont généré des réseaux de chemins et surtout de canaux d'irrigation et de drainage sur lesquels, pour la période moderne et contemporaine, on dispose d'une documentation cartographique abondante et qui, pour la période antique peuvent être reconstitués avec plus ou moins d'exactitude par carto et photo-interprétations et à partir des traces fossiles observables sur les images satellitaires. L'attention portée aux usages agricoles de l'eau est ancienne. Les lignes de sources ont contribué à la localisation des cultures et à un moindre degré de l'habitat, l'utilisation du milieu humide a varié selon l'extension naturelle du plan d'eau. Très tôt les sociétés ont dû procéder à des aménagements. Sans doute la période romaine a-t-elle marqué une étape décisive et donc observable : les travaux de drainage et d'irrigation réalisés changent d'échelle. Les Romains n'ont inventé ni l'irrigation ni le drainage mais l'intégration de la région dans l'espace impérial se traduit dans les aménagements par la mise en place de réseaux techniques régionaux et non plus seulement locaux. Un phénomène analogue se produit à l'époque moderne : dans un premier temps arrivent les eaux d'irrigation du canal de Craponne. Dans un second temps, à partir du XVIIIe s., commence le drainage de la dépression. Les canaux constituent donc les lignes fortes du paysage: sur les marges, un système d'irrigation fondé sur les branches du canal de Craponne; dans la dépression elle-même, un système de drainage dont l'organisation est déterminée par le canal qui, partant de l'étang du Comte, suit le fond de la dépression pour rejoindre au-delà le canal de vidange d'Arles à Port de Bouc, parallèlement au Rhône (Bethemont 1972). La question importante maintenant est la place peut-être sous estimée des aménagements médiévaux.

En revanche, jusqu'à une époque récente, les données dont on disposait pour saisir dans la longue durée la place de l'élevage du mouton dans les paysages et la vie agricole régionale, étaient très limitées et réduites aux indications sur la consommation des espèces fournies par l'archéozoologie (Goudineau 1988). La documentation ne devient importante qu'à la fin du Moyen Âge quand se met en place le système de la transhumance. Au XIXe s., l'élevage ovin était encore une activité dominante; il s'exprime par deux types de drailles : les réseaux de drailles rayonnant autour de mas bien visibles sur la carte d'État Major (80000e) et les grands chemins de transhumance. Pour les périodes antérieures, l'une des découvertes archéologiques importantes de ces dernières années a été la mise en évidence de bergeries antiques sur ce plateau. Elle confirme des propos de Pline: « les plaines de pierre dans la province de Narbonnaise sont aujourd'hui remplies de thym; c'est presque le seul revenu, des milliers de 
moutons y venant de régions lointaines paître ce thym » (Hist. Nat., 21, 57). Sans entrer dans le détail de la discussion qui peut s'instaurer autour de cette découverte, observons ce qu'elle implique pour notre propos. La présence de plusieurs dizaines de milliers de moutons dans la Crau antique a obligatoirement eu des conséquences sur l'économie agricole des régions voisines: les bonnes relations entre troupeaux et cultures ont été certainement assurées par un système de chemins limitant la divagation des bêtes. D'après les textes, un tel système existait encore au Moyen Âge et il sera important d'en repérer les caractéristiques afin de saisir une éventuelle continuité avec la période antique ${ }^{4}$ Durant cette période de fort contrôle de la vie régionale par un pouvoir impérial, il est impensable qu'il n'y ait eu un regard sur la circulation des troupeaux. Si la transhumance a bien existé, comme le suggèrent 0 . Badan, J.-P. Brun et G. Congés (Badan 1995), cela renforcerait une proposition formulée par $\mathrm{P}$. Gros à propos du site de Glanum qui, à l'époque romaine, aurait constitué un lieu de passage des troupeaux à travers les Alpilles (Gros 1995).

L'essentiel de la recherche en archéologie des formes paysagères a porté sur l'organisation des surfaces qu'a générée à l'époque romaine la mise en place de deux types d'axes: les axes de liaison entre centres administratifs que sont les voies romaines et les axes de la centuriation qui ont présidé à la répartition du sol au lendemain de la conquête. Il est de ce fait important d'étudier la manière dont les aménageurs romains - comme leurs successeurs modernes - ont concilié les logiques régionales que sont les passages d'itinéraires de liaison ou les grands aménagements agraires avec les chemins desservant des exploitations agricoles ou assurant les passages des troupeaux et avec les réseaux hydrauliques. Depuis plus de 30 ans, les recherches conduites dans la région du Bas-Rhône ont permis d'apercevoir l'existence de plusieurs centuriations d'orientations différentes. Le premier, M. Guy, avait mis en évidence un réseau quadrillé à proximité d'Arles dans la Crau dont il évaluait l'extension à environ $200 \mathrm{~km}^{2}$; il concluait à des implantations réalisées par tâches (Guy 1954 et 1991). Ses résultats ont été repris par F. Benoit qui, le 12 juin 1964, présentait à l'Académie une communication intitulée « Le développement de la colonie d'Arles et la centuriation de la Crau» (Benoit 1964). F. Benoit proposait une datation fondée sur l'intégration de la ville dans la structure parcellaire; il la datait de l'époque d'Auguste et en faisait une mesure consécutive au lotissement des vétérans de la VIe légion. Cette centuriation serait en relation avec un ancien chemin massaliète reliant directement Entressen à Mouriès. Une vingtaine d'années plus tard, G. Chouquer situait au nord des Alpilles l'un des trois cadastres d'Orange, le cadastre A. En se fondant sur des données onomastiques et la concordance entre un fragment inscrit et le cours fossile de la Duransole, il le localisait au nord des Alpilles. Mise en place à partir d'un point de référence (le locus gromae) situé aux environs d'Ernaginum (Saint-Gabriel) (Chouquer 1983), cette centuriation est limitée par la « voie Aurélienne » dans son tracé au sud des Alpilles; elle intéresse donc la partie nord du territoire d'Arles. Ces constructions parcellaires sont liées à des problèmes de répartition et de mise en valeur de terres. En 1992, le même Chouquer proposait d'identifier un cadastre dit "Arles A " correspondant aux orientations de la trame urbaine d'Arles. Visible en trois secteurs, au nord d'Arles, en Crau (Saint-Martin-de-Crau) et à Maussane, en Camargue, il correspondrait à une seconde série d'assignations (Chouquer 1992). A cette liste, il convient d'ajouter deux propositions plus ou moins inédites, l'une a été faite par $\mathrm{M}$. Faudot (entre 2 et $3^{\circ}$ ouest) (Faudot 1992), l'autre tout récemment, par Ph. Ferando (Ferando 1994). Ces trames se recouvrent partiellement. Si ces centuriations existent 
bien ${ }^{5}$ il faudra en expliquer la genèse. Elles entretiennent une relation avec la réalité paysagère régionale et en particulier avec l'implantation des vétérans autour d'Arles et non dans la Crau ou sur les marges de la plaine comme l'écrivait F. Benoit (Leveau 1995 b). Dans le cas d'un système centurié s'étendant au sud des Alpilles, trois solutions sont possibles : la zone formait une zone de marais (subcessives) entre Crau et Alpilles, mais il a pu aussi y avoir extension de l'occupation romaine grâce au drainage à moins que la vallée des Baux n'ait formé une limite entre deux systèmes.

Actuellement la recherche sur l'organisation des surfaces agraires mérite d'être poursuivie par une prise en compte des phases de l'aménagement agraire autres que d'époque romaine (Gazenbeek 1996) ${ }^{6}$ Or les images satellites permettent d'observer un certain nombre d'anomalies susceptibles de correspondre à des formes héritées. Des structures circulaires correspondent parfois à un carrefour, mais aussi à un centre dont ils conservent la mémoire, ainsi autour de Barbegal ${ }^{7}$ Dans la Crau trois types de parcellaires : à l'ouest, un petit parcellaire d'apparence totalement inorganisé et limité à l'ouest et au nord par la bordure du plateau, qui joue un rôle structurant; à l'est, de celui-ci, un parcellaire plus large et plus régulier s'appuie sur un des axes forts $\mathrm{N}$. N-W ; plus à l'est encore, un autre parcellaire relativement régulier suit en partie à une orientation N. N-E.

Réseaux de drainage, chemins des troupeaux et parcellaires correspondent à des logiques spatiales parfois en contradiction avec celles du réseau viaire. Le réseau viaire actuel est caractérisé par le développement de l'axe de liaison est-ouest Salon-Arles par Saint-Martin-de-Crau au sud de la vallée des Baux. Son tracé diffère sensiblement de celui de la voie romaine qui passait au nord de la vallée et se dirigeait vers Beaucaire et non vers Arles : la vallée est actuellement traversée en deux points par des axes nord sud : à l'ouest, le goulet de Barbegal était déjà franchi par l'aqueduc romain et on $\mathrm{y}$ établit au XVIe s. un pont de $160 \mathrm{~m}$ de long avec 3 arches pour le passage des eaux; à l'est, le tracé emprunté par la route qui va de Saint-Martin-de-Crau à Maussane, coïncide avec une chaussée visible sur les vues aériennes et les images satellites au sud des Tours de Castillon. Cette chaussée formait un gué connu des bergers et des chasseurs avant que le marais du Comte ne soit drainé. Entre les deux, un passage maintenant abandonné reliait Paradou/Maussane à la Crau.

\section{Conclusion}

Les recherches sur la vallée des Baux constituent un bon exemple de ce qu'apporte une recherche paysagère à l'archéologie "intersite». Cette micro-région nous a offert la possibilité de poursuivre la recherche sur les paysages qui avait débuté sur l'Étang-deBerre. Ici, quand l'étude commença il y a dix ans, il s'agissait d'écrire l'histoire d'un ensemble monumental romain, les Moulins de Barbegal et les aqueducs qui les alimentaient. Par ses prolongements, en orientant la recherche vers l'étude des processus d'enfouissement du site au bas du versant (sa taphonomie), la fouille nous a amené à glisser vers l'histoire des paysages. L'importance accordée à la dimension spatiale conduisait à pratiquer une archéologie du «hors site». Celle-ci apportait une meilleure compréhension de l'histoire de la région et pouvait servir à l'élaboration de stratégies de recherche en sauvetage. La plaine d'Arles et la partie occidentale de la vallée des Baux sont en effet menacées par des aménagements autoroutiers. La pose d'une canalisation par Gaz de France a été réalisée, notre réflexion sur « le hors site » et 
les indications issues des prospections, des fouilles et des travaux de carto et photointerprétation, ont contribué à la réussite de l'entreprise ${ }^{8}$.

Ces recherches ont également des développements théoriques. L'intégration de données portant sur des phénomènes observables selon des espaces de différentes dimensions (local, micro régional, régional,...) et des systèmes chronologiques hétérogènes (géologique, longue et moyenne durée historique) nécessitent en effet le recours à des approches qui intègrent la notion d'échelles d'espace et de temps, tiennent compte de la notion d'héritage et admettent les principes de rétroaction. C'est pourquoi dans la présentation des données, il a souvent été fait appel à la notion de système qu'utilisent maintenant de manière courante un certain nombre de sciences humaines, mais peu les disciplines historiques (Jollivet 1992). Dans la mesure où l'existence de contrastes forts entre les unités paysagères qui composent la région favorisait la modélisation des relations homme-milieu, l'étude en cours a conduit à l'élaboration d'une grille d'analyse "systémique » des dynamiques paysagères qui pourrait être généralisée aux dépressions et plaines humides méditerranéennes (Leveau 1997).

Cette même recherche conduit en outre à discuter un concept largement utilisé, «l'anthropisation» des milieux. Les naturalistes qui prêtent attention à l'action de l'homme sur le paysage ont en effet tendance à envisager celle-ci de manière unitaire ; pour la désigner, ils emploient le terme "anthropisation ", comme pour eux du fait de son caractère général. Adopté rapidement par les préhistoriens et valable à l'échelle de la mobilité climatique, ce concept se révèle inadapté à l'étude des sociétés historiques dans la mesure où il ne prend pas en compte les différences fondamentales qui existent entre elles (Leveau, à paraitre). L'action de l'homme sur le milieu est marquée par des discontinuités et des ruptures qui s'expliquent par les techniques dont il dispose ; mais sa capacité à les utiliser est en relation directe avec le niveau de développement des formations sociales.

\section{BIBLIOGRAPHIE}

\section{Bibliographie}

Ambert 1992 : AMBERT (P.) et CLAUZON (G.). - Morphogenèse éolienne et ambiance périglaciaire : les dépressions fermées du pourtour du Golfe du Lion (France méditerranéenne). Zeitschrift für Géomorphologie N.F., suppl. Bd 84, 1992, pp. 55-71.

Badan 1995 : BADAN (O.), BRUN (J.-P.), CONGÉS (G.). - Les bergeries romaines de la Crau d'Arles. Les origines de la transhumance en Provence. Gallia 52, 1995, pp. 263-310.

Ballais 1993 : BALLAIS (.-L.), JORDA (M.), PROVANSAL (M.) et COVO (J.). - Morphogénèse holocène sur le périmètre des Alpilles. In : Leveau (Ph.) et Provansal (M.) (dir.). De la Sainte Victoire aux Alpilles, Publ. de l'Univ. de Provence, 1993, pp. 515-546. 
Bellamy 1996 : BELLAMY (P.) et HITCHNER (B.). - The villa of the Vallée des Baux and the Barbegal Mill : excavations at la Mérindole villa and cemetery, J.R.A., 1996-9, pp. 154-176.

Benoit 1940 : BENOIT (F.). - L'usine de meunerie hydraulique de Barbegal (Arles). Revue Archéologique, 1940-45, 1, pp.19-79.

Benoit 1964 : BENOIT (F.). - Le développement de la colonie d'Arles et la centuriation de la Crau. CRAI, janv.-juin 1964, pp. 156-169.

Bethemont 1972 : BETHEMONT (J.). - Le thème de l'eau dans la vallée du Rhône, Essai de genèse d'un espace hydraulique, Saint-Etienne, Le Feuillet Blanc, 1972.

Bourilly 1911 : BOURILLY (J.) et MAZAURIC (F.). - Note sur la Montagne de Cordes, près Fontvieille, Bull. S.RE, 1911, pp. 307-309.

Bruneton 1995 : BRUNETON (H.). - Stabilité et instabilité des Environnements dans les Alpilles à l'Holocène, DEA de Géographie Physique, Option Géosystème Anthropisé, Aix-en-Provence, 1995.

Chouquer 1983 : CHOUQUER (G.). - Localisation et extension géographique des cadastres affichés à Orange. In : Clavel-Lévêque (M.) (dir.), Cadastres et espace rural, CNRS, Paris, 1983, pp. 288-290.

Chouquer 1992 : CHOUQUER (G.) et FAVORY (F.). - Les arpenteurs romains. Théorie et pratique, Ed. Errance, Paris, 1992, 150p.

Denizet 1928 : DENIZET (M.). - La formation et le dessèchement des marais d'Arles ; l'oeuvre de Van Ens, Marseille, 1928.

Faudot 1992 : FAUDOT (M.). - Les réseaux cadastraux Artésiens. Dialogues d'Histoire Ancienne, 1992, pp. 317-320.

Gazenbeek 1995 : GAZENBEEK (M.). - Occupation du sol et évolution environnementale depuis le Néolithique dans la Montagnette et la partie occidentale des Alpilles (Bouches-duRhône), Thèse pour le Doctorat, Univ. de Provence, Aix-en-Provence, 1995.

Gazenbeek 1996 : GAZENBEEK (M.), LEVEAU (Ph.), MAUFRAS (O.), MOCCI (F.), SINTÈS (M.), TREZINY (H.). - Archéologie des paysages, parcellaires et recouvrements sédimentaires sur le piémont sud des Alpilles. In : Chouquer (G.) (dir.). Les formes du paysage, t. 2, Colloque « Archéologie des parcellaires », Orléans, 28, 29 et 30 mars 1996, Paris, pp. 113-123.

Goudineau 1988 : GOUDINEAU (C.). - Le pastoralisme en Gaule. In : Whittaker (C.R.) (dir.), Pastoral economies in classical Antiquity, Cambridge Philogical Society, 1988, pp. 160-170.

Gros 1995 : GROS (P.). - Hercule à Glanum. Gallia 52, 1995. pp. 311-331.

Guy 1954 : GUY (M.). - Traces du cadastre romain de quelques colonies de la Narbonnaise. Etudes roussillonnaises, IV-3, 1954-1955, pp. 217-238.

Guy 1991 : GUY (M.). - Prospection aérienne et télédétection des structures de parcellaires, p. 105, fig. III. 1. In : Guilaine (J.) (sous la dir.), Pour une archéologie agraire, A. Colin, Paris.

Hayez 1978 : HAYEZ (A.-M.). - In : Études vauclusiennes, juillet 1978.

Jollivet 1992 : JOLLIVET M. (dir.) - Sciences de la nature, Sciences de la société, CNRS, Paris, 1992.

Jorda 1991 : JORDA (M.), PROVANSAL (M.) et ROYET (R.). — L'histoire « naturelle » d'un site de l'âge du Fer sur le piémont méridional des Alpilles. Le domaine de Servanne (Mouriès). Gallia, vol. 47, 1991, pp. 57-66. 
Laval 1994 : LAVAL (H.) et MÉDUS (J.). - Une séquence pollinique subboréal - subatlantique dans la vallée des Baux : changements de végétation, climatiques et anthropiques de l'âge du Bronze à celui du Fer en Provence. Arcs. Sci. Genève, Al, 2, pp. 83-93.

Leveau 1993a : LEVEAU (Ph.) et PROVANSAL (M.) (dir.). - De la Sainte Victoire aux Alpilles, Publ.de l'Univ. de Provence, 1993.

Leveau 1993b : LEVEAU (Ph.) et PROVANSAL (M.). - Systèmes agricoles et paysages au nord-est de l'Étang de Berre depuis le Néolithique. In : Beck (C.) et Delort (R.) (dir.), Pour une histoire de l'environnement. Travaux du programme interdisciplinaire de recherche sur l'environnement, CNRS éd., 1993, pp. 173-200.

Leveau 1995a : LEVEAU (Ph.) Les moulins romains de Barbegal, les ponts-aqueducs du vallon des Arcs et l'histoire naturelle de la vallée des Baux (Bilan de six ans de fouilles programmées), CRAI1995, pp. 115-144.

Leveau 1995b : LEVEAU (Ph.). - Colonie romaine et milieu naturel : Arles et les plaines du BasRhône. In : L'homme et la dégradation de l'environnement. XVes Rencontres internationales d'Archéologie et d'Histoire d'Antibes, 20-21-22 oct. 1994. APDCA, Juan-les-Pins, 1995, pp. 245-262.

Leveau 1997 : LEVEAU (Ph.). - Sociétés historiques et milieux humides. Un « Modèle systémique des données » appliquable aux marais continentaux de cuvette. Nature - Sciences - Sociétés. Dialogues, vol. 5, juin 1997, pp. 5-18.

Leveau à paraître : LEVEAU (Ph.). - L'archéologie des paysages et les époques historiques : les grands aménagements agraires et leur « signature » dans le paysage (anthropisation des milieux et complexité des sociétés). In : Mélanges Robert Delort.

Pinchemel 1988 : PINCHEMEL (Ph. et G.). - La face de la terre. Éléments de géographie, Paris, A. Colin (3e éd. 1994).

Poumeyrol 1953 : POUMEYROL (L.). - In : Gallia 1953, 112 ; Gallia 1954, 430-431 ; Gallia 1960, 305-306 ; Gallia 1967, 403 ; Gallia 1969, 423 ; Gallia 1972, 518 ; Gallia 1977,517.

Provansal à paraître : PROVANSAL (M.), LEVEAU (Ph.), BALLAIS (J.-L.), JORDA (M.). - Les moulins romains et le Marais des Baux. Archéologie et paléoenvironnements, de la protohistoire à l'époque moderne. Séminaire sur L'évolution du milieu physique durant la période historique sur le pourtour de la Méditerranée, Ravello, 5-8 juin 1993.

Sauzade 1990 : SAUZADE (G.). - Les dolmens de Provence occidentale et la place des tombes de Fontvieille dans l'architecture mégalithique méridionale. In : Guilaine (J.) et Gutherz (X.), (dir.), Autour de Jean Arnal, Montpellier, 1990, pp. 305-334.

Stouff 1993 : STOUFF (L.). - La lutte contre les eaux dans les pays du bas Rhône. XIIe-XVe s. L'exemple du pays d'Arles. Méditerranée, 1993-3/4, pp. 57-68.

Treziny 1987-1988 : TREZINY (H.). - In : Gallia Informations, 1987-1988/2, pp. 254-255.

Treziny 1990 : TREZINY (H.). - In : Gallia Informations, 1990, p. 178.

Triat-Laval 1979 : TRIAT-LAVAL (H.). - Contribution pollenanalytique à l'histoire tardi et postglaciaire de la végétation de la basse vallée du Rhône, Thèse, Aix-Marseille III, 1979.

Vaudour 1991 : VAUDOUR (J.). - La notion de géosystème appliquée à l'étude des aqueducs antiques concrétionnés. In : Fabre (G.), Fiches (J.-L.), Paillet (J.-L.) (dir.). - L'aqueduc de Nîmes et le Pont du Gard, Nîmes, 1991, pp. 95107.

Waton-Chabert 1963 : WATON-CHABERT (A.). - Historique du dessèchement de la région d'Arles, de la Durance à la mer. Delta, nº 10-14, 1963. 


\section{Document}

Ferando 1994 : FERANDO (Ph.). - Bilan Scientifique 1994, PACA, p. 167.

\section{NOTES}

1. Recherches en cours par O. Maufras (AFAN) et J. Palet Martinez (Université de Barcelone).

2. Recherches en cours par O. Maufras (AFAN) et J. Palet Martinez (Université de Barcelone).

3. Le système spatial est le produit de l'interaction entre lieux centraux, réseaux de relations, unités d'appropriation, unités administratives et utilisation du sol (Pinchemel 1988).

4. Conduite par J. Palet-Martinez en collaboration avec F. Mocci ( $\mathrm{CCJ}$ ) pour la recherche des traces fossiles, cette recherche a donné des résultats probants.

5. L'inflation de propositions d'identification de centuriations pose problème. Ainsi M. Assénât, (Le cadastre colonial d'Orange, dans RAN 27-28 - 1994-1995, p. 45-55) ajoute cinq nouveaux réseaux à ceux qu'elle avait déjà proposé en 1993. J'ai suggéré l'idée d'un moratoire dans la publication de nouveaux réseaux pour la Gaule du Sud et cette idée a été approuvée par la plupart des spécialistes, en particulier par G. Chouquer, lui-même de plus en plus sensible à la nécessité de placer ce phénomène dans la longue durée et de ne plus limiter la recherche aux constructions antiques (Aux origines antiques et médiévales des parcellaires, dans Histoire et Sociétés rurales, 4, 1995, p. 11-46).

6. Les systèmes spatiaux qui constituent le fond de la trame paysagère de la dépression des Baux et ses abords font l'objet d'une série d'études par carto et photo-interprétation par FI. Mocci (CCJ Aix-en-Provence) et par imagerie satellitaire par M. Sintès (CRA Valbonne).

7. Il est probable que les plus importants des habitats en ont généré un. Leur repérage par l'étude des formes du parcellaire napoléonien devrait permettre de compléter la carte des lieux habités et/ou cultivés. Ce parcellaire pourrait en effet être en relation avec l'occupation médiévale. Mais un parcellaire circulaire a pu aussi être généré par la topographie (dépression de forme circulaire avec drainage en étoile).

8. Comme il était prévisible (et prévu), la tranchée du gazoduc a rencontré un site occupé du Chalcolithique au Premier âge du Fer. Situé aux environs de la cote 200 N.G.F., il confirme les hypothèses présentées sur la montée de l'eau dans la vallée. 
Géoarchéologie lacustre 


\section{L'archéologie subaquatique dans les lacs Alpins Français}

\section{Yves Billaud et André Marguet}

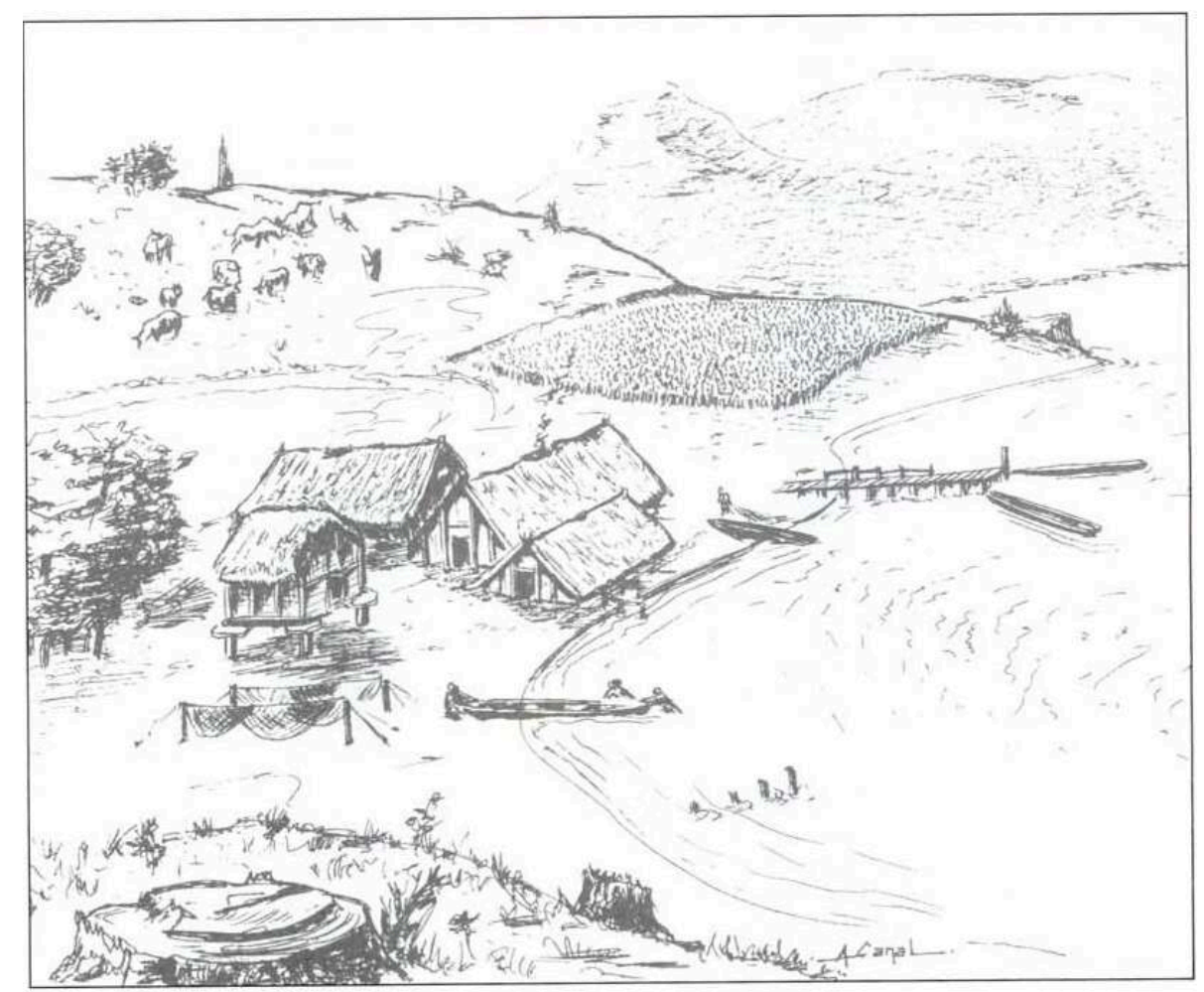

1 Vers la fin du Ve et le début du IVe millé avant notre ère, au Néolithique ancien et moyen I, les rivages des lacs français du nord des Alpes et du domaine jurassiennaire connaissent une lente colonisation puis une véritable expansion de communautés d'agriculteurs sédentaires. Un peu plus tard, au cours des IVe et Ille millénaires, les villages du Néolithique moyen et final se multiplient, dans des espaces amphibies pourtant peu attrayants puisque périodiquement inondés. 
2 Conséquence de cette forte densité d'occupation ancienne, le nombre des découvertes augmente et, ces vingt-cinq dernières années, les recherches en Préhistoire récente concernent de plus en plus souvent les restes de villages lacustres du Néolithique et de l'âge du Bronze (Ier millénaire avant notre ère).

3 Menées de manière extensive sur de rares sites néolithiques des lacs jurassiens de Chalain et de Clairvaux et dauphinois de Paladru, plus ponctuellement dans les lacs savoyards, ces investigations ont montré que l'essentiel de nos connaissances provenait de l'étude de ces gisements : techniques de construction, organisation architecturale et durée d'occupation des villages, travail du bois, outils et modes d'emmanchement, pratiques agricoles, plantes cultivées et collectées pour l'alimentation.

4 La confrontation des études sur la préhistoire lacustre avec des modèles ethnographiques et la multiplication des observations naturalistes sur les données de l'environnement ont permis de donner de la vie quotidienne une image plus complète, bien différente de celle restituée jusqu'ici par les recherches terrestres.

5 C'est justement cette nouvelle manière de percevoir le cadre naturel de cette vie quotidienne qu'il nous semblait intéressant d'évoquer ici, à la fois pour son aspect documentaire et pour l'intérêt historique de l'évolution des techniques interprétatives en archéologie subaquatique ${ }^{1}$.

\section{Historique de la question palafittique}

6 L'histoire de la recherche palafittique a été écrite à maintes reprises. Une abondante bibliographie retrace les principales étapes d'une démarche vieille de plus d'un siècle et l'évolution des concepts (voir en particulier Bandi 1979, p. 28-32; Speck 1981, p. 98-132).

7 Une synthèse historique et chronologique sur le sujet a été présentée par A. Gallay à l'occasion d'un colloque organisé par la Société de Physique et d'Histoire naturelle de Genève sur le thème de L'habitat lacustre préhistorique (Gallay 1983, p. 203-214).

\section{Les cités lacustres : mythes archéologiques et réalités ethnographiques}

8 Après la découverte, en Suisse, des premiers villages des bords du lac de Zurich en 1853-1854, les pêches aux antiquités lacustres, ont montré l'existence de villages préhistoriques d'un type particulier dont on retrouve, sous les eaux ou sur les franges littorales, des vestiges d'un intérêt tout à fait exceptionnel parce que bien conservés.

Pendant plus d'un siècle, cette archéologie lacustre a suscité de vifs débats autour de la question: s'agissait-il de restes d'habitats de terre ferme ou d'habitats surélevés audessus de l'eau? (voir en particulier Pétrequin 1980, p. 778-785; Magny 1984a, p. 41-61).

\section{Au XIXe siècle : la révélation des palafittes}

10 Dès leurs premiers travaux, les archéologues ont cherché à interpréter leurs découvertes et ont proposé l'image bien connue de la cité lacustre. Comment ce schéma a-t-il pu se mettre en place? 
11 En 1853-1854, à la suite d'un hiver long et froid, le niveau du lac de Zurich s'abaisse de manière inhabituelle. A cette occasion, J. Aeppli instituteur d'Obermeilen repère des centaines de pilotis de bois dépassant de la vase et un très abondant mobilier archéologique. Il alerte F. Keller, préhistorien et président de la Société des Antiquaires de Zurich, qui comprend l'importance de ces trouvailles et fait entreprendre des prospections sur d'autres lacs helvétiques, celui de Bienne en particulier où des découvertes avaient été faites, dès 1840, par A. Jahn, E. F. Müller et F. Schwab. L'abondance des trouvailles et la qualité de conservation des vestiges provoquent un véritable engouement pour cette recherche en lacs.

\section{L'origine d'un mythe : une vision romantique des populations lacustres}

12 Des comparaisons ethnographiques permettront à $\mathrm{F}$. Keller d'interpréter ces vestiges. En effet, quelques années plus tôt, en 1834-1835, l'explorateur J. Dumont d'Urville, de retour d'un périple à bord de l'Astrolabe, avait publié d'étonnantes gravures de L.-A. de Sainson représentant les habitations lacustres de Nouvelle-Guinée, villages construits sur des plates-formes de bois, au-dessus des eaux. De toute évidence, cette description, et les textes antiques remis à l'honneur comme celui de l'historien grec Hérodote qui, au Ve s. av. J.-C., décrivait les palafittes de Macédoine, ont servi de modèles pour la reconstitution des cités lacustres préhistoriques - cabanes établies non sur terre ferme mais en des points peu profonds du rivage, sur pilotis-, telles que F. Keller les rendra publiques, en 1854, dans son premier rapport sur Les palafittes celtiques des lacs suisses (Keller 1854, p. 67-101).

13 Les centaines de pilotis et les débris archéologiques sont ainsi attribués à d'anciens villages construits sur l'eau. La cité lacustre était née, présentée même comme une particularité helvétique dans le pavillon suisse de l'Exposition universelle de Paris en 1867. L'idée des palafittes fera son chemin, sans contestations majeures, pendant au moins trois quarts de siècle, abondamment illustrée par les aquarellistes de la Suisse alémanique et romande.

\section{Dès le début du XXe siècle : le temps des controverses}

14 Ce n'est que beaucoup plus tard, que des préhistoriens allemands, suisses et français, profitant des premières études géologiques et botaniques sur les sédiments lacustres et se rendant compte qu'il pouvait exister plusieurs périodes d'occupations successives, en sont venus à contester l'existence de ces villages construits sur l'eau. C'est l'allemand H. Reinerth qui le premier, dans les années 1920-1930, à la suite de ses travaux sur le lac de Constance, exprima l'idée qu'il ne s'agissait pas de stations de pleine eau, mais de constructions sur pilotis, peu élevées sur le rivage, mais non audessus de l'eau (Reinerth 1932, p. 7-144).

15 Vers 1920, P. Vouga met en évidence la succession stratigraphique des villages néolithiques d'Auvernier (Vouga 1934).

16 Au début des années 1940, O. Paret prend définitivement le contre-pied de la théorie des palafittes, et à partir de considérations sur les techniques de construction observées sur le Federsee, va même jusqu'à nier l'existence d'habitations sur pilotis, que ce soit sur le rivage ou au-dessus de l'eau (Paret 1958, p. 46-73). 
17 Nuançant ces positions catégoriques, E. Vogt montre également, à partir de ses fouilles dans le marais de Wauwil, que les villages ont été construits à même le sol, sur des plages émergées (Vogt 1951, p. 193-215).

18 Au milieu du siècle, la vérité semble donc être chez les partisans des villages de terre ferme, installés au bord des lacs puis abandonnés lors de la remontée des eaux. La vision des cités lacustres est pour un temps oubliée.

\section{Les interrogations de la recherche actuelle}

19 A partir des années 1970, de nouvelles recherches dans les milieux amphibies proposent de revenir à la solution des constructions à planchers légèrement surélevés.

20 Ce sont désormais les travaux ethno-archéologiques qui vont servir de base à la réflexion et à l'élaboration des problématiques archéologiques. Vers les années 1972, après plusieurs années de recherches sur le lac de Neuchâtel, C. Strahm propose le schéma d'un habitat surélevé, édifié en zone de battement saisonnier, à l'étiage du lac (Strahm 1975, p. 155-163).

21 En même temps, P. Pétrequin dans le lac de Clairvaux et A. Bocquet dans celui de Paladru, chacun selon des techniques appropriées aux milieux respectifs (littoral émergé dans le Jura et fouilles subaquatiques dans le Dauphiné) se proposent de comprendre, avec le succès qu'on connaît, d'une part les raisons qui ont poussé les hommes de la fin de la Préhistoire à s'installer dans ces régions plutôt inhospitalières et, d'autre part, les relations qui existent entre l'occupation des rives, les pratiques culturales ou artisanales et les fluctuations du niveau des eaux. On cherche également à mieux connaître les conditions de formation des couches archéologiques littorales, qu'elles soient d'origine anthropique ou lacustre. L'étude détaillée des structures et des matériaux découverts, qu'ils soient archéologiques, sédimentaires ou botaniques, l'exploitation des données de la fouille et des analyses des sciences naturelles (sédimentologie, palynologie, dendrochronologie), permettent cette approche.

\section{Historique de la recherche dans les lacs alpins français}

Au milieu du siècle dernier, on connait l'existence de villages préhistoriques enfouis en bordure des lacs subalpins et l'identification de bourgades lacustres dans notre pays suit de très peu les trouvailles helvétiques de 1853-1854.

\section{À partir de 1856, la découverte des cités lacustres}

Le 30 août 1856, des membres de la Société Savoisienne d'Histoire et d'Archéologie de Chambéry et de l'Académie Florimontane d'Annecy, sensibilisés par l'extraordinaire richesse des stations suisses que venait de leur présenter $\mathrm{F}$. Troyon, et séduits par l'imagerie romantique à la mode, mettent en évidence, sur des gisements annéciens de l'âge du Bronze, les premiers vestiges palafittiques français. Les choses iront ensuite très vite.

Au lac d'Annecy en 1856 : 
« ... Les recherches projetées ont été faites sur le lac, aux environs de Duingt, sous la direction de $\mathrm{M}$. Troyon et $\mathrm{M}$. Forel père. $\mathrm{M}$. Gosse $\mathrm{y}$ prend une part très active en plongeant plusieurs fois; bientôt on est sûr de l'existence des pilotis, on retrouve un grand nombre de têtes de pieux, et des débris d'anciennes poteries noires... » (Rabut 1856, p. 208). nomme une commission pour rechercher et explorer les anciennes habitations du lac du Bourget (Rabut 1864, p. 79). Dès lors, et sous l'impulsion d'archéologues pionniers tels que A. Blanc et L. Schaudel à Aiguebelette, J. Costa de Beauregard, le Dr. Despine, G. de Mortillet, A. Perrin et L. Rabut au Bourget, M. Le Roux, C. Marteaux, L. Revon, E. Serand et le Dr. Thonion à Annecy, ainsi que F.-A. Forel, H.-J. Gosse, A. Morlot, F. Thioly et $\mathrm{F}$. Troyon dans le Léman, les lacs alpins livrent d'innombrables vestiges de la période du Bronze (voir compilation bibliographique dans Bocquet et al. 1976a, p. 139-145). Quelques années plus tard, des traces matérielles de l'âge de la Pierre sont identifiées : en 1864 à Brison-St.-Innocent, Meimart et en 1868 à Vieugy, Sous-lesGuerres (voir bilan documentaire dans Marguet et al. 1995, p. 167-196). Les premières publications synthétiques consacrées aux trouvailles lacustres voient le jour entre 1860 et 1878 (en particulier Troyon 1860, p. 77-200; Rabut 1864; Thioly 1868; Perrin 1870; Chantre 1875-1876, p. 168223; Revon 1878, p. 23-32), ce sont de véritables inventaires des stations; d'autres, plus spécialisées, prennent en compte elles aussi les trouvailles lacustres, c'est le cas de celle de G. de Mortillet consacrée aux origines de la chasse, de la pêche et de l'agriculture (De Mortillet 1890). systèmes divers: pinces, dragues ou pelles à godet dont le musée d'Annecy possède d'ailleurs de beaux spécimens, sont à l'origine des importantes collections du Musée Savoisien de Chambéry et du Musée-Château d'Annecy. Des moyens lourds furent même occasionnellement mis en oeuvre dans le lac d'Annecy « ... lorsque la drague fut arrivée à hauteur de l'Ile des Cygnes,... elle rencontra de nombreux pilotis. C'était une station lacustre jusqu'alors inconnue... Les travaux furent repris à droite et à gauche du grand chenal, ce qui amena la découverte de nombreux objets... La drague fut ensuite transportée sur le Roselet, en face de Duingt, puis à Veyrier...» (Serand 1884, p. 101). Ces récupérations d'objets dureront jusqu'en 1874 puis, épisodiquement, au-delà de 1900, la dernière ayant été réalisée en 1908, à l'occasion du Congrès Préhistorique de France de Chambéry lors de l'excursion du 28 août: «... Un vapeur, spécialement 
affrété, était sous pression pour effectuer la visite complète du lac du Bourget. M. le baron A. Blanc avait convoqué des pêcheurs pour opérer des dragages sous les yeux des congressistes. Au Saut-de-la-Pucelle, sur l'emplacement d'une station lacustre, la drague ramène à la surface de l'eau de nombreux échantillons de poteries, qui seront distribués aux congressistes pendant le déjeuner... » (Congrès 1909, p. 924).

\section{Au début du XXe siècle, un oubli momentané}

Durant la première moitié du XXe s., sur pratiquement toutes les stations littorales, à l'exception du lac d'Aiguebelette où L. Schaudel et A. Blanc explorent la station de l'âge de la Pierre (Schaudel 1906, p. 690-692), l'intérêt pour les pêches aux antiquités diminue rapidement. Cependant, les problèmes d'interprétation des vestiges recueillis continuent d'occuper les archéologues; un débat passionné, alimenté par les résultats obtenus dans les tourbières suisses, oppose toujours les tenants d'un habitat sur l'eau à ceux d'un habitat sur terre ferme.

31 En 1904, F.-A. Forel au chapitre Antiquités lacustres, les palafitteurs de son imposante monographie limnologique du Léman, dresse la carte des stations lémaniques (47 stations) en intégrant celles de la rive savoyarde (11 stations) (Forel 1904, p. 424-442). En 1908, dans sa synthèse sur les stations lacustres d'Europe, R. Munro reprendra cet inventaire et la description des stations lémaniques et l'étendra à l'ensemble des gisements savoyards (Bourget 7 sites, Aiguebelette 1, Annecy 4) (Munro 1908, p. 86-112).

Également en 1908, au Congrès Préhistorique de France de Chambéry, M. Le Roux, conservateur du Musée d'Annecy et P. Guinier, professeur de botanique, dans leurs publications de l'outillage de silex, de la faune et des végétaux issus des dragages du chenal du Thiou en 1884, démontrent, pour la première fois dans nos régions, l'absolue nécessité d'étudier avec les trouvailles matérielles les restes organiques conservés dans le sédiment lacustre « ... l'extracteur ramena ensuite, de la partie sous-jacente à une couche épaisse et durcie de limon lacustre, des morceaux du niveau archéologique, formé d'un lacis à consistance tourbeuse de végétaux, où l'on a recueilli tout l'outillage préhistorique, mêlé aux débris des cabanes : fragments de crépissage en terre, portant l'empreinte en creux des clayonnages; débris innombrables de feuilles de roseaux, qui devaient servir de couchettes ou de litière, ou à boucher les interstices des branches de sapin, qui formaient le toit des habitations... » (Le Roux 1909, p. 547-566 ; Guinier 1909, p. 567571). C'est le véritable début de la collaboration entre archéologues et naturalistes dans notre région.

À cette même époque, compte tenu de l'abondance des mobiliers archéologiques récupérés, se mettent en place les premières classifications typologiques, en particulier pour la céramique (Morin-Jean 1909, p. 600-609; Coutil 1915, p. 386-402, pl. I-XII, p. 430-431, pl. XII).

En 1921, au 3e Congrès de l'Association des préhistoriens, des archéologues classiques et des numismates du Bassin du Rhône, à Besançon, deux communications prennent en compte le domaine lacustre alpin : « ... P. Vouga... expose le résultat des fouilles opérées par lui dans les couches néolithiques stratifiées des palafittes suisses...» (ces travaux sont à l'origine de la chronologie des stations littorales néolithiques) et $\mathrm{E}$. Chantre « ... En étudiant la répartition des palafittes dans le bassin du Rhône, suivant leurs âges,... constate que dans les régions où ont été élevées des bourgades lacustres, les stations 
terrestres d'habitat sont fort rares, n'existent pas ou n'ont pas encore été signalées... » (Rhodania 1921, p. 52, 87).

Si les basses eaux exceptionnelles de 1921 ont amené localement un regain d'intérêt pour les recherches lacustres: L. Blondel dresse le plan des stations de la rade de Genève (Blondel 1923, p. 88-112) et $\mathrm{H}$. Müller explore, à pied sec, les vestiges néolithiques du lac de Paladru (Bocquet 1994, p. 5-7), rares sont les mentions qui concernent les lacs savoyards et pourtant le Musée-Savoisien de Chambéry détient des objets découverts cette année là par H. Müller «... lac d'Aiguebelette... Stations des Roseaux et de Petite-Ile... des ramassages en 1921, lors d'une baisse des eaux du lac, ont livré un abondant matériel de silex... » (Dumont 1995, p. 47).

Dans son Manuel d'Archéologie préhistorique, celtique et gallo-romaine, Age du Bronze, paru en 1924, J. Déchelette fait une remarque intéressante au sujet de la position relative des villages « ... Certaines particularités distinguent cependant les cités lacustres de l'époque du bronze. La distance qui les sépare de la rive n'est plus limitée à 40,50 ou 90 mètres, elle atteint jusqu'à 300 à 400 mètres... » (Déchelette 1924, p. 112).

G. Goury, dans son Précis d'Archéologie Préhistorique intitulé L'Homme des Cités lacustres, présente les dernières statistiques dont les chiffres surprennent: " ... Suisse 383 stations dont Léman 26 (en comptant la rive française), Aiguebelette 2, Annecy 4, Bourget 7... (Goury 1931, p. 72-97).

\section{Les années 1930, les premières plongées archéologiques}

L'année même de la découverte des stations du lac de Zurich, le 24 août 1854, A. Morlot, assisté en surface de F. Troyon et de F.-A. Forel, entreprend la première prospection en plongée, de la station de Morges, sur la rive vaudoise du Léman « ... nous avons enfin fait l'essai de nos tubes sur les pilotis de Morges, et nous nous sommes promenés au milieu des pieux avec une dizaine de pieds d'eau sur la tête... » (Martin-Kilcher 1979, p. 6-7).

Dès 1937-1938, des pionniers de la recherche subaquatique, le Dr. Favre au lac d'Annecy, puis le Pr. J.-J. Pittard, à La Vorze sur la rive française du Léman, emploient, à des fins archéologiques, l'appareil de plongée autonome inventé, vers 1930, par le Commandant Y. Le Prieur, "... composé d'un masque dans lequel arrive l'air en quantité réglée par un manodétendeur... nous avons décidé de dresser un relevé topographique de la station... Nous avons utilisé, pour effectuer ce relevé, des moyens modernes : le scaphandre, permettant d'explorer et de placer des signaux au pied des pilotis et l'avion pour photographier l'ensemble de ces signaux...» (273 repères signalant 420 pilotis ont été installés et photographiés) (Pittard 1938, p. 16-30).

\section{De 1954 à 1974, les travaux de R. Laurent}

À partir de 1950, le développement de la plongée autonome va permettre l'observation in situ des gisements sous-lacustres anciennement repérés.

41 Les principes généraux de cette nouvelle démarche sont présentés par A. Hamard du Centre de Documentation et de Recherches Préhistoriques du Musée de l'Homme, dans une note intitulée Préhistoire et Hommes-Grenouilles (séance du 25 novembre 1954 de la Société Préhistorique Française) «... Loin d'être épuisées en résultats scientifiques, la vase ou la tourbe de nos lacs..., qui trop souvent n'a été fouillée qu'au moyen de 
dragues peu soucieuses de stratigraphie ou de bonne conservation des pièces, peuvent encore fournir, outre des outillages lithiques... de très abondants résidus végétaux... Les débris organiques se prêteront... aux essais de datation au moyen du radiocarbone ou de la dendrochronologie (pilotis)... Il convient toutefois de ne pas s'illusionner sur les possibilités théoriques des fouilles sub-aquatiques. Si la fouille d'une palafitte située aujourd'hui - par suite de l'apport sédimentaire ou du lent retrait des eaux - sur la berge d'un lac, est difficile..., autrement compliquée et délicate est la fouille subaquatique... Tous les lacs français, bien entendu, n'ont pas eu de palafittes, mais bon nombre d'entre eux - ainsi que des marais - paraissent susceptibles d'explorations méthodiques. Il conviendrait d'en dresser l'inventaire, en se basant sur la littérature archéologique et géologique...» (Hamard 1954, p. 481 - 484). La discussion est engagée, et M.-R. Sauter de l'Université de Genève, dans une correspondance à la Société Préhistorique Française à propos de la note Préhistoire et Hommes-Grenouilles, souligne à nouveau la difficulté des fouilles sub-aquatiques et doute de leur efficacité «... On peut faire - et je pense plus particulièrement aux stations dites lacustres - des relevés de pilotis, aboutissant à des plans de stations, on peut pratiquer du ramassage d'objets gisant sur le fond..., on peut faire des trous plus ou moins fructueux ; mais ce ne sont pas là des fouilles... Les seules fouilles utiles qu'on puisse faire, si l'on veut faire du travail de vrai préhistorien, sont d'abord d'ordre stratigraphique. Or, il est exclu de faire de la stratigraphie sous l'eau !... » (Sauter 1955, p.l 16).

À partir de là, l'archéologie lacustre va mettre au point des techniques particulières d'intervention qui permettent de pratiquer des recherches sous deux à quatre mètres d'eau. Certaines d'entre elles, à l'origine des méthodes actuelles comme la triangulation, sont expérimentées dès 1953-1954 par R. Laurent et le Groupe de Recherches Archéologiques Lacustres de l'Union rhodanienne de Lyon (GRAL) sur les gisements de Meimart, de Grésine, de Châtillon, du Saut-de-la-Pucelle et de Conjux, dans le lac du Bourget, sur ceux du lac d'Aiguebelette, au Crêt-de-Chatillon et au Roselet, dans le lac d'Annecy (voir les Informations archéologiques de Gallia Préhistoire dans Combier 1959, p. 193-195 ; 1961, p. 310-314 ; 1963, p. 280-283 ; 1977, p. 655-668 et 1980, p. 517-520). Le 15 avril 1959, dans une conférence à l'Académie florimontane sur le thème Annecy à l'heure des palafittes, le Dr. P. Servettaz invite à reprendre des fouilles subaquatiques sur les vestiges immergés du lac d'Annecy (Académie florimontane 1959, p. 11-12). Sur la rive savoyarde du Léman, J.-C. Périllat et des membres du Club Subaquatique du Léman prospectent les gisements de l'âge du Bronze de Thonon-lesBains, de Nernier et de Sciez (Académie chablaisienne 1965, p. 19).

C'est à partir de 1965-1966 que seront réalisés les premiers prélèvements de pilotis destinés aux datations par le radiocarbone. Le tableau des dates fournies à cette époque, sur des matériaux malheureusement souvent mal positionnés stratigraphiquement, présente la liste des résultats compris entre 5000 et 2000 ans BP, avec les lieux des prélèvements, les années des recherches, les matériaux analysés et leur provenance sur les gisements, les références du laboratoire, les dates ${ }^{14} \mathrm{C} B P$ avec l'écart-type, les intervalles calibrés, ainsi que les contextes archéologiques tels qu'ils étaient alors perçus (fig. 1). 
1- Liste des analyses ${ }^{14} \mathrm{C}$ réalisées par R. Laurent, dans les années 1960-1970, pour des vestiges lacustres des périodes comprises entre 5000 et $2000 \mathrm{BP}$

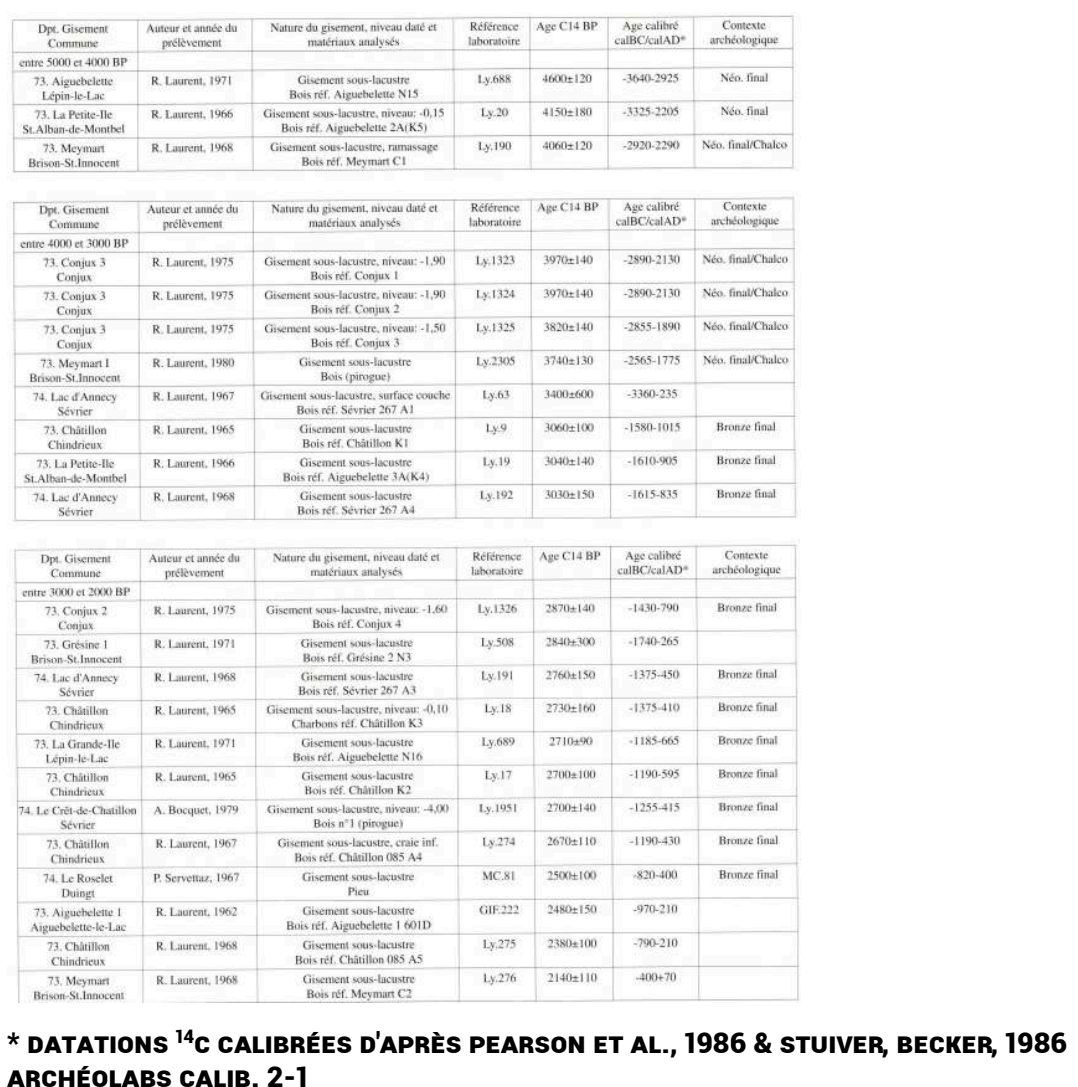

Pendant ce temps, O. Paret est traduit en français et dans Le mythe des cités lacustres et les problèmes de la construction néolithique, il démontre, en douze points, que les villages lacustres ont été construits à même le sol des plages libérées des eaux, et relance la polémique (Paret 1958, p. 46-73).

Dans une communication au 85e Congrès national des Sociétés savantes de Chambéry, le 8 avril 1960, sur le thème de La sédimentation postglaciaire et les palafittes des lacs de Savoie, P.-A. Gidon, s'appuyant sur l'étude des anciens niveaux des lacs et sur la nature des sédiments prélevés sur des sites archéologiques, conclut hâtivement «... ces villages étaient lacustres, et même assez éloignés des rivages pour qu'aucun galet ou gravier de dimensions centimétriques n'ait pu y être apporté de la rive, par les courants... » (Gidon 1962, p. 1318).

\section{La fin des années 1970 et le début des années 1980, l'état de la question}

Après l'arrêt des travaux de R. Laurent, vers 1974, les lacs d'Aiguebelette, du Bourget et d'Annecy sont délaissés, mais, au cours de ces années, il a constitué une très importante documentation (archives inédites, notes manuscrites, articles) qui vient d'être remise à la bibliothèque du DRASSM d'Annecy à l'occasion d'un dépouillement documentaire (Dumont 1997, p. 37-46).

47 La recherche subaquatique se tourne alors vers la fouille systématique. Dès 1972, A. Bocquet et le Centre de Documentation de la Préhistoire Alpine (CDPA) de Grenoble 
fouillent les vestiges d'habitats néolithiques du gisement des Baigneurs à Charavines (Isère), dans le lac de Paladru. Les méthodes et les matériels sont adaptés et perfectionnés pour répondre aux nécessités de la recherche pluridisciplinaire: exploration des couches par décapages horizontaux, repérage des vestiges et des structures dans les trois dimensions, prélèvement de tous les sédiments qui entourent les objets archéologiques (voir l'exposé des méthodes et l'essentiel des données chiffrées dans Bocquet 1994, p. 92-102).

En 1976, des mobiliers issus des stations de Charavines, Les Baigneurs (Bocquet 1976a, p. 145-151), d'Aiguebelette (Bocquet 1976b, p. 151-153), d'Annecy, Le Port (Bocquet et al. 1976b, p. 165-168), des collections anciennes des musées d'Annecy, de Chambéry et de Grenoble et de quelques autres gisements sont étudiés par A. Bocquet et publiés, ainsi que l'inventaire général des lacs alpins français (Bocquet et al. 1976a, p. 139-145), dans le livret-guide de l'excursion A9 du IXe Congrès de l'Union Internationale des Sciences Préhistoriques et Protohistoriques.

Autour du chantier-école des Baigneurs et de son responsable, R. Castel et le Centre d'Archéologie Lacustre d'Aix en Savoie (CALAS) réactualisent le recensement des sites du lac du Bourget (Castel 1983), P. Persoud et la section archéologique du Club Subaquatique Alpin (CSA) entreprennent de revisiter les gisements immergés dans celui d'Annecy (Marguet et al. 1984, p. 66-69). Ces bonnes volontés seront bientôt relayées et encadrées, à partir de 1980, par le Centre National de Recherches Archéologiques Subaquatiques (CNRAS). Plus récemment, Y. Billaud comme membre du club La Coulée Douce de Sévrier puis comme responsable de l'AREOLL, reprend, en collaboration avec le CNRAS/DRASSM, des activités archéologiques essentiellement orientées vers l'expertise des sites connus et l'établissement d'un inventaire des gisements.

\section{Potentiel archéologique des sites lacustres}

Nous l'avons vu plus haut, les années 1970 ont été marquées par la reprise des recherches sur des vestiges d'habitats néolithiques faiblement immergés, en bordure des lacs jurassiens à Clairvaux-les-Lacs (Jura), Station III (Pétrequin 1986b, p. 95-106), et dauphinois à Charavines, Les Baigneurs (Isère, lac de Paladru) (Bocquet 1974, p. 43-49).

51 Dans les gisements lacustres et palustres, les matériaux périssables (bois, fibres végétales, etc.) sont dans d'excellentes conditions de conservation. La masse des données recueillies en stratigraphie est considérable et tous ces mobiliers sont absents des fouilles terrestres : poteaux en bois des habitations, copeaux de débitage, éléments des planchers en bois ou en écorces, litières végétales, restes botaniques et graines, zones foyères, quelquefois éléments des parois et des charpentes, récipients ou ustensiles en bois et en vannerie, emmanchements, etc. Ces gisements, quoique d'accès difficile, constituent des archives de tout premier ordre.

Les méthodes et les techniques d'investigation sont différentes selon qu'il s'agit de domaines humide ou immergé, même à faible profondeur. Dans nos régions, les fouilles se pratiquent principalement en plongée, mais certains sites jurassiens sont fouillés à l'abri de caissons précaires dans lesquels le niveau de l'eau peut être abaissé par pompage. Toutes ces techniques sont maintenant largement connues (voir en particulier Bocquet et al. 1985, p. 137-157 ; Pétrequin 1986b, p. 95-106; Ruoff 1973, p. 125-140 et 1981, p. 62-70). Ces vingt-cinq dernières années, la multiplication des fouilles 
subaquatiques a considérablement amélioré les techniques d'exploration (relevés et plans systématiques, décapages stratigraphiques, échantillonnages importants, observations précises et détaillées, etc.) et a déterminé des conditions favorables pour une recherche rigoureuse et élargie.

Compte tenu de la complexité du milieu, les résultats obtenus depuis 1970 sont la preuve de l'efficacité d'une approche pluridisciplinaire qui intègre, de manière globale, les techniques de terrain et celles de laboratoire, les sciences de l'archéologie et celles du paléoenvironnement.

Cette collaboration est un des faits les plus remarquables, et si sa mise en oeuvre se révèle coûteuse, les résultats sont à la mesure de notre attente :

- étude sédimentologique des dépôts en rapport avec les variations du niveau des lacs et avec le climat ;

- détermination des abondants pollens, afin de connaître l'évolution locale du cadre végétal ;

- étude des graines et des macrorestes végétaux, pour une bonne connaissance des rapports entre le milieu végétal et son exploitation par l'homme ;

- détermination des plans de maisons par l'étude des bois de construction utilisés ;

- datations relative et absolue par l'étude dendrochronologique des phases d'abattage des arbres et des périodes de reconstruction;

- détermination des essences végétales des pieux et des bois horizontaux pour connaître l'exploitation des forêts;

- étude des mobiliers en rapport avec les vestiges de construction (copeaux), les aires d'activités spécialisées, les zones des rejets et leur chronologie relative, etc. (Pétrequin 1980, p. 778-785).

\section{Les questions, une problématique}

Dans le schéma interprétatif - villages lacustres sur pilotis/villages sur terre ferme - la problématique archéologique s'est longtemps réduite à la recherche d'éléments de l'histoire de l'environnement pour répondre à la question : quel était le niveau des lacs pendant l'occupation de leurs rives par les hommes préhistoriques?

Puis l'interprétation archéologique - villages sur terre ferme $=$ niveau plus bas qu'aujourd'hui = climat plus sec - est devenue partie intégrante des raisonnements des naturalistes qui ont adopté l'idée d'un abaissement du niveau des lacs subalpins comme preuve d'un climat plus sec pendant le Subboréal ; les hauts niveaux de l'Atlantique et du Subatlantique, périodes d'absence ou d'abandon des habitats littoraux, étant la preuve d'un climat alors plus humide.

Dans sa thèse Une approche paléoclimatique de l'Holocène : les fluctuations des lacs du Jura et des Alpes $d u$ nord françaises, travail fondamental pour comprendre la problématique naturaliste de la question palafittique et démonstratif d'une stratégie de recherche où sont prises en compte les données spatiales (les lacs jurassiens et subalpins français) et temporelles (l'Holocène), M. Magny rappelle ces interrogations et souligne la nécessité de bien individualiser :

- «d'une part, une problématique d'ordre archéologique: les habitats lacustres préhistoriques sontils des habitats construits sur terre ferme ou sur pilotis? Elle implique une recherche spécifique, centrée sur l'observation et l'interprétation de structures architecturales ;

- d'autre part, une problématique de type naturaliste : quel était le niveau d'un lac pendant l'occupation de ses rives par un groupe préhistorique? C'est une autre 
façon de poser la question précédente, mais c'est aussi une question différente : une régression n'implique pas forcément un habitat sur terre ferme ni une transgression un habitat sur pilotis...». archéologues et naturalistes sont difficiles à mettre en place, essentiellement en raison de la spécificité de chaque discipline, et en particulier des exigences de l'échantillonnage : «... un seul point de prélèvement ne pouvait convenir à toutes les disciplines à la fois !... » (Magny 1991, p. 3-8).

\section{Les acquis méthodologiques, un milieu original, des méthodes particulières}

Dans le cadre de cette communication, il semblait intéressant de souligner cette spécificité, au travers des recherches sur le Quaternaire qui ont favorisé les études sédimentologiques appliquées aux séquences stratigraphiques des sites archéologiques pour restituer leur environnement et dresser une séquence chrono-climatique de référence.

Un article essentiel de J.-L. Brochier, Les sédiments: documents archéologiques, paru au printemps 1988 dans le dossier Archéologie et sédiment du n³1 des Nouvelles de l'Archéologie, auquel on se reportera utilement pour justifier, s'il en est besoin, la démarche géoarchéologique, montre bien l'intérêt qu'il y a à multiplier ces études et propose une certaine méthodologie d'approche du terrain où, d'un côté, l'archéologue travaille avec les éléments de la culture matérielle et, de l'autre, les spécialistes des sciences de la terre et de la nature reconstituent le milieu naturel :

«... le sédiment se révèle être un document archéologique à part entière... Avant tout autre vestige, il devient matière première d'étude pour l'archéologue qui ne peut plus l'ignorer... ».

61 Dans deux chapitres, également intéressants, Hors du site d'habitat: quand le sédiment révèle l'espace géographique occupé par l'homme et Sur le site d'habitat: quand le sédiment reflète la vie des hommes, il montre les relations entre une recherche horizontale, spatiale, qui prend en compte l'espace géographique d'une culture et une approche verticale, stratigraphique.

Dans le premier cas, par des explorations dans l'environnement de sites (tranchées, sondages, carottages),

«... il s'agit de mieux comprendre ce qui lie une culture à l'espace qu'elle occupe et cela en travaillant plus en synchronie que ponctuellement en diachronie... En l'absence de tout mobilier archéologique, une séquence sédimentaire peut être une magnifique image de l'occupation humaine. L'analyse d'un système - habitats, versants occupés, amont/aval, rythmes d'érosion/sédimentation - permet de retracer la vie, non pas d'un site, mais d'un ensemble de sites (même si tous ne sont pas connus),...».

63 La reconstitution des paléoenvironnements, successions de phases climatiques et de paysages, ne se contente plus

« ... des données obtenues sur les sites d'habitat car elles ont toutes les chances d'être déformées par une trop forte anthropisation (il faut leur adjoindre des données prélevées loin de l'habitat)... ».

Dans l'autre cas, par l'observation des superpositions stratigraphiques, J.-L. Brochier montre comment, en étudiant la dynamique des dépôts (phases de construction, 
d'utilisation, d'abandon, apports naturels, etc.), il est possible de considérer les variations horizontales de certains faciès sédimentaires comme de véritables faits anthropiques (Brochier 1988, p. 15-17).

Pour les domaines littoraux du Plateau suisse et du Jura français, de nombreux ouvrages et articles indispensables illustrent cette nouvelle approche méthodologique, chronostratigraphique et palethnographique de la sédimentologie, réalisée sous l'angle archéologique et basée sur une connaissance plus systématique du milieu lacustre et de sa dynamique. On citera entre autres, dans un ordre chronologique de parution, les travaux de M. Magny, de J.-L. Brochier et M. Joos, et de B. Moulin dans lesquels on trouvera la bibliographie générale sur ce sujet (Magny 1978; Brochier et al. 1982, p. 43-67 ; Magny 1986, p. 129-132 ; Magny 1987, p. 181-211 ; Magny 1991, p. 49-144 ; Moulin 1991, p. 1-127 ; Magny 1992, p. 27-49).

66 À la fin des années 1960, la reprise et la multiplication des fouilles en bords de lacs, notamment en Suisse, entraîne un renouveau de l'archéologie lacustre où les études naturalistes sont davantage prises en compte, même si elles se limitent encore souvent à l'analyse d'une seule et unique colonne stratigraphique échantillonnée par chaque spécialiste.

C'est sans doute l'un des apports essentiels des fouilles entreprises à Clairvaux par P. Pétrequin et à Charavines par A. Bocquet, que d'avoir élaboré une problématique globale où collaborent archéologues et naturalistes, tout en laissant à chacun la liberté de sa démarche. S'agissant de la sédimentologie, ces fouilles ont marqué un renouveau méthodologique.

Pour étayer ce propos, on empruntera à M. Magny quelques éléments caractéristiques de l'approche pluridisciplinaire engagée dans ce domaine sur des habitats littoraux; ils sont présentés dans un texte synthétique de référence, Sédimentologie lacustre et archéologie, paru dans le dossier Archéologie et sédiment du n³1 des Nouvelles de l'Archéologie.

En rapport avec la question palafittique, il était important de rechercher des critères pour apprécier la profondeur du dépôt à analyser. Par l'étude des sédiments qui se forment actuellement sur les lacs jurassiens, trois catégories de critères ont été retenus par M. Magny :

- " ... la nature des dépôts: les tourbes correspondent aux faciès littoraux d'atterrissement, et les craies lacustres aux faciès lacustres proprement dits ;

- la granulométrie des dépôts : les sédiments exposés à l'action des vagues en raison de la faible profondeur de l'eau, sont plus grossiers que les sédiments déposés à plus forte profondeur;

- les types de concrétions constituant les craies lacustres: les craies...sont constituées de différents types de concrétions dont la répartition montre une certaine zonation sur la plateforme littorale...en fonction de la profondeur... ».

Plusieurs niveaux d'observation sont donc à distinguer, qu'il s'agisse de couches archéologiques, fumiers composés essentiellement des apports anthropiques, ou de couches stériles qui les séparent, limons, craies ou sables d'origine naturelle. Les couches archéologiques font l'objet d'investigations qui ne se limitent plus aux seuls artéfacts, mais qui concernent également le repérage des structures sédimentaires caractéristiques (cordons littoraux, rigoles d'érosion, niveaux de condensation, etc.) et leur position stratigraphique par rapport aux structures archéologiques.

«... Il faut prendre conscience qu'il ne s'agit pas là d'une tâche dévolue au sédimentologue, sinon il devrait être le seul à fouiller! Il s'agit au contraire d'une 
recherche qui doit compter parmi les préoccupations constantes des archéologues au cours de la fouille d'un site lacustre... ».

71 Dans cette démarche de reconstitution des mouvements d'un lac avant, pendant et après l'installation d'un habitat, et dans la perspective de comprendre comment cet habitat s'inscrit dans la dynamique lacustre, quelques principes s'imposent :

- «... la nécessité de travailler sur plusieurs colonnes disposées en transects (repérage des lacunes, des faciès latéraux...) ;

- l'apport essentiel d'un échantillonnage réalisé selon une maille très serrée (corrélations stratigraphiques, précision des reconstitutions...) ;

- l'importance de la collaboration avec la palynologie, en particulier pour les références chronologiques qu'elle offre (chronozones...)... » (Magny 1988, p. 18-20).

72 Les sédiments lacustres ont imposé, par l'abondance du matériel d'origine organique conservé et la complexité des modes de dépôt, une approche pluridisciplinaire où sont intégrées les recherches culturelles, chronologiques et la reconstitution des modes de vie et des paysages.

H. Richard, dans un bref article Milieux lacustres. Sciences de la nature et archéologie paru dans le Courrier du CNRS, démontre l'ambition d'une telle démarche qui, pour aboutir à la reconstitution des modes d'exploitation du milieu, tente de replacer les habitats dans un cadre chronologique, physique et végétal précis et d'évaluer l'impact des installations humaines sur le dynamisme naturel d'un lac et sur celui du couvert végétal.

Le palynologue qui étudie les sites lacustres où les pollens sont très nombreux et parfaitement conservés, a dû, comme le sédimentologue, pour répondre aux questions concernant les variations de niveaux des lacs, mettre au point une nouvelle méthode d'analyse des sédiments. Fondée sur l'établissement de modèles actuels, notamment le comportement de certains taxons, et sur de très nombreuses analyses, cette réflexion méthodologique a permis de proposer une évolution de l'habitat néolithique et protohistorique en termes de pratiques agricoles, dans un environnement végétal que les analyses palynologiques anciennes permettaient déjà de retracer dans ses grandes lignes.

Autre particularité de ces milieux anaérobies, la possibilité qu'ils offrent pour les études paléoethnobotaniques. L'analyse des macrorestes végétaux conservés s'est avérée fondamentale pour la description des relations entre l'homme et son environnement végétal. L'identification des restes de plantes renseigne sur l'alimentation; la nature des sols cultivés et les techniques de production agricole (nature des cultures, saisons des semailles, techniques de moissons, conservation et stockage...) ont pu être abordées grâce à la connaissance des comportements écologiques et sociologiques des plantes ; l'abondance des graines et des fruits met en évidence le rôle important de l'exploitation des ressources naturelles et permet de comprendre la manière dont sont employées les terres défrichées aux alentours d'un village ; la détermination des essences de bois précise les actions de défrichements et l'emploi de ces bois pour la construction; la répartition spatiale de tous ces vestiges permet de proposer une organisation du village (zones de stockage, de dépotoirs, etc.) (Richard 1989, p. 24-25).

76 Une autre technique est indissociable de l'archéologie lacustre : la dendrochronologie qui analyse les cernes annuels de croissance des arbres et permet de dater les bois en comparant leurs rythmes de croissance respectifs. 


\section{En paléoclimatologie}

- Une approche paléoclimatique de l'Holocène: les fluctuations des lacs du Jura et des Alpes du Nord françaises (Magny 1991) ;

- Le climat à la fin de l'âge du Fer et dans l'Antiquité (500 BC-500 AD). Méthodes d'approche et résultats (Collectif 1992).

- Une histoire du climat, des derniers mammouths au siècle de l'automobile (Magny 1995a) ;

- Les sédiments des lacs, miroir du climat (Magny 1995b, p. 60-65). 


\section{En dendrochronologie}

- La dendrochronologie ou le passé lu dans le bois. Un nouveau laboratoire du Musée cantonal d'archéologie (Lambert et al. 1976, 101-110) ;

- L'état de la dendrochronologie en Europe occidentale et les rapports entre dendrochronologie et archéologie en Suisse (Lambert et al. 1977. p. 73-97) ;

- Application dendrochronologique à l'étude structurelle de sites archéologiques palustres de Suisse et de France alpine (Orcel,1980, p. 25-38);

-Analyse dendrochronologique des bois de la station littorale d'Auvemier-Port (Orcel et al. 1982, p. 117-129) ;

- La dendrochronologie et l'interprétation des structures d'habitats néolithiques. L'exemple de Montilier/Platzbiinden (lac de Morat, Suisse) (Ramseyer 1985, p. 20-31) ;

- A propos dendrochronologie : science ou technique de datation? le " bon choix " dans l'application archéologique (Billamboz 1986, p. 112-113);

- La méthode dendrochronologique (Ruoff 1986, 19-24);

- Le bois raconte l'histoire des hommes et de la forêt (Billamboz 1987, p. 30-38);

- Dendrochronologie et préhistoire (Lambert et al. 1990, p. 143-152).

\section{Les problèmes archéologiques, géologiques, climatiques et botaniques}

Des contributions synthétiques sur ces questions ont été présentées à l'occasion du colloque organisé par la Société de Physique et d'Histoire naturelle de Genève sur le thème de L'habitat lacustre préhistorique auxquelles on se reportera pour l'essentiel des problèmes archéologiques posés :

- Etat actuel des connaissances sur les problèmes archéologiques (Pétrequin 1983, p. 215-232) ;

- Aspect climatologique et botanique (Schweingruber 1983, p. 233-245);

- L'habitat lacustre préhistorique ; problèmes géologiques (Brochier 1983, p. 247-260).

Les relations entre l'habitat palafittique et les variations du niveau des eaux restant une question de première importance, d'autres articles présentent la vision d'une stratégie pour l'analyse archéologique de ces gisements, voir en particulier :

- Archéologie lacustre et dynamique culturelle (Magny 1984b. p. 243-250);

- Historique des recherches. Les idées et les méthodes (Pétrequin 1986a, p. 13-26) ;

- La stratigraphie et la dynamique de sédimentation. Le point de vue de l'archéologue (Pétrequin, 1986c, p. 107-127) ;

- Habitats littoraux présents et passés: confrontation entre un modèle ethnoarchéologique et une analyse de site archéologique (Nicoud 1992, p. 239-255).

Les vingt-cinq dernières années de recherches sur les vestiges lacustres peuvent être considérées comme exemplaire des démarches nouvelles en archéologie préhistorique et de ces récents progrès.

L'application de modèles paléoenvironnementaux à un raisonnement archéologique a donné un nouveau souffle à l'étude de la préhistoire lacustre: les conditions climatiques des bords des lacs, les relations homme/milieu, les organisations socioéconomiques et le fonctionnement des sociétés agricoles peuvent, dès lors, être précisées. Pour résumer, et pour mieux cerner la spécificité de l'habitat palafittique comme adaptation à un milieu naturel particulier et comme manifestation de 
contraintes économiques et culturelles, on extraira de l'article de M. Magny Un cadre climatique pour les habitats lacustres préhistoriques? les points fondamentaux :

«Depuis 10 ans, une recherche systématique a été entreprise sur les fluctuations holocènes du niveau des lacs du Jura afin d'établir quel était l'environnement climatique des habitats lacustres préhistoriques jurassiens et subalpins. Les fluctuations du niveau de ces lacs ont été reconstituées à partir de l'étude sédimentologique de leurs remplissages et par la mise en oeuvre d'une méthode spécifique... Les séquences stratigraphiques analysées ont été échantillonnées sur des sites archéologiques qui offrent des références chronologiques très précises grâce à la dendrochronologie. Mais le plus souvent, il s'agit de séquences échantillonnées en dehors de tout site archéologique, l'objectif étant de couvrir l'ensemble de l'Holocène et de disposer d'une base de données suffisante pour aboutir à une histoire des lacs et du climat au cours des 10 derniers millénaires. Ces travaux ont permis d'aboutir à un schéma paléohydrologique régional où l'histoire holocène des lacs jurassiens apparaît caractérisée par l'alternance de phases transgressives et régressives d'ordre pluriséculaire. L'origine climatique de ces fluctuations est confirmée par le parallélisme existant entre l'histoire des lacs du Jura et celle des glaciers et de la limite supérieure de la forêt dans les Alpes suisses et autrichiennes... : les transgressions lacustres sont en phase avec des avancées des glaciers et des abaissements de la timberline, et inversement. D'autre part, grâce en particulier à la précision des références chronologiques disponibles sur les sites archéologiques, il est possible de montrer que les fluctuations des lacs jurassiens au cours des 6 derniers millénaires se calquent sur les variations de la teneur de l'atmosphère en ${ }^{14} \mathrm{C} . .$. "

«Il reste maintenant à comparer l'histoire des stations littorales à celle des lacs et du climat qui vient d'être retracée par une approche naturaliste indépendante de toute interprétation archéologique concernant les structures d'habitat. Pour procéder à cette comparaison, une courbe de fréquence des habitats littoraux a été établie pour le Néolithique et l'âge du Bronze en se basant uniquement sur les références dendrochronologiques actuellement disponibles pour la France et la Suisse, soit près de 150 références... Les phases majeures d'habitat lacustre coïncident avec des périodes de faible teneur de l'atmosphère en ${ }^{14} \mathrm{C}$, c'est-à-dire avec des phases au climat plus chaud. Ces corrélations permettent de mettre en évidence que le développement des stations littorales préhistoriques s'inscrit bien au cours de phases régressives, telles qu'elles ont pu être définies dans le Jura... ». "On se gardera toutefois de conclure hâtivement à un déterminisme trop mécaniste du climat sur l'habitat lacustre préhistorique. Si cet habitat s'inscrit effectivement à l'intérieur de régressions, cela ne signifie en aucune manière que la durée des deux phénomènes soit identique : celle des régressions a sans doute largement excédé celle des villages... » (Magny 1993a, p. 1619-1625).

$88 \mathrm{Au}$ nord-ouest des Alpes, principalement sur les lacs du Plateau suisse, directement menacés par d'importants travaux d'infrastructure, les recherches en milieu humide se sont développées à partir des années 1970.

En multipliant les hypothèses de travail, en particulier d'observations sur l'environnement actuel, les recherches les plus récentes permettent de donner des cultures des IVe-IIIe millénaires av. J.-C. et du début du Ier une image bien différente de celle qu'on avait jusqu'alors. Une abondante littérature traduit l'évolution des méthodes d'analyses étroitement liées aux sciences naturelles qui aident à l'interprétation des vestiges archéologiques que nous ne pouvons pas développer dans cette contribution. Voir en particulier les catalogues :

- Cahiers d'Archéologie Romande (fouilles d'Yverdon, Garage-Martin et Avenue des Sports (VD), d'Yvonand (VD), d'Auvernier-Port, La Saunerie, Les Graviers, Brise-Lames (NE), lac de Neuchâtel) ; 
- Die neolithischen Ufersiedlungen von Twann (fouille de Douanne (BE), lac de Bienne) ;

- Archéologie Neuchâteloise (fouilles de Cortaillod-Est, d'Hauterive-Champréveyres et de St.Blaise/Bains-des-Dames, lac de Neuchâtel) ;

- Archéologie Fribourgeoise (fouilles de Delley/Portalban II, lac de Neuchâtel et de Muntelier/ Platzbiinden, lac de Morat). lacustres du début du Néolithique moyen jusqu'à la fin du Bronze ancien (ce qui reste encore tout à fait exceptionnel dans les lacs français), et de Charavines, Les Baigneurs, gisement du Néolithique final, constituent des ensembles remarquables.

91 expériences des fouilles sur le lac de Neuchâtel, ont mis en oeuvre dans un cadre universitaire et de recherches, un large éventail de spécialités qui ont abouti à l'incontournable monographie sur le sujet :

fouilles de A. Bocquet, Centre de Documentation de (CDPA) sur le gisement dauphinois des Baigneurs, dans un cadre institutionnel qui n'a pas permis la création d'un véritable groupe de travail, la publication générale des fouilles arrêtées en 1986 est en cours de réalisation. Des études préliminaires ont été publiées, certaines sur des thèmes précurseurs de la discipline pour les Alpes du Nord :

- Premiers résultats dendrochronologiques dans les structures de la station des Baigneurs à Charavines (Isère) (Bocquet et ai 1975, p. 15-20);

- Recherches sur la compréhension des structures du village des Baigneurs à Charavines (Bocquet 1980, p. 23-33) ;

- La sédimentologie lacustre spatiale : étude d'une surface d'habitat sur la station des Baigneurs, lac de Charavines (Brochier 1982, p. 51-55);

- Caractérisation typologique, étude statistique et répartition spatiale de la céramique du site Néolithique final de Charavines, Les Baigneurs (Isère) (Ferrer-Joly 1988);

- Les rapports entre les déchets anthropiques et les structures de la station du Néolithique récent de Charavines, Les Baigneurs (Isère) : étude sur l'organisation de l'espace (Christien 1988) ;

- Histoire d'une inondation : la couche de craie B2 du site néolithique des Baigneurs à Charavines, lac de Paladru, France (Brochier et al. 1992, p. 61-82) ;

- L'organisation spatiale de ta station de Charavines, Les Baigneurs (hère) (Christien et al. 1993, p. 63-71) ;

- L'architecture d'un village néolithique à Charavines dans l'Isère (Bocquet 1995, p. 25-33).

\section{État des connaissances sur les occupations littorales des lacs alpins français}

À quelques exceptions près et faute de fouilles d'envergure, la collaboration interdisciplinaire, telle que nous venons de la décrire pour une approche globale des habitats littoraux, n'a pas encore de véritable existence dans le domaine géographique concerné par ce chapitre, à savoir les lacs savoyards d'Aiguebelette et du Bourget et haut-savoyards d'Annecy et du Léman (fig.2) ${ }^{2}$. 
2- Situation géographique des lacs d'Aiguebelette, du Bourget, d'Annecy et du Léman dans les Alpes de Savoie

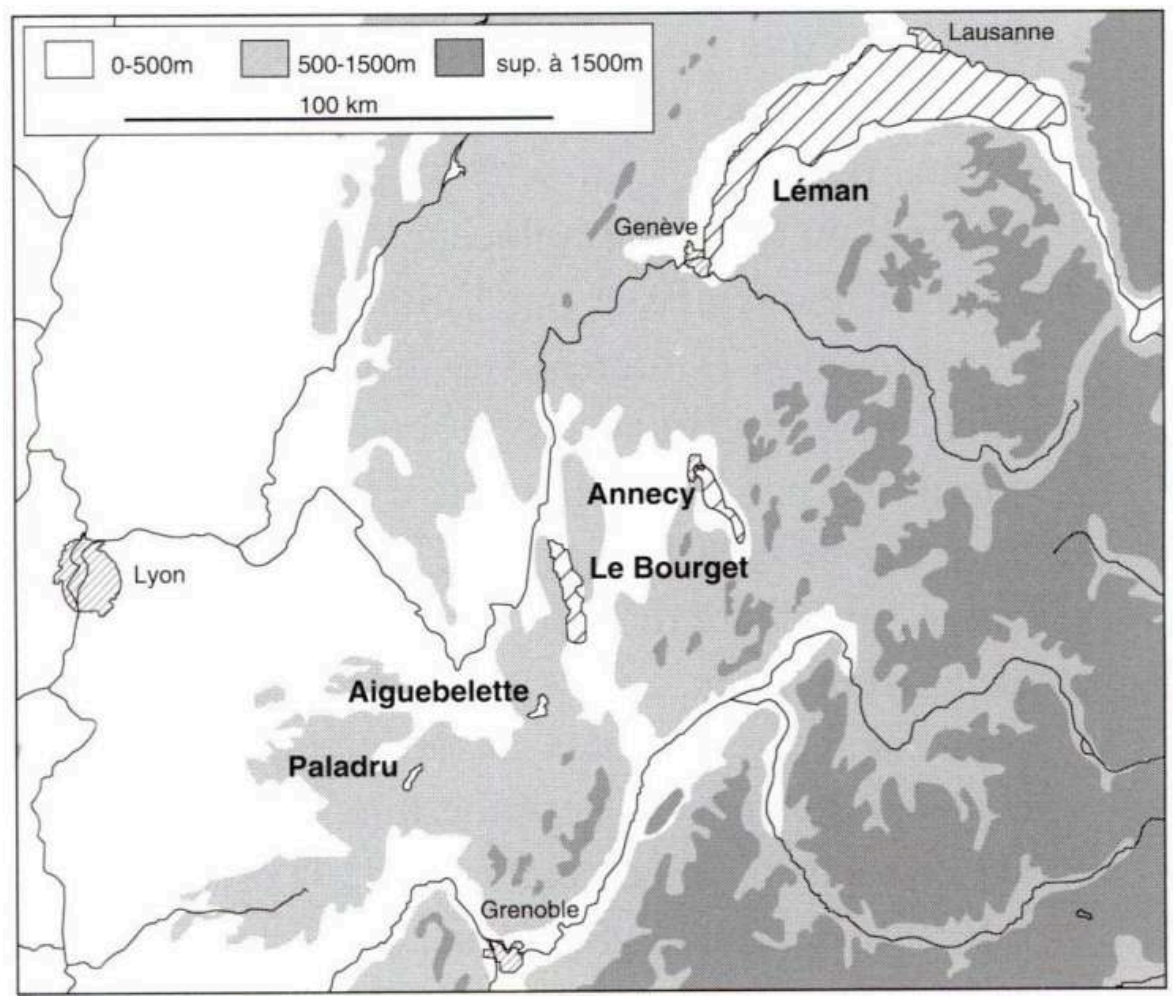

Des données nouvelles nous sont fournies sur des gisements immergés pour lesquels les vestiges sont bien datés par le radiocarbone ou par la dendrochronologie. A partir d'interventions ponctuelles récentes, il est possible de faire le point sur la documentation accumulée pour le Néolithique et l'âge du Bronze ; elle est en partie publiée dans les actes du Colloque d'Ambérieu-en-Bugey (Marguet et al. 1995, p. 167-196) et le sera prochainement dans ceux du XIIIe Congrès de l'Union Internationale des Sciences Préhistoriques et Protohistoriques (UISPP) de Forli (Italie) (Billaud et al. à paraître).

\section{La problématique de recherche et les méthodes d'investigation}

En 1976, la carte de répartition des stations littorales immergées dans les lacs alpins français d'Aiguebelette et du Bourget en Savoie, d'Annecy et du Léman en HauteSavoie, mentionnait 41 gisements pour lesquels la typologie permettait une attribution chronologique: Néolithique moyen 2, Néolithique récent/final 13, Bronze ancien 1, Bronze final 21, âge indéterminé 4.

Mais jusqu'au début des années 1980, rares étaient les gisements bien datés, seuls 5 l'étaient à la suite d'analyses de pilotis par le radiocarbone, et plus rares encore ceux pour lesquels des observations stratigraphiques avaient été réalisées.

À la fin des années 1970, les datations dendrochronologiques très précises, obtenues notamment par le laboratoire de Neuchâtel mis en place pour l'exploitation des bois des fouilles d'Auvernier, avaient beaucoup précisé les chronologies existantes, elles s'appliquaient globalement aux cadres chrono-typologiques adoptés pour nos régions. 

ancienne, les sites des lacs savoyards et haut-savoyards étaient mal connus, des choix méthodologiques ont été élaborés par le Centre National de Recherches Archéologiques Subaquatiques (CNRAS) et l'Association pour la Recherche et l'Etude des Occupations Littorales Lacustres (AREOLL) : localisation, état de conservation et chronologie des gisements. Dans un but de protection du patrimoine archéologique lacustre (inventaire des gisements) et de connaissance des peuplements palafittiques (datation des sites), des prospections subaquatiques ont été réalisées pour l'élaboration de la carte archéologique. Ces deux équipes, bien que de nature et de taille différente, travaillent en étroite collaboration depuis plus de 10 ans. Un inventaire systématique des gisements et leur diagnostic sont en cours de réalisation, tant sur des sites anciennement connus que sur des gisements inédits. Au delà de l'aspect purement technique de l'intervention en milieu subaquatique, ce travail vise, en premier lieu :

- le repérage du gisement et la délimitation des emprises archéologiques avec rattachement topographique des axes de référence au système cadastral terrestre ;

- l'identification spatiale d'éventuels secteurs privilégiés par la topographie de pilotis, dans des unités triangulaires de $5 \mathrm{~m}$ de côté, implantées en divers endroits du gisement (fig. 3) ;

- l'évaluation de l'état de conservation des ensembles sédimentaires par la reconnaissance de la nature des fonds, à l'aide de carottages pratiqués suivant des profils longitudinaux et transversaux (fig. 4);

et en second lieu :

- l'échantillonnage d'un nombre significatif de pilotis bien topographiés pour le calage chronologique du gisement en datation absolue par la dendrochronologie et le radiocarbone ;

- le prélèvement, dans un sondage limité $\left(2 \mathrm{~m}^{2}\right)$, d'un choix de mobiliers pour le positionnement chrono-typologique des vestiges et l'attribution typologique des collections anciennes mises au jour hors de tout contexte ;

- l'élaboration des références sédimentologiques et palynologiques régionales, par carottages, pour la reconstitution paléogéographique des fluctuations des lacs et de l'histoire de la végétation. 
3- Répartition planimétrique des pilotis topographiés sur le gisement de l'âge du Bronze ancien de Sévrier, Les Mongets (Haute-Savoie, lac d'Annecy)

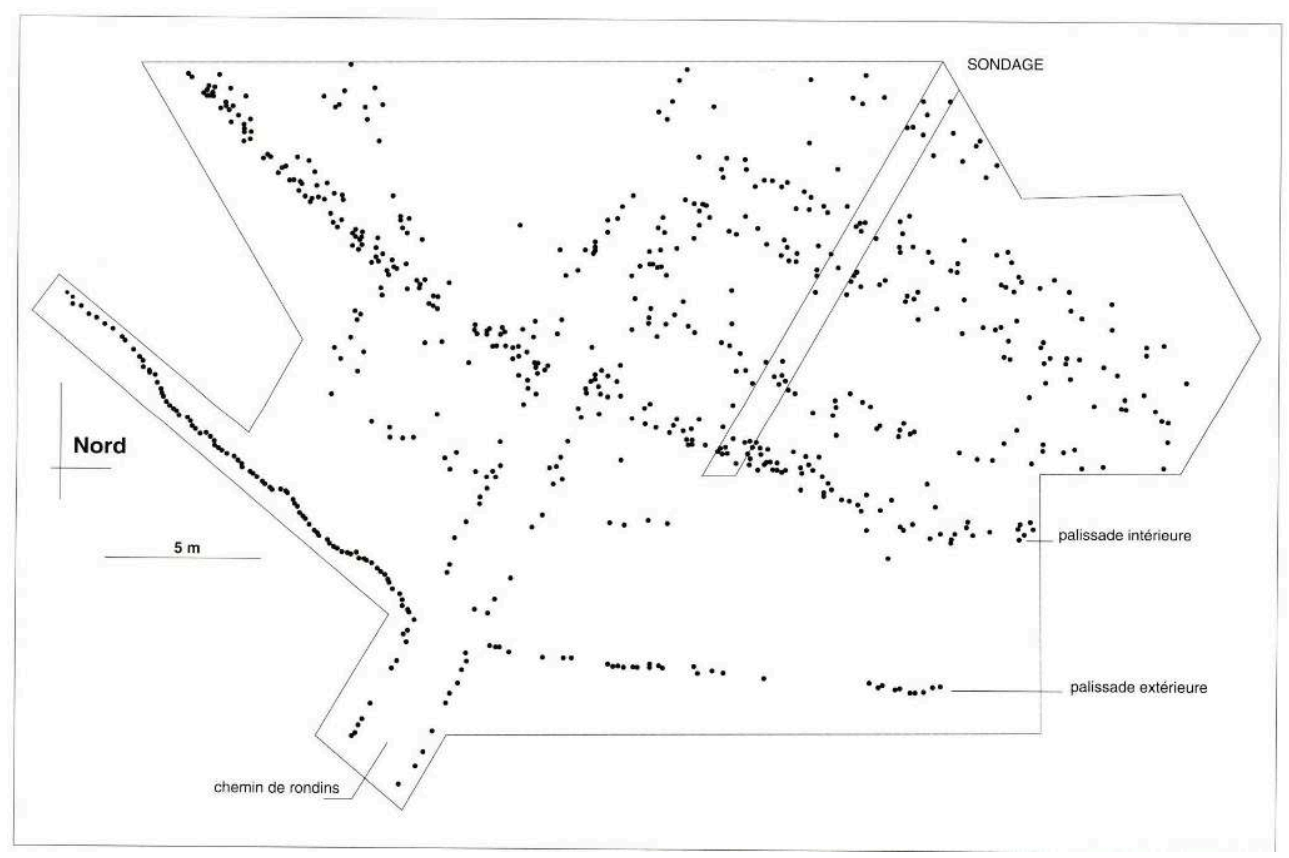

4- Plan bathymétrique et définition des emprises archéologiques, à niveaux organiques en place (hachures serrées) et à indices de limons teintés par lessivage des fumiers (hachures larges), déterminées par les carottages sur le gisement de l'âge du Bronze final de Brison-St.-Innocent, Grésine-Ouest (Savoie, lac du Bourget)

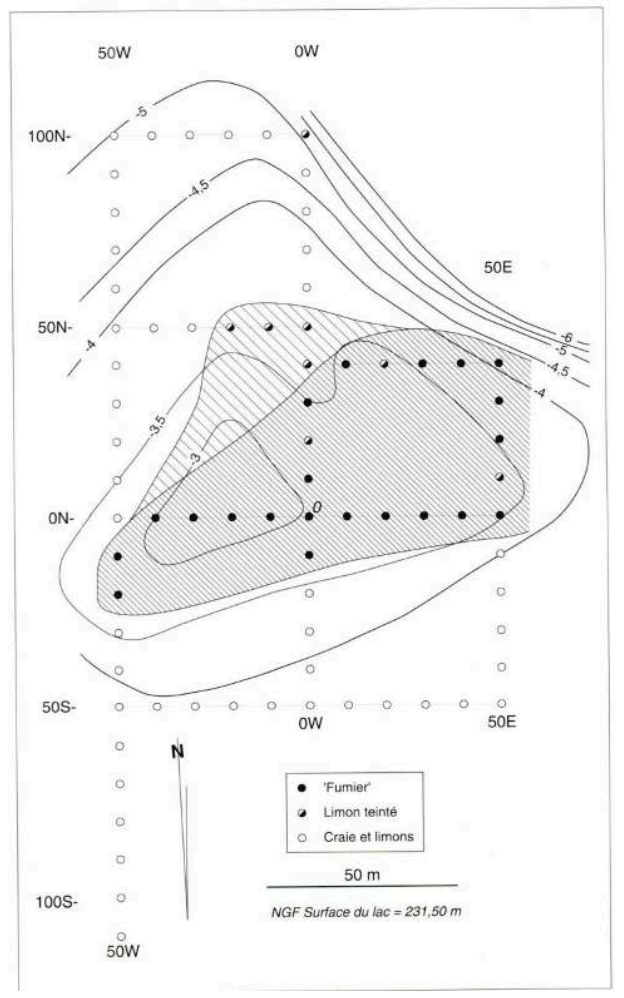




\section{Le contexte géomorphologique et climatique}

102 Des lacs, dont le niveau a varié, ont occupé les dépressions du Bourget, d'Annecy et du Chablais, dans cette zone subalpine. Le contexte paléogéographique de leur évolution spatiale, postérieurement aux glaciations, est largement connu par les études spécialisées (voir en particulier Vernet et al. 1971; Benedetti-Crouzet 1972 et Monjuvent et al. 1987 qui font le point bibliographique pour les lacs Léman, d'Annecy et du Bourget). La morphologie des cuvettes lacustres holocènes, le système lacustre et les remplissages sont notamment traités dans :

- Les lacs français (Delebecque 1878);

- Une approche paléoclimatique de l'Holocène: les fluctuations des lacs du Jura et des Alpes du Nord françaises (Magny 1991, p. 15-48).

Les schémas paléoclimatique et chronologique déjà esquissés, en particulier pour le domaine lémanique (voir sur ce sujet Olive 1972, p. 253-264 ; Gallay et al. 1979, p. 44-49 ; Gaillard et al. 1981, p. 117-121; Gallay et al. 1981, p. 129-157 et Magny et al. 1981, p. 159-169), ont été considérablement mis à jour, par les naturalistes et les archéologues, dans le cadre d'un programme DGRST (1982-1983) puis d'un contrat ATP du CNRS (1984) intitulé Paléoenvironnement holocène des Alpes françaises du Nord et leur piémont (Vivian et al. 1986). 45 spécialistes de différentes disciplines (sédimentologie, géomorphologie, climatologie, paléobotanique, palynologie, paléozoologie, paléoethnologie, techniques de datation) ont rassemblé les données récentes et réalisé des études complémentaires qui font le point sur l'environnement holocène et la Préhistoire dans les Alpes du Nord. Les résultats de ce travail, le premier du genre dans nos régions et pour lequel de nombreux gisements du domaine lacustre ont été échantillonnés par nous (Magny et al. 1985, p. 253-277 et Magny 1991, p. 415-480), sont présentés, par période culturelle et par étape de l'histoire de la végétation, dans :

104 -Tableau diachronique de l'Holocène et du Tardiglaciaire dans les Alpes du Nord et leur piémont. Préhistoire et paléoenvironnement (Bintz et al. 1989, p. 51-60).

Au cours des dix derniers millénaires, les lacs, soumis aux variations climatiques, ont vu leur niveau varier à plusieurs reprises jusqu'à des temps très récents. Evolution des bassins lacustres et possibilités d'implantation humaine sur les rivages sont par conséquent à mettre en étroite relation.

Bien que très différents par leur dimension, par leur altitude, par l'étendue et la zone géographique de leur bassin versant, les lacs concernés, qu'ils soient jurassiens ou alpins, possèdent un certain nombre de caractères communs. Ce sont tous des lacs à stratification chimique et biologique, riches en carbonates de calcium. Ces données strictement limnologiques mises à part, nous ne retiendrons pour les comparer que le critère morphologique côtier, avec plate-forme littorale (beine) et rupture de pente (mont). C'est sur ces beines peu profondes, dont la largeur dépend de la sédimentation de dépôts d'origine biochimique (précipitations des carbonates), de l'accumulation des apports terrigènes arrachés aux pentes des bassins versants et de la redistribution dynamique des matériaux littoraux déplacés sous l'action érosive des vagues, que nous retrouvons les vestiges archéologiques faiblement immergés, en général peu distants des rivages actuels (Magny 1991, p. 9-48).

107 L'examen stratigraphique, les analyses des sédiments et des pollens, les calages chronologiques, ont permis de retracer les variations du niveau de plusieurs lacs 
durant l'Holocène, comme le montre le graphique de comparaison entre les variations à court terme $\mathrm{du}^{14} \mathrm{C}$ résiduel atmosphérique et les fluctuations du niveau des lacs du Jura dressé par M. Magny du Laboratoire de Chrono-écologie de Besançon (Magny 1995a, p. 86).

Pour les périodes néolithique et de l'âge du Bronze et sans préjuger de la date ni de la durée des installations humaines, les lacs subalpins et jurassiens « ... portent la marque de fluctuations climatiques pluriséculaires entrecoupées d'épisodes secondaires, en particulier au cours de l'Atlantique et du Subboréal... ».

Dans le modèle régional d'évolution paléohydrologique constitué à partir de l'étude de 21 lacs des régions du Jura central et méridional et de la zone subalpine, M. Magny distingue les phases pluriséculaires suivantes au cours de l'Holocène (les dates radiocarbones sont indiquées : $\mathrm{BP}$, les dates radiocarbone calibrées : cal. $\mathrm{BC}$, et les dates dendrochronologiques : $\mathrm{BC})$ :

• « ...début du Boréal (de 9000 à $8700 \mathrm{BP}$ environ) : régression;

- milieu du Boréal : transgression qui commence vers $8700 \mathrm{BP}$ et s'achève vers $8300 \mathrm{BP}$; elle peut se prolonger jusque vers $8000 \mathrm{BP}$;

- fin du Boréal-première moitié de l'Atlantique ancien : régression qui commence vers 8300 BP et s'achève vers 6800 BP ;

- deuxième moitié de l'Atlantique ancien : transgression qui commence vers $6800 \mathrm{BP}$ (soit environ $5800 \mathrm{cal} . \mathrm{BC}$ ) et s'achève vers $6100 \mathrm{BP}$ (soit environ $5100 \mathrm{cal} . \mathrm{BC}$ );

- transition Atlantique ancien-Atlantique récent : régression qui commence vers $6100 \mathrm{BP}$ et s'achève vers $5700 \mathrm{BP}$ (soit environ $4800 \mathrm{cal}$. BC);

- milieu de l'Atlantique récent : transgression qui commence après 4800 cal. $B C$ et s'achève avant 3800 cal. BC;

- fin de l'Atlantique récent (vers $3800 \mathrm{cal}$. $\mathrm{BC}$ ) : régression; cette phase a été aussi reconnue au lac de Neuchâtel où elle commence avant $3810 \mathrm{BC}$ et s'achève après $3679 \mathrm{BC}$;

- début du Subboréal : transgression qui commence après 3800 cal. $\mathrm{BC}$...et s'achève entre environ 2800 BC et 2200 cal. BC selon les lacs... ;

- milieu du Subboréal : régression. Il s'agit de la phase la mieux marquée de l'Holocène qui s'est traduite dans plusieurs cas par une importante érosion ; elle s'achève après 1865-1532 cal. $\mathrm{BC}$, et vraisemblablement après $1700 \mathrm{BC}$ d'après la séquence stratigraphique de La Motte-aux-Magnins à Clairvaux ;

- dernier tiers du Subboréal : transgression qui commence après $1700 \mathrm{BC}$ et s'achève avant $1050 \mathrm{BC}$;

- fin du Subboréal : régression qui commence avant $1050 \mathrm{BC}$ et s'achève après $850 \mathrm{BC}$; cette phase est tripartite aux lacs de Pluvis et d'Annecy... » (Magny 1993b, p. 253-282).

110 À partir des études sur les alternances de sédiments fins, de matériaux détritiques plus grossiers et d'horizons organiques, témoins privilégiés des phases transgressives et régressives, plusieurs modèles d'évolution ont été proposés, notamment pour les lacs du Bourget et d'Annecy. Les analyses sédimentologiques (M. Magny) et palynologiques (H. Richard) entreprises depuis plus de dix ans dans les lacs savoyards (Hautecombe, Conjux et Châtillon au lac du Bourget; Les Marais, Angon, Le Port, Les Mongets, Le Roselet et Ruphy au lac d'Annecy) permettent de les intégrer parfaitement aux séquences climatiques holocènes du Jura. Les lacs subalpins ont connu une évolution parallèle indépendamment de leur régime glaciaire; ainsi l'histoire des habitats préhistoriques du Léman ne montre aucune différence majeure avec celle des lacs du Jura. 

d'Annecy : Climasilac, un projet sur les variations du niveau du lac d'Annecy depuis 15000 $B P$ est mené en collaboration (convention Climasilac/Conseil Général/Ministère de la Culture/Laboratoire de Chrono-écologie); des sondages de reconnaissance de stratigraphies et des prélèvements de carottes ont eu lieu à St.-Jorioz, Le Beau, sur 17 mètres de profondeur (altitude de départ 446,95/altitude atteinte 430,00; lac normal à $446,97 \mathrm{~m} \mathrm{IGN}$ ) et sont actuellement en fin d'analyses sédimentologique et palynologique. Toujours dans la zone de compréhension des recherches lacustres, à l'occasion des travaux de terrassements pour la construction d'un parking à Annecy, quai Eustache Chappuis, nous avons observé et échantillonné les séquences sédimentaires majeures de ce secteur de l'exutoire du lac et mis en évidence, à 6 mètres sous le niveau du sol actuel (altitude 442,40/442,80m NGF), un ancien chenal d'âge préhistorique dont les litages de matériaux organiques (débris végétaux et charbons de bois), scellés par des alluvions grossières (celles du Fier ?), sont datés par le radiocarbone de $8885 \pm 60 \mathrm{BP}$ et $8735 \pm 64$ BP. La confrontation des données spécifiquement naturalistes avec les données archéologiques calées chronologiquement s'est également poursuivie par l'étude des échantillons prélevés à l'occasion de prospections subaquatiques sur les quelques gisements qui marquent la première phase d'occupation du lac d'Annecy, à Sévrier, Les Charretières (date radiocarbone $5315 \pm 50$ BP), à St.-Jorioz, Les Marais (abattages dendrochronologiques entre-3794 et-3783), à Annecy-le-Vieux, La Tour (radiocarbone $4832 \pm 41$ BP) ou du Bourget à St.-Pierre-de-Curtille, Hautecombe (abattages en-3842 et-3835).

Très récemment, des travaux de DEA ont été le signe de cette collaboration :

- Paléoécologie et paléoéconomie d'un site de l'âge du Bronze : étude des paléosemences de Chindrieux, Châtillon (lac du Bourget, Savoie) (Jacquot 1994);

- Analyse pollinique du site du parking de l'Hôtel-de-Ville à Annecy (Haute-Savoie) (Chassepot 1996).

\section{Les aspects archéologiques et chronologiques}

Quelques travaux récents font le point de nos connaissances sur le peuplement des littoraux alpins; on y trouvera une bibliographie générale sur le contexte chronoculturel régional :

- Chindrieux, Châtillon (lac du Bourget, Savoie) : ultime occupation des lacs alpins français à l'âge du Bronze? (Billaud et al. 1992, p. 277-310).

- Le site Bronze final de Tougues à Chens-sur-Léman (Haute-Savoie) : stratigraphie, datations absolues et typologie (Billaud et al. 1992, p. 311-347).

- Etat des connaissances sur les périodes d'occupation littorale du lac d'Annecy... (Billaud et al. 1993, p. 41-50);

- La fin de la Préhistoire dans le lac du Bourget : trente siècles d'occupations littorales? (Marguet et al. 1993, p. 21-21-36);

- Le Néolithique des lacs alpins français. Bilan documentaire (Marguet et al. 1995, p. 167-196) ;

- L'âge du Bronze dans les lacs alpins français. Bilan des travaux récents (Billaud et al. à paraître). 
115 Des travaux universitaires sont en cours, qui ont pour sujet les matériaux provenant des recherches subaquatiques de la région, qu'il s'agisse de trouvailles anciennes :

- L'âge du Bronze final dans les stations littorales immergées du lac du Bourget (Savoie) (I. Kerouanton, thèse de l'Université de Paris I, sous la direction de C. Mordant) ;

de travaux plus récents :

- La céramique Bronze final de Tougues à Chens-sur-Léman (Haute-Savoie) (F. Launay, maîtrise de l'Université de Paris I, sous la direction de P. Brun);

117 ou englobant des trouvailles lacustres ;

- L'occupation néolithique de la Savoie (P.-J. Rey, maîtrise de l'Université de Chambéry, sous la direction de A. Bocquet).

\section{L'occupation du territoire}

\section{Un catalogue mis à jour}

118 Pour le Néolithique, pas moins de 31 gisements sont recensés : 8 pour le Néolithique moyen (Bourget 2, Annecy 4, Léman 2) et 23 pour le Néolithique récent/final (Aiguebelette 3, Bourget 5, Annecy 4, Léman 11) ; ce nombre n'était que de 15 en 1976 (2 et 13).

Pour l'âge du Bronze, l'inventaire systématique en cours augmente sensiblement leur nombre: 22 sites étaient connus en 1976, 32 le sont aujourd'hui (Aiguebelette 2, Bourget 11, Annecy 7, Léman 11) (Bronze ancien 1, Bronze final 31).

Les tableaux ci-après donnent, sans tenir compte des moyens de datation, le nombre des gisements recensés à ce jour (en bas), comparé à celui des gisements connus en 1976 (en haut), par périodes d'occupations littorales (fig. 5).

5- Tableaux du nombre des gisements sous-lacustres

\begin{tabular}{|l|c|c|c|c|c|c|c|c|c|c|}
\hline & Sites & Gisements & MA & GR & LT & BF & BA & NR & NM & Ind. \\
\hline Lac d'Aiguebelette & 4 & 5 & $/$ & $/$ & $/$ & 2 & $/$ & 2 & $/$ & 1 \\
\hline Lac du Bourget & 8 & 11 & $/$ & $/$ & $/$ & 6 & $/$ & 4 & $/$ & 1 \\
\hline Lac d'Annecy & 4 & 5 & $/$ & $/$ & $/$ & 3 & 1 & 1 & $/$ & $/$ \\
\hline Lac Léman & 13 & 20 & $/$ & $/$ & $/$ & 10 & $/$ & 6 & 2 & 2 \\
\hline & 29 & 41 & $/$ & $/$ & $/$ & 21 & 1 & 13 & 2 & 4 \\
\hline
\end{tabular}

D'après A. Bocquet. CDPA, 1976.

\begin{tabular}{|l|c|c|c|c|c|c|c|c|c|c|c|}
\hline & Sites & Gisements & MO & MA & GR & LT & BF & BA & NR & NM & Ind. \\
\hline Lac d'Aiguebelette & 5 & 6 & $/$ & $/$ & $/$ & $/$ & 2 & $/$ & 3 & $/$ & 1 \\
\hline Lac du Bourget & 13 & 25 & $/$ & 2 & 3 & $/$ & 11 & $/$ & 5 & 2 & 2 \\
\hline Lac d'Annecy & 17 & 21 & $/$ & 2 & 1 & 2 & 7 & 1 & 4 & 4 & $/$ \\
\hline Lac Léman & 23 & 31 & 1 & $/$ & 1 & $/$ & 11 & $/$ & 11 & 2 & 5 \\
\hline & 58 & 83 & 1 & 4 & 5 & 2 & 31 & 1 & 23 & 8 & 8 \\
\hline
\end{tabular}

AM. (CNRAS) DRASSM \& YB. AREOLL. 01/97.

Par période chronologique

À partir des données bibliographiques (Bocquet et al. 1976a) et à la suite des travaux d'inventaire du CNRAS/DRASSM et de I'AREOLL (début 1997)

121 La carte de localisation des gisements néolithiques (en noir) et de l'âge du Bronze (en blanc) permet une visualisation de l'occupation du territoire lacustre savoyard et hautsavoyard pour ces périodes (fig. 6). 
6- Cartes de localisation des gisements sous-lacustres du Néolithique (en noir) et de l'âge du Bronze (en blanc) de l'espace savoyard et haut-savoyard

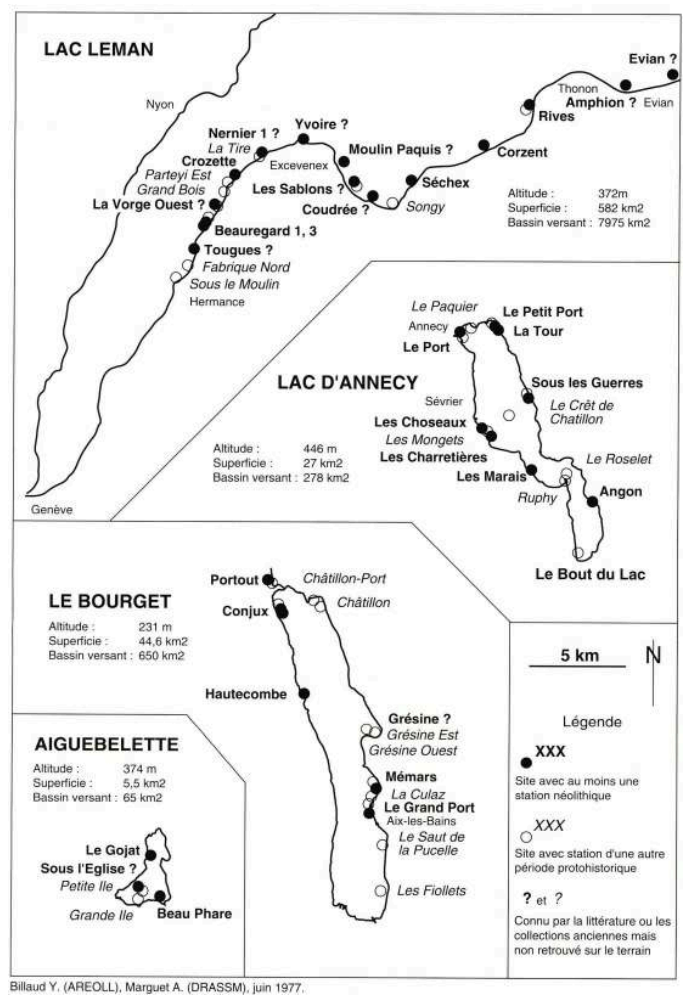

\section{Néolithique ancien}

- Aucun indice connu alors que le schéma des fluctuations des lacs montre, durant l'Atlantique, des périodes régressives qui pouvaient être propices aux installations (à la fin du VIe et au début du Ve millénaire avant notre ère, des traces matérielles des premiers agriculteurs sont connues dans des gisements terrestres proches).

\section{Néolithique ancien/moyen}

123 - La première approche des rivages, attestée à Sévrier, Les Charretières, durant la

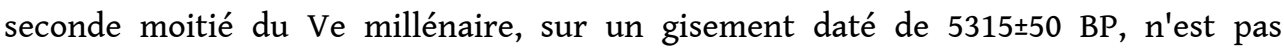
confirmée par la dendrochronologie. Pour la première fois en France de l'Est, est avérée une présence littorale datée des $44 \mathrm{e} / 41 \mathrm{e}$ s. que seules la Suisse orientale et l'Allemagne du Sud-Ouest connaissaient.

\section{Néolithique moyen}

124 - Au début du IVe millénaire, les occupations littorales s'intensifient sur les lacs du Bourget, d'Annecy et du Léman (partie suisse de la rive sud), comme d'ailleurs sur ceux du Plateau suisse. Dès les 39e/38e s., une première phase est bien individualisée : en Savoie, à St.-Pierre-de-Curtille, Hautecombe en-3842 et vers (-3835) (Cortaillod, NMB, Chasséen ?) et en Haute-Savoie, à St.-Jorioz, Les Marais en-3783/82 (Cortaillod classique ?). 
125 - Les mobiliers que l'on s'attendrait à trouver pour les périodes de la transition Cortaillod tardif/Cortaillod Port-Conty, au milieu du IVe millénaire, présents dans les lacs du Jura, sont absents ici. Cependant trois gisements au moins s'y rattacheraient, datés par le radiocarbone des 37e/36e/35e s.: pilotis d'Annecy-le-Vieux, La Tour (4832 \pm 41 BP), pilotis de Sévrier, Les Choseaux (4775 \pm 75 BP), matériaux organiques de Conjux, La Chatière ( $4730 \pm 180 \mathrm{BP})$.

126 - Pour les périodes de la seconde moitié du IVe millénaire, en particulier celles couvrant les $34 \mathrm{e}$, 33e et 32e s., aucun vestige n'est observé à part les quelques pilotis de St.-Pierre-de-Curtille, Hautecombe ( $4540 \pm 50 \mathrm{BP})$, phases également absentes dans les lacs de Chalain et de Clairvaux.

\section{Néolithique récent}

127 - Le passage du IVe au IIIe millénaire, observé dans les lacs du Jura et de Suisse occidentale, n'est connu dans les Alpes du Nord que sur le gisement d'Annecy-le-Vieux, Le Petit-Port ou 32 années d'occupation ont été datées, entre-3058 et-3026 ; la pauvreté des objets découverts ne permet pas de les attribuer culturellement (influences Horgen des groupes du Plateau suisse ou première manifestation Proto CSR, au 31e s.). Dans le Léman, les gisements de Thonon-lesBains, Le Port de Rives et de Chens-sur-Léman, Beauregard 1, également pauvres en mobiliers, ont livré des bois dont les phases d'abattage se situent entre-3094 à-3049 à Rives et (-3043) à - 3035/34 à Beauregard.

\section{Néolithique récent/final}

128 - Dans la première moitié du IIIe millénaire, les lacs savoyards connaissent, comme tout le domaine subalpin, une forte occupation: Conjux, La Chatière; Messery, Crozette ; Aiguebelette-leLac, Beau-Phare 1; St.-Alban-de-Montbel, La Petite-Ile; Thonon-lesBains, Le Port-de-Rives ; Novalaise, Le Gojat ; Brison-St.-Innocent, Mémars 1 ; mis à part ce dernier dont les phases d'abattage se situent entre (-2595) et (-2529), leur datation par le radiocarbone, entre les $29 \mathrm{e} / 27 \mathrm{e}$ s., et leurs vestiges comparables à ceux de Charavines, Les Baigneurs, (seul gisement régional de référence dont les dates dendrochronologiques situent la première phase d'installation vers les années-2668/-2867) les apparentent et permettent de les attribuer au groupe de Lüscherz.

\section{Néolithique final}

129 - Au milieu du IIIe millénaire, la fin du Néolithique de faciès Saône-Rhône (trouvailles anciennes d'Annecy, Le Port et de Veyrier-du-Lac, Vieugy-Nord) est confirmée et précisée par la mise en évidence, à Conjux, La Chatière, de mobiliers attribuables au groupe d'Auvernier, dans un ensemble stratigraphique des 26e/25e s. (phases d'abattage estimées vers-2525, entre-2442 et-2427, et certaine en-2440). Ces phases d'abattage sont également présentes à Talloires, Angon en - 2446 et-2435. Sur le Léman, le gisement de Messery, Crozette, daté uniquement par le radiocarbone des 26e/23e s. (3950 \pm 45 BP), pourrait, lui aussi, y être rattaché.

130 - Les traces des occupations de la seconde moitié du IIIe millénaire n'ont pas été confirmées. Pourtant, des objets typiques des influences cordées du Plateau suisse 
(haches-marteaux) avaient été découverts au siècle dernier dans les lacs Léman et d'Annecy.

\section{Néolithique final/Bronze ancien}

131 -À la fin du IIIe millénaire, comme dans les lacs du Plateau suisse, la transition du Néolithique final au Bronze ancien, durant les 23e/22e s., n'est pas observée (abandon de l'habitat lacustre?).

\section{Bronze ancien}

132 - Les éléments de la civilisation rhodanienne mis en évidence sur la rive nord du Léman restent très isolés ; ils soulignent la rareté des renseignements provenant des domaines lacustres, aussi bien en Suisse occidentale que dans la France de l'Est, jusqu'aux 17e/ 16e s. Dans un tel schéma, il est important de signaler le jalon reconnu dans le lac d'Annecy pour ces périodes, à Sévrier, Les Mongets, daté par le radiocarbone de $3595 \pm 50,3490 \pm 50$ et $3465 \pm 50$ BP et par la dendrochronologie (phases d'abattage, avec réserve, entre-1716 et-1665).

\section{Bronze moyen}

133 - Dans l'espace géographique considéré, aucun indice lacustre n'est actuellement reconnu pour cette période, la remarque est générale pour le domaine occidental (raisons climatiques et/ou rupture culturelle?).

\section{Bronze final}

134 - La phase ancienne du Bronze final, attestée par le mobilier BF $1 / 2 a$ découvert à Annecy, Le Port, n'est toujours pas datée par la dendrochronologie.

135 - Les premiers abattages sont datés de-1071, dans l'ensemble 3 de Tougues à Chens-surLéman (début du BF $2 b$, phase moyenne du Bronze final alpin). Sur presque tous les gisements des lacs alpins français, trois groupes de dates apparaissent nettement aux lie, $10 \mathrm{e}$ et $9 \mathrm{e}$ s., respectivement autour de-1075/-1050, juste après-1000 et vers-900/-875.

136 - Dans la seconde moitié du 9e s., un important niveau organique riche en mobiliers de la période palafittique incluse dans le BF $3 \mathrm{~b}$ a été mis en évidence au lac du Bourget, dans un sondage réalisé à Chindrieux, Châtillon: vingt huit phases d'abattage sont datées de-906 à-814, ultime phase qui semble marquer la fin des installations littorales dans les lacs alpins.

\section{Les datations par le radiocarbone et la dendrochronologie}

137 Le nombre des gisements immergés recensés augmente régulièrement et le corpus des dates progresse parallèlement.

Dans notre démarche d'inventaire, et dès le début, parallèlement à la définition du contexte géomorphologique, la nécessité de situer chaque gisement en chronologie absolue était la préoccupation essentielle. 
139 Dès 1982-1983 nous avons eu recours à la datation ${ }^{14 C}$ et dendrochronologique pour interpréter les vestiges découverts dans la baie d'Albigny, à Annecy-le-Vieux, Le PetitPort, là où des recherches subaquatiques avaient montré une très forte érosion de la plate-forme littorale, sur les $140 \mathrm{~m}^{2}$ prospectés. Description des surfaces topographiées et ramassages ont donc été complétés par le prélèvement des 125 pieux destinés à la dendrochronologie. 108 bois analysés ( 51 chênes, 30 sapins, 13 aulnes, 6 bois blancs, 3 frênes, 2 aulnes, 2 érables, 1 hêtre), ont permis la répartition, sur plans, des différentes périodes d'abattage et la mise en évidence d'une organisation architecturale. Il s'agit de plusieurs structures quadrangulaires (cabanes) dont les phases de construction et de reconstruction s'échelonnent sur 32 années d'occupation au moins, entre-3058 et-3026. Les dates dendrochronologiques ont également permis de calibrer les dates ${ }^{14} \mathrm{C}$ de 2 échantillons, un sapin (cernes 5-12), 4580 \pm 70 BP correspondant à la date

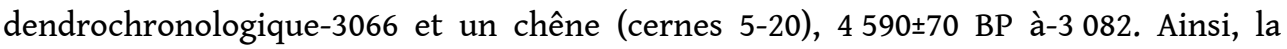
situation chronologique retenue pour le gisement du Petit-Port place les phases d'abattage des bois dans le 31e s. avant notre ère, ce que la pauvreté des vestiges matériels n'avait pas permis (Marguet et al. 1988, p. 67-87).

140 Dans le but de constituer une séquence de référence pour la période de l'âge du Bronze final dans la région alpine, des échantillons de bois ont été prélevés, en novembre 1983, par le CNRAS et le Laboratoire Romand de Dendrochronologie (LRD) sur les sites archéologiques immergés du Crêt-de-Chatillon à Sévrier, du Roselet à Duingt dans le lac d'Annecy, et de Conjux, La Chatière dans celui du Bourget. A la faveur du contrat d'ATP sur le Paléoenvironnement holocène des Alpes du Nord et de leur piémont, prélèvements et analyses se sont poursuivis en 1984 .

\section{Des séquences locales synchronisées}

141 Les pieux de chêne du Crêt-de-Chatillon ont fourni deux séquences : l'une, 9 000ACPI, 123 ans à partir de 10 échantillons, située entre les années - 1022 et-900 (fig. 7) et l'autre, 9006ACH, 153 ans, 4 échantillons, un peu plus ancienne, entre les années-1218 et-1066 ; ceux du Roselet ont permis de constituer les séquences 9000ARO, 125 ans, 6 échantillons, entre-1004 et-880 et 9005ARO, 292 ans, 14 échantillons,-1324 et-1033. Ces séquences locales, synchronisées entre elles, ont montré, du moins sur une certaine durée de leur occupation, la contemporanéité de ces gisements. Par ailleurs, pour permettre la calibration des séquences, les cernes 5 à 15 et 165 à 180 d'un pieu du Roselet à Duingt (ANP39) ont été datés par le radiocarbone (GIF. $6486: 2950 \pm 60$ et Gif. $6487: 2880+60 \mathrm{BP})$. 
7- Sévrier, Le Crêt-de-Chatillon (Haute-Savoie, lac d'Annecy)

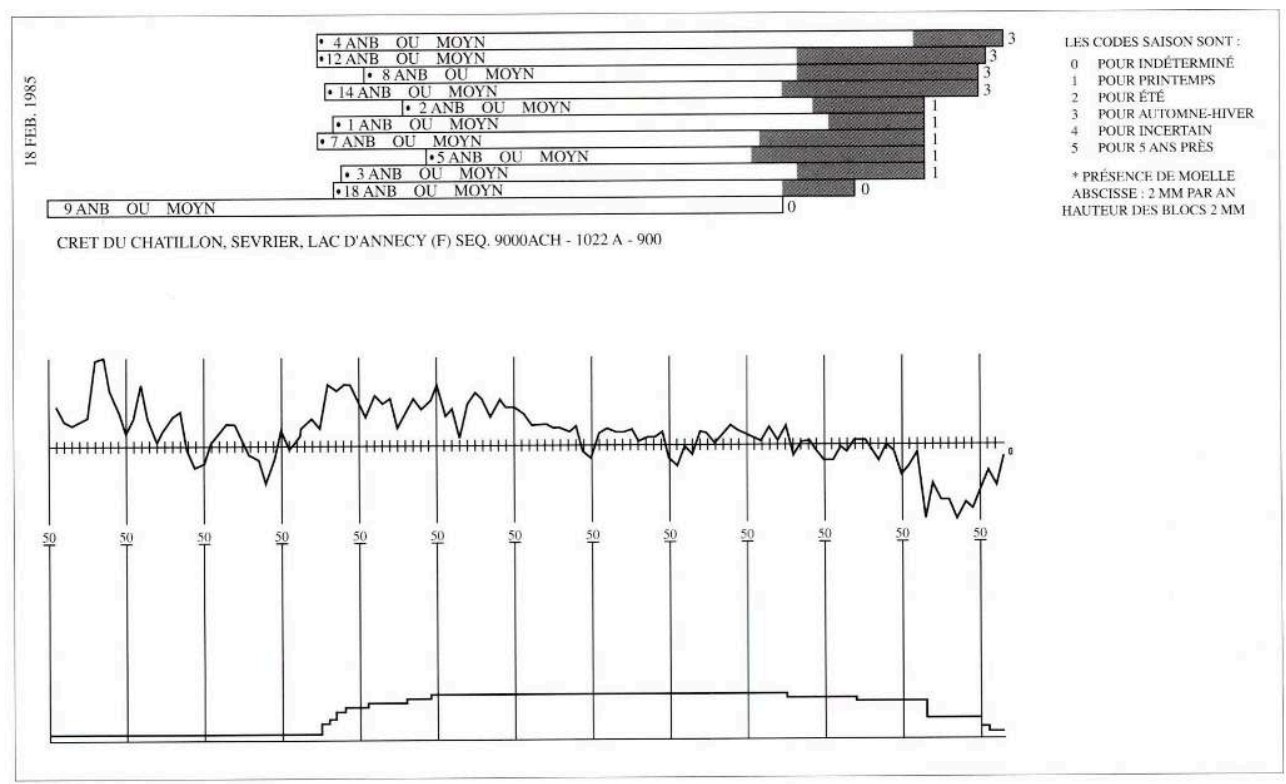

diagramme de présentation de LA PREMIÈre SÉquenCe dendrochronologique datée pour LE CHÊNE, RÉFÉreNCE 9000ACH SITUÉE ENTRE LES ANNÉES-1022 ET-900, POUR UN gISEMENT DE L'Âge DU BRONZE FINAL DES ALPES DU NORD (RAPPORT DU LABORATOIRE ROMAND DE DENDROCHRONOLOGIE LRD5/R1395 DU 06.02.1985)

\section{Des séquences régionales datées}

Dans un deuxième temps, ces séquences ont pu être corrélées avec les courbes des sites lémaniques de Morges, Les Roseaux (VD), séquence 9000RO, 225 ans, 9 échantillons, entre-1277 et-1053, de Genève, Les Paquis A (GE), 9000GPA, 145 ans, 9 échantillons, entre-1200 et-1056 et de Corsier-Port (GE), 7006GCP, 76 ans, 153 échantillons entre-925 et-850. Obtenues par un système de dérive qui utilisait les références créées à partir des bois de Neuchâtel et de Zurich déjà corrélés avec les séquences allemandes (d'après Becker 26 juin 1986), ces séquences locales ont abouti à la constitution des deux premières références régionales globales de l'âge du Bronze pour les Alpes françaises du Nord : 0001BRO entre les années-1324 et-1033 et 0002BRO entre-1022 et-850. Ces résultats ont été publiés par le groupe de travail pour la dendrochronologie, le 28 février 1985 (Orcel et al. 1985, p. 153-176 et Orcel et al. 1990, p. 281-287).

\section{Une référence régionale absolue}

En avril 1986, la poursuite des prélèvements, en particulier à Brison-St.-Innocent, Grésine dans le lac du Bourget et leur analyse a permis la constitution d'une séquence 9000FSG de 170 ans à partir de 13 échantillons, entre les années-1047 et-878 et le comblement du hiatus existant par la proposition d'une séquence globale continue pour les périodes de la fin de l'âge du Bronze alpin : 0003BRO entre les années-1324 et-850.

Ainsi, pour la première fois, une relation entre les gisements lacustres des Alpes et ceux d'autres régions de l'Europe occidentale était établie, à l'intérieur d'une chronologie absolue (Bocquet et al. 1988, p. 435-444). 


\section{Les dates obtenues par le radiocarbone}

Parmi les 57 analyses réalisées pour le CNRAS/DRASSM et l'AREOLL depuis 1980, sur des vestiges lacustres des périodes comprises entre $9000 \mathrm{BP}$ et l'actuel, 44 dates concernent la fin de la Préhistoire, la Préhistoire récente et la Protohistoire, entre 9000 et 2000 BP. Dans ce catalogue, 2 d'entre elles se rapportent à des litages végétaux piégés du début de l'Holocène, hors de tout contexte préhistorique, dans un ancien exutoire du lac d'Annecy (site d'Annecy, quai E. Chappuis, parking de l'Hôtel-de-Ville), 24 proviennent de gisements archéologiques du Néolithique (Aiguebelette 2, Bourget 8, Annecy 11 et Léman 3), 15 de sites de l'âge du Bronze (Aiguebelette 1, Bourget 6, Annecy 7 et Léman 1 ) et $3 \mathrm{~d}$ 'autres gisements protohistoriques (Bourget 1, Annecy 2).

Les données ${ }^{14} \mathrm{C}$ présentées ci-après sont classées chronologiquement, par âge $\mathrm{BP}$ car elles sont trop peu nombreuses pour l'être selon leur appartenance culturelle. Elles sont données par tranches de dix siècles avec localisation du gisement (département, lieu-dit, commune), auteur des prélèvements et références administratives des opérations, nature des gisements (niveaux et matériaux analysés), référence des laboratoires $($ ARC $=$ Archéolabs, $\mathrm{GIF}=$ Centre des faibles radioactivités, $\mathrm{LY}=$ Centre de datation par le radiocarbone), âge ${ }^{14} \mathrm{C}$ BP avec un écart-type, intervalle calibré en années av. J.-C. (d'après Pearson et al. 1986, Stuiver et Becker 1986, à $95 \%$ de probabilité), contexte archéologique et appartenance culturelle lorsque celle-ci est bien individualisée (pl. 1 en fin d'article).

\section{Les séquences dendrochronologiques}

147 Avec les datations relatives qui mettent en évidence des successions chronologiques et sur la base des mesures dendrochronologiques fournies par le Laboratoire Romand de Dendrochronologie (LRD) et Archéolabs, il est possible de présenter, pour les gisements néolithiques et de l'âge du Bronze des Alpes du Nord, un tableau récapitulatif des séquences locales datées (Néolithique 13 séquences et 116 bois datés, Bronze 32 séquences et 287 bois datés). Dans ce tableau, seules sont présentées les séquences datées (plusieurs dizaines ne le sont pas encore), réalisées à l'initiative du CNRAS/ DRASSM et de l'AREOLL ; à notre connaissance, il n'en existe pas d'autres pour ces périodes et pour ces régions (pl. 2 en fin d'article).

Compte tenu de la faiblesse de l'échantillonnage et de la courte croissance des bois, des interruptions de plusieurs siècles sont constatées ; cette absence de continuité entre les séquences ne permet donc pas encore la constitution d'une référence régionale pour ces périodes.

149 Pour le Néolithique, les mesures à notre disposition montrent quatre périodes principales d'abattage au cours des 39/38e, 31e, 28e et 26/25e siècles avant notre ère et indiquent que les gisements savoyards ont connu des phases d'occupations échelonnées sur plus de quatorze siècles, entre les années-3842 à Hautecombe et-2435 à Angon (fig. 8). 
8- Représentation graphique des séquences dendrochronologiques (Quercus et $A b i e s$ ) et des phases d'abattage datées pour les gisements lacustres du Néolithique

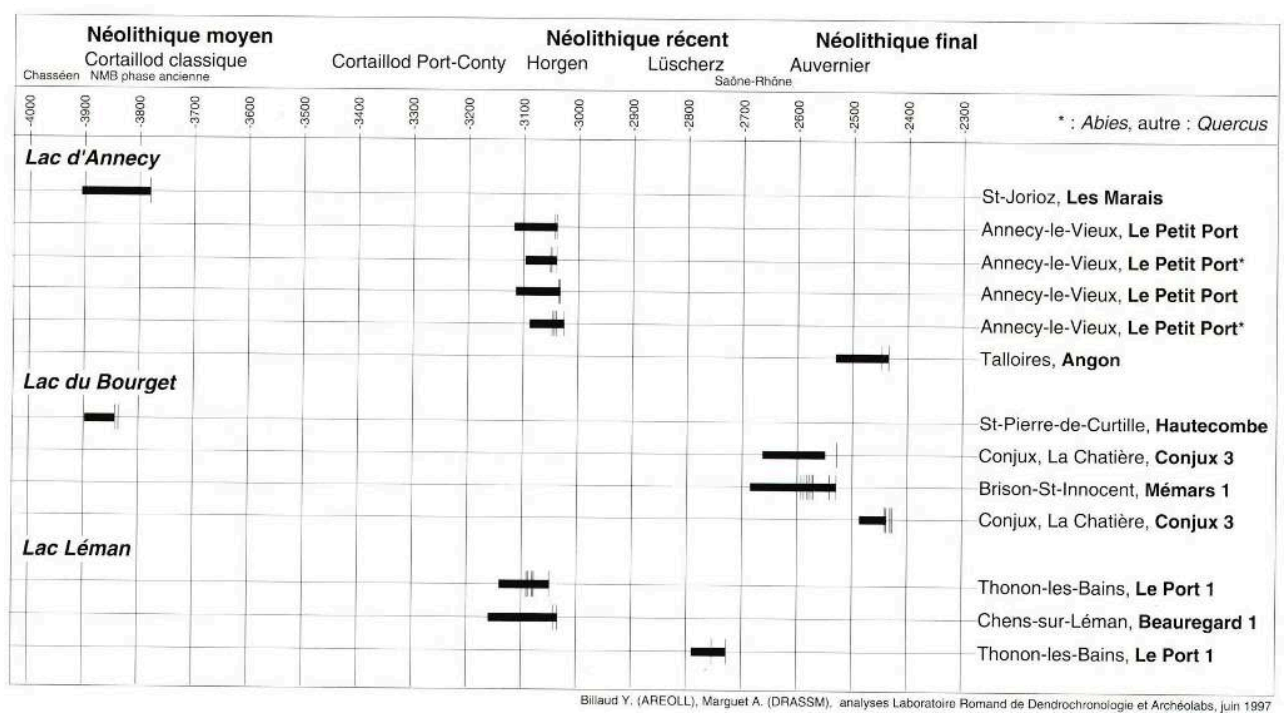

Pour l'âge du Bronze, on note également quatre périodes principales d'abattage des arbres, au cours des 18e/17e s. pour le Bronze ancien, aux lie, 10e et 9e s. pour le Bronze final (fig. 9).

9- Représentation graphique des séquences dendrochronologiques (Quercus et $A b i e s$ ) et des phases d'abattage datées pour les gisements lacustres de l'âge du Bronze

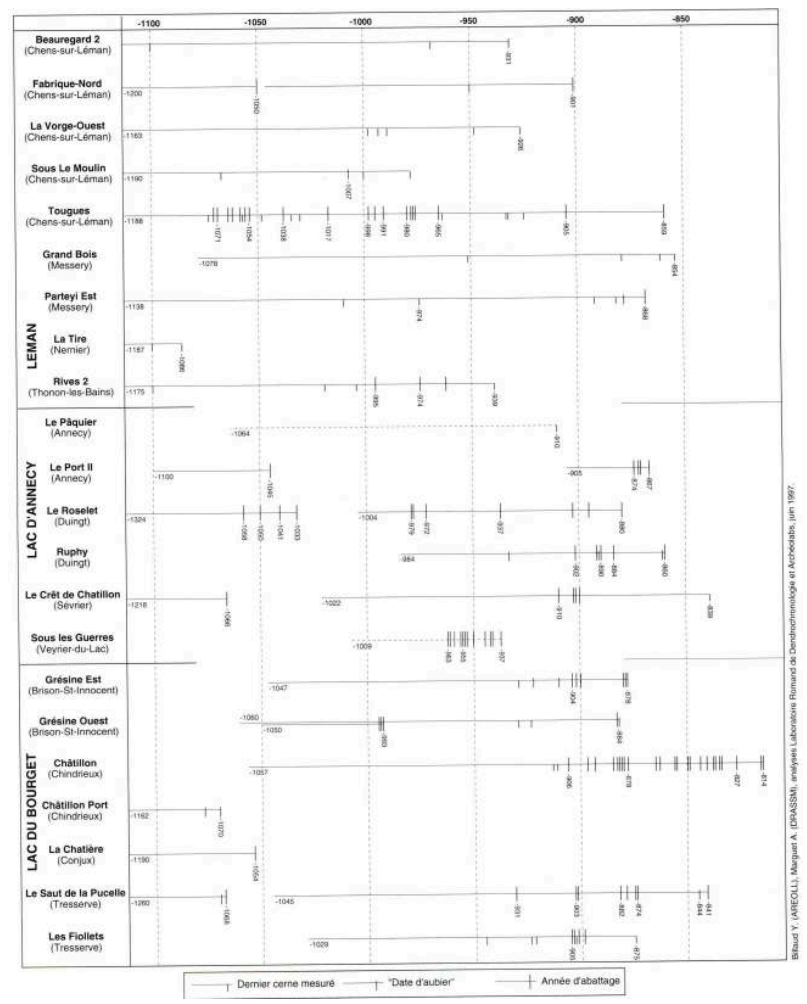

151 Ces premières datations absolues, même si notre propos n'est pas de les considérer comme des repères définitifs, donnent la durée possible des occupations durant au moins 265 ans, entre les années-1079 (date estimée) à Chens-sur-Léman, Tougues (ensemble stratigraphique inférieur) et-814 à Chindrieux, Châtillon et positionnent les 
mobiliers recueillis dans les phases moyenne et récente de l'âge du Bronze final alpin (BF 2b, 3a et 3b).

Les tableaux qui suivent, illustrent de manière synthétique, les diverses traces d'occupations littorales actuellement datées par le radiocarbone (partie haute du tableau, intervalle calibré à $95 \%$ de probabilité) et par la dendrochronologie (partie basse du tableau, moyenne des phases d'abattage) (fig. 10-13).

10- Datations ${ }^{14} \mathrm{C}$ calibrées ( 2 sigma) et périodes d'abattage datées par la dendrochronologie

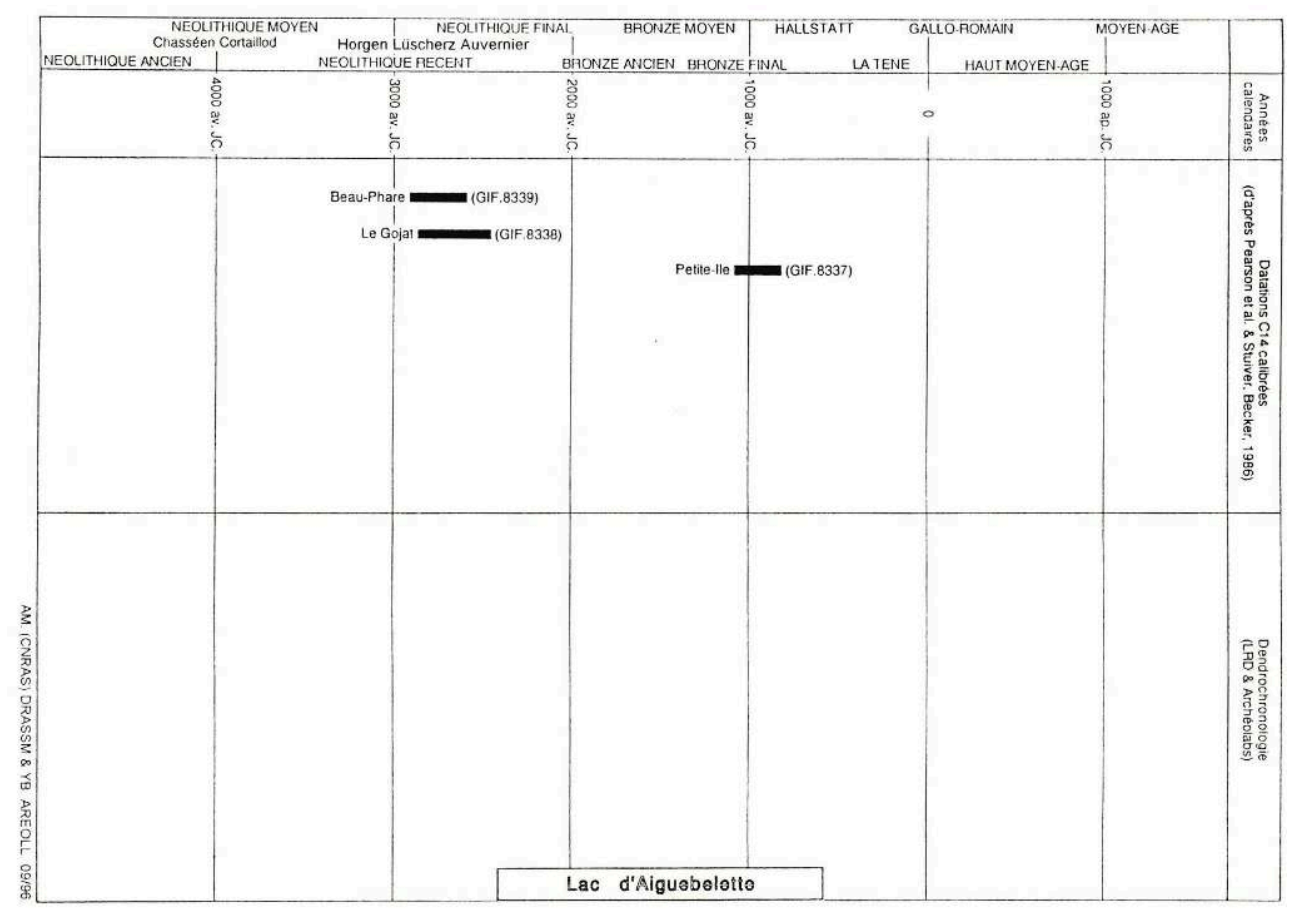

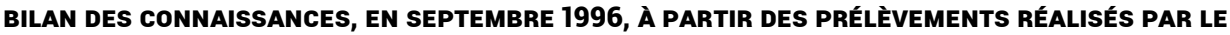
CNRAS SUR LES gISEMENTS SOUS-LACUSTRES DU LAC D'AIgUEBELETTE (SAVOIE) 
11- Datations ${ }^{14} \mathrm{C}$ calibrées ( 2 sigma) et périodes d'abattage datées par la dendrochronologie

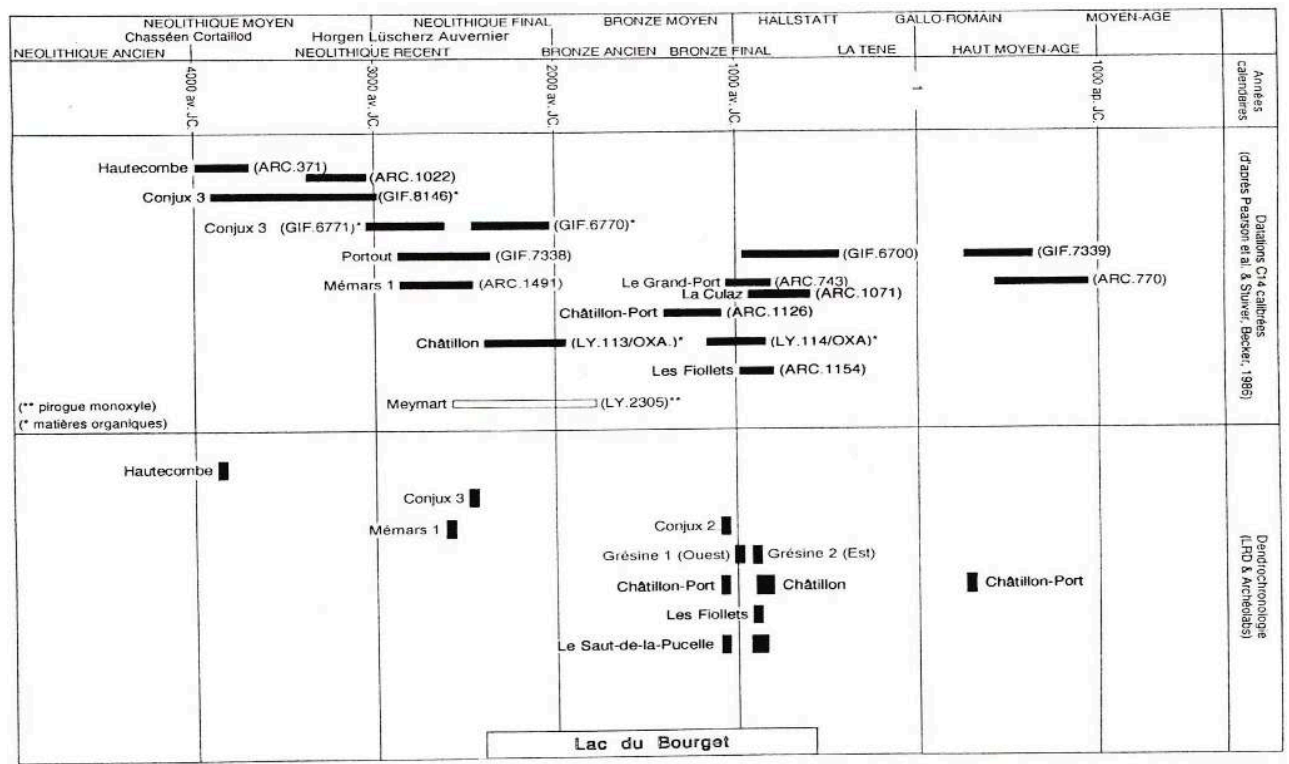

BILAN DES CONNAISSANCES, EN SEPTEMBRE 1996, À PARTIR DES PRÉLÈVEMENTS RÉALISÉS PAR L'AREOLL, LE CALAS ET LE CNRAS/DRASSM SUR LES GISEMENTS SOUS-LACUSTRES DU LAC DU BOURgET (SAVOIE)

12- Datations ${ }^{14} \mathrm{C}$ calibrées ( 2 sigma) et périodes d'abattage datées par la dendrochronologie

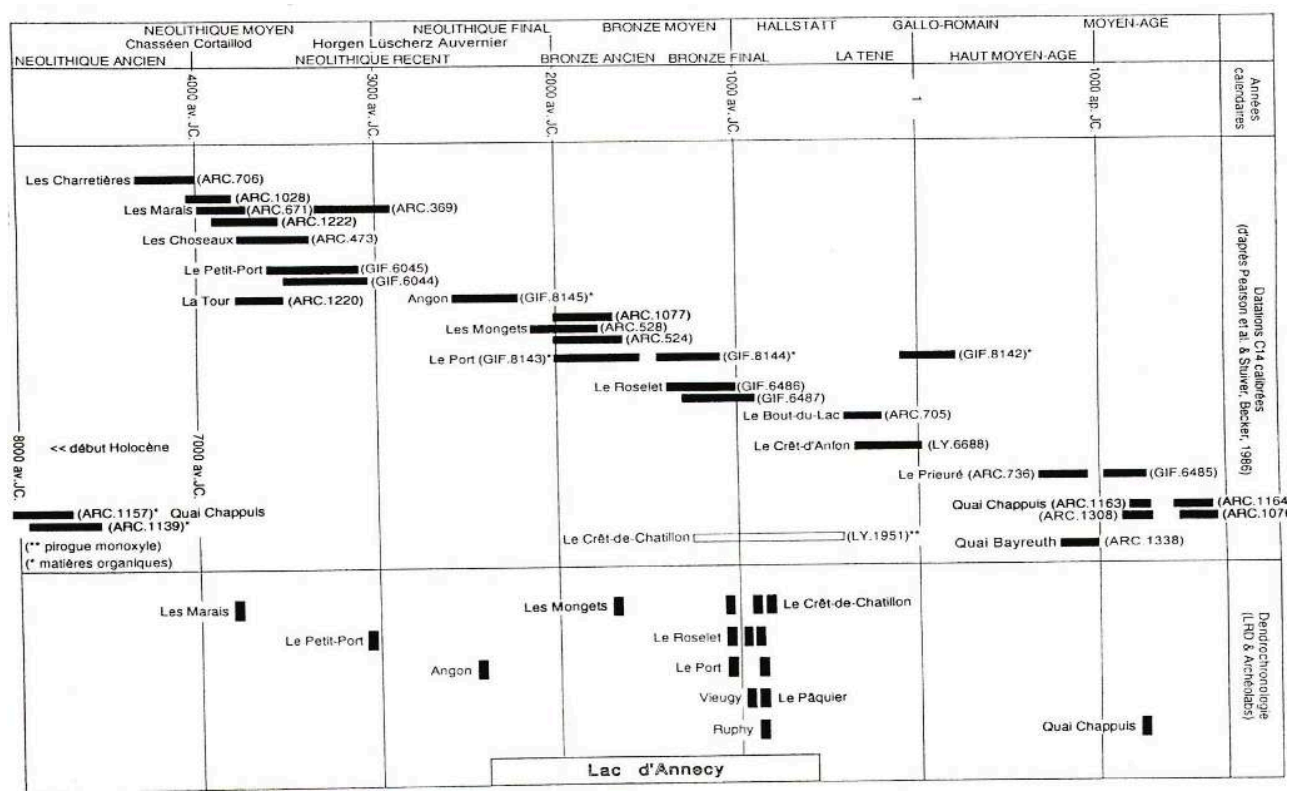

BILAN DES CONNAISSANCES, EN SEPTEMBRE 1996, À PARTIR DES PRÉLÈVEMENTS RÉALISÉs PAR L'AREOLL ET LE CNRAS SUR LES gISEMENTS SOUS-LACUSTRES DU LAC D'ANNECY (HAUTE-SAVOIE) 
13- Datations ${ }^{14} \mathrm{C}$ calibrées ( 2 sigma) et périodes d'abattage datées par la dendrochronologie

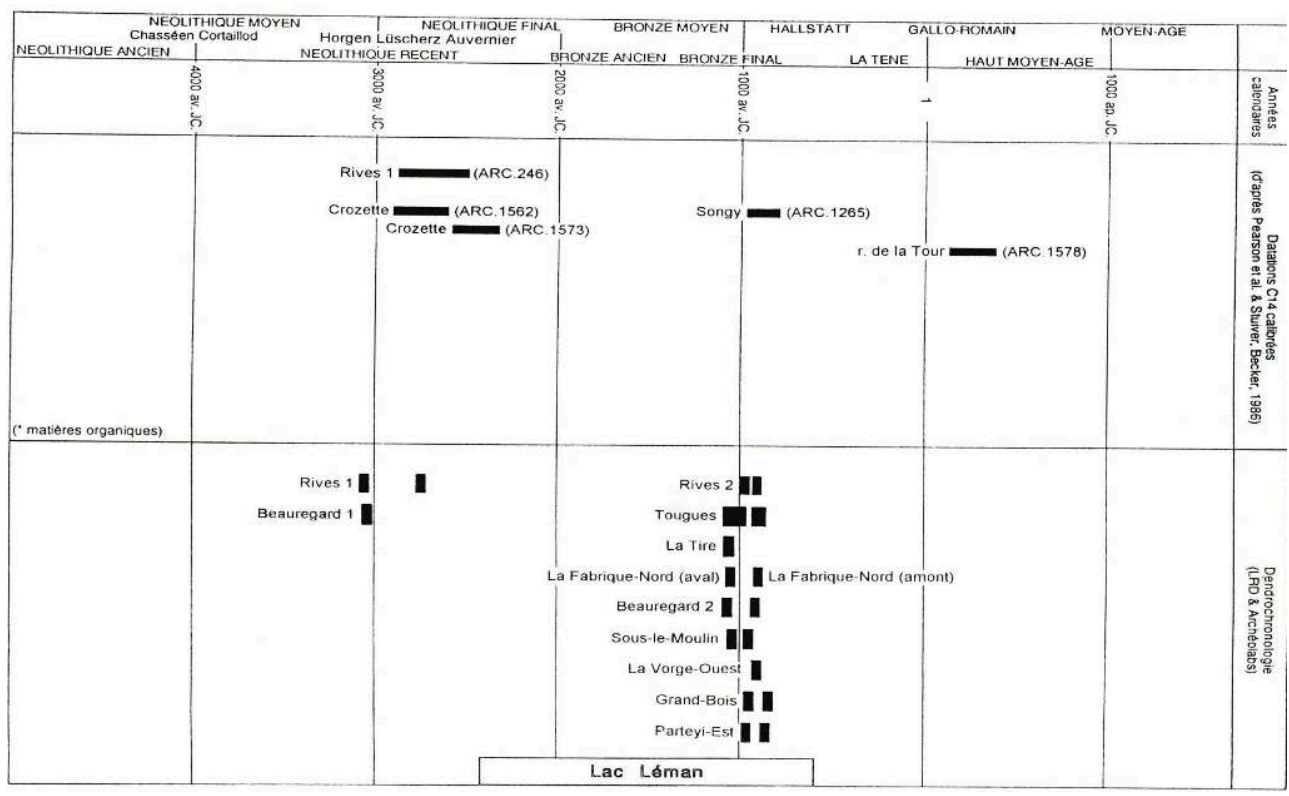

BILAN DES CONNAISSANCES, EN JANVIER 1997, À PARTIR DES PRÉLÈVEMENTS RÉALISÉS PAR LE CNRAS/DRASSM SUR LES gISEMENTS SOUS-LACUSTRES DE LA RIVE FRANÇAISE DU LAC LÉMAN (HAUTESAVOIE)

\section{L'état de conservation des gisements}

Des carottages systématiques, suivant des transects rivage-large, ont permis de définir le contexte géomorphologique des sites littoraux et d'observer l'état de conservation des gisements étudiés. Les observations étaient ponctuelles, elles deviennent systématiques pour les opérations les plus récentes; un schéma général peut être esquissé en tenant compte des particularités de chaque site, de l'orientation du rivage, de la morphologie de la beine, de la dynamique lacustre, etc.

Les données sur la morphologie particulière de chaque gisement (superficie des emprises archéologiques, nature des vestiges, situation dans le paysage, position altitudinale des vestiges, extension des couches sédimentaires, etc.) ne peuvent être abordées ici; on les trouvera dans les Bilans scientifiques de la Région Rhône-Alpes (DRAC, Service Régional de l'Archéologie), dans les Bilans scientifiques des Centres Nationaux (Direction du Patrimoine, Sous-Direction de l'Archéologie) et dans les Chroniques des découvertes archéologiques dans le département de la Haute-Savoie (La Revue Savoisienne, Académie Florimontane d'Annecy).

D'une manière générale, l'érosion des niveaux archéologiques est très importante, voire totale sur la plupart des gisements; dans le meilleur des cas, seuls subsistent encore quelques éléments lourds (matériels lithique et céramique). Pour quelques rares sites, les couches archéologiques de matériaux végétaux (fumiers) n'ont été repérées qu'en limite du gisement : ce sont les derniers dépôts organiques en direction du large (dans le lac d'Annecy, Néolithique final d'Angon et Bronze final du Port 2, du Crêt-deChatillon et du Roselet). Plus rarement encore, des couches anthropiques sont mieux préservées, érodées seulement pour partie ou décentrées par rapport à la plus forte répartition des vestiges. Dans cette catégorie, les sites Néolithique moyen de Hautecombe dans le lac du Bourget et des Marais dans celui d'Annecy, les gisements 
Néolithique final de Mémars 1 et de Conjux 3 au Bourget, du Port I d'Annecy, le site de l'âge du Bronze ancien des Mongets dans le lac d'Annecy, ceux de l'âge du Bronze final de Châtillon, du Saut-de-la-Pucelle, de Grésine-Ouest au Bourget, celui de Ruphy dans le lac d'Annecy et de Tougues dans le Léman, mériteraient une attention toute particulière ou au moins une réflexion sur la manière dont il faudrait les exploiter avant leur dégradation complète. Quelques gisements n'ont pas été retrouvés, vraisemblablement à la suite de l'ensablement des vestiges. A cet égard, les causes de la disparition des stations littorales (processus de l'érosion naturelle) et les moyens possibles de protection sont largement traités dans Archéologie et érosion. Mesures de protection pour la sauvegarde des sites lacustres et palustres (pour le domaine géographique concerné, voir en particulier Corboud 1996, p. 85-96) (pl. 3 en fin d'article).

\section{Le point sur les données récentes}

156 Compte tenu de l'aspect fragmentaire des données actuelles, tant dans le domaine des matériaux archéologiques (vestiges mobiliers et éléments architecturaux) que dans celui des repères chronologiques (dates des premières installations, durées des phases d'occupation et d'abandon), lacunes essentiellement dues aux conditions méthodologiques longtemps précaires (ramassages d'objets hors stratigraphie, datations ${ }^{14} \mathrm{C}$ de pilotis mal positionnés) puis à la faiblesse des moyens mis en oeuvre (équipes restreintes, faibles superficies fouillées, échantillonnages dendrochronologiques peu importants), il n'est évidemment pas possible de tirer, pour l'instant, des conclusions définitives sur l'histoire des peuplements lacustres des Alpes françaises du Nord, au Néolithique et à l'âge du Bronze. Néanmoins, les opérations systématiques de prospection des lacs savoyards, menées depuis plus de quinze ans, donnent chaque année plus d'informations.

Les mobiliers anciennement recueillis avaient permis l'identification des populations littorales et la définition des grands traits culturels du Néolithique moyen de faciès Cortaillod, du Néolithique récent Saône-Rhône, du Néolithique final cordé et des phases récentes de l'âge du Bronze final ; les recherches actuelles précisent nos connaissances dans trois directions principales : paléoclimatologie, chronologie, culture matérielle.

Dans le domaine de l'environnement, les lacs savoyards sont maintenant bien positionnés dans les séquences climatiques et sédimentaires des références jurassiennes et leurs variations mieux connues. Les analyses sédimentologiques et palynologiques des gisements de Hautecombe, Conjux, et Châtillon au Bourget, des Marais, du Port, d'Angon, des Mongets, du Roselet, de Ruphy et du Bout-du-Lac à Annecy, de Tougues au Léman, permettent de mieux comprendre la dynamique lacustre à la fin du Tardiglaciaire et durant l'Holocène, en particulier à la transition Atlantique/Subboréal, au Subboréal et au début du Subatlantique, et de préciser les conditions d'installation des habitats littoraux.

Pour la chronologie, les prélèvements de matériaux organiques stratifiés et leur datation par le radiocarbone ont mis en évidence de nouveaux repères pour les occupations humaines (Néolithique ancien, Néolithique moyen. Néolithique récent/ final, Bronze ancien). L'échantillonnage des bois (pilotis et madriers horizontaux) et leur analyse ont abouti, souvent avec l'aide du radiocarbone pour les courtes séquences flottantes étayées sur un trop faible corpus, à la constitution d'un premier calendrier 
dendrochronologique de références locales, inexistant il y a seulement une douzaine d'années.

Pour ce qui concerne l'occupation du territoire et la culture matérielle, les prospections systématiques et les sondages réalisés, certes sur des surfaces trop limitées pour comprendre l'organisation spatiale, ont amené des découvertes significatives d'objets en stratigraphie, permettant de replacer, dans leur cadre chrono-culturel, les mobiliers anciennement récupérés hors de tout contexte.

Dans le schéma de développement du Néolithique alpin et des périodes récentes de l'âge du Bronze, nous pouvons intégrer les données typologiques, chronologiques et dendrochronologiques récemment acquises et dégager, par comparaison avec des gisements de la zone de compréhension, certaines affinités culturelles qui faisaient défaut (pénétrations des influences NMB/Chasséen/Cortaillod, contacts rhodaniens, modification des caractères RSFO).

\section{Perspectives et recherches à développer}

Pour les prochaines années, l'objectif essentiel de la recherche palafittique dans les Alpes françaises du Nord devrait être la mise en place structurelle de véritables programmes de recherches pluridisciplinaires consacrés à la reconstitution de l'histoire de l'environnement et des étapes du peuplement.

De tels objectifs scientifiques passent nécessairement par l'acquisition des référentiels à l'intérieur d'une structure favorisant les relations entre chercheurs et le dialogue entre disciplines. Cette collaboration devra aboutir à la reconstitution de l'histoire des peuplements riverains, de la Préhistoire à l'actuel, du cadre paléoclimatique et paléogéographique des fluctuations lacustres depuis la fin du Tardiglaciaire et durant l'Holocène et par conséquent des anciens rivages, de l'histoire de la végétation et des premiers indices d'anthropisation. Participent de cette démarche, les recherches déjà réalisées sur les approches paléoclimatiques des fluctuations holocènes des lacs jurassiens et subalpins (Magny 1993b, p. 253-282), sur le paléoenvironnement holocène des Alpes du Nord (Bintz et al. 1989, p. 51-60) ou en cours sur les variations du niveau du lac d'Annecy depuis 15000 ans BP (projet Climasilac).

L'évaluation du potentiel archéologique par le recensement des sites (palafittes et aménagement littoraux) doit obligatoirement se poursuivre par les méthodes classiques de la prospection subaquatique (carte archéologique des plans d'eau, sondages de diagnostic), auxquelles on devrait pouvoir adjoindre les moyens de reconnaissance de la géophysique et de la sismique. Cette étape est indispensable pour connaître la densité des installations littorales, les périodes d'installation et pour l'appréciation qualitative de l'état de conservation des gisements. La carte archéologique de la rive française du Léman vient d'être réalisée par le CNRAS/ DRASSM (1995-1997) ; celle des lacs de la Savoie est programmée pour les prochaines années (1998-2000).

À partir des données récentes, il parait opportun de prolonger ce type de collaboration et de promouvoir les analyses environnementales pour la compréhension des sites palafittiques. La diversité des types de sédiments et des processus de dépôt a montré la nécessité d'approches multiples et complémentaires; la définition collégiale des problématiques et des nouvelles cibles sur le territoire devrait en être facilitée. 
166 Pour une meilleure connaissance des terroirs, la stratégie d'approche paléoclimatologique et paléohydrologique de l'environnement des sites littoraux n'a plus besoin d'être justifiée; l'observation des sédiments est essentielle pour la définition des relations spatiales et chronologiques entre site naturel et site anthropisé. Des expériences récentes, pertinentes, montrent bien ces périodisations et les interactions homme/milieu :

- Esquisse d'un modèle pour une approche sédimentologique de séquences holocènes en milieu lacustre carbonate (Magny 1987, p. 181-211);

- Mésolithisation et néolithisation d'une zone de moyenne montagne : évolution du peuplement et du paysage de la haute vallée du Doubs (Cupillard et al. 1994);

- Les habitats préhistoriques de l'ancien lac de Fiave-Carera (Trentin-Italie du Nord). Une stratégie d'étude globale sur un site de tourbière (Brochier et al. 1992b, p. 179-203).

Pour nos régions, la réalisation pratique de tels modèles devrait trouver des conditions géomorphologiques favorables, mais peut-être, plus qu'ailleurs, à cause de la disparité des secteurs potentiels de recherche (vaste plan d'eau dans le Léman, littoraux fortement urbanisés à Annecy et au Bourget, cuvette restreinte à Aiguebelette) et du vide universitaire, la réflexion préalable sur la méthodologie à mettre en place sera décisive, même si elle paraît encore difficile pour certains (voir sur ce point Les environnementalistes à la lanterne?, Magny 1996, p. 24-25).

Les contextes géomorphologiques et topographiques généraux une fois définis, la compréhension des aspects spécifiquement archéologiques (la forme de l'habitat, la dimension des sites, l'organisation architecturale d'un village, la durée des occupations, le contexte culturel des installations, les territoires potentiels d'exploitation, etc.), passera vraisemblablement par la fouille plus ou moins extensive et par les analyses globales (mobiliers archéologiques, sédiments, macrorestes, faune, etc.), pour au moins chacune des grandes périodes chronologiques concernées par les phases d'habitat lacustre: Néolithique moyen. Néolithique récent/final, Bronze ancien, Bronze final. L'établissement de cadres typochronologiques dépend de cette orientation des recherches et de leur bonne programmation surtout en ces périodes où la multiplication des chantiers n'est pas la règle.

169 À ce sujet, on signalera que la fouille subaquatique réalisée par A. Bocquet, entre 1972 et 1986 à Charavines, Les Baigneurs, reste le seul exemple d'approche quantitative globale et approfondie d'un gisement néolithique immergé subalpin! (Christien et al. 1993, 63-71 et Bocquet 1993, p. 25-33).

170 À partir des résultats des prospections, il devrait être possible de mieux connaître, par des études microrégionales notamment, la chronologie de chaque gisement (contemporanéité de plusieurs villages dans un même terroir), l'évolution temporelle de l'organisation architecturale du village, l'évolution chronologique des cultures matérielles, les relations entre habitat et milieu pour chaque période et chaque site (reconstitution des variations lacustres); dans cette perpective, le petit bassin lacustre d'Aiguebelette semblerait favorable. Si la carte des gisements reflète l'état de nos connaissances sur les occupations littorales de l'âge du Bronze en Savoie et en HauteSavoie, elle soulève l'intéressante question des territoires potentiels dans un espace géographique donné ; ainsi, sur le rivage de Chens-sur-Léman, la dendrochronologie a mis en évidence la contemporanéité de 5 occupations (villages ?) sur 4,7 km de rivage. 
Dans ce cadre, compte tenu des bonnes conditions de conservation des sédiments lacustres, une politique volontariste en matière de datation devrait être soutenue et programmée entre les intervenants, notamment pour la constitution, par période et par essence, de séquences dendrochronologiques régionales de référence. A ce propos, on se reportera utilement aux réflexions judicieuses de A. Billamboz (Billamboz 1986, p. 112-113). Dans le même ordre d'idée, le recours au radiocarbone pour la calibration devrait être systématique. L'établissement des banques de données dendrochronologiques pourrait trouver une solution rapide par la topographie et l'échantillonnage global des bois de gisements totalement érodés (par exemple certaines stations lémaniques de l'âge du Bronze); cette démarche aurait en outre l'avantage de répondre à la question de l'évolution chronologique et architecturale d'un village et de dater relativement ses différentes structures. Par ailleurs, la datation par le ${ }^{14} \mathrm{C}$ des débris organiques des franges littorales aux couches fortement dilatées, faciliterait l'établissement d'un calendrier des repères chronologiques stratigraphiques nécessaire aux sédimentologues et aux palynologues; recherches qu'il faudrait promouvoir même en l'absence d'occupation humaine connue, sur de nouvelles séquences stratigraphiques où les périodes du Préboréal, du Boréal et de l'Atlantique ancien seraient représentées.

Accepter de faire des choix momentanés dans des programmes, notamment pour l'étude sur les gisements les moins dégradés, rejoindrait les préoccupations de la Tableronde de Marigny Archéologie et érosion et poserait le problème de la protection physique des sites et des milieux littoraux (Collectif 1996).

La précision des résultats obtenus par les naturalistes, et leur pertinence pour l'archéologue, montrent bien la qualité et l'importance des sédiments lacustres pour l'archéologue, même s'il ne s'intéresse pas directement à la question palafittique. C'est cette collaboration entre spécialistes des sciences naturelles et archéologiques qui permettra de préciser l'image des populations lacustres du Néolithique et de l'âge du Bronze dans nos régions ; la pérennité de groupements de chercheurs aux thématiques communes pourrait y contribuer (exemple de l'UMR Laboratoire de Chrono-écologie).

L'étude des paléoenvironnements a montré que la connaissance d'un site et de son occupation nécessite la définition conjointe de problématiques; les rivages lacustres subalpins détiennent un potentiel qui permettrait de répondre aux questions des naturalistes et des archéologues. Espérons que les nouvelles programmations du Conseil National de la Recherche Archéologique (CNRA), en particulier les programmes P14 (Approches spatiales, interactions homme/milieu), P15 (Les formes de l'habitat) et P18 (Approfondissement des chronologies) puissent soutenir ces objectifs (Collectif 1997, p. 351-356, 362). 


\section{Bibliographie}

Académie Chablaisienne 1965 : ANONYME. - Académie Chablaisienne. Séance du 25 septembre 1963. Mémoires et documents publiés par l'Académie Chablaisienne à Thononles-Bains, 56, 1965, p. XIX.

Académie Florimontane 1959 : ANONYME. - Académie Florimontane d'Annecy. Séances des 11 mars et 15 avril 1959. La Revue Savoisienne, 1er et 2e trimestres, 1959, p. 9-12.

Bandi 1979 : BANDI (H.-G.). - Pfahlbaubilder und Pfahlbaumodelle des 19. Jahrhunderts. Archéologie Suisse, $n^{\circ}$ spécial 125 ans de recherches lacustres, 2, 1, 1979, p. 28-32.

Benedetti-Crouzet 1972 : BENEDETTI-CROUZET (E.). - Etude géodynamique du lac d'Annecy et de son bassin versant. 227 p., 76 fig., 38 tabl., 37 ann. (Thèse 3e cycle de l'Univ. de Paris VI, Centre de Recherches géodynamiques, Thonon-les-Bains, juin 1972).

Billamboz 1986 : BILLAMBOZ (A.). - A propos dendrochronologie : science ou technique ? le « bon choix » dans l'application archéologique. Bull. S.P.F., 83, 4, 1986, p. 112-113.

Billamboz 1987 : BILLAMBOZ (A.). - Le bois raconte l'histoire des hommes et de la forêt. Archéologia, 222, mars 1987, p. 30-38.

Billaud et al. 1992 : BILLAUD (Y.), MARGUET (A.), SIMONIN (O.). - Chindrieux, Châtillon (lac du Bourget, Savoie) : ultime occupation des lacs alpins français à l'âge du Bronze ? In : Archéologie et environnement des milieux aquatiques : lacs, fleuves et tourbières du domaine alpin et de sa périphérie. 116e Congrès Nat. Soc. Sav., Commission de Pré-et Protohistoire, Chambéry, 1991. Paris, éd. CTHS, 1992, p. 277-310.

Billaud et al. 1992 : BILLAUD (Y.), MARGUET (A.). - Le site Bronze final de Tougues à Chens-surLéman (Haute-Savoie) : stratigraphie, datations absolues et typologie. In : Archéologie et environnement des milieux aquatiques : lacs, fleuves et tourbières du domaine alpin et de sa périphérie. 116e Congrès Nat. Soc. Sav., Commission de Pré-et Protohistoire, Chambéry, 1991. Paris, éd. CTHS, 1992, p. 311-347.

Billaud et al. 1993 : BILLAUD (Y.), MARGUET (A.). - Etat des connaissances sur les périodes d'occupation littorale du lac d'Annecy. Le nouveau regard apporté par les travaux récents. In : 12e Rencontres Néolithique et Protohistoire Rhône-Alpes, Actualité de la recherche, Lyon, 15 mai 1993. Lyon. Actes des Rencontres Néolithique et Protohistoire Rhône-Alpes, Actualité de la recherche, 8 , Univ. Lyon 2, 1992-1993, p. 41-50.

Billaud et al. à paraître : BILLAUD (Y.), MARGUET (A.). - L'âge du Bronze dans les lacs alpins français. Bilan des travaux récents. XIIIe Congrès UISPP. 8-14 sept. 1996, Forli. (A paraître, 4 p., 6 fig.).

Bintz et al. 1989 : BINTZ (P.), BOCQUET (A.), BOREL (J.-L.) OLIVE (P.). - Tableau diachronique de l'Holocène et du Tardiglaciaire dans les Alpes du Nord et leur piémont. Préhistoire et paléoenvironnement. Bull. S.P.F., 86, 2, 1989, p. 51-60.

Blondel 1923 : BLONDEL (L.). - Relevé des stations lacustres de Genève. Genava, 1, 1923, p. 88-112.

Bocquet 1974 : BOCQUET (A.). - Recherches récentes sur le Néolithique lacustre. Le village des Baigneurs à Charavines (Isère). Archéologia, 69, avril 1974, p. 43-49.

Bocquet 1976a : BOCQUET (A.). - Station littorale immergée des Baigneurs, Charavines (Isère). In : Bocquet (A.), Lagrand (C.), (dir.), Néolithique et âges des Métaux dans les Alpes françaises, IXe Congrès UISPP, Nice. 13-18 sept. 1976, Livret-guide de l'excursion A9. Nice. 1976, p. 145-151. 
Bocquet 1976b : BOCQUET (A.). - Station littorale immergée d'Aiguebelette. In : Bocquet (A.), Lagrand (C.), (dir.), Néolithique et âges des Métaux dans les Alpes françaises, IXe Congrès UISPP, Nice. 13-18 sept. 1976, Livret-Guide de l'excursion A9. Nice. 1976, p. 151-153.

Bocquet 1980 : BOCQUET (A.). - Recherches sur la compréhension des structures dans le village des Baigneurs à Charavines. In : Séminaire sur les structures d'habitat. Organisation collective. Paris. Collège de France, Ethnologie préhistorique, 1980, p. 23-33.

Bocquet 1990 : BOCQUET (A.). - Le village néolithique des Baigneurs à Charavines, lac de Paladru (Isère). In : Die ersten Bauern. Pfahlbaufunde Europas. Band 2, Einführung, Balkan und angrenzende Regionen des Schweiz. Zurich. Schweizerisches Landesmuseum, p. 205-209.

Bocquet 1994 : BOCQUET (A.). - Charavines il y a 5000 ans. La vie quotidienne dans un village néolithique au bord d'un lac des Alpes. Les Dossiers de l'Archéologie, 199, décembre 1994, 104 p.

Bocquet 1995 : BOCQUET (A.). - L'architecture d'un village néolithique à Charavines dans l'Isère. In : Le bois dans l'architecture, Entretiens du Patrimoine, Rouen, 1993. Paris. Actes des colloques de la Direction du Patrimoine, 1995, p. 25-33.

Bocquet et al. 1975 : BOCQUET (A.), ORCEL (C.). - Premiers résultats dendrochronologiques dans les structures de la station des Baigneurs à Charavines (Isère). Nouvelles Archives du Muséum d'Histoire naturelle de Lyon, 13 suppl., 1975, p. 15-20.

Bocquet et al. 1976a : BOCQUET (A.), LAURENT (R.). - Les lacs alpins français. In : Bocquet (A.), Lagrand (C.) (dir.), Néolithique et âges des Métaux dans les Alpes françaises, IXe Congrès UISPP, Nice. 13-18 sept. 1976, LivretGuide de l'excursion A9. Nice. 1976, p. 139-145.

Bocquet et al. 1976b : BOCQUET (A.), LEBASCLE (M. C.). - Station du Port, Annecy (Haute-Savoie). In : Bocquet (A.), Lagrand (C.) (dir.), Néolithique et âges des Métaux dans les Alpes françaises, IXe Congrès UISPP, Nice. 13-18 sept. 1976, Livret-Guide de l'excursion A9. Nice. 1976, p. 165-168.

Bocquet et al. 1985 : BOCQUET (A.), MARGUET (A.). - L'archéologie subaquatique. A milieu et vestiges particuliers, une problématique et des méthodes d'investigations particulières. In : Pelletier (A.), L'archéologie et ses méthodes : prospection, fouille, analyse, restauration. Roanne. Ed. Horvath. 1985, p. 137-157.

Bocquet et al. 1988 : BOCQUET (A.), MARGUET (A.), ORCEL (C.), ORCEL (A.). - Datations absolues sur les stations littorales et l'âge du Bronze final dans les Alpes du Nord. In : Le groupe Rhin-SuisseFrance orientale et la notion de civilisation des Champs d'Urnes, Colloque international, Nemours, 1986. Ed. Association pour la Promotion de la Recherche Archéologique en Ile-de-France (APRAIF), Mémoire du Musée de Préhistoire d'Ile-de-France, 1, 1988, p. 435-444.

Brochier 1982 : BROCHIER (J.-L.). - La sédimentologie lacustre spatiale : étude d'une surface d'habitat sur la station des Baigneurs, lac de Charavines. Bull.S.P.F., 79, 2, 1982. p. 51-55.

Brochier 1983 : BROCHIER (J.-L.). - L'habitat lacustre préhistorique : problèmes géologiques. In : L'habitat lacustre préhistorique. Colloque organisé par la Société de Physique et d'Histoire naturelle, Genève, 19 nov. 1982. Archives des Sciences (Genève), 36, 2, 1983, p. 247-260.

Brochier 1988 : BROCHIER (J.-L.). - Les sédiments : documents archéologiques. Les Nouvelles de l'Archéologie, 31, printemps 1988, p. 15-17.

Brochier et al. 1982 : BROCHIER (J.-L.), JOOS (M.). - Un élément important du cadre de vie des Néolithiques d'Auvernier-Port : le lac. Approche sédimentologique. In : Billamboz et al, La station littorale d'Auvernier-Port. Cadre et évolution. Auvemier 5. Lausanne. Bibliothèque Historique Vaudoise (Cahiers d'Archéologie Romande, 25), 1982, p. 4367. 
Brochier et al. 1992a : BROCHIER (J.-L.), BOCQUET (A.). - Histoire d'une inondation : la couche de craie B 2 du site néolithique des Baigneurs à Charavines, lac de Paladru, France. In : Archéologie et environnement des milieux aquatiques : lacs, fleuves et tourbières du domaine alpin et de sa périphérie. 116e Congrès Nat. Soc. Sav., Commission de Préet Protohistoire, Chambéry, 1991. Paris, éd. CTHS, 1992, p. 61-82.

Brochier et al. 1992b : BROCHIER (J.-L.), CORBOUD (P.), MARZATICO (F.), PUGIN (C.). RACHOUDSCHNEIDER (A.-M.). - Les habitats préhistoriques de l'ancien lac de Fiave-Carera (Trentin-Italie du Nord). Une stratégie d'étude globale sur un site de tourbière. In : Archéologie et environnement des milieux aquatiques : lacs, fleuves et tourbières du domaine alpin et de sa périphérie. 116e Congrès Nat. Soc. Sav., Commission de Pré-et Protohistoire, Chambéry, 1991. Paris, éd. CTHS, 1992, p. 179-203.

Castel 1983 : CASTEL (R.). - Le lac du Bourget. Recensement et état actuel des sites préhistoriques et protohistoriques immergés et réflexions sur 20 ans de plongées archéologiques (1963-1983). 489 p., Rapport CALAS, Aixles-Bains, 1983.

Chantre 1875-1876 : CHANTRE (E.). - Etudes paléoethnologiques dans le Bassin du Rhône. Age du Bronze. Recherches sur l'origine de la métallurgie en France. 2. Gisements de l'âge du Bronze. Paris. Baudry, 1875-1876, 321 p., 186 fig.

Chassepot 1996 : CHASSEPOT (G.). - Analyse pollinique du site du parking de l'Hôtel-de-Ville à Annecy (HauteSavoie). 64 p., 14 fig., 2 ann. (Mémoire de DEA de l'Univ. de Franche-Comté, Besançon, sept. 1996).

Christien 1988 : CHRISTIEN (A.-M.). - Les rapports entre les déchets anthropiques et les structures de la station du Néolithique récent de Charavines, Les Baigneurs (Isère) : étude sur l'organisation de l'espace. 173 p., 58 fig. (Mémoire de maîtrise d'ethnologie de l'Univ. de Paris X, Nanterre, octobre 1988).

Christien et al. 1993 : CHRISTIEN (A.-M.), BOCQUET (A.). - L'organisation spatiale de la station de Charavines-les-Baigneurs (Isère). In : Le Néolithique au quotidien, XVIe colloque interrégional sur le Néolithique, Paris, 5-6 novembre 1989. Paris. Ed. Maison des Sciences de l'Homme D.A.F., $\mathrm{n}^{\circ} 39$. 1993, p. 63-71.

Collectif 1992 : - Le climat à la fin de l'âge du Fer et dans l'Antiquité (500 BC-500 AD). Méthodes d'approche et résultats. Les Nouvelles de l'Archéologie, 50, hiver 1992, 60 p.

Collectif 1996 : Archéologie et érosion. Mesures de protection pour la sauvegarde des sites lacustres et palustres. Actes de la Rencontre internationale, Marigny, lac de Chalain, 2930 sept. 1994. Lons-leSaunier. Centre Jurassien du Patrimoine, 1996, 142 p.

Collectif 1997 ; La recherche archéologique en France. Bilan 1990-1994 et programmation du Conseil National de la Recherche Archéologique. Paris. Ed. Maison des Sciences de l'Homme, 1997,460 p.

Combier 1959 : COMBIER (J.). - Informations archéologiques, circonscription de Grenoble. Gallia Préhistoire, 2, 1959, p. 193-195.

Combier 1961 : COMBIER (J.). - Informations archéologiques, circonscription de Grenoble. Gallia Préhistoire, 4, 1961, p. 310-314.

Combier 1963 : COMBIER (J.). - Informations archéologiques, circonscription de Grenoble. Gallia Préhistoire, 6, 1963, p. 280-283.

Combier 1977 : COMBIER (J.). - Informations archéologiques, circonscription de Rhône-Alpes. Gallia Préhistoire, 20, 2, 1977, p. 655-668.

Combier 1980 : COMBIER (J.). - Informations archéologiques, circonscription de Rhône-Alpes. Gallia Préhistoire, 22, 2, 1980, p. 517-520. 
Congrès Préhistorique 1909 : - Congrès Préhistorique de France, Compte Rendu de la quatrième session de Chambéry, 1908 (excursions générales). Paris. Schleicher Ed., 1909, p. 911-945.

Corboud 1996 : CORBOUD (P.). - Erosion naturelle et disparition des sites préhistoriques immergés du Léman. In : Archéologie et érosion. Mesures de protection pour la sauvegarde des sites lacustres et palustres. Actes de la rencontre internationale de Marigny, lac de Chalain, 29-30 sept. 1994. Lons-leSaunier. Centre Jurassien du patrimoine, 1996, p. 85-96.

Coutil 1915 : COUTIL (L.). - La céramique des palafittes du lac du Bourget (Savoie). Bull. S.P.F. (séance du 25 nov. 1915), 12, 1915, p. 386-402, 4 fig., 11 pl ; p. 430-431, 1 pl.

De Mortillet 1890 : DE MORTILLET (G.). - Origines de la chasse, de la pêche et de l'agriculture. I. Chasse, pêche, domestication. Paris. Lecrosnier, Babé (Bibliothèque anthropologique, XII), 1890, 516 p., 148 fig.

Déchelette 1924 : DECHELETTE (J.). - Manuel d'Archéologie préhistorique, celtique et gallo-romaine, II, Archéologie celtique ou protohistorique, âge du Bronze. Paris. Picard Ed., 1924, 534 p., 212 fig, 5 pl.

Delebecque 1898 : DELEBECQUE (A.). - Les lacs français. Paris. Typographie Chamerot et Renouard, 1898, 436 p., 153 fig., XXII pl.

Dumont 1995 : DUMONT (A.). - Elaboration de la carte archéologique des gisements sous-lacustres savoyards. 65 p., Dépouillement documentaire CNRAS, Annecy, déc. 1995.

Dumont 1997 : DUMONT (A.). - Elaboration de la carte archéologique des gisements sous-lacustres savoyards. 46 p., Dépouillement documentaire DRASSM, Annecy, fév. 1997.

Ferrer-Joly 1980 : FERRER-JOLY (F.). - Caractérisation typologique, étude statistique et répartition spatiale de la céramique du site Néolithique final de Charavines, Les Baigneurs (Isère). 128 p., bibl., 127 pl., XVIII tabl. (Mémoire de Maîtrise de l'Univ. de Paris I, 1986-1988).

Forel 1904 : FOREL (F.-A.). - Antiquités lacustres. Les palafitteurs. In : Le Léman : monographie limnologique, t. 3, 12e partie, chap. III. Histoire. Lausanne. Rouge Ed., 1904, p. 409-509.

Gaillard et al. 1981 : GAILLARD (M.-J.), REYNAUD (C.), WEBER (B.), WEGMULLER (S.). - Les variations tardiglaciaires et postglaciaires du niveau du lac Léman : apport des données palynologiques. Aperçu bibliographique. Archives suisses d'anthropologie générale (Genève), 45, 2, 1981, p. 117-121.

Gallay 1983 : GALLAY (A.). - Esquisse historique de la question palafittique. In : L'habitat lacustre préhistorique, Colloque organisé par la Société de Physique et d'Histoire naturelle, Genève, 19 nov. 1982. Archives des Sciences (Genève), 36, 2, 1983, p. 203-214.

Gallay et al 1979 : GALLAY (A.), CORBOUD (P.). - Les stations préhistoriques littorales du Léman. Où en sont nos connaissances? Archéologie Suisse, $n^{\circ}$ spécial 125 ans de recherches lacustres, 2, 1, 1979, p. 44-49.

Gallay et al. 1981 : GALLAY (A.), KAENEL (G.). - Repères archéologiques pour une histoire des terrasses du Léman. Archives Suisses d'anthropologie générale (Genève), 45, 2, 1981, p. 129-157.

Gidon 1962 : GIDON (P.-A.). - La sédimentation post-glaciaire et les palafittes des lacs de Savoie. In : 85e Congrès Nat. Soc. Sav., section d'archéologie, Chambéry-Annecy, 1960. Paris, éd. CTHS, 1962, p. 13-18.

Goury 1931 : GOURY (G.) - Précis d'Archéologie Préhistorique. L'Homme des cités lacustres. Paris. 1931, 346 p., 146 fig. 
Guinier 1909 : GUINIER (Ph.). - La Palafitte néolithique du Lac d'Annecy : les restes végétaux. In : Congrès Préhistorique de France, Compte Rendu de la quatrième session de Chambéry, 1908 (Palafittes de l'époque néolithique). Paris. Schleicher Ed., 1909, p. 567-571.

Hamard 1954 : HAMARD (A.). - Préhistoire et HommesGrenouilles. Bull. S. P. F. (séance du 25 nov. 1954), 51. 11. 1954, p. 481-484.

Jacquat 1989 : JACQUAT (C.). - Hauterive-Champréveyres, 2. Les plantes de l'âge du Bronze. Contribution à l'histoire de l'environnement et de l'alimentation. Saint-Biaise. Ed. du Ruau (Archéologie neuchâteloise, 8), 113 p., $15 \mathrm{pl}$.

Jacquot 1994 : JACQUOT (K.). - Paléoécologie et paléoéconomie d'un site de l'âge du Bronze : étude des paléosemences de Chindrieux, Châtillon (lac du Bourget, Savoie). 2 vol., 79 p.,21 fig., 11 tabl., 4 ann. (Mémoire de DEA de l'Univ. de Franche-Comté, Besançon, juin 1994).

Keller 1854 : KELLER (F.). - Die keltischen Pfahlbauten in den Schweizerseen. Mittheilungen der Antiquarischen Gesellschaft in Zürich (MAGZ), 1854, 9, 3, p. 67-101.

Lambert et al. 1976 : LAMBERT (G.), ORCEL (C.). - La dendrochronologie ou le passé lu dans le bois. Un nouveau laboratoire du Musée cantonal d'archéologie. Bibliothèques et Musées, Ville de Neuchâtel, 1976, p.101-110.

Lambert et al. 1977 : LAMBERT (G.), ORCEL (C.). - L'état de la dendrochronologie en Europe occidentale et les rapports entre dendrochronologie et archéologie en Suisse. Archives Suisses d'anthropologie générale, Genève, 41,2,1977, p. 73-97.

Lambert et al. 1990 : LAMBERT (G.), LAVIER (C.). - Dendrochronologie et préhistoire. Bull. S.P.F. , $87,5,1990$, p. $143-152$.

Le Roux 1909 : LE ROUX (M.). - La Palafitte néolithique du Lac d'Annecy : outillage, industrie, faune. In : Congrès Préhistorique de France, Compte Rendu de la quatrième session de Chambéry, 1908 (Palafittes de l'époque néolithique). Paris. Schleicher Ed., 1909, p. 547-566.

Leroyer 1985 : LEROYER (C.). - De l'intérêt de différentes études botaniques sur un gisement archéologique : une démarche interdisciplinaire. Nouvelles de l'Archéologie, 19, printemps 1985, p. 8-12.

Lundstrom-Baudais 1977 : LUNDSTROM-BAUDAIS (K.). - Etude des macro-fossiles des sites littoraux d'Auvernier, Brise-Lames, Clairvaux et Charavines, 377 p., 124 fig. (Mémoire de Maîtrise, Faculté des Lettres, Besançon, 1977).

Magny 1978 : MAGNY(M.). - La dynamique des dépôts lacustres et les stations littorales du Grand Lac de Clairvaux (Jura). Paris. Ed. CNRS, centre de recherches archéologiques (Notes et Monographies techniques, 11), 1978, 222 p., 85 fig;, 8 pl.

Magny 1984a : MAGNY (M.). - Les palafittes aujourd'hui : bilan et perspectives. Un siècle d'archéologie lacustre. RAE, XXXV, 1-2(135-136), 1984, p. 41-61.

Magny 1984b : MAGNY (M.). - Archéologie lacustre et dynamique culturelle. In : Eléments de pré et protohistoire européenne. Hommages à Jacques-Pierre Millotte. Paris. Annales Littéraires de l'Université de Besançon, Les BellesLettres, 1984, p. 243-250.

Magny 1986 : MAGNY (M.). - Histoire d'un paysage. Les apports de sondages à la tarière à l'étude d'une station littorale. In : Petrequin (P.) (dir.), Les sites littoraux néolithiques de Clairvaux-les-Lacs (Jura). I. Problématique générale. L'exemple de la station III. Paris. Ed. Maison des Sciences de l'Homme (Archéologie et culture matérielle), 1986. p. 129-132. 
Magny 1987 : MAGNY (M.). - Esquisse d'un modèle pour une approche sédimentologique de séquences holocènes en milieu lacustre carbonaté. In : Travaux français en paléolimnologie, Le Puyen-Velay, 4-6 octobre 1985. Documents du Centre d'Etudes et de Recherche sur les Lacs, Anciens Lacs et Tourbières (CERLAT), Mémoire n 1, 1987, p. 181-211.

Magny 1988 : MAGNY (M.). - Sédimentologie lacustre et archéologie. Les Nouvelles de l'Archéologie, 31, printemps 1888. p. 18-20.

Magny 1991 : MAGNY (M.). - Une approche paléoclimatique de l'Holocène : les fluctuations des lacs du Jura et des Alpes du Nord françaises. 2 vol., 633 p., 314 fig., 84 pl., (Thèse de l'Univ. de FrancheComté, Besançon, juin 1991).

Magny 1992 : MAGNY (M.). - Sédimentation et dynamique de comblement dans les lacs du Jura au cours des 15 derniers millénaires. Revue d'Archéométrie, 16, 1992, p. 27-49.

Magny 1993a : MAGNY (M.). - Un cadre climatique pour les habitats lacustres préhistoriques ? C. R. Acad. Sc., Paris, 316, II, 1993, p. 1619-1625.

Magny 1993b : MAGNY (M.). - Une nouvelle mise en perspective des sites archéologiques lacustres : les fluctuations holocènes des lacs jurassiens et subalpins. Gallia Préhistoire, 35, 1993, p. 253-282.

Magny 1995a : MAGNY (M.). - Une histoire du climat, des derniers mammouths au siècle de l'automobile. Paris. Ed. Errance (Les Hespérides), 1995, 176 p.

Magny 1995b : MAGNY (M.). - Les sédiments des lacs, miroir du climat. La Recherche, 282, déc. 1995, p. 60-65.

Magny 1996 : MAGNY (M.). - Les environnementalistes à la lanterne ? Les Nouvelles de l'Archéologie, 64, été 1996, p. 24-25.

Magny et al. 1981 : MAGNY (M.), OLIVE (P.). - Origine climatique des variations du niveau du lac Léman au cours de l'Holocène. La crise de 1700 à 700 BC. Archives Suisses d'anthropologie générale (Genève), 45, 2, 1981, p. 159-169.

Magny et al. 1985 ; MAGNY (M.), RICHARD (H.). - Contribution à l'histoire du lac du Bourget : recherches sédimentologiques et palynologiques sur le site de Conjux-laChatière (Savoie, France). Revue de Paléohiologie (Genève), 4, 2, 1985, p. 253-277.

Marguet et al. 1984 : MARGUET (A.), ORCEL (A.), ORCEL (C.). - Le lac d'Annecy. In : Archéologie des lacs et des rivières. Vingt ans de recherches subaquatiques en France. Annecy, Musée-Château, catalogue d'exposition, juin-octobre 1984, p. 66-69.

Marguet et al. 1988 : MARGUET (A.), ORCEL (A.), ORCEL (C.). - Problèmes posés par la fouille et l'interprétation des vestiges d'habitats néolithiques dans le lac d'Annecy. Le Petit-Port à Annecyle-Vieux (Haute-Savoie). In : Du Néolithique moyen II au Néolithique final au nord-ouest des Alpes, 12e colloque interrégional sur le Néolithique de l'Est de la France, Lons-le-Saunier, 11-13 oct. 1985. Lons-leSaunier, Musée d'Archéologie et Cercle Girardot, 1988, p. 67-87.

Marguet et al. 1993 : MARGUET (A.). BILLAUD (Y.). - La fin de la Préhistoire dans le lac du Bourget : trente siècles d'occupations littorales? In : La Savoie avant l'Histoire, Mémoires et Documents de la Société Savoisienne d'Histoire et d'Archéologie, 95. 1993, p. 21-36.

Marguet et al. 1995 : MARGUET (A.), BILLAUD (Y.), MAGNY (M.). - Le Néolithique des lacs alpins français. Bilan documentaire. In : Chronologies néolithiques. De 6000 à 2000 avant notre ère dans le Bassin rhodanien, Ambérieu-en-Bugey, 19-20 sept. 1992. Documents du Département 
d'Anthropologie de l'Univ. de Genève, n² 20. Ambérieu-en-Bugey. Société Préhistorique Rhodanienne, 1995, p. 167-196.

Marguier 1993 : MARGUIER (S.). - Mode de dépôt des pollens dans les lacs du Jura : étude du sédiment superficiel et du seston. In : Relations Homme-Milieu. Palynologie et événements cycliques, XIIIe Symposium de l'Association des Palynologues de Langue Française (APLF), Besançon, 20-24 septembre 1993, Livret-Guide de l'excursion 1. Besançon, Laboratoire de Chrono-écologie, 1993, p. $153-158$.

Martin-Kilcher 1979 : MARTIN-KILCHER (S.). - Ferdinand Keller und die Entdekung der Pfahlbauten. Archéologie Suisse, $n^{\circ}$ spécial 125 ans de recherches lacustres, 2, 1, 1979, p. 3-11.

Mignot et al. 1993 : MIGNOT (C.), PETREQUIN (P.). - L'environnement végétal de la station 3 de Chalain : l'apport de l'étude des brindilles et des parois de clayonnage. In : Relations Homme-Milieu. Palynologie et événements cycliques, XIIIe symposium de l'Association des Palynologues de Langue Française (APLF), Besançon, 20-24 sept. 1993, Livret-Guide de l'excursion 1. Besançon, Laboratoire de Chrono-écologie, 1993, p. 139-145.

Monjuvent et al. 1987 : MONJUVENT (G.), NICOUD (G.). - Les paléo-lacs des vallées alpines du Grésivaudan, du Bourget et d'Annecy. France. In : Travaux français en paléolimnologie, Le Puy-enVelay, 4-6 oct. 1985. Documents du Centre d'Etudes et de Recherche sur les Lacs, Anciens Lacs et Tourbières (CERLAT), Mémoire $\mathrm{n}^{\circ} \mathrm{l}, 1987$, p. 213-231.

Morin-Jean 1908 : MORIN-JEAN ( ?). - La céramique du Lac du Bourget. Essai de classification. Sa place dans l'Archéologie européenne. In : Congrès préhistorique de France, compte rendu de la quatrième session de Chambéry, 1908 (Palafittes de l'âge du Bronze). Paris. Schleicher Ed., 1909, p. 600-609.

Moulin 1991 : MOULIN (B.). - Hauterive-Champréveyres, 3. La dynamique sédimentaire et lacustre durant le Tardiglaciaire et te Postglaciaire. Saint-Biaise. Ed. du Ruau (Archéologie neuchâteloise, 9), 1991, 127 p., 79 fig., 16 pl.

Munro 1908 : MUNRO (R.). - Les stations lacustres d'Europe aux âges de la Pierre et du Bronze (Lake Dwellings - Pfahlbauten - Palafitti). Paris. Schleicher Ed., 1908, 294 p., 81 fig., 35 pl.

Nicoud 1992 : NICOUD (C.). - Habitats littoraux présents et passés : confrontation entre un modèle ethnoarchéologique et une analyse de site archéologique. In : Ethnoarchéologie : justification, problèmes, limites, XIIe rencontres internationales d'Archéolgie et d'Histoire, Antibes, 17-19 oct. 1991. Juan-les-Pains. Ed. APDCA, 1992, p. 239-255.

Olive 1972 : OLIVE (P.). - La région du lac Léman depuis 15000 ans : données paléoclimatologiques et préhistoriques. Revue de géographie physique et de géologie dynamique (Paris), XIV, 3, 1972, p. 253-264.

Orcel 1980 : ORCEL (C.). - Application dendrochronologique à l'étude structurelle de sites archéologiques palustres de Suisse et de France alpine. Revue d'archéométrie (Actes du XXe symposium international d'archéométrie), Bull, de liaison du GMPCA, 1, 1980, p. 25-38.

Orcel et al. 1982 : ORCEL (C.), EGGER (H.). - Analyse dendrochronologique des bois de la station littorale d'Auvernier-Port. In: Billamboz et al., La station littorale d'Auvernier-Port. Cadre et évolution. Auvernier 5. Lausanne. Bibliothèque Historique Vaudoise (Cahiers d'Archéologie Romande, 25), 1982, p. 117-129.

Orcel et al. 1985 : ORCEL (C.). ORCEL (A.). - Etat de recherches en mars 1985. In : Groupe de travail pour la dendrochonologie. Etat des chronologies 1985. Dendrocronologia, 3, 1985, p. 153-176, 15 fig. 
Orcel et al. 1990 : ORCEL (C.), ORCEL (A.). - Etat des recherches en dendrochronologie de la Préhistoire à l'époque romaine dans les Alpes et leur piémont. In : Colloque sur les Alpes dans l'Antiquité, V, Pila, Vallée d'Aoste, 11-13 sept. 1987. Aoste. Ed. Société Valdôtaine de Préhistoire et d'Archéologie, Bull, d'études préhistoriques et archéologiques alpines, 1990, p. 281-287.

Paret 1958 : PARET (O.). - Le mythe des cités lacustres et les problèmes de la construction néolithique. Paris. Dunod (La nature et l'homme), 1958, 148 p., $71 \mathrm{ftg}$.

Perrin 1870 : PERRIN (A.). - Etude préhistorique sur la Savoie spécialement à l'époque lacustre (âge du Bronze). Paris. Reinwald ; Chambéry. Perrin, 1870, 34 p., atlas séparé XX pl.

Pétrequin 1980 : PETREQUIN (P.). - Les cités lacustres. La Recherche, 11, 113, juillet-août 1980, p. 778-785.

Pétrequin 1983 : PETREQUIN (P.). - Etat actuel des connaissances sur les problèmes archéologiques. In : L'habitat lacustre préhistorique, Colloque organisé par la Société de Physique et d'Histoire naturelle, Genève, 19 nov. 1982. Archives des Sciences (Genève), 36, 2, 1983, p. 215-232.

Pétrequin 1986a : PETREQUIN (P.). - Historique des recherches. Les idées et les méthodes. In : Petrequin (P.) (dir.), Les sites littoraux néolithiques de Clairvaux-les-Lacs (Jura). I. Problématique générale. L'exemple de la station III. Paris. Ed. Maison des Sciences de l'Homme (Archéologie et culture matérielle), 1986, p. 13-26.

Pétrequin 1986b : PETREQUIN (P.). - La fouille subaquatique de la station III. In : Petrequin (P.) (dir.). Les sites littoraux néolithiques de Clairvaux-les-Lacs (Jura). I. Problématique générale. L'exemple de la station III. Paris. Ed. Maison des Sciences de l'Homme (Archéologie et culture matérielle), 1986, p. 95-106.

Pétrequin 1986c : PETREQUIN (P.). - La stratigraphie et la dynamique de sédimentation. Le point de vue de l'archéologue. In: Petrequin (P.) (dir.), Les sites littoraux néolithiques de Clairvaux-les-Lacs (Jura). I. Problématique générale. L'exemple de la station III. Paris. Ed. Maison des Sciences de l'Homme (Archéologie et culture matérielle), 1986, p. 107127.

Pétrequin et al. 1985 : PETREQUIN (P.), LUNDSTROMBAUBAIS (K.). - L'approche paléoethnobotanique des habitats de milieu humide. Nouvelles de l'Archéologie, 19, printemps 1985, p. $13-22$.

Pétrequin et al. 1986 : PETREQUIN (P.) (dir.). Les sites littoraux néolithiques de Clairvaux-les-Lacs (Jura). I. Problématique générale. L'exemple de la station III. Paris. Ed. Maison des Sciences de l'Homme (Archéologie et culture matérielle), 1986, 406 p., ill., graph., tabl., cartes, plans.

Pétrequin et al. 1989 : PETREQUIN (P.) (dir.). Les sites littoraux néolithiques de Clairvaux-les-Lacs (Jura). II. Le Néolithique moyen. Paris. Ed. Maison des Sciences de l'Homme (Archéologie et culture matérielle), 1989, 508 p., ill., graph., tabl., plans.

Pittard 1938 : PITTARD (J.-J.). - Une nouvelle station lacustre dans le lac de Genève (Léman) (station de la Vorze). Archives suisses d'anthropologie générale (Genève), 8, 1, 1938, p. 16-30.

Rabut 1856 : RABUT (L.). - Compte-rendu de la réunion de la Société Savoisienne d'Histoire et d'Archéologie. 2, 1856, p. 191-214.

Rabut 1864 : RABUT (L.). - Habitations lacustres de la Savoie. Premier mémoire. Mémoire et documents de la Société Savoisienne d'Histoire et d'Archéologie, VIII, 1864, p. 79-145.

Ramseyer 1985 : RAMSEYER (D.). - La dendrochronologie et l'interprétation des structures d'habitats néolithiques. L'exemple de Montilier/Platzbünben (lac de Morat, Suisse). Bull. S.P.F., 82, 1,1985 , p. 20-31. 
Reinerth 1932 : REINERTH (H.). - Das Pfahldorf Sipplingen. Schriften des Vereines für Geschichte des Bodensees und seiner Umgebung, 1932, 59, p. 7-144.

Revon 1878 : REVON (L.). - La Haute-Savoie avant les Romains. Paris. Ed. Champion, Annecy. Ed. L'Hoste, 64 p.. 184 fig.

Rhodania 1921 : ANONYME. - Compte-Rendu du 3e Congrès, Besançon, 1921. Rhodania, 1, 1921, Ass. des préhistoriens, des archéologues classiques et des numismates du Bassin du Rhône, $n^{\circ} 476$, p. $52 ; n^{\circ} 487$, p. $87-88$.

Richard 1985 : RICHARD (H.). - La méthode palynologique et l'évolution du paysage au Néolithique en Europe occidentale. Nouvelles de l'Archéologie, 18, hiver 1984-85, p. 20-22.

Richard 1989 : RICHARD (H.). - Milieux lacustres. Sciences de la nature et archéologie. In : Archéologie en France métropolitaine. Paris. CNRS (Le courrier du CNRS, 73), sept. 1989, p. 24-25.

Richard 1992 : RICHARD (H.). - Perception palynologique de l'évolution de la végétation riveraine des lacs jurassiens : réalité ou fiction? In : Archéologie et environnement des milieux aquatiques : lacs, fleuves et tourbières du domaine alpin et de sa périphérie. 116e Congrès Nat. Soc. Sav., Commission de Pré-et Protohistoire. Chambéry, 1991. Paris, éd. CTHS, 1992, p. 149-159.

Ruoff 1973 : RUOFF (U.). - Constructions sur pilotis et archéologie subaquatique. In : L'archéologie subaquatique, une discipline naissante. Paris. Unesco (Musées et monuments, XIII), 1973, p. 125-140.

Ruoff 1981 : RUOFF (U.). - Die Entwicklung des Unterwasserarchäologie im Kanton Zürich. In : Helvetia archaeologica, 12, 45/48, 1981, p. 62-70.

Ruoff 1986 : RUOFF (U.). - La méthode dendrochronologique. In : Chronologie. Datation archéologique en Suisse. Bâle. Société Suisse de Préhistoire et d'Archéologie (Antiqua, 15), 1986, p. 19-24.

Sauter 1955 : SAUTER (M.). - (Correspondance à propos de Préhistoire et Hommes-Grenouilles). Bull. S. P. F. (séance du 24 mars 1955), 52, 3, 1955, p.l 15.

Schaudel 1906 : SCHAUDEL (L.). - Découverte d'une station de l'âge de la Pierre dans le lac d'Aiguebelette (Savoie). Comptes Rendus de l'Association Française pour l'Avancement des Sciences (AFAS), Congrès de Lyon, 1906. Paris [1907], p. 690-692

Schweingruber 1983 : SCHWEINGRUBER (H.). Aspect climatologique et botanique. In : L'habitat lacustre préhistorique, Colloque organisé par la Société de Physique et d'Histoire naturelle, Genève, 19 nov. 1982. Archives des Sciences, 36, 2, 1983, p. 233-245.

Serand 1884 : SERAND (E.). - Palafittes du lac d'Annecy. Revue Savoisienne, Société Florimontane d'Annecy, 12, 1884, p. 101.

Speck 1981 : SPECK (J.). - Pfahlbauten : Dichtung oder Wahrheit ? Ein Querschnitt durch 125 Jahre Forschungsgeschite. In : Helvetia Archaeologica, 12, 45/48, 1981, p. 98-138.

Stöckli 1986 : STOCKLI (W.-E). - Chronologie absolue et relative. In :Chronologie. Datation archéologique en Suisse. Bâle. Société Suisse de Préhistoire et d'Archéologie (Antiqua, 15), 1986, p. 8-18.

Strahm 1975 : STRAHM (C.). - Nouvelles réflexions sur un vieux problème. Eburodunum I (Institut d'archéologie yverdonnoise), 1975, p. 155-163.

Straub 1990 : STRAUB (F.). - Hauterive-Champréveyres, 4. 'Diatomées et reconstitution des environnements préhistoriques. Saint-Biaise. Ed. du Ruau (Archéologie neuchâteloise, 10), 96 p., 24 pl. 
Thioly 1868 : THIOLY (F.). - Les habitations lacustres du lac de Genève. Almanach de la Suisse romande, Genève, 1868, p. 3-11.

Troyon 1860 : TROYON (F.). - Habitations lacustres des temps anciens et modernes. Lausanne. Bridel Ed., 1860, Mémoires et Documents, Société d'Histoire de la Suisse Romande, XVII, XII-495 p., XVII pl.

Vernet et al. 1971 : VERNET (J.-P.), MEYBECK (M.), PACHOUD (A.), SCOLARI (G.). - Le Léman : une synthèse bibliographique (géologie, structure, sédimentation et hydrologie). BRGM deuxième série, section IV, 2, 1971, p. 47-84.

Vivian et al. 1991 : VIVIAN (R.) (dir.). - Paléoenvironnement holocène et archéologie dans les Alpes du Nord et leur piémont. Paris, éd. CTHS, Section de préhistoire et de protohistoire (Documents préhistoriques, 1), 1991, 184 p., fig., tabl.

Vogt 1951 : VOGT (E.). - Das steinzeitliche Uferdorf Egolzwil 3 (Kt. Lüzern). Zeitschrift für schweizerische Archaologie und Kunstgechichte, 1951, 12,4, p. 193-215.

Voruz 1991 : VORUZ (J.-L.). - Le Néolithique suisse. Bilan documentaire. Genève. Documents du Département d'Anthropologie et d'Ecologie de l'Université de Genève, 17, 1991, 173 p., 31 fig., 4 cartes, $20 \mathrm{pl}$.

Vouga 1934 : VOUGA (P.). - Le Néolithique lacustre ancien. Neuchâtel. Univ. Faculté des Lettres (Recueil des Travaux publiés par la Faculté, 17), 1934.

\section{Document}

Cupillard et al. 1994 : CUPILLARD (C.), MAGNY (M.), RICHARD (H.), RUFFALDI (P.), MARGUIER (S.). - Mésolithisation et néolithisation d'une zone de moyenne montagne : évolution du peuplement et du paysage de la haute vallée du Doubs. 120 p., 54 fig., (Rapport ATP, Archéologie métropolitaine, Besançon, Lab. de Chrono-écologie, janv. 1994).

\section{ANNEXES}

\section{Planches}


PI. 1 - Liste des analyses ${ }^{14} \mathrm{C}$ réalisées par le CNRAS/DRASSM et l'AREOLL, depuis 1980 , pour des vestiges lacustres des périodes comprises entre $9000 \mathrm{BP}$ et l'Actuel

\begin{tabular}{|c|c|c|c|c|c|c|}
\hline $\begin{array}{l}\text { Dpr. Gienenst } \\
\text { Commuate }\end{array}$ & 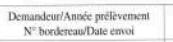 & 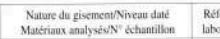 & 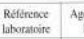 & 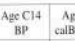 & $\begin{array}{l}\text { Agec calibsé } \\
\text { caliBCralAD }\end{array}$ & 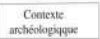 \\
\hline \multicolumn{7}{|l|}{ entre 9000 et $80000 \mathrm{BP}$} \\
\hline $\begin{array}{l}\text { 74. Quai E Curppuis } \\
\text { ANNECY }\end{array}$ & 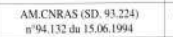 & 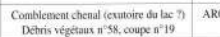 & \begin{tabular}{l|l}
$R C .1157$ & 88 \\
$R$
\end{tabular} & \begin{tabular}{l|l}
$8885+60$ & $-\$ 1$
\end{tabular} & 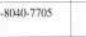 & Indetermine \\
\hline $\begin{array}{l}\text { 74. Oani E. Cluppuis } \\
\text { NNNECY }\end{array}$ & 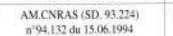 & 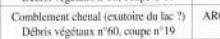 & \begin{tabular}{l|l} 
ARC.1139 & 87 \\
\end{tabular} & \begin{tabular}{l|l}
$8735 E A+$ & -71
\end{tabular} & .7950-7550 & Indsctumine \\
\hline \multirow{2}{*}{\multicolumn{7}{|c|}{ 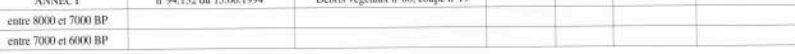 }} \\
\hline & & & & & & \\
\hline $\begin{array}{l}\text { Dipl. Gisensat } \\
\text { Commune }\end{array}$ & 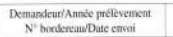 & 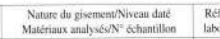 & 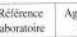 & 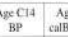 & 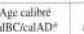 & $\begin{array}{c}\text { Comleste } \\
\text { anthiblogique }\end{array}$ \\
\hline \multicolumn{7}{|l|}{ entre 6000 et 5000 BP } \\
\hline $\begin{array}{l}\text { 74. Les Churtetitures } \\
\text { SEVRRER }\end{array}$ & 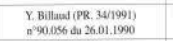 & 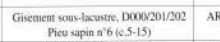 & \begin{tabular}{l|l}
$A R C D N B$ & 53 \\
\end{tabular} & $\begin{cases}315 \pm 50 & -43\end{cases}$ & $-4330-40000$ & Noa indetermine \\
\hline $\begin{array}{l}\text { 74. Lee Miriais } \\
\text { stuoRioz }\end{array}$ & 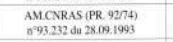 & 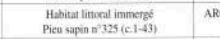 & ARC.1008 51 & 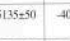 & -4040.5790 & $\begin{array}{l}\text { Nea maycen } \\
\text { Cornalled }\end{array}$ \\
\hline $\begin{array}{l}\text { 74.Les Marais } \\
\text { STJORROZZ }\end{array}$ & 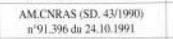 & 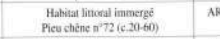 & \begin{tabular}{l|l} 
ARC 671 & 50 \\
\end{tabular} & \begin{tabular}{c|c}
$8070+55$ & -39 \\
\end{tabular} & $3990-3720$ & $\begin{array}{l}\text { Nén moyen } \\
\text { Conallod }\end{array}$ \\
\hline 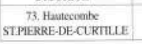 & 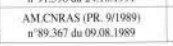 & 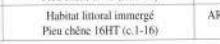 & \begin{tabular}{l|l}
$\operatorname{ARC} 331$ & 50
\end{tabular} & $\begin{array}{ll}\text { sossetot } & -39 \\
\end{array}$ & 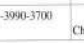 & $\begin{array}{l}\text { Nea. mogen } \\
\text { Chassencontonallod }\end{array}$ \\
\hline 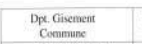 & 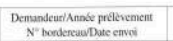 & 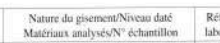 & 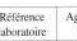 & 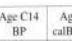 & $\begin{array}{l}\text { Aec calihe } \\
\text { ABCCaAd }\end{array}$ & 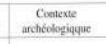 \\
\hline \multicolumn{7}{|c|}{ 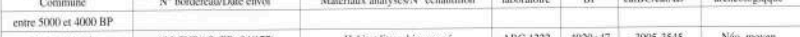 } \\
\hline $\begin{array}{l}74 \text { Les Marals } \\
\text { STJORIOZ }\end{array}$ & 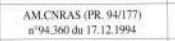 & 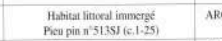 & 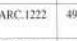 & $99201047 \quad-39$ & $-3 \times 15 .-3545$ & $\begin{array}{l}\text { Nén maycn } \\
\text { Cannillod }\end{array}$ \\
\hline $\begin{array}{l}\text { 74. LA Tour } \\
\text { ANNECYLE-VIIEUX }\end{array}$ & 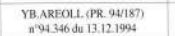 & 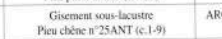 & ARC 1230 $4 x$ & \begin{tabular}{l|l}
$4 \times 32 \pm+1$ & -3
\end{tabular} & -3775.315, & Né, indeterminin \\
\hline $\begin{array}{l}\text { 74. Leschomean } \\
\text { SEVRRER }\end{array}$ & 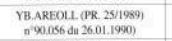 & 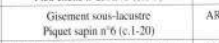 & \begin{tabular}{l|l}
$A R C A 73$ & 47
\end{tabular} & \begin{tabular}{l|l}
$4775 \pm 575$ & -3
\end{tabular} & $-3770-3730$, & Nón. indéterminé \\
\hline $\begin{array}{l}\text { 73. La Chaniere } \\
\text { CoNUTX }\end{array}$ & 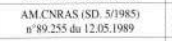 & 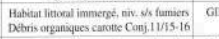 & \begin{tabular}{l|l} 
GIF 8146 & 47
\end{tabular} & \begin{tabular}{|l|l}
$730+180$ & 3
\end{tabular} & $\begin{array}{l}.3960-2925 \\
\end{array}$ & Né, indéterminé \\
\hline $\begin{array}{l}\text { 74.Le Peaii-Pour } \\
\text { ANECY-LE-VIEUX }\end{array}$ & 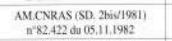 & 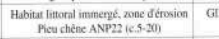 & \begin{tabular}{l|l} 
GiFoons & 4 \\
\end{tabular} & $\begin{array}{l}459 x=70 \\
-3\end{array}$ & -3065 -3005 & 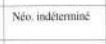 \\
\hline 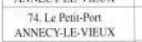 & 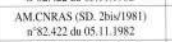 & 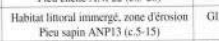 & 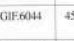 & \begin{tabular}{l|l}
$4580=70$ & -3 \\
\end{tabular} & .3515:0045, & Nen. iostictuming \\
\hline $\begin{array}{l}\text { 73. Hautcombe } \\
\text { SIPIERRE-DE-CIKTIIIE }\end{array}$ & 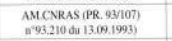 & 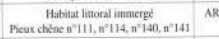 & $\begin{array}{ll}A R C .1022 & 45 \\
\end{array}$ & \begin{tabular}{l|l}
$454010+50$ & -3
\end{tabular} & . & Nita. inditerninine \\
\hline $\begin{array}{l}\text { 74. Le Marais } \\
\text { STJORIOZ }\end{array}$ & 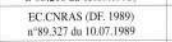 & 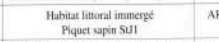 & \begin{tabular}{l|l}
$A R C(369)$ & 4
\end{tabular} & \begin{tabular}{l|l}
$4450 \pm 55$ & -3
\end{tabular} & $-3340-2920$ & Non inderermint \\
\hline $\begin{array}{l}\text { 73. Lo Chatiter } \\
\text { CoNux }\end{array}$ & 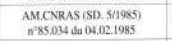 & 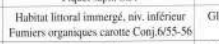 & GIFG771 4 & \begin{tabular}{l|l|}
$4250 \pm 70$ & -3
\end{tabular} & -30042.2615 & Nén ricentufinal \\
\hline $\begin{array}{l}74 \text { C. Curvetce } \\
\text { MESSEYY }\end{array}$ & 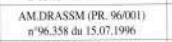 & 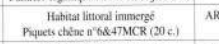 & KRC 1562 & $4170=45 \quad-2$ & $20105=2610$ & Nea nstentifinal \\
\hline $\begin{array}{c}\text { 72 Heso-Phanc I } \\
\text { AIGUBBELETTELELAC }\end{array}$ & 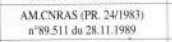 & 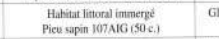 & $\begin{array}{ll}\text { GiF } 8339 & 4\end{array}$ & \begin{tabular}{l|l}
$4 \mid(60)+80$ & $=2$
\end{tabular} & $2910-2590$ & Néo intétermine \\
\hline $\begin{array}{l}\text { 74. Le Punde-Reres } \\
\text { THONON-LES-BANS }\end{array}$ & 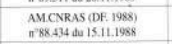 & 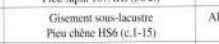 & \begin{tabular}{l|l}
$A R C 2260$ & 4
\end{tabular} & $\begin{array}{ll}4000+50 & =3\end{array}$ & $-2880-2495$ & No. indetermine \\
\hline $\begin{array}{l}\text { 73.Le Gojaj } \\
\text { NoviLAISE }\end{array}$ & 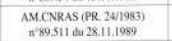 & 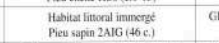 & GiF. 8338 & 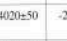 & .2865 .24600$, & Non inditentine \\
\hline $\begin{array}{l}\text { 73. Panour } \\
\text { CHANAZ }\end{array}$ & $\begin{array}{l}\text { 1. Premon (SD. 1984) } \\
\text { n'86.293 du } 10.11 .1986\end{array}$ & 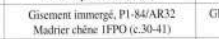 & 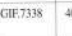 & $\begin{array}{l}4010=70=30 \\
-3\end{array}$ & $.2870-2350$ & Inditerrinine \\
\hline $\begin{array}{l}\text { 73 Meman } 1 \\
\text { BRISON-STINNOCENT }\end{array}$ & 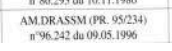 & 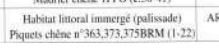 & $\triangle A C C .1491+$ & 4000 tat $=2$ & .2855:24(8) & Nita resecentifinal \\
\hline $\begin{array}{l}\text { Dpl. Gisennest } \\
\text { Cunnaune }\end{array}$ & 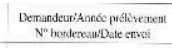 & 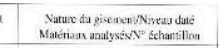 & $\begin{array}{l}\text { Retefremer } \\
\text { hibovalaice }\end{array}$ & $\mathrm{BPP}_{\mathrm{BP}}^{\mathrm{Ag} C 24}$ & 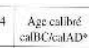 & 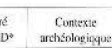 \\
\hline cante $450 \mathrm{Ce}=3600 \mathrm{BP}$ & & & & & & \\
\hline $\begin{array}{l}\text { 74. Crozectic } \\
\text { MFSSERY }\end{array}$ & 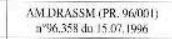 & 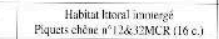 & ARC:1563 & $3950+45$ & $.2555 .-2330$ & Noş. nueventfina \\
\hline $\begin{array}{l}\text { 74. Angea } \\
\text { TAHOIRES }\end{array}$ & 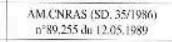 & 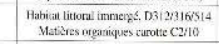 & GilF:8145 & $3910 \div 50$ & $-2575-2210$ & 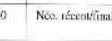 \\
\hline 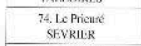 & 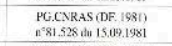 & 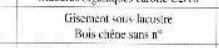 & GIF: 625 & $3890 \pm 00$ & & Instéurnires \\
\hline $\begin{array}{l}\text { 73. Lacharite } \\
\text { Covvux }\end{array}$ & 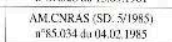 & 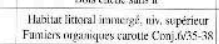 & GIFG770 & $13604 \pm 00$ & $.245-22390$ & 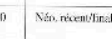 \\
\hline $\begin{array}{l}\text { 73. Caxillen } \\
\text { CUINDIIILX }\end{array}$ & 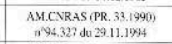 & 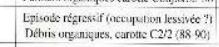 & $\begin{array}{c}\text { LX113 } \\
\text { OXAA }\end{array}$ & $3445 \pm 70$ & $-2396-1929$ & Imbetemrine \\
\hline $\begin{array}{l}\text { 74.1.se Mungerts } \\
\text { SEVRIIER }\end{array}$ & 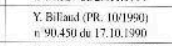 & 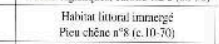 & $A R C 528$ & $3995=50$ & -21401770 & Bronse anticn \\
\hline $\begin{array}{l}\text { 74. Le Mengets } \\
\text { SEVYIIER }\end{array}$ & 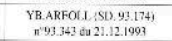 & 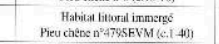 & ARCIOTZ & $3400 \pm 50$ & 20101990 & Bronze arvica \\
\hline 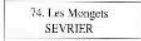 & 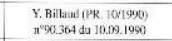 & 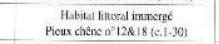 & ARC:524 & $3465 \pm 50$ & .2010 .1635 & Brame encian \\
\hline $\begin{array}{l}\text { 3. L L P Port } \\
\text { ANNECY }\end{array}$ & 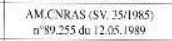 & 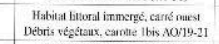 & GII.81433 & $340 \mathrm{n}+7 \mathrm{n}$ & .2011215155 & Indserminé \\
\hline $\begin{array}{l}\text { 74.LPREY } \\
\text { ANNECY }\end{array}$ & $\begin{array}{l}\text { AMCCNRAS ISV .3551985) } \\
\text { n. } 89.255 \text { du } 12.05 .1985\end{array}$ & 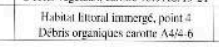 & (ill: $: 114$ & $3035=55$ & 140101045 & laditerning \\
\hline 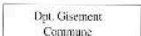 & 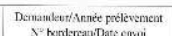 & ture du gisementeniveau dite & Rétitreace & $\mathrm{AgCCI}_{2}$ & Age catione & 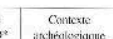 \\
\hline conte 3000 e 125000 BP & & & albrearnic & & CalBCicalat ${ }^{*}$ & \\
\hline $\begin{array}{l}\text { 73. Chathion Rut } \\
\text { CHINORELUX }\end{array}$ & $\begin{array}{l}\text { AM.CNRAS } \\
n=94.101 \text { ith } 2504.19944\end{array}$ & 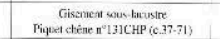 & ARC 126 & $29 \% x=40$ & $-13 \times x-1080$ & Iabjékernioz \\
\hline $\begin{array}{l}\text { 74. Le Roeker } \\
\text { DUINGT }\end{array}$ & 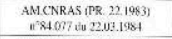 & 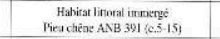 & GilFsass & $295010=68$ & $-1390-1005$ & Hrosec frast \\
\hline $\begin{array}{l}\text { 74. Le Rneleler } \\
\text { DQUNGer }\end{array}$ & 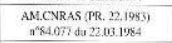 & 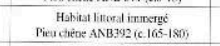 & GiF 6487 & $28880 \leq 501$ & -1295.900 & Brunze final \\
\hline $\begin{array}{l}\text { 73. Cainillan } \\
\text { CHINDERILCX }\end{array}$ & 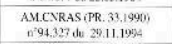 & 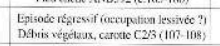 & $\underset{O X_{A}}{I . X 114}$ & 250455 & $-1152: 2835$ & Indelemriaz \\
\hline 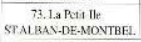 & 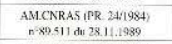 & 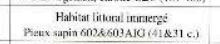 & GIF:S337 & $2770=39$ & $-10809290^{\circ}$ & Bronze final \\
\hline $\begin{array}{l}\text { 73 Le Gruat-Pent } \\
\text { ANX-LLS-BAINS }\end{array}$ & 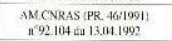 & 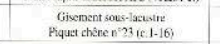 & $\mathrm{ARC}, 243$ & $2 \pi \leqslant \leq \leqslant 0$ & $-1096-205$ & Lisdturnini \\
\hline 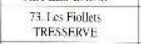 & 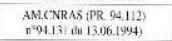 & 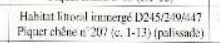 & ARCI1S4 & $272 x+19$ & 07901 & Brozas final \\
\hline $\begin{array}{l}\text { 73. Chatillon } \\
\text { CHINDRIIIIX }\end{array}$ & 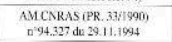 & 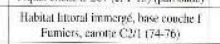 & LY.6024 & $2300 \pm 45$ & sIl6:-803 & 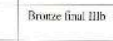 \\
\hline $\begin{array}{l}34 \text { Sungy } \\
\text { SCIEZ }\end{array}$ & 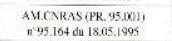 & 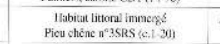 & ARC.1175 & 26933440 & $-9770-500$ & Brengex lisal \\
\hline 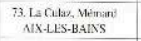 & 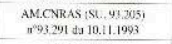 & 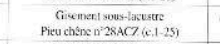 & \begin{tabular}{|l|} 
ARC.1031 \\
\end{tabular} & $26 \in 00 \pm 50$ & .9255993 & Indideraminé \\
\hline $\begin{array}{l}\text { 3. Prerow: } \\
\text { CHANAZ }\end{array}$ & 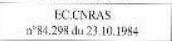 & 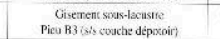 & Gil.67\%(n & 260190 & $.9720-435$ & Bonese final \\
\hline 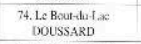 & Y. B.llavd (PR. 34.19911) & 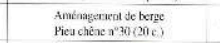 & $A R C$ is & $2255 \pm 5010$ & 405300 & Indécrminté \\
\hline 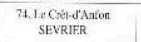 & $\begin{array}{l}\text { PGCNRAS } \\
\text { mry.223 in } 18.10 .1984\end{array}$ & 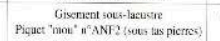 & GIFG6158 & $21000=50$ & $-350+20$ & Trukérerriag \\
\hline
\end{tabular}




\begin{tabular}{|c|c|c|c|c|c|c|}
\hline $\begin{array}{c}\text { Dpt. Gisement } \\
\text { Commune } \\
\text { entre } 2000 \text { et } 1000 \text { BP }\end{array}$ & $\begin{array}{l}\text { Demandeur/Annéc prélèvement } \\
\mathrm{N}^{\circ} \text { bordereau/Date envoi }\end{array}$ & $\begin{array}{l}\text { Nature du gisement/Niveau daté } \\
\text { Matériaux analysés } / \mathrm{N}^{\circ} \text { échantillon }\end{array}$ & $\begin{array}{l}\text { Référence } \\
\text { laboratoire }\end{array}$ & $\underset{\mathrm{BP}}{\mathrm{Age} C 14}$ & $\begin{array}{c}\text { Age calibré } \\
\text { calBC/calAD* }\end{array}$ & $\begin{array}{c}\text { Contexte } \\
\text { archéologiqque }\end{array}$ \\
\hline $\begin{array}{l}\text { 74. Le Port } \\
\text { ANNECY }\end{array}$ & $\begin{array}{l}\text { AM.CNRAS (SU. 35/1985) } \\
\mathrm{n}^{\circ} 89.255 \text { du } 12.05 .1989\end{array}$ & $\begin{array}{l}\text { Habitat littoral immergé, carré ouest } \\
\text { Débris organiques, carotte } 1 \mathrm{AO} / 10\end{array}$ & GIF.8142 & $1940 \pm 50$ & $-90+215$ & Indéterminé \\
\hline $\begin{array}{l}\text { 74. Rue de la Tour } \\
\text { NERNIER }\end{array}$ & $\begin{array}{c}\text { AM.DRASSM (PR. 96/023) } \\
\mathrm{n}^{\circ} 96.358 \text { du } 15.07 .1996\end{array}$ & $\begin{array}{l}\text { Aménagement littoral (débarcadère ?) } \\
\text { Pieu chêne n4NT (c.1-18) }\end{array}$ & ARC. 1578 & $1770 \pm 40$ & $+130+380$ & Indéterminé \\
\hline $\begin{array}{l}\text { 73. Portout } \\
\text { CHANAZ }\end{array}$ & $\begin{array}{c}\text { J.Pernon } \\
\mathrm{n}^{\circ} 86.293 \mathrm{du} 10.11 .1986 \\
\end{array}$ & 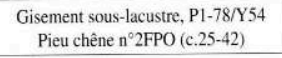 & GIF.7339 & $1590 \pm 70$ & $+260+640$ & Indéterminé \\
\hline $\begin{array}{l}\text { 73. Le Grand-Port } \\
\text { AIX-LES-BAINS }\end{array}$ & $\begin{array}{l}\text { AM.CNRAS (PR. 46/1991) } \\
\text { n92.104 du 13.04.1992 }\end{array}$ & $\begin{array}{l}\text { Gisement sous-lacustre } \\
\text { Piquet saule n }{ }^{\circ} 31\end{array}$ & ARC. 770 & $1355 \pm 120$ & $+430+945$ & Indéterminé \\
\hline $\begin{array}{l}\text { 74. Le Prieuré } \\
\text { SEVRIER }\end{array}$ & Y. Billaud (SD, 19/1983) & $\begin{array}{l}\text { Gisement sous-lacustre } \\
\text { Pieu nASP26 }\end{array}$ & ARC.736 & $1240 \pm 50$ & $+665+940$ & Indéterminé \\
\hline $\begin{array}{l}\text { 74. Chenal du Thiou } \\
\text { ANNECY }\end{array}$ & $\begin{array}{c}\text { AM.CNRAS } \\
\mathrm{n}^{\circ} 95.178 \mathrm{du} 31.05 .1995\end{array}$ & Piquet aulne no 01 (c.1-12) & ARC. 1338 & $1125 \pm 40$ & $+780+990$ & Indéterminé \\
\hline
\end{tabular}

\begin{tabular}{|c|c|c|c|c|c|c|}
\hline $\begin{array}{l}\text { Dpt. Gisement } \\
\text { Commune }\end{array}$ & $\begin{array}{l}\text { Demandeur/Année prélèvement } \\
\mathrm{N}^{\circ} \text { bordereau/Date envoi }\end{array}$ & $\begin{array}{l}\text { Nature du gisement/Niveau daté } \\
\text { Matériaux analysés } / \mathrm{N}^{\circ} \text { échantillon }\end{array}$ & $\begin{array}{l}\text { Référence } \\
\text { laboratoire }\end{array}$ & $\begin{array}{l}\text { Age Cl4 } \\
\text { BP }\end{array}$ & $\begin{array}{l}\text { Age calibré } \\
\text { calBC/calAD* }\end{array}$ & $\begin{array}{c}\text { Contexte } \\
\text { archéologiqque }\end{array}$ \\
\hline \multicolumn{7}{|l|}{ entre $1000 \mathrm{BP}$ et I'Actuel } \\
\hline $\begin{array}{l}\text { 74. Le Prieuré } \\
\text { SEVRIER }\end{array}$ & $\begin{array}{l}\text { AM.CNRAS (SD. 19/1983) } \\
\text { no } 84.077 \text { du 22.03.1984 }\end{array}$ & $\begin{array}{c}\text { Gisement sous-lacustre } \\
\text { Pieu chêne no }{ }^{\circ} \text { ASP17 (c.5-15) }\end{array}$ & GIF.6485 & $860 \pm 50$ & $+1030+1265$ & Indéterminé \\
\hline $\begin{array}{l}\text { 74. Quai E. Chappuis } \\
\text { ANNECY }\end{array}$ & $\begin{array}{l}\text { AM.CNRAS (SD. 93.224) } \\
\text { n95.229 du 07.07.1995 }\end{array}$ & Os (fémur) n $1 / 2334$, coupe $14 / 15$ & ARC. 1308 & $787 \pm 47$ & $+1130+1285$ & Indéterminé \\
\hline $\begin{array}{l}\text { 74. Quai E. Chappuis } \\
\text { ANNECY }\end{array}$ & $\begin{array}{l}\text { AM.CNRAS (SD. 93.224) } \\
\mathrm{n}^{\circ} 94.204 \text { du } 16.08 .1994\end{array}$ & Madrier chêne n ${ }^{\circ} 1002 \mathrm{APK}$, coupe 16 & ARC. 1163 & $774 \pm 40$ & $+1165+1280$ & Indéterminé \\
\hline $\begin{array}{l}\text { 74. Quai E. Chappuis } \\
\text { ANNECY }\end{array}$ & $\begin{array}{l}\text { AM.CNRAS (SD. 93.224) } \\
\mathrm{n}^{\circ} 94.204 \text { du } 16.08 .1994\end{array}$ & Tourbe n53/1, coupe 16 & ARC.1164 & $420 \pm 40$ & $+1415+1625$ & Indéterminé \\
\hline $\begin{array}{l}\text { 74. Quai E. Chappuis } \\
\text { ANNECY }\end{array}$ & 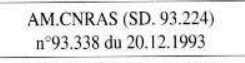 & Pieu pin n 1 APK $(c .1-20)$ & ARC.1076 & $315+50$ & $+1445+1655$ & Moderne \\
\hline $\begin{array}{l}\text { 74. Les Bouchets } \\
\text { YVOIRE }\end{array}$ & 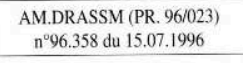 & 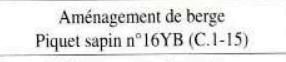 & ARC. 1579 & $110 \pm 40$ & +1670-Actuel & Moderne \\
\hline $\begin{array}{l}\text { 74. Le Crêt d'Anfon } \\
\text { SEVRIER }\end{array}$ & $\begin{array}{c}\text { PG.CNRAS } \\
\mathrm{n}^{\circ} 84.283 \mathrm{du} 18.10 .1984\end{array}$ & $\begin{array}{c}\text { Gisement sous-lacustre } \\
\text { Piquet "dur" n' } \mathrm{n} \text { ANF1 (sur tas pierres) }\end{array}$ & GIF.6687 & moderne & & \\
\hline
\end{tabular}

( Datations 14C calibrées d'après Pearson et al., 1986 \& Stuiver, Becker, 1986) (Archéolabs CALIB. 2-1) 
PI. 2 - Tableau des séquences dendrochronologiques des Alpes du Nord datées de l'âge du Bronze (ancien et final) dans les lacs savoyards, à partir des bois de chêne (Quercus) et de sapin (Abies)

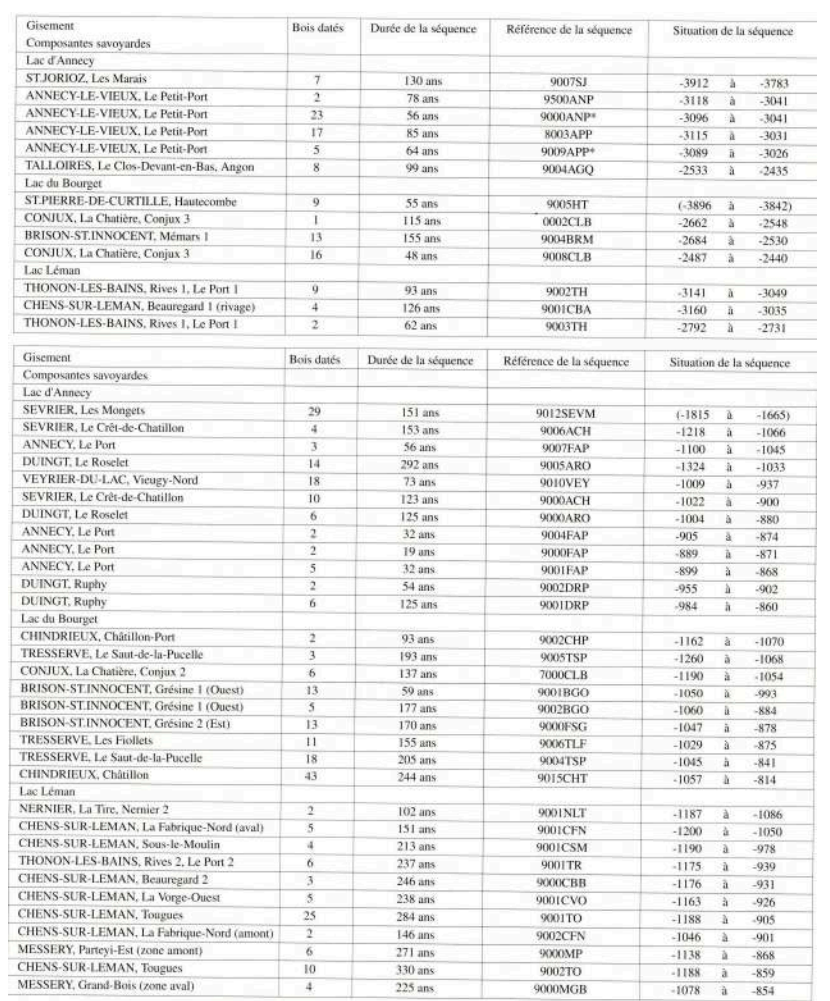

* Abies. () avec réserve. calage radiocarbone.

Analyses Laboratoire Romand \& Dendrochronologie et Archéolabs ; prélèvements CNRAS/DRASSM \& AREOLL. 
PI. 3 - Tableaux des opérations de prospections-sondages réalisées, depuis 1981, par l'AREOLL, le CALAS et le CNRAS/DRASSM dans le cadre du recensement des gisements sous-lacustres pré-et protohistoriques savoyards. Les gisements ayant fait l'objet de prélèvements pour les analyses ${ }^{14 C}$, dendrochronologiques, sédimentologiques et palynologiques sont signalés, ainsi que ceux présentant des limons teintés (LT) et des fumiers de matières organiques conservés (FMO).

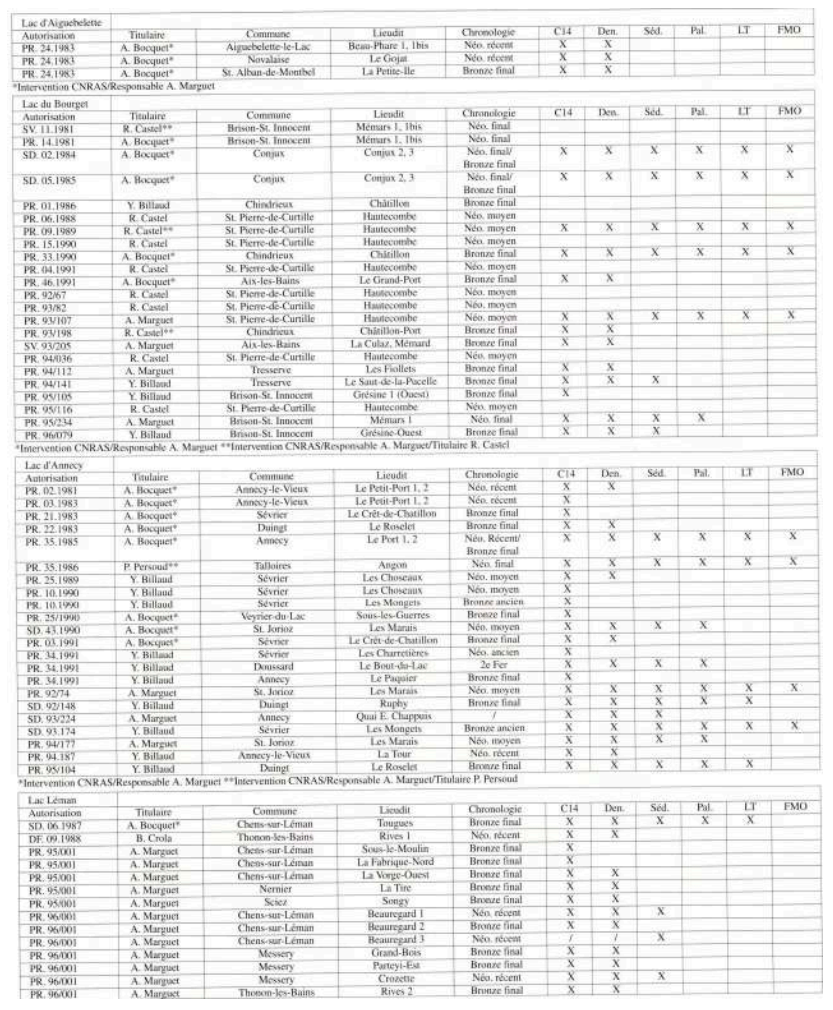

*Intervention CNRAS/Responsable A. Marguet

\section{NOTES}

1. Présentées par A. Marguet sous la forme de deux communications lors des entretiens des 17 et 18 novembre 1995 (1. La protohistoire des lacs alpins ; 2a. Les lacs savoyards), ces contributions sont réunies ici en un seul texte. L'exposé de A. Bocquet (2b. Le Dauphiné), essentiellement consacré à ses travaux sur le gisement néolithique de Charavines, Les Baigneurs et plus particulièrement sur les résultats obtenus dans les domaines de l'organisation spatiale des vestiges et de l'évolution architecturale des structures d'habitation, a déjà fait l'objet d'articles (voir notamment Christien et al. 1993, p. 63-71 et Bocquet 1995, p. 25-33).

2. Bien qu'installé dans un contexte géographique assez semblable, le lac de Paladru, rattaché au domaine isérois du Bas-Dauphiné, n'est pas pris en compte dans cette contribution; on se reportera donc, pour ce qui concerne le seul gisement néolithique repéré sur son rivage, Charavines, Les Baigneurs, aux travaux publiés par A. Bocquet et largement cité en bibliographie (Bocquet 1990, p. 205-209; Bocquet 1995, p. 25-33). 


\title{
L'approche paléoclimatique des habitats lacustres Jura et Alpes du Nord
}

\author{
Michel Magny
}

1 Depuis leur découverte en 1854 par le (suisse Ferdinand Keller, les habitats lacustres ont acquis une place privilégiée dans la recherche archéologique. Cela tient, bien sûr, au matériel mobilier et immobilier que l'on a pu mettre au jour sur ces sites et qui faisait le plus souvent défaut sur les sites terrestres : outils emmanchés, vanneries, tissus, éléments d'architecture... Cela tient aussi à la controverse qu'a suscitée leur interprétation: cités lacustres telles que les avait aussitôt imaginées F. Keller, ou habitats établis directement sur le sol tels que les reconstituaient $\mathrm{E}$. Vogt et $\mathrm{O}$. Paret à la fin des années 1950 ? Cela tient enfin à la collaboration que les archéologues ont ici demandée très tôt aux naturalistes, qu'il s'agisse d'exploiter l'abondance des restes organiques découverts sur ces sites ou d'apporter des arguments décisifs dans la querelle des palafittes.

2 Le développement de fouilles programmées dès les années 1970 en bordure des lacs de Clairvaux et de Chalain sous la direction de P. Pétrequin et les sondages de reconnaissance réalisés depuis les années 1980 par le CNRAS sur les sites immergés des lacs d'Annecy (Haute-Savoie) et du Bourget (Savoie) ont été le point de départ de recherches systématiques visant à reconstituer l'environnement lacustre de ces habitats préhistoriques. Plutôt que de rappeler une nouvelle fois les résultats auxquels ces études ont pu aboutir dans le domaine de l'environnement climatique, résultats qui ont déjà été publiés ailleurs (Magny 1992, 1993b, 1995c ; Magny et Ruffaldi 1995), cette note a pour objet d'évoquer plus particulièrement les stratégies de recherche adoptées et les perspectives qui se dessinent aujourd'hui après plus d'une décennie de collaboration entre archéologues et paléoclimatologues dans le domaine lacustre jurassien et subalpin. 


\section{Les problématiques et les méthodes}

3 L'abondante littérature issue de la querelle des palafittes témoigne de la confusion que cette querelle a longtemps entretenue entre problématiques archéologique et naturaliste. Il est essentiel que chacune soit clairement identifiée. D'une part, la problématique de type archéologique: les habitats lacustres préhistoriques sont-ils construits sur le sol ou sur pilotis? Elle implique une recherche spécifique, centrée sur l'observation et l'interprétation des vestiges architecturaux découverts lors des fouilles. Et, d'autre part, la problématique de type naturaliste : quel était le niveau d'un lac pendant l'occupation de ses rives par un groupe préhistorique? C'est une autre façon de poser la question précédente, mais c'est aussi une question différente: un abaissement du niveau du lac n'implique pas forcément une construction établie directement sur le sol, de la même manière qu'un habitat surélevé ne signifie pas immédiatement une remontée du plan d'eau. Cette seconde problématique implique une autre recherche tout aussi spécifique que la première dans ses méthodes et sa stratégie.

4 S'agissant de la première question, on sait aujourd'hui grâce à la reprise et à la multiplication des fouilles depuis 1970, grâce à des sites remarquables comme celui de Fiave-Carera, et au renouvellement de la problématique archéologique (Pétrequin 1980) que tous les types d'architecture ont existé pendant la Préhistoire en bordure des lacs : maisons construites sur le sol, maisons à plancher rehaussé et maisons sur pilotis.

5 En ce qui concerne la seconde question, l'article publié par J.-L. Brochier et M. Joos en 1982 constitue sans contexte une étape majeure pour la restitution du cadre paléohydrologique des habitats lacustres: les fluctuations du niveau du lac de Neuchâtel pendant le Néolithique y sont reconstituées sur la base d'une approche strictement sédimentologique de la séquence stratigraphique du site d'Auvernier-Port.

6 La première figure (fig. 1) illustre les bases sur lesquelles repose la méthode mise au point pour la reconstitution des variations du niveau des lacs jurassiens et subalpins. L'observation de dépôts actuels prélevés à l'interface eau-sédiment selon des transects perpendiculaires à la rive permet d'identifier des marqueurs bathymétriques. Ces marqueurs sont utilisés ensuite pour restituer la profondeur du milieu de dépôt des sédiments échantillonnés sur une séquence stratigraphique mise au jour lors d'une fouille ou par le biais d'un carottage. Ainsi est-il possible de retracer les fluctuations d'un plan d'eau sur la base d'une approche sédimentologique parfaitement indépendante de toute donnée archéologique. Cette indépendance méthodologique est un préalable indispensable à tout croisement des données naturalistes et archéologiques. 
1- Bases pour la reconstitution des variations du niveau des lacs jurassiens et subalpins

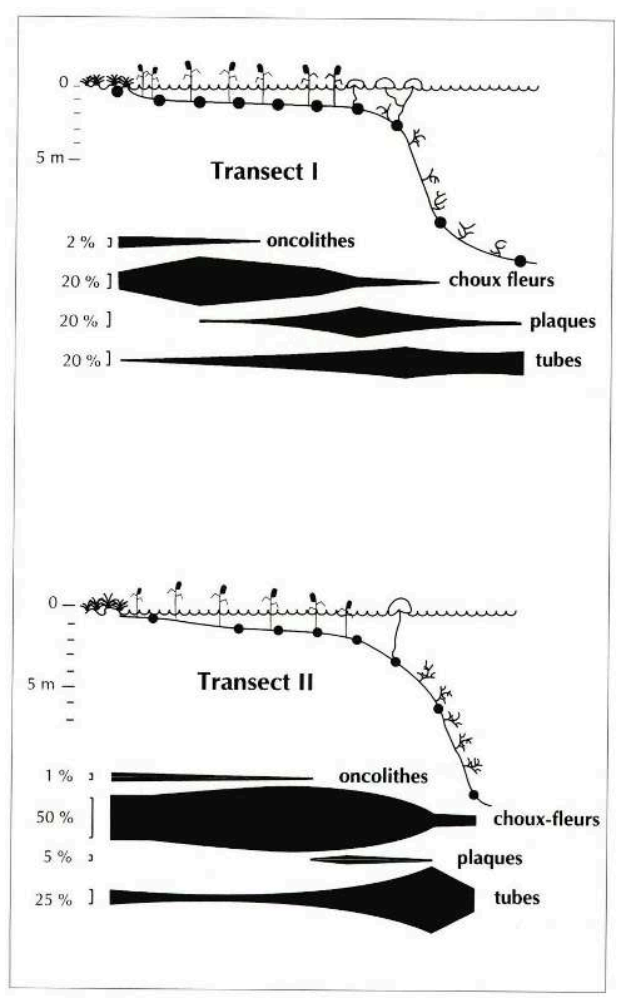

L'analyse d'échantillons prélevés à l'interface eau-sédiment selon deux transects perpendiculaires à la rive dans le grand lac de Clairvaux montre clairement que la distribution des différents morphotypes de concrétions carbonatées (oncolithes, choux-fleurs, plaques et tubes) obéit à une zonation de la rive à la zone profonde du lac. Dans les zones peu profondes des bordures riveraines, où l'hydrodynamisme est important, dominent les oncolithes ; la beine est le domaine du type « choufleur ». Le type plaque coïncide plus particulièrement avec la ceinture des végétaux à feuilles flottantes ou immergées, tels que les nénuphars ou les potamots. Enfin, le type tube connaît un développement maximal dans les zones plus profondes où dominent les Characées (algues vertes). Ainsi la dominance d'un morphotype de concrétion dans un échantillon de craie lacustre fossile peut être utilisée comme un indicateur de la profondeur de son milieu de dépôt. Cette zonation des différents types de concrétions a fait l'objet de contrôles à partir de l'étude de 15 transects échantillonnés dans 9 lacs différents.

\section{Sortir du ghetto}

7 Au cours des 15 années passées, un certain nombre d'études sédimentologiques ponctuelles, effectuées sur des sites archéologiques ou dans leur proximité immédiate, ont ainsi établi de façon rigoureuse la réalité de fluctuations lacustres au cours du Néolithique et de la Protohistoire (Brochier et Joos 1982, Borel et al. 1985, Magny et Richard 1985, Brochier 1986, Magny 1988, Moulin 1991).

Ce premier point acquis, deux problèmes importants restent encore en suspens. Que penser tout d'abord de ces variations de niveau? Sont-elles la conséquence de phénomènes strictement locaux ou aléatoires, ou sont-elles le reflet de phénomènes globaux, d'ordre climatique? Que penser ensuite de l'interruption, provisoire ou définitive, de l'habitat lacustre pendant le Bronze moyen ou à partir de l'âge du Fer? Cette périodisation que l'on retrouve, à quelques exceptions près, dans tout le domaine subalpin n'est-elle pas un indice troublant, quoique tout à fait insuffisant, en faveur de l'interférence du climat? 
On doit reconnaître que les archéologues se sont trop longtemps focalisés sur les sites qu'ils étudiaient; ils se sont longtemps enfermés dans une problématique étriquée, sans se donner davantage de recul dans le temps ou l'espace, ni s'intéresser au développement d'autres recherches. Si la question des fluctuations lacustres au Néolithique et à l'âge du Bronze a été reconnue dès les années 1920, les recherches restent cependant limitées dans l'espace aux seuls sites préhistoriques, et dans le temps aux seules périodes néolithiques et protohistoriques. Comme si l'on s'efforçait en vain de comprendre un épisode sans vouloir prendre en considération toute l'histoire à laquelle il appartient, et comme si les phénomènes en cause (à savoir les fluctuations des lacs subalpins pendant l'Holocène) n'avaient jamais été perçus globalement ni définis en tant que tels.

10 L'archéologie lacustre s'est ainsi trouvée bloquée dans une sorte de ghetto. Tout s'est passé comme si elle avait évolué jusque très récemment en vase clos, sans qu'aucun pont ne soit jamais jeté entre elle et d'autres recherches avec lesquelles elle aurait pu cependant avoir de fructueux échanges. En effet, en Scandinavie où se sont développées la palynologie et l'étude paléoclimatique de l'Holocène, s'est amorcée dès les années 1930 avec T. Nilsson, puis à partir des années 1960 avec G. Digerfeldt, une recherche systématique sur les fluctuations lacustres holocènes et leur signification climatique ; dans les années 1980, cette recherche a ensuite connu un remarquable développement, en particulier en Suisse (Lang 1985) et en Pologne (Ralska-Jasiewiczowa et al. 1987 a et b), par la mise en oeuvre du prograntme IGCP 158 B de l'UNESCO : « Palaeohydrological changes in the temperate zone in the last 15,000 years " sous l'impulsion de B.E. Berglund (Berglund 1979, 1983). C'est dans ce cadre que les deux problématiques, archéologique et naturaliste, se sont enfin rencontrées (Gaillard, 1985), tandis qu'en France, le programme DGRST : «Paléoenvironnement holocène des Alpes françaises du Nord et de leur Piémont » (Vivian 1991) et les fouilles archéologiques de Clairvaux-lesLacs jouaient le même rôle (Magny, Richard 1985).

11 Les illustrations (fig. 2, 3 et 4) rendent compte des résultats acquis dans le Jura et les Alpes du Nord au terme de plus de 10 ans de recherches centrées sur une approche sédimentologique du contexte climatique dans lequel se sont développés les habitats lacustres préhistoriques.

La figure 2 illustre deux informations différentes :

A. Elle montre une courbe des fluctuations du niveau des lacs du Jura et des Alpes du Nord qui couvre l'ensemble de l'Holocène. Cette courbe du fait que les variations des plans d'eau ne sont pas limitées aux seules périodes du Néolithique et de l'âge du Bronze, mais qu'elles caractérisent tout notre interglaciaire. Elle constitue une synthèse de données collectées dans les remplissages sédimentaires de 24 lacs différents dont 4 seulement recelaient des vestiges d'habitats lacustres. L'information présentée ici provient donc principalement de séquences stratigraphiques étudiées hors de tout contexte archéologique.

B. Elle montre que les fluctuations holocènes des lacs jurassiens et subalpins apparaissent globalement en phase avec les mouvements des glaciers et de la limite supérieure de la forêt (ou timberline) dans les Alpes suisses et autrichiennes, et qu'elles peuvent donc être rapportées à des oscillations du climat. 


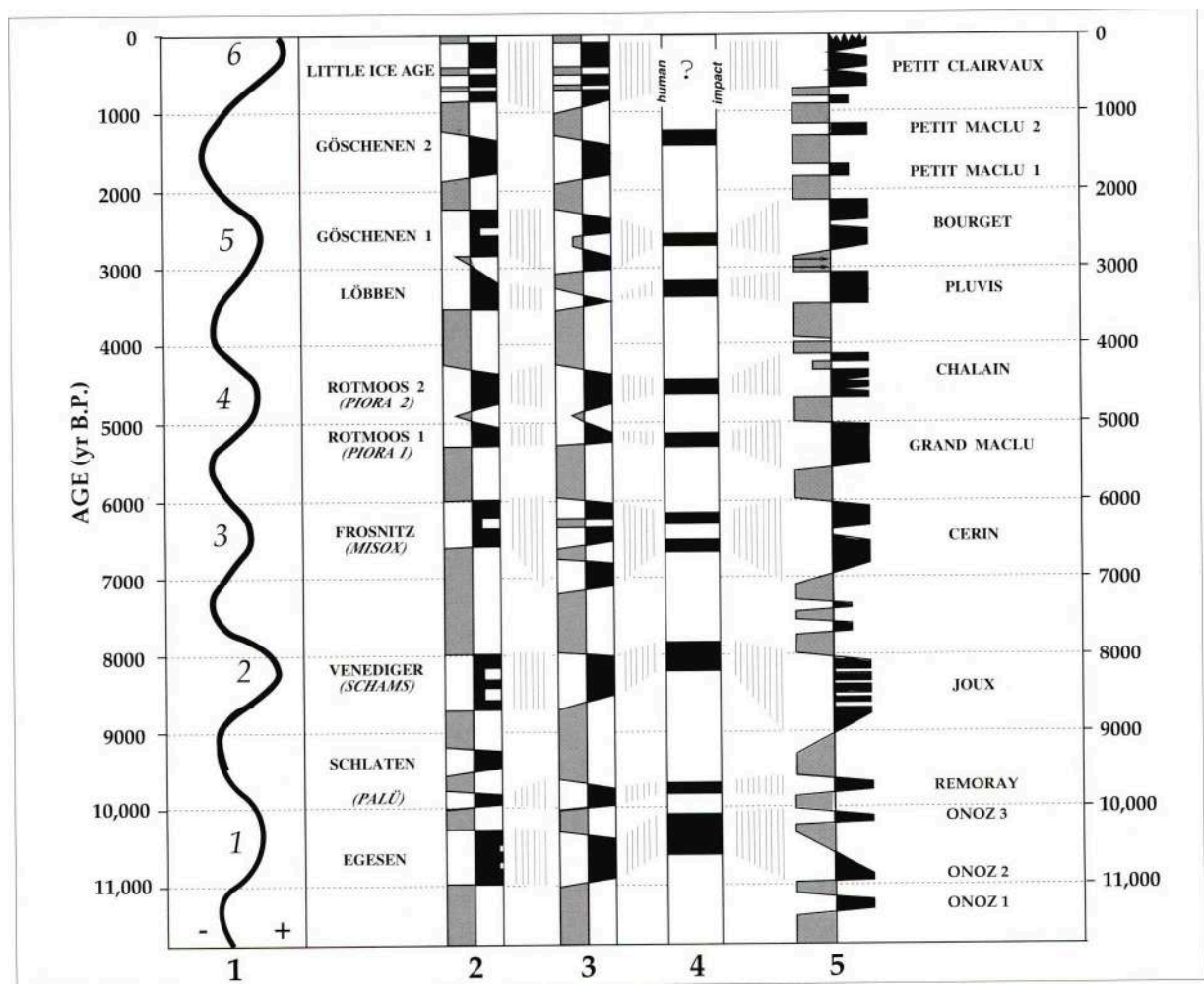

SI L'ON COMPARE, POUR TOUTE LA DURÉE DE L'HOLOCÈNE, LES VARIATIONS DU DÉBIT DE LA HAUTE VISTULE EN POLOgNE (1, D'APRÈS STARKEL 1991), LES MOUVEMENTS DES gLACIERS (2 ET 3) ET DE LA LIMITE SUPÉRIEURE DE LA FORÊT, OU TIMBERLINE (4) RECONSTITUÉS DANS LES ALPES SUISSES (3 ET 4, D'APRÈS ZOLLER 1977 ET BURgA 1987) ET AUTRICHIENNES (2, D'APRÈS BORTENSEHLAgER 1977 ET PATZELT 1977), AVEC LES FLUCTUATIONS DU NIVEAU DES LACS RETRACÉES DANS LE JURA (5, D'APRÈs MAgNY ET RUFFALDI, 1995), ET SI L'ON TIENT COMPTE, POUR CETTE COMPARAISON, DES INCERTITUDES CHRONOLOgIQUES INHÉRENTES À LA MÉTHODE DU RADIOCARBONE, ON REMARQUERA QUE, CONSIDÉRÉES gLOBALEMENT, LES DIFFÉRENTES COURBES PRÉSENTÉES ICI FONT APPARAîTRE DES RYTHMES CLIMATIQUES SIMILAIRES. IL EST POSSIBLE DE RECONNAÎTRE 6 PHASES MAJEURES DE REFROIDISSEMENT, CARACTÉRISÉES PAR UN RENFORCEMENT DU DÉBIT DE LA HAUTE VISTULE EN POLOgNE, UNE AVANCÉE DES gLACIERS ET UN ABAISSEMENT DE LA TIMBERLINE DANS LES ALPES AINSI QUE PAR UNE REMONTÉE DES PLANS D'EAU DANS LE JURA

13 La figure 3 illustre les corrélations qui apparaissent tout au long de l'Holocène entre, d'une part, les phases de renforcement de la teneur de l'atmosphère en ${ }^{14} \mathrm{C}$ résiduel ${ }^{1} \mathrm{et}$, d'autre part, les phases de remontée du niveau des lacs jurassiens et subalpins. Par référence aux facteurs qui contrôlent les variations $\mathrm{du}^{14} \mathrm{C}$ résiduel dans l'atmosphère (Stuiver et Braziunas 1993), ces corrélations suggèrent que les oscillations du climat reflétées par les fluctuations lacustres peuvent être rapportées à des changements affectant la circulation océanique au début de l'Holocène, et, après 6000 avant J.-C., à des changements affectant l'activité du Soleil (Magny 1995b). 


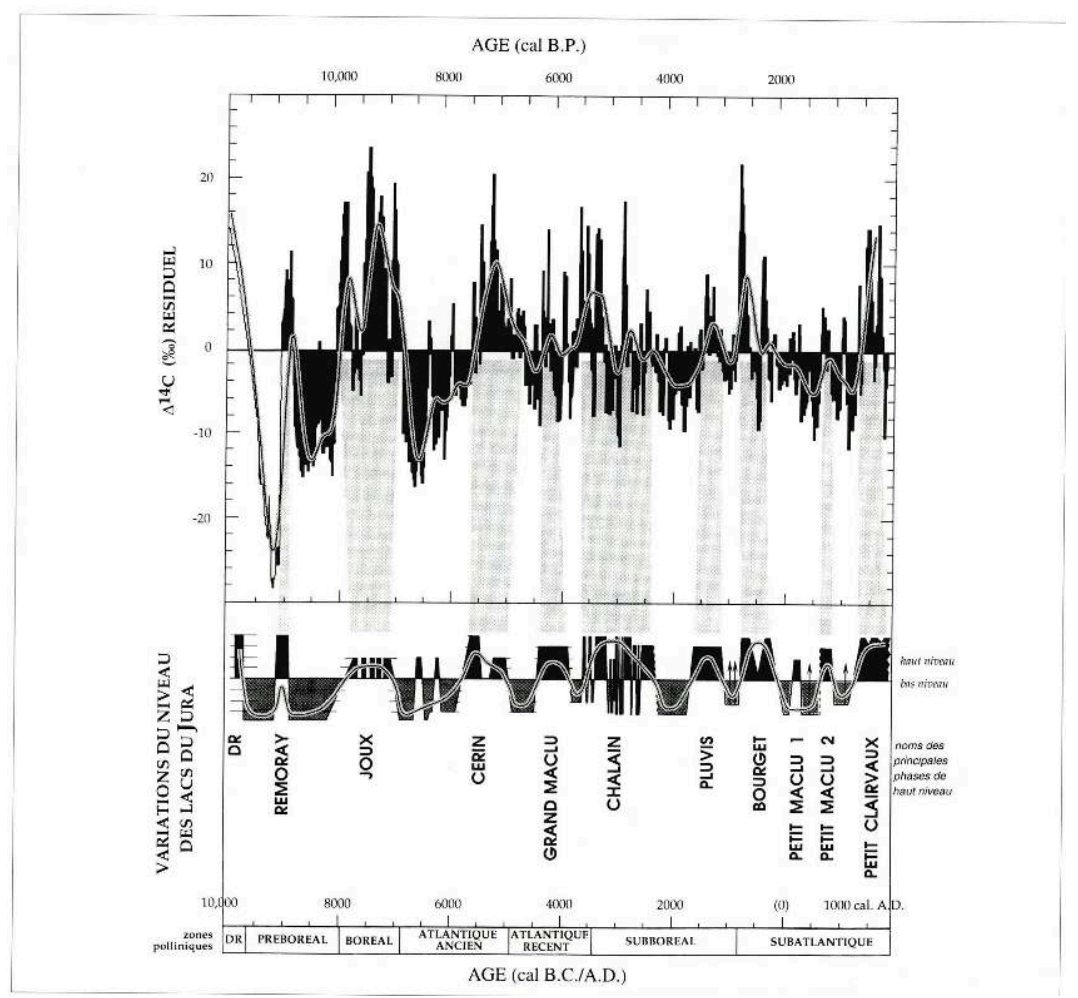

La comparaison entre les variations à court terme $d u{ }^{14} \mathrm{C}$ résiduel atmosphérique et les fluctuations du niveau des lacs du Jura montre que, tout au long de l'Holocène, on observe une corrélation assez étroite entre les périodes de forte teneur de l'atmosphère en ${ }^{14} \mathrm{C}$ résiduel et les phases de hausse du niveau des lacs du Jura, qui marquent ellesmêmes des refroidissements du climat (d'après M. Magny, 1995)

Sur la base des acquis précédents, la figure 4 propose un retour à la question du cadre climatique des palafittes. Toutes les analyses sédimentologiques effectuées sur les sites archéologiques des lacs de Clairvaux, de Chalain, du Bourget et d'Annecy montrent que les habitats lacustres néolithiques et protohistoriques s'inscrivent systématiquement dans des phases d'abaissement des plans d'eau associées à des réchauffements du climat. Mais il ne s'agit là que de conclusions ponctuelles dont on ignore si elles s'appliquent plus généralement à l'ensemble du domaine palafittique subalpin. Pour le vérifier, une courbe de fréquence des habitats littoraux a été établie pour le Néolithique et l'âge du Bronze en se basant uniquement sur les références dendrochronologiques actuellement disponibles pour la France et la Suisse, soit près de 150 références. Les phases majeures d'habitat lacustre coïncident avec des périodes de faible teneur de l'atmosphère en ${ }^{14} \mathrm{C}$, c'est-à-dire avec des phases au climat plus chaud liées à un renforcement de l'activité solaire. Ces corrélations permettent de mettre en évidence que le développement des stations littorales préhistoriques s'inscrit bien au cours de phases d'abaissement des plans d'eau, telles qu'elles ont pu être définies dans le Jura. Elles confirment les données ponctuelles qui avaient pu être obtenues jusqu'à présent (Brochier 1986; Moulin 1991; Jacomet 1980) tout en restituant leur contexte d'ensemble. 
4-

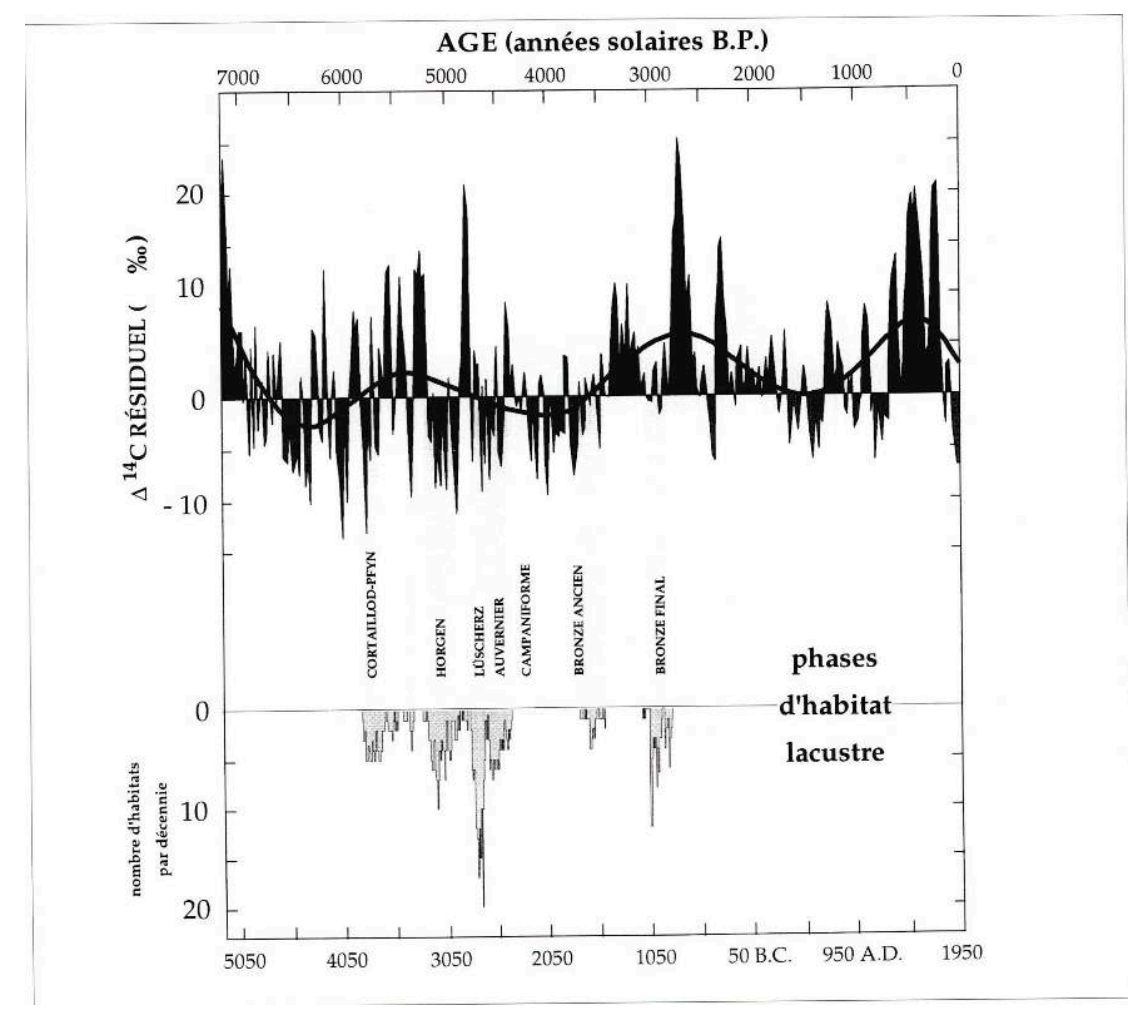

La comparaison entre les variations de la teneur de l'atmosphère en ${ }^{14} \mathrm{C}$ résiduel et les phases du développement de l'habitat lacustre en France et en Suisse (excepté le Bodensee) suggère que la fréquence des habitats des bords de lacs, indiquée ici en nombre d'habitats par décennie, se renforce pendant les périodes de plus faible production de ${ }^{14} \mathrm{C}$ ' c'est-à-dire de plus forte activité du Soleil. La sinusoïde indique les cycles d'environ 2300 ans que marquent les variations du 14c résiduel. D'après M. Magny, 1993c

\section{En guise de conclusion}

L'exposé qui précède suggère plusieurs réflexions sur les collaborations qui se développent de plus en plus largement entre archéologues et naturalistes.

1. Pour répondre aux questions qui lui sont posées par un archéologue, un naturaliste a besoin d'adopter une approche (méthode d'analyse et stratégie de recherche) qui lui soit propre. L'archéologue ne doit donc pas craindre de voir le naturaliste s'écarter quelque peu du site archéologique où s'est nouée leur collaboration...

2. Et cela d'autant plus que le croisement des données archéologiques et paléoenvironnementales (à condition que les unes et les autres aient été élaborées de façon strictement indépendante) peut parfois faire rebondir la problématique archéologique sur des aspects inattendus. Ainsi, l'abandon des rives des lacs jurassiens et subalpins pendant l'âge du Bronze moyen et le premier âge du Fer a pour exacts corrolaires les péjorations climatiques correspondant aux phases de Pluvis et du Bourget dans le Jura (Lobben et Goschenen 1 dans les Alpes), mais leur désertion entre 2400 et 1750 BC intervient alors même que se développe l'une des phases régressives les plus prononcées de l'Holocène (fig. 4). L'influence du climat s'efface ici sans doute devant celle des phénomènes culturels : le développement du Campaniforme et du Bronze ancien marquerait une rupture importante avec les modes culturels antérieurs. Par ailleurs, l'établissement d'une courbe paléoclimatique très précise a récemment permis de suivre pendant plus d'un millénaire, de 
3700 à 2500 av. J.-C., les relations qui ont pu exister dans la zone de la Combe d'Ain (Jura) entre la densité de la population, les modes de subsistance et le climat (Arbogast et al. 1995).

3. Il ne saurait y avoir une communauté de géoarchéologues coupée et isolée de celle des chercheurs qui travaillent à la reconstitution des paléoenvironnements anciens. A moins d'être un fantaisiste, un géoarchéologue est avant toute chose un naturaliste, dont les méthodes de travail et les réflexions doivent tenir compte des avancées réalisées dans sa discipline.

4. De la même manière qu'un archéologue exploite avec une égale rigueur toutes les couches archéologiques qui apparaissent sur un site, il convient d'exploiter de façon aussi exhaustive que possible les données que peut livrer un site pour la reconstitution des environnements anciens, même s'il s'agit de périodes antérieures ou postérieures à celles représentées par les seules couches dites archéologiques. C'est en se fondant sur ce parti pris qu'une courbe climatique intéressant toute la communauté des archéologues-préhistoriens et historiens-a pu être établie à partir des lacs du Jura et des Alpes du Nord. C'est aussi ce type d'approche global et systématique qui a permis de prouver l'arrière-plan climatique des fluctuations du niveau de ces lacs et d'en suggérer les origines. Nul doute que les sites lacustres aient encore beaucoup à apporter sur la connaissance de l'environnement climatique du Paléolithique supérieur, du Mésolithique, ou encore de l'Antiquité et du Moyen Âge.

\section{BIBLIOGRAPHIE}

Arbogast, Magnv, Petrequin 1995 : ARBOGAST (R.-M.), MAGNY (M.), PETREQUIN (P.) Expansions et déprises agricoles au Néolithique : populations, cultures céréalières et climat dans la Combe d'Ain (Jura, France) de 3700 à 2500 av. J.-C. In : L'Homme et la dégradation de l'environnement, XVe Rencontres internationales d'Archéologie et d'Histoire d'Antibes, Juan-lesPins, Ed. APDCA, 1995. pp. 19-41.

Berglund 1979 : BERGLUND (B.-E.) - Palaeohydrological changes in the temperate zone in the last 15000 years. Subproject B, Lake and Mire Environments, Project guide ed. by B. E. Berglund.

Berglund 1983 : BERGLUND (B.-E.) - Palaeohydrological studies in lakes and mires. A palaeoecological research strategy. In : Background to Palaeohydrology (Gregory K. J. ed.), John Wiley and Sons Ltd., 1983, pp. 237-254.

Borel, Brochier, Lundstrom-Baudais 1985 : BOREL (J - L.). BROCHIER (J.-L.), LUNDSTROMBAUDAIS (K.). - Water-level fluctuations of the lake of Paladru (Isère, France) in the Xth. and XIth. centuries A.D. Ecologia Mediterranea, XI. 1, 1985, pp. 179-183.

Bortenschlager 1977 : BORTENSCHLAGER (S.). - Ursachen und Ausmass postglazialer Waldgrenzschwankungen in den Ostalpen. Erdwissentschaftl. Forschung, 13, 1977, pp. 260-266.

Brochier 1986 : BROCHIER (J.-L.). - La baie d'Auvernier, lac de Neuchâtel, Suisse : évolution paléolimnologique et habitats préhistoriques d'après l'étude des séquences sédimentaires. Manuscrit dactyl., Document Musée Cantonal d'Archéologie de Neuchâtel, CH. 1986, 83 p.

Brochier et Joos 1982 : BROCHIER (J.-L.), JOOS (M.). - Un élément important du cadre de vie des Néolithiques d'Auvernier-Port : le lac. Approche sédimentologique. Cahiers d'Archéologie Romande, 25, 1982, pp. 43-67. 
Burga 1987 : BURGA (C.). - Vegetationsgeschichte seit der Späteiszeit. Geographica Helvetica, 2, 1987, pp. 71-80.

Gaillard 1985 : GAILLARD (M. J.). - Postglacial palaeoclimatic changes in Scandinavia and Central Europe. A tentative correlation based on studies of lake level fluctuations. Ecologia Mediterranea, XI, 1, 1985, pp. 159-175.

Jacomet 1980 : JACOMET (S.). - Botanische Macroreste aus den neolitischen Seeufersiedlungen des Areals « Pressehaus Ringier » in Zürich $(\mathrm{CH})$. Stratigraphische und vegetationkundliche Auswertung. Viertelj. der Naturf. Gesells., Zurich, 125, 1980, pp. 73-163.

Lang 1985 : LANG (G.) - Swiss lake and mire environments during the last 15000 years. J. Cramer, Vaduz, 1985,428 p.

Magny 1988 : MAGNY (M.). - Contribution à l'histoire postglaciaire des deux lacs de Clairvaux (Jura, France) : recherches palynologiques et sédimentologiques. In : Lake, Mre and rRvers Environments, Balkema, Lang G., Schluechter C. éd., 1988, pp. 23-29.

Magny 1992 : MAGNY (M.). - Holocene lake-level fluctuations in Jura and the northern subalpine ranges, France : regional pattern and climatic implications. Boreas, 21, 1992, pp. 319-334.

Magny 1993a : MAGNY (M.). - Holocene fluctuations of lake levels in the French Jura and Subalpine ranges, and their implications for past general circulation patterns. The Holocene, 3 , 1993, pp. 306-313.

Magny 1993b : MAGNY (M.). - Solar influences on Holocene climatic changes illustrated by correlations between past lake-level fluctuations and the atmospheric ${ }^{14} \mathrm{C}$ record. Quaternary Research, 40, 1993, pp. 1-9.

Magny 1993c : MAGNY (M.). - Un cadre climatique pour les habitats lacustres préhistoriques ? C. R. Acad. Sc. Paris, 316, II, 1993, pp. 1619-1625.

Magny 1993d : MAGNY (M.). - Une nouvelle mise en perspective des sites archéologiques lacustres : les fluctuations holocènes des lacs jurassiens et subalpins. Gallia Préhistoire, 35, 1993, pp. 253-282.

Magny 1995a : MAGNY (M.). - Palaeohydrological changes in Jura, France and climatic oscillations around the North Atlantic from Allerpd to Preboreal. Géographie physique et Quaternaire, 49, 3, 1995, pp. 401-408.

Magny 1995b : MAGNY (M.). - Successive oceanic and solar forcing indicated by Younger Dryas and Early Holocene climatic oscillations in the Jura. Quaternary Research, 43, 1995, pp. 279-285.

Magny 1995c : MAGNY (M.). - Une histoire du climat, des derniers mammouths au siècle de l'automobile. Paris, Ed. Errance. 1995, 176 p.

Magny et Richard 1985 : MAGNY (M.), RICHARD (H.). - Contribution à l'histoire holocène du lac du Bourget : recherches sédimentologiques et palynologiques sur le site de Conjux-la-Chatière (Savoie, France). Revue de Paléobiologie, 4, 2, 1985, pp. 253-277.

Magny et Ruffaldi 1995 : MAGNY (M.), RUFFALDI (P.). - Younger Dryas and early Holocene lakelevel fluctuations in the Jura mountains, France. Boreas, 24, 1995, pp. 155-172.

Moulin 1991 : MOULIN (B.). - La dynamique sédimentaire et lacustre durant le Tardiglaciaire et le Postglaciaire. Archéologie Neuchâteloise, 9, 1991, pp. 1-142.

Paret 1958 : PARET (O.). - Le mythe des cités lacustres. Paris, Dunod, 1958, 148 p. 
Patzelt 1977 : PATZELT (G.). - Der zeitliche Ablauf und das Ausmass postglazialer Klimaschwankungen in den Alpen. Erdwissentschaftl. Forschung, 13. 1977. pp. 248-259.

Petrequin 1980 : PETREQUIN (P.). - Les cités lacustres. La Recherche, 113, 1980. pp. 778-785.

Ralska-Jasiewiczowa et al. 1987 a et b : RALSKAJASIEWICZOWA (M.). - Vegetational, hydrological and climatic changes infered from IGCP $158 \mathrm{~b}$ studies. In : Berglund B. E. and Gaillard M. J. (eds.) Lake, mine and riverx history, Symposium at Hoor, Sweden, 1826 may 1987. a) pp. 35-38, b) pp. 93-96.

Starkel 1991 : STARKEL (L.). - Long-distance correlation of fluvial events in the temperate zone. In : Temperate Palaeohydrology, Starkel, L., Gregory, K. J. and Thornes J. B, eds., Wiley \& Sons Ltd, 1991, pp. 473-495.

Stuiver et Braziunas 1993 : STUIVER (M.), BRAZIUNAS (T.F.). - Sun, ocean, climate and atmospheric $14 \mathrm{CO}_{2}$ : an evaluation of causal and spectral relationships. The Holocene, 3, 1993, pp. 289-305.

Vivian 1991 : VIVIAN (R.). - Paléoenvironnement Holocene et archéologie dans les Alpes françaises du Nord et leur Piémont. Paris, Ed. du CTHS, 184 p.

Vogt 1955 : VOGT (E.). - Pfahlbaustudien. In : Pas Pfahlbauproblem. Schaffhouse, Schweizerische Gesellschaft fiir Urgeschichte, 1955. pp. 119-219.

Zoller 1977 : ZOLLER (H.). - Alter und Ausmass postglazialer Klimaschwankungen in den Schweizer Alpen. Erdwissentschaftl Forschung, 13, 1977, pp. 271-281.

\section{NOTES}

1. La teneur de l'atmosphère en ${ }^{14} \mathrm{C}$ n'est pas restée stable dans le passé. Elle a connu au contraire d'importantes variations qui sont liées à trois facteurs principaux : les variations d'intensité du champ géomagnétique, les variations d'activité du soleil et la répartition du radiocarbone dans les trois réservoirs entre lesquels il se distribue, c'est à dire l'océan, la biosphère et l'atmosphère. La courbe des variations $d u{ }^{14} \mathrm{C}$ résiduel est celle que l'on obtient après soustraction de l'impact du champ géomagnétique. 


\title{
Annexe
}

\author{
Résumé des interventions orales
}

\section{Sur le thème des grottes}

1 J.-P. Daugas : J'aimerais connaître la façon dont nos collègues naturalistes perçoivent les perturbations anthropiques. Les grottes sont des miroirs extrêmement déformants des phénomènes extérieurs. On pourrait tenter d'évaluer la façon d'en tenir compte dans l'avenir. Voici quelques années, H. Laville avait établi une chrono stratigraphie extrêmement détaillée pour le sud de la France, qu'il voulait climatique; elle comprenait toute une série d'oscillations que l'on élevait au rang d'inter-stadiaires; on s'aperçut par la suite que ce classement n'avait pas de réalité. Cette révision déchirante a été faite. En réalité, les micro-variations correspondaient à l'histoire de la seule cavité où elles ont été enregistrées.

2 A. Beeching: On aurait pu croire que la panacée était la pluridisciplinarité. D’après moi, la géoarchéologie n'est pas qu'un "relookage" du paléo-environnement. Elle sert l'interface emboîtée du paléo-environnement et de l'archéologie culturelle. Je rappellerai l'historique de la mise en évidence des sols de bergerie dans le sud de la France. Le premier pas a été franchi par un fauniste, D. Elmer qui, à Fontbrégoua (fouilles J. Courtin), a remarqué une surabondance de couronnes dentaires de jeunes ovicapridés. Après comparaison, il a pu l'interpréter par une stabulation de troupeaux et il a proposé pour la grotte la fonction de bergerie. Puis il a répété cette observation à Baume de Ronze (fouille A. Beeching). En second lieu, ce sont les travaux des archéologues qui ont permis d'étudier planimétriquement la répartition de ces vestiges, de déterminer le contexte sédimentaire d'où ils étaient issus et à quel point ils n'étaient pas anthropiques au sens classique du terme (pas d'habitat, ou de sol d'habitat...). Troisièmement, la sédimentologie est venue expliquer la nature des sédiments. J. E. Brochier a montré que le sédiment de ces deux grottes existait aussi dans beaucoup des cavités qu'il avait étudiées. Je dirais ensuite que la paléobotanique a un autre sens encore grâce à la palynologie. J. Argant a mis en évidence une surabondance de fougères ou la présence d'espèces feuillues de plaine sur des sites de plateau; ces constatations ont permis de proposer la présence de litières végétales de bergeries. L'anthracologie donnait l'assemblage botanique général de ce contexte 
précis en complément de la palynologie. En cinq, ce sont les différentes disciplines s'attachant à reconstituer le monde animal (malacofaune, rongeurs, oiseaux, reptiles, poissons...) qui, démontrant un abandon cyclique de la cavité, prouvaient a contrario le retour saisonnier des bergeries. Donc chacun amène sa petite pierre tout en gardant en tête sa propre finalité. Je veux monter par cette histoire que ce n'était pas seulement un problème de paléoenvironnement, c'est aussi un problème culturel d'emploi et de fonctionnalité. L'archéologue ne vient pas seulement apporter une chrono-typologie, il est aussi celui qui observe planimétriquement les faits et celui qui dialogue en tout égalité avec les différents spécialistes.

3 J. Argant : A partir du moment où une fouille est engagée sur un site, il faut effectuer des tests. L'exemple, certes très particulier, des grottes-bergeries montre que si nous n'avions pas pratiqué des tests, nous n'aurions pas pu conclure. Nous parlions tout à l'heure des spores de polypodes: leur accumulation n'est pas due au hasard, c'est un phénomène anthropique. L'intérêt de le constater permet en suite d'en comprendre le signal lorsqu'on le retrouve dans de nouvelles analyses. Les tests que nous effectuons sur les sites alpins n'ont rien de ruineux et les résultats sont très importants.

4 J.-L. Brochier: Les sciences de l'environnement ont profité des belles séquences stratigraphiques chronoculturelles de grottes pour se caler chronologiquement. Je crois maintenant qu'il faut faire la démarche inverse, que les sciences du paléoenvironnement reprécisent mieux la notion du temps dans ces séquences pour savoir comment évoluent les sociétés humaines. Nous avons une appréhension du temps qui doit être bien meilleure par les sédiments. Il faut avancer tous ensembles, ne plus se servir uniquement de l'archéologie comme un calage chronologique, mais voir comment circule le temps dans l'enregistrement sédimentaire.

5 M. Campy: Voilà trente ans que je travaille sur les remplissages de grottes. Je suis content d'entendre ce que j'entends ici. Il y a vingt ans, les grands ténors que l'on entendait dans les colloques étaient des gens du Sud-Ouest qui nous racontaient des stratigraphies avec des oscillations climatiques régulières, 30 parfois 40 voire 55 . Nous, nous en voyions moins; nous nous interrogions. Je crois que l'on a réussi à démontrer que ces remplissages de grottes ne sont pas enregistreurs de tous les phénomènes. Qu'enregistre un remplissage de grotte ? entre 5 et $10 \%$ du global, entre 20 ou $25 \%$ du régional et 70 à $80 \%$ du stationnel. Ce qui n'exclut pas de notables exceptions. Tout est donc dans une approche problématisée. On arrive enfin à une gestion critique de l'analyse des remplissages de grottes. Cette démarche ne peut venir que des spécialistes qui peuvent souligner par exemple les hiatus.

6 J.-L. Brochier: Notre image des cultures correspond à la superposition des dépôts de grottes, vision quelque peu faussée. On doit revoir toutes les interfaces entre évolution culturelle et évolution sédimentaire.

\section{À propos de la gestion de la recherche interdisciplinaire}

7 J.P. Bravard: Les sites sur lesquels l'interdisciplinarité a prouvé son intérêt se multiplient. Nous constatons un enrichissement constant au fil des années, lié à l'apport de disciplines nouvelles ou émergeantes. Des sites deviennent des références car ce sont des réussites. Les archéologues auront-ils les moyens financiers d'une telle 
expertise? La question du choix se pose ainsi que celle de la frustration probable de spécialistes dont les services seront refusés faute de moyens. 11 me parait utile de débattre des stratégies en ce domaine. Pourra-t-on tout faire?

A. Marguet: On peut essayer de faire comprendre à nos administratifs que certaines analyses hors de tout contexte anthropisé sont aussi importantes que celles effectuées sur des gisements. Nos collègues de Besançon l'on bien démontré. Toutefois, il ne faut pas être ébloui par un beau site lacustre ou une belle stratigraphie en grotte. C'est prendre un gros risque que de miser tous les moyens sur un ou deux très beaux sites bien préservés. On oublierait alors l'occupation humaine dite de moindre importance dont les stations mériteraient aussi des analyses. Ces journées, à l'initiative du SRA, permettent de poser certaines questions : les membres des CIRA sont-ils prêts à étudier certaines demandes d'analyses? De quelle manière? Quelles sont les moyens que l'on pourrait éventuellement flécher à cette fin?

9 M. Campy: En tant que membre d'une CIRA, je répondrai que les dossiers que nous examinons présentent des demandes d'analyses souvent surévaluées et toujours mal justifiées. Il faut apprendre à se demander : quelles analyses ? Pourquoi faire ? trop de demandes d'analyses n'ont d'autre justification que celle d'éviter de se faire critiquer parce qu'on ne les a pas faites. Souvent nous ignorons la problématique qui guide ces demandes.. Je n'ai pas qu'une critique institutionnelle à apporter, j'ai aussi une critique scientifique.

M. Prestreau : Certains chantiers auront les moyens de financer toutes les analyses utiles et nécessaires. Cependant l'archéologie moderne consiste aussi en un travail sur des portions de territoire. Par manque de financement, on risque de faire des impasses sur des gisements à faible budget, alors que ces sites participent pleinement à une problématique par exemple territoriale. Il devient urgent de trouver une forme de globalisation des moyens.

11 S. Thiebault : Il faut des échanges pour apprendre à faire des choix. Ce qui m'intéresse c'est l'Homme, pas une stratigraphie ou un charbon de bois, je veux comprendre comment l'Homme s'intègre dans son territoire. Il se peut que sur un site jugé de peu d'intérêt, des informations de première importance pour moi ou tel autre spécialiste y figurent. Nous avons, malgré tout, souvent des intérêts différents et il faut beaucoup parler pour éviter les ratés. Personnellement, je me considère comme une archéologue avec un programme précis. Nous aussi, nous avons nos problématiques et il faut les prendre en compte. C'est très difficile de faire de la recherche fondamentale lorsque l'on a des chantiers de courte durée à gérer.

12 J.-L. Brochier: Sur la question du choix, il me semble qu'il vaut mieux fonctionner à l'intérieur de programmes de recherches, plutôt que d'essayer de choisir quelques sites au hasard.

M. Campy : Notre réflexion porte trop sur l'archéologie programmée et pas assez sur le sauvetage. Les budgets que visionnent les CIRA concernent de 80 à 90 \% l'archéologie préventive. Nous avons une épée de Damoclès au dessus de la tête. En ce qui concerne le sauvetage, je pense que l'on doit mener une réflexion poussée au niveau des problèmes analytiques. Les CIRA peuvent jouer un rôle, mais n'en attendons pas trop. Quand on étudie 60 dossiers en 3 jours, on n'a pas le temps de décortiquer comme il le faudrait. La réflexion doit se faire à l'amont de la CIRA. 
14 Un responsable d'opération AFAN : Lorsqu'il nous est demandé d'intervenir, les délais négociés sont extrêmement courts et la problématique n'est pas abordée. Les moyens mis en place pour ce type d'opérations tiennent plus compte de la solvabilité de l'aménageur que des impératifs scientifiques. Si nous devons avoir un point de vue méthodologique sur une région donnée, il faudra aussi que les montages prévoient des réserves financières pour d'éventuelles études paléoenvironnementales, plutôt que de monter des problématiques fallacieuses.

15 J. Burnouf: On ne peut pas opposer une archéologie programmée à une archéologie préventive. Il vaudrait mieux élaborer une stratégie préventive. Dans ce cas, le rôle de la CIRA me parait primordial. Les chantiers de fouilles programmées peuvent être des laboratoires d'expérimentation où l'on peut prendre le temps de l'observation. Ne nous y trompons pas, ce qui manque le plus en préventive, c'est le temps. Il faudrait ensuite établir une relation forte avec des équipes de spécialistes qui auraient étalonné un certain nombre de paramètres. Sur la base d'un bon diagnostic, on pourrait examiner les manières qui permettraient une exploitation correcte du site.

Ph. Leveau : A propos des relations entre archéologues et géoarchéologues, je donnerai l'exemple de l'A 51 qui traverse une région sur laquelle on a des connaissances assez limitées. L'autoroute coupe la rive droite de la Durance, "mangée" par un canal qui date de 1907 puis 1980. Un long mur parallèle au tracé a été mis au jour. Les sondages réalisés par le géoarchéologue ont montré que la topographie plane actuelle de la plaine de la Durance est de création récente. A l'époque romaine, cette topographie était plus complexe; la réalisation du grand mur de $50 \mathrm{~m}$ de long correspond au comblement d'un talweg, à l'aménagement d'un ruisseau et à la création d'une terrasse artificielle. Le site est pauvre, mais la réflexion sur l'environnement montre qu'il y a eu une volonté d'aménagement du paysage, ce qui traduit une importante rupture culturelle visible aussi dans la vallée du Rhône. L'intérêt d'un tel site ne serait pas apparu s'il n'y avait pas eu en même temps cette réflexion sur le paysage.

17 J. Burnouf: Ph. Leveau pose la question de l'archéologie préventive face à l'avancée des nouvelles techniques bien maîtrisées par la fouille programmée, je pense cela peut être un faux problème. J'ai lu récemment une thèse d'historien sur des communautés de ferrons en Normandie; il s'agit d'anciens domaines carolingiens sur lesquels il avait d'anciens ferriers antiques. Cet historien n'est pas archéologue bien qu'ayant pratiqué un peu l'archéologie. Certains points de ses conclusions méritent confirmation archéologique, mais surtout, il n'a pas osé émettre certaines hypothèses parce que ce n'était pas sa spécialité. Sur ce type de gisement, on peut très bien décider qu'une équipe pluridisciplinaire s'investisse et travaille sur les conséquences sur le paysage de l'installation de telles communautés (hydraulique). On met en place un laboratoire d'expérience historique et archéologique de manière à expliquer par ailleurs tout ce que l'on trouve sur d'autres sites d'extraction ou de métallurgie. Ainsi, lorsque sur des grands travaux ou plus généralement en sauvetage on n'a pas le temps ou la possibilité d'élaborer une problématique, on établit de cette manière une relation d'échange entre les praticiens d'une même archéologie sur des problématiques communes.

18 A. Beeching : J'ai abordé la question des sols mal conservés en plein air pour dire qu'il faut les fouiller. Sur nos grands travaux, on a tendance à raccourcir les délais. Pour les analyser, il faut du temps à la fouille et après si l'on veut avoir après coup tous les éléments qu'il faut pour les interpréter. 
S. Thiébaut : La science est en perpétuel changement; quand on voit ce qui a été fait en Valdaine, on a plus la même vision des faits. Pour ma part, je ne sais pas ce que c'est qu'un géoarchéologue. La question ne se pose pas en ces termes. Je crois qu'il y a des équipes plus ou moins bien formées, des équipes qui devraient être formées à la pluridisciplinarité parce que le site aborde tel ou tel point. Deux heures sur un point précis et tout s'éclaire parce que chacun voit les choses tellement différemment de l'autre. C'est aussi comme cela que doit être conduite une fouille.

T. Odiot: Deux problèmes se posent: la formation de l'archéologue de terrain et l'apprentissage auprès d'un géoarchéologue d'un certain nombre de reflex et de certaines grilles de lectures. Quand ceci est acquis, peu importe les institutions de rattachement. Il faut former les gens. Après reste la question de la pérennisation des équipes sur une région; il faut des gens qui connaissent leur terrain et qui, avançant dans leurs recherches, soient aptes à intégrer les informations de nouvelles disciplines. A partir de ce moment là, on peut déboucher sur d'autres types d'approches cohérentes, que ce soit par le biais de la fouille de sauvetage ou de programme.

Ph. Leveau : Au sujet de cette dichotomie sauvetage/programmé; il existe une grande différence entre milieu rural et milieu urbain. En urbain, il y a toujours eu la possibilité d'avoir des moyens conséquents. En rural, grâce aux grands travaux, on peut étudier des sites dits jusqu'à présent de peu d'importance. Ceci a rendu possible les travaux sur les parcellaires fossiles et les fossés.

22 J.-P. Bravard: Il faudrait plusieurs études très détaillées comme en Valdaine ou en Tricastin. toutefois se posera le problème de l'élargissement spatial. Si un modèle spatial est bien calé à grande échelle, on court le risque d'une extrapolation non fondée. Vient un moment dans l'extrapolation spatiale où le changement d'échelle fait franchir des seuils. On n'est plus dans la réponse globale d'un grand système à une évolution qu'on va suivre de l'amont vers l'aval, mais on est dans autre chose. Les seuils peuvent être régionaux et climatiques ou marquer des délimitations culturelles. Lorsque l'on descend vers l'aval dans un système, on accède à un espace intégré plus vaste par l'addition de sous-systèmes. Cela veut dire que si le point aval enregistre le temps, il va enregistrer potentiellement une plus grande densité de phénomènes, qui peuvent refléter le cumul des phénomènes éclatés dans certains soussystèmes et non la réalité de phénomènes survenant dans tous les sous-systèmes considérés.

\section{Fluctuations climatiques, actions humaines et réponses de l'environnement}

M. Campy : Les grands découpages climatiques de l'Holocène ne sont pas sans variations internes. On assimile depuis longtemps Atlantique avec climat chaud et humide, Subatlantique avec climat froid et humide. Ces notions sont dépassées car l'Atlantique a duré 3000 ans durant lesquels beaucoup d'événements sont intervenus. On sait maintenant qu'il y eut vraisemblablement un "petit âge glaciaire" vers 5500. On ne peut donc pas globaliser le climat durant ces grandes phases. Quant au fameux optimum climatique atlantique, il est beaucoup plus centré sur la fin du Boréal et le début de l'Atlantique que sur l'Atlantique dans sa globalité. 

phase torrentielle très marquée qui correspond à une phase de transgression lacustre de M. Magny. géosystèmes. En traitant des coupes en Valdaine, je me suis rendu compte que, à emprise humaine plus ou moins égale, on a des périodes avec ou sans réaction de l'hydro-système. Je pense donc qu'à emprise humaine égale, le paramètre climatique amplifie les signatures sur les pentes et dans les systèmes fluviaux. Je voudrais aussi parler de la validité des bioindicateurs. Chaque discipline a une représentativité différente. La palynologie a un reflet plus régional, alors que l'aspect stationnel est rendu par la malacologie ou l'anthracologie. Ces spécialistes travaillent aussi sur la dynamique de fossilisation. En milieu alluvial on a le reflet du bassin versant quel que soit sa taille alors qu'un travail sur un paléosol reflète l'échelle locale.

\section{Sur le thème des versants}

J.-F Berger : On associe les phytolythes aux champs cultivés, pour ma part, je ne suis pas vraiment d'accord. Quelqu'un peut-il me répondre?

D. Sordoillet : La présence ou l'absence de phytolithes n'est pas une preuve certaine de culture. Céramiques, lithiques ou prélèvements par exemple? Comment le dialogue interdisciplinaire se fait-il à ce niveau ?

29 J.-L. Brochier: Le matériel archéologique sert d'abord à caler plus ou moins précisément la période de mise en place des colluvions. Peu de personnes se sont intéressées à ces dépôts dont on peut tirer quelques informations.

J.-F. Berger: On peut étendre la question aux matériaux archéologiques démantelés dans des alluvions. En Valdaine, de nombreux vestiges épandus dans des alluvions et des colluvions datent du Bronze final I ou du Hallstatt ancien. C'est toujours la deuxième composante de la fourchette qui donne la datation. Sur le TGV, la datation des fossés de drainage par le matériel archéologique est très dangereuse, on retrouve souvent des mélanges sur 4 ou 5 siècles, mais travailler sur des assemblages charbonneux issus de brûlis donnera une datation plus précise.

G. Vernet: On a jamais évoqué les hiatus sédimentaires. Il faut être prudent dans les commentaires. correspond au dernier élément de passage dont la conservation a été permise.

J.-F. Berger : Il faut aussi se pencher sur la définition du terme "colluvion" : lorsqu'on travaille en micromorphologie, on s'aperçoit souvent que l'on observe des sols colluviés et pas seulement des colluvions. A une phase sédimentaire succède une pédogenèse surimposée. Ceci n'est pas forcément visible sur le terrain.

G. Vernet: Dans les milieux colluviés, on peut avoir des niveaux archéologiques parfaitement en place grâce au développement d'une pédogenèse. 11 faut donc être vigilant. 

fouillés dans les grandes vallées du nord de la France. Par ignorance, on les a longtemps décapés sans ménagement tant leur faible puissance et les bioturbations qu'ils avaient subies les rendaient a priori peu utilisables par les archéologues. mis en évidence sur le TGV en Valdaine par exemple. planation très long, réalisé par étapes. Les auteurs de l'étude ont démontré l'existence de processus éoliens tardiglaciaires. Que peut-on penser d'éventuels processus éoliens holocènes en plus du colluvionnement, étant donné la dimension des sédiments, la dessication saisonnière des milieux et la patique des labours?

Bechier: Les sables sont bien tardiglaciaires; ils sont suivis d'une pédogenèse et le site mésolithique dont j'ai parlé arrive après les formations dunaires. A l'Holocène, des phases d'éolisation sont très possibles. Au Gournier (Montélimar), certains sables pourraient s'expliquer ainsi. Il faudrait faire un travail pointu là dessus, mais ce n'est pas facile parce qu'il n'y a pas eu une accumulation importante. Il peut y avoir un premier dépôt sableux de quelques décimètres, une reprise puis une pédogenèse par dessus ; il est alors difficile de certifier qu'il s'agit bien d'un sable éolien. Dans la grotte de Sartanette, qui s'ouvre face au nord, et dans celle du "Gardon" (Ambérieu-en-Bugey), 4 à $5 \mathrm{~m}$ de sable surmontent un niveau médiéval. Il y a donc bien eu des déplacements de sable durant l'Holocène.

Brochier: J'aimerais que l'on revienne sur la notion de sol d'habitat. On retrouve sur ces terrasses des zones d'épandage de matériel archéologique qui recouvrent parfois 20 ha voire 100 ha au Gournier à Montélimar. Comment va-t-on fouiller de telles surfaces? Il n'y a pas un sol d'habitat, mais plusieurs formes de sols d'habitat. Sur une même structure taphonomique de conservation dans ces paléovallons, à certains endroits, on mettra au jour de véritables sols d'occupation, des sols d'habitat à d'autres moments, $30 \mathrm{~m}$ plus loin on peut être en face de sols remaniés ou à des apports colluviés. La situation est complexe, elle doit être suivie lors de la progression de la fouille par le géoarchéologue et par l'archéologue. Ce n'est pas une fouille pour géoarchéologue, il faut les deux composantes. L'archéologue va suivre ce qui est structuré dans la répartition du matériel archéologique et établir une séquence chronotypologique qui va établir le statut de matériel. Le géomorphologue peut alors bénéficier de ces apports alors qu'à la lecture d'une lame mince, il pourra établir qu'il s'agit de colluvions, ce qui ne présume pas de l'authenticité du site. C'est vraiment une collaboration qu'il faut encourager. Par ailleurs, ces grands sites posent des questions sur la taille des habitats, leur mobilité, etc. Il ne faut pas abandonner ces sites en sachant que les réponses ne sont pas à attendre immédiatement.

M. Prestreau: La carte archéologique de la Valdaine montre 140 sites chasséens. Le Chasséen couvre environ un millénaire. En procédant à une répartition dans le temps et dans l'espace, on obtient 2,5 sites par génération de 20 ans. Ce que l'on saisit de la réalité est faible. Les archéologues ont besoin des géoarchéologues pour les aider à établir des modèles d'occupation qui puissent outrepasser cette barrière liée à la conservation des sites. Par ailleurs, on peut s'étonner de la taille gigantesque d'un site de 120 ha comme celui de Montélimar. Pourquoi ne pas imaginer plusieurs sites chasséens faiblement distants dans le temps? 
41 J.-L. Brochier: Nous sommes face à un palimpseste d'occupations successives que l'on n'arrive pas à démêler. Un peu comme dans une grotte, il faut arriver à affiner les stratigraphies pour mieux saisir le temps grâce à la vitesse de sédimentation.

M. Prestreau : Le site de Soucy localisé sur les hautes terrasses de l'Yonne montre à l'évidence qu'il peut exister à des profondeurs insoupçonnées, sous des niveaux de graves stériles, des vestiges en place.

M. Campy : L'exploitation de granulat concernait jusqu'à présent les basses plaines. Or ces entreprises y posent beaucoup de problèmes environnementaux. Les producteurs se reportent sur les hautes terrasses. On va assister dans les années qui viennent à un report des exploitations de plaines alluviales vers les hautes terrasses moins intéressantes pour l'agriculture. L'exemple français de ces hautes terrasses, c'est la vallée de la Somme avec un site comme celui de Saint-Acheul. Pourquoi a-t-on autant de sites acheuléens dans cette vallée? Le fond de la vallée de la Somme n'est pas intéressant pour les exploitants donc toutes les exploitations se sont faites sur les hautes terrasses. L'exploitation des hautes terrasses est donc un problème qui va bientôt tous nous concerner. Ces hautes terrasses contiennent toutes du Moustérien ou de l'Acheuléen.

J.-P. Bravard: On a glissé vers la question de la taphonomie des sites. Des terrasses d'apparence très simple sont en fait extrêmement compliquées. Des recherches ont été effectuées en Aragon par J.-L. Pena Mone: des sites de buttes résiduelles, trop petites pour avoir porté des habitats n'ont pas été fouillées jusqu'à ce que les géoarchéologues démontrent que voici 3000 ans, ces aires étaient assez vastes pour porter des stations qui sont aujourd'hui fossilisées sous des éboulis. Lorsque nous avons débuté notre travail avec A. Le Bot et B. Helly sur Vienne, nous nous sommes demandés pourquoi il y aurait-il du gallo-romain 5 ou $6 \mathrm{~m}$ sous les rues actuelles si le sol étaient recouvertes par $2 \mathrm{~m}$ d'eau lors des grandes crues du XIXe s. ? Le gallo-romain est pourtant là. Ceci pour dire qu'outre la fluctuation en géoarchéologie, il faut tenir compte de la capitalisation du changement ; elle métamorphose tellement le paysage qu'elle change complètement la vision actuelle des choses. Dans tous les milieux, versants, plaines, grottes on a les mêmes questions. Les cartes archéologiques sont loin d'être terminées. C'est là un des gros acquis des collaborations entre entre archéologues, géoarchéologues et historiens.

\section{Sur le thème fluvial}

45 J. Burnouf: Je souhaite que l'on discute du problème d'échelle. Dans la mesure où l'on dit que les réponses de l'amont se trouvent à l'aval, que les réponses sont décalées, que ça se passe en longitudinal et en latéral, de quelle échelle parle-t-on? Y-a-t'il des contradictions entre les échelles : dans une même micro-région ou d'un site à une aire, comment passe-t-on d'une échelle à l'autre?

46 J.-L. Brochier : Il faudrait travailler à toutes les échelles. Il faut obtenir un va-et-vient entre l'échelle du micro-local et celle du régional, voire plus large, car c'est dans ce jeulà qu'on va comprendre les phénomènes. Mais l'obtention des données se réalise à un niveau local. L'exemple de la Valdaine montre que les données sont vraiment percutantes quand on les observe à une grande échelle. Après on peut élargir, établir les correspondances. Il ne faut cependant pas rester à ce niveau. 
47 J. Burnouf: Quel est le temps de réponse d'un cours d'eau de rang supérieur par rapport à celui d'un rang inférieur? Est-il possible de mettre en relation ces temps de réponse avec la quantité de colluvions sur les versants. Quels sont les paramètres qui permettent de réfléchir à cela? L'épaisseur des dépôts? Quelle est la part de la météorologie locale?

48 J.-P. Bravard: Plus on travaille à l'échelon local, plus il faut se méfier du caractère particulier de ce que l'on étudie. Il faut donc multiplier les observations. A microéchelle, il faut spatialiser avant de généraliser. Quand on descend vers l'aval d'un système, il convient de prendre en compte le temps de transfert. Une crue est transmise immédiatement. Avignon sera touchée en même temps que les villes de la haute Isère ; en revanche, la modification de la nature du lit fluvial ou le transport de la charge de fond nécessitent plusieurs siècles. Si on observe la métamorphose d'un fleuve, loin à l'aval de ses sources sédimentaires et si on arrive à dater ce changement, on a daté le changement du fleuve et non celui du facteur climatique qui engendre le phénomène. Il faut combiner toutes les méthodes d'étude des lacs, des versants et des sites pour parvenir à un schéma général.

49 J.-F. Berger : En Valdaine, à l'échelle d'une petite région, on a réussi à montrer que l'on a des réactions plus ou moins identiques et plus ou moins contemporaines dans des bassins versants de rangs différents, bassins de quelques $\mathrm{km}^{2}$, voire de quelques centaines de $\mathrm{km}^{2}$.

50 M. Campy : L'accretion verticale de la Saône est remarquable à cause de la subsidence de la Bresse qui se continue depuis 2 millions d'années. Il doit cependant exister une spatialisation latérale avec d'anciens cours dans le lit majeur. La réflexion de Louis Bonnamour s'est limitée à la position actuelle de la rivière et à la position verticale des ensembles. La Saône a dû avoir des chenaux anciens depuis 5000 ans.

51 L. Bonnamour: L'incidence horizontale à hauteur de Chalon est sans doute moins importante que dans la région d'Anse. On a effectivement des sites dans le lit, des sites sur les berges. Dans les sablières de berges comme à Ouroux, on n'a pas trace de ces anciens lits, je ne dis pas cependant qu'il n'y en a pas. On a cependant des déplacements de berges sur quelques dizaines de mètres dans des méandres.

52 J.-P. Bravard: Le phénomène de subsidence joue très fort dans le Chalonnais et le Maçonnais, mais à l'aval de Villefranche et jusqu'à Anse l'effet de barrage de l'Azergues intervient. Ce barrage, qui a dû se mettre en place aux premiers temps de l'Holocène fait que la sédimentation fine s'est produite de manière très forte dans les 20 ou $30 \mathrm{~km}$ en amont du confluent et a probablement provoqué une stabilisation complète du lit et le remplissage des chenaux qui existaient. Plus à l'amont, le mouvement latéral est plus important.

53 J. Argant: Au niveau de Seurre (21), C. Ferrier a mis en évidence le déplacement latéral du lit de la Saône. On a trouvé à 4,5 km des dépôts atlantiques datés de 6000 environ, dépôts contenant du pollen.

54 J.-P. Bravard : Attila s'est fait enterré avec son cercueil au fond de la Tisza. Il savait très bien que, grâce à la dynamique fluviale, on ne le retrouverait jamais !

55 M. Campy : Je suis demandeur d'explication sur les creux de la Saône dans le profil longitudinal présenté par L. Bonnamour. 

à des seuils rocheux. Ce sont donc des points bloqués. Ce qui expliquerait peut-être qu'on n'a pas de déplacement de hauts fonds. On a plongé, après avoir travaillé sur des documents du service de la navigation, à $3 \mathrm{~m}$; on devait, d'après d'autres travaux, trouver du médiéval. En deux emplacements on a découvert de l'âge du Bronze. C'est le danger de la systématisation. Après j'ai compris pourquoi : les dragues ont travaillé sur des hauts fonds d'argile qui protégeaient nos niveaux habituels que l'on trouvait plus bas. quantification de la capacité de transport et de l'énergie disponible dans la Saône. Dans le secteur de Chalon, la Saône n'a pas d'énergie, ce qui veut dire que les entrées sédimentaires des affluents, qui sont limitées, ne se transmettent pas vers l'aval. La Saône est très stable dans la transmission des éléments grossiers de fond donc : c'est parfait pour archiver en fond de lit des niveaux archéologiques.

B. Mandy: Je voudrais signaler que les opérations de dragage dans le lit des rivières continuent. Les récentes crues ont montré qu'il fallait remettre au gabarit certaines grandes rivières. Des dévasages de rivières deviennent une catastrophe car on n'arrive pas à suivre. Sur le Brivay, la remise en gabarit a permis la mise au jour de 55 pirogues, mais aussi d'un mobilier fabuleux. Nous n'avons pas les moyens de mettre des équipes complètes qui passent avant les dragues.

M. Campy: Il serait important de disposer d'études complètes sur les grandes agglomérations, substrat, sédiments, installations, etc...

61 J.-P. Daugas : Il me semble qu'un travail d'évaluation du potentiel archéologique comme celui présenté par J.-J. Schwein et N. Schneider sur Strasbourg est envisageable sur des villes comme Besançon, Clermont-Ferrand, voire Nantes.

62 A. Bocquet : Lors de l'opération de démolition réalisée vers la République à Grenoble, nous avons effectué quelques fouilles et remarqué que le niveau augustéen était à $5 \mathrm{~m}$ au dessous du niveau actuel de la rue J.-J. Rousseau (rue existant au XVIIIe s.). Par ailleurs, à l'intérieur du castrum romain nous avions vu des amenées de graviers de 40-50 parfois $60 \mathrm{~cm}$ de puissance qui avaient obligé les occupants à surélever leurs habitations. S'agit-il d'inondations du Drac?

63 J.-L. Brochier: Pour l'Holocène, on abandonne les grands tableaux de phasages synchroniques. On évolue vers une mosaïque de paysages dynamiques selon les secteurs. Le climatique se passe à un niveau supérieur, qui fait qu'un phasage existe. Le fait que certains éléments de J.-F. Berger viennent corréler ceux de M. Magny dans les lacs, est un indice portant.

64 J.-P. Bravard: Lorsque des phasages climatiques sont démontrés, à partir de quels niveaux de contraintes les sociétés les enregistrent-elles? Tous les exemples que l'on a étudiés montrent que l'on a une idée fausse des topographies passées et qu'on a mis au point des phasages et des contraintes dont on ne connaît pas le degré de complexité. Ce n'est pas parce que l'on met en évidence des niveaux de crues à Lyon que la presqu'île était invivable. Le dialogue interdisciplinaire ne doit pas s'arrêter là parce que le risque serait grand que chacun écrive son histoire. Il reste des points non résolus : ce qu'est 
une ville, ce que sont les contraintes urbaines, jusqu'où contrôle-t-on la contrainte ; il reste beaucoup à dire.

J.-L. Peiry: Un système fluvial intègre des flux d'eau et des flux de sédiments qui ne sont pas forcément synchrones. Des secteurs distants du système fluvial répondent dans un premier temps uniquement à des crues sans pour autant modifier un changement de style fluvial. Si bien qu'on aura pas forcément un synchronisme entre ce qui se passe dans des secteurs relativement distants et ce qui se passe sur les versants ou dans les parties supérieures des systèmes fluviaux. Si on veut tenter de comprendre. il faut mettre à plat toutes nos observations de terrasses, de versants, du système fluvial... Les concordances peuvent alors permettre d'établir des règles fonctionnelles. Tout ceci est compliqué par le fait que l'on a conjonction de phénomènes anthropiques et de phénomènes climatiques. Si bien qu'à l'échelle locale les facteurs locaux de type anthropique l'emportant, on est incapable. tant que l'on n'a pas observé un grand nombre de sites, d'avoir un avis général.

\section{Sur le thème des "lacs"}

J.-L. Brochier : Les séquences stratigraphiques en grotte sont des faux par les lectures trop évidentes qu'elles provoquent; je pense qu'il en va de même des séquences lacustres. Les couches étudiées sont comme des flashes sur des petits moments de l'histoire d'un lac, une fossilisation parfois de micro événements, du fait que Ton a un contraste trop évident entre le fumier d'habitat et la craie lacustre blanche. Très rapidement on cerne un événement qui peut correspondre à un ou plusieurs abaissement(s) du lac. A Charavines-/es Baigneurs, on voit que Ton a sous la couche Bl, premier niveau d'occupation, d'autres niveaux d'abaissement du lac. Lorsque Ton effectue des corrélations à grande distance entre lacs, que compare-t-on vraiment ? Que met-on vraiment en parallèle? On aboutit toutefois à des conclusions qu'il ne faut pas rejeter et qui permettent d'élaborer des modèles tel celui proposé par M. Magny, modèle sur lequel il faut continuer de travailler. Reste une certaine complexité au niveau du temps, car il existe des variations annuelles, pluri-annuelles, voire pluriséculaires. On voit aussi dans la baie d'Auvergnier, par l'étude d'une douzaine de sites, que les signatures d'un abaissement du lac sont différentes selon les sites; tout cela montre la complexité des milieux lacustres.

67 J.-P. Bravard: J'étais intéressé par la notion de "groupe écologique". Quelle est la résolution spatiale de ces groupes? Est-ce que cela a été testé dans l'actuel?

c. Orsel : A Charavines, on ne connaît pas d'exemple actuel dans les mêmes conditions. Pour estimer les distances, ce n'est donc pas aisé, toutefois je ne pense pas à plus d'un kilomètre.

J.-L. Brochier : Les couches archéologiques sont dues à la production humaine. Elles ont souvent été prises comme homogènes. Les travaux conduits par A. Bocquet montrent qu'en travaillant, on arrive à faire des distinctions. On regroupe ainsi des éthno-faciès sédimentaires que Ton peut classer puis rattacher à différents types d'activités (ruelle, maisons, foyers...). C'est aussi une partie de la géoarchéologie.

M. Prestreau : Lorsque Ton étudie le phénomène lacustre, on constate une importante occupation au Bronze final IIb-IIIa. En Valdaine, on constate au contraire l'absence quasi totale de cette culture. Y-a-t-il complémentarité ? Ou bien a-t-on tout vu ? Cette 
faible fréquentation en Valdaine est d'autant plus troublante que le RSFO "apprécie" particulièrement les fonds de vallées.

71 A. Bocquet : Pour moi, les RSFO étaient très spécialisés dans la métallurgie. Le besoin d'eau les a obligés à occuper les lacs et les rivières.

72 J.-F. Berger: Pour le BF lib, on a quand même 7 sites sur les terrasses.

73 M. Prestreau : Les comparaisons entre les lacs alpins et la Valdaine montrent des variations climatiques contemporaines. Or, un domaine relève du climat méditerranéen alors que l'autre appartient à la zone sub-continentale. Doit-on en déduire que les grands domaines climatiques sont modifiés équitablement?

74 J.-F. Berger : Il existe une cohérence à l'échelle de l'Europe occidentale.

75 J.-P. Bravard: En période fraîche et humide, toute l'Europe occidentale, y compris la Méditerranée, parait touchée de manière synchrone. En revanche, en période sèche, l'Europe méridionale et la basse vallée du Rhône paraissent se distinguer du reste de l'Europe qui est sous influence océanique.

J.-F. Berger : La crise du Hallstatt est aussi forte que le "petit âge glaciaire" en Valdaine.

77 J.-P. Daugas : Le petit âge glaciaire n'est pas qu'une question de zonage nord-sud. La cause initiale semble une modification du courant du Golf stream, un abaissement de la température de l'eau qui modifie le régime des nuages et des vents.

78 J.-P. Bravard: En période froide, la Méditerranée reste un réservoir d'eau "chaude". Elle peut modifie ainsi le climat sur son pourtour.

79 J.-L. Brochier: Il ne faut pas oublier que les milieux lacustres asséchés sont des domaines d'étude importants. Il est possible qu'un jour on découvre des sites lacustres dans ces lacs asséchés.

80 J.P. Bravard: Les milieux humides de Provence sont des milieux paradoxaux, comme l'a montré Ph. Leveau: une morphogenèse active à certaines périodes provoque une érosion des versants qui crée des barrages de vallée favorables aux milieux humides. Ces derniers vont perdurer en raison du maintien de ces barrages. En résulte une permanence des milieux humides qui ne sont plus en phase avec la variabilité du climat. 


\section{Abreviations}

1 APDCA : Association pour la Promotion et la Diffusion des Connaissances Archéologiques.

2 ARENERA : Actes des Rencontres Néolithiques Rhône-Alpes.

3 BRGM : Bureau de Recherches Géologiques

4 et Minières.

5 Bull. S.P.F. : Bulletin de la Société Préhistorique Française.

6 Bull. AFEQ : Bulletin de l'Association Française d'Etude du Quaternaire.

7 C. R. Acad. Sc., : Comptes Rendus à l'Académie des Sciences de Paris.

8 CTHS éd. : Edition du Comité des Travaux Historiques et Scientifiques.

9 R.A.E. : Revue Archéologique de l'Est.

10 UISPP : Union Internationale des Sciences Préhistorique et Protohistorique. 


\section{Credits Illustrations}

1 Sauf indication contraire les auteurs des textes sont également les auteurs des illustrations.

2 A. Canal: Dessins p. 10, 58, 218. 